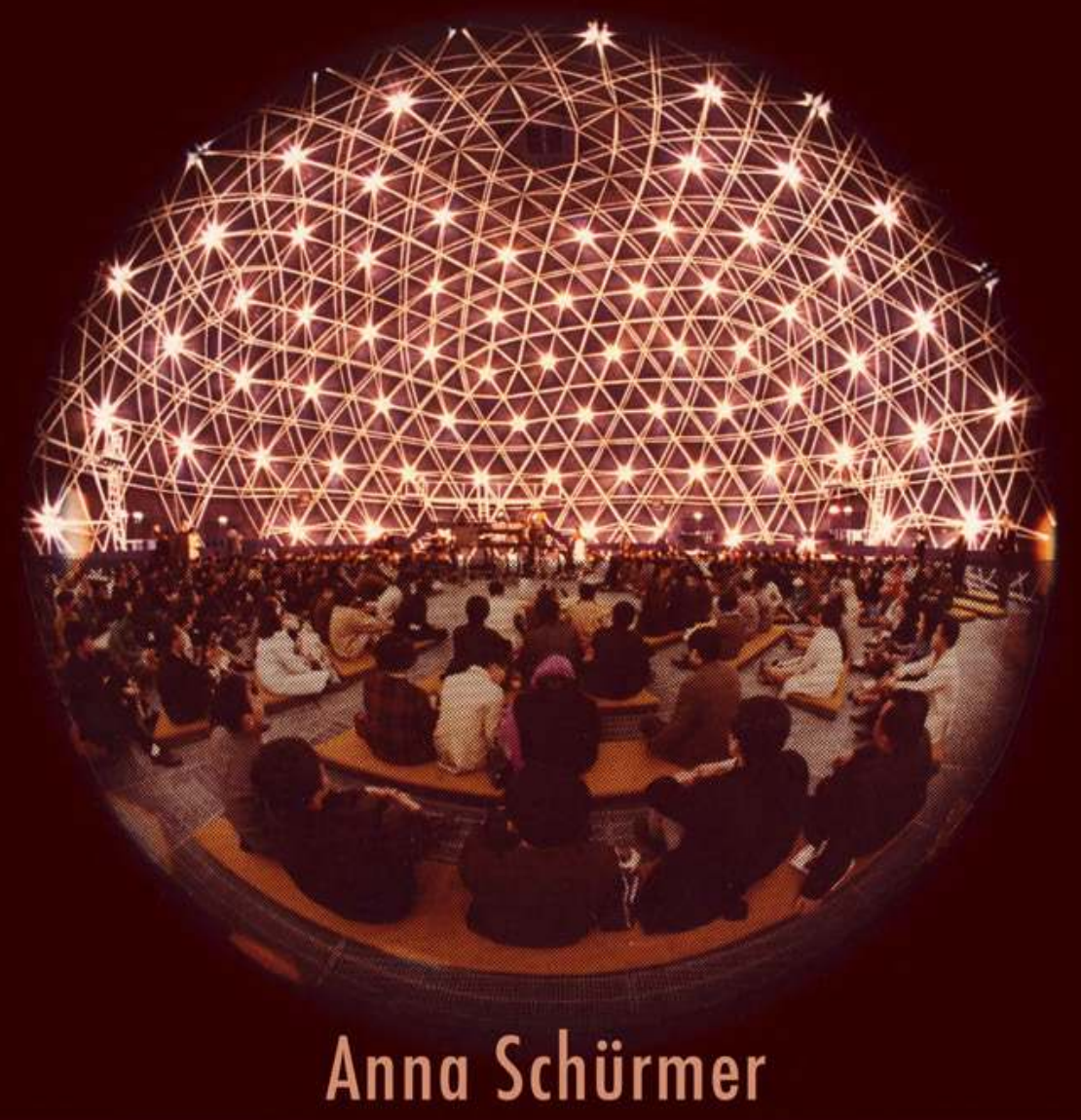

\title{
KLINGENDE EKLATS
}

Skandal und Neue Musik

[transcript] Histoire 
Anna Schürmer

Klingende Eklats

Histoire | Band Iı8 
Für Papa

Anna Schürmer (Dr. phil.), geb. I980, ist Kulturwissenschaftlerin und Musikjournalistin mit besonderem Fokus auf Klangkunst und Soundexperimente. Nach einem DFG-Stipendium am Graduiertenkolleg »Transnationale Medienereignisse« der Universität Gießen war sie von 20I4-20I7 als wissenschaftliche Mitarbeiterin der ERCForschergruppe »The Principle of Disruption« an der TU Dresden beschäftigt. Neben der Lehre und Forschung hält sie Lectures auf Festivals, schreibt für verschiedene Kulturinstitutionen und publiziert regelmäßig Kritiken, Features und Essays in diversen Print- und Funkmedien. 
AnNa Schürmer

\section{Klingende Eklats}

Skandal und Neue Musik

[transcript] 
Die Forschung, die zu dieser Veröffentlichung geführt hat, wurde vom Europäischen Forschungsrat (European Research Council [ERC]) durch das siebte EU-Forschungsrahmenprogramm (FP7/2007-20I3) finanziert / ERC grant agreement no. 3I2454.

\section{Bibliografische Information der Deutschen Nationalbibliothek}

Die Deutsche Nationalbibliothek verzeichnet diese Publikation in der Deutschen Nationalbibliografie; detaillierte bibliografische Daten sind im Internet über http://dnb.d-nb.de abrufbar.

\section{(c) $)(1) \Theta$}

Dieses Werk ist lizenziert unter der Creative Commons Attribution-NonCommercialNoDerivs 4.o Lizenz (BY-NC-ND). Diese Lizenz erlaubt die private Nutzung, gestattet aber keine Bearbeitung und keine kommerzielle Nutzung. Weitere Informationen finden Sie unter https://creativecommons.org/licenses/by-nc-nd/4.o/deed.de

Um Genehmigungen für Adaptionen, Übersetzungen, Derivate oder Wiederverwendung zu kommerziellen Zwecken einzuholen, wenden Sie sich bitte an rights@transcript-verlag.de Die Bedingungen der Creative-Commons-Lizenz gelten nur für Originalmaterial. Die Wiederverwendung von Material aus anderen Quellen (gekennzeichnet mit Quellenangabe) wie z.B. Schaubilder, Abbildungen, Fotos und Textauszüge erfordert ggf. weitere Nutzungsgenehmigungen durch den jeweiligen Rechteinhaber.

\section{(c) 2018 transcript Verlag, Bielefeld}

Umschlagkonzept: Maria Arndt, Bielefeld

Umschlagabbildung: Albert Breiteneicher, BJV

Druck: Majuskel Medienproduktion GmbH, Wetzlar

Print-ISBN 978-3-8376-3983-4

PDF-ISBN 978-3-8394-3983-8

https://doi.org/10.14361/9783839439838

Gedruckt auf alterungsbeständigem Papier mit chlorfrei gebleichtem Zellstoff.

Besuchen Sie uns im Internet: https://www.transcript-verlag.de

Unsere aktuelle Vorschau finden Sie unter

www.transcript-verlag.de/vorschau-download 


\section{Inhalt}

\section{KLINGENDE HISTORIOGRAPHIE (Einleitung) | 7}

\section{REFERENZEN und CHIFFREN (Exposition) | 31}

Die Krise der Jahrhundertwende | 34

Das Schlüsseljahr 1913 | 35

»Futuristengefahr«: Vom Kunst-Skandal zur Kunst des Skandals | 40

Die Sensationslust der >Goldenen Zwanziger | 46

Der >Paris-Modus`: succès de scandale | 48

George Antheil: Bad Boy of Music | 51

Die Unmöglichkeit des Skandals in Zeiten der Diktatur | 55

Die langesStunde Null | 60

>Restauration<: Kulturelle Katharsis | 61

>Reformation ‘: Die Renaissance der Atonalität | 64

>Negation〈: »ohne Rücksicht auf Ruinen« | 66

Versuch einer Definition: Klingende éclats | 68

Avant-Garde: >Tradition versus Innovation< | 70

Rites de Passage: Paradigmenwechsel und Schwellenphasen | 72

Produktion: Inszenierungsstrategien $\mid 74$

Rezeption: Laute(r) Emotionen | 75

Sezession und Isolation: Die >Leiden` der Neuen Musik | 78

\section{AGON und SKANDAL (Durchführung \#1) | 81}

Die Donaueschinger Musiktage: chronique scandaleuse | 85 1921-1933: Die »älteste Baustelle Neuer Musik« | 85

Ab 1949: Die skandalumwitterte Neugeburt Donaueschingens | 90

Die Darmstädter Ferienkurse als agonale Ereignisgeschichte | 106

Vom Fortschrittsoptimismus zum Innovationsimperativ | 108

Der Absolutismus der Moderne | 117 
ELEKTRONISCHE EKLATANZ (Durchführung \#2) | 135

Mensch vs. Maschine: Grundlagen der Technologiekritik | 137

Eskalation 1953/54: Drei Fallbeispiele | 143

>Konkretes Waterloo`: Pierre Schaeffer | 143

>Rauschende Interferenzen ২: Karlheinz Stockhausen | 148

>Organisierte Interpolationen`: Edgard Varèse | 159

Utopie und Dystopie: Paradigmen der Mensch-Maschine-

Dichotomie | 168

Entmenschlichung und Denaturierung: »Was ist Musik?« | 169

Passagen ins Medienzeitalter: »Die dritte Epoche« | 173

Ausblick: Elektropop und die digitale Eklatanz | 177

\section{TRANSKULTURELLE TRANSFERS (Durchführung \#3) | 183}

John Cage und die transatlantische Neuvermessung der klingenden Welt | 186

>Inkubation<: Black Magic Mountain (1948-1952) | 188

$>$ Kulmination< in der Alten Welt (1954-1958) | 197

〉Eskalation`: Das Schlüsseljahr 1958 und die Folgen | 203

Das Ende der eurozentrischen Kulturhegemonie | 210

»Fight Musical Racism« | 211

»Stockhausen serves Imperialism《: Originale - ein transatlantischer Skandal (1961/64) | 215

Transferierende Exkurse | 226

»Topless Cellist«: People \& C. v. Charlotte Moorman (1967) | 226

»Das größte Kunstwerk«: Karlheinz Stockhausen und 9/11 (2001) | 233

QUERSTAND VON KUNST UND POLITIK (Durchführung \#4) | 239

Politische Musikskandale im Umfeld von >1968، | 243

Ein Überblick mit Dieter Schnebel | 243

Politisierung im Elfenbeinturm: Darmstadt im >Krisenjahr 1970<| 250

Das Musiktheater: ১Bühnen der Politikı | 255

Klingender Klassenkampf: Luigi Nonos Intolleranza (1961) | 259

Der Schiffbruch von Hans Werner Henzes Floß der Medusa (1968) | 267

Eine Oper »to end all operas«: Mauricio Kagels Staatstheater (1971) | 286

ANALYTISCHE KONTRAPUNKTE (Reprise) | 297 


\section{KLINGENDE HISTORIOGRAPHIE (Einleitung)}

\section{Skandal und Neue Musik}

Die Musikgeschichte ist auch eine Geschichte ihrer Skandale: Türenschlagen und Buhrufe, Handgemenge und Saalschlachten, Kontroversen und Invektiven begleiteten die klingende Historie nicht nur, sondern sequenzierten sie als ereignishafte Marker. War der Musikskandal bis dato Strukturmerkmal einer zwischen den Polen von Tradition und Innovation verlaufenden, normativ-linearen Fortschrittsgeschichte, bekam der klingende éclat ${ }^{1}$ an der Schwelle und im Verlauf des 20. Jahrhunderts paradigmatischen Eigenwert: Die Skandalträchtigkeit der Neuen Musik ${ }^{2}$ resultierte aus der Provokationslust und dem Innovationsimperativ ihrer Avantgarden. Diese erzeugten nicht nur auf musikästhetischer Ebene dissonante Reibungen, sondern brachten auch soziale Problemfelder zum Klingen. Ihre Skandale können als spezifischer Ausdruck der Moderne interpretiert werden, in welcher der Bruch mit der Vergangenheit und der Schub nach vorne zunächst extrem beschleunigt wurden, um schließlich im pluralistischen anything goes der Postmoderne zu versanden. Musikskandale sind, wie es in zwei der wenigen Publikationen zum Thema heißt, weit mehr als nur der $\gg$ Pfeffer, ohne den [...] die musikhistorische Narration trocken und fade bliebe $\ll^{3}$ und »keine gesellschaftlichen Randphänomene und kulturellen Unfälle, vielmehr: Schlüsselereignisse, Schlüsselerlebnisse. In ihnen öffnet Geschichte, auch Musikgeschichte, einen Spalt breit die Tür. $\aleph^{4}$

1 Aus Gründen der Lesbarkeit werden hier die Begriffe Musikskandal sowie Eklat weitgehend synonym verwendet. Es sei aber bereits hier darauf hingewiesen, dass der französischen Terminus éclat besonders treffende Erklärungsmuster für die Analyse des Musikskandals bereithält. Siehe hierzu ausführlich: Versuch einer Definition: Klingende éclats.

2 Es herrscht beträchtliche Unschärfe zwischen Begriffen wie modern, zeitgenössisch oder avantgardistisch sowie der Groß- und Kleinschreibung von ıneuer` respektive `Neuer Musik«. Im Anschluss an Hermann Danuser wird sie »als eine historische Grundkategorie« verstanden, »bei der alle namhaften Innovationen der Musik des 20. Jahrhunderts [...] Berücksichtigung finden.« Ders.: Neue Musik, in Ludwig Finscher (Hg.): Musik in Geschichte und Gegenwart (MGG), Band 7, Kassel 1997, Sp. 75-122, hier Sp. 77.

3 Hermann Danuser: Lob des Tadels. Der Skandal in der Musikgeschichte, in: Programmbuch der Internationalen Musikfestwochen Luzern 1995, S. 115-125, hier S. 115.

4 Christian Kaden: Skandal und Ritual in der Musik, in Joachim Brügge (Hg.): Musikgeschichte als Verstehensgeschichte, Tutzing 2004, S. 583-596, hier S. 596. 
Im klingenden Eklat werden nicht nur die ästhetischen und moralischen Grenzen des guten Tons überschritten, sondern auch gesellschaftliche Normen auf- und angegriffen: aus dieser Verschränkung gewinnt er sein interdisziplinär wirksames analytisches Potential. In der altgriechischen Wortbedeutung $\sigma \kappa \alpha ́ v \delta \alpha \lambda o v$ (skándalon) kann er als »Stellhölzchen« verstanden werden das bei Berührung zeithistorischer Nervenpunkte losschnellt, indem emotionale Kontrollverlusten eskalieren. Dabei sind weder die Anstoß erregenden Ereignisse noch die von ihnen provozierten Gefühle anthropologische Konstanten; sie sind vielmehr von sozial verankerten Codes abhängig, in Diskurse eingebettet und spiegeln den Wandel kultureller und ästhetischer Zustände, markieren zugleich aber auch soziale und mediale Umbruchszenarien. Musikskandale können demnach auf dem symbolischen Feld der Kunst als Bruchstellen weiter greifender Strukturen verstanden werden: als konfliktive Seismographen gesellschaftlicher Problem- wie ästhetischer Experimentierfelder.

Aufgrund der heterogenen Disposition des Musikskandals kann das in dieser Arbeit angestrebte Ziel, klingende Eklats als gesellschaftlich wie ästhetisch relevante zeithistorische Phänomene auszuweisen und analytisch nutzbar zu machen, nur durch einen disziplinären Dreiklang bewältigt werden: So wird das zeithistorische Forschungsfeld notwendig flankiert von musikwissenschaftlichen Ansätzen, während die Medienkulturwissenschaften als verbindendes Scharnier wirken. Die Auseinandersetzung mit Medien durchzieht mittlerweile nahezu alle geisteswissenschaftlichen Disziplinen, während die Kulturwissenschaft - wie sie sich in Deutschland entwickelt hat - weniger eine Disziplin ist, als vielmehr ein offeneres Methoden-, Theorien- und Perspektivenrepertoire bereithält und sich daher als harmonisierender Kitt der interdisziplinären Reibungen anbietet, die in dieser Arbeit stets mitschwingen.

Mit dem Titel Klingende Eklats. Skandal und Neue Musik werden die analytischen Heb- und Angelpunkte dieser Dissertation verdichtet präsentiert: Sie ist demnach als kulturhistorisch motivierte Ereignisgeschichte im Licht - oder besser in Hörweite ${ }^{5}$ - des klingenden Eklats zu verstehen: Als das Außergewöhnliche durchbrechen Musikskandale die Struktur, die sie formiert, unterbricht oder birgt und ohne die sie schlicht nicht denkbar sind. Sie sind eine diskursive historische Kategorie, denn: Was kann in einer bestimmten Zeit an einem bestimmten Ort, wie und unter welchen Bedingungen überhaupt zum Skandal werden? Im Mittelpunkt der Untersuchung stehen also diskursorientierte Fragen nach der Ereignishaftigkeit von Neuer Musik und speziell nach den kulturdiagnostischen Potentialen ihrer Skandale. Dabei interessieren sowohl spezifische Formen und Funktionen der medialen Kommunikation, als auch die politischen, kulturellen und ästhetischen Bezugnahmen und Transfers sowie die emotionstheoretischen, performativen, medialen und politischen Faktoren der Aufmerksamkeit erregenden Ereignisse, welche die Musikavantgarden nach 1945 provozierten.

5 Ohne musikalische Metaphern überstrapazieren oder inflationär als Argument einsetzen zu wollen, soll hier doch auch für die von visueller Programmatik geprägten Narrative sensibilisiert und auf akustische Analoga aufmerksam gemacht werden. 
Spektakuläre Traditionsbrüche haben insbesondere in der Zeitgeschichte eine Verdichtung erfahren. Es ist weder Zufall, dass Skandale den Aufstieg der Massenmedien begleiteten und also dokumentieren ${ }^{6}$, noch dass ihre symbolischen Inszenierungen den modernen Künsten und theatralischen Inszenierungen nah verwandt sind. ${ }^{7}$ Tatsächlich machten sich insbesondere die Avantgardebewegungen des 20. Jahrhunderts das dramaturgische Moment der Skandalisierung ästhetisch zunutze. In Opposition zur Lebenspraxis und als Reaktion auf die Krise der Repräsentation wurde der Schock zum obersten Prinzip künstlerischer Intention. In Konfrontation mit dem klassischen Erbe wurden Praktiken der Subversion, Innovationskult und Fortschrittsobsession zu zentralen Kategorien der Moderne. Während Peter Bürger 1974 den künstlerischen Vorreitern in seiner Theorie der Avantgarde praktische Folgenlosigkeit attestierte ${ }^{8}$, sollen die Schrittmacher der musikalischen Moderne hier vielmehr als zeithistorische Akteure mit mehr als nur symbolischer Expression und Ausdruckskrfat fokussiert werden.

Nicht nur das Historische Wörterbuch der Rhetorik erkennt in der »dubiose[n] Allianz aus (zeit-, gesellschafts-) diagnostischer Kraft und Hysterie [...] gute Gründe für die Re-Interpretation historischer Ereignisse im Licht des Skandalons. « ${ }^{9}$ Auch in der Enzyklopädie der Neuzeit heißt es, dass Skandale als wichtiges Moment neuzeitlicher Öffentlichkeit sowie als Indiz für die Verläufe gesellschaftlicher Grenzziehungen »die Aufmerksamkeit der Historiker verdienen. $\ll^{10}$ Ausgehend davon hat insbesondere die sozialwissenschaftliche Skandalforschung seit den späten 1980er Jahren einen Aufschwung erfahren, der sich international in zahlreichen Publikationen nie-

6 Aus historischer Perspektive siehe insbesondere Frank Bösch: Öffentliche Geheimnisse. Skandale, Politik und Medien in Deutschland und Großbritannien 1880-1914, München 2009; Ders.: »Historische Skandalforschung als Schnittstelle zwischen Medien-, Kommunikations- und Geschichtswissenschaft«, in Fabio Crivellari/Kay Kirchmann/ Marcus Sandl /Rudolf Schlögl (Hg.): Die Medien der Geschichte. Historizität und Medialität in interdisziplinärer Perspektive, Konstanz 2004, S. 445-464.

Aus kommunikationswissenschaftlicher Sicht siehe besonders die Arbeiten von Hans Mathias Kepplinger: Die Kunst der Skandalierung und die Illusion der Wahrheit, München 2001; Ders.: Die Mechanismen der Skandalisierung. Die Macht der Medien und die Möglichkeiten der Betroffenen, München 2005; Ders.: Publizistische Konflikte und Skandale, Wiesbaden 2009; Ders.: Die Mechanismen der Skandalisierung, München 2012.

Beachte außerdem Steffen Burkhardt: Medienskandale. Zur moralischen Sprengkraft öffentlicher Diskurse, Köln 2006; Larry J. Sabato/Marc Stencel/S. Robert Lichter (Hg.): Peepshow. Media and Politics in Age of Scandal, Lanham 2001; John B. Thompson: Political Scandal. Power and Visibility in the Media Age, Cambridge 2000.

7 Siehe etwa Dirk Käsler: Der politische Skandal. Zur symbolischen und dramaturgischen Qualität von Politik, Opladen 1991.

8 Peter Bürger: Theorie der Avantgarde, Frankfurt am Main 1974.

9 Cornelia Blasberg: »Skandal«, in Gerd Ueding (Hg.): Historisches Wörterbuch der Rhetorik, Band 8, Tübingen 2007, Sp. 923-929, hier Sp. 925f.

10 Gerrit Walther: »Skandal«, in Friedrich Jaeger (Hg.): Enzyklopädie der Neuzeit, Band 12, Stuttgart 2010, Sp. 54-57, hier Sp. 57. 
dergeschlagen hat ${ }^{11}$, die sich jedoch nur bedingt für den ästhetischen Skandal nutzbar machen lassen. Denn während Skandale in Wirtschaft oder Politik meist mit schwerwiegenden Sanktionen einhergehen, erhielten sie in den Avantgardebewegungen des 20. Jahrhunderts eine explizit positive Konnotation: Es kam nicht nur zu einer Ästhetisierung von Provokationen und mithin zu einer $>$ Kunst des Skandals $\triangleleft$; dieser wurde mehr noch zur Währung im Feilschen um das kostbarste Gut und wirkmächtigste Instrument das die massenmediale Ökonomie zu bieten hat: Aufmerksamkeit. ${ }^{12}$ In diesem Fokus bewegt sich die Mehrzahl entsprechender Publikationen aus den Kunst- ${ }^{13}$, Literatur- ${ }^{14}$ und Theaterwissenschaften ${ }^{15}$, die aber nur partiell Aufschlüsse über den Musikskandal versprechen, denn: Kunst-Skandal $\neq$ Kunst-Skandal.

11 Christian Schütze: Skandal. Eine Psychologie des Unerhörten, Bern/München 1985; Andrei S. Markovitz/Mark Silverstein: The Politics of Scandal. Power and Process in Liberal Democracies, New York 1988; Rolf Ebbinghausen/Sighard Neckel (Hg.): Anatomie des politischen Skandals, Frankfurt am Main 1989; Louis Allen: Political Scandals and Causes Celébres since 1945, Chicago 1990; Julius H. Schoeps (Hg.): Der politische Skandal, Stuttgart 1992; Karl Otto Hondrich: Enthüllung und Entrüstung. Eine Phänomenologie des politischen Skandals, Frankfurt am Main 2002; Roland Reichenbach: Skandal und politische Bildung. Aspekte zu einer Theorie des politischen Gefühls, Berlin 2005; Andreas Mayer: Enthüllung und Erregung. Kleine Physiologie des Skandals, Frankfurt 2005; John Garrard/James Newell (Hg.): Scandals in Past and Contemporary Politics, New York 2006; Jens Bergmann/Bernhard Pörksen (Hg.): Skandal! Die Macht öffentlicher Empörung, Köln 2009; Bernhard Pörksen/Hanne Detel (Hg.): Der entfesselte Skandal. Das Ende der Kontrolle im digitalen Zeitalter, Köln 2012.

12 Vgl. Georg Frank: Ökonomie der Aufmerksamkeit. Ein Entwurf, München/Wien 1998.

13 Die Mehrzahl der Publikationen aus dem Bereich der Kunstgeschichte sind anekdotisch gehalten: Gérard Audinet: Les grands scandales de l'histoire de l'art, Paris 2008; Michael G. Kammen: Visual Shock. A History of Art Controversies in American Culture, New York 2006; Heinz Peter Schwerfel: Kunstskandale, Köln 2000; Sabine Fellner: Kunstskandal! Die besten Nestbeschmutzer der letzten 150 Jahre, Wien 1997; Christine Resch: Kunst als Skandal. Der steirische Herbst und die öffentliche Erregung, Wien 1994; Georg Hensel: Theaterskandale und andere Anlässe zum Vergnügen, Stuttgart 1983.

14 Im Bereich der Literaturwissenschaften entstanden in den vergangenen Jahren zwei Handbücher: Hans-Edwin Friedrich: Literaturskandale, Frankfurt am Main 2009; Stefan Neuhaus/Johann Holzner (Hg.): Literatur als Skandal. Fälle - Funktionen - Folgen, Göttingen 2007. An Monographien zu nennen sind Andrea Bartl: Skandalautoren. Zu repräsentativen Mustern literarischer Provokation und Aufsehen erregender Autorinszenierungen, Würzburg 2014; Oliver Bentz: Thomas Bernhard - Dichtung als Skandal, Würzburg 2000.

15 Hervorzuheben sind hier zwei Studien aus dem anglo-amerikanischen Raum: Theodor Ziolkowski: Scandal on Stage. European Theater as Moral Trial, Cambridge 2013; Martin Blackadder: Performing Opposition. Modern Theater and the Scandalized Audience, Westport 2003. Siehe außerdem Karl Christian Führer: »Pfui, Gemeinheit, Skandal!« Bürgerlicher Kunstgeschmack und Theaterskandale in der Weimarer Republik, in: Zeitschrift für Geschichtswissenschaft (57/2009), S. 389-412; Bernd Noack: Theater Skandale. Von Aischylos bis Thomas Bernhard, St. Pölten/Salzburg 2008; Georg Hensel: Theaterskandale und andere Anlässe zum Vergnügen, Stuttgart 1983. 
Bei der Analyse klingender Eklats gilt es daher, die unterschiedlichen Rezeptionshaltungen und Produktionsweisen, die spezifische gesellschaftliche und kulturelle Verankerung sowie die jeweiligen ästhetischen Traditionen zu differenzieren: Auf musikwissenschaftlichem Feld stellte Hermann Danuser 1997 fest, dass eine Erforschung des Musikskandals »insgesamt [...] noch in den Anfängen « steckt ${ }^{16}$, während sein Kollege Christian Kaden 2004 bemerkte, dies sei »ein quasi nicht existenter Forschungsgegenstand. ${ }^{17}$ Das ist nur bedingt richtig, wie ihre Aufsätze zeigen; allerdings wurde der klingende Eklat bislang überwiegend feuilletonistisch in Funk- und Printmedien behandelt. Einen wissenschaftlichen Startschuss setzte 1964 Imre Omray mit seiner Darstellung zum Skandal in der Oper - der Zusatz »eine anekdotische Darstellung « wies allerdings noch stark auf die Charakteristik einer Sensationsgeschichte hin. ${ }^{18}$ Aufsatzsammlungen zum Gegenstand Skandal und Neue Musik stellten im Jahr 2000 die Neue Zeitschrift für Musik und 2013 die Österreichische Musikzeitschrift in Themenheften zusammen ${ }^{19}$, bevor 2004 Martin Eybl mit seiner Dokumentation von Arnold Schönbergs Wiener Skandalkonzerten erste monographische Maßstäbe setzte. ${ }^{20}$ Hervorzuheben für die Relevanz des Themas sind schließlich die $»$ Dokumente zur Musik des 20. Jahrhunderts« im Handbuch der Musik im 20. Jahrhundert, wo ein Kapitel unter der Überschrift »Manifeste - Proklamationen - Skandale « diese nicht nur als relevante Faktoren der Neuen Musik auswies, sondern auch eine erste Zusammenstellung maßgeblicher Dokumente und Quellen bereitstellte. ${ }^{21}$

\section{Der Klang ist die Message}

Der klingende Eklat wird in dieser Studie erstmals kartographiert: er ist ihr vorgängiges Phänomen und ihr analytisches Erkenntnisinteresse - nicht die Vorannahme. Einleitend wird daher die Idee einer Klang-Geschichte herausgearbeitet. Mit der Skizze einer solchen >Klingenden Historiographie` wird der Fokus auf die Konjunktur der interdisziplinären Klangforschung gerichtet und aus dem methodischen und theoretischen Vielerlei ein Ansatz generiert, der Musik nicht nur als historisches Phänomen und als quellenrelevantes Produkt ihrer Zeit ausweist, sondern auf klingendem Material - nämlich audiovisuellen Quellen - basiert.

16 Hermann Danuser: »Agon und Skandal«, in Gianmaria Borio/Ders. (Hg.): Im Zenit der Moderne. Die internationalen Ferienkurse für Neue Musik Darmstadt 1946-1966, Band 2, Freiburg im Breisgau 1997, S. 374ff, hier S. 374.

17 Kaden: Skandal und Ritual in der Musik, S. 583.

18 Imre Omray: Skandal in der Oper [eine anekdotische Darstellung], Leipzig 1964.

19 »Skandal!«, Themenheft der Neuen Zeitschrift für Musik (3/2000); »1913 - Skandalkonzerte«, Themenheft der Österreichischen Musikzeitschrift (2/2013).

20 Martin Eybl: Die Befreiung des Augenblicks. Schönbergs Skandalkonzerte von 1907 und 1908, Wien 2004.

21 Helga de la Motte-Haber/Lydia Rilling/Julia H. Schröder (Hg.): »Dokumente zur Musik des 20. Jahrhunderts«, in Elmar Budde/Helga de la Motte-Haber/Siegfrid Mauser/Albrecht Riethmüller/Christian Martin Schmidt (Hg.): Handbuch der Musik im 20. Jahrhundert in 14 Bänden, Band 14, Laaber 2011. 
»Im Lesesaal ist es flüsterleis« heißt es in Arlette Farges Geschmack des Archivs ${ }^{22}$. Machte die französische Historikerin darauf aufmerksam, dass die Wissensdepots längst audiovisuelle Speicher sind, könnte man sogar postulieren, dass akustische und bildliche Artefakte spätestens seit der Mitte des vergangenen Jahrhunderts genuin das Material für Zeitgeschichte stellen. Audiovisuelle Medien übermitteln nicht lediglich Botschaften, sondern sind selbst auch >messages $<$ : sie bezeichnen fortwährend nicht nur Abwesendes, sondern zugleich auch sich selbst. Auf medienarchäologischer Ebene kennzeichnen sie in ihrer Materialität das technische Signum der Epoche und den kulturtechnischen Wandel der Wissensgenerierung und -überlieferung; auf mediengeschichtlicher Ebene transportieren sie durch ihre Technik der identischen Aufzeichnung und Wiedergabe originäre und authentische Spuren, die - als Resultat live mitgeschnittener Zeitgeschichte - noch immer kaum beachtet werden.

Wenn bislang von audiovisuellen Artefakten die Rede war, sollen diese Überlegungen im Folgenden auf akustische Phänomene verengt und spezifiziert werden: $\mathrm{zu}$ einer Klanggeschichte, die nicht nur von Musik handelt, sondern diese gleichermaBen als Quelle wie als methodischen Taktgeber behandelt. Dieses Vorhaben ist angesiedelt in einem explizit disziplinärem >Dazwischen`verschiedenster Forschungstraditionen, deren Zusammenklang nicht selten dissonante Reibungen erzeugt und doch eine transdisziplinäre Harmonie auf dem weiten Feld der Zeitgeschichte anstrebt. Es ist also geboten, aus den vielen Strängen der Klang-Forschung einen roten Faden zu entwirren und mit diesem ein eigenständiges wissenschaftliches Feld zu bestellen, das die Arbeit methodisch und theoretisch grundiert.

Wenn Farge vom Geschmack des Archivs sprach, verwies die Schülerin Lucien Febres auch auf die mentalitäts- und wahrnehmungsorientierte Geschichtsschreibung, die unter dem übergeordneten Paradigma einer Sinnesgeschichte gefasst werden kann. Die >sensual history< ist kein per se neues Projekt: konzeptualisiert wurde sie bereits in der Tradition der französischen Annales als Historische Anthropologie der Sinneswahrnehmung. ${ }^{23}$ Auch in der anglo-amerikanischen Forschungslandschaft bildete sich im Anschluss an die britischen cultural studies früh ein Bewusstsein für die sensorische Ebene der Geschichte, die auch mit Blick auf akustische Dimensionen wesentlich früher als in der deutschen kartographiert wurde. ${ }^{24}$

22 Arlette Farge: Der Geschmack des Archivs, Göttingen 2011.

23 Lucien Febvre arbeitete bereits $1941 \mathrm{zu}$ »Sensibilität und Geschichte. Zugänge zum Gefühlsleben früherer Epochen«, publiziert in Claudia Honegger (Hg.): Schrift und Materie der Geschichte, Frankfurt am Main 1977, S. 313-334. In dieser Tradition bewegte sich seit den 1980er Jahren besonders Alain Corbin: Pesthauch und Blütenduft. Eine Geschichte des Geruchs, Berlin 1984; Ders.: Die Sprache der Glocken. Ländliche Gefühlskultur und symbolische Ordnung im Frankreich des 19. Jahrhunderts, Frankfurt am Main 1995; Ders.: "Geschichte und Anthropologie der Sinneswahrnehmung «, in Sebastian Conrad/Martina Kessel (Hg.): Kultur \& Geschichte. Neue Einblicke in eine alte Beziehung, Stuttgart 1998, S. 121-140.

24 Insbesondere die Arbeiten von Mark M. Smith belegen die im anglo-amerikanischen Raum weitaus frühere und intensivere Beschäftigung mit dem Klang als Teil einer >sensual history<: Ders.: »Making Sense of Social History«, in: Journal of Social History (37/2003), S. 165-186; Ders.: Listening to Nineteeth-Century America, Chapel Hill 2001; Ders. (Hg.): Hearing History. A Reader, Athens u.a. 2004; Ders. (Hg.): Sensing the Past. Seeing, Hear- 
Dieser Versuch einer klingenden Historiographie ist also in den größeren Rahmen einer Geschichte der Sinne einzuordnen, die zuletzt auch in Deutschland zunehmende Beachtung erfuhr. ${ }^{25}$ Zeithistoriker, die sich der Wahrnehmung als relevanter Ebene der Wissensgenerierung zuwandten, erkannten zwar den Wert von erlebter Geschichte in der >oral history< an, betonten jedoch meist das visuelle Primat in der Moderne und schlossen die auditive Ebene weitgehend aus ihren Forschungen aus. Und das, obwohl die Forderung nach einer stärkeren Beachtung akustischer Artefakte in etwa so alt ist, wie die systematische Beschäftigung mit Quellen selbst. Johann Gustav Droysen etwa bemerkte schon 1857, dass »namentlich vor der Zeit des Bücherdruckens historische Lieder recht eigentlich die historische Meinung vertraten. ${ }^{26}$ Damit gab bereits er einen Hinweis auf die kulturtechnische Verfasstheit des historischen Materials: Das Primat der mündlichen Überlieferung wurde seit dem 15. Jahrhundert sowohl in der Schrift- wie auch in der Musikkultur nach und nach ins typographische Zeitalter der Gutenberg-Galaxis überführt, an deren Stelle - wie Marshall McLuhan bereits 1962 herausarbeitete - um 1900 das elektronische Zeitalter trat: Jede dieser Epochen sei durch das jeweils bestimmende Kommunikationsmedium (prä)formiert, figuriert und strukturiert. Dieses mediale Rohmaterial forme nicht nur die persönlichen Sinnesverhältnisse, sondern auch die Muster gemeinschaftlicher Wechselwirkung. ${ }^{27}$ Wies McLuhan damit Medienwechsel als gesellschafts- wie forschungsrelevante Umbrüche aus, vertreten audiovisuelle Aufschreibesysteme als »Netzwerk von Techniken und Institutionen [...], die einer gegebenen Kultur die Adressierung, Speicherung und Verarbeitung relevanter Daten erlauben ${ }^{28}$, auch in

ing, Smelling, Tasting, and Touching in History, Berkeley/Los Angeles 2007. Siehe auch Constanze Classen: Worlds of Sense. Exploting the Senses in History and Across Cultures, London 1993; James H. Johnson: Listening in Paris. A Cultural History, Berkeley/Los Angeles 1995; Leigh Eric Schmidt: Hearing Things. Religion, Illusion and the American Enlightenment, Chicago 1999; David Howes: Sensual Relations. Engaging the Senses in Culture and Social Theory, Ann Arbor 2003; Ders. (Hg.): Empire of the Senses. The sensual Culture Reader, Oxford 2005; Emily Thompson: The Soundscape of Modernity, Cambridge 2004; Veit Erlmann (Hg.): Hearing Cultures. Essays on Sound, Listening, and Modernity, Oxford 2005; Brandon Labelle: Acoustic Territories. Sound Culture and Everyday Life, New York 2010.

25 Eine frühe sozio-historische Auseinandersetzung mit der Sinnlichkeit war das Handbuch von Dietmar Kamper/Christoph Wulf (Hg.): Das Schwinden der Sinne, Frankfurt am Main 1984. Später folgten etwa Jochen Hörisch: Der Sinn und die Sinne. Eine Geschichte der Medien, Frankfurt am Main 2001; Jan-Friedrich Missfelder: »Ganzkörpergeschichte. Sinne, Sinn und Sinnlichkeit für eine historische Anthropologie«, in: Internationales Archiv für Sozialgeschichte der deutschen Literatur, Band 39 (2/2014), S. 457-475; Robert Jütte: Geschichte der Sinne. Von der Antike bis zum Cyberspace. München 2000.

26 Johann Gustav Droysen: Historik, Band 1: Rekonstruktion der ersten und vollständigen Fassung der Vorlesungen (1857), Stuttgart/Bad Cannstatt 1977, S. 91.

27 Marshall McLuhan: The Gutenberg Galaxy, London 1962; Ders.: Die magischen Kanäle Understanding Media, Dresden/Basel 1994; Ders.: Das Medium ist die Massage. Ein Inventar medialer Effekte, Stuttgart 2011.

28 Friedrich Kittler: Aufschreibesysteme 1800/1900, München 1985. 
der Lesart Friedrich Kittlers spätestens seit der Mitte des 20. Jahrhunderts und in der Diktion Droysens »recht eigentlich die historische Meinung«. Die Möglichkeiten der elektronischen und später digitalen Medien formen im Anschluss an Walter Benjamin nicht nur Das Kunstwerk im Zeitalter seiner technischen Reproduzierbarkeit ${ }^{29}$, sondern prägen auch die Gesellschaft und das Wissen von ihr.

In der Zeitgeschichte fanden solche Ansätze zunächst allerdings nur wenig Wiederhall. Der Grundsatz veritas in actis blieb in der historischen Praxis lange bestimmend: Was in den Akten steht, ist wirklich. Angesichts der Bedeutung audiovisueller Medien aber, so konstatierte Thomas Lindenberger 2004 in seiner Pionierstudie über »Das vergangene Hören und Sehen«, kann die weitgehende Ausklammerung der $>$ Mitsehenden $<$ und >Mithörenden $<$ aus einer die >Mitlebenden $<$ adressierenden Zeitgeschichte nur als Anachronismus bezeichnet werden. ${ }^{30}$ Wenn es auf dem historischen Feld der Sinne im Zuge der medienwissenschaftlichen Durchdringung der Geistes- und Kulturwissenschaften auch zu einem gesteigerten Interesse an $»$ Audiovisionen als Amalgam für eine Vielzahl medialer Kommunikationsformen « ${ }^{31}$ kam, wurde doch in der Regel das Primat des Visuellen in der Moderne betont.

Die Ansätze der > visual history ${ }^{32}$ - Bilder sowohl als Quellen wie auch als eigenständige Gegenstände der historischen Forschung zu betrachten - lieferten denn auch erste methodische Anschlüsse für eine >auditive history<: Gerhard Paul, der bedeutendste deutsche Vertreter eines >pictoral turn in den Geschichtswissenschaften, publizierte im Anschluss an seine bildwissenschaftlichen Studien 2013 auch einen Band zum Sound des Jahrhunderts. ${ }^{33}$ Meist wurde das Präfix >audio< jedoch aus den zeithistorischen Forschungen ausgeschlossen, in denen noch immer eine Nachrangigkeit von Audiovisionen als Gegenstand und Quelle feststellbar ist. Von einem Acoustic Turn, wie ihn Petra Maria Meyer 2008 zur Diskussion stellte ${ }^{34}$, kann - und muss - also keinesfalls die Rede sein. Es geht nicht um die Verkündung eines neuen Paradigmas, sondern um die Stärkung der akustischen Ebene und auditiver Komponenten als gleichberechtigten Bestandteilen einer die Wahrnehmung reflektierenden Zeitgeschichte.

Erste Kritik am visuellen Primat wurde in den 1980er Jahren im Bereich der Historischen Anthropologie laut, wo erste Monographien entstanden, die sich mit den

29 Walter Benjamin: Das Kunstwerk im Zeitalter seiner technischen Reproduzierbarkeit, in Ders.: Gesammelte Schriften, Band 1, Frankfurt am Main 1980, S. 471-508.

30 Thomas Lindenberger: »Das vergangene Hören und Sehen. Zeitgeschichte und ihre Herausforderung durch die audiovisuellen Medien«, in: Zeithistorische Forschungen (1/2004). Online unter URL: http://www.zeithistorische-forschungen.de/1-2004/id\%3D4586 [Zugriff: 31.8 .2017$]$.

31 So Siegfried Zielinskis Bestimmung, die er seinem Entwurf einer »integrierten Mediengeschichte « zugrunde legt: Audiovisionen. Kino und Fernsehen als Zwischenspiele der Geschichte, Reinbek bei Hamburg 1989, S. 11.

32 Gerhard Paul: Visual History. Ein Studienbuch, Göttingen 2006; Ders.: Das historische Auge. Kunstwerken als Zeugen ihrer Zeit von der Renaissance zur Revolution, Göttingen 2004. Siehe auch Martin Sabrow (Hrsg.): Die Macht der Bilder, Radebeul 2013.

33 Gerhard Paul: Sound des Jahrhunderts. Geräusche, Töne, Stimmen 1889 bis heute, Bonn 2013.

34 Petra Maria Meyer (Hg.): Acoustic Turn, München 2008. 
kulturhistorischen Implikationen des Hörens beschäftigten. ${ }^{35} 1993$ widmete die Zeitschrift Paragrana dem »Ohr als Erkenntnisorgan« eine zweibändige Ausgabe. Darin betonte der Anthropologe Christoph Wulf, dass »Laute, Töne, Klänge [...] eine größere Verbreitung und Bedeutung als im Allgemeinen angenommen wird « haben:

»Große Teile der uns umgebenden Geräusch-, Ton- und Klangwelt unterliegen dem historischgesellschaftlichen und geographischen Wandel. [...] Mit der industriellen, der elektromechanischen und der elektronischen Revolution entstehen bis dahin unbekannte Geräusche. [...] Der Hörsinn ist der soziale Sinn. [...] Über die Wahrnehmung von Geräuschen, Lauten, Tönen und Wörtern wachsen wir in eine Kultur hinein. $\ll^{36}$

Manfred Mixner reflektierte im gleichen Band von einem »Aufstand des Ohrs« und stellte nicht nur fest: »Am Ohr haben die meisten Forscher und Theoretiker [...] kein Interesse«, sondern auch: »Es gibt viele Indizien, daß sich das Ohr wieder Gehör verschaffen will, daß es aufsteht gegen seine Mißachtung und Unterdrückung, daß es so etwas wie eine Tendenz zur Enthierarchisierung der Sinne gibt. « ${ }^{37}$ Auch Wolfgang Welsch erwartete im philosophischen Kontext den »Weg zu einer Kultur des Hörens « und das »Großprogramm einer auditiven Kulturrevolution«. Insbesondere die neuere französische Philosophie schenke dem »Ton einer Rede, [...] dem Rhythmus eines Schreibens Aufmerksamkeit und wendet sich Unerhörtem zu. ${ }^{38}$ Welsch verwies also insbesondere auf die poststrukturalistische Theorietradition, die sich nicht nur auf das Hören, sondern oft auch konkret auf die Musikavantgarde bezog. Allen voran nutzten Gilles Deleuze und Félix Guattari musikalische Begriffe wie etwa das »Ritornell« zu ihrer Theoriebildung des Rhizomatischen:

»Die Musik hört nicht auf, ihre Fluchtlinien ziehen zu lassen, gleichsam als `TransformationsVielheiten`, und kehrt dabei sogar ihre eigenen Codes um, die sie abrifizieren und strukturieren; die musikalische Form ist so bis in ihre Brüche und Wucherungen hinein dem Unkraut vergleichbar, ein Rhizom. ${ }^{39}$

Ihre Ideen von der unterirdischen Durchdringung und Enthierarchisierung der Wissensorganisation (wie auch der Sinne) exemplifizierten Deleuze und Guattari insbe-

35 Richard Murray Schafer: Klang und Krach. Eine Kulturgeschichte des Hörens, Frankfurt am Main 1988; Joachim-Ernst Berendt: Nada Brahma. Die Welt ist Klang, Reinbek bei Hamburg 1986; Ders.: Das Dritte Ohr. Vom Hören der Welt, Reinbek bei Hamburg 1990; Robert Kuhn/Bernd Kreutz (Hg.): Das Buch vom Hören, Freiburg im Breisgau 1991; Thomas Vogel (Hg.): Über das Hören. Einem Phänomen auf der Spur, Tübingen 1996; Daniel Schmicking: Hören und Klang. Empirisch-phänomenologische Untersuchungen, Würzburg 2003; David Espinet: Phänomenologie des Hörens. Eine Untersuchung im Ausgang von Martin Heidegger, Tübingen 2009.

36 Christoph Wulf: »Das mimetische Ohr«, in Ders./Dietmar Kamper/Jürgen Trabant: Das Ohr als Erkenntnisorgan, in: Paragrana (1-2/1993), S. 9-14, hier S. $9 f$.

37 Manfred Mixner: »Der Aufstand des Ohrs«, in: Ebd., S. 29-39, hier S. 29/36.

38 Wolfgang Welsch: »Auf dem Weg zu einer Kultur des Hörens?«, in: Ebd., S. 87-103.

39 Gilles Deleuze/Felix Guattari: Tausend Plateaus, Kapitalismus und Schizophrenie, Berlin 2005, S. 20. 
sondere mit Blick auf Pierre Boulez. Auch Michel Foucault sprach mit explizitem Verweis auf den Komponisten davon, seinen »ersten großen kulturellen Choc durch französische Vertreter der seriellen und Zwölftonmusik« erfahren zu haben und dadurch aus dem dialektischen Universum herausgerissen worden zu sein. ${ }^{40}$ Erst so, könnte man pointiert ergänzen, kam Foucault zur diskursanalytischen Ordnung der Dinge und seiner ideengeschichtlich inspirierten Archäologie des Wissens. ${ }^{41}$

Jean-François Lyotard wiederum bezog sich konkret auf die Musikausübung und Kunstauffassung John Cages »als Mittel zum argumentativen Ausbau seiner Philosophie ${ }^{42}$. Vice versa bedienten sich viele zeitgenössische Komponisten intensiv bei der französischen Kulturtheorie. ${ }^{43}$ Roland Barthes widmete speziell dem Zuhören einen Aufsatz $^{44}$, während Wolfgang Welsch auf die ereignisgeschichtliche Verfasstheit von Klängen verwies: »Das Sichtbare verharrt in der Zeit, das Hörbare hingegen vergeht [...]. Sehen hat mit Beständigem, dauerhaft Seiendem zu tun, Hören hingegen mit Flüchtigem, Vergänglichem, Ereignishaftem. $\ll^{45}$ Diese Einschätzung betrifft insbesondere die Aufführungskunst Musik, deren englische Entsprechung performance nicht zufällig dem Performativen nahesteht. ${ }^{46}$

40 Michel Foucault: Interview mit P. Caruso (1967), in Ders.: Schriften, Band 1, Frankfurt am Main 2014, S. 770-793, hier S. 185.

41 Michel Foucault: Die Ordnung der Dinge. Eine Archäologie der Humanwissenschaften, Frankfurt am Main 1971; Ders.: Archäologie des Wissens, Frankfurt am Main 1973. Philipp Sarasin bezeichnete das »Echo« des surrealistischen Autors Raymond Roussel in Foucaults Werk »als die Geburtsstunde der foucaultschen Diskursanalyse«, in Ders.: Michel Foucault zur Einführung, Hamburg 2005, S. 41.

42 Hans-Joachim Heßler: Philosophie der postmodernen Musik. Jean-François Lyotard, Dortmund 2001, S. 92.

43 Ohne hier näher darauf eingehen zu können, bleibt die organische Verbundenheit von poststrukturalistischer Philosophie und den musikalischen Avantgarden als Desiderat festzuhalten. Eine Ausnahme bildet die intensive Auseinandersetzung der experimentellen Elektronika mit Gille Deleuze und Félix Guattari; davon zeugt etwa die Benennung eines einschlägigen Labels nach deren Hauptwerk: Mille Plateaux.

44 Roland Barthes: Zuhören, in Ders: Der entgegenkommende und der stumpfe Sinn, Frankfurt am Main 1990, S. 249-263, hier S. 262.

45 Welsch: Auf dem Weg zu einer Kultur des Hörens, S. 94.

46 Siehe hierzu insbesondere die theaterwissenschaftlichen Arbeiten zum Performativen von Erika Fischer Lichte: Ästhetik des Performativen, Frankfurt am Main 2004; Dies./ Christoph Wulf (Hg.): Theorien des Performativen, Berlin 2001; Dies./Doris Kolesch (Hg.): Kulturen des Performativen, Berlin 1998; Dies.: »Performance as Art - Art as Performance«, in Ulla-Britta Lagerroth/Hans Lund/Erik Hedling: Interart Poetics. Essays on the Interrelations of the Arts and Media, Amsterdam/Atlanta 1997, S. 69-84. Geschichtswissenschaftliche Perspektiven zum Performativen entwickelte etwa Jürgen Martschukat/Steffen Patzold (Hg.): Geschichtswissenschaft und »performative turn«. Ritual, Inszenierung und Performanz vom Mittelalter bis zur Neuzeit, Köln 2003. Zur weiteren Orientierung siehe das Handbuch von Uwe Wirth (Hg.): Performanz - Zwischen Sprachphilosophie und Kulturwissenschaften, Frankfurt am Main 2008. 
Bei den Avantgarden erfuhr der performative und damit ereignishafte Charakter von Musik, der Reproduzierbarkeit wie zum Trotze, eine deutliche Aufwertung. ${ }^{47}$ Weil diese spezifische Ereignishaftigkeit der Musikavantgarden oft an die einmalige Aufführung gebunden war und sich nicht zuletzt in den Reaktionen ihrer Rezipienten spiegelte, bieten sich audiovisuelle Artefakte und insbesondere Live-Mitschnitte als Instrumentarium an, um eine Geschichte klingender Eklats im Sinne einer kulturtheoretisch inspirierten Ereignisgeschichte in Angriff zu nehmen.

Wichtige Impulse für diese >klingende Historiographie` kamen aus den Kulturwissenschaften, bei denen die technischen Dispositive früh ins Zentrum des theoretischen, methodischen und phänomenologischen Interesses rückten. ${ }^{48}$. Dagegen öffneten sich die Geschichtswissenschaften nur langsam medialen Implikationen; erst seit den späten 1990ern kam es auch in den historischen Kerndisziplinen zu einer verstärkten Auseinandersetzung mit den sensorischen Einflüssen der technischen Medien auf die zeithistorische Wissensgenese. ${ }^{49}$ Von hier aus war der Schritt, Klang auch als Medium des Wissenstransfers zu verstehen, nicht mehr weit. Doch weder die medienwissenschaftlich inspirierten Geschichtswissenschaften noch die historisch arbeitenden Medienwissenschaften schenkten dem Auditiven zunächst mehr als punktuelle Aufmerksamkeit. Zwar wurden mediale Artefakte - vom Grammophon und Telefon über Radio und Fernsehen bis hin zum Internet - mit Blick auf die technikhistorischen Bedingungen und ihre Wirkungsweisen reflektiert; allerdings geschah dies nur selten auf einer akustischen Ebene, während sich die Musikwissenschaften, ausgehend von ihrem autonomieästhetischen Grundverständnis und der Fokussierung auf Werk und Schöpfer, vom methodischen und theoretischen Kanon der kulturwissenschaftlich inspirierten Fächer weitgehend abschotten und damit freiwillig den Weg in die disziplinäre Isolation gehen.

Als Sonderfall sind die Sound Studies als interdisziplinäres Forschungsfeld kulturwissenschaftlicher Klangforschung und auditiver Medienkulturen zu nennen. Hier bedient man sich explizit einer Methoden- und Theorievielfalt, die von den Science and Technology Studies, über die Kulturtechnik-Forschung bis hin zur Kulturgeschichte und der historischen Anthropologie entlehnt werden. Ihre Gegenstände entstammen überwiegend der Alltags- und Popkultur, der Wissenschafts- und Technik-

47 Dieter Mersch: Ereignis und Aura. Untersuchungen zu einer Ästhetik des Performativen, Frankfurt am Main 2002.

48 Ein enzyklopädischer Überblick über >Mediale Historiographien` finden sich bei Friedrich Balke/Bernhard Siegert/Joseph Vogl (Hg.): Archiv für Mediengeschichte, Paderborn $2001 \mathrm{ff}$.

49 Siehe etwa Gebhard Rusch (Hg.): Einführung in die Medienwissenschaft. Konzeptionen, Theorien, Methoden, Anwendungen, Wiesbaden 2002; Fabio Crivellari/Kay Kirchmann/Marcus Sandl/Rudolf Schlögl (Hg.): Die Medien der Geschichte. Historizität und Medialität in interdisziplinärer Perspektive, Konstanz 2004; Irmela Schneider/Torsten Hahn/Christina Bartz (Hg.): Diskursgeschichte der Medien, 3 Bände, Wiesbaden 2003; Frank Bösch/Annette Vowinckel: Mediengeschichte, Version 2.0, in: DocupediaZeitgeschichte (29.10.2012), URL: http://docupedia.de/zg/Mediengeschichte_Version_2.0_ Frank_B.C3.B6sch_Annette_Vowinckel?oldid=97423 [Zugriff: 31.8 .2017 ]. 
geschichte sowie der Klangkunst. ${ }^{50}$ Ein Vorteil der Sound Studies sind damit ihr transdisziplinäres und internationales Diskursfeld, das allerdings von den Kernfächern nur partiell beachtet wird und eher eine eigenständige junge Forschungsdisziplin darstellt. ${ }^{51}$ Dennoch verweist diese Entwicklung auf die wachsende Relevanz einer Auseinandersetzung mit Aspekten einer auditiven Kultur. Beschränkt sich die Öffnung der traditionellen Musikwissenschaften gegenüber den Anliegen der Sound Studies bislang noch auf wenige Ausnahmen ${ }^{52}$, ist in den kulturwissenschaftlich orientierten Medienwissenschaften ein Anwachsen derartiger Forschungsaktivitäten festzustellen. ${ }^{53}$ Auch in den Geschichtswissenschaften wird seit einigen Jahren ein dezidiert historisches Interesse am Klang der Zeitgeschichte ${ }^{54}$ laut. Dies belegt die vermehrte Gründung von Forschungsnetzwerken und -gruppen ${ }^{55}$ sowie eine steigende Zahl von Publikationen ${ }^{56}$, die sich in doppelt gemünztem Erkenntnisinteresse mit dem Wissen vom Hören respektive dem Hören als Wissen beschäftigen.

50 Holger Schulze (Hg.): Sound Studies. Traditionen - Methoden - Desiderate. Eine Einführung, Bielefeld 2008; Gisela Nauck (Hg.): Sound Studies (Themenheft), in: Positionen (86/2011). Aus dem angloamerikanischen Raum siehe etwa Michael Bull/Les Back (Hg.): The Auditory Culture Reader, Oxford 2003; Michele Hilmes: »Is There a Field Called Sound Culture Studies? And Does It Matter?«, in: American Quarterly (57/2005), S. 249259; Trevor Pinch/Karin Bijsterveld (Hg.): The Oxford Handbook of Sound Studies, New York 2011; Jonathan Sterne (Hg.): The Sound Studies Reader, London 2012; Ders.: The Audible Past. Cultural Origins of Sound Reproduction, Durham 2003.

51 Eine transnationale Einrichtung ist die »European Sound Studies Association« (ESSA) der Københavns Universitet. An der Berliner Universität der Künste wird ein Masterstudiengang Sound Studies angeboten und die Humboldt-Universität zu Berlin beherbergt das Sound Studies Lab.

$52 \mathrm{Zu}$ nennen ist hier insbesondere Elena Ungeheuer: Ist Klang das Medium von Musik? Zur Medialität und Unmittelbarkeit von Klang in Musik, in Schulze: Sound Studies, S. 5776. Erst in jüngster Zeit kommt es zur vermehrten Ausrichtung von Studienzweigen in der Musikwissenschaft, die sich der >Klangforschung` widmen.

53 Harro Segeberg/Frank Schätzlein (Hg.): Sound. Zur Technologie und Ästhetik des Akustischen in den Medien, Marburg 2005. Die Gesellschaft für Medienwissenschaften hat mit der AG Auditive Kultur Interesse an akustischen Medienkulturen hinterlegt.

54 Daniel Morat: »Der Klang der Zeitgeschichte«, in: Zeithistorischen Forschungen (2/2011), S. 172-177. Ders.: »Sound Studies - Sound Histories. Zur Frage nach dem Klang in der Geschichtswissenschaft und der Geschichte in der Klangwissenschaft«, in: KunstTexte (4/2010), S. 1-8.

$55 \mathrm{Zu}$ nennen sind hier das von der Deutschen Forschungsgemeinschaft (DFG) geförderte Forschernetzwerk »Hörwissen im Wandel« sowie die am Berliner Max-Planck-Institut angesiedelte Forschergruppe »Gefühlte Gemeinschaften. Emotionen im Musikleben Europas«. Auch das von der Fritz-Thyssen-Stiftung geförderte und an der Freien Universität Berlin durchgeführte Forschungsprojekt »Die Klanglandschaft der Großstadt. Kulturen des Auditiven in Berlin und New York 1880-1930« ist hier zu nennen.

56 Siehe etwa Christoph Kleßmann (Hg.): »Politik und Kultur des Klangs im 20. Jahrhundert«, Themenheft in: Zeithistorische Forschungen (8/2011); Jan-Friedrich Mißfelder: »Period Ear. Perspektiven einer Klanggeschichte der Neuzeit«, in: Geschichte und Gesellschaft (37/2011), S. 21-47. 
Den Startschuss zu einer historisch motivierten Klanggeschichte markierte 2004 Thomas Lindenberger, der den audiovisuellen Umbruch in seinem Aufsatz über Das vergangene Hören und Sehen reflektierte:

»Eine Dimension dieses Wandels ist die sich über mehrere Jahrzehnte hinziehende Etablierung der Audiovision als eine alle Lebensbereiche durchdringende Praxis des Realitätsbezugs, der Kommunikation und der Reproduktion sozialer Beziehungen. ${ }^{57}$

Damit wurde freilich nur ein halber Schritt zu einer klingenden Zeitgeschichte getan; Sehen und Hören werden ungeachtet der produktions- und rezeptionsästhetischen Differenzen weiterhin meist im Verbund betrachtet. Wird doch einmal die akustische Dimension fokussiert, beziehen sich die Forschungen überwiegend auf massenkulturelle Ausformungen (wie Parteitagsreden und politischen Kundgebungen) und beiläufige Hörpraktiken (wie Radiohören oder Alltagsgeräusche). Die Beschäftigung mit semantisch aussagekräftigen Klangspuren bestimmt den Diskurs, während Musik und Klang höchstens als Instrument akustischer Mobilisierung, etwa im Kontext von Nationalisierungsprozessen, untersucht werden. ${ }^{58}$ Konzertbesuche sowie Musikhören und kompositorisches Schaffen werden mit Verweis auf die Spezifik des Gegenstands meist nicht nur ausgespart, sondern sogar abgelehnt. Alexa Geisthövel etwa wies 2003 auf das Problem hin, musikalischem Klang einen spezifischen Sinn abzulauschen: Er sei »semantisch informationsarm « und »meist bis zur Unkenntlichkeit deutungsoffen«, da Klänge sich nur bedingt in zitierfähigen Text umsetzen lassen würden. ${ }^{59}$ Aus dem Feld der Sound Studies tönte es im gleichen Jahr fragenreich:

»Kann man Musik erzählen? Ist Musik selbst ein erzählender Diskurs? Muss eine Reflexion über Musik musikalisch sein? Oder verweigert sich Musik gerade ihrer Verschriftlichung und deren diskursiven Ordnungsversuchen, Text seiner Musikalisierung und Auflösung in asignifikante Intensitäten? Welche Rolle spielen die neuen Medientechnologien in diesem Kontext? « ${ }^{60}$

57 Lindenberger: Das vergangene Hören und Sehen.

58 Siehe etwa Celia Applegate/Pamela Potter (Hg.): Music and German National Identity, Chicago 2002; Tillmann Bendikowski (Hg.): Die Macht der Töne. Musik als Mittel politischer Identitätsstiftung im 20. Jahrhundert, Münster 2003; Annemarie Firme/Ramona Hocker (Hg.): Von Schlachthymnen und Protestsongs. Zur Kulturgeschichte des Verhältnisses von Musik und Krieg, Bielefeld 2006; Sven Oliver Müller/Jutta Toelle (Hg.): Bühnen der Politik. Die Oper in europäischen Gesellschaften im 19. und 20. Jahrhundert, Wien 2008; Hansjakob Ziemer: Die Moderne hören. Das Konzert als urbanes Forum 1890-1940, Frankfurt am Main/New York 2008; Peter Stachel/Philipp Ther (Hg.): Wie europäisch ist die Oper? Die Geschichte des Musiktheaters als Zugang zu einer kulturellen Topographie Europas, Wien/Köln/Weimar 2009; Jann Pasler: Composing the Citizen. Music as Public Utility in Third Republic France, Berkeley 2009.

59 Alexa Geisthövel: »Auf der Tonspur. Musik als zeitgeschichtliche Quelle«, in Martin Baumeister/Moritz Föllmer/Philipp Müller (Hg.): Die Kunst der Geschichte. Historiographie, Ästhetik, Erzählung, Göttingen 2009, S. 157-168, hier S. $158 f$.

60 Marcus S. Kleiner/Achim Szepansky: Soundcultures. Über elektronische und digitale Musik (Klappentext), Frankfurt am Main 2003. 
Natürlich ist die semantische Unschärfe von Klang nicht von der Hand zu weisen. Gleichwohl war Musik immer schon mehr als autonomieästhetische Kompositionsgeschichte: Lebensweltliche Bezüge und ästhetische Erfahrungshorizonte, also Werk und Kontext, sind nicht zu trennen und eröffnen damit auch sozialhistorische Forschungsperspektiven. Diese Meinung vertrat allen voran Theodor W. Adorno, der bis heute wichtigste Theoretiker sowie Sprachrohr und Zeitzeuge der Neuen Musik nach 1945. In seiner Musiksoziologie skizzierte er das Projekt einer sozialen Dechiffrierung von Musik »bis in die kleinsten technischen Zellen hinein. « ${ }^{61}$ Noch deutlicher formulierte er diesen Ansatz 1949 in seiner ersten musiktheoretischen Schrift überhaupt, der Philosophie der Neuen Musik, in der er das musikalische Material als »Chiffre oder Symptom für die gesellschaftliche oder politische Situation, in der sie entsteht« beschrieb:

»Nicht nur verengt und erweitert es sich mit dem Gang der Geschichte. Alle seine spezifischen Züge sind Male des geschichtlichen Prozesses. [...] Die Forderungen, die vom Material ans Subjekt ergehen, rühren vielmehr davon her, daß das Material selber sedimentierter Geist, ein gesellschaftlich, durchs Bewußtsein von Menschen hindurch Präformiertes ist. [...] Desselben Ursprungs wie der gesellschaftliche Prozeß und stets wieder von dessen Spuren durchsetzt [...], noch wo beide nichts mehr voneinander wissen und sich gegenseitig befehden. $\ll^{62}$

Nicht zuletzt dieses \Befehden ২ kann mit Blick auf die Skandale der von der breiten Öffentlichkeit weitgehend isolierten Neuen Musik als geschichtsmächtig gelten. Wenn musiksoziologische Versuche mit ästhetischem wie gesellschaftlichem Erkenntnisinteresse auch immer wieder als »vage und rudimentär [...], methodisch unseriös und instabil ${ }^{63}$ bezeichnet wurden, erfahren sie in den aktuellen kulturwissenschaftlichen Debatten doch eine neue Legitimation. In ihrer Auseinandersetzung mit »Aspekten einer Theorie der auditiven Kultur« bemerkte 2010 etwa Sabine Sanio:

»Kunstwerke gelten, im Anschluss an Hegels Ästhetik, als spezifische Darstellung ihrer Epoche, ihre Interpretation und historische Einordnung gilt deshalb als Beitrag zur allgemeinen Geschichtsschreibung. Die bürgerliche Kultur manifestiert sich in herausragenden Kunstwerken, die in Museen und Bibliotheken gesammelt oder in Konzertsälen, Theater- und Opernhäusern zur Aufführung gebracht werden. ${ }^{64}$

Wenn man die Geschichte der Künste auch als Geschichte der Erkundung ihrer Voraussetzungen begreift, kommt es also fast zwangsläufig zur Erforschung der empirischen Realität. Auch die Musikwissenschaftlerin Beate Kutschke plädierte dafür, den

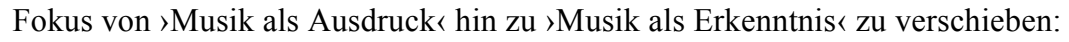

61 Theodor W. Adorno: Ideen zur Musiksoziologie, in Ders.: Musikalische Schriften, Band 1: Klangfiguren, Frankfurt am Main 1959, S. 9-31, hier S. 11.

62 Theodor W. Adorno: Philosophie der Neuen Musik, Tübingen 1949, S. $21 \mathrm{f}$.

63 Siehe etwa Carl Dahlhaus: »Das musikalische Kunstwerk als Gegenstand der Soziologie«, in: IRASM (5/1974), S. 24.

64 Sabine Sanio: »Aspekte einer Theorie der auditiven Kultur«, in: Kunsttexte (4/2010), S. 5. 
»Avantgardemusik operiert $[\ldots]$ als eine Instanz, die weniger eine emotionale auf kollektive Erfahrungen zurückgehende, sondern vor allem eine kognitive Identität stiftet, indem sie mit musikalischen Mitteln, mit den Mitteln der musikalischen Sprachbildung und Symbolisierung auf [...] Wissen [...] Bezug nimmt und im musikalischen Vollzug dieses Wissen oder neu geschaffene Varianten des Wissens vorführt, performiert und distribuiert. ${ }^{65}$

Musik kann dementsprechend als diskursives Zeichensystem verstanden werden und verdankt ihre historische Aussagekraft einer dreifachen Sinnhaftigkeit zwischen Werk, Kontext und Materialität, die auch in der Medialität ihrer akustischen Überlieferung auf außermusikalische Kontexte verweist. Auch Laurenz Lütteken beschrieb Musik als keineswegs abgeschlossen von anderen semiotischen Systemen:

»Begreift man komponierte Artefakte als historisch determinierte Gegenstände, als Ergebnis konkreter Entscheidungen handelnder Menschen [...], dann lassen sich diese Artefakte keineswegs mit jener Schärfe isolieren, wie es die Betrachtung als autonomes Abstraktum nahelegt. Jedes Musikwerk ist Bestandteil einer komplexen Wirklichkeit, durch die keine schroffe Trennung von Text und Kontext verläuft. « ${ }^{66}$

Die Neue Musik verifiziert diese Erwägungen gerade in ihrer Abkehr vom bürgerliche Kulturverständnis sowie vice versa ihrer Abwehr durch das bürgerliche Musikpublikum. Ihre zentralen Anliegen - Schock und Provokation, Subversion und Innovation, Dogma und Absolutismus - wurden auch zu zentralen Kategorien der Moderne selbst: Das 20. Jahrhundert und seine künstlerischen Avantgarden weisen Parallelen auf, indem sie Axiome wie Ent-Subjektivierung und Prinzipien der Dekonstruktion teilen. Die Nachkriegsavantgarde wurde zum Negativabbild eines gesellschaftlichen Umbruchs, der in den Worten Adornos zur $>$ Kulturindustrie $<{ }^{67}$ oder nach Jürgen Habermas zu einem Strukturwandel der Öffentlichkeit und »vom kulturräsonierenden zum kulturkonsumierenden Publikum « ${ }^{68}$ führte. Damit ist diese Arbeit auch als Beitrag zu einer >intellectual history< zu verstehen, wie sie Monika Boll definierte: Als »eine systematische Analyse theoretischer Stellungnahmen mit dem Ziel, deren Bindung, Valenz und Einfluss innerhalb einer konkreten politischhistorischen Konstellation zu ermitteln und die sich für die biographisch-ideelle Verwobenheit ihrer Akteure ins Zeitgeschehen interessiert. « ${ }^{69}$

65 Beate Kutschke: Neue Linke - Neue Musik. Kulturtheorien und künstlerische Avantgarde in den 1960er und 70er Jahren, Köln/Weimar/Wien 2007, S. 22.

66 Laurenz Lütteken: „Wie autonom kann Musikgeschichte sein? Perspektiven eines methodischen Wandels«, in: Archiv für Musikwissenschaft (57/2000), S. 31-39, hier S. 36.

67 Theodor W. Adorno: »Résumé über Kulturindustrie«, in Lorenz Engell/Oliver Fahle/Britta Neitzel/Claus Pias/Joseph Vogl (Hg.): Kursbuch Medienkultur. Die maßgeblichen Theorien von Brecht bis Baudrillard, Stuttgart 2002, S. 202-208.

68 Jürgen Habermas: Strukturwandel der Öffentlichkeit. Untersuchungen zu einer Kategorie der bürgerlichen Gesellschaft, Frankfurt am Main 1990, S. 248-266.

69 Monika Boll: Nachprogramm. Intellektuelle Gründungsdebatten in der frühen Bundesrepublik, Münster 2004, S. 7/10. 
Wenn sich in den letzten Jahren also eine Konjunktur der interdisziplinären KlangForschung feststellen lässt, so sind Musik und akustische Quellen trotz ihres fächerübergreifenden Potentials bislang nicht ins Zentrum des Interesses gerückt. Dabei können Klänge und auditive Spuren für die kulturwissenschaftlich orientierten Medienwissenschaften nach den umfangreichen Forschungen zu Kino oder TV-Serien einen Gegenstand stellen, der deutlich über die bereits geleisteten Arbeiten im Bereich der filmischen Soundebene hinausgeht. ${ }^{70}$

Aber auch für die Geschichtswissenschaften versprechen akustische Artefakte als originäre Zeitzeichen unmittelbaren und authentischen Aufschluss über historische Ereignisse, indem sie nicht nur vom technischen Wandel und ästhetischen Umbrüchen erzählen, sondern auch das Rezeptionsverhalten und damit affektive Sinnesäußerungen abbilden können. Quellenarbeit jedoch basiert, auch 150 Jahre nach Thomas Alva Edisons Erfindung des Phonographen und den damit verbundenen Möglichkeiten der Speicherung und Reproduktion von Daten noch immer zum überwiegenden Teil auf Schriftstücken, während Berge von akustischen Quellen übergangen werden. ${ }^{71}$ Dies liegt nur zum Teil an der unübersichtlichen Archivlandschaft, an rechtlichen Fragestellungen besonders in Hinsicht auf das Urheberrecht oder einer latenten Unsicherheit bezüglich eines angemessenen Umgangs mit dem Material. Noch auf dem Historikertag 2006 in Konstanz stimmte eine Mehrheit der Mitglieder des Historikerverbandes gegen eine Resolution, die darauf abzielte, einen verbesserten Zugang zu audiovisuellen Quellen zu ermöglichen. ${ }^{72}$

Insofern verwundert es nicht, dass die historische Auseinandersetzung mit konkreten audiovisuellen Quellen bislang fragmentarisch und größtenteils wenig überzeugend ist. Eine Ausnahmeerscheinung ist Bodo Mrozek, der 2011 in seinem Aufsatz »Geschichte in Scheiben « über LPs als zeithistorische Quellen reflektierte. ${ }^{73} \mathrm{Da}-$ rin plädierte er dafür, »den mehrdimensionalen Quellenwert von Schallplatten als Ton-, Text- und Bildspeichern auszuschöpfen« und betonte den erkenntnisleitenden Mehrwehrt durch die akustische Ebene des Materials: »Intonation, Rhythmik und Aussprache sind nach rhetorischen Kriterien, beispielsweise in einer politischen Rede, mindestens ebenso wichtig wie die rein kognitiven Informationen. ${ }^{74}$ Zugleich übte er eine differenzierte Quellenkritik akustischer Abbildungen:

70 Siehe hierzu einführend Silke Martin: Die Sichtbarkeit des Tons im Film. Akustische Modernisierungen des Films seit den 1920er Jahren, Marburg 2010; Joachim Polzer (Hg.): Sound - Der Ton im Kino, Berlin 1996.

$71 \mathrm{Zu}$ nennen sind in Deutschland das Deutsche Musikarchiv in Leipzig sowie die Bestände der öffentlich-rechtlichen Rundfunkanstalten. International vergleichbar sind in den USA das National Recording Registry sowie das Sound Archive der British Library.

72 Siehe hierzu ausführlich Christoph Classen/Thomas Großmann/Leif Kramp: »Zeitgeschichte ohne Bild und Ton? Probleme der Rundfunk-Überlieferung und die Initiative >Audiovisuelles Erbe« «, in: Zeithistorische Forschungen (8/2011), S. 130-140. Siehe auch den Tagungsbericht von Kirsten Moritz: »Zeitgeschichte ohne Ressourcen? Probleme der Nutzung audiovisueller Quellen« (Mainz 2012), in: H-Soz-Kult vom 18.10.2012, URL: http://www.hsozkult.de/conferencereport/id/tagungsberichte-4417 [Zugriff: 31.8.2017].

73 Bodo Mrozek: »Geschichte in Scheiben. Schallplatten als zeithistorische Quellen«, in: Zeithistorische Forschungen (8/2011), S. 295-304.

74 Ebd., S. 297. 
»Eine Schallplatte kann vielleicht den Klang, nicht aber das Hörerlebnis ihrer Epoche unmittelbar überliefern. Selbst wenn eine Aufnahme das Verklungene identisch wiedergeben sollte, so bleibt doch die Praxis des Hörens zeit-, raum- und gruppenspezifisch: Die auditive Wahrnehmung des Historikers ist eine andere als diejenige der historischen Subjekte. ${ }^{75}$

Mag diese Einlassung für industrielle Produkte wie Schallplatten oder CDs gelten, deren Status als Massenprodukte in der Tat Konsequenzen für ihren Gebrauch als Quellen erfordert, sparte Mrozek die historisch aussagekräftigsten akustischen Artefakte aus: Live-Mitschnitte historischer Ereignisse, die zuhauf und oft unberührt in den Klangarchiven lagern. Auf diesem unbearbeiteten Rohmaterial kann man nicht nur die Begebenheiten selbst, sondern auch die affektiven Gefühlsäußerungen der zeithistorisch Mitlebenden quasi unmittelbar erleben und gewinnt die Sinnesgeschichte eine wahrhaft sinnliche Ebene hinzu. Einschränkend gilt es aus medientechnischer Perspektive aufnahmetechnische Dispositionen wie etwa die Stellung der Mikrophone zu beachten und auf die besondere Verfasstheit des »Zuhören« im Sinne von Roland Barthes hinzuweisen. Der französische Kulturphilosoph machte darauf aufmerksam, dass »das Ohr, das die Informationen lesbar machen soll, immer schon imprägniert « ist nach bestimmten Codes. Zuhören gelte der Dechiffrierung der Wirklichkeit, um das »Dahinter des Sinns« und sei damit der Hermeneutik verbunden. Es gehe darum, wer spricht und wer sendet, also um die allgemeine Signifikanz:

»Das Zuhören schließt heute nicht nur das Unbewusste, im topischen Sinne des Wortes, in sein Feld ein, sondern sozusagen auch dessen weltliche Formen: das Implizite, das Indirekte, das Zusätzliche, das Hinausgezögerte. Es gibt eine Öffnung des Zuhörens auf alle Formen der Polysemie, der Überdeterminierung und der Überlagerungen, es gibt ein Abbröckeln des Gesetzes, das ein geradliniges, einmaliges Zuhören vorschreibt. $^{76}$

Der Vorteil eines solchen Zuhörens liegt, insbesondere für Ereignisgeschichte und speziell einen Gegenstand wie den Musikskandal, auf der Hand: im Außergewöhnlichen werden nicht nur vermehrt Quellen produziert; diese geben auch Aufschluss über den Wandel ästhetischer Normen und erlauben eine akustische Bewertung der zeitgenössischen (Re-)Produktions- und Rezeptionsbedingungen im unmittelbaren Moment der klingenden Eklats. Damit ist der Anschluss an Musikskandale als wechselseitig zwischen Produktion und Rezeption zu fassenden Ereignissen hergestellt: Die Produktionsseite umfasst die Herstellung musikalischer Kunstwerke durch Komponisten und Interpreten, aber auch die jeweils geltenden technischen Bedingungen der Aufnahmen. Dazu gehört auch die Entscheidung, welche Ereignisse auf Band gebannt und der Öffentlichkeit zugänglich gemacht werden - oder eben nicht.

Die Produktionsebene berührt also auch die Inszenierung von historischen Begebenheiten als Medienereignis beziehungsweise die Verhinderung eines solchen aufmerksamkeitsökonomischen Vorgangs durch Veranstalter, verantwortliche Institutionen oder die Presse. Rezeption auf der anderen Seite lenkt den Blick auf die Hörer und Rezipienten, zu denen mit Rezensenten und Kritikern wiederum mediale Akteure zählen, welche die Wahrnehmung der Ereignisse durch die Öffentlichkeit prägen und 
steuern. Insbesondere das bürgerliche Konzertpublikum in den Auditorien ist eine bislang oft vernachlässigte Akteursgruppe, wird doch Musik meist überwiegend vom Schöpfer und Werk aus betrachtet und ist die unmittelbare Rezeption klingender Ereignisse bar audiovisueller Artefakte nur schwer nachvollziehbar. Dieses Manko kann durch den Einsatz von Live-Mitschnitten behoben werden. Fraglos können audiovisuelle Quellen die Klang- und Rezeptionsnormen ihrer Epoche authentisch übermitteln und subjektiv gefärbten Schriftstücken - wie Kritiken, Briefen oder Augenzeugenberichten - eine weitere, eine sinnliche Ebene hinzufügen. Umberto Eco entwarf bereits 1962 seine Theorie einer Opera aperta $^{77}$, nach der das Kunstwerk als offene Struktur die aktive Koproduktion der Rezipienten benötige und darin eine geschichtliche Vielfalt von Konkretisationen zeitige. Im Anschluss daran entwickelte Hans Robert Jauß 1987 seine Theorie der Rezeption ${ }^{78}$ und forderte,

»die Geschichte [...] der Künste nunmehr als einen Prozess ästhetischer Kommunikation zu begreifen, an dem die drei Instanzen von Autor, Werk und Rezipient [...] gleichermaßen beteiligt sind. Das schloss ein, den Rezipienten als Empfänger und Vermittler, mithin als Träger aller ästhetischen Kultur endlich in sein historisches Recht einzusetzen, das ihm in der Geschichte der Künste vorenthalten blieb, solange sie im Banne der traditionellen Werk- und Darstellungsästhetik stand. ${ }^{79}$

In Anlehnung und Abgrenzung dazu soll hier eine spezifisch musikalische Rezeptionsästhetik formuliert werden: Während Literatur in der Regel von einem Leser reflektiert wird und als Werk unverändert bleibt, wird konzertante Musik im unmittelbaren Augenblick der Aufführung von einem Publikumskollektiv rezipiert. Wenn Jauß die Historizität in der nachträglichen sich wandelnden Rezeption der Werke stark machte, so interessiert in dieser Arbeit besonders der unmittelbare Augenblick der klingenden Ereignisse, der sich nicht zuletzt in den emotionalen Reaktionen des Auditoriums spiegelt. Denn eines ist den Phänomenen Musik und Affekt gemeinsam: Sie sind flüchtig; nur auf der Ebene ihrer unmittelbaren Artikulation sind sie kulturell kodiert, diskursiv eingebettet und damit kontextualisierbar.

Es ist kein Zufall, dass affektgeladene Musikskandale sich meist bei Premieren als außergewöhnlichen und singulären Veranstaltungen mit erhöhtem Aufmerksamkeitspotential ereignen. Hier eröffnen sich nicht nur Anschlüsse an kulturelle Verhaltensroutinen sowie die Funktionsweisen der massenmedialen Aufmerksamkeitsökonomie, sondern auch an die französische Ereignisphilosophie. Gilles Deleuze etwa antwortete auf die Frage »Was ist ein Ereignis?«: »Heute Abend findet ein Konzert statt, das ist ein Ereignis. $\ll^{80}$ Das Beispiel ist gut gewählt, denn ungeachtet der Reproduktionstechnologien ist Konzertmusik und ihre Rezeption weiterhin an den Moment der Aufführung gebunden. Im unvorhersehbaren Erwartungsraum einer Premie-

77 Umberto Eco: Das offene Kunstwerk, Frankfurt am Main 1973.

78 Hans Robert Jauß: Die Theorie der Rezeption - Rückschau auf ihre unerkannte Vorgeschichte, Konstanz 1987.

79 Hans Robert Jauß: »Rezeption, Rezeptionsästhetik«, in: Historisches Wörterbuch der Philosophie, Band 8, Basel 1992, S. 996-1004, hier S. 996.

80 Gilles Deleuze: »Was ist ein Ereignis?«, in Ders.: Die Falte. Leibniz und der Barock, Frankfurt am Main 2000, S. 126-136, hier S. 133. 
re können »Dissonanzen zwischen unterschiedlichen Welten [...] selbst um den Preis der Verdammnis $«{ }^{81}$ anklingen. Solche Konzertereignisse bilden ein Proszenium, das allem voran einen Erfahrungsraum bezeichnet: »In ihrer ganzen unbegriffenen Dichte bringen sie etwas Unerhörtes, nie Gesehenes, Unglaubliches zur Geltung, quasi eine Andersheit, die nur vorläufig und auf Kosten dogmatischer Vorverständnisse verdrängt werden konnte. $\varkappa^{82}$ Ohne weiter auf die komplexe Vielfalt der französischen Ereignisphilosophie eingehen zu können, wird in diesem Exkurs doch vor allem und in den Worten Laurenz Lüttekens eines deutlich: "Musik ist stets an ihre zeitliche Verlaufsform gebunden, erst im Vollzug, im performativen Akt der Aufführung, entfaltet sich ihre prinzipielle Ereignishaftigkeit ${ }^{83}{ }^{3}$ - immer einzigartig und der technischen Reproduzierbarkeit wie zum Trotz nicht wiederholbar.

Bei den musikalischen Nachkriegsavantgarden erfuhr diese Ereignishaftigkeit eine Zuspitzung, indem es zur Aufhebung der tradierten Grenzen zwischen Kunst und Nicht-Kunst sowie zu einer eklatanten Ästhetisierung der Lebenswelt kam. In den Momenten, wenn sich die Empörung der Hörer über den Bruch der Kunstgesetze in performativen Ausbrüchen entlud, wird die von Jaques Derrida formulierte unmögliche Möglichkeit vom Ereignis zu sprechen ${ }^{84}$ möglich: dann ist das Ereignis historisch kontextualisierbar und bezeichnet sich zugleich selbstreferenziell im akustischen Artefakt. Um diese orts- und zeitgebundene Präsenz musikalischer Aufführungen dokumentieren zu können, sind Mitschnitte ungemein wertvolle Quellen: Sie können die emotionalen Kontrollverluste der Rezipienten abbilden, die Musikaufführungen erst zu eklatanten Ereignissen machen, indem sie die ritualisierten Verhaltenskodizes unterlaufen. Im Kontext von Aufführungssituationen, speziell bei Premieren, kann sich eine Art emotionaler Raum bilden, in dem verschiedene und in der Regel widerstreitende Gefühlte Gemeinschaften ${ }^{85}$ in polarisierenden Affekten aufeinanderstoßen. Solche unmittelbar ausbrechenden Gefühle sind - wie Lucien Febvre bereits 1941 bemerkte - ansteckend ${ }^{86}$ und im Anschluss an Ute Frevert eine Form sozialen Handelns und damit geschichtsmächtig. ${ }^{87}$ Erst das Quellenmaterial von LiveMitschnitten macht einen sinnlichen Zugriff auf den unmittelbaren Moment ihres Ereignens überhaupt erst möglich.

81 Ebd., S. 135.

82 Marc Rölli (Hg.): Ereignis auf Französisch. Von Bergson bis Deleuze, München 2004, S. 12. Der Band reflektiert die ganze Dichte französischer Ereignisphilosophie, die hier nur angedeutet werden kann.

83 Laurenz Lütteken: »Komponieren am Ende der Zeit. Überlegungen zum musikalischen Ereignis-Begriff am Beispiel von Bernd Alois Zimmermanns Ekklesiastischer Aktion«, in Thomas Rathmann (Hg.): Ereignis. Konzeptionen eines Begriffs in Geschichte, Kunst und Literatur, Köln/Weimar/Wien 2003, S. 119-136, hier S. 120.

84 Jaques Derrida: Eine gewisse unmögliche Möglichkeit vom Ereignis zu sprechen, Berlin 2003.

85 Diese Formulierung wurde gewählt in Anlehnung an die »Forschungsgruppe Gefühlte Gemeinschaften. Emotionen im Musikleben Europas« des Max-Planck-Institut für Bildungsforschung in Berlin.

86 Febvre: Sensibilität und Geschichte, S. 316.

87 Ute Frevert: »Was haben Gefühle in der Geschichte zu suchen?«, in: Geschichte und Gesellschaft (35/2009), S. 183-208, hier S. 202. 
Audiovisuelle Medien bilden Gefühle also nicht bloß ab; vielmehr verändern und kreieren sie selbst Deutungen und Praktiken des Fühlens und geben Hinweise auf die soziale Normierung und Herstellung von Gefühlen im Zeitalter der Massenmedien. ${ }^{88}$ Kulturwissenschaftlich als genuin soziale Phänomene gedacht und performativ im Moment ihres Vollzugs, ihrer Artikulation und Wahrnehmung, sind Affekte im Umfeld des musikalischen Skandals nicht nur sozial und kulturell modelliert, sondern auch politisch und medial instrumentalisiert und choreographiert.

Will man an die tieferliegenden Wirkungszusammenhänge der diskursiv durchsetzten Strukturen und Prozesse im Umfeld des Musikskandals gelangen, bedarf es eines Zusammenspiels unterschiedlicher Quellenformate: Auf auditiver Ebene sind dies Hörbeispiele von Schlüsselwerken dieser klingenden Ereignisgeschichte, die in der Arbeit mit dem Symbol [ $\delta-\mathrm{x}]$ bedacht und im bibliographischen Anhang als "Audiovisionen « kenntlich gemacht werden. Von besonderer Bedeutung sind dabei Live-Mitschnitte als medientechnische Abbilder der vergangenen klingenden Ereignisse. Freilich müssen die von den Aufnahmen suggerierten Erkenntnisse durch konventionelle Quellenformen kontextualisiert werden, insbesondere Presseerzeugnissen wie Konzertkritiken und Mediendebatten, die durch eine systematische Auswertung einschlägiger Periodika sowie archivarischer Sammlungen gewonnen wurden. ${ }^{89}$ Diese eröffnen durch ihr zeittypisch wandelbares Vokabular sowohl mentalitätsgeschichtliche Kontexte, wie auch Rückschlüsse auf zeitspezifische Erwartungs-, Rezeptions- und Affekträume. Dazu kommt seit der zweiten Hälfte der 1940er-Jahre einschlägiges Archivmaterial wie Hörerzuschriften an die öffentlich-rechtlichen Rundfunkanstalten, die eine Einschätzung gesellschaftlicher Diskursfelder ermöglichen, während autobiographische Zeugnisse wie Tagebuchaufzeichnungen und Briefe eine Innenschau auf die Handelnden und Hörenden (be-)greifbar machen. Erst in der Konfrontation solcher Verbalisierungen lassen sich die (Hör-)Erfahrungen in ihrem zeitgebundenen Kontext analysieren und kulturhistorisch nutzbar machen. Eine wichtige Materialgrundlage für die hier skizzierten erfahrungsgeschichtlichen Fragestellungen ist schließlich die >oral history` als Medium der erzählten Lebensgeschichte: Die zeithistorisch Mitlebenden werden dabei nicht nur als Mithörende und Mitsehende, sondern auch als Sprechende sowie speziell in dieser Arbeit als Klanggebende konzipiert. Es geht im Folgenden also nicht zuletzt um eine Rekonstruktion der jeweils zeitspezifischen Kontexte im Sinne einer Erlebten Geschichte ${ }^{90}$, in der akustische Quellen durch Schriftstücke und Erinnerungen von Taktgebern dieser `klingenden Historiographie` flankiert werden.

88 Siehe hierzu etwa Frank Bösch/Daniel Borutta (Hg.): Die Massen bewegen. Medien und Emotionen in der Moderne, Frankfurt am Main/New York 2006; Patrick Schmidt (Hg.): Medialisierte Ereignisse. Performanz, Inszenierung und Medien, Frankfurt 2010; Sybille Krämer (Hg.): Performativität und Medialität, München 2004.

89 Systematisch ausgewertet wurden: Die Zeit, Der Spiegel, Süddeutsche Zeitung, Frankfurter Allgemeine Zeitung, New York Times sowie die einschlägigen Musikzeitschriften Melos, Neue Zeitschrift für Musik, [Musikblätter des] Anbruch.

90 Armin Köhler/Rolf W. Stoll (Hg.): Erlebte Geschichte. Aufbrüche, Rückblicke, Zeitläufte (DVD), Mainz 2009. 


\section{Anatomie im Stil einer Sonatensatzform}

Der Aufbau dieser Studie, ihre Anatomie, folgt einem klassischen musikalischen Formungsprinzip: der Sonatenhauptsatzform. In der Formenlehre bezeichnet der Begriff insbesondere das Modell und Gestaltungsprinzip einer Sinfonie - also eines größeren Werks mit mehreren Sätzen, das strengen Regeln folgt und doch mit Rücksicht auf das thematische und motivische Material flexibel anwendbar ist. Werden in der Exposition die Themen vorgeführt, wird das thematische und motivische Material in der Durchführung sequenziert, moduliert und variiert, bevor es in der Reprise wieder zusammengeführt und auf den Prüfstand gestellt wird. Eine Anlehnung an dieses Prinzip ist bei einer wissenschaftlichen Arbeit, die sich Musik und Klang zum Gegenstand nimmt, naheliegend: Sätze werden zu Kapiteln, in denen unterschiedliche Themenkomplexe in den Fokus rücken, die jeweils einem spezifischen Spannungsbogen folgen.

Die anatomische Anlehnung an das musikalische Formungsprinzip geht über rein stilistische Gründe hinaus und folgt ebenso methodischen Anliegen: Eines der wichtigsten Elemente einer gelungenen Sonatensatzform ist die Verwendung zweier gegensätzlicher Themen. Aus der Spannung dieses dialektischen Gegensatzpaares gewinnt das Werk seine Charakteristik und Spannung. Deshalb ist nicht nur die Aussagekraft der einzelnen musikalischen Themen wichtig, sondern auch ihre Beziehung zueinander. Diesem Prinzip folgt auch die vorliegende Arbeit. Die beiden spannungsgeladenen Hauptthemen, die sich unter dem übergeordneten Motiv Klingende Eklats dialogisieren, profilieren und kontrastieren, sind: Skandal und Neue Musik. Diesem reibungsintensiven Verhältnis wird in mehreren Sätzen respektive Kapiteln nachgegangen, in denen jeweils spezifische Varianten und Modulationen des Themen-Doppels verhandelt und in den Fokus gerückt werden. Es geht dabei weniger um eine fortlaufende Geschichte; vielmehr werden Musikskandale exemplarisch ins Scheinwerferlicht gerückt um auf ihr kulturdiagnostisches Potential und tieferliegende Strukturen zu verweisen. Der Aufbau folgt dabei keiner streng chronologischen Ordnung um thematische Querverbindungen zu ermöglichen; innerhalb der Sätze aber gibt die Chronologie den verhandelten Ereignissen ihren Takt.

Bevor der konkrete Aufbau skizziert wird, soll zunächst die Auswahl des Korpus begründet werden: Wenn hier überwiegend die bundesrepublikanische Geschichte im »langen Zyklus der Nachkriegszeit « ${ }^{91}$ von 1945 bis in die Mitte der 1970er Jahre im Fokus steht, so hat das verschiedene Gründe. Zum einen war (und ist) Deutschland für die westliche Kunstmusik ein topographisches und diskursives Zentrum; das gilt auch und besonders für die Neue Musik. Gewählt wurde die Fokussierung einer nationalen Szenerie auch deshalb, um in einem klar umrissenen Raum an konkreten Beispielen in ihrem zeitlichen Verlauf die Entwicklungen und Veränderungen sowie die Netzwerke, Strukturen und Diskurse herausarbeiten zu können und einer analytischen Diskussion zu erschließen. Der gewählte Zeitrahmen umfasst zudem einen für diese Arbeit relevanten und von Jürgen Habermas bezeichneten Wandlungsprozess:

91 Stephan Schulmeister: »Die große Krise im Kontext des >langen Zyklus` der Nachkriegszeit«, in Manfred Oberlechner/Gerhard Hetfleisch (Hg.): Integration, Rassismen und Weltwirtschaftliche Krise, Wien 2010, S. 1-34. 
Vom kulturräsonierenden zum kulturkonsumierenden Publikum ${ }^{92}$. Erlebte die Neue Musik nach 1945 - geprägt von der Aufbruchsstimmung nach der deutschen Kapitulation sowie als vormals >entartet` gebrandmarkte und nun von den alliierten Besatzungsmächten explizit geförderte Kunst - zunächst eine Blütephase, rutschte sie seit den 1960er Jahren zugunsten der aufstrebenden Unterhaltungs- und Popkultur in eine Nische und damit ihre Skandale in einen intellektuellen und von der breiten Öffentlichkeit isolierten Sperrbezirk. Schließlich ist die lange Nachkriegszeit durch Umbrüche sequenziert, die ein analytisches Einhaken ermöglichen. Konkret wirft die Arbeit einen Blick auf historische Knotenpunkte, an denen jeweils ein Querstand gesellschaftlicher, ästhetischer und medialer Wandlungsprozesse festzustellen ist.

Der Musikwissenschaftler Hermann Danuser bemerkte, es sei »für die Musikhistorie von besonderem Interesse, die Rolle des Skandals, der Invektive, des heftig ausgetragenen Disputes bei geschichtlich prägnanten Augenblicken und Umbruchphasen zu untersuchen. ${ }^{93}$ Im Anschluss daran folgt diese Arbeit der Hypothese dass Musikskandale als liminale und inkommensurable Kategorie des Übergangs zu verstehen sind. ${ }^{94}$ Der klingende Eklat, so die Schlussfolgerung, bezeichnet als Ereignis gleichermaßen historische Schwellenphasen wie ästhetische Paradigmenwechsel. Es ist jedenfalls kaum ein Zufall, dass sich Saalschlachten und ästhetische Kontroversen gebündelt und verdichtet in Umbruchsituationen ereigneten, die in der Mitte des 20. Jahrhunderts besonders deutlich zutage traten und die These stützen, dass ästhetische und gesellschaftliche Entwicklungen sich bedingen.

Wenn hier auch die klingende Ereignisgeschichte der Bundesrepublik Deutschland in den ersten drei Nachkriegsdekaden im Mittelpunkt des Interesses steht so ist diese Setzung doch keinesfalls statisch zu verstehen. Im Sinne »zirkulierender Referenzen ${ }^{95}$ werden jeweils Rück- und Vorgriffe sowie Exkurse eingeflochten, soweit das historisch-thematische Material diese nahelegt oder sogar erfordert. Dies betrifft nicht nur die Resonanzen politischer und medialer Prozesse in Kunst und Kultur, sondern auch die verbindenden und trennenden Strukturen zwischen den exemplarisch ausgewählten Fallbeispielen. Diese erheben keinen Anspruch auf Vollständigkeit, sondern wurden nach Bedeutung, Reichweite und Resonanz ausgewählt. Strukturieren also aussagekräftige Exempel die Kapitel in sich, wurden diese äußerlich nach dem Prinzip der Sonatenhauptsatzform und nicht zuletzt in Hinblick auf das Material geformt und kulturhistorisch nutzbar gemacht.

92 Habermas: Strukturwandel der Öffentlichkeit, S. 248-266.

93 Danuser: Lob des Tadels, S. 116.

94 Anhaltspunkte zu solchen ästhetischen Revolutionen liefert zum einen Thomas S. Kuhns Modell von Scientific Revolutions, in denen theoretische und historische Wandlungsprozesse »in Bezug auf Begriffsbildung, Beobachtung und Apparaturen« einen nachhaltigen Wandel erfahren«, vgl. Ders.: Die Struktur wissenschaftlicher Revolutionen, Frankfurt am Main 1976, S. 57. Ein anderes Grundlagenmodell bietet das 1909 vom französischen Ethnologen Arnold van Gennep entwickelte Konzept der Übergangsriten (rites de passage), mit dem Wandlungsprozesse als rituelle Abläufe gefasst werden können, vgl. Ders.: Übergangsriten, Frankfurt am Main/New York 2005.

95 Der Begriff wurde im Kontext der Akteurs-Netzwerk-Theorie von Bruno Latour geprägt: "Zirkulierede Referenz. Bodenstichproben aus dem Urwald am Amazonas«, in Ders. (Hg.): Die Hoffnung der Pandora, Frankfurt am Main, S. 36-95. 
In der >Exposition « werden auf der Basis wissenschaftlicher Vorarbeiten und analytischer Vorannahmen zum Musikskandal Referenzen und Chiffren aus der ersten Hälfte des 20. Jahrhunderts extrahiert und zum Versuch einer Definition verdichtet. Musiktheoretisch gesprochen bietet diese `Exposition ‘ das Material und Handwerkszeug für den Hauptteil der Arbeit - die >Durchführung< des zentralen Themen-Doppels Skandal und Neue Musik in den vier Hauptkapiteln, in denen das thematische und motivische Material diskursiv diskutiert, methodisch moduliert und vergleichend variiert:

In Agon und Skandal werden die allgemeinen Entwicklungstendenzen der musikalischen Nachkriegsavantgarde an ihren westdeutschen Zentren - den Donaueschinger Musiktagen und den Darmstädter Ferienkursen für Neue Musik ${ }^{96}$ - als agonale Ereignisgeschichte skizziert. Ausgehend von einer radikalen Negation der Vergangenheit formulierte die junge Komponistengeneration nach 1945 einen Innovationsimperativ, der sich in schockartiger Ästhetik sowie Skandalen in Serie äußerte und zu einem Absolutismus der Moderne verdichtete. Folgen dieser Entwicklung waren die Isolation der Neuen Musik von der Kulturindustrie und die Segregation der Musikkultur in eine E(rnste)- und eine U(nterhaltungs)-Sparte.

In der Folge rückt die Elektronische Eklatanz der Medienmusik der Schlüsseljahre 1953/54 in den Fokus, die anhand dreier Fallbeispiele vergleichend untersucht wird. Die nachrichtentechnischen Innovationen des Krieges begünstigten das musikalische Dämmern des Medienzeitalters, in dem Instrumente und Interpreten von der Maschine als Hypervirtuose abgelöst wurden und das Konfliktfeld Mensch versus Maschine eine Konjunktur erfuhr. ${ }^{97}$ Die neuen Medientechniken bereiteten in Verschränkung mit den weltpolitischen Ereignissen auch einer topologischen Verschiebung des kulturhistorischen Raums den Weg, die im folgenden Kapitel in den Fokus rückt.

Der analytische Fokus auf der Bundesrepublik muss, gerade auch wegen ihrer globalen Bedeutung für die Kunstmusik, Seitenblicke auf andere Kulturkreise einschließen um ex negativo sichtbar werden. Insbesondere die zunehmenden Transkulturellen Transfers mit den USA flankierten die Neue Musik in Deutschland nicht nur, sondern akzentuierten die westliche Avantgarde innerhalb eines konfliktiven transatlantischen Bündnisses. Dabei wurde eine Neuvermessung der klingenden Welt eingeleitet sowie die >eurozentrische Kulturhegemonieく unter dem Einfluss der zeithistorischen Entwicklungen auf den Prüfstand gestellt. ${ }^{98}$

96 Ausgiebige Besuche in den Sammlungen der Donaueschinger Musiktage im Historischen Archiv des Südwestrundfunks (SWR) sowie im Archiv des Internationalen Musikinstituts Darmstadt (IMD) lieferten vielfältiges, größtenteils nicht publiziertes Quellenmaterial.

97 Wichtige Materialien zur Geschichte der Elektronischen Musik finden sich im Historischen Archiv des Westdeutschen Rundfunks (WDR) sowie dem Deutschen Rundfunkarchiv (DRA).

98 Wertvolles Quellenmaterial lieferte 2012 eine Archivreise in die USA: Allgemeine Materialien zur amerikanischen Avantgarde fanden sich in den Beständen der New York Public Library For The Performing Arts (NYPL) und dem Archiv des Museum of Modern Art (MOMA). An den North Carolina States Archives (NCSA) lagern reichhaltige und wenig beachtete Quellen zur Geschichte des Black Mountain College, während in Hinsicht auf die Schlüsselfigur der amerikanischen Avantgarde, John Cage, die Sammlungen am Bard Col- 
Im abschließenden Kapitel Querstand von Kunst und Politik wird die charakteristische Engführung künstlerischer und gesellschaftlicher Protestbewegungen im Umfeld von 1968 fokussiert. Parallel zur Politisierung der Lebenswelt führten viele linkspolitische Komponisten einen musikalischen Klassenkampf, der auf die Entgrenzung von Kunst und Leben zielte und Konzertsäle zu Bühnen der Politik machte. Als Schlüsselmedium des politischen Musikskandals wird dabei das Musiktheater herausgehoben, das in drei legendären - die Dekade der 1960er rahmenden - Fallbeispielen untersucht wird. ${ }^{99}$

Die >Reprise`schließlich führt zum Abschluss noch einmal das thematische und motivische Material diskursiv zusammen. Dabei wird die in der Exposition erarbeitete und in der Durchführung analytisch erschlossene Definition des Musikskandals auf den Prüfstand gestellt, der Gegenstand in die Gegenwart transferiert und von hier auch ein Ohrenmerk auf die Klänge von morgen geworfen: Zukunftsmusik.

lege (John Cage Trust), der Northwestern University Music Library (John Cage Correspondence Collection) sowie die Cage Papers der Wesleyan University konsultiert wurden.

99 Liefern hier die Archive des Internationalen Musikinstitut Darmstadt (IMD) sowie der Akademie der Künste (AdK) allgemeines Material, wird dieses durch personenbezogene Sammlungen zu Luigi Nono (Archivio Luigi Nono), Hans Werner Henze und Mauricio Kagel (Paul-Sacher-Stiftung, PSS) und Privatarchive beteiligter Akteure wie Max E. Keller (MK) und Mary Bauermeister (MB) spezifiziert. 


\section{REFERENZEN und CHIFFREN (Exposition)}

Dieses einleitende Referenzkapitel wurde in Anlehnung an musikalische Formungsprinzipien mit 〉Exposition 〈 überschrieben und dient - wie in Musikwerken - der Präsentation des thematischen Materials, das in der späteren >Durchführung < verarbeitet wird. Weil die Erforschung des Musikskandals als »Kategorie der Musikgeschichte [...] noch in den Anfängen " ${ }^{1}$ steckt und das spezifische Themenfeld Skandal und Neue Musik bislang sogar ein Thema war, »das es so nicht gibt $~^{2}$, ist es für eine grundlegende Einordnung und Kategorisierung des Gegenstands notwendig, weiter auszuholen: Nach einem kurzen historischen Exkurs in die lange Geschichte klingender Eklats, werden auf Basis der historischen Avantgarden aus der ersten Hälfte des 20. Jahrhunderts Referenzen und Chiffren für die Nachkriegsavantgarde abgeleitet und eine grundlegende definitorische Beschreibung und terminologische Fassung des Gegenstandes vorgenommen.

Wenn auch die Skandale im Umfeld der Neuen Musik nach 1945 im Fokus dieser Arbeit stehen, so soll doch nicht der Eindruck erweckt werden, dass der klingende Eklat ein Phänomen der Moderne wäre. Seit dem Beginn der abendländischen Kultur war die »Ächtung des Andersartigen ${ }^{3}$ eine Konstante der Musikgeschichte, in welcher der Skandal zum strukturellen Marker sozio-ästhetischer Umbrüche und Grenzverschiebungen wurde. Bereits im Jahr 347 vor Christi kritisierte Platon »daß immer irgend etwas Neues [...] in der gesamten musischen Kunst aufkommt und daß diese Änderungen [...] durch regellose Gelüste ${ }^{4}$ veranlasst würden. Damit benannte der antike Philosoph wesentliche Bestandteile musikskandalöser Ereignisse: nicht nur die kontroverse musikhistorische Konstellation von >Tradition versus Innovation<, sondern auch die unkontrollierbaren und performativen Affekte, die ästhetische Neuerungen stets begleiten.

1 Gianmaria Borio/Hermann Danuser (Hg.): Im Zenit der Moderne. Die internationalen Ferienkurse für Neue Musik Darmstadt 1946-1966. Geschichte und Dokumentation in vier Bänden, Band 2, Freiburg im Breisgau 1997, S. 374.

2 Christian Kaden: »Skandal und Ritual in der Musik«, in Joachim Brügge (Hg.): Musikgeschichte als Verstehensgeschichte, Tutzing 2004, S. 583-596, hier S. 583.

3 Hartmut Krones: »Multikulturelles, Internationales, Neues und Fremdes in der Musik. Zweieinhalb Jahrtausende Ächtung des Andersartigen«, in Ders. (Hg.): Multikulturelle und internationale Konzepte in der Neuen Musik, Wien 2008, S. 13-30.

4 Platon: »Nomoi II« (660b), in Guther Eigler (Hg.): Platon. Werke in acht Bänden, Band 8, Darmstadt 1990, S. 99. 
Diese Dynamik erfuhr um 1300 einen frühen Höhepunkt, als mit der Ars Nova - deren Translation als >neue Kunst« nicht zufällig Assoziationen an den Begriff der Neue Musik aufkommen lässt - die kirchenmusikalisch tradierte Einstimmigkeit mit der Einführung der Polyphonie revolutioniert wurde. Ein historisches Zeugnis der dogmatischen Abneigung gegen diese Normverstöße ist die berüchtigte Bulle Docta Sanctorum Patrum (1324/25), in der Papst Johannes XXII unter Androhung von Sanktionen bestimmte, »daß niemand von nun an diese oder ähnliche Dinge [...] auszuführen sich anschicke. " ${ }^{5}$ Der Neuerungsprozess freilich war nicht aufzuhalten und wurde - ein weiteres Beispiel ist die Kritik an der hochartifiziellen Kontrapunktik Johann Sebastian Bachs im 17. Jahrhundert - stets begleitet von eklatanten Kontroversen im Spannungsfeld progressiver und restaurativer Kräfte, welche die Grenzverschiebungen des Sag- und Hörbaren markierten.

Über die musikästhetische Neuerungsdynamik hinausgehend, wiesen die Kontroversen stets auch auf die Rolle von Kunst und mithin Musik als Ausdruck sozialer Ordnungen: Immer diente die Bewahrung ästhetischer Normen auch dem Schutz kultureller Konventionen und staatlicher Institutionen. Wenn also die offiziell geförderte Kultur herrschaftsstabilisierend wirkte, markierten Zuwiderhandlungen gegen die geltenden Normen im Umkehrschluss oft Umbruchszenarien, die nicht selten mit ästhetischen Skandalen einhergingen. Dies belegen auch die Entwicklungen infolge der europäischen Säkularisierung und Aufklärung, die nicht nur mit einem Aufschwung des Bürgertums, sondern auch mit einem Wandel auf musikästhetischem Gebiet vonstattengingen.

Die der Kunstmusik ihren alltagssprachlichen Namen gebende Klassik mit dem Wiener Dreigestirn Joseph Haydn (1732-1809), Wolfgang Amadeus Mozart (17561791) und Ludwig van Beethoven (1770-1827) wurde zur Epoche der Transformation vom herrschaftsdienenden zum autonomen Künstler. Insbesondere der Letztgenannte wurde nicht nur zur Schlüsselfigur an der Epochenwende zur Romantik, sondern auch auf musikskandalösem Feld. Beethovens Innovationen provozierten einen Aufschrei der Traditionalisten sowie der Kritiker und illustrieren damit den Aufschwung der meinungsbildenden Presse. Darüber hinaus wurde durch den späteren Ruhm des Bonner Meisters eine für den Musikskandal bedeutsame Narration etabliert, die in der Moderne exemplarische Bedeutung erhielt: Der Verriss von gestern, so lautete die Devise der Avantgarden, sei das ästhetische Paradigma von morgen. Diese Deutung des Kunstskandals fokussiert auch der entsprechende Eintrag in der Enzyklopädie der Neuzeit:

»Auf dem Feld der Ästhetik erwuchsen Skandale meist aus dem Bruch der Regeln des Klassizismus. Die von ihm konstituierten Konventionen zu überbieten oder ganz zu zertrümmern, wurde seit der Romantik zum Pathos des modernen Künstlers, der sich in exzentrischen, schon durch ihre Lebensform Skandale provozierenden Persönlichkeiten [...] verkörperte. ${ }^{6}$

5 Siehe hierzu Helmut Hucke: »Das Dekret $>$ Docta sanctorum Patrum< Papst Johannes' XXII«, in: Musica Disciplina (38/1984), S. 119-131.

6 Gerrit Walther: Skandal, in Friedrich Jaeger (Hg.): Enzyklopädie der Neuzeit, Band 12, Stuttgart 2010, Sp. 54-57, hier, Sp. 56. 
Seit der Mitte des 19. Jahrhunderts kam es zur Wahrnehmung einer Musikgeschichte, deren Traditions- und Innovationsbewusstsein zunehmend »als Spannungsverhältnis zwischen Geschichte und Gegenwart erlebt wurde. ${ }^{7}$ Im historischen Rückblick deutet sich an, dass Skandale historische Schwellen und Umbruchphasen vom Alten zum Neuen markieren, wobei die Saalschlachten und Kontroversen als passagere Handlungsmuster interpretiert werden können: sie stellen "performative Akte dar, über die sich Ordnungen erst etablieren. ${ }^{8}$ Versteht man den Musikskandal in diesem Sinne als Ausweis für Umbruch und Progress, so erhielt er an der Schwelle zur Moderne paradigmatischen Eigenwert und verdichtete sich in der ersten Hälfte des 20. Jahrhunderts in den historischen Avantgardebewegungen: Futurismus und die Emanzipation der Atonalität in den 1910er Jahren schrieben ebenso ein kulturelles Skript für die Eklatanz der Neuen Musik nach 1945, wie die sensationslüsterne Bohème der `Goldenen Zwanziger` und die >Unmöglichkeit des Skandals` zwischen 1933 und 1945. Diese Bewegungen werden im Folgenden skizziert und die hier auftretenden Referenzen und Chiffren abschließend zum Versuch einer Definition verdichtet, die das Handwerkszeug für die >Durchführung` des Themenkomplexes `Skandal und Neue Musik in den vier Hauptkapiteln der vorliegenden Arbeit stellt.

Abbildung 1 - Eklatanter Startschuss in die musikalische Moderne: Arnold Schönberg provoziert das >Wiener Watschenkonzert`(1913)

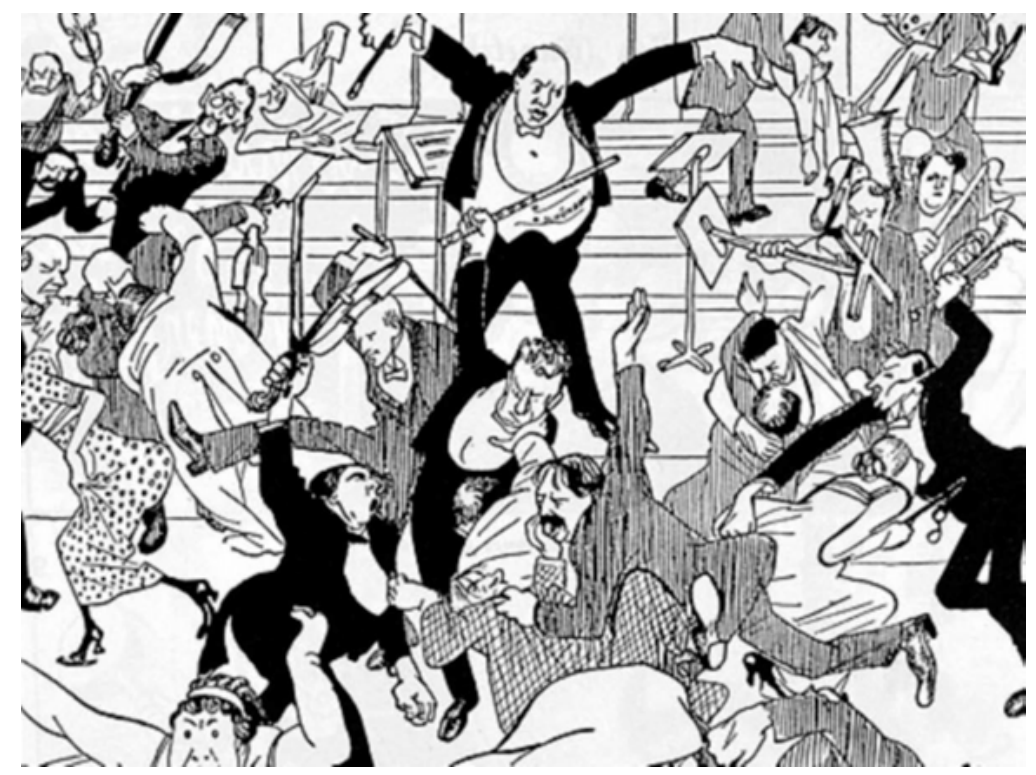

7 Ursula Petrik: Die Leiden der Neuen Musik. Die problematische Rezeption der Musik seit 1900, Wien 2008, S. 18.

8 Robert Stockhammer (Hg.): Grenzwerte des Ästhetischen, Frankfurt am Main 2002. 


\section{Die KRISE DeR JAHRHUndertWende}

»Wir werden im 20. Jahrhundert zwischen fremden Gesichtern, neuen Bildern und unerhörten Klängen leben. Viele, die die innere Glut nicht haben, werden frieren und $[. .$.$] in die Ruinen der Erinnerung flüch-$ ten. «

FRANZ MARC, 1915

Nicht nur in der Musik herrschte seit der Wende zum 20. Jahrhundert ein bipolarer Zeitgeist zwischen Endzeit- und Aufbruchsstimmung. Als paradigmatisch für dieses Proszenium an der Schwelle zur Moderne kann Oswald Spenglers geschichtsphilosophisches Hauptwerk gelten: Von den revolutionären Tendenzen und der als Krise empfundenen Gegenwart der westeuropäischen Welt inspiriert, prägte und spiegelte sein Untergang des Abendlandes ${ }^{9}$ als mentalitätsgeschichtliche Formel eine große Leserschaft. Spengler bediente sich des morphologischen Denkens Goethes und verwandter Traditionen, die sich schon im 19. Jahrhundert das Werden und Vergehen von Staat und Gesellschaft, Stil und Kunst als organischen Wachstums- und Zerfallsprozess vorgestellt hatten. Die Musik, so Wolfgang Krebs, galt Spengler dabei als symbolische Äußerung eines prozesshaften Weltgefüges:

»So wie es in den Spätzeiten der atomisierten Gesellschaft nur noch die fatale politische Alternative zwischen Diktatur und Chaos gibt, so auf der Ebene der Kunst - und zwar aus den gleichen Gründen des Kulturzerfalls - lediglich die Wahl zwischen dem Förmlich-Erstarrten und dem Formlos-Anarchischen; wollte man diese Ansicht in unsere eigene Terminologie übertragen, müssten wir sagen: die Wahl zwischen Epigonalität und Eklektizismus. ${ }^{10}$

Diese Einschätzung ist zutreffend, blickt man auf die Exponenten der Musikavantgarde jener Zeit: Namentlich die Klassiker der Moderne, Arnold Schönberg und Igor Strawinsky sowie die futuristische Bewegung als radikaler Flügel der historischen Avantgarden, überschritten die bis dato geltenden Regeln der Ästhetik in eklatanter Weise und provozierten damit skandalträchtige Reaktionen der Rezipienten. Denn auch beim Publikum in den Konzertsälen entlud sich die Endzeit- und Aufbruchsstimmung der Jahrhundertwende in artifiziellen Gewittern, die den Aufbruch in die musikalische Moderne wetterleuchtend illuminierten. Sowohl die ästhetischen Fortschreibungen als auch die von ihnen provozierten Saalschlachten eröffnen als referentielle Muster vielfältige Deutungsangebote für eine phänomenologische Kategorisierung des Musikskandals.

9 Oswald Spengler: Der Untergang des Abendlandes, Band 1: Gestalt und Wirklichkeit, Wien 1918; Band 2: Welthistorische Perspektiven, München 1922.

10 Wolfgang Krebs: Kultur, Musik und der »Untergang des Abendlandes«. Bemerkungen zu Oswald Spenglers Geschichtsphilosophie [Antrittsvorlesung vom 3. Dezember 1996 in Frankfurt am Main, Universität], S. 8. URL: http://www.wk-wkw.de/texte/aufs/A-KulturMusik-Untergang.pdf [Zugriff: 31.8.2017]. 


\section{Das Schlüsseljahr 1913}

An der Schwelle zur Moderne nimmt das Jahr 1913 eine Schlüsselrolle ein: Damals provozierten das sogenannte >Wiener Watschenkonzert` Arnold Schönbergs sowie der legendäre Pariser Premierenskandal um Igor Strawinskys Le sacre du printemps in den Worten des Musikwissenschaftlers Martin Thrun einen »Sturz ins Jetzt des Augenblicks « ${ }^{11}$ : In den legendären Saalschlachten gewann die schockierende Erfahrung Neuer Musik im mitteleuropäischen Raum Kontur und schrieb gewissermaßen ein kulturelles Drehbuch der musikavantgardistischen Moderne. ${ }^{12}$

Arnold Schönberg überschritt zu Beginn des 20. Jahrhunderts die Normen musikalischer Aufführungsbedingungen durch seine rückhaltlose Emanzipation der Dissonanz. Die Einführung der Atonalen Musik in die Konzertsäle sowie in die Gehörgänge des Publikums eskalierte 1907/08 in legendären Skandalkonzerten im Wiener Musikverein, deren paradigmatische Bedeutung als Gründungsereignisse der Neuen Musik durch Martin Eybl gut dokumentiert sind. ${ }^{13}$ Bei den Uraufführungen von Schönbergs Streichquartett Nr. 1 und der Kammersymphonie op. 9 kam es am Abend des 21. Dezember 1908 zu heftigen Wortwechseln und Gelächter; die Stimmung im Auditorium war also schon polarisiert, als nach der Pause das renommierte RoséQuartett und die Sopranistin Marie Gutheil-Schoder im Strichquartett Nr. 2 [ $\delta$-1.1] das eherne Gesetz der Tonalität hinter sich ließen. Schönberg selbst erinnerte sich an die Reaktionen:

»Das Publikum lauschte dem ersten Satz ohne jegliche Reaktion, weder pro noch contra. Aber sobald der zweite Satz, das Scherzo begann, fing ein Teil des Publikums über einige Figuren, die ihm seltsam erschienen, zu lachen an, und es brach weiterhin an vielen Stellen während dieses Satzes ein schallendes Gelächter aus [...]. Von jetzt ab wurde es schlimmer und schlimmer. $\ll^{14}$

Arnold Schönbergs zweites Streichquartett wurde - in Analogie zu Ludwig vanBeethovens epochemachender Sinfonie Nr. 9 - durch die Hinzufügung einer Sopranstimme zu den vier Streichern, vor allem aber infolge einer Erweiterung der Harmonik durch den rückhaltlosen Gebrauch von Dissonanzen zu einem Schlüsselwerk der Aufbruchs- und Endzeitstimmung der Jahrhundertwende. Die berühmte Vision ferner Welten im letzten Satz `Entrückung`, mit Stefan Georges programmatischen Zeilen

11 Martin Thrun: »Der Sturz ins Jetzt des Augenblicks. Macht und Ohnmacht ‘ästhetischer Polizeiく im Konzert nach 1900«, in Sven Oliver Müller/Jürgen Osterhammel/Martin Rempe (Hg.): Kommunikation im Musikleben. Harmonien und Dissonanzen im 20. Jahrhundert, Göttingen 2015, S. 42-67.

12 Siehe hierzu überblicksweise auch Anna Schürmer: »Der Skandal als kreativer Störfall im Sperrbezirk. Von der produktiven Eklatanz der Neuen Musik 1913|2013«, in: Neue Musikzeitung (8/2013); Dies.: »Klingende Eklats« (Feature), in: Bayerischer Rundfunk/Bayern 4 Klassik (18.8.2014).

13 Martin Eybl: Die Befreiung des Augenblicks: Schönbergs Skandalkonzerte 1907 und 1908. Eine Dokumentation, Wien 2004.

14 Zitiert nach Heinz Steinert: Adorno in Wien, Münster 2003, S. 60. 
»Ich fühle Luft von anderem Planeten«, symbolisierte auch den Aufbruch in neue Klangwelten, der vom Wiener Konzertpublikum mit skandalösen Reaktionen beantwortet wurde.

Ausgelöst wurden die Randale durch das provokative Klatschten junger Schönberg-Anhänger, wodurch sich die Skeptiker zu Gegenkundgebungen aufgefordert sahen. Belegt diese Beschreibung den epochenübergreifenden Konflikt von Innovation und Tradition, so offenbart sich darin auch eine charakteristische Dynamik klingender Eklats, die sich in der Regel als affektive Schneeballschlachten polarisierender Gruppierungen entladen. Martin Eybl sah die Ursache für die Tumulte weniger im Abschied von der Tonalität und keinesfalls in antisemitischen Aktionen gegen den jüdischen Komponisten; vielmehr habe ein grundsätzlicher Umsturz der Werte die Zeitgenossen entsetzt. ${ }^{15}$ Dass das hochaffektiv reagierende Publikum seinerseits die Verhaltensnormen sprengte und damit den Bruch musikästhetischer Konventionen auf rezeptionsästhetischer Ebene spiegelte, darf ebenso als Charakteristikum des $\mathrm{Mu}-$ sikskandals angesehen werden.

Kann diese erste Verkündung der Atonalität als Signum der Moderne mit Martin Thrun tatsächlich als jäher »Sturz ins Jetzt des Augenblicks« beschrieben werden, so endete dieser bald auf dem Boden der Realität, denn das Skandalon der Zwölftonmusik sprach sich bald herum. Der Schock wirkte nicht mehr als unvermitteltes Ereignis, sondern wurde vielmehr vom Publikum antizipiert. Die Wiener Premierenskandale der Jahre 1907 und 1908 begründeten also eine Erwartungshaltung, die sich zunehmend verdichtete und am 31.3.1913 im berühmt-berüchtigten >Wiener Watschenkonzert eskalierte. Auf dem Programm standen mit Arnold Schönberg und seinen Meisterschülern Anton Webern und Alban Berg die Protagonisten der Zweiten Wiener Schule. Anhand von Presseberichten lassen sich die Ereignisse rekonstruieren, wenngleich bei der Analyse dem feuilletonistischen Hang zur sensationellen Schlagzeile relativierende Rechnung getragen werden muss:

»Schon während der ersten Nummer, Sechs Orchesterstücke von Anton Webern, wurde das Publikum unruhig; man lachte auch und zischte, während die Freunde und Anhänger Schönbergs aus Leibeskräften applaudierten. Ähnlich setzte nach Schönbergs Kammersymphonie die Opposition ein. Es wurde gepfiffen, gelacht und geschrien; auf der Galerie kam es zu erregten Auseinandersetzungen. $\ll^{16}$

Aber erst bei Alban Bergs Zwei Orchesterliedern nach Ansichtskartentexten von Peter Altenberg [ $\delta-1.2]$ musste Arnold Schönberg, der das Konzert auch dirigierte, infolge der Tumulte die Aufführung unterbrechen, um nach Wiederherstellung der Ruhe im Saal neu anzusetzen: »Aber gleich darauf brach der Skandal mit unerhörter Heftigkeit los. Pfuirufe durchbrausten den Saal, dazwischen gelten Pfiffe und Hohngelächter: Auf den Galerien schien es zu Handgreiflichkeiten kommen zu wollen und auch im Parterre gab es gegenseitige Bedrohungen. ${ }^{17}$

15 Vgl. Eybl: Die Befreiung des Augenblicks [Klappentext].

16 N.N.: Große Lärmszenen im Musikvereinssaals, in: Neue Freie Presse (1.4.1913), S. 12.

17 Ebd. 
Die Karikatur, die am 6. April in Die Zeit erschien [Abbildung 1] bildet die Ereignisse ab und wurde zur bekanntesten Visualisierung klingender Eklats, die in keiner Publikation zu Musikskandalen fehlt: Arnold Schönberg dirigiert darauf als zentrale Gestalt eine Menge aus prügelnden Konzertbesuchern, unter die sich die befrackten Musiker mit ihren Instrumenten als Schlagstöcken mischen, während im Hintergrund ein ohnmächtiger Hörer abtransportiert wird.

Höhepunkt des legendären Konzertabends war der Moment, als sich der Präsident des Akademischen Verbandes, Erhard Buschbeck, an das aufgebrachte Publikum wandte und einem randalierenden Besucher eine Ohrfeige verpasste: der Mythos des > Wiener Watschenkonzerts` war geboren. Der Saal wurde anschließend abgedunkelt und durch die Polizei geräumt um zu verhindern, »daß der herrliche Musikvereinssaal durch ein solch wüstes Treiben musikalischer Leidenschaften entweiht werde. ${ }^{18}$ Der Konzertabbruch infolge der Tumulte und der geschichtsträchtigen Ohrfeige hatte ein gerichtliches Nachspiel. Auf die Frage, ob er die Ohrfeige gehört habe, antwortete der Zeuge und Operettenkomponist Oscar Straus: »Sicher [...], denn sie war das weitaus Klangvollste des ganzen Abends! ${ }^{19}$

Das »Wiener Watschenkonzert« offenbart nicht nur nahezu alle Ingredienzen musikalischer Skandale, sondern ging als mythenumrankter Startschuss der Moderne in die Musikgeschichte ein, flankiert vom anderen großen Skandal jenes Jahres 1913: Die Ereignisse der Pariser Premiere von Igor Strawinskys Le sacre du printemps $[\boldsymbol{\delta}-$ 2] rechtfertigen das weit verbreitete und fälschlicherweise Claude Debussy zugeschriebene Bonmot vom »massacre du printemps $«^{20}$. Wie wenige Wochen zuvor in Wien, verbreitete sich am 29. Mai 1913 schon während der ersten Takte von Strawinskys hochexpressiver >Vision einer großen heidnischen Feier` Unruhe im Pariser Théâtre des Champs-Élysées: man hörte Gelächter, Pfiffe und Gegenkundgebungen; es wurde geschrien, getrampelt und gelärmt. ${ }^{21}$ Eine $\gg$ schön gekleidete Dame in einer Orchesterloge«, so erinnerte sich die Frau des legendären Tänzers Vaclav Nijinsky, »erhob sich und ohrfeigte einen jungen Mann, der in einer Nachbarloge zischte. Ihr Begleiter stand auf, Karten wurden ausgetauscht. Ein Duell folgte am nächsten Tag. Eine andere Dame der Gesellschaft spie einem Demonstranten ins Gesicht. « ${ }^{22}$ Jean Cocteau, der 1918 als Librettist des kubistischen Balletts Parade selbst Pariser Skandalgeschichte schreiben und den Dadaismus einleiten sollte ${ }^{23}$, erlebte die Ereignisse als Zeuge:

18 N.N.: »Großer Skandal im Musikvereinssaal. Ein abgebrochenes Konzert«, in: Reichspost (1.4.1913), S. 7.

19 Zitiert nach Hartmut Krones: »31. März 1913 - Wiens größtes `Skandalkonzert««, in: Magazin der Gesellschaft der Musikfreunde Wien (4/2013).

20 François Porcile: La belle époque de la musique française 1870-1940, Paris 1999, S. 99.

21 Siehe hierzu François Lesure: Igor Stravinsky. Le sacre du printemps - dossier de presse, Genf 1980.

22 Romola Nijinsky: Nijinsky. Der Gott des Tanzes, Berlin 2009, S. 192.

23 Am 18. Mai 1918 wurde Parade - Ballet réaliste nach Jean Cocteau und mit der Musik Erik Saties und einem Bühnenbild Pablo Picassos im Théâtre du Châtelet von Sergei Djagilews Ballet Russes - den Interpreten der Strawinsky-Premiere - uraufgeführt. 
»Bei der Uraufführung des Sacre spielte der Saal die Rolle, die er spielen musste: Er revoltierte von Anfang an. Man lachte, höhnte, pfiff, ahmte Tierstimmen nach, und vielleicht wäre man dessen auf die Dauer müde geworden, wenn nicht die Menge der Ästheten und einige Musiker in ihrem übertriebenen Eifer das Logenpublikum beleidigt, ja tätlich angegriffen hätten. Der Tumult artete in ein Handgemenge aus. $\ll^{24}$

Was aber war der Stein des Anstoßes? Igor Strawinskys Frühlingsopfer enthielt mit seinen archaischen Rhythmen und der grellen Harmonik durchaus ästhetischen Sprengstoff; auch die von Vaclav Nijinsky verantwortete und getanzte Vergegenwärtigung primitiver Opferrituale löste Befremden aus. ${ }^{25}$ Dazu kam in Paris ein weiteres wichtiges Element klingender éclats, der sich in Cocteaus Bemerkung offenbart, der Saal habe die Rolle gespielt »die er spielen musste«: In der internationalen Kulturhauptstadt und dem Epizentrum der Bohème wurde der Skandal seit der Belle Epoque als untrügliches Signum neuer Kunst begrüßt. Spätestens im fin de siècle wurde Paris »zu einer regelrechten Hochburg des Bühnenskandals ${ }^{26}$ auf der Claqeure über Misserfolg oder eben einen succès de scandale entschieden. Igor Strawinsky reihte sich damit in eine illustre Chronik Pariser Skandalerfolge - wie etwa Richard Wagners Tannhäuser (1861) oder Alfred Jarrys absurdem Schauspiel Ubu Roi (1896) ein, der im Laufe des 20. Jahrhunderts noch weitere Kapitel hinzugefügt werden sollten. Auch deshalb äußerte sich Strawinskys Choreograph Sergej Diaghilew infolge der Premierentumulte rundum zufrieden: »Genau das, was ich gewollt habe $\ll^{27}$.

Während man sich in Paris also über einen succès de scandale freute, zog man im konservativen Wien gegenteilige Konsequenzen. Hier ging es trotz vielfältiger Erfahrungen mit Skandalen nicht um die Provokation als solche, im Gegenteil: Arnold Schönberg gründete seinen $>$ Verein für musikalische Privataufführungen ${ }^{28}$, um seine Werke vor den Angriffen des Publikums zu schützen. Auf den Eintrittskarten wurde vermerkt, dass diese den Inhaber nur unter der Voraussetzung berechtige dem Konzert beizuwohnen, wenn er die Aufführung in keinster Weise störe. Damit wurden Skandale so gründlich ausgeschlossen, »daß dem Publikum nicht einmal mehr positive Reaktionen gestattet waren. $"{ }^{29}$ Die beiden referentiellen Eklats des Frühjahrs 1913 unterschieden sich damit in einem wesentlichen Punkt: der Inszenierung. Abgesehen davon profitierten beide Skandalkomponisten des Schlüsseljahres 1913 von der publizistischen Aushandlung der Ereignisse, die ihr übriges zur Legendenbildung beitrug. Heute gehören beide zum musikalischen Kanon, was als erster Beleg für den Wandel musikalischer Paradigmen, auch in Folge der von ihnen provozierten Skandale, gelten kann.

24 Zitiert nach Volker Scherliess: Igor Strawinsky und seine Zeit, Laaber 1983, S. 117.

25 Kaden: Skandal und Ritual in der Musik, S. 583ff.

26 Petrik: Die Leiden der Neuen Musik, S. 26.

27 Hans-Jürgen Schaal: »Mord auf der Ballettbühne. Der Uraufführungsskandal um Strawinskys \Le Sacre du Printemps««, in: Neue Zeitschrift für Musik (3/2000), S. 16-19, hier S. 16.

28 Siehe zur Programmatik des Vereins Alban Berg: Prospekt des »Vereins für musikalische Privataufführungen« (September 1919).

29 Danuser: Wer hören will, muß fühlen, S. 96. 
Begründete die Intensität der Proteste ein radikales Image der Neuen Musik, wies das gewaltige Medienecho infolge der klingenden Eklats den Skandal als ein Phänomen moderner Öffentlichkeit aus. Wenn diese Tendenz auch im Verlauf des 20. Jahrhunderts eine rasante Beschleunigung erfuhr, waren auflagenträchtige Verrisse in der Musikgeschichte nichts Neues. Davon zeugt das Lexicon of Musical Invective ${ }^{30}$, in dem der Dirigent Nicolas Slonimsky 1953 eine Chronik von Konzertverrissen seit der Zeit Beethovens zusammenstellte und damit seine These von der >NonAcceptance of the Unfamiliar auf ebenso unterhaltsame wie aufschlussreiche Weise exemplifizierte. Dass musikalische Erneuerer stets den Angriffen der Presse ausgesetzt waren, wurde im 20. Jahrhundert zu einer Legitimierungsstrategie der Neuen Musik. Schönberg etwa ging so weit, in einem Programmheft eine negative Kritik Ludwig van Beethovens abzudrucken, woraufhin ein Kritiker bemerkte:

»Daraus, dass man in Wien andere Componisten nicht gleich, sondern erst später überschätzt hat, darf doch unmöglich die ständige Wiener Sorge erwachsen, Herr Schönberg könnte am Ende, ähnlich wie diese, missverstanden werden. Aus der Furcht, einem Componisten nicht gerecht zu werden, wird die Pflicht abgeleitet, ihn als Genie zu preisen, nicht trotz seiner Absurditäten, sondern gerade wegen dieser Angst, wieder einmal einen Beethoven versäumt zu haben. $\ll^{31}$

Diese Legitimierungsstrategien fruchteten zumindest im Falle Arnold Schönbergs und Igor Strawinskys - den heutigen >Klassikern der Moderne ২. Dass die Skandale des Jahres 1913 zu Ursprungsereignissen der musikalischen Moderne stilisiert wurden, belegt auch eine Aussage, die Theodor W. Adorno 1954 in seinem Aufsatz zum Altern der Neuen Musik gleich einem Manifest klingender Eklats formulierte:

»Als Musik zum ersten Male an alledem gründlich irre ward, wurde sie zur Neuen. Der Schock, den diese Musik in ihren heroischen Zeiten, etwa bei der Wiener Uraufführung der >Altenberg-Lieder`von Alban Berg oder der Pariser des `Sacre du printemps` von Strawinsky dem Publikum versetzte, ist nicht bloß, wie die gutartige Apologie es möchte, dem Ungewohnten und Befremdenden als solchem zuzuschreiben, sondern einem Aufstörenden und selber Verstörten. Wer dies Element abstreitet und beteuert, die neue Kunst sei doch gerade so schön wie die traditionelle, erweist ihr einen Bärendienst; er lobt an ihr, was sie selber verschmäht, solange sie unbeirrt dem eigenen Impuls nachhorcht. $\ll^{32}$

Adorno leitete aus den Skandalen des Jahres 1913 also referentielle und grundlegende Kriterien der Neuen Musik ab: Ihr Impuls sei nicht das Schöne, sondern das Verstörende; nicht die Tradition sei ihr Augenmerk, sondern der Auf- und Umbruch. Damit benannte er den Fortschrittsglauben, der in der Mitte des 20. Jahrhunderts zur conditio sine qua non der Neuen Musik avancierte.

30 Nicolas Slonimsky: Lexicon of Musical Invective. Critical Assaults on Composers since Beethoven's Time, New York 1953.

31 Zitiert nach Eybl: Die Befreiung des Augenblicks, S. 30f.

32 Theodor W. Adorno: »Das Altern der Neuen Musik« (1954), in Ders.: Dissonanzen. Musik in der verwalteten Welt, Göttingen 1991, S. 136-159, hier S. 136. 
Insbesondere der Skandal um Igor Strawinskys Le sacre du printemps ging als Erfolgsmoment musikalischer Saalschlachten in die Musikgeschichte ein. Davon zeugt auch die bis heute enorme Rezeption der Ereignisse, etwa in der BBC-Produktion Riot at the Rite (2005). Beide Skandale fanden darüber hinaus Eingang in den Bestseller 1913, in dem Florian Illies hundert Jahre nach den klingenden Ereignissen die Endzeitstimmung vor Ausbruch des Ersten Weltkriegs nicht zufällig aus Sicht der Avantgarden beschrieb. ${ }^{33}$ Überwiegen in der Rezeption auch feuilletonistische und prosaische Momente, so löste doch besonders Schönbergs Methode des Komponierens »mit zwölf nur aufeinander bezogenen Tönen « ${ }^{34}$ eine ästhetische Revolution aus - und als musikalisches Ordnungsprinzip die freie Atonalität ab. Wenn Jean-Francois Lyotard den Kopf der Zweiten Wiener Schule als »Luther der neuen Musik ${ }^{35}$ beschrieb, bezeichnete er damit auch einen Paradigmenwechsel, welcher der christlichen Reformation auf musikästhetischem Gebiet in nichts nachstand. Doch genauso, wie im Protestantismus die Grundlagen des christlichen Glaubens verankert blieben, agierten auch Arnold Schönberg und Igor Strawinsky innerhalb einer musikalischen Traditionslinie. Die radikale Säkularisierung der musikästhetischen und aufführungspraktischen Normen wurde von anderen Avantgarde-Gruppierungen vollzogen. Insbesondere die Futuristen machten den Progress zum ästhetischen Imperativ und aus dem $\gg$ Kunst-Skandal $\ll$ eine $\gg$ Kunst des Skandals $\prec$.

\section{»Futuristengefahr«: Vom Kunst-Skandal zur Kunst des Skandals}

1917 veröffentlichte der deutschnationale Komponist Hans Pfitzner eine Schrift mit dem Titel Futuristengefahr. ${ }^{36}$ Die Polemik war eine publizistische Erwiderung auf die zweite, überarbeitete Fassung von Feruccio Busonis 1906 entstandenem, radikalavantgardistischem Entwurf einer neuen Ästhetik der Tonkunst. ${ }^{37}$ Die daraufhin einsetzende Kontroverse verdeutlicht verschiedene für den Musikskandal relevante Faktoren: Hatte Busonis `Entwurf^ bei seinem Erscheinen noch wenig Resonanz erhalten, schürten wohl auch die legendären Premierenskandale des Jahres 1913 die allgemeine Sensationslust und das Interesse an der musikalischen Avantgarde. Auch spiegelte die Debatte verdichtet die politischen Zeichen der Zeit. Mit antisemitisch gefärbter Polemik sprach Pfitzner der Neuen Musik jegliche Legitimität in der Musiktradition ab und ließ 1920 eine weitere Schmähschrift mit dem aussagekräftigen Titel Die neue Ästhetik der musikalischen Impotenz. Ein Verwesungssymptom? ${ }^{38}$ folgen. Darin entwarf er den später von den Nationalsozialisten aufgegriffenen Begriff des »Musikbolschewismus« und prägte terminologische Kategorien, die nur wenig später für die vom NS als `entartet` gebrandmarkte Kunst gelten sollten.

33 Florian Illies: 1913. Der Sommer des Jahrhunderts, Frankfurt am Main 2012.

34 Arnold Schönberg: Stil und Gedanke, Frankfurt am Main 1995, S. 75.

35 Jean-Francois Lyotard: »Mehrfache Stille - Vielfältiges Schweigen«, in Ders.: Essays zu einer affirmativen Ästhetik, Berlin 1982, S. 95-122, hier S. 114.

36 Hans Pfitzner: »Futuristengefahr. Bei Gelegenheit von Busoni’s Ästhetik«, in: Süddeutsche Monatshefte, Leipzig/München 1917.

37 Ferruccio Busoni: Entwurf einer neuen Ästhetik der Tonkunst, Wilhelmshaven 2001.

38 Hans Pfitzner: Die neue Ästhetik der musikalischen Impotenz: ein Verwesungssymptom?, München 1920. 
Die Berufung auf das >gesunde Gefühl« war im Sprachgebrauch der Zeit ein Bekenntnis zu einer sich unpolitisch gebenden, im Wesentlichen aber antidemokratischen deutschen Innerlichkeit. Im Gegensatz dazu brandmarkte der Vorwurf des >Intellektualismus` eine als undeutsch geltende Neigung zum Fortschritt. Ziel von Pfitzners Bestrebungen war, wie der Komponist Klaus-Karl Hübler verdeutlichte, »die Rettung der deutschen romantischen Tradition vor dem Antideutschen, [...] in welcher Form es auch immer auftritt, als Atonalität, Internationalität, Amerikanismus. ${ }^{39}$ Schließlich illustrierte das von Busoni vertretene Ideal einer von überkommenen Konventionen und ästhetischen Dogmen befreiten Musik nicht nur die Aufbruchsstimmung jener Jahre, sondern ließ durch Pfitzners polemische Erwiderung auch den altbekannten Konflikt von >Tradition versus Innovation< in einer zeittypischen Form aufflammen. Dass dabei im Titel auf die Futuristen verwiesen wurde, lag am Verstörungspotential der bis dahin radikalsten avantgardistischen Strömung der 1910er Jahre: dem Futurismus.

Mit seinem Aufsatz Wer hören will, muß fühlen - Anti-Kunst oder Die Kunst des Skandals $^{40}$ legte Hermann Danuser 1999 nicht nur einen der wenigen Aufsätze zum Thema Musikskandal vor, sondern auch eine aufschlussreiche Studie zu den provozierenden Aktivitäten der futuristischen Bewegung. Schon der Titel verdeutlicht nicht nur die performativ-affektive Seite klingender Eklats, sondern beschreibt auch die Ästhetisierung des Skandals, der im Futurismus konstitutiv für die Kunsterfahrung wurde: »Statt Wirkung und Folge von Kunst ist er ihr Inhalt und Zweck. Damit wird aus dem Skandal der Kunst die Kunst des Skandals. «" ${ }^{41}$ Tatsächlich baute die futuristische Ästhetik auf einem Prinzip des Schocks auf, ihr Antrieb war die maschinelle Technisierung und ihr Chiffre die Zerstörung, denn man erkannte: »Nicht stillschweigend ersetzt eine neue Kunst eine ältere, lautstark geht sie aus deren Zerstörung hervor. ${ }^{42}$ Also machten sich die sparten- und kulturübergreifenden Vertreter der Bewegung an die Dekonstruktion aller Bestimmungsfaktoren klassischer Kunst: Rebellion, Negation und Revolte gegen alles Bestehende wurden damit zu einem destruktiv-ästhetischem Formungsprinzip. ${ }^{43}$

Dass diese Haltung dem Zeitgeist entsprach, liegt auf der Hand: Während die aggressiv zur Schau gestellte Kriegsbegeisterung der Futuristen den Ersten Weltkrieg ankündigte, entsprach die Negation der Vergangenheit dem Aufbruchsgeist der Epochenschwelle. Dagegen war die Maschinenbegeisterung auf die Industrialisierung zurückzuführen, die auch in der Kunst den Umbruch zur Moderne zeitigte. Mit dem Futurismus formulierte erstmals eine Avantgardebewegung einen radikalen Innovationsimperativ, der als Anti-Kunst mit dem klassischen Erbe brach:

39 Klaus-Karl Hübler: »Futuristengefahr. Hans Pfitzners Auseinandersetzung mit Feruccio Busoni im Jahr 1917« (Feature), in: Bayerischer Rundfunk/Bayern 2 (23.9.1984).

40 Hermann Danuser: »Wer hören will, muß fühlen - Anti-Kunst oder Die Kunst des Skandals«, in Dietrich Kämper (Hg.): Der musikalische Futurismus, Laaber 1999, S. 95-110.

41 Ebd., S. 97.

42 Ebd., S. 98.

43 Siehe weiterführend Otto Kolleritsch: Der musikalische Futurismus. Ästhetisches Konzept und Auswirkungen auf die Moderne (Studien zur Wertungsforschung, Band 8), Graz 1976, S. 7. 
»Während Werke klassischer Kunst, auf Dauer angelegt, ihren Sinn aufgrund einer ihnen eingeschriebenen Komplexität erst allmählich entfalten, erfüllt sich Anti-Kunst im singulären Akt der Zerstörung, in plötzlicher Negation. Wenn aber Aggression gegen frühere Kunst zur avantgardistischen Aktion selbst wird, hebt sich die Grenze zwischen Kunst und Leben auf. « ${ }^{44}$

Damit verwies Hermann Danuser auf die Entgrenzungstendenzen, die performative Publikumsansprache und die Betonung eines augenblickszentrierten Ereignischarakters mit ungewissem Verlauf, der die Avantgarden des 20. Jahrhunderts nachhaltig prägen sollte. Dies belegt auch der Bericht von einem der ersten Mailänder Futuristenabende, in welchem Filippo Tommaso Marinetti, der Begründer der Bewegung, die Ästhetisierung und Inszenierung des Skandals als Kunstwerk per se propagierte:

»Eine riesige Menge. Logen und Parkette gestopft voll. Betäubender Lärm der Altmodischen, die das Konzert um jeden Preis stören wollen. Eine Stunde leisteten die Futuristen passiven Widerstand. Zu Anfang des vierten Stückes [...] sah man plötzlich fünf Futuristen [...] von der Bühne herabkommen. Sie [...] griffen mit Hieben, Knüppeln und Spazierstöcken die Altmodischen an, die vor Dummheit und [...] Wut wie betrunken waren. Die Schlacht im Parkett dauerte eine halbe Stunde. $\aleph^{45}$

Der Realitätsgehalt dieser Schilderung sollte angesichts der sensationsheischenden Intention des Verfassers relativiert werden, doch deckt sich der tumultuöse Inszenierungscharakter in Marinettis Aussage mit der Einschätzung Danusers:

»Bei den >serate futuriste $[\ldots]$ artete die künstlerische Darbietung weniger in einem Tumult aus, als dass eine in den Manifest-Texten präfigurierte und performativ vorgestellte Aggression in handgreifliche Auseinandersetzungen zwischen den Beteiligten mündete. Um die Defizienz eines Abends auszuschließen [...] suchten die Futuristen geradezu die Auseinandersetzung, ließen im Bemühen um Provokation nicht locker und reizten bewusst zur Prügelei. [...] Das kämpferische Chaos, das den Charakter solcher Abende bestimmte, würde mißverstanden, erblickte man in ihm nur eine vorübergehende Störung einer an sich kontemplativ aufzufassenden Kunst. Angesichts der beidseitigen Gewaltbereitschaft ist es unerheblich, von welcher Seite [...] die Initialzündung zur aktionistischen Entladung erfolgte. ${ }^{46}$

Wenn die serate futuriste in der Identität von ästhetischer Kunstdarbietung und aktionistischem Tumult ihr Spezifikum hatten, beleuchtet dies nicht nur die performative Ebene klingender Eklats, sondern offenbart auch die von den Futuristen intendierte Kritik an den bürgerlichen Konzertritualen. Im Manifest der futuristischen Bühnendichter etwa wurde nicht nur »von den Autoren und den Schauspielern die Lust ausgepfiffen zu werden« gefordert, sondern auch die

$»$ Verachtung des Premierenpublikums, dessen Psychologie wir folgendermaßen zusammensetzen können: Wettbewerb der Hüte und der weiblichen Garderobe, Stolz auf einen teuer bezahl-

44 Danuser: Wer hören will muss fühlen, S. 98.

45 Zitiert nach Fred K. Prieberg: »Der musikalische Futurismus«, in: Melos (25/1958), S. 124ff, hier S. 126.

46 Danuser: Wer hören will muss fühlen, S. 102f. 
ten Platz, der in intellektuellen Hochmut verwandelt wird, Parterre und Loge von satten und reichen Menschen besetzt, deren naturgemäß hochmütiges Hirn und deren rege Verdauungstätigkeit jede geistige Anstrengung verhindern. « ${ }^{47}$

Dass die Futuristen verstärkt auf die Textgattung des Manifests zurückgriffen ${ }^{48}$, besitzt Erkenntnispotential: Deutet die etymologische Herkunft vom lateinischen manifestus - handgreiflich machen - auf die körperliche und performative Dimension solcher Schriftstücke, weist das ästhetische Aufgreifen der ursprünglich politisch konnotierten Kampfschrift auf die Verschmelzung der gesellschaftlichen und künstlerischen Avantgarden in der Moderne. ${ }^{49}$ Auch der musikalische Flügel um Francesco Balilla Pratella und Luigi Russolo verfasste 1916 mit L'arte dei rumori ein konzeptionelles Manifest, das sich mit der Behandlung von Alltagsgeräuschen auseinandersetzte und damit einen Fingerzeig auf spätere Tendenzen der Neuen Musik gab:

»Wir nähern uns so dem Ton-Geräusch. Diese Evolution der Musik verläuft parallel zur zunehmenden Vielfalt der Maschinen, die überall mit den Menschen zusammenarbeiten [...]. [D]ie Maschine [hat] eine so große Anzahl von Geräuschen geschaffen, dass der reine Ton [...] keine Emotionen mehr hervorruft [...]. Es ist nötig, aus diesem beschränkten Kreis auszubrechen und die Vielfalt der Geräusch-Töne zu erobern. ${ }^{50}$

\section{Abbildung 2 - Luigi Russolo 1914 mit seinen >Intonarumori々}

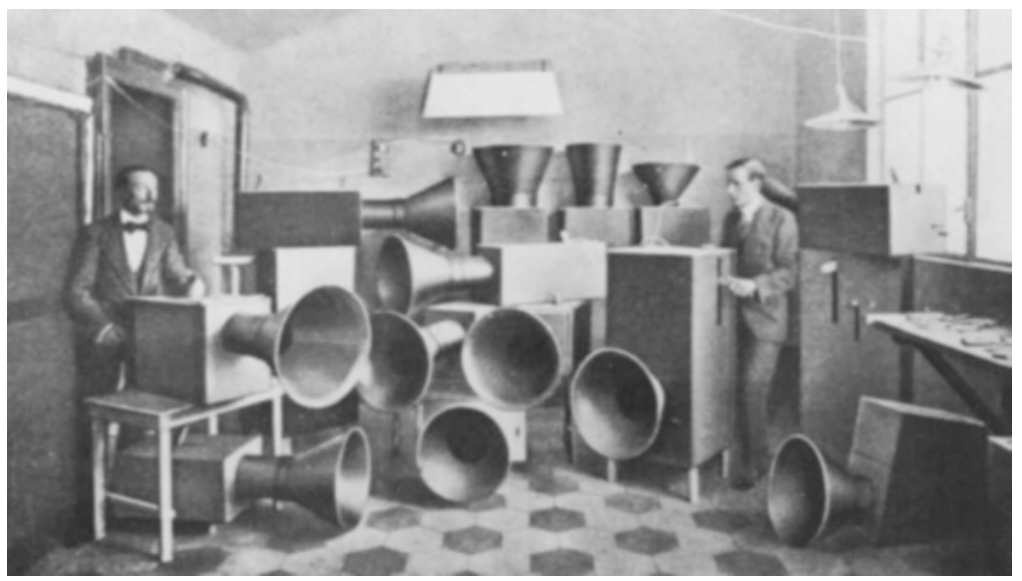

47 Filippo Tommaso Marinetti: »Manifest der futuristischen Bühnendichter«, in Wolfgang Asholt/Walter Fähnders (Hg.): Manifeste und Proklamationen der europäischen Avantgarde (1909-1938), Stuttgart/Weimar 2005, S. 19 f.

48 Siehe hierzu ausführlich etwa Umbro Apollonio: Der Futurismus. Manifeste und Dokumente einer künstlerischen Revolution 1909-1918, Köln 1972.

49 Siehe weiterführend Wolfgang Asholt (Hg.): Die ganze Welt ist eine Manifestation. Die europäische Avantgarde und ihre Manifeste, Darmstadt 1997; Johanna Klatt/Robert Lorenz (Hg.): Manifeste. Geschichte und Gegenwart des politischen Appells, Bielefeld 2011.

50 Luigi Russolo: »Die Geräuschkunst«, in Asholt/Fähnders: Manifeste und Proklamationen, S. 30f. 
Zeugnis dieser Lärmkunst ist Rusollos bereits 1913 auf Tonband aufgenommene Komposition Risveglio di una cittá [§-3]: Abgesehen von der medientechnischen Bedeutung dieser sehr frühen Aufnahme, auf der die >Lärmtöner ein breites Spektrum modulierter und rhythmischer abstrakter Geräusche erzeugen und damit das industrielle »Erwachen einer Stadt« evozieren, spiegelt ihr Einsatz sinnfällig die futuristische Vermischung von Kunst und Technologie, Geräusch und Musik.

Der Zeichner Enrico Novelli Yambo hielt die Wirkung des intonarumorischen Orchesters 1914 in einer Karikatur sinnbildlich fest [Abbildung 3]: Indem er die >Lärmtöner` als knatternde Kriegsgeräte darstellte, visualisierte er nicht nur die futuristische Faszination an militärischer Aggression, sondern auch die Musikalisierung des Lärms, was der Zeichner durch die comichaften Geräuschblasen unterstrich. Indem Yambo im unteren Bildrand zentral einen benzinbetriebenen Motor abbildete, verwies er nicht zuletzt auf die von Francesco Balilla Pratella im Manifest der futuristischen Musiker bereits 1911 beschworen »Herrschaft der Maschine und das sieghafte Reich der Elektrizität $\aleph^{51}$. Tatsächlich definierte der technologische Fortschritt die Musik im Zeitalter der Maschine, die nach 1945 in der Elektronischen Eklatanz mündete und eskalierte.

Abbildung 3 - Das futuristische

Orchester: ^Herrschaft der Maschiner

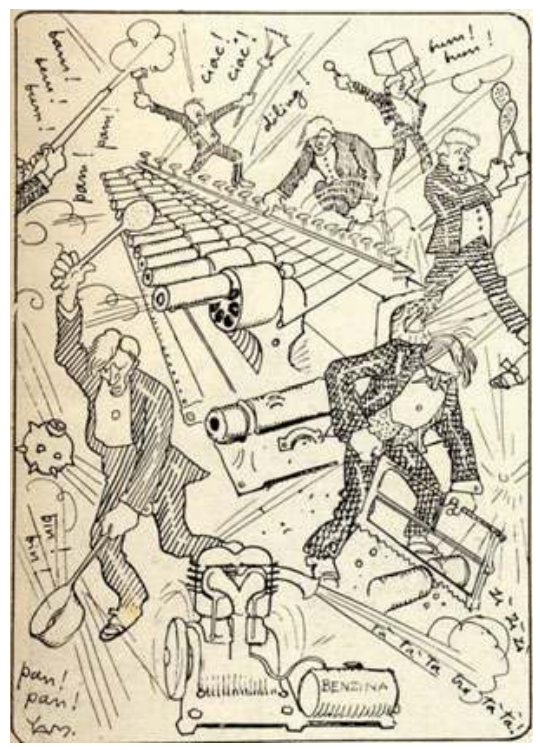

So zukunftsweisend die Ideen der futuristischen Musiker teils auch waren, bestand doch ein grundsätzliches Problem in der »Vergeistigung ihrer künstlerischen Vorstellungen in den Manifesten [...], in denen Forderungen an die Kunst konstruiert wurden, die praktisch nicht eingelöst wurden, vielleicht auch nicht eingelöst werden konnten. ${ }^{52}$ Der Musikpublizist Fred Prieberg etwa bezeichnete die futuristische Musik 1960 als »rundweg lächerlich«; lediglich die »Vielfalt der Geräusche« sei »damals etwas Neues, Beunruhigendes $«^{53}$ gewesen. Die Bedeutung des Futurismus wird in der Forschung, wenn überhaupt, meist nur als kurzfristige Leistung und temporärer Ausdruck einer Epoche der Krise und des Umbruchs gewürdigt. ${ }^{54}$

51 Francesco Balilla Pratella: »Manifest der futuristischen Musiker«, in Asholt/Fähnders: Manifeste und Proklamationen, S.18.

52 Diana Keppler: »Der Futurismus oder Die Musik im Zeitalter der Maschine«, in Forschungszentrum Populäre Musik der Humboldt-Universität Berlin (Hg): PopScriptum 7: Mensch und Maschine, Berlin 2001, S. 11f.

53 Fred Prieberg: Musica ex machina. Über das Verhältnis von Musik und Technik, Berlin 1960, S.41f.

54 Siehe etwa Hansgeorg Schmidt-Bergmann: Futurismus. Geschichte, Ästhetik, Dokumente, Reinbek bei Hamburg 1993, S.70f; Eugen Mayer-Rosa: Musik und Technik. Vom Futurismus bis zur Elektronik, Wolfenbüttel 1974, S.52. 
Dass den ästhetischen Errungenschaften heute wenig Stellenwert eingeräumt wird, liegt nicht zuletzt an dem Umstand, dass die Bewegung - ganz im Einklang mit der Zeit - den Krieg verherrlichte. In Marinettis Manifest des Futurismus hieß es:

»Wir wollen die Museen, die Bibliotheken und die Akademien jeder Art zerstören [...]. Wir wollen die Liebe zur Gefahr besingen. [...] Schönheit gibt es nur noch im Kampf. [...] Wir wollen den Krieg verherrlichen - diese einzige Hygiene der Welt. ${ }^{55}$

Der künstlerische Ansatz des Futurismus war also auch ein Ausdruck der wachsenden Aggressionsbereitschaft in Europa, wo der Krieg zunehmend als Katharsis gedeutet wurde. Darin erwies sich die Bewegung in den Worten Hermann Danusers »als Vorkämpferin für totalitäre Gesellschaftsformen; der italienische Futurismus für den Faschismus, der russische für den frühen Sowjet-Kommunismus, die lebensphilosophische Indifferenz von Rationaliät und Irrationalität für den Nationalsozialismus. $\ll^{56}$

Infolge des zermürbenden und verlustreichen Ersten Weltkriegs wurde dem aggressionsbetonten futuristischen Konzept die Legitimation entzogen und die Bewegung versandete. Die Ideen ästhetischer Diskontinuität und De(kon)struktion lebten allerdings fort und bildeten einen fruchtbaren Humus für die künstlerische Moderne. Sowohl die elektronische Musik, die nach 1945 beträchtliche Eklatanz entwickelte, als auch die Happenings von Fluxus und Aktionskunst sind kaum denkbar ohne die von den Futuristen entwickelten Konzepte; dazu gehört die Maschinenbegeisterung ebenso wie die Betonung überraschender Ereignishaftigkeit, die radikale Negation der Tradition, die bewusste Ansprache des Publikums, die Entgrenzung von Kunst und Leben sowie die Zusammenführung verschiedener künstlerischer Disziplinen. In dieser Tradition stand auch der Dadaismus als eine Art pazifistische Variante des Futurismus. Bar des Aggressionstriebes, kann Dada mit Sabine Sanio als künstlerische Reaktion auf den Schock des Ersten Weltkrieges interpretiert werden:

»Schon der sinnlose Name war eine Verweigerungsformel, die sich gegen alle bestehende [...] Kunst und Kultur gleichermaßen stellte. Von den [...] Futuristen hatten die Dadaisten die Techniken der Inszenierung übernommen, um die untergehende bürgerliche Vorkriegsordnung, die mit bombastischem Gehabe und totalitärem Geltungsdrang inszenierten Ideologien zu verspotten. Die Haltung der Verweigerung äußerte sich als Clownerie, Maskerade, Ulk, Bluff oder reiner Unsinn und setzte jede Kontemplation und Verehrung von Kunst ihrem Gelächter aus. « ${ }^{57}$

Tristan Tzara, ein bedeutender Dichter der Bewegung, bezeichnete »Dada selbst [als] Skandal« - und zwar nicht »als künstlerischen Vorgang «, sondern durch den essentiellen Faktor der »Überraschung, die Apollinaire als bedeutenden poetischen Faktor empfahl $\aleph^{58}$. Für die >Goldenen Zwanziger und ihre charakteristische Lust am Spektakel ist die provokante Anti-Kunst der Dadaisten ein idealer Stichwortgeber.

55 Filippo Tommaso Marinetti: »Manifest des Futurismus«, erschienen in: Le Figaro (20.2.1909).

56 Danuser: Wer hören will muss fühlen, S. 100.

57 Sabine Sanio: 1968 und die Avantgarde, Sinzig 2008, S. 43 f.

58 Tristan Tzara: Sieben (7) Dada Manifeste, Hamburg 1998, S. 13. 


\section{Die Sensationslust der >Goldenen Zwanzigerı}

Nach den entbehrungsreichen Jahren des Ersten Weltkrieges strebte nicht nur die Gesellschaft nach einem Neuanfang; auch die Weichen der musikalischen Ästhetik standen auf Fortschritt. Zwar löste sich die gewaltverherrlichende futuristische Bewegung infolge der allgemeinen Kriegsmüdigkeit auf, doch erlebten ihre Ideale nach 1918 eine weitere Hochphase. Die Musik befreite sich, analog zu anderen bürgerlichen Normen, ein weiteres Stück aus den akademischen Zwängen der Tradition. Dabei boten die >Goldenen Zwanziger` in ihrer mondän-provokativen Gesellschaftshaltung einen idealen Nährboden und die perfekte Kulisse für klingende Eklats.

Infolge des Krieges kam es zu einer medientechnischen Beschleunigung, die mit einer ausgesprochenen Konjunktur der Maschinenmusik auch künstlerische Blüten trieb. Der Ausbau des Rundfunks und der Fernmeldetechniken verlieh den Künsten erstmals eine transatlantische und kosmopolitische Note, auch wenn Europa in kulturellen Belangen vorerst federführend blieb. An den Kulturzentren der >Alten Welt< gründete sich manche künstlerische Existenz vor allem darauf, dass man Tagesgespräch war und in den Klatschspalten der aufstrebenden Sensationspresse erwähnt wurde. Man wollte das Neue und begrüßte daher die provokanten Bestrebungen der Avantgarden. Das legt etwa eine Aufstellung des Musikwissenschaftlers Martin Thrun nahe: »Allein in den Grenzen des Deutschen Reiches sind zwischen 1918 und 1933 rund 50 Vereine oder freie Initiativen für Neue Musik in 27 Städten nachweisbar, von denen etliche mit Sendegesellschaften des Rundfunks kooperierten. $"{ }^{59}$

Allen Bemühungen um die zeitgenössische Tonkunst voran, stand 1921 die Gründung der Donaueschinger Musiktage, die als ältestes und wichtigstes Festival Neuer Musik in die Geschichte eingingen: In der Schwarzwälder Provinzstadt wurde nicht nur das radikale Image der historischen Musikavantgarde begründet, sondern nach 1945 auch der Nachkriegsavantgarde zu neuer Blüte verholfen. ${ }^{60}$ Wenn man also einerseits von einer Konjunktur der Neuen Musik in den 1920ern sprechen kann, so setzte in jenen Jahren auch die Idee der Sezession, also ihre gesellschaftliche Nischenbildung und Isolierung, ein. Ein Jahresbericht des Schott-Verlages verglich die Neue Musik 1928 mit der »Ausübung einer neuen Religion, [die] gewissermaßen in Katakomben vor sich ging. $\ll^{61}$ Diese Abspaltung hatte Schönberg selbst durch die Gründung seines >Verein für musikalische Privataufführungen ` befördert, die eine ungeneigte Hörerschaft von den Konzerten ausschloss. Die aufstrebende Massenkultur tat ein Übriges zu dieser Entwicklung. Aber auch die Rezipienten hatten aus den Eklats der Gründerjahre gelernt. Das öffentliche Bild der Neuen Musik selektierte das Publikum, das die avancierte Musik entweder mied oder aber in Erwartung eines Skandals sensationslüstern aufsuchte. Dafür spricht die Tatsache, dass Feste für Neue Musik in jenen Jahren überall mit Tumulten konfrontiert waren. ${ }^{62}$

59 Martin Thrun: Neue Musik im deutschen Musikleben bis 1933, Band 2, Bonn 1995, S. 656.

60 Siehe hierzu das Kapitel Die Donaueschinger Musiktage: chronique scandaleuse.

61 Schott Music (Hg.): »Jahresbericht 1928«, in: Zeitgenössische Musik aus dem Verlag B. Schott's Söhne, Mainz 1928, S. 3.

62 Anton Haefeli: Die Internationale Gesellschaft für Neue Musik (IGNM). Ihre Geschichte von 1922 bis zur Gegenwart, Zürich 1982, S. 148. 
Wenn etwa die B.Z. am Mittag nach einem Berliner Konzert am 29. März 1919 titelte: $»$ Konzertschlacht. Musikalische Expression-, Futur- und andere Isten ${ }^{63}$, verdeutlicht diese Schlagzeile auch den Bezug zu den historischen Avantgardebewegungen der 1910er Jahre. In einem Brief beschrieb Hans Jürgen von der Wense 1919 typische Merkmale solcher tumultuösen Konzertabende:

»Gestern Abend war hier ein Konzert nur mit radikaler Musik, [Arnold] Schönberg, [Hermann] Scherchen, [Alban] Berg, [Heinz] Tiessen, [Eduard] Erdmann. Ich war mit [Leo] Spies und [Edgar] Byk dort. Es kam zu absolut tollen Szenen. Einige Stücke mussten unterbrochen werden, so wurde gezischt. Ich benahm mich in höchster Leidenschaft [...]. Schrie wie am Spieß des Heiligen Geistes. Mit Donnerton: >Die Pharisäer triumphieren. Aber zum letzten Mal!< Eine Dame mir ins Gesicht brüllte: `Gehen Sie doch zum Arzt, Sie Idiot!« Ich: >Pfeifen Sie nur auf uns - wir pfeifen auf Sie! « ${ }^{64}$

Solche oder ähnliche Szenen, welche die polarisierten Kämpfe um die Neue Musik durch das Publikum dokumentieren, kann man für die Jahre 1918-1933 an allen kulturellen Zentren Europas finden. In dem Bericht von der Wenses zeigt sich darüber hinaus auch die deutliche Lust am Skandal und seiner Inszenierung, wie wiederum Martin Thrun feststellte:

»Das teils präventiv mitgebrachte Instrumentarium verhieß eine [...] Variante des Skandals, bei der die >Kampfmittel« nicht länger mehr der spontanen Abwehr dienten, sondern im Zuge einer intendierten Gegendemonstration zum Einsatz kamen $[\ldots] .{ }^{65}$

Den Kritikern schien die neue Form des Protests weitaus bedenklicher als die impulsive Empörung des Publikums, weil »mehr der kalte Vorsatz zu opponieren als echte Notwehr bedrängter Gemüter « ${ }^{66}$ ausschlaggebend war. Besonders deutlich trat dieser bewusst inszenierte Skandalimpuls im mondänen Epizentrum der Bohème - Paris zutage. Die französische Hauptstadt, damals Schmelztiegel der internationalen Kunstszene, verzeichnete eine derartige Skandaldichte, dass sie als Chiffre für die zahllosen éclats der Dekade herangezogen werden kann. Davon zeugen nicht zuletzt international verständliche und gängige Ausdrücke wie succès de scandale (Skandalerfolg), épater le bourgeoisie (Nieder mit dem Spießbürgertum) sowie enfants terribles und claqueure (Randalierer), die den Skandalisierungsimpuls in den Künsten bezeichnen und die nach dem ereignisreichen Pariser fin de siécle in den 1920er Jahren eine weitere Konjunktur erlebten.

63 Adolf Weißmann: »Konzertschlacht. Musikalische Expression-, Futur- und andere Isten«, in: B.Z. am Mittag (31.3.1919).

64 Brief von Hans Jürgen von der Wense an Wilhelm und Elisabeth Mayer (29.3.1919), in Ders.: Geschichten einer Jugend. Tagebücher und Briefe. Ausgewählt, erläutert und mit einem Nachwort von Dieter Heim, München 1999, S. 181.

65 Thrun: Der Sturz ins Jetzt des Augenblicks [unveröffentlichtes Vortragsmanuskript].

66 Max Marschalk: »Kampf um Arnold Schönberg. Das vierte Philharmonische Konzert«, in: Vossische Zeitung (4.12.1928). 


\section{Der ১Paris-Modusı: succès de scandale}

Die Häufung Pariser Saalschlachten inspirierten den Musikwissenschaftler Volker Tarnow zur Rede von einer »Chronique Scandaleuse $«{ }^{67}$ und auch Ursula Petrik bezeichnete Paris als regelrechte $»$ Hochburg des Bühnenskandals $\aleph^{68}$. Hermann Danuser sprach der Stadt mit Blick auf den Eklat sogar die Bedeutung eines »Modus« zu:

»Der Paris-Modus kennzeichnet eine offenere, aufgeschlossenere Haltung, die den Skandal als ein untrügliches Signum neuer Kunst begrüßt. Sie greift überall dort, wo statt einer Werkautonomie eine publikumsbezogene Wirkungsästhetik vorausgesetzt ist [...], in deren Geschichte der succès de scandale sich vielfach bestätigt hat. ${ }^{69}$

Wenn auch die englische Phrase des `no such thing as bad publicity den Skandalerfolg bezeichnet, so war Paris doch so etwas wie die europäische Kulturhauptstadt klingender éclats. Schon während des Ancien Régime waren Kabale und Intrigen in Mode gekommen: 1733 hatte Paris seinen ersten modernen Skandal, als konservative >Lullysten` und progressive >Ramisten` die Uraufführung von Jean-Philippe Rameaus Hippolyte et Aricie mit öffentlichen Schmähungen, Spottliedern und Parodien zur Arena des Kampfes >Tradition versus Innovation « machten.

Bald schon folgten die Kontroversen um Christoph Willibald Gluck, dessen sogenannte »Reformopern« zwischen 1770 und 1780 für einen heftigen Streit sorgten, indem sie die Ablösung des bis dato geltenden Stils der Barockoper begünstigten. Noch begnügte man sich mit gelehrten Disputationen in schöngeistigen Salons und nur gelegentlichen Grobheiten in den Konzertsälen. Doch spätestens mit der Durchsetzung der Französischen Revolution 1799 wurde die Provokation des bürgerlichen Musikpublikums unter der Losung sépater le bourgeois « konstitutiv für das Pariser Kunst- und Kulturleben. Auch Volker Tarnow führte die eklatante Dynamik auf sozial- und strukturhistorische Wandlungsprozesse zurück:

»Die Chronik der Skandale verzeichnet ein bemerkenswertes Crescendo im 19. Jahrhundert. Soziologisch betrachtet war das wahnwitzige Tempo, mit dem Paris von Skandal zu Skandal eilte, eine Folge der Französischen Revolution. Dritter und vierter Stand wollten nicht nur in Wirtschaft und Nationalversammlung mitmischen, sondern auch im Theater. Die Romantik kannte noch den Salon als gesellschaftliches Korrektiv. Hier entschied die Oberschicht über Aufstieg oder Untergang; Liszt, Chopin und Paganini gingen diesen Weg, Berlioz nutzte schon stärker plebiszitäre Elemente. Doch der Strukturwandel der Öffentlichkeit schuf bald ein neues, allmächtiges Forum: das Theater selbst. Hier herrschte die Kanaille in geradezu absolutistischer Weise. $\aleph^{70}$

67 Volker Tarnow: »Chronique scandaleuse. Spucken, Beißen, Stühle schmeißen«, in: Partituren (12/2007), online abrufbar unter URL: http://www.kultiversum.de/Musik-Partituren/ Paris-Musikleben-Skandal.html [Zugriff: 31.8.2017].

68 Petrik: Die Leiden der Neuen Musik, S. 26.

69 Danuser: Wer hören will, muß fühlen, S. 96.

70 Tarnow: Chronique scandaleuse. 
Nicht nur Tarnow führte die Zuspitzung des Kunstlebens in Anlehnung an Jürgen Habermas' auf den Strukturwandel der Öffentlichkeit ${ }^{71}$ zurück und zeichnete den Konzertsaal als sozialen Versammlungs- und Verhandlungsraum aus. Auch die Musikhistoriker Sven Oliver Müller und Jutta Toelle sprachen in ihrem gemeinsamen Band zur europäischen Oper im 19. und 20. Jahrhundert von Bühnen der Politik, die »einen öffentlich wirksamen und politisierbaren Kommunikationsraum zur Verfügung « stellten, der sich »durch das Zusammenspiel zwischen musikalischen Reizen, kulturellen Bedingungen und der gesellschaftlichen Rezeption « ergab. ${ }^{72}$

Diese Darstellung trifft etwa auf die Premiere von Richard Wagners Tannhäuser zu, die 1861 ein bekanntes Kapitel Pariser Skandalgeschichte schrieb: In Deutschland wegen revolutionärer Umtriebe per Steckbrief gesucht, schaffte es Wagner in Paris, seine Oper am ersten Haus der Stadt unterzubringen: der Grand Opéra. Der Abend endete in einem Tumult, bei dem die Ästhetik allerdings nur eine untergeordnete Rolle spielte. Zwar reagierte das Publikum erbost auf die Verweigerung der üblichen Ballettmusik zu Beginn des zweiten Aktes; der eigentliche Skandal aber war eine politische Hofintrige gegen Wagner als Schützling Louis Napoleons. Mit den Krawallen wurden also soziale Konflikte um den Status der französischen Aristokratie ausgetragen. Julia Haungs skizzierte die eklatanten Ereignisse, die auch allgemein gültige Rückschlüsse auf das Pariser Rezeptionsverhalten zulassen:

»Nachdem der erste Teil glatt über die Bühne gegangen war, hofften die Sänger schon, der Eklat bleibe aus. Doch dann [...] veranstalteten die Herren des Jockeyclubs infernalischen Lärm. Mit lautem Lachen und Zwischenrufen übertönten sie die zarten Klänge [...]. Minutenlang mussten die Sänger unterbrechen. In der zweiten und dritten Aufführung steigerte sich der Lärm bis zum Tumult. Die Protestler hatten ihre Störungen mittlerweile professionalisiert und mit silbernen Jagdpfeifen aufgerüstet. Damit pfiffen sie jeden aufkommenden Applaus nieder. ${ }^{73}$

Charles Baudelaire soll im Anschluss an die Ereignisse befürchtet haben: „Was wird Europa von uns denken, und was wird man in Deutschland von Paris sagen? Diese Handvoll Rüpel bringt uns alle miteinander in Verruf! ${ }^{74}$ - Diese $» H e r r e n$ des Jockeyclubs« waren bezahlte Claqueure, die gegen Geld Aufführungen zu Erfolg oder Skandal verhalfen und deren Praktiken eine Erklärung für die Häufung klingender ecláts im Pariser Musikleben liefern: 1896 musste Alfred Jarrys surrealistisches Theater Ubu Roi bei seiner Premiere im Théâtre de L'EEuvre aufgrund von Tumulten unterbrochen werden und 1902 machte die von Gelächter und Störungen begleitete Uraufführung von Pelleas et Melisande Claude Debussy zu einer Berühmtheit. Spätestens aber mit Strawinskys (mas)sacre du printemps wurde Paris 1913 zur Hochburg des intendierten Bühnenskandals. Vier Jahre später feierte das \Ballet réaliste〈Para-

71 Jürgen Habermas: Strukturwandel der Öffentlichkeit. Untersuchungen zu einer Kategorie der bürgerlichen Gesellschaft, Frankfurt am Main 1990.

72 Sven Oliver Müller/Jutta Toelle (Hg.): Bühnen der Politik. Die Oper in europäischen Gesellschaften im 19. und 20. Jahrhundert, München 2008, S. 16.

73 Julia Haungs: »13.03.1861 - Die Pariser Premiere von Wagners `Tannhäuser` gerät zum Skandal«, in: Südwestrundfunk/SWR2 (13.03.2013).

74 Ebd. 
de unter der Regie von Jean Cocteau am Théâtre du Châtelet einen succès de scandale. Wie bei Strawinskys Frühlingsopfer, tanzte Sergej Diaghilevs Ballets Russes, Erik Satie steuerte die Musik sowie Pablo Picasso das Bühnenbild bei. Ein Kritiker von La Grimace schrieb daraufhin, der »unharmonische Clown Satie« habe seine Musik aus Schreibmaschinen und Rasseln komponiert und sein Komplize, der »Stümper Picasso«, spekuliere auf die »nie endende Dummheit der Menschen«. Guillaume Apollinaire schließlich, »dem Dichter und naiven Visionär«, gelinge es, »alle Kritiker, alle Stammgäste der Pariser Premieren, alle Lumpen aus der Butte und die Trunkenbolde vom Montparnasse zu Zeugen des extravagantesten und sinnlosesten aller verhängnisvollen Produkte des Kubismus zu machen. ${ }^{75}$ Der sowjetische Schriftsteller Ilja Ehrenburg erlebte und beschrieb die spektakuläre Premiere:

»Die Musik gab sich modern, das Bühnenbild war halb kubistisch [...]. Die Parterregäste rannten zur Bühne und schrien markdurchdringend: >Vorhang! ‘ [...] Und als ein Pferd mit kubistischer Schnauze eine Zirkusnummer vorführte, verloren sie endgültig die Geduld: `Tod den Russen! Picasso ist ein Boche! Die Russen sind Boches!^ Picassos Freunde jedoch waren begeistert. $\ll^{76}$

Deuten die Beschimpfungsformeln »Tod den Russen!« und »Boches« im Jahr 1917 auf die Konflikte der Kriegsgegner hin, so bargen die Verschmelzung der Künste und ihre avantgardistischen Spielformen auch Anlass für ästhetische Kritik. Das Engagement von Sergej Diaghilevs Ballets Russes lässt schließlich vermuten, dass Cocteau einen succès de scandale nach dem Vorbild Strawinskys anstrebte. Laut Zeugenberichten kam es im Nachgang zu einem heftigen Streit zwischen Erik Satie und dem Musikkritiker Jean Poueigh, der im Carnet de la Semaine einen Verriss publiziert hatte. Daraufhin schrieb Satie eine Postkarte mit dem Wortlaut: »Monsieur et cher ami - vous êtes un cul, un cul sans musique! Signé Erik Satie«. Der Kritiker verklagte den Komponisten und so kam es zu einem gerichtlichen Nachspiel, bei dem Satie zu acht Tagen Gefängnis verurteilt wurde. ${ }^{77}$

Die heute legendären Saalschlachten und Skandalerfolge schufen eine Erwartungshaltung, die bis weit ins 20. Jahrhundert hinein Bestand haben sollte. Noch 1954 sprach Edgard Varèse infolge der tumultuösen Premiere seiner Komposition Déserts von einem »regular Parisian scandale. $\aleph^{78}$ Doch je mehr dieser Impuls um sich griff, umso seltener wurden >echte`Skandale, die sich als überraschende Ereignisse ex nihilo entladen. Vielmehr erfuhr der succés de scandale eine Professionalisierung, nicht zuletzt durch Claqueure, die seit 1820 eine $>$ Assurance de succès dra-

75 Zitiert nach Grete Wehmeyer: Erik Satie, Regensburg 1974, S. 209.

76 Zitiert nach Wilfried Wiegand: Picasso, Reinbek 2002, S. 93 f

77 Siehe weiterführend Andreas Münzmay: »)That Mysterious Ragく. Wie Erik Satie in >Parade` das merkwürdige Verhältnis zwischen Theater und Wirklichkeit komponiert«, in Sidonie Kellerer/Astrid Nierhoff-Fassbender/Fabien Theofilakis (Hg.): Missverständnis - Malentendu: Kultur zwischen Kommunikation und Störung (Studien zur Moderneforschung, Band 4), Würzburg 2008, S. 225-241.

78 Brief von Edgard Varèse an Carlos Chavez (24.6.1960), in Paul-Sacher-Stiftung (PSS): Sammlung Edgard Varèse, Korrespondenzen, S. 985. Siehe hierzu ausführlich den Abschnitt Organisierte Interpolationen: Edgard Varèse im Kapitel Elektronische Eklatanz. 
matique , also eine Sicherstellung des dramaturgischen Erfolges durch Applaus gegen Entgelt anboten. Das Epizentrum der inszenierten Krawalle war nicht nur wegen seiner eklatanten Geschichte das Théâtre des Champs-Élysées. Auch seine Architektur nach italienischem Vorbild begünstigte das soziale Interagieren während der Vorstellung. ${ }^{79}$ Wer etwas Geld und bestimmte Interessen hatte, mochten sie politischer oder privater Natur sein, konnte mithilfe der bezahlten Unruhestifter alles erreichen: Triumpf wie Misserfolg. Man kann die Angebote der Claque in diesem Sinne als frühes Marketinginstrument verstehen, das erst nach und nach von den massenmedialen Praktiken abgelöst wurde. 1960 berichtete der amerikanische Pianist und Komponist George Antheil im Rückblick von der Dynamik der Pariser Auditorien in den 〉Goldenen Zwanzigern<:

»[Z]um Beispiel konnte man hier für bloße dreitausend Francs [...] ein 〉Genieく sein, für zweitausend ein >großes Talent` und für lumpige tausend `eine hoffnungsvolle Begabung«. Natürlich zahlten nur unerfahrene Ausländer, [...] da es überall Claquen gab und jedermann genau wusste, dass anhaltender, ohrenbetäubender Beifall bei einem Konzert eher einer dicken Brieftasche $[\ldots]$ zuzuschreiben war. $\ll^{80}$

Wenn George Antheil auch über die Pariser Mechanismen der Skandalisierung spottete, verstand der selbst ernannte Bad Boy of Music dieses Geschäft doch wie kaum ein anderer seiner Zeit.

\section{George Antheil: Bad Boy of Music}

Am 30. Mai 1922 segelte der 21jährige Komponist George Antheil von New York nach Europa, um sich einen Namen als »a new ultra-modern pianist composer ${ }^{81}$ und »futurist terrible $«^{82}$ zu machen. Er hielt Wort und so bietet er heute referentielle Anschlusspunkte für eine Kategorisierung des Musikskandals: Antheil darf 1) als herausragender Vertreter der transnationalen Bohème gelten, die mit Lust am éclat dem Skandalimpuls im Paris der 20er Jahre zu einer Blütephase verhalf. Seine exemplarische Bedeutung generiert sich 2) aus dem Umstand, dass er als Exponent der frühen US-amerikanischen Moderne dies und jenseits des Atlantiks Skandale generierte und so Anhaltspunkte für die transkulturellen Transfers zwischen der >Alten` und der $>$ Neuen Welt bietet. Seine Inszenierungsstrategien im Verbund mit den aufstrebenden Massenmedien können 3) als wegweisend für die Rolle von Musikskandalen in der Moderne gelten. Schließlich und 4) offenbart der Fall Antheil wertvolles Quellenmaterial: Nicht nur gewährt seine Autobiographie Bad Boy of Music Einblicke in die Intentionen (s)einer Perspektive als Skandalkomponist; durch einen glücklichen Zufall ist zudem eine sehr frühe filmische Quelle von Publikumstumulten erhalten.

79 Katharine Ellis: »Who Cares if You Listen? Audience Behaviour(s) in Nineteenth-Century Paris«. Vortrag auf der Tagung: »The Art of Listening - Trends und Perspektiven einer Geschichte des Musikhörens « in Berlin (12-14.7.2012).

80 George Antheil: Bad Boy of Music, Berlin 1960, S. 130.

81 Robert Morse Crunden: Body \& Soul. The Making of American Modernism, New York 2000, S. 315.

82 Carol J. Oja: Making Music Modern. New York in the 1920s, New York 2000, S. 75. 
Antheils erste europäische Station war Berlin, von wo aus er 1922 zu den schon damals berühmt-berüchtigten Musiktagen nach Donaueschingen reiste. Hier lernte er sein Vorbild Igor Strawinsky kennen, der den provokanten Jungkomponisten dazu ermutigte, sein Künstlerglück in Paris zu suchen. In der französischen Hauptstadt klingender éclats mit dem besonderen Rezeptionsverhalten des dortigen Publikums, fand der Amerikaner die idealen Bedingungen, um sich als »futurist terrible« einen Namen zu machen:

»Ich hatte Skandale in Deutschland erlebt, aber dies hier versprach wirklich etwas Ordentliches zu werden. Die Franzosen sind eine andere, leidenschaftlichere Rasse, Abkömmlinge jenes Mobs, der den Karren zur Guillotine folgte! Die Katastrophe blies mir ihren Atem in den Nacken. $\ll^{83}$

Inspiriert von diesem Klima, erhielt George Antheil schon 1923 die Möglichkeit, sein Pariser Debüt im legendären Théâtre des Champs-Elysées zu geben, wo er seine vom technischen Fortschritt inspirierten Klavierstücke Airplane Sonata und Death of Machines aufführte [ $\delta$-4.1]. Der geräuschhafte >Bruitismus $<$, die ostinaten Wiederholungen und die extreme Dynamik seiner Musik erzeugten bei den Hörern Ängste vor einer entfesselten Maschinerie, wie sie im Laufe des Jahrhunderts immer wieder manifest werden sollten. Hatte seine antiromantisch-mechanistische Ästhetik schon in Berlin für Aufsehen gesorgt, provozierte sie in Paris für einen echten succès de scandale. Sein erstes Konzert am 4. Oktober 1923 bescherte dem Theater einen weiteren geschichtsmächtigen Eintrag in seinem Skandalregister, den der Komponist selbst in Worte fasste:

»Das berühmte Theater auf dem Champs-Elysées war gefüllt mit Berühmtheiten des Tages unter andern Pablo Picasso, Igor Strawinsky, Georges Auric, Darius Milhaud, James Joyce, Erik Satie, Man Ray, Diaghilev, Miró, Artur Rubinstein, Ford Maddox Ford und unzähligen andern [...]. Mein Flügel wurde an die Rampe geschoben, vor den ungeheuren kubistischen Vorhang von Fernand Léger, und ich fing an zu spielen. Fast unverzüglich begann der Lärm. Ich erinnere mich noch, daß Man Ray jemand in der ersten Reihe eine Ohrfeige versetzte. Marcel Duchamp stritt laut mit einem andern in der zweiten Reihe. In einer Loge in der Nähe schrie Erik Satie: ১Welche Präzision! Welche Präzision!^ und klatschte Beifall. Irgendein Spaßvogel unter den Technikern richtete die Scheinwerfer ins Publikum. Einer traf James Joyce ins Gesicht und tat seinen empfindlichen Augen weh. In einer der Logen stand ein stämmiger Dichter auf und schrie: >Ihr seid alle Schweine!^ Auf dem Rang erschien die Polizei und verhaftete die Surrealisten, die, weil ihnen meine Musik gefiel, alle verprügelten, die etwas dagegen einzuwenden hatten. Erst volle zwanzig Minuten nachdem ich mit meinem Programm fertig war, wurde die Ruhe wiederhergestellt [...]. Doch seit dem 4. Oktober 1923 wußte in Paris jeder, wer ich war [...]. Am nächsten Morgen erschienen Karikaturen von mir auf den Titelseiten der Pariser Zeitungen [...]. Von diesem Augenblick an wusste ich, dass ich der neue Liebling von Paris war. ${ }^{84}$

83 Antheil: Bad Boy of Music, S. 139.

84 Ebd., S. 146. 
Dieser Ausschnitt aus Antheils Autobiographie birgt eine Vielzahl an Hinweisen auf die Dynamik musikskandalöser Ereignisse: Die letzte Bemerkung - er sei nun der »neue Liebling von Paris« - ist charakteristisch für die Pariser Begeisterung für jeden succès de scandale. Für diesen Erfolg inszenierte und vermarktete sich Antheil also bewusst als enfant terrible. Auch verdeutlicht der Textausschnitt die Dichte des Pariser Kulturlebens, wo sich zu jener Zeit spartenübergreifend die internationale Avantgarde versammelte. Schließlich birgt Antheils Bemerkung, »irgendein Spaßvogel unter den Technikern richtete die Scheinwerfer ins Publikum «, einen quellenrelevanten Hinweis. Der Beleuchter handelte im Auftrag des Experimentalfilmers Marcel L'Herbier, der für eine Szene seines Stummfilms L'Inhumaine (F 1924) eine passende Kulisse für einen Massentumult suchte, die das Skript vorsah: Georgette LeBlanc spielt darin die gefeierte Sängerin Claire Lescot. Als diese einen mächtigen russischen Galan verschmäht, inszeniert dieser während eines Konzerts im Théâtre des Champs-Elysées mithilfe von Claqueren eine Saalschlacht, die - noch bevor Claire zu singen beginnt - das komplette Auditorium ergreift. L'Herbier wusste um die aufsehenerregenden Konzerte des amerikanischen enfant terrible und bemerkte in einem späteren Interview: »Antheil hat seine absolut revolutionäre Musik gespielt, die ein großes Pfeifkonzert verursachte, die den Saal genau in die Stimmung brachte, die ich für den Auftritt der Sängerin [...] gebraucht hatte. $\ll^{85}$

Tatsächlich setzte also nicht nur die futuristisch anmutende Klangsprache George Antheils die tumultuöse Kulisse in Szene, sondern auch die dramaturgischen Bemühungen des Regisseurs. Margaret Anderson, Herausgeberin der Zeitschrift Little Review, verhalf Marcel L'Herbiers Intentionen durch eine Zeitungsannonce zu ihrer Realisierung und dem Publikum in einer frühen Form von Öffentlichkeitsarbeit auf die Barrikaden:

»Es waren zweitausend Leute, sie waren ganz besondere Leute, es handelte sich sozusagen um 〉Tout-Paris . Sie waren (alle) aus Neugier gekommen, weil Film immer noch etwas Zweifelhaftes, Mysteriöses an sich hatte und sie waren alle in Abendkleidung gekommen [...]. Man musste ihnen eine Vorstellung bieten, also hatte man mir Jean Börlin und sein schwedisches Ballett angeboten. Georges Antheil, ein amerikanischer Pianist, spielte auch ein Stück, um die Leute zu unterhalten, während wir die Filmaufnahmen vorbereiteten. ${ }^{86}$

Es richtete also nicht - wie Antheil geglaubt hatte - »irgendein Spaßvogel unter den Technikern [...] die Scheinwerfer ins Publikum«. Vielmehr benötigte der Kameramann für die Aufnahme der Publikumstumulte einen ausgeleuchteten Zuschauerraum. Was sich dort abspielte, zeigen die Originalszenen in L'Herbiers Film [ $\delta$-4.2]: In den Reihen des Auditoriums eskalieren laute(r) Emotionen: Leute stehen auf und schütteln die Fäuste, in den Gesichtern spiegelt sich Erregung, Empörung und Ratlosigkeit, aber auch Belustigung und Begeisterung. Das Publikum verhielt sich also antinormativ gegenüber dem bürgerlichen Konzertzeremoniell und geradezu sinnbildlich für einen klingenden Eklat.

85 Zitiert nach Jean-André Fieschi: »Autour du Cinématographe. Entretien avec Marcel L’Herbier«, in: Cahiers du Cinéma (202/1968), 26-43, hier S. 34.

86 Ebd. 
Nicht nur die visuellen Szenen dieser frühen und wertvollen filmischen Quelle unterstützen die analytische Vorstellungskraft mit Blick auf das Phänomen Musikskandal. Aussagekräftig ist auch die Untertitelung des Stummfilms, wo es an jener Stelle eskalierender Affekte heißt: »toute la salle fiévreuse se passionne pour ou contre cette femme sinhumaine«" Hier wird das antagonistische Gegeneinander polarisierender Reaktionen deutlich, die als symptomatisch für Saalschlachten gelten können; genauso wie die phänomenologische Beschreibung, dass sich der Tumult wie ein Brand auf das ganze Publikum ausdehnt und die Affekte also ansteckend sind. Schließlich wird auch der Inszenierungscharakter klingender éclats an diesem Beispiel deutlich: Von Seiten des Komponisten und Regisseurs genauso, wie durch das sensationslüsterne Publikum und die Medien, die den Skandalerfolg bis nach New York kabelten. George Antheil berichtete, dass ihm sein amerikanischer Agent im Anschluss Glückwunsche telegraphiert habe.

Angetrieben vom Skandalerfolg seiner mechanistischen Ästhetik schrieb Antheil infolge der Pariser Ereignisse sein bekanntestes Werk: Ballet Mécanique (1926). Auch dieses entstand im Verbund mit dem frühen Experimentalfilm, diesmal in Zusammenarbeit mit dem abstraktkubistischen Regisseur Fernand Léger, was die Nähe der Neuen (Medien-)Musik und der jungen Filmkunst illustriert. Sowohl Légers filmische [ $\delta-4.3]$, als auch Antheils kompositorische [ $\delta$-4.4] Interpretation eines >Balletts der Maschinen< zeigen sich inspiriert von einer entfesselten Maschinerie und entwickeln ihre Logik aus der Kommunikation zwischen Natürlichem und Künstlichem, von Mensch und Maschine: Tanzen bei Léger automatisierte Motoren und sich wiederholende Kreise und Dreiecke in unmenschlicher Präzision, trieb Antheil seine mechanistische Ästhetik kompositorisch auf die Spitze: In der bekanntesten Fassung seines Ballet Mécanique verwendete er 16 Pianolas, also mechanische Klavie-

Abbildung 4-George Antheil: >Prophet der Maschinenmusik

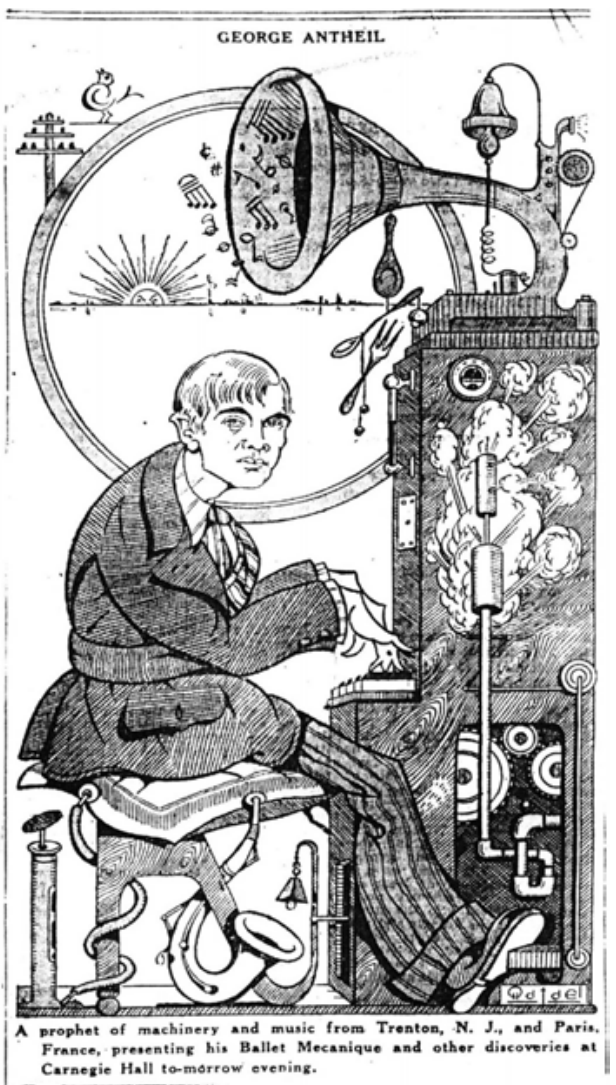
re als perkussives Triebwerk: Harte Dissonanzen, ausgedehnte Cluster, Akkordballungen mit über 30 gleichzeitig angeschlagenen Tönen, etwa 600 Wechsel in 1240 Takten sowie synkopierten Sequenzen unterstreichen - unterstützt durch vier Xylophone, zwei elektrische Klingeln, zwei Flugzeugpropeller, Tamtam, vier große Trommeln und Sirenen - eine schockartige Maschinenästhetik. 
Sowohl die Pariser Uraufführung am 19. Juni 1926 als auch die amerikanische Premiere am 10. April 1927 wurden denkwürdige Skandale - allerdings auf unterschiedliche Art, wodurch sich transkulturelle Vergleichsmöglichkeiten eröffnen: Während Antheil in Paris einen weiteren succès du scandale feiern konnte, wurde das Konzert in der New Yorker Carnegie Hall zu einem Skandal der desaströsen Art: Amerika liebte Show und Spektakel und so bewarb der Produzent Donald Friede das Gastspiel des Bad Boy of Music in seinem Heimatland übertrieben als Sensation und rührte kräftig die Werbetrommel für den Skandalkomponisten und seine mechanistische Ästhetik [Abbildung 4]. Dieser maßlos geschürten Erwartungshaltung konnte das Werk nicht standhalten, zumal die sensationsheischende Inszenierung mit einer »doppelten Anzahl von Klavieren, einem phantastisch geschmacklosen Vorhang und Flugzeugpropeller ${ }^{87}$ den musikalischen effet zugunsten eines reißerischen Effekts verdrängte. Auch besaß das amerikanische Publikum nicht die Offenheit des europäischen und besonders des Pariser Kulturlebens gegenüber der Avantgardekunst. In der Folge verglich Antheil die unterschiedlichen nationalen Proszenien:

»Der Ruhm sucht einen in Paris, London, New York oder Berlin auf völlig verschiedene Weise heim. In Paris lautet die allgemeine Reaktion auf einen sogenannten succès du scandale: >Das wollen wir uns doch mal ansehn; wo Rauch ist, könnte auch Feuer sein $\prec$ In New York heißt es dagegen allzuoft: >Hier ist zuviel Rauch; gehen wir lieber raus, es riecht schlecht..${ }^{88}$

Nicht nur finanziell wurde das Gastspiel des Bad Boy of Music in seinem Heimatland zum Desaster. Auch der Tenor der amerikanischen Kritiken war überwiegend abwertend und zielte auffallend in Richtung der französischen Hauptstadt, wie George Antheil treffend zusammenfasste: »Na, gestern Abend hat es New York aber sogar Paris einmal gezeigt! « ${ }^{89}$ Hier findet sich ein Hinweis auf das zunehmende Selbstbewusstsein der USA gegenüber der eurozentrischen Kulturhegemonie, das allerdings erst nach dem Zweiten Weltkrieg zu einer transatlantischen Neuvermessung der klingenden Welt führen sollte. ${ }^{90}$ Dazwischen lagen Jahre, die als eine Art Anti-Chiffre klingender Eklats gelten können.

\section{Die UnMÖgLichKeIt des SKandals IN ZEITEN DER DiKTATUR}

Will man eine Geschichte musikalischer Skandale im 20. Jahrhundert schreiben, so gäbe es gute Gründe, die Jahre zwischen 1933 und 1945 auszuklammern. Denn während die klingenden Eklats der 1910er und 1920er Jahre als Blaupause für die Zeit nach 1945 herangezogen werden können, markieren die Jahre der nationalsozialistischen Herrschaft eine Leerstelle, im Rahmen derer der Skandalimpuls insbesondere

87 Antheil: Bad Boy of Music, S. 210.

88 Ebd, S. 147.

89 Ebd., S. 213.

90 Siehe hierzu ausführlich das Kapitel Transkulturelle Transfers und darin besonders den Abschnitt Das Ende der Eurozentrischen Kulturhegemonie. 
in Deutschland immer weiter zurückgedrängt wurde. Während des >Dritten Reiches verlernte die gleichgeschaltete Gesellschaft den Impuls zu Aufruhr und Skandal sind diese doch Ausdruck freier und demokratischer Meinungsäußerung.

Der Mangel klingender Ereignisse zwischen 1933 und 1945 eröffnet im Anschluss an die demokratietheoretische Skandalforschung allerdings auch spezifische Ansätze für eine sozialhistorisch grundierte Theorie des ästhetischen Skandals. Stellte der Geschichts- und Politikwissenschaftler Julius H. Schoeps in seiner Erforschung des politischen Skandals fest, dass »ein Mindestmaß an Meinungs- und Pressefreiheit notwendig [ist], damit der Skandal öffentlich diskutiert werden kann «"1 , brachte der Publizist Christian Schütze die Grundthese seiner Studie zur Psychologie des Unerhörten aphoristisch auf den Punkt: »Wo es Skandale gibt, ist einiges faul, wo sie fehlen, alles. $\ll^{92}$ Kurzum: auch der ästhetische Skandal wurde in den Zeiten der Diktatur gleichsam unmöglich gemacht.

Eine ausführliche Aufnahme jener Jahre in eine Chronologie klingender Eklats vor 1945 grenzt schon mangels Beispielen an ein Ding der Unmöglichkeit, denn: wo kein Aufeinanderprallen divergierender Ansichten stattfinden kann - da ist auch kein Skandal möglich. Allerdings eröffnet diese Annahme ex negativo eine weitere analytische Eingrenzung des Phänomens Musikskandal. Der Mangel klingender Eklats im Dritten Reich weist die Kulturpolitik als integralen Bestandteil der gleichgeschalteten nationalsozialistischen Gesellschaft aus und belegt im Umkehrschluss gleichermaßen die Bedeutung des Skandals als Instrument demokratischer Herrschaftskontrolle. Schließlich spielen die Jahre zwischen 1933 und 1945 für den weiteren Verlauf der Neuen Musik im 20. Jahrhundert eine maßgebliche Rolle: Sie prägten die Kulturtechniken und Strukturen sowie die Klänge und Themen der Nachkriegsavantgarde, aber auch ihre gesellschaftliche Bedeutung und Rezeption der Neuen Musik nach Kriegsende.

Freilich sind die zwölf Jahre der nationalsozialistischen Herrschaft kein völlig losgelöster Raum aus dem (musik-)skandalösen Vor- und Nachher: Waren Skandale in der Weimarer Republik auch Ausdruck der pluralistischen Demokratie, entdeckte die faschistische Bewegung gegen Ende der 1920er Jahre die Skandalisierung unerwünschter Personen und Ausdrucksformen als Instrument der Herrschaftskontrolle. Randalierende Braunhemden, eine faschistische Variante der Pariser Claqueure, waren keine Seltenheit auf den Bühnen der Weimarer Republik; statt gegen Bezahlung, machten diese Musikaufführungen und Konzerte zu Podien der eigenen kulturpolitischen Ziele: Mit der Ausrufung der Gleichschaltung 1933 wurden Skandalisierungen zu einer Strategie der nationalsozialistischen Machteroberungsphase bis 1938. Diese Jahre sind als Schwellenphase zu verstehen, bei der die Diffamierung missliebiger Personen zum Instrument bei der Errichtung und Legitimierung des totalitären Herrschaftssystems wurde.

Auf politischem Feld etwa wurde 1934 die Ausschaltung der SA nicht nur durch Berichte über einen geplanten Putschversuch, sondern auch durch pikante Gerüchte über die homosexuellen Neigungen ihres Anführers Ernst Röhm gerechtfertigt. Diese galten durch den $\S 175$ nicht nur als Straftatbestand, sondern auch als peinlicher Makel. Die skandalisierende Kommunikation der NS-Propaganda darf im Anschluss da-

91 Julius H. Schoeps: Der politische Skandal, Stuttgart/Bonn 1992, S. 8.

92 Christian Schütze: Skandal. Eine Psychologie des Unerhörten, Bern/München 1985, S. 24. 
ran als Legitimierungsstrategie für die rigiden Maßnahmen bei der Niederschlagung der paramilitärischen Sturmabteilung der NSDAP gelten. ${ }^{93}$ Und auch in der Kunst kam es nach Gründung der NS-Reichskulturkammer am 13. März 1933 zu Störmanövern, die den Skandal als Instrument der faschistischen Konsolidierung ausweisen. Dabei wurden nicht nur Konzertsäle zu Bühnen der faschistischen Politik gemacht, sondern - wie Kai Nowak in seiner Dissertationen Projektionen der Moral zu Filmskandalen in der Weimarer Republik darstellte - auch das aufstrebende Kino. ${ }^{94}$

Innerhalb der Musikkultur trafen die Störmanöver der nationalsozialistischen Claqueure parteigemäß insbesondere jüdische und linkspolitische Musiker, aber auch sentarteter Stilrichtungen wie den Jazz oder eben die Neue Musik. Als Beispiel und Platzhalter für ähnlich gelagerte Fälle und Folgen der faschistischen Politisierung der Musik ${ }^{95}$ in der auch skandalanalytisch relevanten Epochenschwelle um 1933, kann Ernst Kréneks Oper Jonny spielt auf [ $\delta-5]$ gelten, die bei ihrer Premiere 1927 einen Skandalerfolg erzielte und bis heute als Vorzeigebeispiel für die Freiheit der Künste in der Weimarer Republik gilt. Der schwarze JazzGeiger Jonny wurde zur Ikone einer traditionszersetzenden $\mathrm{Mu}$ sikkultur, die dem europäischen Künstlertum mittels >amerikanophiler Musik eine Auffrischung Abbildung 5-Ernst Kréneks »Jonny« wird zum Symbol »Entarteter Musik« (1938)

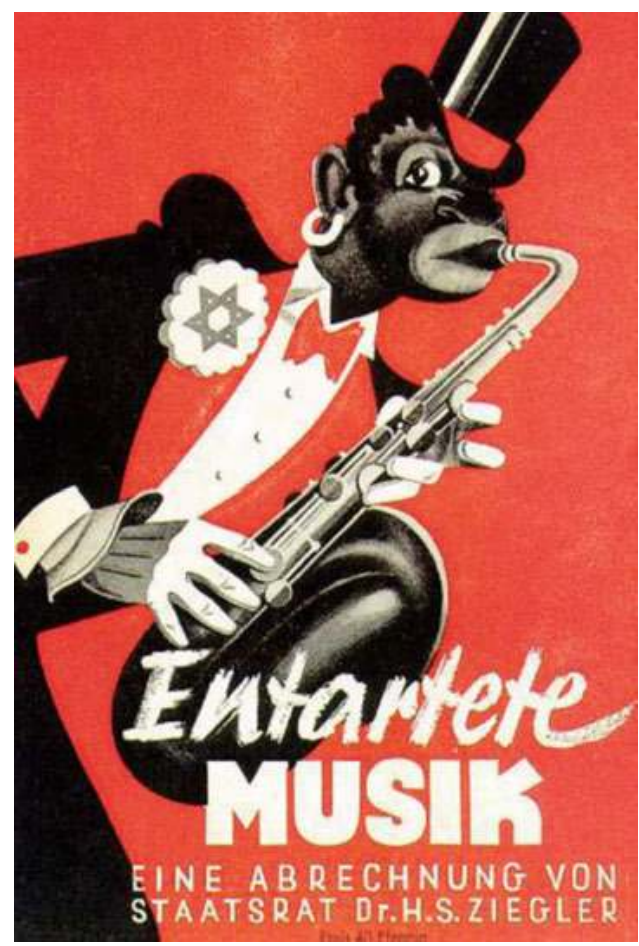
verpasste.

In der Dekade der inszenierten Sensationen wurde die eifrig befehdete Jazz-Oper auch durch die aufstrebenden Massenmedien zum Selbstläufer: In der ersten Spielzeit feierte Jonny mit 421 Aufführungen weltweit Erfolge, bevor viele Konzerte ab 1929 von faschistisch konnotierten Unruhen begleitet wurden.

93 Siehe hierzu weiterführend Heinz Höhne: Mordsache Röhm. Hitlers Durchbruch zur Alleinherrschaft, 1933-1934, Reinbek bei Hamburg 1984; Friedrich Koch: Sexuelle Denunziation. Die Sexualität in der politischen Auseinandersetzung, Hamburg 1995.

94 Kai Nowak: Projektionen der Moral. Filmskandale in der Weimarer Republik, Göttingen 2015.

95 Eckhard John: Musikbolschewismus. Die Politisierung der Musik in Deutschland 19181938, Stuttgart 1994. 
Bei der österreichischen Premiere in Wien wurde auf Flugblättern hetzerisch gereimt: »Jonny spielt auf und Jazz ist Trumpf. Die Kunst versinkt im Judensumpf. $«{ }^{96} \mathrm{Ab}$ 1933 wurde die Oper in bitterer Umkehrung ihrer Popularität als sentartete Musik und der Komponist als `Kulturbolschewist` gebrandmarkt. Die bekannte Abbildung des schwarzen Musikers Jonny, das Titelbild von Ernst Kréneks Klavierauszug, wurde zum Symbol für die Gleichschaltung von Kunst im Dritten Reich: Bei den Reichsmusiktagen in Düsseldorf wurde nach dem Vorbild der Münchner Ausstellung Entartete Kunst am 24. Mai 1938 Entartete Musik ausgestellt. Das Titelbild zierte, genauso wie das Begleitheft der Ausstellung - die Abrechnung von Staatsrat Dr. H.S. Ziegler ${ }^{97}$ - eine zeittypische Karikatur von Jonny, die alle Züge der nationalsozialistisch diffamierenden Rassenlehre zeigt [Abbildung 5]. Die Ausführungen Zieglers veranschaulichen treffend die Stoßrichtung der nationalsozialistischen Publizistik gegen den >Musikbolschewismus $<$. Parteigetreu wetterte der Generalintendant des Deutschen Nationaltheaters in Weimar gegen das Judentum - den »Vergewaltiger« des »Deutschen Kulturgutes« - das alle Abarten der Musik verantworte:

»Jeder einigermaßen Klardenkende muß heute nachgerade wissen, daß das Judentum [...] als Ferment der Dekomposition und als Verspotter aller deutschen Tugenden und Charaktergrundwerte gewirkt und [...] gerade mit den Mitteln des Schrifttums, der Scheinwissenschaft, der Künste und der Presse geleitet worden ist [...]. Denn schließlich ist ja gerade die Musik, die hier in Frage steht, einer der heiligsten Bezirke unseres ganzen inneren Daseins. $\iota^{98}$

Wenn Ziegler forderte, die Musik müsse von allen Faktoren bereinigt werden die dem deutschen Gefühl entgegenstünden, dann betraf dies nicht nur Schlager, Operetten und den Jazz. Erstaunlich ausführlich und kenntnisreich war Zieglers Diffamierung der Neuen Musik als »Gegenstand snobistischer Verhimmelung« und »intellektuell-dekadenter Betrachtungen«:

»[W]enn die größten Meister der Musik in der Tonalität und aus dem ganz offenbar germanischen Element des Dreiklangs empfunden und geschaffen haben, dann haben wir ein Recht, diejenigen als Dilettanten und Scharlatane zu brandmarken, die diese Klanggrundgesetze über den Haufen schmeißen und [...] entwerten wollen. [...] Ich bekenne mich [...] zu der Anschauung, daß die Atonalität als Ergebnis der Zerstörung der Tonalität Entartung und Kunstbolschewismus bedeutet. ${ }^{99}$

Zur Veranschaulichung wurden Portraits von Komponisten wie Arnold Schönberg und Anton Webern, Ernst Toch und Franz Schreker, Kurt Weill und Ernst Krének, Darius Milhaud und George Antheil gedruckt. Auch die einschlägigen AvantgardeMagazine Melos sowie die Musikblätter des Anbruch wurden abgebildet und mit folgender Unterschrift versehen: »In diesen Blättern wurde der Musikbolschewismus

96 Das Faksimile des Flugblatts wurde als Exponat der Wanderausstellung »Das verdächtige Saxophon - >Entartete Musik 10.3.2008) präsentiert.

97 Hans Severus Ziegler: Entartete Musik - Eine Abrechnung, Düsseldorf 1938.

98 Ebd., S. $6 f$.

99 Ebd., S. 16, 22f. 
hochgezüchtet! « ${ }^{100}$ Auf einer weiteren Seite wurde in Bild und Wort gegen führende Musikpublizisten gewettert: Adolf Weißmann, ein Kritiker des Anbruch, wurde als $»$ Verfasser der >Musik in der Weltkrise«« tituliert und gegen Heinrich Strobel, den Leiter der Donaueschinger Musiktage und Herausgeber von Melos, nicht minder boshaft polemisiert: Unter einer boshaft karikierenden Zeichnung wurde er als »Avantgardist des jüdischen Kulturbolschewismus« diffamiert und angefügt, er mache die Zeitschrift »zum Tummelplatz aller Dolchstoße gegen das Deutsche in der Musik. ${ }^{101}$ Zieglers ausführliche Beachtung der Neuen Musik spiegelt ihr offensichtlich von der NS-Kulturpolitik erkanntes Gefahrenpotential als freiheitlich-avancierte Kulturform. Man könnte die Angriffe der faschistischen Polemik selbst als Skandal oder Skandalisierung werten; allerdings deutete die Schrift mehr noch die Unmöglichkeit des Skandals im Zeichen einer Diktatur an, die ganz bewusst mit dem Pluralismus der Weimarer Republik brach:

$»$ Der Nationalsozialismus hat [...] seine Totalitätsansprüche für alle Gebiete des deutschen Lebens angemeldet $[\ldots]$. Der hat von Aufgabe und Umfang des Nationalsozialismus keine rechte Vorstellung, der da meint, daß der für das ganze Volksleben ausgeschaltete Überindividualismus der liberalistischen Vergangenheit für die Gebiete der Kunst bestehen bleiben dürfe. « ${ }^{102}$

Keiner der in Düsseldorf diffamierten Musiker konnte seiner beruflichen Tätigkeit im Dritten Reich weiter nachgehen. Aufführungs- und Berufsverbot waren der Anfang, Verfolgung und Deportation bis hin zur Ermordung das Ende der Pluralität. Wenn Amaury du Closel ihre Monographie zur >entarteten Musik « mit Erstickte Stimmen ${ }^{103}$ betitelte, wird auch deutlich, dass die Gleichschaltung der Gesellschaft mit der Möglichkeit abweichender Meinungen auch Skandale im Ansatz vereitelte. Charakterisiert man klingende Eklats durch ihre Spezifik polarisierender Meinungsbekundungen und damit als Instrument demokratischer Herrschaftsausübung, so wurden solche Mechanismen nach der Errichtung des totalitären Regimes spätestens ab 1938 unmöglich gemacht. Anders herum gesagt: Ein Austragen und Aufeinanderprallen divergierender Ansichten und Auffassungen kann sich nur unter den Bedingungen einer kulturräsonierenden Gesellschaft ereignen. Wenn auch musikhistorische Arbeiten zu diesem Gegenstand bislang fehlen, so darf Hans-Edwin Friedrichs Bemerkung zu Literaturskandalen allgemein für die Künste gelten:

»Paradoxerweise sind Demokratien aufgrund ihres erhöhten Freiheitsgrades extrem skandalträchtige Gesellschaften, während totalitäre Systeme weitgehend skandalfrei bleiben. Deren Skandalfreiheit verdankt sich einer aktiven Unterdrückung von Skandalen und dient dem Bestreben, sich als störungsfrei funktionierende Gesellschaft zu präsentieren. ${ }^{104}$

100 Ebd., S. 7.

101 Ebd., S. 9.

102 Ebd., S. 3ff.

103 Amaury du Closel: Erstickte Stimmen. »Entartete Musik« im Dritten Reich, Wien/Köln 2010.

104 Hans-Edwin Friedrich:» Literaturskandale. Ein Problemaufriss«, in Ders. (Hg): Literaturskandale, Frankfurt am Main 2009, S. 7-28, hier S. 11. 
»Autoritäre Systeme«, so schloss Friedrich seine Überlegungen ab, »verhindern die Entstehung des Skandals, eines Instruments, das in der freien Gesellschaft den Mißstand gleichzeitig anzeigt und aus der Welt schafft. ${ }^{105}$ Wo also der Staat die Kontrolle über die Massenmedien und öffentliche Versammlungen ausübt, kann es nur schwerlich zu einer polarisierenden Erregung innerhalb der Gesellschaft kommen. Das Ausbleiben von (Kunst-)Skandalen zeigt sich in allen diktatorischen Systemen; Martin Sabrow beschrieb sie daher als Korrektiv der Macht:

»Doch so stark die strukturelle Skandalaffinität von Diktaturen in der Moderne auch sein mag, so gebricht es ihnen doch an dem entscheidenden Resonanzraum, in dem die Trias von Mißstand, Aufsehen und Empörung sich entfaltet und ihre machtbedrohende Kraft gewinnt: nämlich einer autonomen Öffentlichkeit, die ihre Entrüstung gegen die Macht in Stellung zu bringen in der Lage ist. ${ }^{106}$

Wenn Sabrow also »Skandale ohne Öffentlichkeit« als »einen begrifflichen Widersinn« darstellte, schrieb er diesen eine systemstabilisierende Kraft zu und wies genauso wie Rolf Ebbinghausen und Sighard Neckel »die Existenz einer freien Öffentlichkeit ${ }^{107}$ innerhalb einer kulturräsonierenden Öffentlichkeit als konstituierendes Moment für ihre Entstehung aus. Damit eröffnen sich auch Anschlüsse an Jürgen Habermas, der die bürgerliche Publizität in seiner Studie zum Strukturwandel der Öffentlichkeit als »Sphäre der zum Publikum versammelten Privatleute« beschrieb. ${ }^{108}$ Stellt diese Öffentlichkeit der Macht also das Prinzip der Kontrolle entgegen, schlug Habermas mit der Bezeichnung der Öffentlichkeit als Publikum außerdem einen terminologischen Bogen zu theatralen Ereignissen; andersherum kann ein Konzertpublikum als Teil der Öffentlichkeit ein Indikator für das bürgerliche Mitspracherecht innerhalb eines staatlichen Systems sein. Im Nationalsozialismus verstummten die Auditorien sowohl vor der großen politischen Bühne, als auch den Konzertpodien und belegen damit die These von der Unmöglichkeit des Skandals in Zeiten der Diktatur. Für die weitere definitorische Eingrenzung des Phänomens >Musikskandalく soll daher der Sonderfall totalitärer Skandalisierungen als Mittel diktatorischer Machtergreifung weitgehend ausgeklammert werden, während die Verdichtung klingender Eklats nach 1945 den Skandal als Bestandteil demokratischer Erneuerung ausweist.

\section{Die lange iStunde Null}

Nach der Zäsur durch die nationalsozialistische Diktatur, stand Deutschland vor einer Wegmarke, die gemeinhin als >Stunde Null bezeichnet wird. Wenn diese Kategorisierung auch umstritten ist - angeführt werden meist gesellschaftliche Kontinuitäten

105 Ebd., S. 19.

106 Martin Sabrow: »Politischer Skandal und moderne Diktatur«, in Ders. (Hg.): Skandal und Diktatur. Formen öffentlicher Empörung im NS-Staat und der DDR, Göttingen 2004, S. 7-32, hier S. 17.

107 Rolf Ebbinghausen/Sighard Neckel (Hg.): Anatomie des politischen Skandals, Frankfurt am Main 1989, S. 19.

108 Habermas: Strukturwandel der Öffentlichkeit, S. 42f. 
vor und nach $1945^{109}$ - ist der jahresgenaue Schnitt doch eine genau fixierte Zeitmarke, an der sich der Aggregatszustand der deutschen Musiktradition veränderte und klingende Eklats nach ihrer diktatorischen Verhinderung wieder zu einem Teil der sich neuformierenden demokratischen Gesellschaft wurden. Dies geschah allerdings nicht schlagartig, sondern in mehreren Etappen und Umbruchsituationen. Im Anschluss an die Begriffsbildung einer »langen Stunde Null ${ }^{110}$, werden die Jahre von 1945-48 im Folgenden als Konglomerat kleinerer Epochenschwellen verstanden, die zeitversetzt einen größeren Umbruch markierten und die sich in einem analytischen und terminologischen Dreischritt von >Restauration`, >Reformation` und `Negation fassen lassen.

\section{`Restauration`: Kulturelle Katharsis}

Unmittelbar nach der deutschen Kapitulation bezog man sich einmal mehr auf Oswald Spenglers kulturpessimistische Analyse vom Untergang des Abendlandes und ließ damit die Endzeitstimmung der Jahrhundertwende und dem Ende des Ersten Weltkriegs wiederaufleben. In Die Zeit hieß es etwa im Mai 1946:

»Heute befinden wir uns in einer ähnlichen verzweifelten Stimmung wie 1919 [...]. Wieder herrscht die Auffassung vor, daß Europa aus eigener Schuld sein großes geschichtliches Erbe vertan und verspielt hat, daß seine Zeit vorüber ist. [...] Zunächst müssen wir dem Philosophen [Oswald Spengler] Gerechtigkeit zugestehen, daß er mit dem Worte >Untergang` nicht die äußere Zerstörung, nicht die Vernichtung der Städte und der alten Kulturstätten gemeint hat, sondern den inneren, unaufhaltsamen Niedergang [...], als die innere Kraft versiegte, die Kraft zu schöpferischen Leistungen von Kunst, Wissenschaft und Politik. «" ${ }^{111}$

In diesen allgemein grassierenden Kulturpessimismus mischte sich zugleich die Hoffnung auf das kreative Potential der Niederlage als $>$ kulturelle Katharsis $\left\langle{ }^{112}{ }^{\text {, }}\right.$, welche die schlechte Gegenwart enden und eine bessere, in die Vergangenheit zurückverweisende Zukunft beginnen lasse:

109 Die Komplexität der Diskussion um »Kontinuitäten und Brüche im Musikleben der Nachkriegszeit« wäre projektfüllend. Daher sei hier auf das gleichnamige DFG-Projekt an der Universität der Künste in Berlin verwiesen.

110 Hans Braun/Ute Gerhard/Everhard Holtmann: Die lange Stunde Null. Gelenkter sozialer Wandel in Westdeutschland nach 1945, Baden-Baden 2007.

111 Ernst Samhaber: »Vom Untergang des Abendlandes«, in: Die Zeit (16.5.1946).

112 Der Gedanke der kathartischen Kraft des Krieges grassierte vor allem nach dem Ersten Weltkrieg und wurde etwa bearbeitet von Helmut Fries: Die große Katharsis. Der Erste Weltkrieg in der Sicht deutscher Dichter und Gelehrter, Konstanz 1995; Petra Ernst/Sabine A. Haring/Werner Suppanz (Hg.): Aggression und Katharsis. Der Erste Weltkrieg im Diskurs der Moderne, Wien 2004; Lars Koch: »Der Erste Weltkrieg als kulturelle Katharsis und literarisches Ereignis«, in Ders./Stefan Kaufmann/Niels Werber (Hg.): Der Erste Weltkrieg. Ein interdisziplinäres Handbuch, Stuttgart/Weimar 2013, S. 97-142. 
»Eines lehrt uns die Geschichte [...]: Nicht der Frieden und das Wohlleben, nicht äußere Güter oder irdische Macht geben den Menschen die Kraft zu schöpferischen Leistungen, sondern der Geist allein, und er kann sich inmitten von Not und Elend, nach verheerenden Kriegen und inmitten großer Gefahren manchmal freier entfalten, als nach einem Sieg, der nur auf roher Gewalt beruht. ${ }^{113}$

Auch der Musikkritiker Hans Heinz Stuckenschmidt machte in dieser Situation zwei Möglichkeiten aus: »Man kann Oswald Spenglers Pessimismus aufwärmen [...]. Oder man kann vermuten, die Menschheit stehe am Beginn einer neuen Kulturepoche. ${ }^{114}$ Während er damit die Idee einer >Stunde Null aufgriff, äußerte sich sein jüngerer Kollege Heinz-Klaus Metzger, der zu einem wichtigen Sprachrohr der jungen Nachkriegsavantgarde avancieren sollte, rückblickend skeptischer:

"Zunächst einmal gab es nach der Befreiung, die von den meisten Deutschen als Zusammenbruch erlebt worden ist, was hätte es auch sonst geben sollen, das Bedürfnis nach einem Neuanfang. [...] Und dann entstand dieser Mythos der Stunde Null. Man sah immerhin noch die Chance eines Neuanfangs, nachdem ja alles, was vorher herrschte, zu Bruch gegangen war. Die Stunde Null war fast so eine Idee eines Neuanfangs aus dem Nichts. Damit ist es natürlich faktisch nichts gewesen. Die alten Kontinuitäten gingen weiter. Immerhin empfinde ich die paar Jahre zwischen 1945 und 1949, also [...] diese Besatzungszeit, als die freieste Zeit, die ich in Deutschland erlebt habe. ${ }^{115}$

Nach der Agonie der Kriegsjahre kam es jedoch zunächst zu einer Rückbesinnung auf das kulturelle Erbe. Dabei wurden zur symbolisch-identitätsstiftenden Sinnerzeugung zum einen das normative Konzept einer >deutschen Kulturnation< bemüht sowie zum anderen an die unterbrochenen Entwicklungslinien der historischen Avantgarden angeknüpft. »Weil man die nachhinkenden Gespenster der jüngsten Vergangenheit vertreiben wollte«, so bemerkte der Musikwissenschaftler Ulrich Dibelius, »bot sich der Rückgriff auf die Vorvergangenheit an«:

»Da alles Handeln im Bewusstsein eines Neuanfangs stand, erinnerte man sich daran, wie es denn nach dem Ersten Weltkrieg angefangen habe. Auch damals hatte man auf einem Nullstand begonnen, hatte aus zerschlagenen Voraussetzungen und erwachenden Hoffnungen Prinzipien einer neuen Kunst entwickeln müssen. [...] Allein, so begierig sich die Älteren nach 1945 umsahen, [...] nirgendwo entdeckten sie den Elan, die genialische Gipfelstürmerei von damals. Wo war überhaupt die Jugend? ${ }^{116}$

Die jugendlichen Gipfelstürmer ließen zunächst auf sich warten; zu tiefgreifend war die Zäsur infolge der Gleichschaltung und Isolierung durch die nationalsozialistische Diktatur. Zunächst musste erst einmal das Feld bereitet werden, auf dem eine neue Künstlergeneration wachsen und Blüten treiben konnte.

113 Samhaber: Untergang des Abendlandes.

114 Hans Heinz Stuckenschmidt: »Entwicklung oder Experiment?«, in: Melos (3/1955), S. 65-67.

115 Klaus Heinz Metzger: »Veränderte Situation«, in: MusikTexte (22/1987), S. 25.

116 Ulrich Dibelius: Moderne Musik nach 1945, München 1998, S. 30f. 
In der traditionsreichen Avantgardezeitschrift Melos, die unmittelbar nach Kriegsende wieder ins Leben gerufen wurde, hieß es 1946 in Auswertung einer Umfrage:

»Zu den traurigsten Erkenntnissen der 12 Hitlerjahre gehört für unsere Musikwelt die völlige Fremdheit der Jugend gegenüber der neueren Musik. Heute zeigt sich die Jugend vielfach genauso prüde und beengt gegenüber ungewohnten Klängen und Gebilden wie vor 40 Jahren jene Greise [...] des Epigonentums, denen schon Richard Strauss (wenn nicht gar Wagner) als Ende der Musik erschien. ${ }^{117}$

Zunächst gaben also die Väter den Ton an, angetrieben von den Fragen: »Wie eigentlich sollte man nach all der Zeit des Zwangs und der Unfreiheit komponieren, wie anfangen, wie einen Faden der Entwicklung, der zerrissen war, wiederaufnehmen? Wo sollte man anknüpfen, wo sich angleichen und wo unterscheiden? « ${ }^{118}$

In dieser Situation bekam die Rückbesinnung auf das klassische Erbe einen zentralen Stellenwert in allen kulturellen Bemühungen. Im Ringen um kulturelle Orientierung bot die ideelle Anlehnung an das Konzept der >deutschen Kulturnation` Anhaltspunkte für die Kompensation des politischen Bedeutungsverlustes. 1946 etwa schrieb der Komponist Kurt von Wolfurt an den Musikwissenschaftler und Kritiker Wolfgang Steinecke:

»Ich bin der Meinung, daß wir Deutschen, wie wir politisch wohl für immer ausgespielt haben, nun erst recht zeigen müssen, daß wir trotz allem das Volk der Denker, Dichter, Musiker und Wissenschaftler geblieben sind, wie etwa zur Zeit Goethes. ${ }^{119}$

Die kulturelle Lage war also weniger von einem tiefgreifenden Bewusstseinswandel geprägt, als vielmehr von »einem geschmeidigen Anpassungsprozess an neue politische Gegebenheiten bei geringst möglichem Identitätsverlust. ${ }^{120}$ Dies war auch notwendig, so verdeutlichte Ulrich Dibelius, da damals selbst die Musik aus der ersten Hälfte des 20. Jahrhundert

»auf den Hörer derart außergewöhnlich und überraschend [wirkte], daß er es ohne das Gefühl einer zeitlichen Diskrepanz aufnahm. Für ihn war es Gegenwart. Nur ein kleiner Kreis hatte vermocht, während der Jahre des Verbots neue Werke von Hindemith oder von Strawinsky insgeheim kennenzulernen. Von Schönberg dagegen wussten eigentlich nur seine Freunde und Schüler. $\aleph^{121}$

In dieser Situation kam es - um eine Formulierung von Ernst Bloch aus dem Jahr 1935 aufzugreifen - zu einer »Gleichzeitigkeit des Ungleichzeitigen«, also einem Aufeinandertreffen ungleicher historischer Wertigkeiten als Ausdruck für Krisen-

117 Heinz Thiessen: »Wie sollen wir aufbauen?«, in: Melos (14/1946), S. 16.

118 Dibelius: Moderne Musik, S. 24.

119 Brief Kurt von Wolfurts an Wolfgang Steinecke (27.8.1946), zitiert nach Borio/Danuser: Im Zenit der Moderne, Band 1, S. 66.

120 Monika Boll: Nachprogramm. Intellektuelle Gründungsdebatten in der frühen Bundesrepublik, Münster 2004, S. 30

121 Dibelius: Moderne Musik, S. 26. 
und Umbruchsituationen. ${ }^{122}$ Reinhart Koselleck beschrieb dieses Topos später als paradigmatische Erfahrung einer \Sattelzeit`, in der historische Erfahrungsschichten sowie in die Zukunft weisende Erfahrungshorizonte aufeinandertreffen. ${ }^{123}$ Im 20. Jahrhundert, so interpretierte Michael Makropoulos dieses modernitätstheoretische Motiv, komme die Offenheit der Zukunft in ihrer ganzen Ambivalenz und Kontingenz zum Tragen: »als Möglichkeitsbedingung von Innovation« sowie zugleich »als Quelle fundamentaler Verunsicherung. ${ }^{124}$

Die Jahre von 1945 bis 1948 können als eine solche liminale Zwischenphase verstanden werden: Mit einem rückwärtsgerichteten Halt in der Tradition und einer Art nachholender Bewegung wurde eine Brücke über die mehrjährige Zäsur der NSDiktatur geschlagen. Auf der Suche nach Kontinuitätslinien wandten sich einstige Skandalkomponisten wie Igor Strawinsky oder Paul Hindemith dem Neoklassizismus zu, der im Vakuum der Schwellenphase eine gleichsam autoritative Selbstbestätigung versprach. Doch langsam aber sicher regten sich »Unbehagen an der deutschen Kulturemphase ${ }^{125}$ und Kräfte die darauf drängten das Leck der historischen Ungleichzeitigkeit zu schließen und den radikalen Sprung nach vorne zu wagen. In Theodor W. Adorno fand die junge und progressive Nachkriegsavantgarde einen wirkmächtigen Sprecher, der die theoretische Einbettung der Neuen Musik publizistisch vorantrieb und begleitete. Die Währungsreform am 21. Juni 1948 markierte in den Westzonen das Ende der restaurativen Phase und leitete eine >klingende Reformation « ein.

\section{Reformation`: Die Renaissance der Atonalität}

Mit der Währungsreform wurden nicht nur politisch und ökonomisch die Weichen auf Fortschritt gestellt. Auch Theodor W. Adorno verabschiedete die Phase der musikalischen Restauration: »Der Nachkriegsgeist, in allem Rausch des Wiederentdeckens, sucht Schutz beim Herkömmlichen und Gewesenen. Aber es ist in der Tat gewesen. ${ }^{126} 1949$ legte der bis heute bedeutsamste Theoretiker Neuer Musik mit seiner ersten Buchveröffentlichung in Deutschland nach dem Krieg zugleich sein musikphilosophisches Hauptwerk vor, in dem er den Fortschrittsgedanken zur Philosophie der Neuen Musik ${ }^{127}$ erhob. Darin thematisierte er eine radikale Autonomieästhetik und eröffnete das dialektische Wettkampfszenario >Tradition versus Innovation` unter zeitgenössischen Vorzeichen. Seine Überlegung exemplifizierte er in den zwei Teilen seines Buches: »Schönberg und der Fortschritt« sowie »Strawinsky und die Restauration«.

122 Ernst Bloch: Erbschaft dieser Zeit, Frankfurt am Main 1985.

123 Vgl. Reinhart Koselleck: Vergangene Zukunft, Frankfurt am Main 1988.

124 Michael Makropoulos: »Historische Semantik und Positivität der Kontingenz. Modernitätstheoretische Motive bei Reinhart Koselleck«, in Hans Joas/Peter Vogt (Hg.): Begriffene Geschichte. Beiträge zum Werk Reinhart Kosellecks. Frankfurt am Main 2011, S. 481-513, hier S. 501.

125 Boll: Nachtprogramm, S. 33.

126 Theodor W. Adorno: »Die auferstandene Kultur«, in: Frankfurter Hefte (5/1950), S. 469477, hier S. 469f.

127 Theodor W. Adorno: Philosophie der neuen Musik, Tübingen 1949. 
In seiner Schrift trug Adorno also den sich dem Neoklassizismus zuwendenden Igor Strawinsky zu Grabe, hob stattdessen den progressiveren Arnold Schönberg auf den Thron und erklärte die Atonalität als alleinigen state of the art der Musikavantgarde. Den Progress erklärte Adorno zur ultimativen Wertungskategorie für den musischen Agon der Moderne, indem er einen »Kanon des Verbotenen« ausformulierte:

»Wenn nicht alles trügt, schließt er heute bereits die Mittel der Tonalität, also die der gesamten traditionellen Musik, aus. Nicht bloß, daß jene Klänge veraltet und unzeitgemäß wären. Sie sind falsch. Sie erfüllen ihre Funktion nicht mehr. Der fortgeschrittenste Stand der technischen Verfahrungsweise zeichnet Aufgaben vor, denen gegenüber die traditionellen Klänge als ohnmächtige Clichés sich erweisen. Es gibt moderne Kompositionen, die in ihrem Zusammenhang gelegentlich tonale Klänge einstreuen. Kakophonisch sind solche Dreiklänge und nicht Dissonanzen $[\ldots] .{ }^{128}$

Die Zwölftontechnik Arnold Schönbergs versprach in der Nachkriegssituation nicht nur ein Ende musikalischer Klischees, sondern bot inmitten der Verunsicherungen auch ein Regelwerk an. Die Tatsache, dass Schönberg nicht nur ein ästhetischer Visionär, sondern auch Jude war, mag die Konjunktur der von den Nationalsozialisten verfemten Avantgardeästhetik verstärkt haben. Nicht wenige Komponisten orientierten sich dabei an Adornos berühmtem kulturkritischen Diktum: »Nach Auschwitz ein Gedicht zu schreiben, ist barbarisch ${ }^{129}$. Die musikalische Interpretation dieser Aussage lautete mit Blick auf Adornos ehemaligen Lehrer Arnold Schönberg oft: Nach Auschwitz lässt sich authentisch nur noch in einer atonalen Sprache schreiben.

Zur Renaissance der Atonalität trug nicht nur das publizistische Bemühen Theodor W. Adornos sondern auch die Haltung der Alliierten bei, welche »die Restitution des Kulturlebens zum Neuaufbau einer demokratischen Gesellschaft unterstützten, sofern die jeweiligen Indikatoren als politisch unbedenklich erachtet wurden. ${ }^{130}$ In diesem Kontext löste Arnold Schönbergs »Methode des Komponierens mit zwölf nur aufeinander bezogenen Tönen ${ }^{131}$ nach 1948 - gleich einem historischen Loop wie schon nach dem legendären »Wiener Watschenkonzert« 1913 - eine ästhetische Revolution, oder besser noch: Reformation aus. Wenn Jean-Francois Lyotard Arnold Schönberg als den »Luther der neuen Musik « ${ }^{132}$ bezeichnete, beschrieb er damit einen Paradigmenwechsel, welcher der protestantischen Reformation auf ästhetischem Gebiet kaum nachstand. Dabei profitierte die Nachkriegsavantgarde nicht zuletzt vom Erstarken eines immens wichtigen Akteurs: dem Rundfunk. Explizit mit einem Bildungsauftrag ausgestattet, wurden die öffentlich-rechtlichen Rundfunkanstalten zu einer geistigen »Oase der Marktenthobenheit« jenseits des ökonomischen Prinzips. ${ }^{133}$

128 Adorno: Philosophie der Neuen Musik, S. 40.

129 Theodor W. Adorno: »Prismen. Kulturkritik und Gesellschaft«, in Ders.: Kulturkritik und Gesellschaft I, Darmstadt 1998, S. 9-30, hier S. 30.

130 Petrik: Die Leiden der Neuen Musik, S. 123.

131 Schönberg: Stil und Gedanke, S. 75.

132 Jean-Francois Lyotard: Mehrfache Stille - Vielfältiges Schweigen. Essays zu einer affirmativen Ästhetik, Berlin 1982, S. 95-122, hier S. 114.

133 Martin Walser: »Geburtstag einer Oase«, in Gerd Haedeke (Hg.): Kulturradio. Erinnerungen und Erwartungen, Köln 1996, S. 75f. 
Insbesondere die anspruchsvollen Nachtprogramme der dritten Sender boten der Neuen Musik auf institutioneller Ebene ein intellektuelles Forum und wurden - wie Gutenbergs Buchdruck bei der christlichen Reformation - zum Verbreitungsmedium der Kulturerneuerung. Dabei wurde zunehmend ein radikaler Fortschrittsgedanke bestimmend, wie ihn 1952 der Musikkritiker Hans Heinz Stuckenschmidt im Avantgardemagazin Melos thematisierte:

»Deshalb muss das Prinzip der unablässigen Innovation durch die junge Generation fortbestehen, denn die abendländische Musik [...] hat ihren unvergleichlichen geistigen Höhenflug nur erreichen können, als sie [...] sich dem Gesetz unablässiger Wandlung und Entwicklung überantwortete. ${ }^{134}$

Allerdings entstammte Hans Heinz Stuckenschmidt, wie Arnold Schönberg und Theodor W. Adorno, der Väter-Generation, die schlussendlich von ihrem eigenen Fortschrittsverdikt eingeholt wurde. In ihrem Windschatten formierten sich junge Komponisten, die auf eine Fortsetzung der musikalischen Innovationsgeschichte und den nächsten radikalen Schnitt drängten: War Schönberg der Luther der Neuen Musik, so wurde der Serialismus der Nachkriegsavantgarde zu ihrer reformierten Kirche. Das Credo ihrer Anhänger war - anstelle eines konfessionellen Bekenntnisses zur deutsche Kulturtradition - die Negation der Vergangenheit und ein kompromisslos vertretener Innovationsimperativ.

\section{`Negation`: »ohne Rücksicht auf Ruinen»}

Die Währungsreform markierte nicht nur eine Renaissance der historischen Avantgarden, sondern wurde auch den jungen Komponisten zum Symbol. Dieter Schnebel, evangelischer Pfarrer und progressiver Nachkriegskomponist, bemerkte eine Parallele zwischen dem Wiederaufbau und der Neuen Musik: »In Frankfurt entstanden damals reihenweise die wenig schmeichelnden Neubauten - aber wir fanden sie schön. Man hätte im alten Stil wiederaufbauen können - aber man wollte nicht. Ähnlich war das in der Musik. « ${ }^{135}$ Nach Restauration und Reformation bekundete also nicht nur das Publikum - wie exemplarisch ein Leser von Melos - seinen »Hunger nach neuer Musik. ${ }^{136} \mathrm{Im}$ Windschatten der historischen Vorreiter reformulierte eine junge Generation von Komponisten das Konzept einer fortschreitenden >Avant-garde < als normatives kunsthistorisches Konzept. Infolge der Zäsur durch Faschismus und Krieg waren die Protagonisten dieser Entwicklung in der Regel nicht nur zu jung, um die erste Blütezeit der Neuen Musik bewusst erlebt zu haben; auch hatten sie jahrelang eher mit Bomben als mit Tönen hantiert: Hans Werner Henze (1926-2012) etwa war als Funker für Panzerverbände ausgebildet worden und Karlheinz Stockhausen (1928-2007), dessen Vater an der Ostfront und dessen psychisch labile Mutter dem Euthanasieprogramm zum Opfer fielen, half als 16jähriger in einem mobilen Lazarett hinter der Westfront. Viele europäische Intellektuelle und Künstler hatten sich, wie

134 Hans Heinz Stuckenschmidt: »Die unbedeutende Minderheit«, in Melos (5/1952), S. 129-134.

135 Dieter Schnebel im Gespräch mit der Autorin am 12.8.2012.

136 N.N.: »Hunger nach neuer Musik«, Leserzuschrift in: Melos (3/1951), S. 92. 
etwa der italienische Komponist Luigi Nono (1924-1990), in den Widerstandsbewegungen engagiert, während andere aus der Emigration die Entgrenzung und Neuordnung der klingenden Welt einleiteten. Diese Generation war es, die der Kunstmusik nach 1945 mit einer bedingungslosen Negation der Vergangenheit ihren zeithistorisch geprägten Stempel aufdrückte. Ihre Vertreter, so zeigt exemplarisch eine Bemerkung Stockhausens, interpretierten die Nachkriegssituation nicht kulturpessimistisch; vielmehr wollte man die einmalige historische Chance nutzen:

»Vergesse man aber nicht, dass selten eine Komponistengeneration so viele Chancen hatte und zu solch glücklichem Augenblick geboren wurde, wie die jetzige: Die Städte sind radiert - und man kann von Grund auf neu anfangen, ohne Rücksicht auf Ruinen und geschmacklose Überreste. ${ }^{137}$

Die junge Komponistengeneration nahm das von Adorno formulierte Fortschrittstheorem wörtlich: ihre Protagonisten wollten nicht nur das Leck der historischen Ungleichzeitigkeit schließen und den Anschluss zur Gegenwart herstelle, sondern vielmehr den radikalen Sprung in die Zukunft wagen. Dabei offenbarten sich Parallelen zur Nachkriegsliteratur aus dem Umfeld der Gruppe 47, das zeigt eine programmatische Bemerkung von Hans Werner Richter anno 1946:

»Der moralische, geistige und sittliche Trümmerhaufen, den eine verlorene Generation zurückgelassen hat, wächst ins Unermeßliche [...]. Vor dem rauchgeschwärzten Bild dieser abendländischen Ruinenlandschaft [...] verblassen alle Wertmaßstäbe der Vergangenheit. [...] Aus der Verschiebung des Lebensgefühls, aus der Gewalt der Erlebnisse, die der jungen Generation zuteilwurden und die sie erschütterten, erscheint ihr heute die einzige Ausgangsmöglichkeit einer geistigen Wiedergeburt in dem absoluten und radikalen Beginn von vorne zu liegen. ${ }^{138}$

In diesem Geiste, so bemerkte Martin Thrun, wurde »manchen Künstlerästhetiken die Negation von Ausdruck zum Gebot. $\ll^{139}$ Diese negative Ästhetik entsprang nicht nur historischen Konstellationen, sondern eröffnet auch Anschlüsse an ein konfliktives Generationenkonzept ${ }^{140}$, das in der >langen Nachkriegszeit` eine Verschärfung erfuhr. Soziologisch lässt sich diese Dynamik mit Pierre Bourdieus Feld-Theorie denken: Demnach ergeben sich mit dem »Eindringen von Neulingen, die einfach schon aufgrund ihrer [...] sozialen Zusammensetzung Neuerungen bei Produkten oder Produktionstechniken ${ }^{141}$ anstreben, große Umwälzungen und dies nicht zuletzt deshalb, weil es der jüngeren Generation stets wesentlich um »Diskontinuität, Bruch, Differenz, Revolution ${ }^{142}$ gehe.

137 Karlheinz Stockhausen: »Zur Situation des Metiers« (1953), in Ders.: Texte zur Musik, Band 1, Köln 1963, S. 45-61, hier S. 48.

138 Hans Werner Richter: »Warum schweigt die junge Generation?«, in: Der Ruf (2/1946), S. 55.

139 Thrun: Der Sturz ins Jetzt des Augenblicks (Vortragsmanuskript).

140 Siehe hierzu weiterführend den kanonischen Text von Karl Mannheim: »Das Problem der Generationen«, in: Kölner Vierteljahreshefte für Soziologie 7 (1928/29), S. 157-184.

141 Pierre Bourdieu: Die Regeln der Kunst, Frankfurt am Main 2001, S. 357.

142 Ebd., S. 253. 
Die jungen Komponisten wollten also Epoche machen und wurden zu Statthaltern einer markanten Epochenschwelle, wie sie Reinhart Koselleck definiert hat: Die bestürzende Erfahrung der »Dynamisierung und Verzeitlichung der Erfahrungswelt« und der »offenen Zukunft mit einer Vielfalt der Perspektiven« schuf das Bewusstsein, in einer Übergangsphase zu leben, »in der es immer schwerer wird, die überkommenen Traditionen mit den notwendigen Neuerungen zu vermitteln. « ${ }^{143}$ Der zunehmend eklatante und agonale Wettstreit um Innovation wurde dabei zur liminalen Kategorie der sich nach 1945 häufenden Schwellenphasen und Umbruchszenarien.

\section{Versuch einer Definition: KLingende Éclats}

Will man aus den oben vorgestellten Referenzen und Chiffren der ersten Hälft des 20. Jahrhunderts eine Definition des Musikskandals nach $1945 \mathrm{zu}$ destillieren, so muss grundlegend festgehalten werden, dass der klingende Eklat von anderen Formen der Skandalisierung zu unterscheiden ist. Diese Feststellung gilt zunächst einmal für die Differenzierung politisch oder wirtschaftlich motivierter sowie ästhetisch begründeter skandalöser Ereignisse. Denn während Betroffene der ersten Kategorie meist mit schweren Sanktionen zu rechnen haben, schlagen öffentliche Kritik und Anfeindungen in der Kunst oft in Achtung und Ruhm um. ${ }^{144}$ Haben Skandalisierte auf sozialen Feldern also fast immer mit negativen Folgen zu rechnen, ist der Kunstskandal für die Betroffenen oft positiv konnotiert und also erstrebenswert. Nicht nur erhalten Skandalkünstler ein hohes Maß an öffentlicher Aufmerksamkeit, die im Verlauf des 20. Jahrhunderts zu einer immer kostbareren Währung avancierte; auch gelten skandalisierte Kunstwerke als wegweisender Ausweis für ästhetischen Fortschritt sowie als Metaerzählung der künstlerischen Moderne. Einen Sonderfall markieren hier nur die Jahre des Dritten Reichs, als auch künstlerische Pluralität und Innovation ernsthaft bekämpft und sanktioniert wurden. Ist dieser Sonderfall eher im Feld des Polit- anstatt des Kunstskandals einzuordnen, so gilt das Gebot der differenzierten Betrachtung auch innerhalb der Künste, denn: Kunst-Skandal $\neq$ Kunst-Skandal.

Hans-Edwin Friedrich gab mit Blick auf den Literaturskandal an: »zwischen den einzelnen Künsten besteht in Bezug auf ihre Skandalträchtigkeit kein prinzipieller Unterschied. « ${ }^{145}$ Dieser Einschätzung ist entschieden zu widersprechen. Besonders zwei Faktoren sind für eine Differenzierung ästhetischer Skandale aufschlussreich: Der spezifische Ausdruck der Kunstsparten (Materialität/Medialität) sowie die besonderen Merkmale ihrer jeweiligen Rezeptionsbedingungen. Funktionieren etwa Literatur und Bildende Kunst als materiell verfasste Objekte in Zwiesprache mit einem mehr oder weniger isolierten Betrachter, sind Theater, Opern und Konzerte von transitorischer Flüchtigkeit geprägt, an das raumzeitliche Setting der Aufführung gebunden und entfalten ihre spezifische performative Ästhetik in der »Ko-Präsenz im Ver-

143 Reinhart Koselleck: »Das 18. Jahrhundert als Beginn der Neuzeit«, in Ders. (Hg.): Epochenschwellen und Epochenbewusstsein (Poetik und Hermeneutik, Band 12), München 1987, S. 269-282, hier S. 278f.

144 Lydia Jeschke: »Hören, fühlen, denken. Über Lust und Frust des Musikerlebens«, Teil 3: »Aufruhr im Konzertsaal«, in: Südwestrundfunk/SWR2 (1.7.2009).

145 Friedrich: Literaturskandale S. 16. 
hältnis zwischen Darstellern, Zuschauern und Szene. « ${ }^{146}$ Martin Eybl, der Chronist der referentiellen Schönberg-Skandale, gab zu bedenken, dass Musik innerhalb der Künste als Sonderfall zu gelten habe: Im Gegensatz zu sprachbasierten Ausdrucksformen wie der Literatur oder dem Theater seien hier vorrangig ästhetische Gewohnheiten und deren Störung ausschlaggebend für skandalöse Reaktionen. ${ }^{147}$ Diese Einschätzung gilt besonders für die Instrumentalmusik, während das Musiktheater in seiner multimedialen Anlage wiederum als Sonderfall zu behandeln ist. Wenn Eybl eine Typologie musikalischer Skandalformen als offene Aufgabe bezeichnete, wird diese Vakanz im Folgenden mit dem Versuch einer Definition des Musikskandals auf Basis des oben aufgeworfenen Referenzrahmens angegangen. Zuvor sind ein paar grundlegende Worte zur Terminologie des Gegenstands geboten.

Der etymologische Ahne des modernen Skandals liegt im altgriechischen $\sigma \kappa \alpha ́ v \delta \alpha \lambda o v$ (skándalon) womit zunächst die Auslösevorrichtung einer Tierfalle und somit ein losschnellendes Gerät bezeichnet wurde. Liegt bereits hier die Sprengkraft des neuzeitlichen Skandals begründet, wurde dieser im lateinischen scandalum zum biblischen >Stein des Anstoßes`. Im 17. Jahrhundert wurde der scandale in Frankreich zum Synonym für negatives öffentliches Aufsehen und in dieser Bedeutung ab dem 18. Jahrhundert in ganz Europa übernommen. Seitdem bezeichnet der Skandal ein aufsehenerregendes Ereignis sowie auch den Diskurs darüber - er wurde also um eine mediale Komponente erweitert. ${ }^{148}$ In diesem Sinne gelten in dieser Arbeit gleichermaßen Saalschlachten wie auch ihre publizistische Ausbreitung und die öffentlich geführten Kontroversen als Musikskandal. Steckt im französischen scandale außerdem die Bedeutungskomponente von Lärm, so ist damit ein weiterer Schritt hin zur Eingrenzung des klingenden Eklats gemacht. Apropos: Der dem Skandal verwandte und oft synonym verwendete Begriff scheint insbesondere in seiner französischen Diktion - éclat - in vieler Hinsicht geeignet für eine Differenzierung des Musikskandals von den anderen Formen der Skandalisierung.

Beschreibt der Skandal eine zeitlich längere Folge von Ereignissen und ist in die zeitliche Struktur eines Vor- und Nachher eingebettet, steht der Eklat tendenziell für ein einmaliges und punktuelles Geschehen oder den Höhepunkt skandalöser Ereignisse. Der Begriff scheint damit geeignet, den Moment der Eskalation zu fassen, der sich auf musikalischem Feld meist innerhalb eines konzentrierten Konzertsettings entlädt. In seiner weiter gefassten französischen Ausprägung wird der éclat unter anderem als musikalische Vortragsbezeichnung für einen plötzlich aufscheinenden Klang verwendet wird. Mit seinen Bedeutungskomponenten wie `Splitter`, `Spren-

146 Erika Fischer-Lichte/Jens Roselt: »Attraktion des Augenblicks - Aufführung, Performance, Performativ und Performativität als Theaterwissenschaftliche Begriffe«, in Dies./Christoph Wulf (Hg.): Theorien des Performativen, in: Paragrana 10 (1/2001), S. 237-254, hier S. 238.

147 So Martin Eybl in seinem Beitrag »Skandal als Phänomen moderner Öffentlichkeit« auf dem Workshop des DFG-Sonderforschungsbereichs »Moderne«: »Wien und Zentraleuropa um 1900: Die >unscharfen Ränder Zentraleuropas« (Budapest, Oktober 1998).

148 Siehe hierzu Gerrit Walther: »Skandal«, in Friedrich Jaeger (Hg.): Enzyklopädie der Neuzeit, Band 12, Stuttgart 2010, Sp. 54-57; Cornelia Blasberg: »Skandal«, in Gerd Ueding (Hg.): Historisches Wörterbuch der Rhetorik, Band 8, Tübingen 2007, Sp. 923-929. 
gung « und `Knall«, aber auch 〉Spiegelungく und `Schein` ist er zudem sinnlich breiter aufgestellt und damit in der Lage, performative Sensationen und audio-visuelle Ereignisse zu erfassen, wie sie in der Neuen Musik bedeutsam wurden. Schließlich besitzt der éclat im Vergleich zum überwiegend pejorativ besetzten Skandalbegriff eine >heroischer Bedeutungskomponente. Beim Sonderforschungsbereich Helden der Universität Freiburg und insbesondere im Teilprojekt »Der éclat des Helden - Formen auratischer Repräsentation ${ }^{149}$ findet der Begriff prominente Verwendung. Hier wird der eklatante Sinngehalt von Glanz und Ausstrahlung(skraft) fokussiert und damit als konzeptualisierte Artikulationsform zur Beschreibung des Heroischen an den Topos des Heldenglanzes angeschlossen.

Der so verstandene éclat beschreibt also nicht nur seine Wirkung auf und die Wahrnehmung durch die Gesellschaft, sondern auch eine wesentliche Qualität für den Begriff des Heroischen als Epiphanie. Dieser steht in einem grundsätzlichen Spannungsverhältnis zwischen der unmittelbaren Präsenz der Heldentat und der Notwendigkeit, diese ihrer gesellschaftlichen Wirksamkeit wegen zu kommunizieren, das heißt zu semantisieren und zu medialisieren. In seiner Vieldeutigkeit zwischen Krise und Strahlkraft ist der Begriff des éclat also prädestiniert für die analytische Beschreibung von den Skandalen der Musikavantgardisten, die sich in ihrer Vorreiterrolle konstitutiv zwischen aufsehenerregendem Ärgernis und heldenhafter Neuerschließung der klingenden Welt bewegten. Es ist somit sicher kein Zufall, dass Pierre Boulez - ein wichtiger >Skandalierer der Nachkriegsavantgarde - 1965 eine Komposition mit Éclat betitelte und das Stuttgarter Festival für Neue Musik den vielschichtigen Begriff als Namen wählte.

Wenn im Folgenden die Begriffe Skandal, Eklat und éclat aus Gründen der Lesbarkeit synonym verwendet werden, sind diese Überlegungen doch als grundlegend für den Musikskandal zu verstehen, der im Folgenden mittels einer Typisierung und Kategorisierung der vorangegangenen Referenzen und Chiffren definitorisch verdichtet und damit das analytische Handwerkszeug dieser Dissertation vorgestellt wird.

\section{Avant-Garde: 'Tradition versus Innovation`}

Die einfachste weil allgemein verbindliche Kategorie des Phänomens Musikskandal findet sich im aufgeladenen Widerspruchspaar von >Tradition versus Innovation<. Der Kampf zwischen Progress und Bewahrung ist so alt wie die Musik selbst und konstituierender Bestanteil ihrer Geschichte, die einem wiederkehrendem Muster folgte: Etablierte Normen und Regeln wurden hinterfragt und angegriffen, bevor die Neuerungen ihrerseits eine Konsolidierung und Etablierung erfuhren, um schließlich wiederum aufgebrochen zu werden. Wenn das dialektische Begriffspaar von Tradition und Innovation damit ein historisches und zeitenübergreifendes Phänomen ist, so erfuhr die Einstellung zur Geschichte - als Punkt der Abstoßung oder Anknüpfung seit dem 19. Jahrhundert einen aufschlussreichen Wandel:

149 »Der >éclat` des Helden - Formen auratischer Repräsentation des Helden in Frankreich vom 17. bis zum 19. Jahrhundert«, Teilprojekt des Sonderforschungsbereichs $948 » H e l-$ den - Heroisierungen - Heroismen. Transformationen und Konjunkturen von der Antike bis zur Moderne«. 
»Erst mit den Idealen der Aufklärung hielt der Gedanke Einzug, im Fortschreiten der Zeitläufe eine Progression der Menschheit zu erkennen, wodurch die Gleichzeitigkeit traditioneller und innovativer Praktiken nicht mehr wertneutral verstanden wurde. ${ }^{150}$

Im frühen 20. Jahrhundert entwickelte sich der Fortschrittsgedanke zu einem Credo in der Selbstzuschreibung der Avantgardekünstler und muss mit Blick auf die AvantGarde wörtlich verstanden werden, die dem Wortverständnis nach eine prozesshafte, eindeutig nach vorne gerichtete Erscheinung ist. Dass der Begriff der französischen Militärsprache entstammt und eine kriegerische Vorhut bezeichnet, ist für die Avantgardebewegungen des 20. Jahrhunderts wörtlich zu verstehen: So evozierten die ästhetischen Vorreiter immer wieder Feindberührungen, während das Peloton, das gesellschaftliche Hauptfeld, meist erst in ihrem Windschatten das ausgekundschaftete Terrain betrat. Avantgarde wird in diesem Sinne nicht als Bezeichnung einer zeitlichen Strömung verwendet, sondern als Konzept. Diese Ungleichzeitigkeit des Gleichzeitigen ist den Avantgarden intrinsisch implementiert: schon die semantische Wortbedeutung setzt ein Verständnis der Differenz von Vorhut, Gros und Nachhut voraus: Vorläufer und Nachzügler sind demnach in der Gegenwart gleichzeitig anwesend. Kann dieser Gedanke als historiographisches Organum der Arbeit mitgedacht werden, entwickelte das Spannungsverhältnis von Tradition und Innovation im Verlauf des 20. Jahrhundert eine ungeheure Eigendynamik. Dafür sprechen nicht zuletzt die polarisierenden Reaktionen in den Konzertsälen, in denen dieser Konflikt lautstark zum Ausdruck und zum Tragen kam.

Der Fortschrittsgedanke avancierte nach den legendären Saalschlachten des Jahres 1913 zu einem grundlegenden Theorem der Moderne, mit dem die Kategorie des Skandals als Motor für Progress und Beweis für ästhetische Innovation etabliert wurde. Ein ideologiegeschichtliches Konzept wurde dabei ebenso wichtig wie problematisch: Der Glaube an die normative Kraft einer linearen Fortschrittgeschichte. Beschrieb Walter Benjamin den Fortschritt 1940 unter dem Eindruck der weltpolitischen Ereignisse als \Sturm $\prec$ in den Flügeln des >Engels der Geschichte ${ }^{151}$, bezeichnete ihn Frank Hentschel im Anschluss an postmoderne Theoriebildungen ${ }^{152} 2006$ als ein "geschichtsphilosophisches Axiom, [das] fast zwangsläufig einen teleologischen Geschichtsplot ${ }^{153}$ erzeuge. Eben dieser Fortschrittsglaube erfuhr nach 1945 eine eklatante Beschleunigung und wurde zu einem Leitprinzip der Musikavantgarde. Es gilt die These, dass die referentiellen Skandale einen Bruch der bis dato geltenden Normen und also einen Paradigmenwechsel innerhalb eines jeweils spezifischen kulturhistorischen Settings markierten. Wenn der Kulturhistoriker Georg Bollenbeck für die Moderne vor 1945 herausarbeitete, diese sei »kein Zustand, sondern ein Pro-

150 Michael Custodis: Die soziale Isolation der neuen Musik. Zum Kölner Musikleben nach 1945, Stuttgart 2004, S. 150.

151 Walter Benjamin: »Über den Begriff der Geschichte« [1940], in Ders.: Gesammelte Werke, Band 1, Frankfurt am Main 1991, S. 690-708 und besonders S. 697f.

152 Siehe Jean-François Lyotard: Das postmoderne Wissen, Wien 2012; Ders.: Der Widerstreit, München 1989; Wolfgang Welsch: Unsere postmoderne Moderne, Berlin 2002.

153 Frank Hentschel: Bürgerliche Ideologie und Musik, Frankfurt am Main/New York 2006, S. 161. 
zess $\aleph^{154}$, gilt dies ebenso für die Nachkriegsavantgarde, deren Skandale die progressiven Schwellen dieses Prozesses markierten. Es scheint daher fruchtbar, die Avantgarde »als wiederkehrendes Ergebnis historischer Umbruchsituationen, als Antwort auf das für Epochenschwellen charakteristische Auseinanderklaffen von Erfahrung und Erwartung ${ }^{155}{ }^{15 u}$ verstehen.

\section{Rites de Passage: Paradigmenwechsel und Schwellenphasen}

Musikskandale deuten auf Paradigmenwechsel hin - das spiegelt sich auch in den als referentiell vorgestellten Fallbeispielen. Deren Auswahl erfolgte keineswegs willkürlich, sondern trägt vielmehr den Wandlungsprozessen im Umfeld des Ersten Weltkriegs als einschneidender Zäsur Rechnung: Sowohl in den Jahren vor 1914, als auch nach 1918 kam es zu einer Häufung von klingenden Eklats. Es gilt hier die Hypothese, dass diese Ereignisse keineswegs zufällig zustande kamen, sondern vielmehr Ausdruck historischer Schwellenphasen waren. Sie weisen auf eine Verdichtung der Zeit-Zeichen hin, die in den Konzertsälen als sozialen Versammlung- und Verhandlungssorten eskalierten und eine öffentliche Bühne fanden.

Vor 1914 waren solche Zeichen etwa der unverkennbare Aggressionstrieb und die Kriegsbegeisterung der Futuristen, die - indem sie Kampfhandlungen geradezu provozierten - symbolisch auf den Ersten Weltkrieg wiesen und Konzerte zu performativen Schlachtfeldern ästhetischer Erfahrung machten. Weniger offensichtlich ist der Kampfesimpuls im Falle der tumultuösen und referenziellen Premieren Igor Strawinskys und Arnold Schönbergs im Schlüsseljahr 1913. Aber auch diese Ereignisse fanden in einem Klima des Auf- und Umbruchs statt, wenn dabei auch keine besonders ausgeprägte Aggressionsbereitschaft - zumindest seitens der Künstler festzustellen war. Hier lag der Sprengstoff in der Ästhetik selbst, die das Ende des tonalen Zeitalters und den Beginn der abstrakten Moderne markierte. Die Skandale schrieben gewissermaßen ein Drehbuch für die späteren Avantgarden, wie Jennifer Schuessler 2012 in der New York Times ausführte:

»The premieres helped write a modern cultural script. Artists have been trying to provoke audiences ever since, elevating shock to an artistic value, a sign that they are fighting the good fight against oppressive tradition and bourgeois morality. ${ }^{156}$

Auch die Musikskandale des Schlüsseljahres 1913 gingen mit einer ebenso künstlerisch wie sozial konnotierten Umbruchphase einher, die vom Kampf zwischen Tradition und Innovation, Bürgerlichkeit und Progressivität, Restauration und Reformation geprägt war; mit ästhetischen Mitteln wurden hier die Zeichen der Zeit in Klang gesetzt. Ähnliches gilt für die Jahre der Weimarer Republik, als sich in der Folge des Ersten Weltkriegs zwischen 1918 und 1933 eine weitere Schwellenphase auftat, die

154 Georg Bollenbeck: Tradition, Avantgarde, Reaktion. Deutsche Kontroversen um die kulturelle Moderne 1880-1945, Frankfurt am Main 1999, S. 29.

155 Dolores Sabaté Planes/Jaime Feijóo: 1910-2010: Hundert Jahre Avantgarde. Ein Vorwort, in dies. (Hg.): Apropos Avantgarde. Neue Einblicke nach Einhundert Jahren, Berlin 2012, S. 9-12, hier: S. 9.

156 Jennifer Schuessler: »Shock Me if You Can«, in: New York Times (14.9.2012). 
vielfältige paradigmatische Veränderungen nicht nur in der Gesellschaft, sondern auch in den Künsten und ihrer Wahrnehmung zeitigte. Hans Robert Jauß bemerkte in seiner Theorie der Rezeption, dass

»der Umbruch vom Alten zum Neuen erst an der [...] sich abzeichnenden Grenzlinie von `Epochenschwellen` erkennbar [wird]: an der Umbesetzung von Funktionen [...] des bisherigen Weltmodells. ${ }^{157}$

Jauss verwies damit auf Hans Blumenberg, der solche Epochenschwellen als >unmerklichen Limes` bezeichnete. ${ }^{158}$ Werden Skandale in einem größeren historischen Rahmen der Erneuerung von Normen und sozialen Ordnungen verortet, so können sie als Kategorie herangezogen werden, die den flüchtigen Augenblick des Umbruchs - den Moment, wenn das Pendel kurz stillsteht bevor es die Richtung ändert bezeichnet. Zum Ereignis wurden die klingenden éclats im Moment ihrer Eskalation: wenn sie sich unvorhergesehen und überraschend innerhalb eines repräsentativen Settings entluden. Dafür spricht auch die Tatsache, dass insbesondere Uraufführungen den Rahmen für die bedeutendsten Musikskandale lieferten, wie Thomas F. Kelly in seiner Diskussion musikalischer Premieren verdeutlichte:

»Each great work has its infancy, when it is new and fresh, when tradition, admiration, and history have not yet affected its shape, when its audience is unencumbered by previous expectations. $\ll^{159}$

Mit dem Überraschungsmoment unvoreingenommener Erwartungshaltung nannte Kelly zwei wichtige Faktoren für das Zustandekommen klingender Eklats. Mit Blick auf Epochenschwellen können diese auch mit Hermann Danuser als eine Art ästhetischer Grenzmarkierung verstanden werden:

»Am Ausgang der historischen Entwicklung neuer Kunstarten, Gattungen, Stile, Ästhetiken stehen meist Konflikte, Auseinandersetzungen, Kämpfe. Denn zunächst stößt alles, was außerhalb der etablierten [...] Grenzen einer Kunsttradition liegt, rezeptionsästhetisch auf eine Verweigerung der Akzeptanz, die nur durch den Austrag eines Konflikts überwunden werden kann. $\ll^{160}$

Ästhetische Kontroversen traten insbesondere in historischen Umbruchsituationen auf und bezeichneten über künstlerische Belange hinausgehend den Wandel sozialer und kultureller Normen. Sie waren passagere Ereignisse im Rahmen gesellschaftlicher Wandlungsprozesse und mithin Bestandteil von Übergangsriten - jenen Rites de passage, die der französische Ethnologe Arnold van Gennep bereits 1909 analytisch beschrieb: Auf Trennungsriten (rites de separation) folgen Schwellenriten (rites de marge), die letztlich in abschließenden Angliederungsriten (rites d'agrégation) mün-

157 Hans Robert Jauß: Die Theorie der Rezeption - Rückschau auf ihre unerkannte Vorgeschichte, Konstanz 1987.

158 Hans Blumenberg: Aspekte der Epochenschwelle, Frankfurt am Main 1976.

159 Thomas Forrest Kelly: First Nights. Five Musical Premieres, New Haven 2000, S. 12.

160 Danuser: Wer hören will, muß fühlen, S. 95. 
den. ${ }^{161}$ Der Musikskandal wird in diesem Sinne als eine liminale Kategorie des Übergangs verstanden, in der sich kulturelle Bruchstellen künstlerisch und performativ offenbaren - und zwar gleichermaßen auf Produktionsebene (Ästhetik, Inszenierung, Medien) wie auch in den Verhaltens- und Funktionsweisen der Rezeptionsseite (Publikum, Presse). Nicht zuletzt in dieser Verklammerung verschiedener gesellschaftlicher Akteure und Gruppierungen liegt das kulturdiagnostische Potential klingender Eklats.

\section{Produktion: Inszenierungsstrategien}

Der Wandel, den ästhetische Skandale bezeichnen, betrifft also gleichermaßen die Produktion wie auch die Rezeption der jeweils zeitgenössischen Kunst. Ursula Petrik beschrieb mit Blick auf die referentiellen Musikskandale Arnold Schönbergs beide Seiten, wenn sie den »Bruch mit der Tonalität [...] als das wohl radikalste Phänomen innerhalb der Neuen Musik und gleichzeitig als ein erhebliches Motiv für deren vielfache Ablehnung ${ }^{162}$ bezeichnete. Ausgehend von den eklatanten Gründungsereignissen der musikalischen Moderne etablierte sich auf Produktionsseite ein ästhetischer Fortschrittsglaube, der konstituierend für das Selbstverständnis der Neuen $\mathrm{Mu}-$ sik wurde. Die Negation der tradierten Normen entsprach einem Innovationsimperativ, der im 20. Jahrhundert als »Absolutismus der Moderne« eine paradigmatische und dogmatische Eigendynamik entwickelte und Affirmation zum ebenso ästhetisch wie politisch konnotierten Schimpfwort machte.

Den Schöpfern der Neuen Musik wurden die performativen Ausbrüche des Publikums zum Beweis ihrer Fortschrittlichkeit. Die Komponisten agierten zunehmend unabhängig vom Hörergeschmack und rebellierten damit gleichermaßen gegen die bürgerlichen Verhaltensnormen der `Kulturindustrie`, deren Charakteristik Theodor W. Adorno ebenso polemisch wie treffend auf den Punkt brachte: »Kunst schlägt heute alles mit Ähnlichkeit. « ${ }^{163}$ Die Avantgarde wurde zu einem kritischen Konzept mit dem versucht wurde, der $»$ Reproduktion des Immergleichen ${ }^{164}$ ästhetische Differenz entgegenzustellen und damit die Aura des Kunstwerks im Zeitalter seiner technischen Reproduzierbarkeit ${ }^{165} \mathrm{zu}$ schützen. Der Skandal war dabei nicht nur zum Ausweis zukunftsweisender Innovation, sondern gewann an der Schwelle zum Zeitalter der Massenmedien noch eine weitere Bedeutungsebene hinzu: ohne die Aufmerksamkeit der Presse wären die Kontroversen in den Konzertsälen verhallt. Wenn Arnold Schönberg und Igor Strawinsky von der öffentlichen Aufmerksamkeit infolge der Saalschlachten profitierten, so erkannte Martin Eybl darin ein Tauschgeschäft zwischen Künstlern und Medien, von dem beide Seiten profitieren:

161 Arnold van Gennep: Rites de passage, Paris 1909; Übergangsriten, Frankfurt am Main/New York 2005.

162 Petrik: Die Leiden der Neuen Musik, S. 7.

163 Max Horkheimer/Theodor W. Adorno: »Kulturindustrie. Aufklärung als Massenbetrug«, in Ders.: Dialektik der Aufklärung, Frankfurt am Main 1987, S. 128-176, hier S. 128.

164 Ebd., S. 142.

165 Walter Benjamin: »Das Kunstwerk im Zeitalter seiner technischen Reproduzierbarkeit«, in Ders.: Gesammelte Schriften, Band 1, Frankfurt am Main 1980, S. 471-508. 
»Der Skandal ist für die Medien eine leicht verkäufliche Ware und zugleich das prestigeträchtige Wundmal des wahren Künstlers. Immer mehr junge Tonkünstler erflehten das Ausgepfiffenwerden [...], weil es Richard Wagner, weil es Bruckner und Hugo Wolf so sehr förderte. ${ }^{166}$

Schon in der Weimarer Republik und im Paris der >Goldenen Zwanziger häuften sich Inszenierungsstrategien von Künstlern wie dem Bad Boy of Music - George Antheil - welche die öffentliche Wirkmächtigkeit klingender éclats erkannten. Es ist also kein Zufall, dass Skandale die Entwicklung der Presse zum Massenmedium begleiteten und dokumentierten. Auch die Ereignishaftigkeit von Musikskandalen hängt unmittelbar mit ihrer medialen und kommunikativen Vermittlung sowie ihrer (Re-)Produktion innerhalb einer demokratischen Öffentlichkeit zusammen. Wenn 2012 etwa Vallejo Gantner, der künstlerische Direktor des New Yorker Performance Space 122 mit Blick auf die Strawinskys (mas)sacre du printemps feststellte: »a Rite of Spring-style riot is every presenter's dream ${ }^{167}$, deutet dies auf eine Ökonomie der Aufmerksamkeit ${ }^{168}$ hin, die Georg Frank in seiner gleichnamigen Monographie für die Moderne herausarbeitete. Ausgehend von der Überlegung, dass gesellschaftliche Ordnungen vorrangig von medialer Wahrnehmung beherrscht werden, lassen sich seine Ergebnisse für den Wissenschaftsbetrieb mühelos auch auf den Kunst- und Kulturmarkt übertragen: Ärger und Irritation des Publikums sind nicht selten ein bewusst provoziertes Marketinginstrument - und die größte Strafe für ein Werk und seinen Schöpfer demnach keine vernichtende Kritik, sondern Missachtung. Der Kunsthistoriker Heinz Steinert fasste diesen Gedanken in einem griffigen Satz zusammen: »Am unerfreulichsten ist der Skandal der ausbleibt. « ${ }^{169}$ Über dieses Bonmot hinausgehend wurde den Komponisten die Provokation des Publikums auch ästhetisch bedeutsam. Im Anschluss an die Futur- und Dadaisten kam es in der zweiten Hälfte des 20. Jahrhunderts verstärkt zu Inszenierungsstrategien und performativen Aufführungskonzepten, die eine Reaktion des Publikums nicht nur evozierten, sondern geradezu sistierten. Der Ärger, die Irritation und auch die Gegenwehr des Oublikums wurden zum Bestandteil des Kunstereignisses, nicht etwa dessen Störung.

\section{Rezeption: Laute(r) Emotionen}

Auf die Normbrüche der Komponisten reagierte das Publikum seinerseits mit einem Bruch der bürgerlichen Verhaltensnormen. Wer die Konzerte durch Lärm störte, negierte ihren Kunstcharakter und brachte den Willen zum Ausdruck, sich derartige Musik nicht bieten zu lassen. Waren solche Äußerungen auch oft spontane Bekundungen des Missfallens, so zeigten sich dabei doch immer wieder Inszenierungsstrategien, wovon das teils präventiv mitgebrachte Stör-Instrumentarium wie Trillerpfeifen, Röhrenschlüssel oder gar Stinkbomben zeugt. Martin Thrun erkannte darin »ein

166 Eybl: Die Befreiung des Augenblicks, S. 29f.

167 Schuessler: Shock Me if You Can.

168 Georg Frank: Ökonomie der Aufmerksamkeit. Ein Entwurf, München/Wien 1998.

169 Heinz Steinert: »Am unerfreulichsten ist der Kunstskandal der ausbleibt. Anmerkungen zu Arbeitsbündnissen in der Kunst«, in Christine Resch: Kunst als Skandal, Wien 1994, S. 9-35, hier S. 9. 
offenkundiges Indiz für die Opposition eines enttäuschten wie konsternierten, mehrheitlich der Oberschicht angehörenden Abonnement-, Fest- oder Vereinspublikums ${ }^{170}$ und benannte damit auch die sozialen Faktoren des Musikbetriebs. Hier wurden also, wie Martin Eybl im Zusammenhang mit den Schönberg-Skandalen feststellte, die »alten Normen musikalischer Aufführungsbedingungen im Zeitalter des bürgerlichen Musikbetriebs [...] gesprengt. « ${ }^{171}$

Die Radikalität der ästhetischen Erfahrung beantwortete das Publikum mit nicht minder radikalen Verhaltensweisen, die als affektive Reaktionen auf die schockierende Diskrepanz von Erfahrung und Erwartung verstanden werden können. Damit rücken Gefühls- und Rezeptionstheorien in den Fokus des analytischen Interesses. Hans Robert Jauß setzte in seiner Theorie der Rezeption erstmals den »Rezipienten als Empfänger und Vermittler, mithin als Träger aller ästhetischen Kultur« in sein historisches Recht, »das ihm in der Geschichte der Künste vorenthalten blieb, solange sie im Banne der traditionellen Werk- und Darstellungsästhetik stand. ${ }^{172}$ Der Schritt vom passiven Akt des Empfangens zur aktiven und produktiven Rezeption vollzog sich erst mit der Emanzipation des bürgerlichen Individuums und nahm im Verlauf der Moderne Fahrt auf. Hier kam es im Anschluss an Umberto Eco zur 〉Öffnung des Kunstwerks`, wobei das Konzept als Chiffre für die aktive Beteiligung des Rezipienten an der Generierung des Kunstwerks steht. ${ }^{173}$ Beschreibt die literaturwissenschaftlich geprägte Rezeptionsästhetik eher den hermeneutischen Prozess historischer Exegese und Interpretation, ist die Wahrnehmung von Musik, die im unmittelbaren Augenblick der Aufführung von einem Publikumskollektiv rezipiert wird, etwas anders gelagert: Während Literatur in der Regel von einem Leser reflektiert wird und als Werk unverändert bleibt, ist die Aufführungskunst Musik von einer temporalen Flüchtigkeit geprägt und generiert damit viel deutlichere Anschlüsse an unmittelbare Affekte, die sich in klingenden éclats ereignishaft entladen.

Die Verhaltensweisen der Auditorien offenbaren als historische Zeichen Hinweise auf zeitgebundene Normen: Waren lautstarke Meinungsäußerungen des Publikums noch im 18. Jahrhundert normaler Bestandteil musikalischer Aufführungen, etablierte sich mit dem Aufkommen einer bürgerlichen Musikkultur eine passive Rezeptionshaltung. ${ }^{174}$ Seit dem späten 19. Jahrhundert wurde die Zurückhaltung der Gefühle im abgedunkelten Saal zu einer Regel des Anstandes. Der Kulturhistoriker Peter Gay sprach in diesem Zusammenhang von einer » Art of Listening « ${ }^{175}$ und Elias Canetti von einem >Ritual des Stockens : »Jede Bewegung ist unerwünscht, jeder Laut ver-

170 Thrun: Der Sturz ins Jetzt des Augenblicks (Vortragsmanuskript).

171 Eybl: Die Befreiung des Augenblicks, S. 25.

172 Jauß: Theorie der Rezeption, S. 5.

173 Umberto Eco: Das offene Kunstwerk, Frankfurt am Main 1973.

174 James H. Johnson stellte die Frage »Why did audiences grow silent?« in den Mittelpunkt seiner Monographie Listening in Paris (Berkeley 1995).

175 Peter Gay: »The Art of Listening«, in Ders.: The Naked Heart (The Bourgeois Experience: Victoria to Freud), New York 1995, S. 1-25. Siehe hierzu auch den Bericht zur Konferenz »The Art of Listening«, die vom 12.-17. Juli 2012 im Berliner Radialsystem stattfand, URL: http://www.hsozkult.de/conferencereport/id/tagungsberichte-4434 [Zugriff: 31.8.2017]. 
pönt [...], alle äußeren Reaktionen darauf unterbleiben.« ${ }^{176}$ Der Literaturnobelpreisträger konstatierte in Masse und Macht eine grundsätzliche Ähnlichkeit rhythmischer Massen als Erscheinungsform der Macht. Während Individuen über Distanzen bestimmt seien, könne es bei Menschenansammlungen als einem von Affekten geleiteten Gebilde zu einem Zustand der »Entladung« kommen, bei dem alle »ihre Verschiedenheiten loswerden und sich als gleiche fühlen. «" ${ }^{177}$

Wenn Canetti auch im bürgerlichen Konzertbetrieb eine ritualisierte >Stockung der Gefühle< diagnostizierte, kann der Musikskandal als Ausnahmeerscheinung gelten, der ex negativo Rückschlüsse auf soziale und anthropologische Wandlungsprozesse erlaubt. Die affektiven Entladungen in den Konzertauditorien weisen insbesondere die Avantgarden als ein Brennglas solcher Dynamiken aus. Deren Provokationen ließen die verstummten Auditorien wieder laut werden und das Publikum in polarisierenden Affekten und unkontrollierbaren Gefühlen wie Empörung und Zorn, aber auch Unsicherheit und manchmal hilfloser Komik aus dem ritualisierten Handlungskorsett ausbrechen. Der Musiksoziologe Christian Kaden beschrieb diese Dynamik mit Blick auf den Skandal um Igor Strawinskys Le sacre du printemps:

»Namentlich zwischen Publikum und Bühne etabliert sich ein Dialog der Verfeindungen. Von unten her röhrt man, lacht man. Von oben gibt man um kein Jota nach. Die negativen Impulse prasseln aufeinander in einer Minus-Minus-Kaskade, unversöhnlich. Aber auch zwischen den Zuschauern [...] tobt der Krieg. Der Teufel ist los auf allen verfügbaren Sozialisierungsebenen. Namentlich diese Zweidimensionalität negativer Aufladung macht es, daß der Skandal relativ rasch zur Krise kommt. Das Pulver wird nach sämtlichen Seiten verschossen. ${ }^{178}$

Derlei Gefühlsäußerungen können im Anschluss an das Metzler Lexikon Avantgarde verstanden werden »als Berühren der empfindlichen Stellen der moralischen, religiösen, politischen, sozialen, kulturellen >Häuteくmit denen Menschen als gesellschaftliche Wesen ebenfalls umspannt sind. ${ }^{179}$ Auch aus Sicht der Musikpsychologie wurden Umbruchszenarien anhand veränderter Bewusstseinszustände und Affekte der Rezipienten beschrieben. Rudolf Brandl etwa bemerkte, dass der Konflikt zwischen dem Aufbrechen alter- und der Etablierung neuer Regeln stets einhergeht »mit Fremdheitserfahrungen, mit Verstörung, Verwirrung und einer Un- und Umordnung der Sinne. Alterierende Körper- und Bewußtseinsverfassungen paaren sich dabei gegebenenfalls mit existentiellen Empörungen oder auch Euphorien. ${ }^{180}$ Neben Unmutsäußerungen wurde nicht zuletzt Gelächter zum Gradmesser ästhetischer und sozialer Wandlungsprozesse. ${ }^{181}$

176 Elias Canetti: Masse und Macht, München 1994, S. 39.

177 Ebd., S. 14.

178 Kaden: Skandal als Ritual, S. 587.

179 Hubertus van den Berg/Walter Fähnders (Hg.): Metzler Lexikon Avantgarde, Stuttgart/Weimar 2009, S. 185f.

180 Rudolf M. Brandl: »Musik und veränderte Bewußtseinszustände«, in: Herbert Bruhn, Rolf Oerter, Helmut Rösing (Hg.): Musikpsychologie. Ein Handbuch, Reinbek bei Hamburg 1993, S. 599-610, hier S. 599.

181 Siehe hierzu Ludger Scherer/Rolf Lohse (Hg.): Avantgarde und Komik, Amsterdam 2004. 
Im Anschluss daran manifestiert sich der Musikskandal auch durch die affektiven Kontrollverluste der Rezipienten, die ihrerseits Hinweise auf Paradigmenwechsel und Epochenschwellen geben können: Als passagere Handlungsmuster stellen die Affekte performative Akte dar, über die sich Ordnungen des Sicht-, Zeig- und Hörbaren erst etablieren. ${ }^{182}$ Der Konflikt von >Tradition versus Innovation « eskalierte fast immer in einem paradigmatischen Gegeneinander der Gefühle als innerer Dramaturgie der klingenden Ereignisse. Neil Blackadder sprach in seiner Schrift über Modern Theatre and the scandalized audience von einer durch Gefühle, Emphase und Kontrollverluste geprägten Polarität von Reaktionen. Dabei offenbare sich in der Sprengung der tradierten Verhaltensregeln (»primarly disorderly«) Widerstand gegen das Werk und/oder den Schöpfer, der sich in Dupliken (»rejoinders«), physischen Gesten oder auch organisierten Gruppendemonstrationen, verbunden mit Lärmproduktion in Form von Rufen, Pfiffen oder Trampeln, ausdrücke. ${ }^{183}$ Damit lässt sich die Hypothese von Musikskandalen als geprägt durch >laute(r) Emotionen`verifizieren, die sich stets in einem polarisierten Schlagabtausch gleich einer raffektiven Schneeballschlacht entluden. Systemtheoretisch resultiert daraus, wie bei einer Luftschaukel, ein Überschwingverhalten, also eine Ereignisfolge ohne Anfang und Ende. ${ }^{184}$ Der Musikwissenschaftler Martin Thrun erkannte darin eine Art allgemeingültiger Verlaufsform, die er anhand von Konzerttumulten in den Jahren der Weimarer Republik skizzierte:

»Vielfach begannen Störungen mit unwillkürlichem Gelächter, das sich wie ein Lauffeuer verbreitete. Hinzu kamen willentliche Unmutsäußerungen wie Zischen, Husten, Scharren, Türenschlagen, die unter dem Beifall der Gegenseite schlimmstenfalls zur Unterbrechung oder zum endgültigen Abbruch des Spiels führten. In den Pausen dominierte, von eventuellen Handgreiflichkeiten abgesehen, verbaler Schlagabtausch. ${ }^{185}$

Thrun erkannte in diesen Affekten einen >Sturz ins Jetzt des Augenblicks $<$. Während auf Produktionsseite ästhetische Konventionen gesprengt wurden, durchbrach auch das Publikum seine Verhaltensnormen und die von Elias Canetti diagnostizierte >Stockung der Gefühle<. Anstelle des tradierten Konzertzeremoniells trat in den Worten von Christian Kaden »ein Statt-Ritual, Ersatz-Ritual, dort Platz greifend, wo Kult und Ritus als solche bereits ins Abseits verbannt wurden. ${ }^{186}$

\section{Sezession und Isolation: Die sLeiden der Neuen Musik}

Während die Medien den Impuls zum Skandal publizistisch vervielfältigten und Komponisten in Anlehnung an die zu Klassikern avancierten ehemaligen Skandalierer ein radikales Image der Neuen Musik etablierten, standen die Publikumsreaktio-

182 Siehe hierzu etwa Bernhard Waldenfels: Der Stachel des Fremden, Frankfurt am Main 1990.

183 Neil Blackadder: Modern Theatre and the Scandalized Audience, Westport 2003, S. 12.

184 Siehe hierzu Paul Watzlawik: Menschliche Kommunikation. Formen, Störungen, Paradoxien, Bern 1971.

185 Thrun: Der Sturz ins Jetzt des Augenblicks [Vortragsmanuskript].

186 Kaden: Skandal und Ritual in der Musik, S. 595. 
nen paradigmatisch für die Rezeptionsprobleme, welche die Neue Musik auch im weiteren Verlauf der Moderne aufwarf. Schon in ihren Anfängen wurde klar, dass sie im bürgerlichen Musikleben nicht annähernd jenen Stellenwert erhalten würden, die den Werken der Klassiker zukam. Ursula Petrik erkannte in dieser problematischen Rezeption Die Leiden der Neuen Musik und begründete ihre These mit Blick auf ökonomische, soziologische, ideologische, politische und kulturelle Kriterien:

»Faktum ist, dass sich seit dem frühen 20. Jahrhundert eine tiefgreifende Diskrepanz zwischen den ästhetischen Vorstellungen der Komponisten und den Hörerwartungen des Publikums aufgetan hat, und dass die rasant fortschreitenden ästhetischen Entwicklungen seither Musikschaffende und -rezipienten einander nach und nach entfremdet haben. ${ }^{187}$

Im Verlauf der Moderne kam es zur Sezession der Neuen Musik vom Massengeschmack, der die klingende Avantgarde zunehmend in einem intellektuellen Elfenbeinturm verortete, den ihre Protagonisten selbst aktiv miterbauten. Martin Thrun sprach in diesem Zusammenhang von einer:

»Fragmentierung kultureller Lebenswelten als die notgedrungene Aus- oder Abgrenzung moderner Künste und ihrer Schöpfer von Institutionen der sogenannten bürgerlichen Hauptkultur; im Nachhinein begriff man Sezessionen als Stadien der Sedimentierung von Kultur [...]. Selbst wenn die Ansicht zutreffen sollte, dass die Vielfalt von Szenen zum Inbegriff enthierarchisierter Musikkultur geworden ist, wird man nicht außer Acht lassen können, dass die heutzutage vielerorts präsente Neue-Musik-Szene von eigentümlicher Abkunft ist. ${ }^{188}$

Damit beschrieb Thrun zwei schwerwiegende Folgen der referenziellen Skandale: Das Ende von Leitkulturen im zunehmenden Pluralismus Moderne sowie Die soziale Isolation der Neuen Musik, die Michael Custodis in seiner Studie zum Kölner Musikleben nach 1945 herausarbeitete, die über ihre raumzeitlichen Parameter hinaus Anschlusspotential besitzt. ${ }^{189}$ Mit den historischen Saalschlachten begann die Metamorphose der zeitgenössischen Kunstmusik vom gesellschaftlichen Ereignis hin zur Spezialsache elitärer Kreise, deren Auswüchse bis in die oft pauschale Ablehnung Neuer Musik in der Gegenwart reichen.

Diese Abwehrhaltung wurde freilich oftmals von den Künstlern selbst intendiert, indem die kulturbürgerlichen Rituale vehement abgelehnt wurden. Zugleich kann die durch intellektuelle Komplexität provozierende Sprache der Neuen Musik als Gegengewicht zur einsetzenden >Popkulturalisierung « der Massenkultur verstanden werden. Dafür spricht nicht zuletzt die zunehmend hermetische Unterscheidung von sogenannter U(nterhaltungs)- und E(rnster)-Musik, die zu einem charakteristischen Merkmal in der (Post-)Moderne wurde: Während der Unterhaltungsmusik jeglicher Kunstcharakter abgesprochen wird, trägt die Kunstmusik seitdem den Ernst im Namen. In dieser dialektischen Sedimentierung erkannte Frank Hentschel eine Vielzahl von Ideologien,

187 Petrik: Die Leiden der Neuen Musik, S. 8.

188 Thrun: Der Sturz ins Jetzt des Augenblicks (Vortragsmanuskript).

189 Custodis: Die soziale Isolation der neuen Musik. 
»die der Konstitution der Szene dienen und die die Hörhaltung der Szene-Mitglieder bis hin zum Verlassen des Konzertsaals beeinträchtigen [...]. So viel wird man sagen können: daß die Selbstdarstellung der Komponisten neuer Musik und die Hörhaltung ihrer Rezipienten einen sozialdistinktiven Sinn besitzen [...]. Mit Blick auf das Thema der ästhetischen Erfahrung läßt sich aber festhalten, daß Ideologie und gesellschaftliche Dynamiken das Hörverhalten von $\mathrm{Mu}-$ sik offenbar tief beeinflussen können. ${ }^{190}$

Auch Hentschel betonte also die Zusammenhänge zwischen ästhetischen und gesellschaftlichen Dynamiken, die sich in einer distinktiven Haltung von Mitgliedern aus dem Kreis der Neuen Musik und ihrem Publikum manifestieren. Zwar verblieben die klingenden Eklats der Neuen Musik im Verlauf des 20. Jahrhunderts zunehmend im inneren Zirkel der Musikavantgarde und wurden damit zu >Skandalen im Sperrbezirkı. Dennoch muss der isolierte Bezirk der musikalischen Avantgarden als sozioästhetischer Faktor und ihre Vertreter als intellektuelle Akteure und Agenten der Moderne ernst genommen werden: Die Skandale der Neuen Musik verliehen dem kulturellem Störfall `Skandak eine produktive Note und wiesen den Fortschrittscharakter und das Innovationstheorem als konstituierende Kraft für die Formierung der musikalischen Moderne aus. Erst die zerrütteten Kunstwerke sind, noch einmal gesprochen mit Adorno: »Male des geschichtlichen Prozesses. « ${ }^{191}$

190 Frank Hentschel: »Ästhetische Erfahrung und die Ideologie der Hochkultur in der neuen Musik«, in: Paragrana 15 (2/2006), S. 121-132, S. 132.

191 Adorno: Philosophie der Neuen Musik, S. 38. 


\section{AGON und SKANDAL (Durchführung \#1)}

Als Deutschland im Frühjahr 1945 die bedingungslose Kapitulation unterzeichnete, waren nicht nur viele Städte und Menschenleben zerstört, sondern ein ganzes kulturelles Wertesystem. Indem die Kunst während der NS-Diktatur dem allgemeinen Gleichschaltungsprozess unterworfen wurde und jedes Wort, jedes Bild und jeder Klang in den Dienst des totalen Krieges gestellt worden war, hatten die deutsche $>$ Kulturnation< und ihre Musiktradition einen faulen Beigeschmack bekommen. Der Musikwissenschaftler Ulrich Dibelius machte zur Situation des deutschen Musiklebens nach dem Zweiten Weltkrieg eine banal erscheinende Bemerkung, die gleichwohl analytisches Anschlusspotential besitzt: "Zwölf Jahre Nazi-Regime, davon nahezu sechs Jahre Krieg, hatten zu einer schaurigen Reduzierung aller Lebensfunktionen geführt. « ${ }^{1}$

Die >Kulturnation < Deutschland, deren bildungsbürgerliche Identität als `Land der Dichter und Denker nicht zuletzt auch durch ihre klassische Musiktradition geformt und in den Worten des Satirikers Karl Kraus in den kriegerischen Konflikten des 20. Jahrhunderts als »Volk der Richter und Henker « ${ }^{2}$ pervertiert - wurde, lag im Frühjahr 1945 also in Agonie. Ist es Zufall, dass aus diesem kulturellen Todeskampf nur zwei Buchstaben gestrichen werden müssen, um zum altgriechischen Wortstamm des Wettkampfwesens zu gelangen: agōn ('A yóv)? Wenn Dibelius' Kollege Hermann Danuser im Begriffspaar von Agon und Skandal ${ }^{3}$ ein Paradigma für die Dynamik der Neuen Musik nach 1945 erkannte, scheint an dieser Stelle ein kleiner begriffsgeschichtlicher Exkurs geboten, der das agonale Prinzip in eine erstaunliche Nähe zur Dynamik des klingenden Eklats rückt.

Abgeleitet von der öffentlichen Versammlung (agora), bezeichnete der Agon in der griechischen Antike das Wettkampfprinzip, das gleichermaßen für sportliche und künstlerische Konkurrenzen wie für den demokratischen Rechtsstreit und das rhetorisch-theatrale Prinzip von Rede und Gegenrede galt. ${ }^{4}$ Damit ist eine erste Kongruenz

1 Ulrich Dibelius: Moderne Musik, München 1998, S. 23.

2 Karl Kraus kulturkritische Wendung lautete: »Die deutsche Bildung ist kein Inhalt, sondern ein Schmückedeinheim, mit dem sich das Volk der Richter und Henker seine Leere ornamentiert.« Siehe Ders.: »Die vorletzten Tage«, in: Der Spiegel (26/1964), S. 76.

3 Hermann Danuser: »Agon und Skandal«, in Borio, Gianmario/Ders. (Hg.): Im Zenit der Moderne. Die internationalen Ferienkurse für Neue Musik Darmstadt 1946-1966, Band 2, Freiburg im Breisgau 1997, S. 374ff.

4 Siehe zur Begriffsgeschichte des »Agon«: Karlheinz Barck/Martin Fontius/Dieter Schlenstedt/Burkhart Steinwachs/Friedrich Wolfzettel (Hg.): Ästhetische Grundbegriffe, Band 
zum modernen Skandalbegriff über die verschränkten Faktoren von öffentlicher Aufmerksamkeit und polarisierender Konkurrenz hergestellt. Aber erst an der Schwelle zum 20. Jahrhundert wurde der Agon durch Denker wie Jacob Burckhardt, Friedrich Nietzsche und Johan Huizinga zum Basisfundament der griechischen Kultur erklärt und damit zur kulturtheoretischen Formel aufgewertet, die zur Beschreibung der Eklatanz Neuer Musik nach 1945 Anschlusspotential besitzt.

Nietzsche machte das agonale Prinzip fruchtbar, indem er die Funktion des Wettstreits im Verzicht auf endgültige Hierarchien beschrieb und darin einen Zwischenraum der Kontingenz als Ort schöpferischer Potenz erkannte: »Jede Begabung muß sich kämpfend entfalten. $\aleph^{5}$ In eine ähnliche Richtung zielte auch Johan Huizinga, der die Nähe des Agonalen zum Spiel betonte: Der spielerische Wettstreit setze Energie und Kraft frei und erhalte damit das Potential, verfestigte Strukturen zu durchbrechen und Innovation hervorzubringen. ${ }^{6}$ Wenn damit ein Link zum agonalen Innovationsstreben der Avantgarden im 20. Jahrhundert gesetzt werden kann, legt der Konnex von Spiel und Öffentlichkeit auch den Charakter eines Kräftemessens nahe, das zugleich der Unterhaltung der Zuschauer diente. Auch dieser Gedanke baut eine Brücke zum ästhetischen Skandal in der Moderne, der ebenfalls Komponenten von Amüsement unter der Aushandlung künstlerischer Deutungshoheiten enthält. Die kulturelle Bedeutung des Agonalen kann schließlich in der Serialität der turnusmäßig wiederkehrenden Agone gesehen werden, die sich in der Festspielkultur der Moderne konserviert hat.

Jacob Burckhardt dagegen erkannte das agonale Prinzip als wesentlichen Integrationsfaktor der griechischen Zivilisation: Nicht nur sei der Agon ein Ventil für kulturelle Konflikte, indem er nicht der gegenseitigen Vernichtung, sondern vielmehr als Kompensation für Kriege diene und also durch Konkurrenz Gemeinsinn erzeuge; der geregelte Wettstreit sei darüber hinaus ein das griechische Leben bestimmendes und stimulierendes Grundprinzip. ${ }^{7}$ Nietzsche merkte in diesem Zusammenhang an, dass »der griechische Genius den einmal so furchtbar vorhandenen Trieb gelten ließ und als berechtigt erachtete«, diesem aber durch »den edelsten hellenischen Grundgedanken, den Wettkampf« eine »orphische Wendung« einschrieb:

»[M]an beseitigt den überragenden einzelnen, damit nun wieder das Wettspiel der Kräfte erwache: ein Gedanke, der der `Exklusivität des Genius im modernen Sinne feindlich ist, aber voraussetzt, daß in einer natürlichen Ordnung der Dinge es immer mehrere Genies gibt, die sich gegenseitig zur Tat reizen, wie sie sich auch gegenseitig in der Grenze des Maßes halten. ${ }^{8}$

1, Stuttgart/Weimar 2000, Sp. 582f; Joachim Ritter/Karlfried Gründer/Gottfried Gabriel (Hg.): Historisches Wörterbuch der Philosophie, Band 1, Basel 1971, Sp. 112f.

5 Friedrich Nietzsche: »Homers Wettkampf« (1872), in Ders.: Werke in drei Bänden, München 1954, Band 3, S. 291-299, hier S. 295. Siehe hierzu auch Vasile Padurean»: Das Phänomen des Agon«, in Ders.: Spiel - Kunst - Schein. Nietzsche als ursprünglicher Denker, Stuttgart 2008, S. 83-107.

6 Johan Huizinga: Homo ludens. Vom Ursprung der Kultur im Spiel (1939), Reinbek 2009.

7 Jakob Burckhardt: »Der koloniale und agonale Mensch«, in Ders.: Griechische Kulturgeschichte, Band 4, München 1977, S. 82-117.

8 Nietzsche: Homers Wettkampf, S. 295. 
Dieser orphische Gedanke des Agons wurde von 1938 bis 1945 in der gleichgeschalteten nationalsozialistischen Gesellschaft unmöglich gemacht, indem der Wettstreit zum blutigen Kampf sowie das Spiel zu tödlichem Ernst mutierte und damit gleichermaßen Agon wie Skandal als Ausdruck polarisierender Meinungen ausgeschlossen wurden. Umso wichtiger wurde das agonale Prinzip nach 1945, als nach der kulturellen Agonie der Kriegsjahre der Wettstreit um kulturelle Normen neu entfachte und sich als überaus fruchtbar für die Reorganisation des deutschen Kulturlebens und besonders die Dynamik der Neuen Musik erwies: Der Wettlauf um Innovationen mutierte zur Kerndisziplin der musikalischen Streitkultur in der Moderne und darüber hinaus: JeanFrançois Lyotard modifizierte das agonale Prinzip in seiner La condition postmoderne zu einem Phänomen der Postmoderne. Er erkannte darin eine Paralogie, also einen Möglichkeitsraum des Wandels und der Neuerung, der nicht an dauerhaften Konsens gebunden ist. $^{9}$

$\mathrm{Zu}$ den bekanntesten Agonen der musikalischen Moderne avancierten nach 1945 die Donaueschinger Musiktage sowie die Darmstädter Ferienkurse für Neue Musik. Als Nachfahren der antiken Festspielkultur kam beiden Festivals im doppelten Wortsinn von agōn sowohl Bedeutung als Versammlungs- wie als Verhandlungsorten ästhetischer Normen zu. In diesen Arenen der Neuen Musik kam es zu einem verschärften Wettstreit um Innovationen, allerdings verblasste der öffentliche Charakter der antiken Agone zunehmend zulasten einer intellektuellen Spartenbildung und Segregation. Diese Entwicklung ging einher mit einer topographischen Dezentralisierung: Waren sowohl Skandale wie auch die Avantgarden vor dem Zweiten Weltkrieg noch Sache der urbanen Zentren gewesen, wanderten diese nun in die Provinz ab. Zu dieser Entwicklung machte der Musikwissenschaftler Hartmut Krones 2008 aufschlussreiche Bemerkungen:

»Was war Donaueschingen vor der 1921 erfolgten Gründung der Musiktage [...]. Was war Darmstadt vor der Installierung von unorthodoxen, gegen den Strich bürstenden Internationalen Ferienkursen? Es waren Provinzstädte, die zumindest auf dem Gebiet der Musik kaum der Allgemeinheit bekannt waren. Zentrum waren diese beiden deutschen Orte allerdings nur für einige wenige Tage bzw. Wochen, doch Ausstrahlungskraft besaßen sie schließlich während des gesamten Jahres, und `Darmstadt` wurde sogar zum Synonym für prononciertes Komponieren schlechthin. Daß der Zentrumswerdung auch die Hybris folgte, die allein selig machende Wahrheit bzw. Qualität ausschließlich selbst gepachtet zu haben, soll allerdings nicht verschwiegen werden. Die Intoleranz und Überheblichkeit eines Zentrums der Peripherie gegenüber hat sich auch in Darmstadt eingestellt - wie im Falle des Papstes von Avignon. $\ll^{10}$

Der Rückzug aus den urbanen Zentren ging mit einer inneren Spartenbildung der Neuen Musik sowie der äußerlichen Segregation vom regulären Musikbetrieb und einem breiten Publikum einher. Gleichzeitig entwickelte die Szene - >wie im Falle des Papstes von Avignon - ein starkes und zunehmend dogmatisches Sendungsbewusstsein.

9 Jean-François Lyotard: Das postmoderne Wissen, Wien 2012.

10 Hartmut Krones: »Multikulturelles, Internationales, Neues und `Fremdes` in der Musik. Zweieinhalb Jahrtausende Ächtung des Andersartigen«, in Ders. (Hg.): Multikulturelle und internationale Konzepte in der Neuen Musik, Wien 2008, S. 13-30, hier S. 30. 
Diese sich um 1950 herausbildenden Merkmale beeinflussten auch die Struktur klingender Eklats: Kontroversen wurden immer seltener vor und von einem konsternierten bürgerlichen Auditorium ausgetragen, sondern zunehmend polemisch und oft publizistisch im inneren Kreis der Szene. Dies stellte auch Hermann Danuser fest, der in diesem Kontext zwei verschiedene Typen des Musikskandals beschrieb:

»Eine grundsätzliche Differenz besteht $[\ldots]$ zwischen einem Skandal, der sich innerhalb einer Musikkultur ereignet - z.B. innerhalb der Avantgardekultur [...] - und einem Skandal, der aus einem Konflikt zwischen verschiedenen Musikkulturen - z.B. den Polemiken zwischen Avantgarde- und tradierter Konzertkultur - resultiert. ${ }^{11}$

Das Jahr 1945 markierte in diesem Zusammenhang eine Schwelle ästhetischer Erfahrung: Hatten die Provokationen der historischen Avantgarden das bürgerliche Konzertpublikum geschockt und zu Tumulten animiert, verschob sich die Skandaldynamik nun hin zu einer internen Streitkultur. Zu den wichtigsten Schauplätzen und Zentren dieser Entwicklung wurden die beiden provinziellen Pole der Neuen Musik - Donaueschingen und Darmstadt - denen jeweils eine spezifische Bedeutung zukam:

Die 1921 gegründeten Donaueschinger Musiktage besaßen bereits eine Tradition als eklatantes Zentrum der Neuen Musik, als man sie 1949 neu aufleben ließ und mit einer beispielhaften chronique scandaleuse die zweite Phase der musikalischen Moderne einleitete. Mit ihrer kurzen Dauer von drei hoch konzentrierten Festivaltagen und dem (fast) ausschließlich aus Uraufführungen bestehenden Programm, erlebte Donaueschingen im Nachkriegsjahrzehnt - auch in Anlehnung an seine eklatante Gründungsgeschichte - Skandale in Serie, bei denen die Protagonisten der Neuen Musik reihenweise ebenso skandal- wie aufmerksamkeitsträchtig auf die Bühne der Musikgeschichte traten: Als zyklische Wiederholung ähnlicher Ereignisse, wurde hier der klingende Eklat zum seriellen Ordnungsprinzip der Neuen Musik und zum provokanten Signum der Nachkriegsavantgarde.

Ähnliches galt für die Darmstädter Ferienkurse für Neue Musik, die allerdings einen Strukturwandel des Musikskandals prägten: Sie wurden zum Schauplatz des innerästhetischen Ringens und der selbstreferenziellen Isolierung der Avantgardekultur. Bar der Donaueschinger Tradition, war den 1946 neu begründeten Ferienkursen eine noch deutlichere Abkehr und Negation von der Tradition eingeschrieben. Als mehrwöchiges Branchentreffen stellte Darmstadt zudem ein diskursiv geprägtes Äquivalent zum Uraufführungsort Donaueschingen dar und verfügte darüber hinaus mit Theodor W. Adorno über ein prominentes Sprachrohr einer am Theorem des Fortschritts orientierten Kunstsprache. Seine musiktheoretischen Texte prägten und spiegeln bis heute intrinsisch die konfliktive Gemengelage der Neuen Musik nach 1945, indem »sie Anlaß für begeisterte Zustimmung, stillschweigende Abstandnahme und entsetzten Widerspruch wurden. $\ll^{12}$

11 Danuser: Im Zenit der Moderne, Band 2, S. 375.

12 Ebd., Band 1, S. 438. 


\section{Die Donaueschinger Musiktage: CHRONIQUE SCANDALEUSE}

Wenn mit Blick auf die Donaueschinger Musiktage von einer chronique scandaleuse die Rede ist, geschieht dies auch mit Verweis auf die Begriffsgeschichte der Wendung. In Meyers Großem Konversationslexikon wurde die Phrase 1906 als »(namentlich böswillig übertriebene) Geschichte von den Torheiten und Lastern einer Zeit oder eines Orts $«{ }^{13}$ beschrieben. Die Musiktage in der kleinen Stadt Donaueschingen im Schwarzwald wurden zu einem solchen Ort und lassen sich dementsprechend historiographisch als Skandalchronik fassen. Die inhaltliche und methodische Orientierung an den Donaueschinger Musiktagen begründet sich nicht allein durch die eklatante Häufung klingender Eklats, sondern auch durch den Umstand, dass die Geschichte des Festivals weitgehend kongruent lief mit der Etablierung der Neuen Musik als eigenständiges Kapitel der Musikgeschichte: Die Gründung 1921 fällt nicht nur mit einer ersten Hochphase sowie der Begriffsbildung der »Neuen Musik « zusammen. ${ }^{14}$ Mehr noch bot Donaueschingen der historischen Musikavantgarde in den 1920er Jahren ein erstes öffentliches Forum und so scheint es zielführend, zunächst die erste Phase des Festivals zu beleuchten, um auf Basis dieser Referenz die Entwicklungen nach 1945 analytisch in den Fokus zu rücken.

\section{1-1933: Die »älteste Baustelle Neuer Musik«}

1909, als sich die Endzeitstimmung der Jahrhundertwende in den historischen Avantgardebewegungen verdichtete, wurde Heinrich Burkard in Donaueschingen zum Fürstlich Fürstenbergischen Musikdirektor ernannt. 1913, im Jahr der eklatanten Initiierung der musikalischen Moderne durch die legendären Premierenskandale Arnold Schönbergs und Igor Strawinskys, folgte mit der Gründung der Gesellschaft der Musikfreunde Donaueschingen eine weitere Grundsteinlegung für das weltweit älteste Festival Neuer Musik. Um 1920 reifte bei den Musikfreunden die Idee, ein Musikfest für junge aufstrebende Talente zu veranstalten, die am 31. Juli 1921 in der »1. Donaueschinger Kammermusik zur Förderung der zeitgenössischen Tonkunst« mündete. Dass Donaueschingen seine wegweisende Bedeutung als Speerspitze der Neuen Musik erlangte, lag am Engagement von Einzelpersonen (Heinrich Burkard), einem Förderkreis (den Musikfreunden) und der Unterstützung durch einen zahlungskräftigen Mäzen (Haus Fürstenberg).

Mit der Ausrufung eines ausschließlich der Avantgarde zugewandten Festivals besetzten diese verantwortlichen Akteure eine Art Marktlücke des modernistischen Zeitgeists. Die Donaueschinger Musiktage erlangten ihre Bedeutung also auch durch den Umstand, dass in der Schwarzwälder Provinzstadt diese Vakanz schlichtweg als erstes erkannt wurde.

13 Meyers Großes Konversations-Lexikon (1905-1909), Band 4, Leipzig 1906, S. 127. Online abrufbar unter URL: http://www.zeno.org/nid/20006426557 [Zugriff: 31.8.2017].

14 Der Musikkritiker Paul Bekker prägte den Begriff 1919 in einem Vortrag und festigte ihn 1923 in seiner gleichnamigen Schrift: Neue Musik (Gesammelte Schriften, Band 3), Stuttgart/Berlin 1923. 
Gleich in den ersten Jahren ihres Bestehens erfolgten richtungsweisende Experimente, die den Ruf und das Selbstverständnis der Donaueschinger Musiktage als »älteste Baustelle « ${ }^{15}$ begründeten. Dabei griff man nicht zuletzt auf die skandalträchtigen Machenschaften der historischen Avantgarden zurück: 1924, elf Jahre nach dem denkwürdigen >Wiener Watschenkonzert`, bot Donaueschingen der von Arnold Schönberg geprägten Dodekaphonie ein Forum, bevor ein Jahr später mit Igor Strawinsky der zweite Skandalkomponist des Schlüsseljahres 1913 aufs Programm gesetzt wurde.

Die zentrale Figur aber war Paul Hindemith, der um 1920 ein Triptychon skandalöser Opern-Einakter geschaffen hatte: In Mörder, Hoffnung der Frauen [ร-6.1] thematisierte der Komponist mit schrillen Blechbläserdissonanzen und kantigen Schlagwerkmarkierungen einen Geschlechterkrieg und höchstes Begehren. Dagegen setzten in Sancta Susanna [ร-6.3] sphärische Klänge und tönende Raserei die Geschichte einer Nonne in Klang, die sich ihrer Körperlichkeit bewusstwird und der Jesusfigur am Kreuze hingibt: der Vorwurf der Blasphemie zog noch 1977 nach einer Aufführung in Rom eine Strafanzeige gegen den Bürgermeister und den Opernintendanten der Stadt nach sich. Den dritten Teil des Triptychons bildet Das Nusch Nuschi [ร-6.2], ein burleskes und irrwitzig karikierendes `Spiel für burmanische Marionetten<. Als skandalös wurden nicht nur die freizügigen Liebesphantasien empfunden, sondern vor allem die Szene eines Kastrationsversuchs, der von Klängen aus einem >heiligen Gral der Musikgeschichte untermalt wurde: Richard Wagners Tristan und Isolde. Diese eklatante Gemengelage provozierte nicht nur bei der Uraufführung in Stuttgart (1921) einen ausgewachsenen Skandal, sondern 1922 auch in Hamburg und Frankfurt am Main; dort wurde überdies Strafanzeige wegen Erregung öffentlichen Ärgernisses im Sinne der $\S \S 166$ und 183 StGB gestellt. ${ }^{16}$ In einer zeitgenössischen Kritik war zu lesen, die Aufführung bedeute »eine Entweihung unserer Kunststätte. Der Inhalt ist von nicht mehr zu beschreibender Gemeinheit. Alles, was uns heilig ist, wird hier von nicht deutschem Geist in den Schlamm gezogen. $"{ }^{17}$ Wurde hier bereits die Sprache der deutschen Kunstkritik zwischen 1933 und 1945 antizipiert, so präsentierte man in Donaueschingen nach Schönberg und Strawinsky gerne das neue enfant terrible der Musik: zwischen Hindemith und den Musiktagen kam es zu einer glanzvollen Doppelkarriere ${ }^{18}$, die nicht zuletzt durch die aufmerksamkeitsträchtige Orientierung an Skandal und Progress befeuert wurde.

Nach der Unterbrechung dieser explosiven Verbindung infolge der nationalsozialistische Machtergreifung 1933 resümierte der Spiegel 1950 im Rückblick auf die Ereignisse, die Empörung um Hindemiths provozierende Operneinakter habe »den Na-

15 So der langjährige Leiter der Donaueschinger Musiktage, Armin Köhler (1952-2014) im $»$ Versuch einer Standortbestimmung der Donaueschinger Musiktage «, in Ders./Rolf W. Stoll (Hg.): Die Innovation bleibt immer auf einem Fleck. Die Donaueschinger Musiktage und ihr Metier. Begleitende Texte zum Festival, Mainz 2011, S. 317-326.

16 Siehe hierzu ausführlich Siglind Bruhn: Hindemiths große Bühnenwerke, Waldkirch 2009, S. $21 \mathrm{ff}$.

17 Zitiert nach Reiner Nägele/Vera Trost: Hoch Stuttgart! Hoch die Musik-Kritik! Hoch die Säue! Paul Hindemith in Stuttgart (Ausstellungskatalog), Stuttgart 1995, S. 66.

18 Andreas Jakubczik: Donaueschingen und Paul Hindemith. Stationen einer Doppelkarriere 1921-1930, Hamburg 2004. 
men des Komponisten unter die Leute gebracht. Den Rest besorgte Donaueschingen. ${ }^{19}$ Skandale bedürfen stets einer verklärenden Historisierung und im Falle Hindemiths forcierten die Veranstalter selbst die Bildung eines eklatanten Gründungsmythos. Dies belegt auch die Bemerkungen einer SWR-Dokumentation aus dem Jahr 1966:

»Die Donaueschinger Tradition avantgardistisch zu sein, geht von Hindemith aus [...]. Seine Musik der 20er Jahre hat die Faszination des Schocks, sie fegt überlebte ästhetische Wertungen hinweg, gibt sich unbekümmert bis zur Hemdsärmeligkeit. Der Foxtrott im Konzertsaal empört die Philister, ungestüme kraftmusikalische Bewegungslinien, kühle Harmonik, spiegeln das Lebensgefühl der Nachkriegszeit, die Devise: Épater le bourgeois. «"

Zumindest rückblickend war das erklärte Ziel also - ganz im sensationslüsternen Stil der >Goldenen Zwanziger < - die Bürgerlichkeit mit der avantgardistischen ErschlieBung ästhetischen Neulands zu schockieren. Dazu gehörte auch die künstlerische Nutzbarmachung neuer Technologien, die im Verlauf der musikalischen Moderne immer wieder die Gemüter erhitzten sollten. Nach der kriegsverherrlichenden Maschinenbegeisterung der Futuristen, machte sich 1926 erstmals auch in Donaueschingen das technizistische Signum der Epoche bemerkbar. Damals rückten »Originalkompositionen für mechanische Instrumente $\ll{ }^{21}$ nicht nur auf die Bühne, sondern auch in den Brennpunkt der Diskussion. Infolge der entrüsteten Kritikerreaktionen machten sich die Veranstalter einen Spaß daraus, die »Rosinen aus dem Kritikerkuchen« zu picken und in einem Sonderheft des Badeblattes zu publizieren. ${ }^{22}$ In den Debatten um die Maschinenmusik kündigten sich bereits die Konflikte um die Eklatanz der elektronischen $\mathrm{Mu}$ sik nach 1945 an. $^{23}$

Vor der Zäsur durch die nationalsozialistische Gleichschaltung des Kulturlebens erlebten die Donaueschinger Musiktage 1929 mit dem Badener Lehrstück vom Einverständnis - einer Gemeinschaftsproduktion von Paul Hindemith, Kurt Weill und Bertolt Brecht - einen Skandal, der auch Rückschlüsse auf den Zeitgeist der Zwischenkriegsjahre erlaubt. ${ }^{24}$ Grundlage der Produktion war Brechts Hinwendung zu »Lehrstücken ${ }^{25}$, die auch Hindemiths Vorstellung einer Gemeinschaftsmusikidee entsprachen. Das gemeinsame Ziel einer Distanzaufhebung zwischen Publikum und Darstellern be-

19 NN: »Gebt mir mal ne Bratsche«, in: Spiegel (15.6.1950), S. 36-38.

20 N.N.: »Donaueschingen - Tradition der Avantgarde«, in: Südwestrundfunk (26.10.1966), einsehbar im Archiv des SWR: FS Baden-Baden, Produktionsnummer/ID: 66632.

21 So der Titel des Konzerts vom 25.7.1926, wo Werke für Welte-Mignon, elektronisches Klavier und mechanische Orgel uraufgeführt wurden.

22 Siehe hierzu ausführlich Werner Zintgraf: Neue Musik 1921-1950. Donaueschingen, BadenBaden, Berlin, Pfullingen, Mannheim, Horb am Neckar 1987, S. 36.

23 Siehe hierzu ausführlich das Kapitel Elektronische Eklatanz.

24 Siehe hierzu Karl Laux: »Skandal in Baden-Baden. Bericht von 1929 und Kommentar von 1972«, in Hindemith-Institut (Hg.): Hindemith-Jahrbuch, Frankfurt am Main 1972, S.166180.

25 Siehe hierzu etwa Klaus-Dieter Krabiel: Brechts Lehrstücke. Entstehung und Entwicklung eines Spieltyps, Stuttgart und Weimar 1993. 
deutete für Hindemith die Einbeziehung von Laien in den musikalischen Produktionsprozess, während Brecht in Analogie zu politischer Subversion »eine Art Aufstand des Hörers, seine Aktivierung und seine Wiedereinsetzung als Produzent $\aleph^{26}$ forderte. Tatsächlich probte das Publikum beim Badener Lehrstück den Aufstand. Der Schauspieler Theo Lingen verkörperte die Rolle des Clowns, an dem sich die Gemüter besonders erhitzten:

»Clown Schmidt war mit sich und allem unzufrieden und hatte dauernd psychische, aber auch physische Schmerzen, und seine beiden Begleiter, ebenfalls Clowns, rieten ihm, nun doch alle die Gliedmaßen, die ihn schmerzten, einfach abzuschneiden. [...] Im Laufe des Stückes wurden mir nun sämtliche Gliedmaßen kunstfertig amputiert. Mit einem Blasebalg, der Blut enthielt, mußte ich auch noch das Blut dazu spritzen: das war dem Publikum nun wirklich zu viel. Und als man mir dann noch den Kopf absägte, da ich über Kopfschmerzen klagte, brach ein Skandal aus, wie ich ihn nie wieder am Theater erlebt habe. Alles, was nicht niet- und nagelfest war, flog auf die Bühne. ${ }^{27}$

Im Ullstein Nachrichtendienst hieß es im Anschluss, das Lehrstück sei das »Höchste an unbegreiflicher Geschmacksverwirrung [...], ein Sammelsurium von Lächerlichkeiten und Rohheiten « ${ }^{28}$. Dagegen riet Willi Schuh in der Neuen Zürcher Zeitung »zur Abkehr vom Nur-Aktuellen und zur Besinnung auf wirkliche Werte [...]. Dann wäre dieses Experiment doch nicht ganz umsonst gewesen. ${ }^{29}$ Der von der Uraufführung verursachte Skandal war einer der Gründe, dass die Verantwortlichen der Stadt BadenBaden das Festival zeitweilig nicht länger unterstützten, so dass es im kommenden Jahr - wenn auch nur einmalig - in Berlin stattfinden musste.

Zeitgeschichtliche Male trug das Werk nicht nur durch Brechts explizite Hinwendung zum Kommunismus. Das Lehrstück animierte auch das Publikum durch die Inszenierung von Gewalt und korrespondierte so mit den Unruhen am Vorabend des Totalitarismus. 1938 wurde das »Schandwerk« im programmatischen Begleitheft zur Ausstellung Entarte Musik mit der »Schießbudenatmosphäre eines Jahrmarkts« verglichen: »Hindemith hat sich mit diesem Opus so kompromittiert, daß jetzt hoffentlich die Reaktion gegen diese Gaukelei einsetzt. Die Inflation in der Musik muss endlich liquidiert werden. ${ }^{30}$ Diese Abrechnung war Höhepunkt und Abschluss der musikalischen Gleichschaltung, die nationalsozialistische Claquere nicht zuletzt auch durch Skandalisierungen als Legitimierungsstrategie bei der Machteroberung durchsetzten. Mit Aufstieg und Fall der Stadt Mahagonny wurde 1930 ein anderes Gemeinschaftswerk Bertolt Brechts und Kurt Weills von der NS-Propaganda als übelstes kommunistisches Machtwerk verschrien.

26 Zitiert nach Josef Häusler: Spiegel der Neuen Musik: Donaueschingen. Chronik - Tendenzen - Werkbesprechungen, Kassel 1996, S. 106.

27 Zitiert nach Werner Mittenzwei: Das Leben des Bertolt Brecht oder Der Umgang mit den Welträtseln, Band 1, Frankfurt am Main 1987, S. 315f.

28 Zitiert nach Zintgraf: Neue Musik, S. 40.

29 Ebd.

30 Hans Severus Ziegler: Entartete Musik - Eine Abrechnung (Begleitheft zur Ausstellung Entartete Musik), Düsseldorf 1938, S. $31 \mathrm{f}$. 
Es war einer der letzten Theaterskandale in der Weimarer Republik. Parallel zum Erstarken des Faschismus wurde auch bei den Donaueschinger Musiktagen die progressive Ausrichtung angefeindet und alle der Entartung verdächtigen Kompositionen aus den Programmen verbannt. Vor allem sich zurückgesetzt fühlende Musiker, so führte Werner Zintgraf in seiner Dokumentation der Festivalgeschichte aus, »wehrten sich im Kampfbund gegen eine Verjudung des Musikbetriebes, gegen den Donaueschinger Kreis und die Internationale Gesellschaft für Neue Musik. « ${ }^{31}$ Zwar wurde das Festival auch nach der nationalsozialistischen Machtübernahme noch bis Kriegsbeginn fortgeführt, allerdings in einer grotesken Verstümmelung als $>$ Neue deutsche Volksmusik Donaueschingen $<$ :»Wo einst die atonale Musik in Reinkultur ihre letzte Hochzüchtung erlebte«, so zitierte Zintgraf den Journalisten Wilhelm Matthes, »da musizierte man in diesen Tagen neue deutsche Volksmusik mit Laute, Gitarre, Mundharmonika und zweistimmigen Kanons. $\aleph^{32}$ Und in der amtlichen badischen Zeitung Der Führer hieß es programmatisch:

»Eine auf Blut und Boden begründete Musik entsteht neu im Anschluss an die große kulturelle Überlieferung, Musik und Gesinnung werden wieder eins [...]. Eines steht fest: [...] Donaueschingen hat sich zurückgefunden, ist rehabilitiert und hat sich losgelöst von einer Epoche der Entartung. $\ll^{33}$

1936 erklang in Donaueschingen »Alte und neue Kammermusik aus dem schwäbischalemannischen Raum« und 1937 positionierte sich der nun federführende Peter Hermann im Programmbuch der Musiktage zugunsten einer »mitschaffenden Bejahung der nationalsozialistischen Bewegung «:

»In diesem großen Strom der Verwirklichung höchster deutscher Ideale bildet auch die neue Musik einen helfenden und erzieherischen Bestandteil. Nicht einzelne Künstler und Komponisten sind es mehr, die nach Originalität um jeden Preis haschen wollen, es sind nur ehrliche Mitarbeiter an dem Bauwerk einer neuen deutschen Kultur. $\ll^{34}$

Statt ästhetischem Fortschritt wurden nun reaktionäre Spielarten der Musik fokussiert. Experiment und Progress wurden gleichbedeutend mit Entartung und der Konflikt zwischen Tradition und Innovation zum ideologisch aufgeladenen und blutig geführten Kampf. Mit der Gleichschaltung des Musiklebens und dem Ende eines demokratischen Pluralismus wurden schließlich auch Skandale als Ausdruck polarisierender Meinungen unmöglich gemacht. ${ }^{35}$ Spätestens mit dem Kriegsbeginn 1939 endete die erste Blütephase der Neuen Musik nicht nur in Donaueschingen, sondern in ganz Deutschland und in weiten Teilen Europas. Der Zweite Weltkrieg bedeutete eine Zäsur von rund einer Dekade, nach der Deutschland vor den Ruinen einer Musikkultur stand, aus deren Trümmern - wiederum in Donaueschingen - eine neue Avantgarde auferstand.

31 Zitiert nach Zintgraf: Neue Musik, S. 40.

32 Ebd., S. 74.

33 Ebd.

34 Ebd., S. 90.

35 Siehe hierzu das Unterkapitel Die Unmöglichkeit des Skandals in Zeiten der Diktatur in der Exposition Referenzen und Chiffren. 


\section{Ab 1949: Die skandalumwitterte Neugeburt Donaueschingens}

Als man in Donaueschingen fast unmittelbar nach dem Krieg die Tradition der Musiktage wiederaufnahm, bot die progressive und eklatante Gründergeschichte wichtige Anhaltspunkte für die Neubesinnung des Festivals im Speziellen sowie der Neukonstituierung des Musiklebens im Allgemeinen. Allerdings spiegelte das Programm der Jahre 1946 und 1947 zunächst die restaurativen Tendenzen jener ersten Konsolidierungsphase nach der Kriegskatastrophe. Der Festivalchronist Werner Zintgraf stellte fest: »Gemessen an der revolutionären Bedeutung der früheren [...] Kammermusikfeste erfüllte die $>$ Neue Musik 1947 [...] weder Bahnbrechendes noch Richtungsweisendes ${ }^{36}$. In den Stuttgarter Nachrichten stimmte Kurt Honolka die Nachwuchslücke bedenklich: »Mehr Chancen für die Jungen, ohne Rücksicht auf Stil und Grad der Radikalität, weniger Repräsentation - das dürfte künftig eine wichtige Aufgabe für die Programmgestalter der zeitgenössischen Musik sein. « $^{37}$

1948 fielen die Donaueschinger Musiktage infolge der Währungsreform aus und man nutzte diese Pause für einen wirklichen Neuanfang unter der Federführung des Musikwissenschaftlers Heinrich Strobel. Von Demagogen der nationalsozialistischen Kulturpolitik als »Avantgardist des jüdischen Musikbolschewismus $\aleph^{38}$ gebrandmarkt, wurde Strobel nun Leiter des wichtigsten Festivals Neuer Musik und zugleich der Musikabteilung am neu gegründeten Südwestfunk in Baden-Baden ernannt. ${ }^{39}$ Den Hauptanteil der Donaueschinger Renaissance ab 1950 hatte dieser "große Mäzen des 20. Jahrhunderts, allmächtiger Anreger und Lenker moderner Kompositionspolitik: Der Rundfunk. ${ }^{40}$

Damit waren die Weichen für die skandalumwitterte Neugeburt der Musiktage gestellt: In der ersten Hälfte der 1950er Jahre setzte eine beispiellose chronique scandaleuse ein, in deren Zug nahezu alle maßgeblichen Protagonisten der Neuen Musik mit mehr oder weniger großem Getöse auf die Bühne der Musikgeschichte traten. Zwar baute man dabei auf der Tradition des Schocks der frühen Jahre auf, doch geschah dies unter veränderten zeithistorischen Bedingungen: Während sich die Komponisten von den verdächtig gewordenen Traditionen radikal lossagten und das kreative Potential in der Negation der Vergangenheit suchten, nutzten die Rezipienten nach der >Unmöglichkeit des Skandals in Zeiten der Diktatur ${ }^{41}$ mit Verve ihr neu gewonnenes Recht auf freie Meinungsäußerung. Der tumultuösen Dynamik der 1950er Jahre verdanken die Donaueschinger Musiktage nicht nur bis heute ihren radikalen Ruf; diese Jahre eröffnen auch einen Blick auf die wichtigsten Positionen, Akteure und Mechanismen der Nachkriegsavantgarde zwischen Agon und Skandal.

36 Zintgraf: Neue Musik, S. 124

37 Ebd., S. 143.

38 Ziegler: Entartete Musik, S. 9.

39 Siehe zu den biographischen Kontinuitäten und Brüchen des Kulturlebens vor und nach 1945 und speziell zu Heinrich Strobel Ernst Klee: Das Kulturlexikon zum Dritten Reich. Wer war was vor und nach 1945, Frankfurt am Main 2007, S. 600.

40 Zintgraf: Neue Musik, S. 149.

41 Siehe hierzu den entsprechenden Abschnitt im Expositions-Kapitel Referenzen und Chiffren. 


\section{Skandal in Serie (1951-1953)}

Stand das Festival 1950 mit der Einladung Paul Hindemiths noch einmal ganz im Zeichen der Rückbesinnung auf die skandalumwitterte Gründerzeit, wehte ab 1951 ein neuer Wind durch Donaueschingen. Die Musikgeschichte war trotz der nationalsozialistischen Zäsur vorangeschritten und der Provokateur von einst nun Bestandteil der Restauration, die von der klingenden Reformation der jungen Komponistengeneration überholt wurde. Es waren allen voran drei Akteure, die in den Jahren 1951-1953 mit tumultuösen Auftritten ins Rampenlicht der Musikgeschichte traten: Pierre Boulez, Karlheinz Stockhausen und Luigi Nono. Dabei gewann insbesondere ein ästhetisches Konzept an Bedeutung: die Serie. Nicht nur machte die jungen Nachkriegsavantgarde den Serialismus, bei demhochdifferenzierte Reihen das Kompositionsprinzip bestimmen, zum musikalischen state of the art; ihre Donaueschinger Auftritte produzierten auch klingende Eklats in Serie. Zwar widerspricht diese Reihung dem Charakter des Skandals als überraschendes und unvorhersehbares Ereignis, allerdings wurde durch die zyklische Wiederholung und Häufung ähnlicher Ereignisse ein neues Ordnungsprinzip der Musikavantgarde etabliert. Zufall ist das wohl kaum, denn: »Serielle Produktion, Strukturen und Ästhetiken der Serialität und serienförmige Zeit- und Verhaltensordnungen sind ein ausgezeichnetes Signum der Moderne. ${ }^{42}$

1951 trat Pierre Boulez (1925-2016) mit gerade einmal 26 Jahren ins avantgardistische Rampenlicht, als seine Polyphonie $X$ [ $\delta-7.1]$ in Donaueschingen den ersten charakteristischen Skandal der Nachkriegsjahre lostrat. Organisiert nach rhythmischen Zellen denen alle anderen Elemente unterworfen sind, besteht das Klangergebnis aus fragmentierten, zersplitterten und scheinbar bezugsfreien Einzeltönen der 18 Instrumente. Der Komponist Dieter Schnebel verfolgte die tumultuöse Premiere 1951 am heimischen Radiogerät:

»Die Premiere von Boulez' Polyphonie X endete in einem Skandal. Da gab's unglaubliche Zwischenrufe: Unerhört! Schweinerei! Aufhören! Die Leute waren wirklich wütend, da hat sich eine Aggressivität aufgestaut. Meine Erinnerung war: Da kommt ja kein normaler Ton vor. Aber als ich kürzlich eine CD mit den historischen Aufnahmen hörte habe ich mir gedacht: Was ist das nur für ein schönes und zahmes Stück? ${ }^{43}$

Zehn Jahre später verwendete Schnebel die bei der Premiere der Polyphonie $X$ vernommenen Publikumsreaktionen in seiner Glossolalie [ $\delta-20]$ : Mit Sprache beginnt das biblische `Zungenreden`, Ausführungen über Musik und Alltagslaute verwirren sich $\mathrm{zu}$ Klang und erregen ratlose Heiterkeit. Es wird auskomponiert geröchelt, gepfiffen, geschrien und die Verhaltensmuster der Hörer zum performativ-ästhetischen Bühnenereignis. Schnebels Bemerkung gibt darüber hinaus Hinweise auf den Wandel der Hörgewohnheiten - und damit auf die Konsolidierung, ja sogar Kanonisierung ehemaliger Skandalwerke.

42 Benjamin Beil/Lorenz Engell/Jens Schröter/Herbert Schwaab/Daniela Wentz: »Die Serie. Einleitung in den Schwerpunkt«, in: Zeitschrift für Medienwissenschaft 7 (2/2012), S. 1016, hier S. 10.

43 Dieter Schnebel im Gespräch mit der Autorin am 12.8.2012. 
1951 jedoch waren die Ohren mitnichten an Werke wie jene Polyphonie $X$ gewöhnt. Sie war ein erstes Manifest der jungen Nachkriegskomponisten die sich anschickten, alle Bezüge zur Vergangenheit zu negieren. Boulez' Komposition traf einen sensiblen Nerv und provozierte die für Skandale so typisch polarisierenden Reaktionen des Publikums: Störte die eine Hälfte die Aufführung mit Zwischenrufen und der Imitation von Tiergeräuschen, antworte die andere mit Applaus und Bravos. ${ }^{44}$ Auch die Pressevertreter übten sich in Meinungsfreiheit. ${ }^{45}$ Der Rezensent der Rheinischen Post analysierte treffend den »kleinen Skandal, einem von der Art, wie sie leider selten geworden sind - zeugen sie doch von der Lebendigkeit aufeinanderprallender Meinungen«:

»Bei dieser Uraufführung gab es Lächeln, Lachen, Zwischenrufe und Trillerpfeife. Und es gab danach die hitzigsten Erörterungen um ein Etwas, das einige fälschlicherweise für Musik gehalten hatten. Und doch war dieses Etwas [...] von sehr ernst zu nehmender Art. Hier wagt mit zweifelloser Ehrlichkeit jemand die Atomisierung des Klangs, jeder Thematik, aller Melodik zum Trotz. [...] Authentischer geht es nicht. $\aleph^{46}$

Nach der >Unmöglichkeit des Skandals in Zeiten der Diktatur` war die pluralistischdemokratische Sprache des Skandals nicht nur in deutschen Zeitungen, sondern auch in den Auditorien wieder zu vernehmen. Die Hörer nahmen die Möglichkeiten der freien Meinungsäußerung dankbar an. Die Baseler Nationalzeitung etwa berichtete von einer jungen Dame, die »eine ihr vom Hals baumelnde Trillerpfeife an die Lippen $«{ }^{47}$ setzte, die sie offenbar in einer ganz konkreten Erwartungshaltung zum Konzert mitgebracht hatte. Dagegen reagierte die Frankfurter Allgemeine Zeitung in einem Tonfall, der die Diktion der nationalsozialistischen Kulturkritik noch einmal aufleben ließ:

»Nach welchem Konstruktionsprinzip der Totengräber der Musik Boulez vorgegangen ist, interessiert uns keineswegs. >Entartet` wäre noch ein schmeichelndes Lob für einen Fall, bei dem man nur von einem Verwesungsprozess sprechen kann. ${ }^{48}$

Heinz Pringsheim stellte in seinem Radiobericht einen zeithistorischen Bezug zur 1948 erfolgten Währungsreform und den Schrecken der Atombombe her:

»Polyphonie $\mathrm{X}$ - das erinnert an den Tag X, den Tag der Währungsreform. Eine Währungsreform, eine Umwertung aller Werte erstrebt ja offensichtlich auch der junge Komponist. Man hat ja schon wiederholt darauf hingewiesen, dass es in der Neuen Musik eine Richtung gibt, die die Elemente der Musik zu atomisieren sucht. Boulez geht einen großen Schritt weiter: er schreitet unverzagt zur Atom-Zertrümmerung. « ${ }^{49}$

44 Dominique Jameux: Pierre Boulez, Cambridge 1991, S. 47 f.

45 Eine Sammlung der Pressestimmen finden sich in SWR: P06483.

46 N.N.: »An der Wiege der Neuen Musik«, in: Rheinische Post (11.10.1951).

47 N.N: »Zeitgenössische Musik in Donaueschingen«, in: Nationalzeitung Basel (11.10.1951).

48 N.N.: »Exzeß der Zersetzung «, in: Frankfurter Allgemeine Zeitung (10.10.1951).

49 Das Manuskript der Sendung finden sich im SWR: P06264. 
Wenn Pringsheim in Boulez' Werk mit Verweis auf die Währungsunion eine »Umwertung aller Werte« erkannte, kann die Konstruktion der Polyphonie X tatsächlich als kompositiorische Analogie des Wiederaufbaus verstanden werden: Serielles Komponieren - die Berechnung aller musikalischen Parameter wie Höhe, Dauer und Lautstärke nach Reihen - wurde zu einem wesentlichen Charakteristikum der Nachkriegsavantgarde. Intellektuelle (De-)Konstruktion und ästhetische Negation folgten auf die emotionalen Schrecken des Krieges und die nationalsozialistische Vereinnahmung der kulturellen Traditionen. Aussagekräftig für die eklatante Konstituierung der seriellen Musik ist ein Brief, den der Reutlinger Oberbürgermeister Oskar Kalbfell nach der umstrittenen Premiere der Poyphonie X an Friedrich Bischoff, den Intendanten des Südwestrundfunks, schrieb. Mit Bezug auf den Boulez-Skandal kritisierte Kalbfell nicht nur die finanziellen Mittel, die der öffentlich-rechtliche Rundfunk für die Experimente eines kleinen Kreises von »Snobisten und Fanatikern« ausgebe, sondern betonte auch die emotionalen Auswirkungen der Negationsästhetik:

»Viele der Anwesenden haben sich empört und hielten das Ganze für eine Verirrung [...] und sie erklärten, daß [...] die Musik von Boulez ihre physischen und seelischen Kräfte verzehre [...]. Nicht nur ich persönlich, auch meine Freunde, die von Musik viel verstehen, haben bei der gestrigen Aufführung an vielen Stellen einen beinahe körperlichen Schmerz empfunden - es war so ohrenbetäubend, der Lärm der Instrumente derart wild durcheinander, verrückt und ohne Thema! [...] Ich bin empört und muß Ihnen das in aller Offenheit sagen [...]. Boulez, nein, das ist zu viel! « ${ }^{50}$

Deutlich kündigte Kalbfells Brief die Leiden der Neuen Musik ${ }^{51}$ an, die in der zweiten Hälfte des 20. Jahrhunderts chronisch werden sollten: Die Isolierung der Musikavantgarde vom bürgerlichen Konzertbetrieb, ihre Ignorierung durch die öffentlichen Rezeption sowie die Kritik an ihrer Subventionierung durch den Rundfunk: »Müssen wir [...] zusehen, wie öffentliche Gelder für derartige Experimente verwendet werden, deren negativer Wert von Vornherein feststeht? « ${ }^{52}$ Heinrich Strobel nahm gegenüber seinem Intendanten Stellung zu diesem, wie er schrieb, »Gemisch von Unkenntnis, provinzieller Engstirnigkeit und Bösartigkeit«:

»Ich selbst habe an allen Donaueschinger Festen teilgenommen [...]. Die Werke, die damals aufgeführt wurden, stammten in der Tat von jungen Leuten. Heute ist ein großer Teil dieser jungen Leute weltberühmt geworden. Damals waren sie weit mehr umkämpft als heute das Werk von Boulez [...]. Wenn Herr Kalbfell schreibt, >es sei nichts Positives geschaffen worden, die Musik hätte ohrenbetäubend geklungen, der Lärm der Instrumente sei derartig wild durcheinander geklungen, verrückt und ohne Themen`, so sind dies Argumente, mit denen man wirklich nicht mehr aufwarten kann. Dasselbe hat man von Beethoven, von Wagner, von Richard Strauss und von Strawinsky behauptet. ${ }^{53}$

50 Brief von Oskar Kalbfell an Friedrich Bischoff (8.10.1951), SWR: P06264.

51 Ursula Petrik: Die Leiden der Neuen Musik. Die problematische Rezeption der Musik seit etwa 1900, Wien 2008.

52 Ebd.

53 Heinrich Strobel: »Stellungnahme zum Brief von Herrn Oberbürgermeister Oskar Kalbfell an Herrn Intendant Bischoff« (19.10.1951), in SWR: P06264. 
Auch der Dirigent Hans Rosbaud legitimierte die schockhaft empfundene Ästhetik mit Verweis auf die turbulenten Gründerjahre der musikalischen Moderne:

»Ich nahm selbst am Musikfest des Jahres 1921 teil und habe heute noch die tumultartigen Szenen in Erinnerung, die bei der Aufführung von Werken Hindemiths, Kreneks u.a. vor sich gingen. Nur wenige Jahre später fragten sich nicht nur die Fachleute [...], was wohl jene ersten Zuhörer dieser neuen Musik veranlasst haben mochte, in so handgreiflicher Weise zu protestieren. Die damals angefochtene und leidenschaftlich abgelehnte Musik wird von uns heute fast der Klassik zugezählt. « ${ }^{54}$

Rosbaud verwies darüber hinaus auf die Jahre der NS-Herrschaft, »als reaktionäre Dilettanten sich anmaßten, von Staatswegen der Kunst eine Entwicklungslinie vorzuschreiben « und setzte also die Kunstfreiheit in pars pro toto für die Demokratiefähigkeit der Gesellschaft ein. Abschließend hob der Dirigent den Rundfunk als »Mäzen der Geistesfreiheit« heraus, der seine geschichtliche Verpflichtung erkannt habe, »bewusst und mit Überzeugung für das Neue in der Musik einzutreten. $" ~ " 55$ Dass man sich außerdem in der Rolle der radikalen Neuerer gefiel, belegt anekdotisch ein Geschenk, das Heinrich Strobel im Anschluss an das Festival 1951 von der Gesellschaft der Musikfreunde im Namen des Fürsten zu Fürstenberg überreicht wurde. Der Festivalleiter bekam einen Spazierstock, auf dem aphoristisch zu lesen stand:

»Schwenk ihn, wenn fürder wieder Boulez-Klänge

Aufmuntern wollen keck zum Handgemenge. $\ll^{56}$

Ein solches Handgemenge provozierte in Donaueschingen ein Jahr später auch der damals 24jährige Karlheinz Stockhausen (1927-2007), dessen Spiel für Orchester [ $\delta$-8.1] - so hieß es in der Badischen Zeitung - „die Ehre widerfuhr ausgepfiffen zu werden. « ${ }^{57}$ Die Werkkonzeption beruht auf einem Punktualismus, dem eine radikale Abkehr von allen melodischen und harmonischen Verbindungen eingeschrieben ist. Das Klangergebnis ist eine kontrastreiche Musik, erhellt von leuchtenden Blitzen des Schlagwerks und dem gedämpften Schein der übrigen Instrumente, was Robin Maconie von einer $»$ Nocturne mit explodierenden Granaten ${ }^{58}{ }^{58}$ sinnieren ließ. Für Aufregung sorgten nicht nur die durch das expressive Schlagwerk ausgelösten Kriegsassoziationen, sondern auch eine ganze Reihe von unkonventionellen Instrumenten, darunter ein großes Trinkglas: Bei der Premiere sollte dieses in einer Generalpause zum Klingen gebracht werden - der Perkussionist aber traf das Glas so hart, dass es zersplitterte und auch in den Erinnerungen des Komponisten den klirrenden Startpunkt für »einen der legendär gewordenen Skandale ${ }^{59}$ setzte.

54 Hans Rosbaud: »Pflege zeitgenössischer Musik im Allgemeinen; Donaueschinger Musiktage im Besonderen« (5.11.1951), in SWR: P06264.

55 Ebd.

56 Brief von Max Rieple an Heinrich Strobel (20.12.1951), in SWR: P06264.

57 N.N.: »Donaueschinger Bilanz«, in: Badische Zeitung (16.10.1952), in: Ebda.

58 Robin Maconie: Other Planets. The Music of Karlheinz Stockhausen, Oxford 2005, S. 85.

59 Karlheinz Stockhausen: SPIEL (1952) für Orchester (Booklet), in: Stockhausen-Edition Nr. 2 (1991), S. 13. 
Wie schon ein Jahr zuvor, war eine Vielzahl in- und ausländischer Pressevertreter nach Donaueschingen gereist, die den Musiktagen vielstimmige Aufmerksamkeit zollten. ${ }^{60}$ Die Berichte der Rezensenten belegen auch in diesem Fall, dass sich die Proteste in dem für Musikskandale charakteristischen Gegeneinander polarisierender Affekte entluden. Das Offenburger Tageblatt etwa titelte: »Wütende Pfiffe und demonstrativer Beifall« und bezeichnete Stockhausen als »Bürgerschreck«, der »mit allen Traditionen bricht ${ }^{61}{ }^{2}$. Dass der Skandal mittlerweile zur erwarteten Ingredienz der Donaueschinger Musiktage geworden war belegen die Stimmen in der Frankfurter Allgemeinen und der Süddeutschen Zeitung. Stellte die FAZ fest, »ohne ein Enfant terrible [...] geht es hier offenbar nie $a b «^{62}$, hieß es in der SZ: »Strobel hat Jahr für Jahr sein Enfant terrible, dem er ans Licht hilft. ${ }^{63}$

Auch der Briefwechsel zwischen Heinrich Strobel und Karlheinz Stockhausen belegt, dass eine skandalträchtige Provokation durchaus erwünscht war. So schrieb der Festivalleiter, er wolle Stockhausen »als neuen deutschen Boulez sozusagen zum ersten Mal in Donaueschingen herausstellen. $\ll{ }^{64}$ An anderer Stelle heißt es, von dem Stück erhoffe er »die Sensation in Donaueschingen ${ }^{65}$. Als Stockhausen berichtete, andernorts sein Kreuzspiel [ $\delta$-8.2] dirigieren zu wollen ${ }^{66}$, war Strobel von dieser Idee wenig erfreut: »denn Sie wissen ja, dass ich Sie in Donaueschingen als neuen Namen herausstellen wollte. ${ }^{67}$

Die Medien reagierten wie gewünscht: Dem Schwarzwälder Boten erschienen die »scharfen Pfiffe der Ablehnung [...] so berechtigt wie milde, verglichen mit den Kennzeichnungen, die von Mund zu Mund gingen. ${ }^{68}$ Allerdings unterschlugen die Pressevertreter ihren eigenen Anteil an der eklatanten Inszenierung der seriellen Musik, denn die Kritiker konzentrierten sich fast ausschließlich auf die >Problemstücke ২ und offenbarten damit auch die aufkeimende Sensationslust der Massenmedien. Schließlich waren die Rezensenten - wie eine Bemerkung im Münchner Merkur nahelegt - auch verunsichert durch die historisch überlieferte Narration, gemäß der avantgardistische Wegbereiter und ihre Meisterwerke zunächst oftmals auf Ignoranz und Ablehnung stoßen, um nur wenig später zu Klassikern erklärt zu werden:

»Fast keiner der zahlreichen Experten wagte es, sich bei dieser Musik zu einem rückhaltlosen Ja oder Nein aufzuraffen. Nahezu alle versteckten sich [...] hinter der Angst, man könne ein auftauchendes Genie verkennen, wie man früher die Bedeutung Richard Wagners und anderer GroBer nicht rechtzeitig erkannte. ${ }^{69}$

60 Eine Sammlung der Pressestimmen findet sich in SWR: P 06263.

61 N.N.: »Wütende Pfiffe und demonstrativer Beifall«, in: Offenburger Tageblatt (13.10.1952), in: Ebd.

62 Frankfurter Allgemeine Zeitung (15.10.1952), in: Ebd.

63 Süddeutsche Zeitung (15.10.1952), in: Ebd.

64 Brief von Heinrich Strobel an Karlheinz Stockhausen (24.1.1952), in SWR: P 06262.

65 Brief von Heinrich Strobel an Karlheinz Stockhausen (13.5.1952), in: Ebd.

66 Brief von Karlheinz Stockhausen an Heinrich Strobel (5.3.1952), in: Ebd.

67 Brief von Heinrich Strobel an Karlheinz Stockhausen (18.3.1952), in Ebd.

68 Schwarzwälder Bote (14.10.1952), in SWR: P 06263.

69 Münchner Merkur (15.10.1952), in: Ebd. 
Die Neue Zeitung Berlin bekannte: »Alles ist Neuland. Die Orientierung fällt schwer. Ist es Vision oder Spekulation? ${ }^{70}$ Trotz dieser für Schwellenzeiten charakteristischen Unsicherheiten wurde das Wirken der jungen Generation doch allgemein mit einem radikalen Aufbruch verbunden. Einige Kritiker erwiesen sich dabei als hellsichtig: In der Neuen Zürcher Zeitung hieß es, dass sich »solch abwegiges Tönespiel [...] elektrischer Tonerzeuger bedienen ${ }^{71}$ müsse und in den Badischen Neuesten Nachrichten stand geschrieben, diese »Musik hätte eigentlich der neuen elektroakustischen Instrumente bedurft, denn sie ist ein Laboratoriumsprodukt. ${ }^{72}$ Tatsächlich residierte Stockhausen zu jener Zeit in Paris, wo er am Studio d'Essay, der Forschungsstelle des französischen Rundfunks für musique concrète, seine Experimente im Bereiche der elektronischen Klangmittel und der Bandschnittkomposition kultivierte. Seine Lautsprechermusik erregte ein Jahr später in Köln ihre tumultuöse Geburt und bildet ein Herzstück der Elektronischen Eklatanz. ${ }^{73}$

In Donaueschingen wurde jene musique concrète 1953 zum nächsten großen Skandalon der Musiktage, als die Franzosen Pierre Schaeffer und Pierre Henry mit der $>$ konkreten< Lautsprecheroper Orphée 53 [\$-12] in die Skandalchronik des Festivals einging. ${ }^{74}$ In der stürmischen Empörung über die Tonbandmusik ging damals ein weiterer Skandal fast unter: Auch Due espressioni per orchestra [ $\delta$-9.1] des jungen Italieners Luigi Nono (1924-1990) evozierte die für Musikskandale typische Dynamik. In der zeitgenössischen Presse ${ }^{75}$ kann man nachlesen, dass Nono »neben einiger Zustimmung auf entschiedene Ablehnung ${ }^{76}{ }^{6}$ gestoßen und »das Publikum in zwei Lager» geteilt worden sei. ${ }^{77}$ Wichtiger noch war der Umstand, dass mit den Donaueschinger Skandal(erfolg)en der Jahre 1951-53 nicht nur die Protagonisten der Nachkriegsavantgarde - Pierre Boulez, Karlheinz Stockhausen und Luigi Nono - der Reihe nach auftraten, sondern dass ihre Skandale die serielle Negationsästhetik erst relevant machten.

1954 reihte sich auf Empfehlung Stockhausens ${ }^{78}$ ein weiterer Protagonist der Neuen Musik in die Skandalchronik der Donaueschinger Musiktage ein und durchbrach zugleich das von der seriellen Troika etablierte Ordnungsschema: John Cages von Gelächter und Protesten begleitete Europapremiere in Donaueschingen [ $\mathcal{\delta}-15.2$ ] sowie sein eklatanter Auftritt bei den Darmstädter Ferienkursen für Neue Musik 1958 [ $\delta$-15.3] veränderten die Paradigmen der Neuen Musik ein weiteres Mal und setzten eine transkulturelle Neuvermessung der klingenden Welt in Gang und Klang. ${ }^{79}$

70 Neue Zeitung Berlin (17.10.1952), in: Ebd.

71 Neue Zürcher Zeitung (24.4.1952), in: Ebd.

72 Badische Neueste Nachrichten (13.10.1952), in: Ebd.

73 Siehe hierzu das Kapitel Rauschende Interferenzen: Karlheinz Stockhausen.

74 Siehe hierzu das Kapitel Konkretes Waterloo: Pierre Schaeffer.

75 Eine Sammlung der Pressestimmen findet sich in SWR: P06485.

76 N.N.: Donaueschinger Musiktage 1953, in: Schwäbisches Tagblatt (17.10.1953).

77 N.N.: »Konkrete Musik in Donaueschingen. Ein Rückblick auf die Tage«, in: Schwäbische Zeitung (17.10.1953).

78 Stockhausen berichtete Heinrich Strobel am 5.3.1952 in einem Brief von »hochinteressanten amerikanischen Versuche (prepared piano etc.)«, in SWR: P 06262.

79 Siehe hierzu den Abschnitt John Cage und die transatlantische Neuvermessung der klingenden Welt im Kapitel Transkulturelle Transfers. 


\section{Fortschrittsglaube und -kritik: „Neue Musik und Humanitas»}

Bei den Rezipienten provozierten die serielle Negationsästhetik und die Skandale in Serie nicht nur Empörung, sondern leiteten auch die charakteristische Sezession der Avantgarde vom bürgerlichen Kulturbetrieb ein, die Michael Custodis als Soziale Isolation $^{80}$ und Ursula Petrik als Leiden der Neuen Musik ${ }^{81}$ bezeichneten. Beide Autoren referierten damit auf die Entfremdung der von einem breiten Publikum, das zunächst tumultuös reagierte, um schließlich den Konzerten fernzublieben. 1952 aber war die Aufmerksamkeit durch die Medien und insbesondere die Protektion des bildungsbeauftragten Rundfunks noch sichergestellt. Die schockierende Ästhetik wurde mehr noch als konstituierendes Merkmal der Neuen Musik sowie als normale und sogar willkommene Begleiterscheinung im Progress der Musikästhetik begriffen.

Dennoch nahmen die Verantwortlichen das sich abzeichnende Dilemma ernst, nachdem mehrere Berichterstatter des Donaueschinger Jahrgangs 1953 eine >Entmenschlichung d der Musik befürchtet hatten und damit ein Schlagwort der Avantgardekritik kreierten. So sprach etwa die Neue Zürcher Zeitung von einer »Denaturierung « infolge der »klanglichen und rhythmischen Spielereien, als deren bezeichnendster Zug die Aufspaltung in ausgetüftelte Einzelerscheinungen von rein strukturellem Interesse erscheint. ${ }^{82}$ Die Badischen Neuesten Nachrichten ergänzten, dass die »intellektuelle Organisation als leitendes Kompositionsprinzip folgerichtig zur Mißachtung des Menschen ${ }^{83}$ führe. In diesem Kontext erscheint der Vortrag »Neue Musik und Humanitas ${ }^{84}$, den Heinrich Strobel 1953 bei den Donaueschinger Musiktagen hielt, als unmittelbare Reaktion auf diese Vorwürfe. Auch der Festivalleiter erkannte, dass die serielle Negationsästhetik der jungen Komponistengeneration »enthumanisiert« wirke, aber »immerhin die Möglichkeit habe, die Tonsprache einer neuen, in steigendem Maß von der Technik beeinflussten Epoche« und damit »der wahrhaft klingende Ausdruck der Moderne « zu werden. Diese Aussage begründete Strobel mit psychologischen sowie explizit zeithistorischen Bezugnahmen:

»Wollen die jüngsten Komponisten eine Verbindlichkeit [...] dadurch erreichen, daß sie unter Negierung aller bisherigen Konventionen [...] die ganze seelische Gespanntheit des modernen Menschen zum Ausdruck zu bringen versuchen? [...] Ist die Musik unserer Jüngsten, der seit langer Zeit $[\ldots]$ wieder eine europäische Gemeinschaft zukommt, ein Widerhall der modernen Seele, die zwischen den dunklen Träumen Kafkas und der schaudernden Angst vor neuen atomistischen Gewalten verzweifelnd hin und her gerissen wird? ${ }^{85}$

80 Michael Custodis: Die soziale Isolation der neuen Musik. Zum Kölner Musikleben nach 1945, Stuttgart 2004.

81 Petrik: Die Leiden der Neuen Musik.

82 N.N.: »Donaueschinger Musiktage 1953«, in: Neue Zürcher Zeitung (27.10.1953), in SWR: P06485.

83 Karlheinz Ebert: »Standort und Richtung der Neuen Musik«, in: Badische Neueste Nachrichten (17.10.1953), in: Ebd.

84 Heinrich Strobel: »Neue Musik und Humanitas«, Vortrag bei den Donaueschinger Musiktagen am 11. Oktober 1953, publiziert in der Heftbeilage von Melos (11/1953).

85 Ebd. 
Die serielle Negationsästhetik verschreckte nicht nur Hörer, sondern riss auch eine Kluft innerhalb der Komponistenszene. Der 1896 geborene Hugo Herrmann etwa hielt Strobels Vortrag für »sehr notwendig [...], die mehr oder weniger verwirrten Geister [der jungen Generation] zur Besinnung anzuregen«:

»Ist denn der anfängliche Fortschrittsglaube [...] nicht nur mehr Fortschritt um des Fortschrittes willen? [...] Die Musik als allein physikalisches Phänomen ergründen zu wollen, ist wohl [...] nur eben eine Teillösung. [...] Die Säkularisation hat den Schaffenden [...] in die weite Dürre der künstlerischen Freiheit und des progressiven Fortschrittglaubens geschickt. ${ }^{86}$

Die Kluft zwischen Fortschritts- und Traditionsglaube vertiefte sich in den kommenden Jahren. Als der Mäzen Max zu Fürstenberg 1955 Intentionen äußerte, »das Musikfest abzuschiessen bzw. nur noch 2jährig durchzuführen « ${ }^{87}$, initiierte Strobel 1956 eine weitere Diskussionsrunde unter dem Motto »Wie soll das weitergehen«? In seinem Vorspruch zur Disputation thematisierte er die sektiererischen Tendenzen:

»Niemand kann leugnen, dass die seit langem bestehende Kluft zwischen der zeitgenössischen Musik und dem Publikum sich neuerdings zu einer Riesenschlucht erweitert hat. [...] Als ich ein Knabe war, gelangten die ersten Opern von Richard Strauss zur Uraufführung. Ihre stofflichen und musikalischen Kühnheiten erregten die Hörer. Die gesamte gebildete Welt diskutierte diese Ereignisse. [...] Wie aber steht es mit den Jüngsten? [...] Willi Schuh hat darauf hingewiesen, dass ihre Werke nur noch in den Studios der Rundfunkanstalten, den >Brutöfen des Avantgardismus` aufgeführt werden. [...] Das Musikleben [...] nimmt von der neuesten Entwicklung überhaupt keine Notiz [...]. Seien wir ehrlich: auch die beispielgebende Generation der Zwölftonmusik [...] ist nicht in das öffentliche Musikleben gedrungen. ${ }^{88}$

Diese Isolation kommentierte Strobel mit einem Zitat der Weltwoche zu religiösen Problemfragen, das ohne weiteres auch auf die jüngsten Musiker übertragbar sei:

»Die normalen Sterblichen, so sagt man, interessieren sich für nichts als ihr Motorrad, ihr Vergnügen, ihren Kitsch. Sie sind die Masse, die anderen die Auserwählten der Elite. Doch anstatt das Salz der Erde zu sein, das den Teig schmackhaft macht, frönen sie in erhabener Absonderung als blutlose >reine Geister einem intellektuellen Narzißmus. ${ }^{89}$

Strobel führte die Ablehnung nicht nur auf die intellektuelle Hermetik der jungen Komponisten, sondern auch auf die >Kulturindustrie〈 zurück, die Theodor W. Adorno und Max Horckheimer zwischen 1933 und 1944 in ihrer Dialektik der Aufklärung beschrieben: »Kultur heute schlägt alles mit Ähnlichkeit. ${ }^{90}$ Neue Musik wurde in dieser Gesellschaft zum zunächst befehdeten und dann ignorierten Anderen.

86 Brief von Hugo Herrmann an Strobel (20.11.1953), in SWR: P06261.

87 Ebd.

88 Heinrich Strobel: Vorspruch zur Disputation, in SWR: P06260. Text und Diskussionsrunde fanden einen publizistischen Nachhall in: Melos (23/1956).

89 Ebd.

90 Horkheimer/Adorno: Kulturindustrie, S. 129. 


\section{Dogmatismus und Segregation}

Einen gewichtigen Anteil an dieser Entwicklung trug die zunehmend absolutistisch agierende `serielle Troika der jungen Generation: Pierre Boulez, Karlheinz Stockhausen und Luigi Nono [Abbildung 6 $]^{91}$.

Abbildung 6-Die sserielle Troika^(v.l.n.r.): Luigi Nono, Pierre Boulez und Karlheinz Stockhausen bei den Donaueschinger Musiktagen 1957

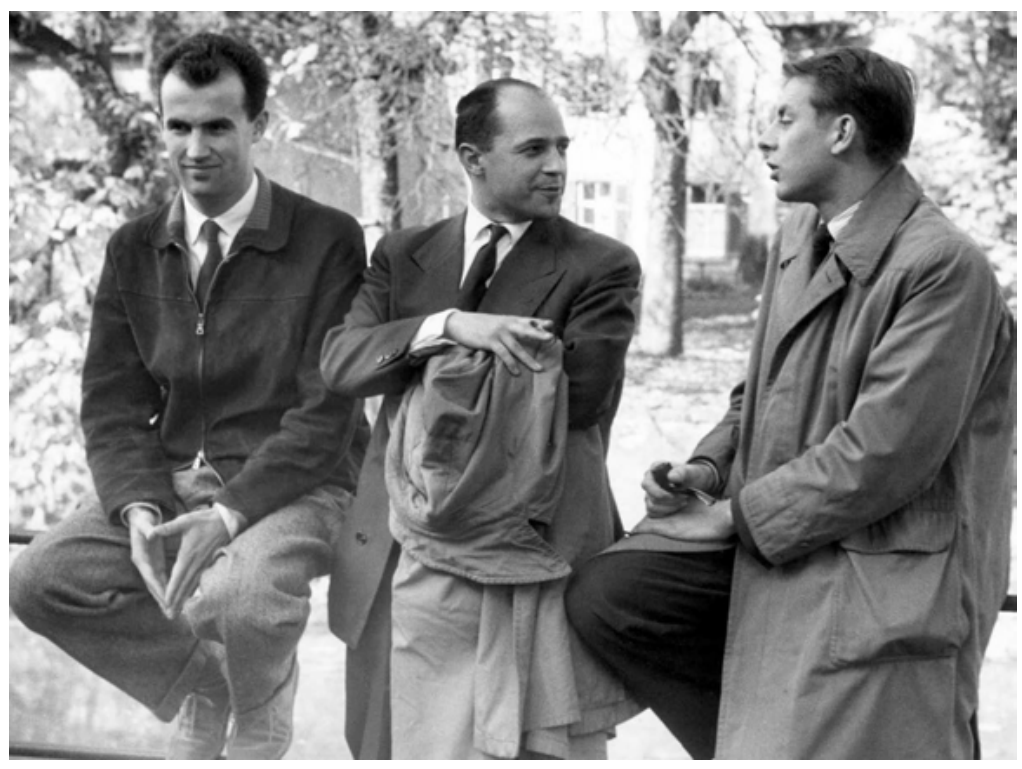

Hermann Danuser bezeichnete die drei Komponisten als »Klub der seriellen Musik« und vermutete dahinter eine »Mythogenese $«$, die auf eine

»Analogie zur >Wiener Schule` (mit Schönberg, Berg, Webern) und gar zur >Wiener Klassik « (mit Haydn, Mozart, Beethoven) abzielte - und in diesem Vergleich zudem unmittelbar die Internationalität $[\ldots]$ gegenüber den beiden anderen Konstellationen zum Ausdruck bringt $[\ldots]$, stand doch im Hintergrund der Mythogenese auch die historische Versöhnung Italiens, Frankreichs und Deutschlands in einer transnationalen Musikkultur eines neuen Europas. ${ }^{92}$

Das zunehmend dogmatische Gebaren dieses paneuropäischen »Klub der seriellen Musik« kritisierte auch der griechische Komponist und Architekt Iannis Xenakis - der 1955 mit seiner individualästhetischen und stochastischen Komposition Metastaseis $[\delta-10]$ einen veritablen Skandalerfolg erzielt hatte - und führte dies auf zeithistorische Konflikte zurück:

91 Siehe hierzu ausführlich den folgenden Abschnitt dieses Kapitels: Die Darmstädter Ferienkurse als agonale Ereignisgeschichte.

92 Borio/ Danuser: Im Zenit der Moderne, Band 2, S. 378f. 
»Die Neue Musik befand sich fest in den Händen der Serialisten [...]. Die Programmleiter der deutschen Rundfunkanstalten standen hinter der seriellen Musik, um nicht zuletzt auch sich selbst zu beweisen, dass die deutsche Musik noch etwas zu sagen habe. Dann gab es Komponisten wie Boulez, die glaubten, die absolute Musik gefunden zu haben. Alles, was davon abwich, zählte nicht. Die Franzosen, Deutschen und Italiener bildeten einen exklusiven, einflußreichen Klub der seriellen Musik. ${ }^{93}$

Der polemisch vertretene Dogmatismus der seriellen Troika richtete sich nicht nur gegen die ältere Generation, sondern auch gegen traditionsbewusstere Altersgenossen wie Hans Werner Henze. Von diesem zeigte sich Karlheinz Stockhausen schon 1952 in einem Brief an Heinrich Strobel »maßlos enttäuscht $«{ }^{94}$ und initiierte einen offenen Konflikt, der als ein Grund für die Auswanderung Hans Werner Henzes 1953 nach Italien gelten kann. ${ }^{95}$ In Donaueschingen markierte 1957 der Boykott von Henzes hymnisch-schönen Nachtstücken und Arien nach Gedichten von Ingeborg Bachmann [ $\delta-11]$ den Bruch innerhalb der jungen Komponistengeneration.

In einem Brief an Strobel bemerkte Henze im Vorfeld der Aufführung, seine Komposition sei »ein schlussstück, ein antimodernes, eines gegen die modernität die einen ja nun doch wirklich nur noch aus allen 12 loechern anoedet. ${ }^{96} \mathrm{Im}$ Gegenzug wurde sein Werk von den Exegeten der seriellen Negationsästhetik boykottiert: »Von meinem Platz im Saal konnte ich sehen«, so erinnerte sich Henze später bitter, »wie bereits nach den ersten Takten Boulez, Stockhausen und mein Freund Nono [...] den Saal verließen, ganz demonstrativ, jeder konnte und sollte es sehen. ${ }^{97}$ Dieter Schnebel verkehrte damals im Lager der radikalen Komponisten und bestätigte, dass die Nichtbeachtung der seriellen Prinzipien zur 〉Exkommunikation〈Henzes geführt habe: »Indem er richtig in Dur komponierte - war er für uns einfach abgemeldet. $\ll^{98}$ Jahre später thematisierte Henze in einer filmischen Dokumentation der Ereignisse nicht nur die ästhetischen Grabenkämpfe, sondern auch die Hörerreaktionen:

»Mit den Nachtstücken hatte ich wohl die extremste Gegenposition zum kalten, seelenlosen Unmenschlichkeitslook erreicht [...] und so nimmt es nicht Wunder, dass bei der UA [...] drei Vertreter des anderen Extrems: Boulez, Nono, Stockhausen, demonstrativ schon nach den ersten Takten aufsprangen und den Saal verließen. Das Kopfschütteln wollte an diesem Abend gar kein Ende mehr nehmen. Ingeborg und ich waren plötzlich Luft für die Leute. Es herrschte im Überbau eine gewisse Form von Verärgerung. Wohl auch, weil das Publikum unser Stück lebhaft gefeiert hatte. Und es trat so eine Art Bann in Kraft. ${ }^{99}$

93 Andréas Varga Bálint: Gespräche mit Iannis Xenakis, Zürich/Mainz 1995, S. 38.

94 Brief von Karlheinz Stockhausen an Heinrich Strobel (5.3.1952), in SWR: P 06262.

95 Siehe hierzu ausführlich den Abschnitt Der Absolutismus der Moderne im folgende Kapitel: Die Darmstädter Ferienkurse als agonale Ereignisgeschichte.

96 Brief von Hans Werner Henze an Heinrich Strobel (1.8.1957), in SWR: P 06258.

97 Hans Werner Henze: »Die Schwierigkeit, ein bundesdeutscher Komponist zu sein. Neue Musik zwischen Isolierung und Engagement«, in Hanns-Werner Heister/Dietrich Stern (Hg.): Musik 50er Jahre, Berlin 1980, S. 50-77, hier S. 64.

98 Dieter Schnebel im Gespräch mit der Autorin am 12.8.2012.

99 Harold Woetzel: 75 Jahre Donaueschinger Musiktage: Das Ende der Musik (Dokumentarfilm), in: SWF (1969). 
Im gleichen Film gab Pierre Boulez mit Blick auf die ungleich verteilte Publikumsgunst zu Protokoll: »In uns herrschte Feindseligkeit aus verschiedenen Gründen, zugegeben: wir waren ziemlich aggressiv. Aber anders hätten wir nicht überlebt und wären vollständig untergegangen. ${ }^{100}$ Tatsächlich feierten Publikum und Presse ${ }^{101}$ die Nachtstücke und Arien als das überragende Werk des Donauschinger Festivaljahrgangs 1957: Schätzte ein Rezensent, dass sich der »31-jährige Komponist [...] in diesem [...] Werk ganz vom papierenen Zwölfton-Spekulationen gelöst und [...] einen

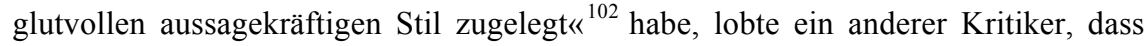
Henze in seinem italienischen Domizil »das A und O aller Musik, die Melodie für sich entdeckt ${ }^{103}$ habe. Im Gegensatz dazu erreichte Heinrich Strobel im selben Jahr ein offener Brief, der die Ablehnung der seriellen Avantgarde durch das bürgerliche Publikum anekdotisch beleuchtet. In dem »Über 12-Ton-Lyrik « ${ }^{104}$ betitelten Schriftstück hieß es voll triefender Polemik:

»Bei dem diesjährigen Donaueschinger Dichtertreffen machten neuartige Versuche experimentierfreudiger jungdeutscher Dichter grosses Aufsehen. Man verzichtet nunmehr völlig auf den Sinngehalt der Worte in seiner uns Heutigen nichts mehr bedeutenden, abgegriffenen Banalität. Vielmehr entwickelte einer der führenden Köpfe der jungen Lyrik, Arnold Schöntal, eine revolutionierende Methode sprachlich-lyrischer Entäusserung [...] Wir bringen nachstehend einige der bedeutendsten lyrischen Versuche dieser Art [...]:

Laz misehm tol

La ! Zmis ehmt olla

$\mathrm{Z}-\mathrm{mis} \mathrm{e}^{\prime} \ldots \mathrm{hm} \ldots \mathrm{Tol} ! \ll$

Polemiken wie diese bezeugen die Abwehr der Neuen Musik durch das Bildungsbürgertum, die den Skandalimpuls in der Nachkriegszeit befeuerte. Als der Eklat allerdings zunehmend zur erwartbaren Ingredienz bei Aufführungen neuer Musik wurde und seine Ereignishaftigkeit verlor, wurde der Skandal zunehmend zum Ritual innerhalb einer segregierten Musikkultur.

\section{Endzeitsonate: Der Skandal als Ritual}

Je öfter das bildungsbürgerliche Publikum den Avantgarde-Veranstaltungen fernblieb, umso seltener kam es zum Eklat. Spezialauditorien und die serielle Autonomieästhetik tilgten nicht nur die öffentliche Aufmerksamkeit und Vielfalt der Neuen Musik, sondern damit auch wichtige Zutaten erfolgreicher Skandalisierungen. Das zunehmende Ausbleiben eklatanter Ereignisse war aber auch Zeichen der Konsolidierung einer neuen Ordnung. Obschon immer wieder kleinere Pfeifkonzerte und Provokationsversuche den klingenden Eklat beschworen, verkam der Skandal in den Worten des Musiksoziologen Christian Kaden zum »Statt-Ritual, Ersatz-Ritual, dort Platz greifend,

\section{Ebd.}

101 Eine Sammlung der Pressestimmen findet sich in SWR: P06167.

102 N.N., in: Backnanger Kreiszeitung (23.10.1957), in: Ebd.

103 Heinz Pringsheim, in: Deutsche Woche (30.10.1957), in: Ebd.

104 Offener Brief von Prof. Dr. med. K. Konrad an den Südwestdeutschen Rundfunk (31.10.1957), in SWR: P06258. 
wo Kult und Ritus als solche bereits ins Abseits verbannt wurden. $\ll^{105}$ Diese ritualisierten Pfiffe nahm Erich Dorflein 1957 in einer Rezension für Melos »als Stichwort für Zeitfragen«:

»Nach der Aufführung der `Structures von Pierre Boulez ertönten einige Pfiffe. Sofort entstand die Atmosphäre für erregte Debatten. Ein Grauhaariger stürzte sogar auf einen Studenten zu, um ihm den Mund zuzuhalten. In einer anderen Ecke des Saales aber ermunterte ein anderer die Jugend, ihrer Opposition freien Lauf zu lassen. Ihm gefiel offenbar die Erregung. [...] Ein anderer sagte: »Wie ich Leute begeistert klatschen sah, die bestimmt nichts von dem Gehörten verstehen, mußte ich eben pfeifen.« Das ist vielleicht überheblich, verrät aber die typisch jugendliche Opposition gegen die Snobs. Den jungen Menschen stört das Arrangierte des Avantgardismus. ${ }^{106}$

Der Skandal wurde zum Ritual, das belegt auch das Foto eines Claquers [Abbildung 7], das der Südkurier 1959 mit der Bildunterschrift abdruckte: $\gg$ Pfeifen ist hier nicht verboten [...]. Als anregen-

\section{Abbildung 7 - »Pfeifen ist hier nicht verboten«: Der Skandal als Ritual}

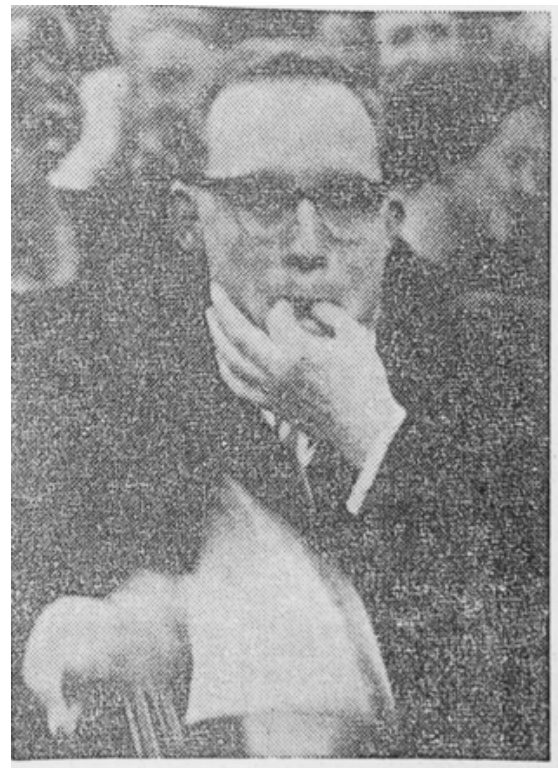

PFEIFEN ist hier nidht verboten... Als anregendes Nebengeräusch für den Beifall ist es sogar jenen Neutönern ein süßer Ton im Ohr, die ein Erstarren des Kampfgeistes von einst befürchten. Fotos: Finke des Nebengeräusch für den Beifall ist es jenen Neutönern ein süßer Ton im Ohr die ein Erstarren des Kampfgeistes von einst befürchten. $«{ }^{107}$ Der Kritiker der Bonner Nachrichten meldete »Nichts Neues in Donaueschingen « und polemisierte gegen die »Sensationslüsternen [...], für die neu gleichbedeutend mit skandalisierend ist «:

»Provinz, der vergeistigte und pseudovergeistigte Musikertyp; fraglos viel Müßiggänger, geistige und seelische Abenteurer, Neugierige [...], Clochardtypen. [...] Pfiffe und Buhrufe [wurden] nachdrücklich laut [...]. Für und Wider aber stand ohne Fanatismus in Front, eher als sogenannte Gaudi [...]. Revolutionen und Revolutiönchen (in Permanenz) hatten von jeher ihr Fleckchen Raum [...]. Und schließlich hat Auflehnung als Grundsatz und Gewohnheit über Jahrzehnte hin etwas erfrischend Konservatives. ${ }^{108}$

105 Kaden: Skandal und Ritual, S. 595.

106 Erich Dorflein: »Pfiffe als Stichwort für Zeitfragen«, in: Melos (24/1957), S. $103 \mathrm{f}$.

107 C. Reindl: »Das Bild der Musiktage in Donaueschingen«, in: Südkurier (20.10.1959).

108 Kurt Scheid: Donaueschinger Konzert am Rande. Alt- und Neo-Orthodoxe, in: Bonner Nachrichten (21.10.1959). 
Berichtete 1960 der Kritiker Antoine Goléa von Besuchern, die »kaltblütig den Skandal vorausplanen ${ }^{109}$, fasste 1964 ein Rezensent von Die Zeit das Ende der Donauschinger Skandalchronik in Worte: »Die leidenschaftliche Reaktion, das Auf-die-Barrikaden-Gehen, das Zeter und Mordio gibt es nicht mehr. « ${ }^{110}$ Tatsächlich ereigneten sich Skandale, wie sie in der Nachkriegszeit an der Tagesordnung waren, nach 1970 kaum noch. Schalten Diktaturen den Skandal mit der pluralistisch-demokratischen Öffentlichkeit aus, hat paradoxerweise das postmoderne Anything goes mit den Tabus auch echte Skandalisierungen beseitigt. Dennoch prägt das kontroverse Kunst-Verständnis die Rezeption der Donaueschinger Musiktage bis in die Gegenwart, wie eine ironische Schrift des italienischen Komponisten Hubert Stuppner mit dem Titel Endzeit-Sonate $^{111}$ aus dem Jahr 1999 beispielhaft verdeutlicht:

»Dieses Jahr einmal nicht nach Donaueschingen, sagte ich mir, als ich vergangenen Herbst [...] von der Eröffnung eines modernen `Kur- und Krankheitszentrums für leidende zeitgenössische Komponisten las. Dieses Sanatorium sei, so der Chronist, am Ende eines unglücklichen musikalischen Jahrhunderts in bezeichnender Weise vis-à-vis zum exzessivsten musikalischen Dionysos-Fest der Neuzeit, eben jenen Donaueschinger Musiktagen [...], die aus der musikalischen Krankheit dieses Jahrhunderts, der Neurose eines kontroversen und schockierenden Kunst-Verständnisses nicht mehr ein und aus wußten und physisch wie musikalisch dem Wahnsinn verfielen. ${ }^{112}$

Im Anschluss thematisierte Stuppner eine neuerliche Endzeitstimmung an der Wende zum dritten Jahrtausend durch die »Verdrängung jedweden Tabus von Schock und Skandal« und beschwor den innovativen Widerstandsgeist der historischen Avantgarden in seiner kulturkritischen Funktion:

»Die vollkommen genormte, von der Staatsräson gelenkte und auf absolute Sicherheit bedachte internationale Gemeinschaft hätte Grund genug, die radikale utopische Zukunftsmusik als Manifest einer vollständig emanzipierten Menschheit zu fürchten. [...] Der moderne Konsum- und Dienstleistungsstaat, in dem schon lange nicht mehr Philosophen und Künstler das Rückgrat der Gesellschaft bilden, sondern die Staatsanwälte des genormten `Common Sense〈, erschrickt vor den Exzessen des sogenannten musikalischen Unnatürlichen, er haßt die Manifestation des Abnormen, die Installation des Absurden, die Gegenlogik des Paradoxen, die Frostschauer, die Schweißausbrüche, die Phantasmagorien. ${ }^{113}$

Abschließend fragte Stuppner, »warum [...] die so gedemütigten Komponisten nicht den Aufstand « proben und wo »die streitbaren Apologeten des Neuen« geblieben seien. Ganz ausgestorben sind sie nicht; bei der heute jungen Komponistengeneration mehren sich die Zeichen eines Aufbruchs - wenn auch meist ohne Tumulte des verstummten

109 Antoine Goléa: »Olivier Messiaens Chronochromie«, in: Melos (29/1962), S. $10 f$.

110 Heinz José Herbort: »Nicht jedes Jahr eine Handvoll Genies und Meisterwerke«, in: Die Zeit (30.10.1964).

111 Hubert Stuppner: Endzeit-Sonate. Frankenstein oder Die Minnesänger des Untergangs. Eine Satire, ein Totentanz, eine Parabel, Regensburg 1999.

112 Ebd., S. 5ff.

113 Ebd., S. $219 \mathrm{ff}$. 
Publikums mit seinen tiefgefrorenen Ritualen. Das prominenteste der aktuellen enfants terribles ist der Konzeptkomponist Johannes Kreidler, der weiß: »Widerstände konstituieren Kunst, denn Kunst muss verdächtig sein. «14 $^{114} 2012$ störte Kreidler das Eröffnungskonzert der Donaueschinger Musiktage im Protest gegen die Fusion der SWROrchester Baden-Baden und Freiburg und knüpfte damit an die lange Skandaltradition des Festivals an. Er trat auf die Bühne, band eine Geige und ein Cello an ihren Saiten zusammen und verkündete:

»Komponieren bedeutet ein Instrument bauen [...]. Aber Institutionen müssen die Mittel zur Verfügung stellen. Wenn sie selbst Hand anlegen - nimmt die Kunst schaden [...]. Dies hier ist kein Kunstwerk - so sieht die Fusion zweier gewachsener Klangkörper aus [...]. Wollen Sie auf diesen Instrumenten spielen? -Sie müssen [...]. Und wo der Damm schon einmal gebrochen ist - können wir ja auch gleich die ARD-Sendeanstalten fusionieren. « ${ }^{115}$

Abbildung 8 - Das »unspielbare Instrument«: Johannes Kreidler protestiert 2012 in Donaueschingen gegen die Fusion der SWR-Klangkörper

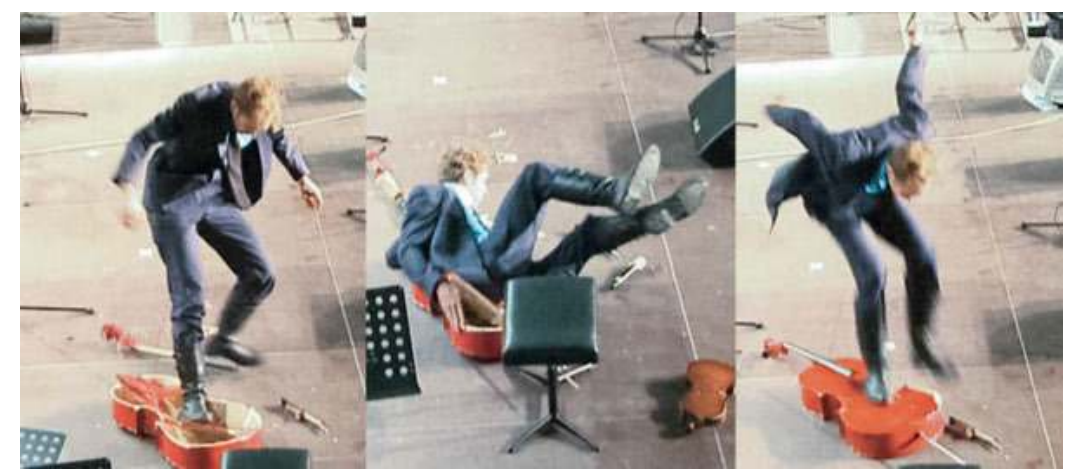

Anschließend zertrümmerte der Komponist das unspielbare Instrument [Abbildung 8], während - begleitet von Buhrufen und Applaus - Flugblätter von den Rängen ins Parkett der Donauhalle segelten. Kreidler weiß, dass er durch seine provokanten Aktionen in der kostbarsten Währung des Medienzeitalters profitiert - Aufmerksamkeit:

»Marketing ist nicht die Intention, aber eine willkommene Begleiterscheinung - für die Sache. Meine Aktionen sind politische Kunst und sollen im Scheinwerferlicht stehen und gezielt medial verbreitet werden. Im Wortsinn der Avantgarde geht es darum, mit einer signifikanten Aktion vorzustoßen und von da aus auch ästhetisch verkrustete Strukturen aufzubrechen. Wir leben in einer Zeit von einiger Dynamik - unvermeidlich sind dann aber auch Kontroversen. Es bewegt sich wieder etwas in der Kunstmusik. Auf diesen Wandel darf man aber als Künstler nicht nur reagieren, sondern muss ihn auch antizipieren. ${ }^{116}$

114 Johannes Kreidler im Gespräch mit der Autorin am 20. Juni 2014.

115 Kreidlers Aktion zur Fusion der SWR-Sinfonieorchester ist einsehbar unter URL: http://www.youtube.com/watch?v=QRMrujtd8CM [Zugriff: 31.8.2017].

116 Johannes Kreidler im Gespräch mit der Autorin am 20.7.2014. 
Mit provokanten Konzepten und zeitgemäßen Themen verortet sich Kreidler in der Gegenwart: Für Fremdarbeit (2009) lagerte er den Produktionsprozess der Werkgenese - wie ein global aufgestellter Konzern - an Komponisten in Indien und China aus und betrieb damit eine Art klingender Kapitalismus- und Globalisierungskritik. Auch mit dieser Aktion traf er einen Nerv:

»Es kam damals ein Feature über Fremdarbeit im Deutschlandradio Kultur. Danach erreichte die Redaktion ein Brief, in dem ein Hörer schrieb: `Ich würde Ihnen empfehlen, dem ,Komponisten“, der sich in Indien und China für 15 Euro zuarbeiten lässt, in meinem Namen eins in die Fresse zu hauen. Solchen sogenannten Kreativen und Selbstdarstellern muss man nicht auch noch ein Podium bieten. $<-$ Mich freut diese Reaktion natürlich, denn sie zeigt: Meine Arbeit bewegt. $\aleph^{117}$

Mit Product Placements rief er 2008 eine Diskussion über Schöpfungshoheit hervor: Für die elektronische Komposition von 33 Sekunden entnahm er aus rund 70.000 Werken kleinste Teile und füllte für jeden eine GEMA-Meldung aus, die er mit einem Lastwagen zur Generaldirektion der Verwertungsgesellschaft transportierte und damit eine öffentliche Diskussion über das geltende deutsche Urheberrecht anfachte. ${ }^{118} 2010$ lieferte sich Kreidler mit dem Komponisten Claus-Steffen Mahnkopf und dem Musikphilosophen Harry Lehmann eine publizistische Kontroverse um die Digitalisierung der Musik, die einen auch ästhetisch grundierten Generationenkonflikt offenlegte. ${ }^{119}$ 2017 folgte mit Earjobs ein weiteres kulturkritisches Stück, in dem er die ökonomischen Begleitumstände der Musikproduktion zum Thema machte: darin bezahlte er sein Publikum fürs Hören von Muzak und Neuer Musik - unter Berücksichtigung des gesetzlichen Mindestlohns. ${ }^{120}$

Sind dies auch avantgardistische Randnotizen in der pluralistischen Musikkultur der Gegenwart, zeigen sie doch: Johannes Kreidlers Konzepte sind kontrovers, weil sie durch aktuelle Themen wie Digitalisierung und Medialität, Kapitalismus- und Institutionenkritik, Globalisierung und Nationalisierung bewegen. Im Gegensatz zum Gros seiner Kollegen beherrscht er die Ökonomie der Aufmerksamkeit und erreicht mit seinen Aktionen eine breite Öffentlichkeit. Er schafft es so nicht nur seine Produkte auf dem Markt zu platzieren, sondern erzeugt auch einen Querstand von Kunst und Leben, wie ihn die historischen Avantgarden provozierten und lässt damit ein stückweit auch deren Abwehr des Affirmativen wiederaufleben: Die provokative und produktive Widerständigkeit der zur Legende gewordenen klingenden Eklats, die nach 1945 neben den Donaueschinger Musiktagen insbesondere bei den Darmstädter Ferienkursen für Neue Musik kultiviert wurden.

117 Ebd. Eine Dokumentation findet sich auf der Homepage des Komponisten, URL: http://www.kreidler-net.de/fremdarbeit.html [Zugriff: 31.8.2017].

118 Die Dokumentation der Aktion findet sich unter URL: http://www.kreidler-net.de/ productplacements.html [Zugriff: 31.8.2017].

119 Siehe hierzu ausführlicher den Abschnitt Kontroversen um die digitale Revolution der Musik im Kapitel Elektronische Eklatanz.

120 Eine Dokumentation der Aktion im Berliner Haus der Kulturen der Welt findet sich unter URL: http://www.kreidler-net.de/werke/earjobs.htm [Zugriff: 31.8.2017]. 


\section{Die DARMSTÄdTER FERIENKURSE ALS AGONALE EREIGNISGESCHICHTE}

»Zur Historie der Ferienkurse gehören auch ihre Skandale. ${ }^{121}-$ Wenn Hermann Danuser den klingenden Eklat als konstitutiv für die Geschichte der Darmstädter Ferienkurse für Neue Musik erklärte, stand dies nach der deutschen Kapitulation kaum zu vermuten. Als der Musikjournalist Wolfgang Steinecke 1946 zum Kulturreferenten ernannt wurde und im Jagdschloss Kranichstein die ersten Ferienkurse initiierte, besaß Darmstadt - anders als Donaueschingen - keinerlei musikavantgardistische Traditionen. Zwar kann die im Jugendstil gehaltene Künstlerkolonie auf der Mathildenhöhe als architektonischer Kristallisationsort der Moderne bezeichnet werden, doch schien 1945 der äußere Zustand gegen jedes kulturelle Programm zu sprechen. Das legt auch eine Beschreibung Erich Kästners nahe, der die Stadt 1946 besuchte:

»Darmstadt existiert im Grunde nicht mehr. Es wurde in einem zwanzig-Minuten-Angriff aus der Welt geschafft. Die Einwohnerzahl sank in dieser maßlosen Drittelstunde von 120 auf 80 tausend Menschen, und an Bewohnbarem blieb keine Hundehütte übrig. Heute sind die Straßen sauber geräumt, >peinlich s sauber, ist man versucht zu denken. Die vernichtete Stadt liegt da wie ein totes Schmuckkästchen. Die Trambahn fährt von einem zum anderen Stadtende wie über einen feierlich geharkten Friedhof.« ${ }^{122}$

Nicht nur sämtliche Konzertsäle waren vernichtet; Darmstadt musste infolge der Zerstörung auch seinen Status als hessische Landeshauptstadt an Wiesbaden abgeben. Allerdings barg eine engagierte Kulturpolitik in dieser Situation auch die Möglichkeit eines Neuanfangs, wie ihn Karlheinz Stockhausen 1953 in Worte fasste: »Die Städte sind radiert - und man kann von Grund auf neu anfangen, ohne Rücksicht auf Ruinen und geschmacklose Überreste. « ${ }^{123} \mathrm{Im}$ Programmheft der ersten Ferienkurse formulierte auch Wolfgang Steinecke ein Manifest des musikalischen Neubeginns:

»[Z]wölf Jahre lang hat eine verbrecherische Kulturpolitik das deutsche Musikleben seiner führenden Persönlichkeiten und seines Zusammenhanges mit der Welt beraubt. Der Niedergang der deutschen Musikkultur, über den man mit Kulturbetrieb und K.d.F.-Opium hinwegzutäuschen suchte, wirkte sich am verhängnisvollsten bei der inzwischen herangewachsenen deutschen $\mathrm{Mu}$ sikergeneration aus. [...] Heute sind die engen Grenzen [...] gefallen. Möglichkeiten freier Entfaltung sind uns wiedergegeben. Aber diese Möglichkeiten können nur ausgeschöpft werden, wenn sie erkannt, wenn sie, zumal von der jungen Generation, freudig bejaht und mit eigener Initiative ergriffen werden. ${ }^{124}$

121 Borio/Danuser: Im Zenit der Moderne, Band 2, S. $374 f$.

122 »Erich Kästner über das kriegszerstörte Darmstadt« (1946), in: Zeitgeschichte in Hessen, URL: http://www.lagis-hessen.de/de/subjects/idrec/sn/edb/id/1845 [Zugriff: 31.8.2017].

123 Karlheinz Stockhausen: Zur Situation des Metiers (1953), in Ders.: Texte zur Musik, Band 1, Köln 1963, S. 45-61, hier S.48.

124 Zitiert nach Rudolf Stephan: »Kranichstein. Vom Anfang und über einige Voraussetzungen«, in Ders. (Hg.): Von Kranichstein zur Gegenwart. 50 Jahre Darmstädter Beiträge zur Neuen Musik, Stuttgart 1996, S. 21-27, hier S. 21. 
Steinecke hatte für die Darmstädter Ferienkurse also schon 1946 eine progressive und internationale junge Komponistengeneration im Blick. Allerdings spiegelte das Programm zunächst die restaurativen Tendenzen der ersten Nachkriegszeit: »Auf die erste Phase der Orientierung der jungen Deutschen«, so rekapitulierte Steinecke 1952, sei eine zweite Phase gefolgt, »in der das Werk Arnold Schönbergs wieder Verbreitung gefunden habe. ${ }^{125}$ Fast unmerklich kam es erst im dritten Schritt zu einer Akzentverschiebung auf die junge Generation. Dies legen auch die Worte nahe, die Herbert Eimert der ersten Ausgabe der programmatischen Zeitschrift Die Reihe voranstellte:

»Eingeschliffene Denkgewohnheiten hatten sich ausgerechnet, es müsse nach dem zweiten Weltkrieg in der Musik etwas Ähnliches geschehen wie nach dem ersten; aber der Aufbruch hat sich nicht wiederholt. Heute haben sich die Jungen [...] von Schönberg und Strawinsky gelöst, nicht geräuschvoll und protestierend, auch nicht in Gruppen und mit programmatischen Bekenntnissen, sondern unbemerkt, vereinzelt, sich allmählich vortastend und endlich doch so etwas wie eine Bewegung auslösend. ${ }^{126}$

Die Neue Musik aus der Feder der jungen Nachkriegsgeneration nahm auch in Darmstadt erst mit dem Beginn der 1950er Jahre richtig Fahrt auf - und zwar nicht mehr stillschweigend, sondern mit einer zunehmend eklatanten Eigendynamik. In diesem Zusammenhang sprach Hermann Danuser im Anschluss an Reinhart Koselleck von einer »agonalen Ereignisgeschichte der Ferienkurse $«{ }^{127}$, die weniger durch Einmaligkeit, als durch eine semantische Schicht im Kreuzungspunkt von Vergangenheit und Zukunft bestimmt sei. ${ }^{128}$

Wenn Musikskandale also in ereignishaften Momentaufnahmen die Geschichte der Internationalen Darmstädter Ferienkurse für Neue Musik schichteten, so unterschieden sich diese in ihrer Struktur von den klingenden Eklats der Vergangenheit: Hatten jene meist aus einem Konflikt zwischen verschiedenen Musikkulturen und Ästhetiken am Kreuzungspunkt von >Tradition versus Innovation« resultiert, zog sich der Musikskandal nach 1945 ins Innere der Avantgardekultur zurück. Mehr noch als für das konzentrierte Uraufführungsfestival in Donaueschingen, galt dies für die als mehrwöchiges Branchentreffen konzipierten Ferienkurse in Darmstadt. Diese wurden zum Treffpunkt einer radikalen jungen Generation von Komponisten, die als >Darmstädter Schule in die Geschichte der Neuen Musik einging und zum Synonym für prononciertes Komponieren schlechthin wurde. Statt auf die Gunst des Publikums zu setzen, reformulierten und verschärften ihre Protagonisten das avantgardistische Fortschrittstheorem zu einem mitunter dogmatisch betriebenen Innovationsimperativ, der von nun an den musischen Agon bestimmte und schließlich in einem >Absolutismus der Moderne` mündete.

125 Zitiert nach Borio/Danuser: Im Zenit der Moderne, Band 1, S. 90.

126 Herbert Eimert: Vorwort, in Ders./Karlheinz Stockhausen (Hg.): Die Reihe, Band 1: Elektronische Musik, Wien/Zürich/London 1955, S. 7.

127 Borio/Danuser: Im Zenit der Moderne, Band 2, S. 374.

128 Ebd., Band 1, S. 213. Die entsprechende Argumentation Reinhart Kosellecks findet sich in Ders.: Vergangene Zukunft, Frankfurt am Main 1988, S. 145. 


\section{Vom Fortschrittsoptimismus zum Innovationsimperativ}

Mit dem Verweis auf die »agonale Ereignisgeschichte« gab Hermann Danuser gleichermaßen eine Charakteristik der Darmstädter Ferienkurse, wie auch eine Methodik für ihre Untersuchung an die Hand. Hatte das altgriechische A $\gamma \omega \dot{v} v$ in seiner Urform den Schauplatz eines Kräftemessens bezeichnet, so galt dies in geradezu sinnfälliger Weise für die Ferienkurse:

»Insgesamt also besaß Darmstadt den Charakter eines Schauplatzes, bei dem der agonale Disput, der Kampf um die musikalische Vorherrschaft, das Ringen um das Preislied sich zutrugen - nicht immer offen, meist eher latent, immer wieder aber explosionsartig aufbrechend. Darmstadt hatte stets seine `Opfer`. Kein Sieger konnte sicher sein, nicht morgen als Verlierer vom Platz zu gehen und durch die nächste oder übernächste Woge im Prozeß der Avantgarde zum Opfer stigmatisiert $\mathrm{zu}$ werden. « $^{129}$

Der Wettlauf um unerhörte Innovationen wurde der jungen Komponistengeneration zur künstlerischen Meisterprüfung. Kritische Distanz des Publikums wurde zum Qualitätsmerkmal und der musikhistorische Revisionsprozess im Konflikt zwischen Traditionsbewahrung und Fortschrittsstreben um ein Vielfaches beschleunigt. In seiner kurzen Schrift zum »Lob des Tadels« exemplifizierte Hermann Danuser seine Gedanken zur Rolle des Skandals in der Musikgeschichte mit Verweis auf die Map of Misreading des amerikanischen Literaturwissenschaftler Harold Bloom und paraphrasierte die »Topographie des Fehllesens « mit Blick auf die eklatante Musikentwicklung nach 1945:

»Statt eines Verstehens früherer Kunstleistungen sei in der Moderne ein missverstehendes VerLesen für einen Autor notwendig, um durch solchen geistigen Vatermord zu eigenständigem künstlerischen Schaffen zu gelangen. ${ }^{130}$

Dieses Prinzip wurde in Darmstadt exzessiv verfolgt: Indem der anfängliche Innovationsoptimismus zunehmend als normativer Imperativ gedeutet wurde, kann die Geschichte der Ferienkurse strukturell als ein rasches Aufeinanderfolgen verschiedener rebellischer Richtungen beschrieben werden. Pointiert ausgedrückt entwickelte sich Darmstadt zur Bastion einer permanenten Revolution, die immer wieder dazu verdammt war, ihre Kinder zu fressen. Das Haltbarkeitsdatum neuer Regeln verkürzte sich exponentiell und eine Entwicklung löste die andere in immer kürzeren Schritten ab. Diese Struktur war begleitet von Polemiken und Kontroversen, Skandalen und Eklats. Insbesondere zwischen 1948 und 1958 ertönte in regelmäßigen Abständen die französische Heroldsformel: »Der König ist tot - lang lebe der König. « ${ }^{131}$

129 Borio/Danuser: Im Zenit der Moderne, Band 2, S. 376.

130 Hermann Danuser: »Lob des Tadels. Der Skandal in der Musikgeschichte«, in: Programmbuch der Internationalen Musikfestwochen Luzern 1995, S. 115-125, hier S. 122.

131 Siehe hierzu Anna Schürmer: »Darmstadt hatte stets seine Opfer, oder: Die Revolution frisst ihre Kinder«, in: Neue Musikzeitung (2/2014), S. 4. Online abrufbar unter URL: http://www.nmz.de/artikel/die-revolution-frisst-ihre-kinder [Zugriff: 31.8.2017]. 


\section{»Strawinsky c’est la misére»}

Theodor W. Adorno erhob 1948 das Innovationsparadigma zur Philosophie der Neuen Musik $^{132}$. Unter den Überschriften »Schönberg und der Fortschritt« sowie »Strawinsky und die Restauration« trug er den mit dem Neoklassizismus liebäugelnden Igor Strawinsky als restaurativ zu Grabe und hob stattdessen den progressiveren Arnold Schönberg auf den Thron. Damit gab Adorno der schwelenden Konkurrenz zwischen einer klassizistisch-akademischen Auffassung der Neuen Musik und einer fortschrittsgläubigen atonalen Avantgarde ein kontroverses Motto. Dies stellte auch Heinz-Klaus Metzger heraus, der bald zum wichtigsten musiktheoretischen Nachfolger Adornos in Darmstadt avancieren sollte. Die Philosophie der Neuen Musik, so Metzger,

»wurde als Pamphlet verkannt, und eben auf die Provokation dieses Mißverständnisses hin war sie strategisch zweifellos berechnet: ein einziger dialektischer Blitz sollte die Finsternis durchfahren und, vielzackig gebrochen, Schönberg beleuchten und Strawinsky erschlagen. « $^{133}$

Dieser dialektische Blitz hielt den Streit über die Ausrichtung der Neuen Musik über mehr als eine Dekade am Köcheln und wurde schon im Erscheinungsjahr von Adornos Musikphilosophie bei den Ferienkursen durchgesetzt. Wenn der Blick in die Programme von 1948 auch einen ästhetisch breiteren Zugang suggeriert, bemerkte Wolfgang Steinecke doch, dass sich die Kursteilnehmer »in einer zunächst einseitigen und heftigen Reaktion Schönberg auf ihr Panier schrieben und Hindemith für reaktionär erklärten. $«{ }^{134}$ Ein Jahr später beklagte ein Rezensent des Fachblattes Melos ein »Übergewicht der Zwölftöner unter den Darmstädter Dozenten«, was zu einer »Tendenz zur Diffamierung von Vertretern der nichtatonalen Moderne $«{ }^{135}$ führe. Dies traf insbesondere Igor Strawinsky, der - wie Hans Ulrich Engelmann in seiner Genesis der Darmstädter Schule bemerkte - von den »elitär gewordenen Sektierern der nunmehr so genannten >Darmstädter Schule 〈 belächelt $«{ }^{136}$ wurde. Als Engelmann 1949 als junger Komponist den Schönberg-Kurs bei René Leibowitz besuchte, hätte dieser unter dem Motto »Strawinsky c'est la misére ${ }^{137}$ gestanden. In diesem Sinne berichtete auch der Spiegel:

»Strawinsky rangiert sehr zuunterst auf dieser Jakobsleiter. Er ist bei ihnen gefürchtet und gemieden wie der leibhaftige Gottseibeiuns, vor dem sie sich bekreuzigen und schleunigst Reißaus nehmen, wo sie seiner Musik ungewollt in den Weg laufen. (138 $^{138}$

132 Theodor W. Adorno: Philosophie der Neuen Musik, Tübingen 1949.

133 Heinz-Klaus Metzger: »Erinnerung nicht nur an die Vorfreude«, in Stefan Müller-Doohm (Hg.): Adorno-Portraits. Erinnerungen von Zeitgenossen, Frankfurt am Main 2007, S. 164174, hier S. 165.

134 Wolfgang Steinecke: »Drei Jahre Kranichstein«, in: Hessische Nachrichten (24.12.1948).

135 Paul Waltner: »Internationale Ferienkurse in der Krise«, in: Melos (16/1949), S. 242-245.

136 Hans Ulrich Engelmann: »Zur Genesis der Darmstädter Schule« (1946), in Rudolph Stephan (Hg.): Von Kranichstein zur Gegenwart. 50 Jahre Darmstädter Ferienkurse, Stuttgart 1996, S. 50-54, hier S. 52.

137 Ebd.

138 N.N.: »Marsch der alten Karbonaden«, in: Der Spiegel (29/1949), S. 32f. 
Spätestens 1950, mit dem Beginn von Theodor W. Adornos Lehrtätigkeit in Darmstadt, waren die Weichen endgültig auf eine atonale Fortschreibung der Musikgeschichte gestellt. In jenem Jahr sprang der Philosoph für den erkrankten Arnold Schönberg ein, dessen musikalisches Melodram Der Überlebende aus Warschau auf dem Programm stand. Nach der Uraufführung 1948 in Alberquerque hatte das Time Magazine vor »grausamen Dissonanzen « gewarnt. ${ }^{139}$ Bei der deutschen Erstaufführung zwei Jahre später in Darmstadt wurden weniger die abstrakten Klänge zum Skandalon, als vielmehr die zeithistorisch problematische Thematik. Dieter Schnebel sang damals als junger Komponist im Chor der Ferienkursteilnehmer und erinnerte sich, dass nur der sensible Gegenstand einen Aufstand im Auditorium verhindert habe. Allerdings hätte die Rezeption von Schönbergs Kriegs-Oratoriums den kontroversen Umgang mit dem nationalsozialistischen Erbe sinnfällig illustriert. ${ }^{140}$ Schon im Vorfeld war es zu einer seltsamen Mischung politischer und ästhetischer Zeit- und Streitfragen gekommen, die der Musikwissenschaftler Friedrich Hommel 1992 rückblickend skizzierte:

»Es gab eine Anfrage in der Stadtverordnetenversammlung, ob die Aufführung nicht zu untersagen wäre. [...] Es wäre doch wohl das beste, wenn man unter Neuanfang verstünde, den ganzen Streit, der zum Krieg und all dem geführt hat in der Nazi-Zeit - aus, Schluß, vergessen, laßt die alten Dinge ruhen! [...] Das weiß man doch, daß die Leute das nicht hören! Nur eine Minorität! - Und im Handumdrehen ist wieder dasselbe: [...] Also die Neigung zu sagen, ach laß - bis zu der Einstellung [...]: Irgendwie hat die Kriegskatastrophe ja eine Klärung gebracht. [...] Schließlich hat es doch zum Staate Israel geführt! Und die sitzen doch heute in Kalifornien und Hollywood oder sonst wo! Das ist der zentrale Gegensatz gewesen. Wir haben doch im eigenen Land noch genug! ${ }^{141}$

Deutlich wird in Friedrich Hommels Erinnerungen die Verschränkung ästhetischer und zeithistorischer Vorbehalte gegen Arnold Schönbergs hochpolitisches Oratorium Der Überlebende aus Warschau. Heinz-Klaus Metzger sang damals gemeinsam mit Dieter Schnebel im Chor der Ferienkurse und erkannte in den Konflikten außerdem die über 1945 hinausgehenden Kontinuitäten der NS-Diktatur, die sich selbst innerhalb der progressiven Avantgardekultur manifestierten:

»Man kann sich heute nicht mehr vorstellen, was das trotzdem für Nazis waren, und was da für Widerstände [...] bestanden. Der Männerchor [...] war objektiv viel zu schwach besetzt, weil sich nicht mehr Kursteilnehmer fanden, die bereit waren, da mitzusingen - und das offen aus politischen Gründen. Da hörte man dann solche Sätze wie [...]: ১Das sollen die Juden selber singen . Das Stück war selbst in diesen Kreisen gegen die deutsche Ehre. [...] Es gab Widerstände im Orchester [...], daß es da nicht einen jüdischen Text begleiten muß, der etwas für Gojim Unzumutbares enthält. « ${ }^{142}$

139 N.N., in: Time Magazin (15. 11.1948).

140 Dieter Schnebel im Gespräch mit der Autorin am 12.8.2012.

141 Bernd Leukert: »Musik aus Trümmern. Darmstadt 1949«, in: MusikTexte (45/1992), S. 20-27, hier S. 24f.

142 Ebd., S. 25. 
1956 gab es ein weiteres Nachspiel dieser Kontroverse, das die Kontinuitäten im deutschen Kulturleben vor und nach 1945 illustriert. Damals bezeichnete der Kritiker Hans Schnoor das Werk als »jenes widerwärtige Stück, das auf jeden anständigen Deutschen wie eine Verhöhnung wirken muss. ${ }^{143}$ Zehn Jahre nach Kriegsende löste Schnoors nationalistisch und antisemitisch versetzte Konzertkritik einen auch medial ausgetragenen Schlagabtausch aus, der die gesellschaftlichen Widersprüche der Nachkriegsdekade paradigmatisch illustriert: Auf einer Tagung der Evangelischen Akademie für Rundfunk und Fernsehen eskalierte der Konflikt, als mehrere Teilnehmer die Diskussion mit Schnoor verweigerten. Daraufhin veröffentlichte der Journalist Walter Dierks in der FAZ einen »Bericht über das Scherbengericht«, der auch im Fachblatt Melos abgedruckt wurde:

»Was Schnoor betreibt, die Verbindung seiner Art von Kritik an Neuer Musik und am gegenwärtigen Musikbetrieb mit einem antisemitischen Grundaffekt ist nicht nur ein nationalsozialistisches Phänomen, sondern es ist eine nationalsozialistische Aktion. « ${ }^{144}$

Der Artikel heizte eine Mediendebatte an, in die sich unter anderem Theodor W. Adorno einschaltete, den Schnoor in mehreren Kritiken als Verursacher der $>$ Frankfurter Vergiftung « des WDR bezeichnete und dabei ausschließlich mit dem im Exil abgelegten jüdischen Namen Wiesengrund apostrophierte. Auf die sich häufenden Vorwürfe, er schreibe Kritiken »mit antisemitischem Unterton und dem Vokabular des NS-Journalismus von ehedem ${ }^{145}{ }^{14}$, konterte Schnoor mit einer Privatklage gegen die $»$ Welle rufmörderischer Aktionen. ${ }^{146}$ Wurde Schönberg in dieser Affäre ${ }^{147}$ zum Symbol der innerdeutschen Nachkriegskonflikte, so neigte sich seine Verehrung in den Kreisen der Musikavantgarde gemäß dem beschleunigten Innovationsparadigma der Darmstädter Ferienkurse schon 1951 wieder ihrem Ende.

\section{»Schoenberg est mort!»}

Als Arnold Schönberg im Juli 1951 starb, manifestierte sich das wachsende Selbstbewusstsein der jungen Generation auch durch symbolischen Vatermord. Nur wenige Wochen nach Schönbergs Tod verkündete der gerade einmal 26jährige Pierre Boulez in einem gezielt platzierten Aufsatz: »Schoenberg est mort! « Der in der Wir-Form verfasste Text war ein pointiert formuliertes Verdikt der jungen Komponisten:

$»$ Paradoxerweise besteht die wesentliche Erfahrung, die sein Werk bietet, darin, daß es verfrüht ist, verfrüht insofern, als es ihm an bewußtem Wagemut fehlt. [...] Wir wollen keine lächerliche Verteufelung betreiben, sondern den einfachsten Sinn für Realität sprechen lassen, wenn wir sagen, daß nach den Entdeckungen der Wiener Schule jeder Komponist unnütz ist, der sich außer-

143 Hans Schnoor, in: Westfalen-Blatt (16.6.1956).

144 Walter Dirks: »Bericht über ein Scherbengericht«, in: Melos (7-8/1956), S. 233f.

145 Fred K. Prieberg: Musik im NS-Staat, Frankfurt am Main 1982, S. 22.

146 Hans Schnoor: Harmonie und Chaos. Musik der Gegenwart, München 1962, S. 235-241, hier S. 240.

147 Minutiös aufgelistet wurde die Affäre in Boll: Nachtprogramm, S. 213-221. 
halb der seriellen Bestrebungen stellt [...]. Hüten wir uns, Schönberg als eine Art Moses anzusehen, der im Angesicht des Gelobten Landes stirbt [...]; es ist an der Zeit, den Fehlschlag zu neutralisieren. [...] Wir haben nicht das geringste Interesse an einem törichten Skandal [...], wenn wir jetzt ohne Zögern sagen: Schönberg ist tot. ${ }^{148}$

Diese Polemik lässt sich mit Pierre Bourdieus konfliktivem Generationenkonzept erklären, demnach es den Jüngeren stets wesentlich um »Diskontinuität, Bruch, Differenz, Revolution ${ }^{149}$ gehe. Dieses erfuhr bei den Ferienkursen seit 1950 nicht nur eine Verschärfung, sondern machte: 〉(Darmstädter) Schuleく. Die junge Komponistengeneration nahm Adornos Fortschrittstheorem wörtlich und machte die Ferienkurse zur Arena eines agonalen Wettkampfs um Innovationen. Der rituelle Opfertod der antiken Agone wurde dabei zum seriell wiederkehrenden symbolischen Vatermord: Waren die neoklassizistisch orientierten Paul Hindemith und Igor Strawinsky mit der ausschließlichen Hinwendung zur Dodekaphonie in Ungnade gefallen, markierte die physische und symbolische Grablegung Schönbergs einen neuerlichen Umbruch durch die Jungen Komponisten, wie ihn Herbert Eimert 1952 in einer gleichnamigen Sendung für den WDR in Worte fasste:

»Kaum hat sich die Zwölftonmusik einige Sympathien verschafft, kaum sind ihre konstruktiven Grundsätze aus den Nebeln der Geheimwissenschaft herausgetreten und tonsetzerisch fassbar geworden [...], kaum hat sich die Situation der Zwölftonmusik ein wenig gefestigt, da treten nun diese jungen Komponisten auf, denen das Non plus ultra der Zwölftonreihentechnik nicht mehr genügt. Wir beginnen zu begreifen, daß dieses vermeintliche Ende der Musik zugleich ein Anfang ist. ${ }^{150}$

Boulez hatte in seinem programmatischen Aufsatz »die Reihe eine logische geschichtliche Konsequenz « ${ }^{151}$ genannt und damit dem angestrebten Paradigmenwechsel ein ästhetisches Motiv gegeben. Der Serialismus war dominiert vom Gedanken einer musique pure: die kompositorische Kontrolle aller klingenden Parameter wie Tonhöhe, Metrik, Dynamik und Klangfarbe sollte Musik von allen Trübungen wie Redundanz und Wiederholungen, Spekulation und Geschmacksfragen befreien. Durch die objektiv-kalkulatorische Ordnung und die integrale Rationalisierung der Musik hoffte man nicht nur dem »Romantico-Klassizismus « zu entgehen, mit dem Pierre Boulez Arnold Schönbergs Dodekaphonie als reaktionär gebrandmarkt hatte. Der Serialismus kann darüber hinaus mit seiner programmatschen Vermeidung hierarchischer Strukturen auch als politische Angelegenheit und originärer Ausdruck der Nachkriegszeit gedeutet werden: Ein unromantischer, intellektuell konstruierter Neuaufbau, der die Negation einer verdächtig gewordenen Vergangenheit und die Dynamik des Wiederaufbaus und eines nach vorne gerichteten Vergessens ästhetisierte. ${ }^{152}$

148 Pierre Boulez: »Schönberg ist tot«, in: Melos (2/1974), S. 62-64, hier S. $63 \mathrm{f}$.

149 Bourdieu: Die Regeln der Kunst, S. 253.

150 Herbert Eimert: »Junge Komponisten 1952«, in: Musikalisches Nachtprogramm des Nordwestdeutschen Rundfunks vom 29.5.1952.

151 Boulez: Schönberg ist tot, S. 62.

152 Die Positionen der seriellen Musik lassen sich nachvollziehen anhand der programmatischen Zeitschrift Die Reihe, die von 1955-1962 herausgegeben wurde. 
Die von Boulez publizistisch eingeleitete Wende zum Serialismus wurde in Darmstadt ab 1952 auch aufführungspraktisch vollzogen: Im sogenannten >Wunderkonzert $<$ kam es mit Pierre Boulez' 2. Klaviersonate [ $\delta-7.2]$, Karlheinz Stockhausens Kreuzspiel [ $\delta$ 8.2] und Luigi Nonos Lorca-Epitaphe [א-9.2] erstmals zu einer gemeinsamen Manifestation der jungen Generation in einem Konzert, das skandaltypisch von Pfiffen und Beifall begleitet wurde. Im Anschluss schrieb Stockhausen an Wolfgang Steinecke, er bewundere dessen Mut bei der Programmgestaltung: »Neben Dr. Eimert sind Sie der einzige Mensch in Deutschland, der die Konsequenz aus den letzten paar Jahrzehnten zieht und mit uns wenigen geht, die man normaler Weise ins Irrenhaus wünscht. « ${ }^{153}$ $\mathrm{Zu}$ einem weiteren Schlüsselereignis wurde am 23. Juli 1953 eine Veranstaltung zum 70. Geburtstag des Schönbergschülers Anton Webern, die es laut Hermann Danuser verdienen würde, »in eine noch zu schreibende Ereignisgeschichte der Neuen Musik einzugehen. ${ }^{154}$ In provozierenden Stellungnahmen traten an jenem Abend die Protagonisten der jungen Generation für den seriellen Fortschritt ein, den sie in Weberns Werk als stilbildend identifizierten. Das vehemente Auftreten der Jungkomponisten provozierte noch in der Nacht ihrer Manifestation einen Eklat, den Stockhausen seinem Kollegen Karel Goeyvaerts schilderte:

»Die Zusammenfassung Deiner Worte, des Boulez-Artikels und meiner Analyse hat einen Bienenschwarm entfacht! Herr Schibler hat noch in der Nacht eine sehr dumme Streitschrift gegen uns geschrieben und an alle verteilt. Es ist bis zum Minister gegangen. Wir wären eine Gruppe, die die Humanität liquidierte etc. Und endlich hat man gesagt, wir wären Kommunisten und wieso man uns so herausstellen könnte. ${ }^{155}$

In seinem »Rundschreiben« kritisierte der Schweizer Komponist Armin Schibler, dass der Serialismus »die Schärfe eines weltanschaulichen Bekenntnisses angenommen« habe und wetterte gegen die » bespielhaft snobistische Gesinnung « und »gewaltsamer Erzwingung von Konzertskandalen und Polemiken«:

»Die junge Komponistengruppe hat diese bedauerliche, unter Schicksalszwang vollzogene und darum tieftragische Entwicklung auf den Kopf gestellt, indem sie daraus eine Vorbereitung der von ihnen erstrebten Elimination des Humanen aus der Kunst herausdeuten möchte [...]. Ihre mögliche Wahrhaftigkeit sehe ich darin, daß sie dem >Kaputt< ehrlich in die Augen sehen, was nach dem Kriegsende historischen Stellenwert gehabt hätte. Aus der Situation des Ruinenschuttes aber eine neue Weltanschauung mörteln zu wollen, die das Versagen europäischen Geistes in den letzten hundert Jahren als zukünftige Dauererscheinung sanktioniert, hieße, bewußte Regression in die anonyme Kollektivität der auf die Betätigung der dringendsten Lebensbedürfnisse abgesunkenen Massengesellschaft der Gegenwart zu fördern. ${ }^{156}$

153 Brief von Karlheinz Stockhausen an Wolfgang Steinecke (21.7.1952), zitiert nach Imke Misch/Markus Bandur: Karlheinz Stockhausen bei den Internationalen Ferienkursen in Darmstadt 1951-1996. Dokumente und Briefe, Kürten 2001, S. 34.

154 Borio/Danuser: Im Zenit der Moderne, Band 1, S. 213.

155 Brief von Karlheinz Stockhausen an Karel Goeyvaerts (23.8.1953), zitiert nach Misch/Bandur: Karlheinz Stockhausen, S. 69.

156 Armin Schibler: Rundschreiben [1953], zitiert nach Borio/Danuser: Im Zenit der Moderne, Band 3, S. 66-68. 
Schibler setzte die serielle Negationsästhetik in Relation zum Zeitgeist und schloss: »[D]ie abstrakte, scheinbar progressive Sozialidee, die der conditio humana nicht mehr Rechnung trägt, schlägt um in bitterste Reaktion gegen Menschlichkeit. « ${ }^{157}$ Damit rekurrierte er zum einen auf das Schlagwort der `Dehumanisierung 〈, das zu einem nachhaltigen Kritikpunkt an der Neuen- und insbesondere der elektronischen Musik wurde. ${ }^{158}$ Wenn sich in seiner Argumentation zum anderen eine Anlehnung an Adornos sozio-ästhetische Musikphilosophie ausmachen lässt, so wurde mit der Ablösung Schönbergs auch die Bedeutung seines Propheten relativiert. Herbert Eimert verwies nicht nur auf den Willen der jungen Generation, »eine musikalische Ordnung zu errichten, die ständig in Frage gestellt wird «, sondern stigmatisierte nun auch den Philosophen des Fortschrittstheorems als restaurativ:

»Ich verrate kein Geheimnis: die Kritik an Webern ist heute im Wesentlichen die in der Schönbergschen Dialektik befangene Kritik Adornos, der die Situation dieser jungen Komponisten als eine \Situation des Kaputt < bezeichnet hat. Richtig ist daran genau so viel, wie vor etwa 30 Jahren an der ganz ähnlich argumentierenden Kritik Hans Pfitzners an der damals jungen Musik richtig gewesen ist. ${ }^{159}$

Brisanz erhielt diese Bemerkung durch die Gleichsetzung Adornos mit dem deutschnationalen Komponisten, der 1917 in seiner Schmähschrift vor Futuristengefahr warnte und die Avantgarde mit faschistischem Vokabular diffamierte. ${ }^{160}$

\section{Das Altern der [Philosophie der] Neue[ste]n Musik}

Mit dem Aufstieg der seriellen >Darmstädter Schule`sah sich Theodor W. Adorno, der einstige Philosoph des musikalischen Progresses, plötzlich mit dem Vorwurf der Restauration konfrontiert. Er reagierte unverzüglich und hielt 1954 seinen berühmten Rundfunkvortrag zum Altern der Neuen Musik ${ }^{161}$, der die Diskussionen nachhaltig befeuerte. Einleitend rekurrierte er auf die >heroischen Zeiten nannte den Skandal als ein konstituierendes Moment der Moderne:

»Als Musik zum ersten Male an alledem gründlich irre ward, wurde sie zur Neuen. Der Schock, den diese Musik in ihren heroischen Zeiten, etwa bei der Wiener Uraufführung der AltenbergLieder von Alban Berg oder der Pariser des `Sacre du printemps $\measuredangle$ von Strawinsky dem Publikum versetzte, ist nicht bloß, wie die gutartige Apologie es möchte, dem Ungewohnten und Befremdenden als solchem zuzuschreiben, sondern einem Aufstörenden und selber Verstörten. ${ }^{162}$

157 Ebd.

158 Siehe hierzu ausführlich das Kapitel Elektronische Eklatanz.

159 Herbert Eimert: »Junge Komponisten bekennen sich zu Anton Webern«, in Borio /Danuser: Im Zenit der Moderne, Band 2, S. 58-65, hier S. 59.

160 Siehe hierzu im Kapitel Referenzen und Chiffren den Abschnitt Futuristengefahr.

161 Theodor W. Adorno: Das Altern der Neuen Musik, in Ders.: Dissonanzen. Musik in der verwalteten Welt, Frankfurt am Main 1980 (Gesammelte Schriften, Band 14), S. 143-167.

162 Ebd., S. 143. 
Adorno erkannte also den eklatanten Fortschritts- und Widerstandsgeist als conditio sine qua non der Avantgarde. Mit dem Altern der Neuen Musik, so führte er weiter aus, sei nichts Anderes gemeint, als dass dieser Impuls in ihr verebbe und kritisierte die »Unverbindlichkeit eines Radikalismus, der nichts mehr kostet« sowie eine »Gefahr des Gefahrlosen «. ${ }^{163}$ Der Serialismus opfere die integrale Einheit des Kunstwerks, indem der Kompositionsvorgang gänzlich in der konstruktivistischen und mechanistischen Generierung des Reihenmaterials aufgehe. Diese Negationsästhetik deutete er im soziologischen Geist der kritischen Theorie: Durch die Austreibung des künstlerischen Subjekts sei die serielle Musik »in hoffnungsloser Vereinzelung [...] als Spiegelung des hilflos Einsamen« befangen. ${ }^{164}$ Damit gerate sie »in Widerspruch zu ihrer Idee« und mutiere zu einer »Höllenmaschine [...], die gnadenlos abläuft, bis das Schicksal sich erfüllt hat und er [der Hörer] aufatmen darf. « ${ }^{165}$ Eine Antwort aus dem seriellen Lager auf diese Grundsatzkritik ließ nicht lange auf sich warten. In seiner berühmten Replik vom Altern der Philosophie der Neuen Musik vollzog Heinz-Klaus Metzger die Wachablösung von der Schönberg-Schule auch publizistisch:

»Es ließe übers Altern der Neuen Musik sich reden, wenn mit dieser, wie es legitim wäre, die Musik der Schönberg-Nachfolge gemeint würde, von welcher die neueste Musik entschiedener sich absetzt als selbst jene von einer tonalen Ära. [...] Man darf wohl [...] von der Philosophie des `Alterns der Neuen Musikı sagen, daß sie ihrer inneren Zusammensetzung nach das Altern eben der Musik, für die ihr Autor einsteht, widerspiegelt. Dies ist gemeint mit dem Altern der Philosophie der Neuen Musik. « ${ }^{166}$

Indem Metzger Adorno »des Vorurteils gegen die heutige Produktion« überführte, übernahm er auch die Rolle des Sprachrohrs der jungen Komponisten, zu deren Theoretisierung und Kanonisierung er nun seinerseits maßgeblich beitrug. Metzger machte klar, dass die soziologische Perspektive für die Beurteilung der Musik aus der zweiten Hälfte des 20. Jahrhunderts nicht ausreichen könne. Noch vor dem Erscheinen von Adornos Negativer Dialektik ${ }^{167}$ proklamierte er das Ideal einer >Musica negativaく, in der es weniger darauf ankomme was geschaffen, als darauf was abgeschafft werde. Ernst Krenek, einer der als veraltet abqualifizierten Komponisten, sprang daraufhin Adorno gegen die »avantgardistischen Snobs« bei:

»Das Bewußtsein, daß wir in einer Welt beständigen Wechsels leben, steigert sich zu einer Art Besessenheit, die in den Schrittmachern der Moderne [...] die heillose Angst erzeugt, daß, wenn sie nicht erbarmungslos die Arterienverkalkung des Gestrigen anprangern, sie hinter dem heutigen Schwung des sausenden Webstuhls der Zeit zurückbleiben könnten. ${ }^{168}$

\section{Ebd.}

164 Ebd., S. 159.

165 Ebd., S. 152.

166 Heinz-Klaus Metzger: »Das Altern der Philosophie der Neuen Musik«, in Herbert Eimert/Karlheinz Stockhausen (Hg.): Die Reihe, Band 4: Junge Komponisten, Wien 1958, S. 64-80, hier S. 78.

167 Theodor W. Adorno: Negative Dialektik, Frankfurt am Main 1966.

168 Ernst Krenek: »Vom Altern und Veralten der Musik«, in Ders.: Zur Sprache gebracht. Essays über Musik, München 1958, S. 371-378, hier S. 317. 
Mit diesem Bild beschrieb Krenek »den kinetischen Charakter unserer Zivilisation « und bezeichnete damit gleichermaßen den dogmatischen Gestus, der bewirke, dass »jeder ihrer Phasen ein starr in sich abgeschlossenes Ausdrucks-Modell zugeordnet sei, das beim Eintritt der nächsten Phase sinnlos wird. ${ }^{169}$ Wenn der Komponist damit den ästhetischen Absolutismus der seriellen Jungkomponisten anprangerte, radikalisierte und aktualisierte Metzger mit seiner theoretischen Replik letztlich lediglich das von Theodor W. Adorno entworfene Fortschrittstheorem. Auch deshalb ist es bezeichnend, dass er wenig später vom Adorno-Verächter zu einem Verfechter mutierte. 1962 modifizierte und steigerte Metzger Adornos für die Kritik am Serialismus zentralen Aufsatz zum Altern der jüngsten Musik ${ }^{170}$ und machte den Philosophen zudem zum Widmungsträger. Auch unter dem Eindruck der aleatorischen und anarchischen Experimente John Cages, der 1958 in Darmstadt seinen europäischen Durchbruch erlebte ${ }^{171}$, erklärte Metzger das Ende der seriellen Phase und damit auch das >Altern « seiner nun etablierten Protagonisten, der >seriellen Troika< Pierre Boulez, Karlheinz Stockhausen und Luigi Nono.

Die Kontroverse zwischen Theodor W. Adorno und Heinz-Klaus Metzger um Das Altern der [Philosophie der] Neuen [jüngsten] Musik ${ }^{172}$ spiegelt mehr als nur das Spannungsverhältnis zwischen zwei Generationen: Sie ist Ausweis für die ungeheure Dynamik der Neuen Musik nach 1945 und die Re-Formulierung ihres anfänglichen Fortschrittsoptimismus zu einem Innovationsimperativ als einem charakteristischen Signum der musikalischen Moderne. Bereits 1954 hatte Adorno unter dem Eindruck des dogmatischen Gebarens der jungen Serialisten der 〉Darmstädter Schule $<$ und unter Relativierung seines eigenen Fortschrittstheorems gewarnt:

»Der Begriff des Fortschritts verliert sein Recht, wo Komponieren zur Bastelei, wo das Subjekt, dessen Freiheit die Bedingung avancierter Kunst ist, ausgetrieben wird; wo eine gewalttätige und äußerliche Totalität, gar nicht so unähnlich den politischen totalitären Systemen, die Macht ergreift. ${ }^{173}$

Adornos Warnung zielte auf den sich verschärfenden agonalen Wettstreit um künstlerische Vormachtstellung und die ästhetische Deutungshoheit innerhalb der Neuen $\mathrm{Mu}$ sikkultur. Wenn auch das Bild von Darmstadt als autoritär regiertem Elfenbeinturm etwas »klischee- wenn nicht gar zwanghaftes $«{ }^{174}$ hat, können die Ferienkurse von totalitären Komponenten doch nicht freigesprochen werden, die Anschlüsse an den postmodernen Diskurs zum >Absolutismus der Moderne` nahelegen.

169 Ebd.

170 Heinz-Klaus Metzger: »Das Altern der jüngsten Musik« (1962), in Ders.: Musik wozu, Frankfurt am Main 1980, S. 113-128.

171 Siehe hierzu ausführlich den Abschnitt John Cage und die tranatlantische Neuvermessung der klingenden Welt im Kapitel Transkulturelle Transfers.

172 Siehe weiterführend auch Wulf Konold: »Adorno - Metzger. Überblick zu einer Kontroverse«, in Heinz-Klaus Jungheinrich (Hg.): Nicht versöhnt. Musikästhetik nach Adorno, Kassel 1987.

173 Adorno: Das Altern der Neuen Musik, S. 161.

174 Borio/Danuser: Im Zenit der Moderne, Band 2, S. 13. 


\section{Der Absolutismus der Moderne}

Führende postmoderne Theoretiker erkannten in der Moderne ein totalitäres Prinzip und führten dieses auf das gesteigerte Innovationsstreben zurück. Dazu gehört mit Jean-François Lyotard ein ausgewiesener Musik-Denker, der den Niedergang »universalistischer Diskurse [...] der Moderne: der Erzählungen [récits] vom Fortschritt « ${ }^{175}$ verkündete und das von einem normativen Fortschrittsgedanken aufgeladene Projekt der Moderne für gescheitert erklärte. ${ }^{176}$ Die konstitutive Vorreiterfunktion der Avantgarde bezeichnete er als automatisiert: diese bescheinige der Moderne das Vorherrschen eines totalitären Prinzips, das auch auf gesellschaftlicher Ebene Züge von Despotismus in sich trage. ${ }^{177}$ Noch deutlicher brachte diesen Gedanken Wolfgang Welsch in Unsere postmoderne Moderne ${ }^{178}$ zum Ausdruck. In der habituellen Vorreiterfunktion der Avantgardisten erkannte er ein Topos der Aufklärung, deren rigider Rationalismus in Deutschland eine »terminologische Ausdrücklichkeit« entwickelt habe. Dabei sei das »progressive Moment [...] in den Rang einer absoluten Verheißung auf[gerückt] und wurde mit Erlöserfunktionen betraut. $«{ }^{179}$ In diesem Umschlag emanzipatorischer Bemühungen in diktatorische Realitäten erkannte Welsch die moderne Dialektik von »Traditionsbruch und Innovationsschritt« sowie die restriktive Kehrseite des Fortschritts - den »Absolutismus der Moderne«:

»Es ist evident, daß die ästhetische Moderne des 20. Jahrhunderts insgesamt und in jeder ihrer Gattungen einen eklatanten Bruch mit der Tradition vollzogen hat. Sie hat sich je durch einen radikalen Innovationsschritt konstituiert. [...] Tradition stand insgesamt nicht auf dem Prüfstand, sondern am Schafott. [...] Nun hat allerdings genau diese - nicht moderate, sondern radikale und unerbittliche - Negation von Tradition [...] diese andererseits mit einem schweren Folgeproblem belastet. Je radikaler die Abstoßung allem Vorgegebenen ist, um so ausschließlicher und verbindlicher muß der neue, durch den radikalen Innovationsschritt gesetzte Boden werden. Indem man alle Brücken zur Tradition abbricht und alle Alternativen zur Moderne negiert, wird diese Moderne selbst tendenziell absolut. Man befreit sich zwar vom Zwang traditioneller Vorgegebenheiten, tauscht dafür aber einen neuen Zwang ein: den der Ausschließlichkeit des jetzt geltenden Bodens. [...] Das [...] Paradigma wurde auf Jahrzehnte hinaus verbindlich, und seine Vertreter verstanden sich sehr erfolgreich darauf, Abweichler zu diskriminieren und wirkliche Innovationen auszuschließen. ${ }^{180}$

Wenn Welsch seine Überlegungen auch mit Blick auf die funktionalistische Architektur der Nachkriegszeit anstellte, so bietet seine Theorie doch Anschlüsse an den musischen Agon, wie er bei den Darmstädter Ferienkursen bestritten wurde und der den Absolutismus der musikalischen Moderne exemplarisch illustriert.

175 Jean-François Lyotard: Der Widerstreit, München 1989, S. 12.

176 Jean-François Lyotard: Das postmoderne Wissen, Wien 2012.

177 Siehe weiterführend Susanne Kogler: Adorno versus Lyotard. Moderne und postmoderne Ästhetik, Freiburg 2014; Hans-Joachim Heßler: Philosophie der postmodernen Musik: Jean-François Lyotard, Duisburg 2001.

178 Wolfgang Welsch: Unsere postmoderne Moderne, Berlin 2002.

179 Ebd., S. 88.

180 Ebd., S. $92 \mathrm{ff}$. 


\section{»Darmstadt hatte stets seine Opfer»}

Die absolutistische Kehrseite des Fortschrittsgedankens, der bei den Serialisten der Nachkriegsavantgarde in einem Imperativ mündete, bietet Muster für die Erklärung der dogmatischen Tendenzen innerhalb der >Darmstädter Schule $<$ im agonalen Wettstreit um Innovationen: Indem sich die Exegeten vom Zwang traditioneller Gegebenheiten befreiten, wurde die Ausschließlichkeit des jetzt geltenden Bodens zu einem neuen Zwang. Aus diesem permanenten Kampf um ästhetische Vorherrschaft folgerte Hermann Danuser:

»Darmstadt hatte stets seine Opfer. Kein Sieger konnte sicher sein, nicht morgen als Verlierer vom Platz zu gehen, durch die nächste oder übernächste Woge im Prozeß der Avantgarde zum Opfer stigmatisiert zu werden. ${ }^{181}$

Mit dem Übergang in die serielle Phase der Neuen Musik wurden Vertreter nicht-atonaler Richtungen zunehmend polemisch diskriminiert. Als etwa Hermann Scherchen 1954 Arnold Schönbergs Orchestertranskription von Johann Sebastian Bachs Präludium und Fuge BWV 552 dirigierte, ertönte ein schriller Pfiff, der zur Unterbrechung der Aufführung führte. Die Störung wurde Ernst Krenek zufolge von Luigi Nono verursacht, der »als Repräsentant des radikalen Flügels der damaligen Avantgarde [...] seine Verachtung für solch altmodisches Zeug zum Ausdruck brachte. « ${ }^{182}$ Adorno schrieb daraufhin an den Geiger Rudolf Kolisch: »Du wirst bemerken, daß die Opposition in Kranichstein weniger von den reaktionären, als von den Zwölf-Töne-Wüterichen im Stile von Boulez ausgeht. $«{ }^{183}$ Der Skandal war also ins Innere der Avantgarde gewandert.

Die Verachtung der Serialisten traf nicht nur ältere Komponisten, sondern auch Altersgenossen. Zum prominentesten Opfer wurde Hans Werner Henze, der nicht gänzlich auf harmonische Anklänge an die Tradition verzichten wollte. Henze war, gerade einmal 20jährig, bereits 1946 auf Vermittlung seines Lehrers Wolfgang Fortner zu den Ferienkursen nach Darmstadt gekommen. Gemäß der allgemeinen Entwicklung tastete er sich über neoklassizistische Stücke im Stile der Hindemith-Rezeption zur Zwölftontechnik vor und trat zunächst als Wortführer seiner Generation in Erscheinung. Doch anders als seine Altersgenossen Boulez, Stockhausen und Nono, sah er die Entwicklung einer aktuellen Musiksprache nicht an einen Bruch, sondern eine sorgsame Fortentwicklung der Traditionen gebunden. Obwohl sich Henze selbst in der Rolle des fortschrittlichen Provokateurs gefiel, gehörte er mit dem seriellen Paradigmenwechsel und der Profilierung seiner herausragenden Repräsentanten plötzlich zum alten Eisen. Ein Schlüsselerlebnis wurde 1950, im Jahr der Schönberg-Renaissance, die Aufführung seiner Zweiten Sinfonie, die Dieter Schnebel als Zeuge und als »tödliche Kränkung« für Henze erlebte:

181 Borio/Danuser: Im Zenit der Moderne, Band 2, S. 376.

182 Brief von Ernst Krenek an Hans Moldenhauer, zitiert nach Hans und Rosaleen Moldenhauer: Anton Webern. Chronik seines Lebens und Werkes, Zürich 1980, S. 620.

183 Zitiert nach Rolf Tiedemann: »Nur ein Gast in der Tafelrunde. Theodor W. Adorno: kritisch und kritisiert«, in: Stephan: Von Kranichstein zur Gegenwart, S. 149-155, hier S. 151. 
»Bei der zweiten Sinfonie gibt es am Schluss den prächtig instrumentierten Choral Wie prächtig leuchtet der Morgenstern - und er ist daraufhin ausgepfiffen worden. Danach ist Henze nie mehr nach Darmstadt und ist ausgewandert nach Italien. ${ }^{184}$

Als Hans Werner Henze Johann Sebastian Bach zitierte, unterschrieb er symbolisch die Scheidung von seinen der seriellen Negationsästhetik verpflichteten Altersgenossen. Zwar wird seine Auswanderung »in erster Linie mit seinem Faschismustrauma sowie sozialen Repressionen, zumal in Zusammenhang mit seiner Homosexualität, begründet ${ }^{185}$; doch muss sie auch mit dem Verlust seiner repräsentativen Funktion innerhalb der >Darmstädter Schule< gesehen werden. Diese entwickelte sich für Henze zum Inbegriff der musikpolitisch gegen ihn gerichteten Tendenzen - darauf deuten auch seine teils von bitterer Polemik durchzogenen Erinnerungen hin: »In Italien«, so erklärte er, »ruhen keine skandaltrunkenen Augen auf mir. Hier lebend habe ich keine Veranlassung, mich an dem Wettstreit der Künstler zu beteiligen. « ${ }^{186}$ Weiter wetterte er gegen $»$ Schmalspur-Diaghilews [die] erwachsene Autoren mahnen, mehr dissonant zu schreiben oder weniger, Beschlüsse verkünden darüber, was in ist und was out, wissen, was man heute noch schreiben kann. $«{ }^{187}$ Besondere Aussagekraft besitzen schließlich folgende Zeilen:

»Abgesondert wie immer schon, glaubte ich damals, in der Allianz mit gleichaltrigen Komponisten weiterzukommen [...] Im Allgemeinen existierte damals Solidarität zwischen den jungen Autoren, man lernte voneinander [...]. Dann bildeten sich kleine Gruppen, die einander befehdeten, Intoleranz machte sich breit, Positionen wurden bezogen und verteidigt [...]; das geht bis zum offenen Kampf, geführt unter Mitwirkung von gruppeneigenen Presse-Ideologen, unter rücksichtsloser Benutzung von Schlüsselpositionen, Einflusssphären, mit der Strategie von Wirtschaftskapitänen. ${ }^{188}$

In diesem Zitat offenbart sich nicht nur die Paradoxie des Absolutismus der musikalischen Moderne: War die serielle Negationsästhetik der `Darmstädter Schuleく einerseits als Reaktion auf die faschistische Instrumentalisierung der Künste zu verstehen, pflegten ihre Vertreter doch zugleich selbst einen totalitären Führungsstil. Entstand die Nachkriegsavantgarde außerdem in expliziter Ablehnung der Kulturindustrie, war sie zugleich ihr negatives Abbild. Darüber hinaus finden sich in dem Zitat Henzes auch Hinweise auf seine Politisierung, die im Schlüsseljahr 1968 mit dem Schiffbruch seines >oratorio volgare e militare ‘ Das Floß der Medusa in einem der größten Skandale der modernen Musikgeschichte mündete, der den Querstand von Kunst und Politik in den 1960er Jahren exemplarisch illustriert. ${ }^{189}$

184 Dieter Schnebel im Gespräch mit der Autorin am 4.8.2012.

185 Borio/Danuser: Im Zenit der Moderne, Band 2, S. 17.

186 Hans Werner Henze: »Die Bundesrepublik Deutschland und die Musik« (1967/68), in Ders.: Schriften und Gespräche 1955-1979, Berlin 1981, S. 115-122, hier S. 120.

187 Ebd.

188 Ebd.

189 Siehe hierzu das Kapitel Querstand von Kunst und Politik und besonders den Abschnitt Der Schiffbruch von Hans Werner Henzes >Floß der Medusa< (1968). 
Die absolutistische Kehrseite des Fortschrittsgedankens bekam auch Bernd Alois Zimmermann (1918-1970) zu spüren, der trotz zahlreicher Aufführungen und Würdigungen als Komponist zeitlebens isoliert blieb. Zum Schlüsselerlebnis wurde auch ihm das sogenannte $>$ Wunderkonzert $<1952$, als seine Exerzitien neben den radikalen seriellen Arbeiten von Pierre Boulez, Karlheinz Stockhausen und Luigi Nono erklangen [ $\boldsymbol{\delta}$ 7.2/8.2/9.2]. Klaus Ebbeke vermutete, dass die »Darmstädter Uraufführung für Zimmermann einen veritablen Schock bedeutet haben muss. [...] Plötzlich sah sich Zimmermann im Lager der Konservativen, im Lager der Väter. ${ }^{190}$ Unter dem Eindruck dieser Erfahrung entstanden 1953 seine Unzeitgemäße Betrachtungen zur Musik der jungen Generation, in denen Zimmermann die »Anwendung von Mitteln um ihrer selbst willen « kritisierte: »Man kann beispielsweise hören, daß dieser oder jener Komponist Wert auf die Feststellung legt, daß er >echte Zwölftonmusik schreibe. « ${ }^{191}$

Auch im Fall von Ernst Alois Zimmermann erfolgte die Isolierung von der >Darmstädter Schule` durch seine Weigerung, deren streng serielle Kompositionsästhetik zu bedienen. Dies lag nicht nur an seinem Alter zwischen den Generationen Zimmermann war rund zehn Jahre älter als Boulez, Stockhausen und Nono - und seinem partiellen Festhalten an Harmonie und Tonalität, sondern auch an seinem Wohnort Köln. Die Domstadt war fest in serieller Hand, repräsentiert durch den progressiven Westdeutschen Rundfunk mit seiner Gallionsfigur Karlheinz Stockhausen und dem Studio für elektronische Musik. Dieses individuelle Spannungsfeld sprengte den Rahmen einer persönlichen Auseinandersetzung und spiegelte nach Michael Custodis Die soziale Isolation der Neuen Musik:

»Das allgemeine Musikleben wird [...] mit großem Interesse verfolgt und von einer spezialisierten Tages- und Sensationspresse begleitet, gespeist und beeinflusst, die von der Publikation interner Fehden, Allianzen und Skandale lebt. Durch ihre begrenzte soziale Ausdehnung fehlen der neuen Musik aber diese verästelten musikindustriell tief durchdrungenen Mechanismen und Instrumente. Das Beispiel dieses biographisch relevanten Konflikts [...] zeigt, wie sehr die gesellschaftliche Randständigkeit der neuen Musik die Abgrenzung solcher Auseinandersetzungen in äußere und innere Kreise verstärkte, so dass Außenstehende, die keinen Anteil an diesen Informationsströmen haben, kaum die vielen Nuancen und stillen Zeichen in der Interaktion der Szene deuten oder gar die zugrundeliegenden Ursachen und Hintergründe rekonstruieren können. « ${ }^{192}$

Custodis beschrieb am Beispiel Bernd Alois Zimmermanns also die fehlende Verankerung der Avantgarde im Bewusstsein der breiten Öffentlichkeit, die vice versa durch den ungleich größeren kommerziellen Erfolg Zimmermanns und auch Hans Werner Henzes im allgemeinen Musikleben veranschaulicht wird. Seine Überlegungen eröffnen darüber hinaus Anschlüsse an den in Darmstadt vollzogenen Wandel des Skandaltypus: Statt im Konflikt zwischen verschiedenen Musikkulturen zu eskalieren, zog sich der klingende éclat ins Innere der Avantgardekreise zurück.

190 Klaus Ebbeke (Hg.): Bernd Alois Zimmermann. Dokumente zu Leben und Werk, Berlin 1989, S. 42.

191 Bernd Alois Zimmermann: »Unzeitgemäßen Betrachtungen zur Musik der jungen Generation«, in: Melos (11/1952), S. 305-307.

192 Custodis: Soziale Isolation, S. 99f. 


\section{Skandal im Elfenbeinturm}

Bei der >Darmstädter Schule` ging die zweite und ursprüngliche Wortbedeutung von Agon, die einer öffentlichen Versammlung, verloren; stattdessen wurde das Wettkampfprinzip übersteigert. Dies belegt etwa eine Anekdote von den Ferienkursen des Jahres 1955. Nachdem der Pianist Marcel Mercenier Karlheinz Stockhausens Klavierstücke VI-VIII hatte abbrechen müssen, schilderte der Komponist die Ereignisse in einem Brief an seinen Kollegen Karel Goeyvaerts. Eine Grille hatte das Publikum durch Zirpen »bei den vielen und manchmal ganz langen Pausen« erheitert. Davon animiert eskalierten nach dem zweiten Satz im Auditorium die Affekte:

»Schreien, Lachen, Pfiffe, jeder fff-Ton mit einer Lachsalve beantwortet, und dann das immer lauter werdende Sprechen im Hintergrund des Saales, viele geräuschhafte Laute [...]. Boulez schrie einmal laut: silence s'il vous plait! Und noch ein paar grobe Schimpfworte [...]. Aber das alles half nichts: eine Atmosphäre, in der man deutlich spürt, daß Unheil auf einen zukommt. Als es zu laut wurde [...], sprang ich auf [...] klappte die Noten zusammen und ging gemütlich aber festen Schrittes aus dem Saal [...]. Hinterher Gepfeife, Geschreie etc. $\aleph^{193}$

Der Mitschnitt der Aufnahme ${ }^{194}$ belegt Stockhausens Aussage, die neben der Schilderung der eskalierenden Affekte auch eine Innenschau auf die Unabhängigkeit der Komponisten von ihrem Publikum eröffnet: »Ein paar Snobisten sind mit uns. Man kann die an einer Hand aufzählen, die wirklich verstehen, was man will. Machen wir uns darauf gefasst, noch lange lange Geduld zu haben « ${ }^{195}$. Trotz oder wegen ihrer Skandale und der absolutistischen Allüren übernahmen die Serialisten in Darmstadt das Steuer. Angesichts ihres dogmatischen Führungsstils im Zeichen des Fortschrittsparadigmas klagte Ernst Krenek 1956 in einem Brief an Wolfgang Steinecke:

»Es wird eine gewisse rein äußerliche Radikalisierung der >neuen〈 Musik begünstigt, indem besonders die Konzerte der jungen Generation zu rein internen Angelegenheiten werden, bei welchen die jungen Herrschaften instinktiv das irgendwie Sensationelle bejubeln, während sie das `Neue des vorigen Jahres schon als `traditionell ablehnen, ohne sich über eine solidere Wertsetzung recht klar zu werden. ${ }^{196}$

Krenek beschrieb damit nicht nur die radikal beschleunigte Innovationsdynamik der Darmstädter Ferienkurse, sondern illustrierte auch den Umstand, dass nicht nur die Neue Musik selbst, sondern auch ihre Kontroversen zu rein internen Angelegenheiten wurden.

193 Brief von Karlheinz Stockhausen an Karel Goeyvaerts (15.06.1955), zitiert nach Misch/Bandur: Karlheinz Stockhausen bei den Internationalen Ferienkursen, S. 112.

194 Karlheinz Stockhausen: Klavierstücke V-X (1955), in: Schallarchiv des Internationalen Musikinstituts Darmstadt (IMD): B006367838 / DVD 6b

195 Ebd.

196 Brief von Ernst Krenek an Wolfgang Steinecke (20.8.1956), zitiert nach Claudia Maurer Zencka: Und dann ins Eck gestellt. Ernst Krenek als vermittlungswillige (und geschmähte) Vaterfigur, in Stephan, Von Kranichstein zur Gegenwart, S. 157-163, hier S. 160. 
Diesen Wandel der Widerstände gegen die Neue Musik diskutierte Karlheinz Stockhausen 1960 in einer Radiodebatte im WDR mit Theodor W. Adorno, der einen »Mangel an affektiver Besetzung« diagnostizierte:

»Heute ist es ja so, dass sich die Leute gar nicht mehr aufregen über die moderne Musik, dass sie sie nicht schroff ablehnen [...]. Sondern es wird [...] betrachtet als eine Spezialität für Spezialisten zwischen verschiedenen Kulturgütern, die einen selber nichts rechtes angeht [...]. Und dieser Mangel an affektiver Besetzung, dieser Mangel an Leidenschaft [...] der ist die Form, unter der die Ablehnung heute geschieht [...]. Diese Gelassenheit und Neutralität ist eigentlich nur die Maske, die sich der Widerstand anlegt, während dahinter doch eine Feindseligkeit sich versteckt. $\ll^{197}$

Die teils selbst gewählte Isolation einer Kunst aus dem Elfenbeinturm haftete der Neuen Musik von nun an als Stigma an. Den Wandel der avantgardistischen Rezeptions- und Skandaltypologie kommentierte auch Die Welt 1957 wie folgt:

»Die Extremisten haben die Überhand gewonnen, und die Avantgarde ist so weit vorgeprescht, daß sie die Verbindung mit dem Gros zu verlieren droht und Gefahr läuft, abgeschnitten zu werden. Ja, es fehlt nicht an Draufgängern, die bewußt die Brücken hinter sich abbrechen und sich in ihrer Isolierung häuslich einrichten wollen - gleichsam als begänne mit ihnen nicht ein neues musikalisches Zeitalter, sondern die Musik überhaupt. ${ }^{198}$

Die breite Öffentlichkeit wandte sich von der Neuen Musik ab und nahm von ihren ästhetischen Richtungskämpfen kaum mehr Notiz. Zum öffentlichen Skandal wurden allenthalben außermusikalische Ärgernisse, wie etwa 1960 die Kantata Opus 34 von Giselher Klebe nach vier Gedichten von Hans Magnus Enzenzberger. ${ }^{199}$ In kirchlichen Kreisen mokierte man sich über diese »Kunst des Ekels - oder Ekel der Kunst«: Es ginge weniger um eine Musik, »die für die meisten nicht einmal Tongedudel« sei, sondern vielmehr um »diese physischen Ekel erregenden Verse mit ihrer ordinären Diktion«, gegen die man »flammend Protest als Christen, als Deutsche« erhebe. ${ }^{200}$ Wolfgang Steinecke vermutete hinter »diesen Polemiken in den meisten Fällen zugleich einen Generalangriff auf die Internationalen Ferienkurse und die Neue Musik überhaupt. « ${ }^{201}$ Die kollektive Ablehnung führte besagter Artikel in Die Welt nicht zuletzt auf die selbstreferenzielle Skandaldynamik der Darmstädter Avantgarde zurück:

197 Das Gespräch wurde publiziert bei Karlheinz Stockhausen: »Der Widerstand gegen die Neue Musik. Diskussion mit Theodor W. Adorno«, in: Texte zur Musik, Band 6, Köln 1989, S. 458-483. Die Tonbandaufzeichnung ist zudem online abrufbar unter URL: http://ubumexico.centro.org.mx/sound/adorno_theodor/radio/Adorno-Theodor_Radio_ Stockhausen-Karlheinz.mp3 [Zugriff: 31.8.2017].

198 Heinz Joachim, in: Die Welt (29.7.1957).

199 Bei den vier Gedichten Enzensberger handelte es sich um Utopia, Geburtsanzeige, Prozession, Verteidigung der Wölfe.

200 Peter Heinemann: »Kunst des Ekels - oder Ekel der Kunst«, in: St. Thomasbote (September 1960), IMD: A100108-201242-12.

201 Siehe hier die Signaturen im Archiv des IMD: A100108-201242; IMD-A100108-201243. 
»Es gehört zu diesem Bild, daß Sprecher des Darmstädter Kreises mehr oder minder unverblümt die ganze musikalische Entwicklung seit Bach als Irrweg bezeichnen [...]. Es war Prof. Theodor W. Adorno vorbehalten, die These aufzustellen, daß eine Musik, die keine Schockwirkungen auslöse, nicht als wesensvolle »neue« Musik gelten könne [...]. Vieles [...] nahm er freilich zurück durch die Warnung vor der Gefahr permanenter Infantilität [...]. Diese Warnung richtete sich unüberhörbar an den »linken Flügel« der Avantgardisten, wo man es offenbar darauf anlegt, die Schockwirkung in Permanenz zu erklären. ${ }^{202}$

Auch Karlheinz Stockhausen nahm in der Radiodebatte mit Adorno 1960 Bezug auf das »Argument, dass es Zeit wird, mit der permanenten Revolution Schluss zu machen.« Man wolle sich nicht explizit vom großen Hörerkreis abwenden, denn »damit würden wir den Prozess der Spezialisierung selber unterschreiben.« Allerdings habe man kein Recht dazu, Menschen dazu zu bringen, sich für etwas zu interessieren: »Das wären diktatoriale Gelüste, die uns gar nicht anstünden. ${ }^{203}$ Der Musikwissenschaftler Ulrich Dibelius erkannte im hermetisch betriebenen autonomieästhetischen Innovationsparadigma der Darmstädter Schule zugleich konservative Momente:

»Jede Neuerung enthält einen Doppelaspekt: Sie muss sich vom bisher Existenten erkennbar unterscheiden, und dies bedeutet zugleich, daß sie den herausgehobenen Rang der Novität nur erlangen kann, wenn das schon Gewohnte, Alte seinen Entwicklungsstand beibehält, indirekt stützt sie es also auch, ist progressiv und konservativ im selben Moment. ${ }^{204}$

Indem man Schockwirkung in Permanenz erzeugte, wurde das Erregungspotential ritualisiert. Das von Adorno prononcierte >Aufstörende und selber Verstörte ließ die Neue Musik nicht nur altern; isoliert von der Öffentlichkeit verlor sie auch ihre gesellschaftliche Wirkung. ${ }^{205}$ Mit dem Abschied des bürgerlichen Publikums übernahmen die Avantgardisten den Tumult selbst - freilich zum Preis ästhetischer Unschärfe:

»Das latente Erregungspotential, wenn überhaupt noch vorhanden und nicht zur `Indifferenz (Dahlhaus) verkommen, hatte sich auf die Sache selbst zurückgezogen: gelegentlich anhebende Auseinandersetzungen, Polemiken, Diskussionen drehten sich um das Auseinanderklaffen kompositorischer Standpunkte, Überzeugungen oder Stilrichtungen, die Diskrepanz in der Auslegung identischer ästhetischer Begriffe. $\aleph^{206}$

Die selbstreferentielle Skandallust der Darmstädter Kreise erfuhr etwa 1961 Ernst Krenek, der schon 1956 die »rein äußerliche Radikalisierung« der Neuen Musik durch »sensationsbegierige junge Herrschaften « kritisiert hatte. ${ }^{207}$ Fünf Jahre später kam deren Antwort bei der Aufführung seiner `Grand opéra〈 Das Leben des Orest.

202 Heinz Joachim, in: Die Welt (29.7.1957).

203 Stockhausen: Der Widerstand gegen die Neue Musik.

204 Ulrich Dibelius/Frank Schneider: Neue Musik im geteilten Deutschland, Band 4, Berlin 1999, S. 420.

205 Adorno: Das Altern der Neuen Musik, S. 143.

206 Dibelius/Schneider: Neue Musik im geteilten Deutschland, S. 421.

207 Brief von Ernst Krenek an Wolfgang Steinecke (20.8.1956), zitiert nach Stephan: Von Kranichstein zur Gegenwart, S. 160. 
Die Premiere wurde, wie sich der Intendant des hessischen Landestheaters Gerhard F. Hering echauffierte, von »demonstrativen Störungen durch einen jugendlichen Kreis von Kranichsteinern « sowie »Chöre schallenden Gelächters und die nicht minder geistvollen Argumente trampelnder Füsse« torpediert. Er verwehre sich gegen Proteste, die in »rüden und permanenten Terror « ausarten und »auf andere Besucher wie eine Halbstarken-Kundgebung wirken mussten. ${ }^{208}$ In seiner Antwort betonte Steinecke die besonderen Eigenschaften der »Kranichsteiner als Publikum « und verteidigte die berüchtigte »Streitkultur der Darmstädter« im Dienste der Kunst: »Bei der Konfrontierung Kunstwerk - Publikum sprühen Funken; auch einige Fehlzündungen muss man in Kauf nehmen können. « ${ }^{209}$ Der Intendant des Landestheaters verwehrte sich gegen diese »schmückenden Beiworte« für ein »mehrstündiges Gelächter und Getrampel«:

»Sie sprechen von `Residenz der kritischen Geister〈, von `freier und lebendiger Diskussion<. Wunderbar! Aber: Diskutiert man mit den Füßen? Sind Gelächter und Lärm Argumente? Das Wort Kritik kommt von `krino $=$ ich unterscheide. Im Lärm läßt sich nichts mehr unterscheiden. Urteil setzt Artikulation voraus, Toleranz gute Manieren. ${ }^{210}$

Steinecke habe dieses »sacrificium intellectus wie der Pionier die kalkulable Explosion einer Sprengladung« inszeniert. Dies sei nicht nur unfair, sondern gefährlich:

»Wenn Sie sich erinnern mögen: die unselige Zeit der Geistesächtung, der Gewissensknebelung hat $[\ldots]$ scheinbar harmlos damit begonnen, daß junge Menschen in Konzert- und Theatersälen durch Lärm und Gelächter ihre Mitbürger daran hinderten [...] zu hören. [...] Nicht lange danach mussten tausende von Künstlern dieses Land verlassen, ihr Werk wurde verboten, verbannt, verbrannt. Unter ihnen war Ernst Krenek. ${ }^{211}$

Bei Ernst Krenek kreuzten sich die politischen und ästhetischen Absolutismen der Moderne: War die Darmstädter Streitkultur einerseits eine kunstfreiheitliche Reaktion auf die NS-Gleichschaltung, so agierte die Nachkriegsavantgarde andererseits selbst autoritär - gerade weil sie aus einer totalitär geprägten Gesellschaft erwuchs. Unter dem Eindruck der Erlebnisse im hessischen Landestheater diagnostizierte Bernd Alois Zimmermann »angesichts so gezielter und wohlvorbereiteter Demonstrationen« einen »kalten Krieg zwischen den Kontrahenten verschiedener stilistischer Richtungen, um nicht zu sagen: Marschrichtungen! « $^{212}$ In Darmstadt, so schrieb er an anderer Stelle, wüte eine $»$ Revolution, [die] wie Saturn, ihre eigenen Kinder verschlingt. ${ }^{213}$

208 Brief von Gerhard F. Hering an Wolfgang Steinecke (7.9.1961), in IMD: A100072202254-18.

209 Offener Brief von Wolfgang Steinecke an Gerhard F Hering (13.9.1961), in IMD: A100072-202254-17.

210 Offener Brief von Gerhard F. Hering an Wolfgang Steinecke (25.9.1961), in IMD: A100072-202254-14.

211 Ebd.

212 Brief von Bernd Alois Zimmermann an Wolfgang Steinecke (19.7.1962), in IMD: A100072-202254-14.

213 Ebd. 


\section{Die Revolution frisst ihre Kinder}

Mit der Propagierung eines radikalen Fortschrittsimperativs hatten die Revolutionsführer der jungen Generation die Innovationsdynamik der Darmstädter Ferienkurse befeuert. Damit besiegelten sie aber nicht nur die gesellschaftliche Isolierung der Neuen Musik, sondern schrieben gewissermaßen auch das Drehbuch ihrer eigenen Wachablösung. Hatten Luigi Nono, Karlheinz Stockhausen und Pierre Boulez einst symbolund skandalträchtig Arnold Schönberg und Theodor W. Adorno, Hans Werner Henze und Bernd Alois Zimmermann für veraltet erklärt, so geschah ihnen dies bald selbst: kaum etabliert, wurden sie die Gejagten.

Zum ereignishaften Umbruchsmoment wurde der legendäre Aufritt John Cages bei den Darmstädter Ferienkursen im 〉Schlüsseljahr 1958^. Bei seiner europäischen Erstaufführung 1954 im Rahmen der Donaueschinger Musiktage noch belächelt, leitete der Amerikaner vier Jahre später eine »Epochenzäsur « ${ }^{214}$ ein, indem er den seriellen Dogmatismus ad absurdum führte. In seinen Vorträgen »Changes«, »Communication « und »Indeterminacy« erhob er Zufallsprozesse und Alltagsgeräusche, Entgrenzung und Theatralität zu kompositorischen Prinzipien. ${ }^{215}$ Damit stellte er dem vermeintlich sinnvollen Avantgarde-Diskurs einen scheinbaren Unsinn entgegen - und deckte damit auch einen »Prozeß der Selbsthistorisierung ${ }^{216}$ bei den Exponenten der >Darmstädter Schule auf. Sein Durchbruch symbolisierte mehr als nur eine gehaltsästhetische Wende, sondern war auch Ausdruck für die künstlerischen und kulturellen Wandlungsprozesse infolge der weltpolitischen Kräfteverschiebungen. ${ }^{217}$

Die junge Komponistengeneration der Nachkriegsavantgarde alterte und die Kontroversen um Cage stehen sinnbildlich für den Zerfall der seriellen Troika: »Zwischen Stockhausen und Boulez entstanden zunehmend Spannungen und Rivalitäten, und Nono kehrte nach einer Kontroverse [...] Darmstadt den Rücken. « ${ }^{218}$ Boulez und Stockhausen überwarfen sich in der Beurteilung der aleatorischen Experimente John Cages. Zeigte sich Stockhausen grundsätzlich interessiert und nahm die Zufallsverfahren teilweise in seine Arbeit auf, bezog Boulez mit Cages Hinwendung zu aleatorischen Experimenten entschieden Stellung gegen den Amerikaner. Der zwischen 1949 und 1962 dokumentierte Briefwechsel ${ }^{219}$ spiegelt den Umschlag von freundschaftlichkünstlerischem Austausch zu einem offenen Konflikt. 1957 formulierte Boulez mit Alea eine flammende Polemik gegen die Willkür des Zufalls. ${ }^{220}$

214 Heinz-Klaus Metzger: Fragment zum Thema Komet (Erinnerungen an Cage), in Stephan: Von Kranichstein zur Gegenwart, S. 250f, hier S. 251.

215 Die Vorträge wurden veröffentlicht in John Cage: Silence. Lectures and Writings, Middletown 1961. Communication ist außerdem als Tondokument überliefert, in: Darmstadt Aural Documents, Box 2, NEOS Music GmbH 2012.

216 Borio/Danuser, Im Zenit der Moderne, Band 1, S. 91.

217 Siehe hierzu ausführlich den Abschnitt John Cage und die transatlantische Neuvermessung der klingenden Welt im Kapitel Transkulturelle Transfers.

218 Petrik: Die Leiden der Neuen Musik, S. 139.

219 Jean-Jaques Nattiez (Hg.): >Dear Pierre〈, >Cher Johnく. Der Briefwechsel zwischen Pierre Boulez und John Cage, Hamburg 1997.

220 Pierre Boulez: »Alea« (1957), in Ders.: Werkstatt-Texte, Berlin 1972, S. 100-113, hier S. $100 / 102$. 
Dass John Cage im folgenden Jahr bei den Ferienkursen ausgerechnet den Platz des kurzfristig verhinderten Boulez einnahm, ist eine augenzwinkernde Randnotiz mit Symbolcharakter: Es war der Moment, in der die transkulturelle und pluralistische Moderne das abendländische Musikverständnis auf den Prüfstand stellte, wenn auch nicht ohne Gegenwehr. Hatte Boulez ästhetisch gegen die Willkür des Zufalls argumentiert, kritisierte Luigi Nono die aleatorische Verweigerung politischer und historischer Verantwortung. Sein Vortrag Geschichte und Gegenwart in der Musik heute ${ }^{221}$ markierte 1959 gleichermaßen den Moment seiner Politisierung wie auch der Abspaltung von der `Darmstädter Schuleく, den Heinz-Klaus Metzger publizistisch vollzog:

»Der Komponist scheint immer noch weiter jenes starre, $[\ldots]$ serielle Verfahren festhalten zu wollen, das 1952 ein wichtiges methodisches Stadium der Entwicklung des Komponierens war, heute aber nicht mehr gemeint werden kann, wenn man ernsthaft von sserieller Musik spricht. [...] So erklärt sich vielleicht die Gereiztheit [...]. Er hielt einen unverantwortlichen Vortrag, in dem viel von der Verantwortung des Komponisten die Rede war: man verstand, daß er positiv nur sich selbst meinte. Allerdings sprang er mit anderen Erscheinungen der gegenwärtigen Musik in einer Weise um, die an ihrer Kenntnis zweifeln ließ. Besonders peinlich berührte es, daß er gegen Abwesende namentlich [John Cage], gegen Anwesende [Karlheinz Stockhausen] hingegen anonym polemisierte. «222

Damit schied Luigi Nono 1959, so bemerkte der Regisseur Peter Konwitschny, mit einem »Eklat aus dem Kreis der elitären Elfenbeinturmbewohner aus. « ${ }^{223}$ Während der kommunistische Komponist 1961 mit seinem Musiktheater Intolleranza die Dekade der politischen Musikskandale einleitete ${ }^{224}$, rang man bei den Ferienkursen um die Einheit der 〉Darmstädter Schule〈. Stockhausen etwa bemerkte 1960 in seinem Vortrag Vieldeutige Form, dass »die Musiker wieder einmal ins polemische Stadium gekommen« seien. Darin erkannte er auch Abnutzungserscheinungen der Schule machenden Nachkriegsavantgarde Darmstädter Prägung und warnte vor deren Zerfall:

»Das macht das Alter, Berühmtheit verdirbt den Charakter. Nur so lange man kämpfen muss, ist jeder dem andern am nächsten. Der Widergeist will Zerstörung und manch einer der sogenannten Kritiker würde mit größtem Vergnügen zusehen, wenn einer gegen den anderen stünde. [...] Wer hat nicht alles die Götter abgeschafft, um sich an Ihre Stelle setzen zu können. Machen Sie mich fertig. $\ll^{225}$

221 Luigi Nono: »Geschichte und Gegenwart in der Musik heute«, in Jürg Stenzl: (Hg.): Luigi Nono. Texte, Studien zu seiner Musik, Zürich 1975, S. 34-40.

222 Heinz-Klaus Metzger: »Kranichsteiner Musiktreffen beendet«, in: Der Mittag (11.9.1959). Siehe auch Borio/Danuser: Im Zenit der Moderne, Band 2, S. 259-263.

223 Arbeitsgespräch zwischen Peter Konwitschny, Peter Rundel, Hans-Joachim Schlieker und Werner Hintze, in: Programmheft zur Inszenierung von Luigi Nonos Musiktheater Intolleranza an der Deutschen Oper Berlin (2001).

224 Siehe hierzu ausführlich das Kapitel Querstand von Kunst und Politik sowie insbesondere den Abschnitt Klingender Klassenkampf: Luigi Nonos `Intolleranzaく(1961).

225 Karlheinz Stockhausen: »Vieldeutige Form« (1960), in Ders.: Texte, Köln 1964, S. $245-$ 251, hier S. 248. Ein von Zwischenrufen durchzogener akustischer Mitschnitt der Lesung findet sich im Schallarchiv des IMD: B006491334/17b. 
Dies übernahm ausgerechnet Heinz-Klaus Metzger, der den Text bei den Ferienkursen für den abwesenden Stockhausen vortrug - versehen mit gereizten Kommentaren `à la Adorno<. Auf dessen Warnung vorm Altern der Neuen Musik 1954 bezog sich Metzger 1962 mit seinem Aufsatz zum Altern der jüngsten Musik ${ }^{226}$, in dem er den fortschrittverpflichteten Richtspruch über die serielle Troika sprach und bei ihren Protagonisten mit Verweis auf John Cage veraltetes europäisches Denken diagnostizierte. Er kritisierte die »Stabilisierung der Musik« und ätzte, dass »Komponisten, deren Namen eben noch Fanale der musikalischen Subversivität waren, an deren Sinn irre geworden zu sein« scheinen: Pierre Boulez, der vormals »einzige sichtbare Repräsentant des musikalischen Fortschritts«, hätte den »Verrat, die Rückkehr zu positiven Werten« vollzogen. Luigi Nono fertigte er als »seriellen Pfitzner« ab und Stockhausen, dem »technisch alles zu danken« sei, wäre die Schöpfung des integralen Kunstwerks misslungen:

»Es gibt im zwanzigsten Jahrhundert keine Reife der Künstler mehr. Ist Kunst ihrem einzigen noch möglichen Sinn nach heute subversiv, so ist die Subversivität nicht mehr durchzuhalten: [...] Niemand scheint mehr imstande, bis an seinen Tod immer neue Abnormitäten zu erzeugen: der Umschlag in Norm, Konvention, Affirmation, schließlich Apologie des herrschenden Zustands droht allen, und manchmal fallen die Spätwerke heut außerordentlich früh an. $\ll^{227}$

Mit der Kritik am Darmstädter Fortschrittsparadigma wurde ein Paradigmenwechsel angezeigt, zumal die Ferienkurse nach dem plötzlichen Tod Wolfgang Steineckes 1961 ihre prägende Figur verloren. Unter seinem Nachfolger Ernst Thomas entstand ein Machtvakuum, in der verschiedene Richtungen miteinander konkurrierten. Die amerikanische Avantgarde markierte eine radikale Gegenbewegung zur offiziellen Linie Darmstadts, wo man an der abendländischen Idee des Meisterwerks festhielt:

»Die Zeit von Fluxus und Aktionskunst brach an, aber diese Avantgarde wurde in Darmstadt ausgeschlossen. Denn während Fluxus in Düsseldorf, Wiesbaden, Wuppertal und andernorts sein nicht nur fröhliches Treiben veranstaltete und nach dem Sinn von Kunst fragte [...], stabilisierte sich in Darmstadt eine selbstzufriedene und unantastbare Moderne. ${ }^{228}$

Auf die selbstreferenzielle Konsolidierung der Darmstädter Ferienkurse deutet auch das veränderte Rezeptionsverhalten hin, dem sich 1961 der Kritiker von Der Mittag »als einem immerhin wesentlichen Konzertfaktor« widmete:

»Pfeifen bedeutet nach altem Brauch Widerspruch [...]. Dennoch aber erhob sich nach den Darbietungen ein fast selbstverständlicher Beifall [...]. Merkwürdig aber blieb, daß das Publikum seine Skepsis entweder unter Beifall verbarg oder sich [...] nur schweigend verhielt. Die leidenschaftlichen Auseinandersetzungen, die das Musikleben [...] so befruchtet und gesteuert haben, sind entschwunden. « $^{229}$

226 Heinz-Klaus Metzger: »Das Altern der jüngsten Musik« (1962), in Ders.: Musik wozu, Frankfurt am Main 1980, S. 113-128.

227 Ebd., S. 128.

228 Pascal Decroupet: »Tudors letzter Auftritt in Darmstadt«, in Borio/Danuser: Im Zenit der Moderne, Band 2, S. 273-275, hier S. 275.

229 N.N., in: Der Mittag (8.12.1961). 
Nach den Jahren aktiver Teilnahme beruhigte sich die von Wolfgang Steinecke apostrophierte »Streitkultur der Darmstädter ${ }^{230}$. Die Demokratisierung des avantgardistischen Absolutismus wurde illustriert durch den endgültigen Zerfall der seriellen Troika: Der ehemals revoluzzerhafte Pierre Boulez führte 1976 mit der Leitung des >Jahrhundertrings « bei den Bayreuther Festspielen seinen 1968 getätigten Aufruf »Sprengt die Opernhäuser in die Luft ${ }^{231}$ ad absurdum und Luigi Nono besetzte das politische Feld, während an Karlheinz Stockhausen 1974 der letzte symbolische Vatermord der Darmstädter Revolution verübt wurde.

\section{Der Sturz des letzten Königs}

John Cage wurde bis 1990 nicht mehr zu den Ferienkursen eingeladenen, und doch leiteten seine provozierenden Auftritte 1958 das Ende verbindlicher Normen ein und mündeten Mitte der Siebziger Jahre im postmodernen anything goes. Die Zwischenzeit kann als Latenzphase verstanden werden, in der sich in Darmstadt die zeithistorischen Tendenzen der Politisierung verdichteten und zum Sturz des letzten Königs führten: Karlheinz Stockhausen.

Zwar hielt man nach dem Abschied von Luigi Nono und Pierre Boulez zunächst an Karlheinz Stockhausen als nun alleinigem Vordenker Darmstadts fest, doch erfuhr die serielle Ästhetik eine Ent-Dogmatisierung und evozierte die Begriffsbildung einer $>$ Postseriellen Musik $\iota^{232}$ : es mehrten sich die Forderungen nach einer Aufweichung der hierarchischen Strukturen und einer Vielseitigkeit in Form und Ausdruck. Im Anschluss an die Ferienkurse 1968, als Stockhausens Musik für ein Haus den unumstrittenen Schwerpunkt bildete, erreichten die Leitung Beschwerdebriefe über den autoritären Führungsstil des Komponisten. Ein Jahr später kritisierte der linkspolitische Musikjournalist und Ferienkursteilnehmer Reinhard Oehlschlägel in mehreren Berichten die Institutionalisierung Stockhausens, die dem Innovationsparadigma Darmstadts zuwiderlaufe. $^{233}$

Wiederum ein Jahr später wurden die von den Studentenunruhen und Straßenporotesten im Umfeld von 1968 adaptierten Praktiken von den Ferienkursteilnehmern in einer Vollversammlung erprobt. Die Ereignisse des >Krisenjahres 1970〈stehen paradigmatisch für die Politisierung der Neuen Musik, die im Kapitel Querstand von Kunst und Politik fokussiert nachgezeichnet und mit Blick auf ihre Skandalträchtigkeit analysiert wird. Hier soll dagegen der Schwerpunkt auf den Sturz des letzten Königs von Darmstadt gelegt und so der Endpunkt der permanenten Revolution bei den Ferienkursen für Neue Musik beleuchtet werden.

Es ist bezeichnend, dass im Sammelband Musikkulturen in der Revolte Karlheinz Stockhausens Ende in Darmstadt 1974 mit der Vollversammlung der Teilnehmer 1970

230 Brief von Wolfgang Steinecke an Gerhard F. Hering (13.09.1961), in IMD: A100072202254-17.

231 Pierre Boulez: »Sprengt die Opernhäuser in die Luft«, in: Der Spiegel (40/1967), S. 166174.

232 Siehe hierzu den letzten (sic!) Eintrag in Ulrich Michels/Gunter Vogel: dtv-Atlas Musik, Band 2: Musikgeschichte vom Barock bis zur Gegenwart, München 2013, Sp. 558f.

233 Reinhard Oehlschlägels Berichte über die Darmstädter Ferienkurse 1969 finden sich in IMD: A100110-201261-02. 
in Relation gesetzt wird. ${ }^{234}$ Die am Archiv des Internationalen Musikinstituts Darmstadt (IMD) bewahrten Protokolle ${ }^{235}$ belegen, dass die hitzigen Debatten um Mitspracherecht, Internationalisierung, Demokratisierung und eine Enthierarchisierung der Ferienkurse dem Führungsanspruch Stockhausens zuwiderliefen. Gleichwohl nahm der Komponist zunächst aktiv als Wortführer an der Versammlung teil, bevor er sie wegen einer Probe verlassen musste und damit ein stückweit seine eigene Demontage begünstigte.

Die in der Transkription des Mitschnitts verzeichneten Zwischenrufe verraten nicht nur den von der Studentenbewegung inspirierten Charakter eines >Sit-Ins〈, sondern von Beginn an auch eine gereizte Stimmung gegenüber Stockhausen, der sich über den »Polizei-Ton« beschwerte und mit Blick auf die Zusammenstellung einer Mitgliederdelegation seinen Standpunkt klarmachte: »Wir sind hier kein Diskutierklub. Ich möchte als Künstler Berater haben, die auch ein künstlerisches Urteil fällen können.« Die daraufhin folgenden Einwände, »dass hier tatsächlich von unten eine Initiative der jungen Leuten emporgekommen ist «, belegen sowohl den Generationenkonflikt, als auch den wachsenden Widerspruchsgeist gegen die Darmstädter Gallionsfigur. Bevor sich diese Zeichen der Revolte in Abwesenheit Stockhausens verdichteten, wurde zunächst die gesellschaftliche Isolation von Neuer Musik thematisiert. Die studentischen Teilnehmer sahen Alternativen in der Pop- sowie der politisch engagierten Musik; beide Spielarten lehnte Karlheinz Stockhausen mit Verweis auf die Autonomieästhetik der Neuen Musik ab. Ihm seien mehrere große Pop-Anthologien gewidmet worden und dabei habe sich herausgestellt,

»dass wir den Pop-Musikern enorm viel zeigen können, [...] wir passen [aber] irgendwie fachlich nicht zusammen. Dazu sind wir zu intellektualisiert [...]. Genau so wie die Free Jazz-Leute [...], die versuchen die extremsten Produkte der Neuen Musik einfach zu imitieren. ${ }^{236}$

Stockhausens Aussage illustriert den Bedeutungszuwachs der Popkultur und verdeutlicht die charakteristische Mischung aus Arroganz und Furcht, wie ihn die Vertreter der Hochkultur gegenüber der aufstrebenden Unterhaltungsmusik kultivierten. ${ }^{237}$ Nirgends geschah dies deutlicher als in Deutschland und konkret in Darmstadt, wo die Sezession von E(rnster)- und U(nterhaltungs)-Musik zementiert wurde. Auch in der Diskussion über politisch engagierte Musik beharrte Stockhausen auf ästhetischer Autonomie und erklärte: »Wenn sie gut ist, kann sie von mir aus Mao Tse Tungs kleine Zehen besingen.«

234 Martin Iddon: »Pamphlets and Protests: The End of Stockhausen's Darmstadt«, in Beate Kutschke (Hg.): Musikkulturen in der Revolte. Studien zu Rock, Avantgarde, Klassik im Umfeld von $>1968<$, Stuttgart 2008, S. 55-63.

235 Die Zitate beziehen sich, sofern nicht anders vermerkt, auf das »Protokoll der Vollversammlung der Ferienkursteilnehmer am 03.09.1970«, in IMD: A100111-201270-14.

236 Ebd., S. 80f. Tatsächlich bezogen sich Popgruppen wie Jefferson Airplaine, The Greatful Dead oder die Beatles sowie aktueller die isländische Pop-Avantgardistin Björk explizit auf Karlheinz Stockhausen.

237 Siehe hierzu weiterführend Hans-Peter Reinecke: »Popularmusik und geängstigte Musikologen«, in Helmut Rösing (Hg.): Rock, Pop, Jazz im musikwissenschaftlichen Diskurs, Hamburg 1992, S. 5-14. 
Damit traf er den Widerspruchsgeist einer gegen die Autoritäten aufbegehrenden Generation. Beispielhaft warf der linke Musikkritiker Reinhard Oehlschlägel Stockhausen vor: »Sie wollen doch nur monopolistisch Ihre Ästhetik durchsetzen!« Noch deutlicher wurde der Aufstand gegen die Lichtgestalt der Neuen Musik in der englischen Simultanübersetzung durch den US-amerikanischen Komponisten Warren Burt:

»I think, his narrow view was one of the things that is killing Darmstadt. That he is here in his royal kingdom, and that he is afraid that some of us rock the show, bringing the pop musician in and might make it a primary focus that one might make Karlheinz Stockhausen a little less known, a little less shining light [...] He is afraid that someone might overshadow him, regardless artistic merit $[\ldots]$. The festival topped by him $[\ldots]$ by a one-man-festival. $\varkappa^{238}$

Als Stockhausen die Versammlung wegen einer Probe verlies, formulierte die Opposition noch deutlicher eine Debatte für und wider der Kölner Gallionsfigur Neuer $\mathrm{Mu}-$ sik. Der damalige Kompositionsstudent Peter Michael Hamel bemerkte, man könne »doch nicht warten, bis Herr Stockhausen tot ist, um weiterzumachen.« Während auch der Schweizer Komponist und Journalist Max E. Keller den Darmstädter »Monotheismus « verurteilte, versuchte Stockhausens damalige Frau Mary Bauermeister zu schlichten: »not as his wife«, sondern weil man die künstlerischen Anliegen durch »fights which are internally« schwächen würde. Wenn Oelschlägel Stockhausen Monopolismus vorwerfe, liege er allerdings richtig: »because Karlheinz is a strong personality.« Trotz dieses Schlichtungsversuches standen die Weichen auf Veränderung.

Wenn eine tiefere Bedeutung der Vollversammlung von der Forschung auch meist bestritten wurde und etwa der Avantgarde-Dichter Hans G Helms in einer WDR-Fernsehdokumentation von einer »Misslungenen Revolution ${ }^{239}$ sprach, zeitigten die Ereignisse doch Folgen: Dass die Ferienkurse seitdem im 2jährigen Turnus als Biennale stattfinden, mag Zufall sein; wahrscheinlicher aber ist, dass man zunächst einmal Gras über den Aufstand der Teilnehmer wachsen lassen wollte. Die musikalische Stilistik erfuhr nach dem vielfach geäußerten Unbehagen an der >monotheistisch`vertretenen seriellen Ästhetik eine größere Bandbreite. Auch und konkret - so formulierte es Reinhard Oehlschlägel - zur »Abwehr von ästhetischen Monopolbestrebungen Karlheinz Stockhausens. $\ll^{240}$ Die Vollversammlung brachte also nicht nur die gesellschaftliche Politisierung in den avantgardistischen Elfenbeinturm, sondern kündigte auch den Sturz des letzten >Darmstädter Königs` an, der sich vier Jahre nach den Ereignissen des Krisenjahrgangs 1970 vollzog. Der Ausschluss mehrerer marxistischer Teilnehmer aus Stockhausens Kompositionskurs provozierte eine Flut wütender Reaktionen: In einem Brief hieß es, der Komponist greife »zu faschistischen Methoden $\aleph^{241}$ und das Manifest einer »Initiative zur Gründung einer Vereinigung sozialistischer Kulturschaffender« parodierte die Machtallüren Stockhausens:

238 Ebd., S. 87.

239 Hans G Helms: »Dokumentation einer misslungenen Revolution. Internationale Ferienkurse für Neue Musik Darmstadt, 23. August bis 4. September 1970«, in: WDR 1972.

240 Reinhard Oehlschlägel: »Vorbericht über die Internationalen Ferienkurse für Neue Musik 1972 in Darmstadt«, in: Deutschlandfunk (24.07.1972).

241 Brief von Jürgen Lösche, Johannes Vetter und Gerhard Stäbler (04.09.1974), in: IMD: A100112-201279-18. 
»Den Kursteilnehmern [...] zu Darmstadt widerfährt die Gnade, in stiller Andacht heilige Weihen höherer Weisheit aus dem Munde St. Stockhausens zu empfangen. Um den ungehemmten Fluß seines göttlichen Geistes zu gewährleisten fordert St. Stockhausen uneingeschränkte Unterordnung [...]. Sämtliche selbst mikrominimale Regungen werden mit Disziplinierungsmaßnahmen bestraft. [...] Wäre Stockhausen Politiker, hätten wir einen Diktator mehr in der Welt. $\ll^{242}$

Der letzte König von Darmstadt wurde vom Volk gestürzt und die Degradierung 1975 auch offiziell vollzogen. Am 23. November schrieb Ernst Thomas, der Leiter der Darmstädter Ferienkurse, dem Komponisten:

»Die Ferienkurse werden 1976 nun 30 Jahre alt, und dies entspricht zwei Künstlergenerationen, auf die nun eine dritte folgen sollte. Dazu müssen wir mehr und mehr Versuche mit jüngeren Begabungen anstellen. Das bedeutet nun beileibe nicht, daß ich auf die Meister verzichten wollte [...]; sie bleiben ein unentbehrliches Rückgrat der Kurse. [...] Mit anderen dürren Worten: ich kann künftig auch die Meister nur im Wechsel von Kursen zu Kursen einladen. ${ }^{243}$

Als der Komponist Zugeständnisse andeutete - »Auf Konzerten bestehe ich nicht. Als Honorare können Sie vorschlagen, was Sie wollen ${ }^{244}$ - wurde Thomas noch deutlicher. ${ }^{245}$ Karlheinz Stockhausen prognostizierte daraufhin, diese Briefe wären »historische Dokumente, über die zukünftige Generationen sich ganz bestimmt mit sehr viel Interesse unterhalten werden. ${ }^{246}$ Tatsächlich können diese Schriftstücke als Belege für einen Umschlag in ein >post-serielles Z Zeitalter verstehen, der bereits mit dem Aufstieg John Cages und dem Zerfall der >seriellen Troika eingeleitet worden war. Dem Ende ästhetischer Absolutismen folgte allerdings eine gewisse Beliebigkeit, die sich als dauerhaft stabile Unterlage für viele musikalische Techniken und Einflüsse erwies, allerdings ohne die Vielfalt der musikalischen Richtungen und einem Nenner fassen zu können. Aufschlussreich ist in diesem Zusammenhang der entsprechende Eintrag des dtv-Atlas Musik:

»In den 1970er Jahren verlieren Material, Technik und Ratio an Reiz. Fortschritts- und Wachstumsglaube werden erschüttert (68er Unruhen), auch der Drang in Kunst und Musik zu absoluter Neuheit. Die Avantgarde-Haltung gerät in eine Krise: man sucht wieder die Gemeinschaft und den Hörer. $\ll^{247}$

242 Handout von Jürgen Lösche, Johannes Vetter und Gerhard Stäbler: Verpackungskünstler Stockhausen,1974, IMD-A100112-201279-19.

243 Brief von Ernst Thomas an Karlheinz Stockhausen (23.10.1975), in IMD: A100052201069-08.

244 Brief von Karlheinz Stockhausen an Ernst Thomas (01.11.1975), in IMD: A100052201069-06.

245 Brief von Ernst Thomas an Karlheinz Stockhausen (01.11.1975), in IMD: A100052201069-07.

246 Brief von Karlheinz Stockhausen an Ernst Thomas (02.12.1975), in IMD: A100052201069-05.

247 Michels/Vogel: dtv-Atlas Musik, Band 2, Sp. 559. 
Spätestens mit dem Abschied Karlheinz Stockhausen aus Darmstadt endete die Ära ästhetischer Absolutismen, die Denker wie Jean-François Lyotard und Wolfgang Welsch als Merkmal der Moderne ausmachten, kurz: die Postmoderne dämmerte. Auch Hermann Danuser sah diese als das Ergebnis einer Wechselwirkung von historischen Ereignissen und dem Ende des Fortschrittsdenkens, welches die Avantgarde ihres Wortsinnes beraubte:

»Seit Mitte der siebziger Jahre, ausgelöst zumal durch die Ölkrise 1973/74, als das ökonomische, politische und kulturelle Fortschrittsdenken in Europa in tiefe Zweifel gestürzt wurde, ist gleichzeitig im Bereich der Kunst und Ästhetik die jahrzehntelange (freilich niemals unangefochtene) Vorherrschaft der Geschichtsphilosophie `Moderne` in eine Krise geraten, in deren Verlauf der Grundsatz, Kunst müsse neu sein, um als authentisch gelten zu können, aufgelöst oder gar in sein Gegenteil verkehrt wurde. $\ll^{248}$

Danuser datierte den »Postmodernen Exitus« in Darmstadt auf »jenen denkwürdigen Sommer 1976«, den er als »Kampf um das Ende der Avantgarde« beschrieb:

»Wir befinden uns $[\ldots]$ bei den Darmstädter Ferienkursen, der einst berüchtigten Hochburg der Neuen Musik [...]. Mit immer neuen Kühnheiten kann [...] immer weniger Aufsehen erweckt werden. Aber siehe, plötzlich ereignet sich Unerwartetes: Der Geiger Sascha Gawriloff bringt die Violin-Sonate eines jungen deutschen Komponisten, Hans-Jürgen von Bose, zur Uraufführung, nein: er will sie zur Uraufführung bringen. Denn ein rasch zum Tumult anwachsender Lärm einer Gruppe von `Zuhörern` macht es dem Geiger unmöglich, das Werk zu Ende zu spielen. Was ist der Stein des Anstoßes? - Die Einfachheit dieser Musik, ihre tonale Disposition, die Selbstverständlichkeit, mit der hier dem avantgardistischen `Kanon des Verbotenen` (in dessen Servitut sich die Neue Musik begeben hat) Hohn gesprochen wird [...]. Die Provokateure von einst erscheinen unvermutet als Provozierte. Der Spieß hat sich umgedreht! « ${ }^{249}$

Spätestens seit der Epochenzäsur von der Moderne zur Postmoderne folgte die Musikgeschichte keinem linearen Fortschrittsgedanken mehr, sondern wurde zu einer pragmatisch-funktionalen Kategorie. Wenn Stockhausen seine Demontage in Darmstadt als »historische Dokumente« bezeichnete, kann man ihm also ein stückweit recht geben. Er selbst zeigte noch rund 25 Jahre später Interesse an den Vorgängen und bat das Internationale Musikinstitut Darmstadt in einem Brief um Klärung. Im Antwortschreiben rekonstruierte Wilhelm Schlüter die Ereignisse:

»In einer Sitzung am 9. August 1974 hat der damalige Programmbeirat für die Ferienkurse 1976 einen stotalen Wechsel ( (Punkt 1 des Protokolls) [...] vorgeschlagen. [...] Was Sie betrifft, reagierte er vor allem auf den Misserfolg der Seminare [...], nachdem Sie drei marxistisch orientierte Komponisten - darunter Gerhard Stäbler - zum Verlassen des Raumes aufgefordert hatten [...]. Auch Ihre Programmbeiträge [...] wurden damals programmpolitisch [...] eher rückläufig eingeschätzt. « ${ }^{250}$

248 Hermann Danuser: Die Musik des 20. Jahrhunderts, Laaber 1992, S. 400.

249 Danuser: Lob des Tadels, S. 125.

250 Brief von Wilhelm Schlüter an Karlheinz Stockhausen (23.2.2000), in IMD: A100052201069-05. 
Erst 1996 kam Karlheinz Stockhausen noch einmal zu den Ferienkursen nach Darmstadt. Als der Komponist seine Bereitschaft für ein weiteres Engagement suggerierte, wurde ihm geantwortet, man wolle »aus künstlerischen und ästhetischen Gründen [...] alle zwei Jahre die Komponistendozenten komplett austauschen. ${ }^{251}$ Daraufhin erwiderte Stockhausen: »Sie wollen also Komponisten als Schnittblumen offerieren und keine Bäume mehr pflanzen. Nichts im Universum kann nach diesem Muster überleben. $\ll^{252}$ Als die Darmstädter Revolution das letzte ihrer Kinder fraß, folgte dem Heroldsruf »Der König ist tot« keine Ausrufung eines neuen Oberhaupts. Im postmodernen anything goes wurden Führungsfiguren überflüssig. Stockhausens Abschied markierte endgültig das Ende ästhetischer Absolutismen und den Beginn der pluralistischen Postmoderne. Aber mit den Königen, wurden auch die Revolutionen aus der Kunstmusik vertrieben.

251 Brief von Solf Schaefer an Karlheinz Stockhausen, 9.1.1997, zitiert nach Misch/Bandur: Stockhausen, S. 566.

252 Ebd. 



\section{ELEKTRONISCHE EKLATANZ (Durchführung \#2)}

Die im Kapiteltitel gesetzte Formel einer `Elektronischen Eklatanz`verweist sinnfällig auf die besondere Spezifik des Gegenstandes, wie er im Folgenden fokussiert wird: Wie der Skandal bezeichnet der Eklat etwas, das Anstoß und Aufsehen hervorruft, fügt dem aber akustische Bedeutungszuschreibungen wie Sprengung oder Knall hinzu. In seiner französischen Ausprägung wurde der éclat darüber hinaus als affektive Vortragsbezeichnung für einen plötzlich auftretenden Klang verwendet. Und eben diese Komponente trifft die besondere Spezifik der elektronischen Musik: Die seit den frühen 1950er Jahren jäh und ohne sichtbare Schallquelle aus den Lautsprechern strömenden Klänge waren im wahrsten Sinne des Wortes >unerhört ${ }^{1}$ und Aufsehen erregend - aber wenn das Publikum aufblickte: war die Bühne leer beziehungsweise von Maschinen bevölkert [Abbildung 9].

Abbildung 9->Die Maschine als Hypervirtuoser: Uraufführung von Karlheinz Stockhausens »Gesang der Jünglinge« am 30.05.1956 im großen Sendesaal des WDR

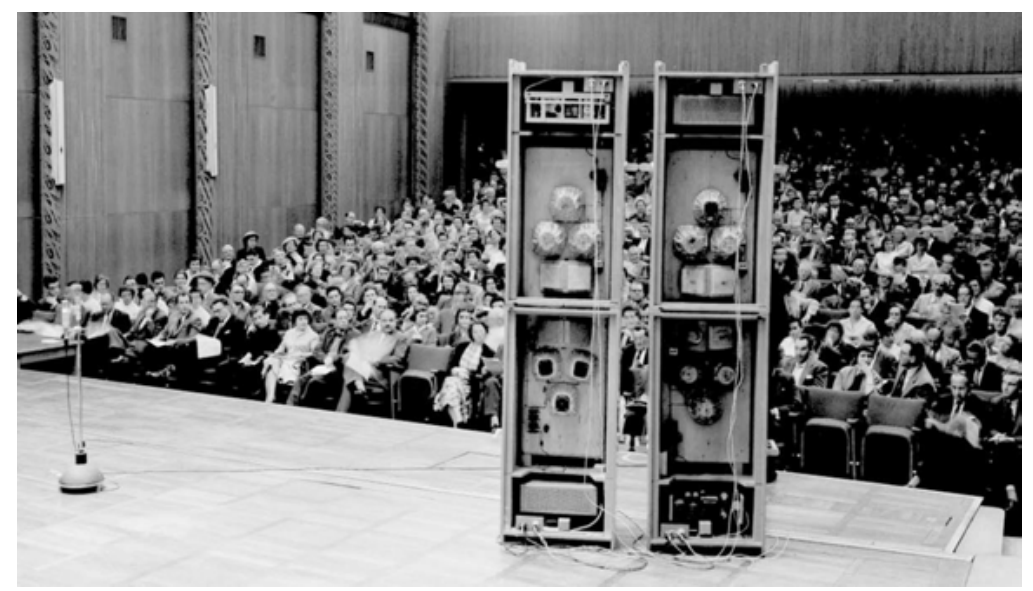

1 Die Tatsache scheint bemerkenswert, dass das skandalrelevante Wort der Empörung speziell auf den Hör-Sinn rekurriert. 
Die frühe Lautsprechermusik provozierte nicht nur durch ihre Verweigerung des szenisch-visuellen Elements die Gemüter; vielmehr brach die elektronische Musik mit nahezu allen bis dato gültigen Normen des Konzertbetriebs und des musikalischen Werkbegriffs: Tradierte Paradigmen wie Komposition, Partitur, Interpret, Aufführungssituation, Geschlossenheit und Zeitlichkeit wurden mit dem Schritt in die synthetische Klangerzeugung auf den Kopf gestellt. Auf diesen Bruch der Produktionsund Darstellungskonventionen reagierten die Hörer ihrerseits mit veränderten Wahrnehmungs- und Verhaltensnormen in der Rezeption von Musik: Sie füllten die entstandene Leerstelle des Konzertzeremoniells mit eskalierenden Affekten. Die >Elektronische Eklatanz beschreibt also sowohl die Skandalträchtigkeit, als auch die spezifische materielle Ästhetik der elektronischen Musik, die mehr als alle anderen ästhetischen Ausdrucksformen Musik ihrer Zeit war: Die doppeldeutig >unerhörten Klänge illustrieren das Dämmern des Medienzeitalters auf sinnliche Weise, während ihre Skandale auf die veränderte Rezeptionsästhetik sowie die Pressetechniken der Kulturindustrie und der Massenkultur verweisen.

Die Geschichte der elektronischen Musik ist nicht zu trennen von der allgemeinen Historie der musikalischen Nachkriegsavantgarde - und doch besaß und entwickelte die Medienmusik eine Eigendynamik, die über die Zentren der Neuen Musik in Donaueschingen und Darmstadt hinausreicht. Auch unterscheidet sich die Elektroakustik von der instrumentalen Konzertmusik durch ihre Materialität auf Basis der medientechnischen Möglichkeiten jener Zeit. In dieser Eigenschaft war sie untrennbar mit der Entwicklung des Radios verbunden, das in den 1950er Jahren ebenso zum medium wie zur message der Musikavantgarde avancierte: Die aktive Beteiligung des in Deutschland bis heute staatsnahen Rundfunks an der Förderung und Produktion der Neuen Musik spricht dafür, dass sie (kultur-)politisch gewollt war. Wenn die entsprechenden Sendungen auch überwiegend in den anspruchsvollen Nachtprogrammen der dritten Sender liefen, agierten die mit einem Bildungsauftrag versehenen öffentlich-rechtlichen Rundfunkstationen doch explizit »im Interesse einer radikalen, autonomen und von äußeren funktionellen Zwängen so weit wie möglich abgelösten Ästhetik der Avantgardemusik «².

Darüber hinaus veränderten die neuen medientechnischen Möglichkeiten von Aufnahme, Speicherung und massenhafter Distribution die Hör- und Rezeptionsweisen genauso wie die Produktions- und Darstellungskonventionen von Musik in eklatanter Weise: seit den 1950er Jahren, dem »Radiojahrzehnt der Bundesrepublik «" wurde die Reproduktion von Musik, die in vergangener Zeit für Konzertsaal und Opernhaus geschrieben worden war, selbstverständlich. Obgleich nun der Rundfunk zu einer solchen musikalischen Konservenfabrik wurde, geschah gerade hier etwas Unerwartetes: Elektroakustische Hörkunst kam ins Spiel - eine Musik die ganz funktionell aus den spezifischen technischen und institutionellen Gegebenheiten des Radios hervorging.

2 Rudolf Frisius: Unsichtbare Musik - Akustische Kunst - Veränderungen des Hörens, online abrufbar unter URL: http://www.frisius.de/rudolf/texte/tx348.htm [Zugriff: 31.8.2017].

3 Monika Boll: Nachprogramm. Intellektuelle Gründungsdebatten in der frühen Bundesrepublik, Münster 2004, S. 51. 
Der Schritt in die musikalische Synthetik veränderte die Paradigmen und Rituale des Musikmachens und -hörens grundlegend unter den Bedingungen des Medienzeitalters. Die elektronische Musik wurde zum Ausdruck einer kulturellen und gehaltsästhetischen Wende unter dem technizistischen Signum der Moderne. Damit eröffnet sie spezifische analytische Zugriffsmöglichkeiten aus dem Bereich der medienwissenschaftlich inspirierten Kulturwissenschaften: Die Genese der Medienmusik war nicht nur begleitet von einem beständigen Rauschen aus Technologiekritik, wie einleitend skizziert wird; nach 1945 wurde die Lautsprechermusik auch zum medientechnischen state of the art und zum klingenden Zeichen eines historisch, ästhetisch und medial grundierten Umbruchs, der mit dem Fokus auf drei exemplarische Fallbeispiele der Jahre 1953/54 ins analytische Blickfeld gerückt wird: diese manifestieren sich als verdichteter Dreh- und zeithistorischer Angelpunkt der >Elektronischen Eklatanz $\prec$ und weisen auf die Paradigmen der Mensch-Maschine-Dichotomie zwischen Utopie und Dystopie.

\section{MENSCH VS. MASCHINE: GRUNDLAGEN DER TECHNOLOGIEKRITIK}

Wenn auch die Eklatanz der elektronischen Musik in der zweiten Hälfte des 20. Jahrhunderts eine neue Qualität erreichte, ist doch die Kritik am technischen Fortschritt sehr viel älter und war immer mit der Angst verbunden, dass Maschinen den Menschen ersetzbar machen und damit die Kunst >entmenschlichen « und >dehumanisieren<. In seinem Grundlagenwerk zur frühen Lautsprechermusik, Musica ex Machina, bemerkte Fred Prieberg bereits 1960 mit Verweis auf Jonathan Swift und Jean Paul, dass die »Beseelung der Maschine [...] die Voraussetzung dafür [war], daß die Kunst sich ihrer bemächtigte, um eine völlig neue Region künstlerischer Wirksamkeit aufzudecken. $\varkappa^{4}$ Diese neue Welt der Klangerzeugung und -wahrnehmung allerdings beschwor auch Ängste und Widerstand, wie sie das `Andere ‘ auf allen sozialen Feldern hervorruft. Insbesondere technischen Errungenschaften wurden zunächst selten freudig besungen; vielmehr schlug ihnen oft erbitterte Abwehr von den Bewahrern der Tradition entgegen. Die Kritikpunkte waren dabei stets mehr oder weniger die Gleichen, wie Kathrin Passig in ihrem Aufsatz zu Standardsituationen der Technologiekritik verdeutlichte: Immer seien technische Neuerungen in der Kulturkritikbranche auf Widerwillen gestoßen und mit öffentlich geäußertem Missmut über das Neue einhergegangen. ${ }^{5}$ Diese historische Kontinuität ist sowohl als Ausdruck des Spannungsverhältnisses zwischen Tradition und Innovation, als auch als Beleg für Generationenkonflikte lesbar und gibt damit Hinweise auf Epochenschwellen. Musikästhetik, Aufführungspraxis und Instrumentenbau sind nicht erst seit der Industrialisierung an die Fortschreibung der technischen Mittel gekoppelt, die stets in einer Mischung aus Neugier, Ignoranz und Angst begrüßt wurden.

4 Fred Prieberg: Musica ex Machina. Über das Verhältnis von Musik und Technik, Berlin 1960, S. 10.

5 Kathrin Passig: Standardsituationen der Technologiekritik, in: Merkur (12/2009), online abrufbar unter URL: http://www.eurozine.com/articles/2009-12-01-passig-de.html [Zugriff: 31.8 .2017$]$. 
Der Möglichkeitsraum der elektronischen Klangerzeugung beginnt bereits um 1750, als experimentierende Visionäre im Zuge der Industrialisierung die Erzeugung von Klängen durch mechanische Reibung entdeckten; schon im 19. Jahrhundert wäre die elektronische Tonerzeugung mithilfe eines Wechselstromdynamos technisch realisierbar gewesen; aber erst die Erfindungen von Phongraph und Grammophon in den 1890er Jahren wurden gleichermaßen zur Initialzündung der modernen Musikindustrie wie der elektronischen Musik, die im Verlauf des 20. Jahrhunderts, auch bedingt durch die weltpolitischen Fortschreibungen der Moderne, zur tönenden Realität wurde: Mechanische Schwingungen wurden nun durch Mikrophone in Wechselströme umgewandelt, durch Telefone und Lautsprecher in akustische Schwingungen transformiert und so im doppelten Wortsinn >unerhörteく Klänge zu Gehör gebracht. ${ }^{6}$

Seit der Jahrhundertwende und besonders im Vorfeld des Ersten Weltkrieges griff auf nahezu allen gesellschaftlichen Feldern eine bisweilen aggressive Technologiebegeisterung um sich. Auf dem Feld der historischen Avantgarden wurde insbesondere den Futuristen die Maschine zum programmatischen Symbol eines bedingungslosen Fortschrittsdenkens. Die futuristische »Ekstase der Zerstörung, von Blut und Mord ${ }^{7}$, so bemerkte Fred Prieberg 1960, symbolisierte die Motivation, durch Vernichtung aller tradierten Formen einen leeren Raum für eine künftige Welt zu schaffen. Die Begeisterung der Futuristen für Maschinen und ihre ausgeprägte Kampfeslust deckte sich mit der gesellschaftlichen Stimmung und den zunehmend technischen Rüstungsanstrengungen im Vorfeld des Ersten Weltkriegs, die vor und während des Zweiten noch gesteigert werden sollten. ${ }^{8}$

Wenn auch bereits Heraklit von Ephesos im fünften Jahrhundert v. Chr. erkannte: `Krieg ist der Vater aller Dinge`, so werden die innovatorischen Leistungen der Kriege unter Historikern heute meist bestritten. Mit Blick auf die Regression des Kulturlebens und die kulturelle Agonie der Kriegsjahre während der nationalsozialistischen Herrschaft ist diese Skepsis einerseits angebracht - andererseits setzte gerade der kulturelle Kahlschlag nach 1945 einen ungeheuren Aufbruchswillen auf dem Feld der Kunst frei. Über das ideelle Innovationspotential hinausgehend, wurden infolge der Kriegsrüstungen auch technische Grundlagen für den künstlerischen Neuanfang geschaffen. Kaum einer hat die Bedeutung des Militärischen für das Zivile und das Ästhetische so prägnant zum Thema gemacht wie der Begründer der deutschen Medienkulturwissenschaft: Friedrich Kittler.

Wenn sich langsam auch unter Militär- und Technikhistorikern der Konsens und der Diskurs darüber mehren, dass Kriege technischen Innovationen den Boden bereiteten $^{9}$, ist Friedrich Kittlers medienarchäologische a-priori-Setzung des Technischen

6 Zur Geschichte der elektronischen Klangerzeugung siehe Elena Ungeheuer/Martin Supper: »Elektronische Musik«, in Ludwig Finscher (Hg.): Die Musik in Geschichte und Gegenwart (MGG), Band 2, Kassel 1995, Sp. 1717ff.

7 Prieberg: Musica ex Machina, S. 17f.

8 Siehe hierzu ausführlich den Abschnitt »Futuristengefahr«: Vom Kunstskandal zur Kunst des Skandals in der Exposition dieser Arbeit: Referenzen und Chiffren.

9 Darauf deutet eine zunehmende Zahl an Tagungen hin: »Zur Interdependenz von Krieg und Technik«, Würzburg (31.3.2014-1.4.2014); Aachen (14.11.2014); »Medien - Krieg Raum« Erlangen/Nürnberg (11.7.-13.7.2014); »Krieg der Ingenieure? Der Erste Weltkrieg in Technik und Wissenschaft«. 
und seine These vom bellizistischen Charakter der Medien ${ }^{10}$ in den traditionellen Geisteswissenschaften ähnlich umstritten wie die Maschinenmusik selbst: Rainer Bayreuther etwa bezweifelte »Friedrich Kittlers Bedeutung für die Musikwissenschaft «, da dessen kühne Behauptungen »an den gegenwärtigen Diskurs des Faches beim besten Willen nicht anschlussfähig « ${ }^{11}$ seien. Wenn Bayreuther befürchtete, dass »im weißen Rauschen des Medienaprioris [...] jeglicher Gehalt und alle wahrheitsfähige Bedeutung « ${ }^{12}$ verschwinde, reproduziert er damit eine Standardsituation der Technologiekritik, wie sie nicht nur der Medienmusik, sondern auch der Medientheorie vonseiten der klassischen Geisteswissenschaften kanonisch entgegenschlägt. Aus den Reihen der medienwissenschaftlich interessierten Historiker heißt es etwa, Telefon und Telegraf seien vor den Kriegen entstanden und damit - abgesehen vom Computer - unabhängig von militärischen Zäsuren zu betrachten. Die »Hypostasierung medialer Materialität zum Letztbegründungsargument ${ }^{13}$ unterschlage mithin alles - so bemerkte mit Dieter Mersch auch ein Vertreter der ästhetischen Theorie »was aus dem Maschinenmodell herausfällt, was also Medientheorie als Technikgeschichte nicht beschreiben kann. « ${ }^{14}$

Wenn demnach das Problem die Einlösung theoretischer Versprechen am konkreten Fall ist, kann die elektronische Musik ein solches Exempel statuieren: Hier ist der medienarchäologische Blickwinkel in der Lage, blinde Flecken der disziplinären Forschungstradition aufzudecken, wobei es gilt, »der Medientheorie den spezifischen theoretischen Einsatz der Geschichtswissenschaft, die historische Relativität, an die Seite zu stellen ${ }^{15}$ und anhand musikästhetischer Beispiele zu prüfen. Fakt ist, dass die beiden Weltkriege Zäsuren darstellten, die der Neuen Musik zu einem ihrer entschiedensten Sprünge in der Moderne verhalfen: der elektronischen Klangerzeugung. Im Ersten Weltkrieg verbesserten nachrichtentechnische Innovationen wie Telefon, Telegrafie und Funk nicht nur die Kommunikation im Feld; diese Errungenschaften leiteten nach 1918 auch das Zeitalter des massenhaft verbreiteten Radios ein und schlugen sich nicht zuletzt auch musikästhetisch nieder: Die Entwicklung von Instrumenten der Nachrichtentechnik wurde in den 1920ern durch die Konstruktion neuer elektro-mechanischer Musikinstrumente wie Leon Theremins >Ätherophon`, Thaddeus Cahils >Harmonium $<$ oder Friedrich Trautweins >Trautonium (flankiert. ${ }^{16}$

10 Vgl. hierzu insbesondere Friedrich Kittler: Grammophon, Film, Typewriter, Berlin 1986. Die Verschränkung von Kultur und Technik durchzieht sein komplettes Werk und kulminiert in dem unabgeschlossenen, als Tetralogie angelegten monumentalen Publikationsprojekt »Musik und Mathematik« (Paderborn 2009-2015).

11 Rainer Bayreuther: »Friedrich Kittlers Bedeutung für die Musikwissenschaft«, in: Musikforschung 65 (2/2012), S. 99-113, hier S. 99.

12 Ebd., S. 110.

13 Fabio Crivellari/Kay Kirchmann/Marcus Sandl/Rudolf Schlögl (Hg.): Die Medien der Geschichte. Historizität und Medialität in interdisziplinärer Perspektive, Konstanz 2004, S. $28 \mathrm{f}$.

14 Dieter Mersch: Medientheorien zur Einführung, Hamburg 2006, S. 207.

15 Jan-Friedrich Mißfelder: Endlich Klartext. Medientheorie und Geschichte, in Jens Hacke/Matthias Pohlig (Hg.): Theorie in der Geschichtswissenschaft, Frankfurt/New York 2008, S. 181-198, hier S. 197f.

16 Siehe hierzu weiterführend Peter Donhauser: Elektrische Klangmaschinen, Böhlau 2007. 
Zeitgleich forderte eine Vielzahl progressiver Komponisten, dass sich die Musikschaffenden nicht mehr eskapistisch den unzeitgemäß ländlichen Klängen des 19. Jahrhunderts, sondern Formen industrieller Arbeit zuwenden sollten. ${ }^{17}$ Ernst Krenek etwa verwendete in seiner Jazz-Oper Jonny spielt auf (1926) Geräusche von Telefonen, Staubsaugern und Eisenbahnen. Auch der amerikanische Bad Boy of Music, George Antheil, baute IInstrumente wie Propeller oder Schiffshupen in seine Kompositionen ein, denen er nicht nur technoaffine Titel - wie Mechanismus, Airplaine Sonata oder Ballet Mécanique - gab, sondern denen er die Technisierung auch durch eine enorme dynamische Bandbreite und mechanisch hämmernde Rhythmen einschrieb $[\delta-4]^{18}$

Mit ihrer Konjunktur wurde die Maschine allerdings zugleich, wohl nicht zuletzt infolge der Kriegs- und Krisenerfahrungen, als Zeichen für Zerstörung ausgewiesen und kulturell verarbeitet. Fritz Lang etwa koppelte in seinem Film Metropolis (1927) die kulturkritische Utopie an eine weibliche Roboterfigur mit dem Aussehen Marias und visualisierte damit die Gefahrenmomente der Mensch-Maschine-Dichotomie, die im Verlauf der Moderne und nochmals verstärkt durch die Digitalisierung bis heute ein deutliches Crescendo erfahren hat. Auch die Experimente mit mechanischer und bald elektronischer Musik waren von Beginn an begleitet von negativen Stimmen, die den Klang als künstlich und >homunkulisch ‘ charakterisierten oder von ihrem >toten Klangcharakter s sprachen. ${ }^{19}$ Hatte der erste industriell geführte Krieg die perfekte Anti-Utopie des humanistischen Fortschrittsglaubens geliefert, wurde die Maschinenmusik zum eklatanten Symbol für die Entmenschlichung von Kunst und damit zum technologiekritischen Skandalon, das in den Konzertsälen, der Presse und Kulturkritik sowie in einschlägigen Publikationsorganen wie Melos oder den Musikblättern des Anbruch ${ }^{20}$ vielfach öffentlich angeprangert und verhandelt wurde.

Die Möglichkeiten der medientechnischen Nachrichtenübertragung veränderten indes nicht nur die Ästhetik, sondern im Anschluss an Philip Auslander ${ }^{21}$ oder Jay David Bolter und Richard Grusin ${ }^{22}$ auch die Wahrnehmungskonventionen und mithin die Rezeption und Perzeption von Musik. Auf der Distributionsebene schließlich »boten sich die neuen technischen Medien Schallplatte, Radio und Tonfilm an, die musikalische Botschaft einem breiteren Zuhörerkreis zugänglich zu machen. ${ }^{23}$ Die-

17 Hans Joachim Braun: Themen der Technik in der Musik des 20. Jahrhunderts, in Gerhard A. Stadler/Anita Kuisle (Hg.): Technik zwischen Akzeptanz und Widerstand. Gesprächskreis Technikgeschichte 1982-1996, Münster/New York/München/Berlin 1999, S. $167-$ 189, hier S. 168.

18 Siehe hierzu ausführlich auch das Expositionskapitel Referenzen und Chiffren.

19 Wolfgang Voigt: »Zum Problem der Akzeptanz und der >natürlichen〈 Klangwirkung elektronischer bzw. mechanisch-elektronischer Musikinstrumente«, in: Systematische Musikwissenschaft (6/2003), S. 307-312, hier S. 307.

20 Die Gesamtausgabe der Musikblätter des Anbruch wurde als Faksimile herausgegeben von der Universal Edition (Hg.): Der Anbruch 1919-1937 (CD-ROM), Wien 2001.

21 Philip Auslander: Liveness. Performance in a Mediatized Culture, London/New York 2008.

22 Jay David Bolter/Richard Grusin: Remediation. Understanding New Media, Cambridge 2002.

23 Braun: Themen der Technik in der Musik des 20. Jahrhunderts, S. 169. 
se reichweitenstarken und massenmedialen Potentiale wurden ab 1933 von der nationalsozialistischen Propaganda erkannt und ausgiebig genutzt: Mit den laut- und reichweitenstarken Klängen etwa eines >Hellertion` ergaben sich, wie es exemplarisch in einer nationalsozialistischen Zeitung hieß, »ungeahnte Möglichkeiten, [...] die Menschen unwiderstehlich in ihren Bann zu zwingen. ${ }^{24}$ Die Ästhetik konnte dem »deutschen Kulturempfinden« freilich nicht genügen, wie die Vossische Zeitung 1931 mit Verweis auf die Neue Musik feststellte:

»Was die rein musikalische Qualität des Hellertion betrifft, ließe sich nur sagen, daß die wildeste Negermusik weich wie Samt dagegen klingt; es ist eine so aufreizende, wüste Zwischentonmusik, daß Schönberg und Schreker wie Schlummerlieder dagegen klingen. ${ }^{25}$

Obwohl den Nationalsozialisten also kaum an einer Entwicklungsförderung der >entarteten $<$ und >kulturbolschewistischen` Musikavantgarde lag, legten ihre militärisch motivierten Forschungen auf dem Gebiet der Nachrichtentechnik einen medialen Grundstock für die elektronische Musik, die nach 1945 zu ihrem Einsatz kam. Ein markantes Beispiel für die Verknüpfung propagandistischer, militärischer und elektroakustischer Interessen im Dritten Reich ist der Elektroakustiker Oskar Vierling. ${ }^{26}$ Für die Olympischen Sommerspiele 1936 in Berlin entwickelte er mit der >GroßtonGlimmlampen-Orgel - auch genannt `KdF-Großton-Orgel - einen Vorläufer späterer Synthesizer und stattete die Reichsparteitage mit leistungsstarken Lautsprechern aus, um die Reden der NS-Größen verzerrungsfrei über das kilometerweite Zeppelinfeld in Nürnberg hörbar zu machen. Forschungsaufträge der Wehrmacht veranlassten Vierling $1941 \mathrm{zu}$ weiteren elektroakustischen Experimenten, die ihm den formal unzutreffenden, wenngleich griffigen Titel »Reichstoningenieur ${ }^{27}$ einbrachten.

Auch Gegner des NS-Regimes erkannten die Verbindung von militärischen und akustischen Innovationen: In den >Goldenen Zwanzigern den Einsatz von Pianolas in seinem Ballet Mécanique für Furore gesorgt; im Seekrieg brachten seine mechanischen Klaviere die Filmdiva Hedy Lamarr auf die Idee für ein `Secret Communication Systemく. Das 1941 eingetragene Patent US 2292387 $\mathrm{A}^{28}$ sollte die Störanfälligkeit funkgesteuerter Torpedos minimieren, indem ein Sender und ein Empfänger eine Piano-Notenrolle nutzten, um das Signal auf unvorhersehbare Weise in einem Bereich von 88 Frequenzen zu ändern (ein Klavier hat 88 schwarze und weiße Tasten) und damit zu codieren.

24 Zitiert nach Wolf D. Kühnelt: »Elektroakustische Musikinstrumente«, in Akademie der Künste (Hg.): Für Augen und Ohren (Katalog 127), Berlin 1980, S. 68.

25 Zitiert nach Voigt: Zum Problem der Akzeptanz, hier S. 308.

261933 entwickelte Vierling mit dem `Electrochord einen elektronisch verstärkten Flügel (heute im Deutschen Museum in München ausgestellt) und verfasste einschlägige Aufsätze: »Das elektrische Musikinstrument. Schwingungserzeugung durch Elektronenröhren«, in: Zeitschrift des Vereins deutscher Ingenieure, Band 76 (26/1932), S. 627; Ders.: Das elektroakustische Klavier, Berlin 1936; Ders.: Eine neue elektrische Orgel, Berlin 1938.

27 Diese Geschichte basiert auf einem Zufallsfund des Technik-Historikers Norbert Ryska, muss aber noch geschrieben werden. Siehe einleitend Frank Thadeusz: »Tarnname Schornsteinfeger «, in: Der Spiegel (16/2011), S. 122.

28 Das Patent findet sich bei der United States Patent and Trademark Office (USPTO). 
Zwar kam das Frequency-Hopping Spread Spectrum (FHSS), zu Deutsch: Frequenzsprungverfahren, im Zweiten Weltkrieg nicht mehr zum Einsatz; heute aber findet es sich in einer Reihe drahtloser Technologien. Bekannt wurden seine Erfinder allerdings nicht durch ihr Kriegsgerät, sondern durch ästhetische Skandale: Während George Antheil dank seiner provozierenden Maschinenästhetik als Bad Boy of Music in die Musikgeschichte des 20. Jahrhunderts einging, legte die Filmdiva 1933 mit ihrem Auftritt in Gustav Machatýs Film Ekstase die mutmaßlich erste Nacktszene der Filmgeschichte hin. ${ }^{29}$

Mit Blick auf Friedrich Kittlers These zur ästhetischen Umnutzung von Heeresgerät, belegt die Anekdote um George Antheil und Hedy Lamarr, dass nicht immer der Krieg den Anstoß zu medienmusikalischer Innovation gibt, sondern die Genese geradewegs andersherum verlaufen kann. Dass ästhetische Innovation für das Kriegerische nutzbar gemacht werden kann, zeigt etwa auch die Geschichte von Leon Theremin, der mit seinem >Äterophon` nicht nur das erste und bis heute einzige berührungslos spielbare Musikinstrument erfand; das medientechnische Prinzip des Musikgeräts, also die bewegungs- und abstandssensible Abhängigkeit des Signals von seiner Position, wurde zum Vorläufer moderner Alarmanlagen. ${ }^{30}$

Kittlers These darf also nicht als Einbahnstraße vom Militärischen zum Ästhetischen verstanden werden. Und doch gilt sie für die nachrichtentechnische Aufrüstung des nationalsozialistischen Regimes, wo die Forschungen auf akustischem Feld zwar vorrangig kriegerischen Zwecken dienten - und doch fast nebenbei die technischen Möglichkeiten für eine elektronisch generierte Musik schufen, die unmittelbar nach Kriegsende an den neu geschaffenen öffentlich-rechtlichen Rundfunkanstalten entstand. Vor diesem Hintergrund lässt sich Kittlers lineare Gleichung, dass der »Mißbrauch von Heeresgerät, das für Blitzkriege aus Panzerdivisionen, Bombergeschwadern und U-Boot-Rudeln konstruiert war, zur Rock Musik « ${ }^{31}$ führte, am historischen Material nachvollziehen: Zweifellos machten die Kommunikationstechniken im Zweiten Weltkrieg einen Innovationsschritt und legten die Medienbasis für die Entwicklung der elektronisch verstärkten und generierten Musik. Weit mehr noch als auf die Rock Musik allerdings, wiesen die technischen Errungenschaften auf die elektroakustische Kunstmusik, die unmittelbar nach Kriegsende - oft konkret auf der Basis von ausrangierten Gerätschaften der Nachrichten- und Fernmeldetruppen der geschlagenen Wehrmacht - entstand; und zwar Jahrzehnte vor Ausbildung der elektronisch verstärkten Unterhaltungsmusik. ${ }^{32}$

29 Die Geschichte von Hedy Lamarr und George Antheil wurde von Journalisten ausgiebig, in der Wissenschaft bislang nur ansatzweise erfasst. Siehe einführend Hans-Joachim Braun: Advanced Weaponry of the Stars, in: AmericanHeritage.com (4/1997).

30 Siehe hierzu meinen Vortrag auf der Jahrestagung der Gesellschaft für Medienwissenschaften (GfM) 2017 zum Thema `Zugänge : »Theremin: Ein alarmierender Missbrauch eines (meta)physi(kali)schen Musikgeräts« (Erlangen, 5. Oktober 2017).

31 Friedrich Kittler: »Rock Musik. Ein Mißbrauch von Heeresgerät«, in Theo Elm/Hans H. Hiebel (Hg.): Medien und Maschinen. Literatur im technischen Zeitalter, Freiburg 1991, S. 245-257, hier S. 252f.

32 Anna Schürmer: »Von >Arms« zu >Arts«. Musikalische Umnutzung von Heeresgeräten« (Feature), in: Deutschlandfunk (20.2.2016); Dies.: »Elektronische Musik, ein Missbrauch von Heeresgerät?«, in: Neue Musikzeitung (11/2014), S. 3. 
Die elektronische Musik wurde zu einem paradigmatischen Skandalon der Nachkriegsavantgarde und bot sowohl den Hörern und Kritikern in den Konzertsälen wie auch den Rezipienten an den Rundfunkgeräten viele Anlässe, um »zu diskutieren, zu schimpfen oder sich zu begeistern. ${ }^{33}$ Diese polarisierenden Gefühlsäußerungen belegten die besondere zeithistorische und ästhetische Bedeutung der Elektroakustik, indem sie zum musikalischen Sturz in die mediale Gegenwart führten: »Der richtige Augenblick«, so stellte Herbert Eimert einer der ersten Publikationen zu elektronischer Musik voraus, »ist die Elementarform der Geschichte. Denn nur wo Zeit und Epoche sich kreuzen, haben künstlerische Entwicklungen Beweiskraft. « ${ }^{34}$ Zeugen und Exempel dieser Geschichte sind drei Skandale der Schlüsseljahre 1953/54, welche die `Elektronische Eklatanz` der Medienmusik in Klang und Szene setzen.

\section{ESKaLATION 1953/54: Drei FaLLBEISPIELE}

Die Zeichen des Umbruchs in die Ära elektronischer Medien verdichteten sich in der Mitte des 20. Jahrhunderts. Dabei kristallisierten sich insbesondere die Jahre 1953/54 als Schlüsselmoment heraus, als unterschiedliche Spielarten der elektronischen $\mathrm{Mu}-$ sikerzeugung für eklatante Furore sorgten: In Donaueschingen feierte Pierre Schaeffers Musique concrète, die medientechnische Bearbeitung von Alltagsklängen mittels Tonband, eklatante Premiere. In Abgrenzung zur konkreten Lautsprechermusik experimentierte zeitgleich Karlheinz Stockhausen am Elektronischen Studio des WDR auf der Basis von Sinustongeneratoren an einer »authentischen Musik« durch synthetische Klangerzeugung. Einen Mittelweg beschritt Edgard Varèse, der sich 1954 mit Déserts - dem ersten Werk das elektronische Klänge mit Instrumentalmusik kombinierte - in die eklatante Chronik des Pariser Théâtre des Champs-Élysées einreihte.

\section{ıKonkretes Waterloo: Pierre Schaeffer}

Der französische Nachrichteningenieur Pierre Schaeffer begann in der Résistance gegen die deutsche Besatzung seine experimentelle Radioarbeit. Nach der Befreiung von Paris 1944 trat er als Rundfunkpionier an die Öffentlichkeit und entwickelte am Club d'Essay der Radiodiffusion-Télévision Française seine `Konkrete Musikı:

»Während die bisher gebräuchliche und übliche Musik von Anfang an in eine Partitur niedergeschrieben wird und dann Note für Note von einem Instrumentalisten oder Sänger wiedergegeben werden muß, ist die `Musique Concrète aus Tönen oder Klanggestalten komponiert, die bereits vorher mit elektro-akustischen Mitteln (Schallplatte, Tonband) festgehalten werden. ${ }^{35}$

33 Marietta Morawska-Büngeler: Schwingende Elektronen. Eine Dokumentation über das Studio für Elektronische Musik des Westdeutschen Rundfunks in Köln 1951-1986, Köln 1988, S. 23.

34 Herbert Eimert: »Gruß an Hanns Hartmann« (Vorwort), in Ders./Karlheinz Stockhausen (Hg.): Die Reihe, Band 1: Elektronische Musik, Wien 1955, S. 5.

35 Pierre Schaeffer: »Programmnotiz für die Donaueschinger Musiktage 1953«, in SWR: P/06204. Siehe auch Ders.: Musique Concrète - von den Pariser Anfängen um 1948 bis zur Elektroakustischen Musik heute, Stuttgart 1974. 
Damit bezeichnete Schaeffer die veränderten (Re-)Produktions-, Speicherungs-, Distributions- und Rezeptionsgrundlagen dieser >konkreten` Musik, die ohne aufführende Musiker auskam und Alltagsgeräusche in zeitlicher und räumlicher Entgrenzung ästhetisierte. Folgerichtig wurden die ersten Ergebnisse der phonogenen Klangexperimente 1948 unter dem Titel Etudes de bruits via Radio der Öffentlichkeit präsentiert. Ab 1949 kam es zur Zusammenarbeit des Ingenieurs Pierre Schaeffer mit dem Pianisten, Schlagzeuger und Komponisten Pierre Henry, die im Gemeinschaftswerk Orphée 53 [\$-12] mündete, das 1953 bei den Donaueschinger Musiktagen zum vieldiskutierten Skandalon wurde.

Schon der Entschluss der beiden Urheber, mit den neuen Medientechniken den Ur-Mythos der Musik - die Legende von Orpheus und Eurydike, die 1606 in Claudio Monteverdis L'Orfeo zur ersten Oper der Musikgeschichte wurde - aufzugreifen, zeugte von einer sendungsbewussten Herausforderung: In Anlehnung an »Orpheus, der die wilden Tiere zähmt, der die Götter zu Tränen rührt, aber dennoch [...] einsam bleibt«, so Schaeffer in seinem Werkkommentar, entlocke die musique concrète »der Natur neue Klänge, sie bezwingt die Mittel der Technik, indem sie auf elektroakustischem Wege neue Bereiche [...] des künstlerischen Ausdrucks erschließt. ${ }^{36}{ }^{3}$ Konzipiert als konkrete Kammeroper, verband das >spectacle lyriqueく Klänge vom Tonband mit Text, Live-Partien und szenischer Darstellung - und brachte den Donaueschinger Saal derartig ins Toben, dass »nicht mehr zu unterscheiden [war], was wütender Protest, was fanatische Zustimmung, was amüsierter Ulk, was Nervenentladung und was das Stück selber war. $\ll^{37}$

Im Verlauf des Stückes wechseln sich gesungene Passagen mit gesprochenen Rezitativen und schwelenden Interpunktionen elektroakustischer Klangsplitter ab. In der vierten Nummer >les monstres` wird mittels der Tonbänder eine unheimliche und bedrohliche Programmmusik erzeugt. Insgesamt aber wirkt Orpheé zu großen Teilen wie eine Hörspiel-Collage, die von vielen avancierten Komponisten als reaktionär und sogar dilettantisch empfunden wurde. Nur das eruptiv-kühne >rupture finale`, das Schaeffers Co-Autor Pierre Henry im Alleingang realisierte, provozierte qua Ästhetik heftige Reaktionen: Menschliche Stimmen werden zur Unkenntlichkeit verzerrt und also dehumanisiert. Die Schlüsselpassage ereignet sich nach etwa zehn Sekunden, wenn die elektronisch-schleifenden Katerakte donnernd detonieren.

Die elektroakustisch generierte Explosion erzeugte nicht nur schlachtenähnliche Szenen in der zum Konzertsaal umfunktionierten Donaueschinger Turnhalle, sondern war mit Blick auf die jüngste Vergangenheit auch höchst assoziationsreich. Marietta Morawska-Büngeler vermutete in den noch frischen Kriegserlebnissen einen Grund für die tumultuösen Reaktionen auf die akustischen Detonationen von Band. ${ }^{38}$ Derartige Schlüsse legen auch die zahlreichen Pressestimmen nahe. ${ }^{39}$ Zum überwiegenden Teil stürzten sich die Kritiker der Donaueschinger Musiktage 1953 in ihren Berichterstattungen auflagenträchtig auf die skandalöse Orpheé-Premiere und kamen in ihren Rezensionen sehr konkret auch auf ihre Kriegsassoziationen beim Zuhören der

36 Ebd.

37 Walter Dirks: »Bericht und Reflexion über Donaueschingen«, in: Frankfurter Hefte (11/1953), S. 833-841, hier S. 840f.

38 Morawska-Büngeler: Schwingende Elektronen, S. 95.

39 Eine Sammlung der Pressestimmen findet sich in SWR: P06485. 
>unerhörten`Klänge zu sprechen: die konkreten Tonbandmanipulationen wurden

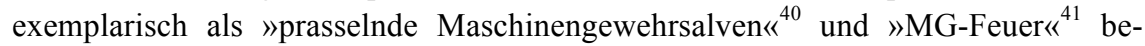
schrieben. Der Journalist Walter Dirks warnte gar, man könne »mit solcher >Musik [...] einen Krieg entfesseln«:

»Einmal kann man mit Hilfe der geduldigen Bänder und der enormen Lautsprecher quantitativ so gewaltig steigern wie man will: im Ernstfall, bis die Mauern zusammenbrechen wie in Jericho oder die Trommelfelle platzen und die Nervenfasern reißen. Zum zweiten kann man alle Assoziationen ausbeuten, welche den Menschen vertraut oder unheimlich sind [...]. ${ }^{42}$

Wenn die Hörer durch die enorme Lautstärke der elektronisch verstärkten und via Lautsprechern verteilten Klänge an Kriegsgeräusche erinnert wurden, so war die Herkunft dieser Assoziationen sehr konkret: Das Magnettonband war eine Kriegserfindung, die das deutsche Oberkommando bei Versuchen über Codebrechung entwickelt hatte. ${ }^{43}$ Sucht man nach weiteren Ursachen der skandalumwitterten szenischen Nachtaufführung von Orpheé 53, liefert die Interpretation des Musikpublizisten Rudolf Frisius weitere Anhaltspunkte:

$»$ Wenn man die heftige polemische Wut, die Pierre Schaeffer in Donaueschingen provozierte verstehen will, muß man sich klar machen, wie radikal seine konkrete Musik schon in den Anfangsjahren mit allen Ritualen des Konzert- und Festivalbetriebes gebrochen hatte. Die öffentliche Aufführung dieser technisch produzierten Musik war von Anfang an ein Skandalon und ist es weithin auch bis heute geblieben. $\ll^{44}$

Frisius betonte also die aufführungspraktischen Ritualbrüche durch die Tonbandmusik, die erst via Lautsprecher hörbar gemacht wurde und deren Klänge den Rezipienten ungeheuerlich anmuteten. Schaeffer selbst hatte in diesem Zusammenhang schon im März 1950, nach dem ersten Konzert mit musique concrète in der Ecole Normale de Musique, apodiktisch bemerkt:

»Die Gäste dieses Abends waren die ersten, denen etwas für Konzertbesucher Wesentliches vorenthalten wurde: Es saßen keine Musiker auf dem Podium. Diese Gäste erlebten auch als erste eine Probe des noch Ungehörten: nicht nur bislang nie gehörte Klänge, sondern auch Klangverbindungen, von denen sich nicht sagen ließ, ob sie vorherbestimmten Gesetzen von Komponisten folgten, oder ob sie einfach dem Zufall entsprungen waren. Und wenn von dieser neuen Sprache ein Bann ausging, so war sie doch auch befremdlich, um nicht zu sagen ungehörig. $\ll^{45}$

40 Karlheinz Ebert: »Standort und Richtung der Neuen Musik«, in: Badische Neueste Nachrichten (17.10.1953).

41 Kurt Honolka: »Konkrete, abstrakte und andere Experimentiermusik«, in: Stuttgarter Zeitung (13.10.1953).

42 Dirks: Bericht und Reflexion über Donaueschingen, S. 840f.

43 Kittler: Mißbrauch, S. 255.

44 Rudolf Frisius: Elektronik - Live? (1997), URL: http://www.frisius.de/rudolf/texte/ tx801.htm [Zugriff: 31.8 .2017$]$.

45 Zitiert nach ebd. 
>Unerhört` waren die elektroakustischen Klänge in der ganzen Bedeutungsvielfalt des Wortes: außerordentlich, nie vernommen sowie empörend - und das Publikum benahm sich entsprechend. Nicht nur Die Welt titelte infolge der tumultuösen Uraufführung auflagenträchtig: »Ein ungeheurer Skandal! « ${ }^{46}$ Weitere Schlagzeilen wie: »Die wilde Nacht von Donaueschingen $\aleph^{47}$, $»$ Klang, Geräusch, Beifall und Pfiffe ${ }^{48}$ oder »Schreckenskammer und Lachkabinett ${ }^{49}{ }^{4}$ verdeutlichen die heftigen Reaktionen des Premierenpublikums auf das »konkrete Opernfiasko ${ }^{50}$. Die Rezensenten mokierten sich gleichermaßen über die technische Verfasstheit wie auch über die künstlerische Qualität des Orphée. Für die ästhetische Kritik darf der Bericht in der Neuen Zürcher Zeitung, welche die als exemplarisch gelten. Hier hieß es, dass das, »was die Sensation der Musiktage bilden sollte«, sich »als ein eklatanter Fehlschlag« erwies,

»dessen künstlerische Unzulänglichkeit nur noch von der Anmaßung übertroffen wird, die darin liegt, das über eindreiviertel Stunden sich hinschleppende Lamento in bewußte Parallele zu den am Anfang neuer musikalisch-thetralischer Epochen stehenden Orfeo-Werke [Claudio] Monteverdis und [Christoph Willibald] Glucks zu setzen. Der tückischste Feind der >musique concréte hätte nicht heilloser kompromittieren können, als es deren Schöpfer mit diesem an Stil und Geschmacklosigkeit [...], an kindischen Spielereien mit Symbolen und an billigem Lyrismus (in Text und Musik) ertrinkenden Machwerk getan haben. $\ll^{51}$

Hier wurde also nicht nur eine Verletzung musikalischer Traditionen moniert, sondern auch Dilettantismus als Grund für den »eklatanten Fehlschlag« angegeben. Aber auch die technische Verfasstheit des Orphée provozierte das >konkrete Operfiasko<. Infolge der Ereignisse reflektierte Heinrich Strobel, der künstlerische Leiter der Donaueschinger Musiktage, in seinem Vortrag Neue Musik und Humanitas die Probleme, auf welche die Lautsprechermusik stoße:

»Man hat nicht mit Unrecht den Einwand erhoben, daß sich die neueste Musik immer mehr vom natürlichen Klang der Instrumente [...] entfernt. In der Tat nähert sie sich jenen neuen mechanischen Klangmitteln, die von kühnen Technikern, Ingenieuren und Forschern gefunden wurden [...]. Nur ist es zweckmäßig, daß die Techniker bei der Technik bleiben und nicht glauben, die Arbeit des Künstlers übernehmen zu können. Der Gedanke mag erschreckend wirken, daß der Komponist in Zukunft vielleicht wirklich nicht mehr mit Notenpapier und Bleistift, sondern mit Magnetophonstreifen und Lautsprecher arbeiten wird. [...] Die Frage ist: wird der Mensch ein Opfer der von ihm entfesselten mechanischen Klangmaterie oder wird er sie sich unterwerfen? ${ }^{52}$

46 Heinz Joachim: »Ein ungeheurer Skandal«, in: Die Welt (13.10.1953).

47 L. E. Reindl: »Die wilde Nacht von Donaueschingen«, in: Südkurier (15.5.1953).

48 Hans Heinz Stuckenschmidt: »Klang, Geräusch, Beifall und Pfiffe«, in: Die Neue Zeitung (14.10.1953).

49 Willy Werner Göttig: »Schreckenskammer und Lachkabinett in Donaueschingen«, in: Frankfurter Abendpost (14.10.1953).

50 N.N.: »Konkretes Opernfiasko in Donaueschingen«, in: Pfälzer Abendzeitung (14.10.1953)

51 N.N.: »Donaueschinger Musiktage 1953«, in: Neue Zürcher Zeitung (27.10.1953).

52 Heinrich Strobel: »Neue Musik und Humanitas«, der Vortrag wurde abgedruckt in der Beilage von Melos (11/1953). 
Strobels publizistische Reaktion auf die skandalösen Wellen der Empörung, welche die Lautsprecheroper schlug, thematisierte nicht nur den Vorwurf, dass diese Art von Musik die Sphäre der Kunst verlasse oder zumindest transformiere; er deutete darüber hinaus einen Paradigmenwechsel im Verständnis der abendländischen Musik an. Auch thematisierte der künstlerische Leiter der Donaueschinger Musiktage den Umstand, dass die Medienmusik von Technikern praktiziert werde und deutete damit das ästhetische Unvermögen des studierten Ingenieurs Pierre Schaeffers an. Der so Geschmähte reagierte seinerseits umgehend in einem offenen Brief an die Hessischen Nachrichten:

$»$ Ich bin nicht der Ansicht Doktor Strobels. [...] Das Finale von `Orphée [...] verdient nicht das Gelächter der Snobs, den provinzlerischen Wirbel und die doktrinären Zurechtweisungen von Donaueschingen. Erst ein wirkliches Publikum wird über unsere Arbeit entscheiden. [...] Was aber nun die Techniker betrifft, so erlaube ich mir in aller Bescheidenheit Herrn Dr. Strobel entgegenzuhalten, daß zur Zeit, da sich diese Musik im Entwicklungsstadium befindet, ein Techniker (der ich ja bin) förderlicher ist als etwa ein genialer Komponist. [...] Was nun die Kritiker betrifft - wie kann man ihre schlechte Laune ernst nehmen? Sie müßten sich ihrerseits mit einer neuen Materie vertraut machen! Die Dilettanten - das sind zur Zeit sie! « ${ }^{53}$

Pierre Schaeffer ätzte also gegen die provinzielle Lage Donaueschingens und das absolutistische Gebaren der deutschen Nachkriegsavantgarde. Auch kritisierte er die Unkenntnis der Kritiker in technischen Belangen. Der offene Brief wurde auch in der Zeitschrift Melos abgedruckt und dort unmittelbar der scharfen Reaktion des Kritikers Heinz Joachim gegenübergestellt:

»Der Duktus des offenen Briefes von Pierre Schaeffer spielt das alte leidige Lied, der abgedroschene Klagegesang der Uneinsichtigen und Unbelehrbaren, die sich so in ihre Ideen verrannt haben, daß ihre Urteilskraft getrübt scheint. [...] Und schließlich: ein lahmer Gaul wird ja nicht dadurch zum Derby-Sieger, daß man den Arzt, der ihn röntgt, moralisch disqualifiziert oder zum - Beckmesser stempelt. ${ }^{54}$

Mit der Allegorie des Beckmessers, dem pedantischen Kritiker aus Richard Wagners Meistersingern von Nürnberg, wurde dem Schöpfer der musique concrète ein wenig schmeichelhaftes Gesicht gegeben: Wagner hatte Beckmesser als streng regelkonformen, akademisch konservativen und an den Vorschriften klebenden Charakter gezeichnet, der zu eigener künstlerischer Leistung und Kreativität nicht fähig ist. Diese Typisierung wurde nun auf Pierre Schaeffer zurückgeworfen und blieb an ihm haften. Trotz der publizistischen Verbreitung der Donaueschinger Konflikte wurde Orphee 53 für ihn alles andere als ein succès de scandale, ganz im Gegenteil: Zwei Jahre nach den eklatanten Ereignissen fragte der französische Musikkritiker Antoine Golea bei Heinrich Strobel nach einer erneuten Vorführung der musique concrète in Donaueschingen an und distanzierte sich dabei explizit von Pierre Schaeffer:

53 Pierre Schaeffer: »Offener Brief an die Hessischen Nachrichten«, in: Melos (21/1954), S. $138 \mathrm{f}$.

54 Heinz Joachim: »Das Mißverständnis von Pierre Schaeffer«, in: Melos (21/1954), S. 140f. 
»Wie steht es mit der experimentellen Musik? Ich habe mit Pierre Henry, dem alleinigen Oberleiter der Pariser Musique concrète, seitdem Schaeffer praktisch, wenn nicht theoretisch, zurückgetreten ist, darüber [...] ein entscheidendes Gespräch gehabt. Er weiss ganz genau, dass die Katastrophe des letzten Jahres einer Einstellung zuzuschreiben ist, die vor allem durch das Amateurhafte in Schaeffers Wollen und Gebaren hervorgerufen wurde. Er hat auch der ganzen Arbeit des Studios eine entschieden seriösere und wissenschaftlichere Richtung gegeben. Er wäre gewillt, Ihnen ein Werk eigener Komposition [...] zu liefern, bittet Sie aber, um jede Komplikation mit Schaeffer [...] zu vermeiden, mit Ihrem Vorschlag an ihn persönlich heranzutreten, als jetzigen Exponenten des Pariser Studios. ${ }^{55}$

Der Vorfall beendete nicht nur die Zusammenarbeit zwischen den beiden CoAutoren des Orpheé, sondern besiegelte gewissermaßen auch die Ära der musique concrète. 1996 schrieb Josef Häusler im Rückblick, dass »trotz mancher Anstrengung kein Werk der Musique concrète von absolut musikalischem Rang entstanden ${ }^{56}$ sei. Auch Schaeffers Landsmann Pierre Boulez wetterte in der Enzyklopédie de la musique unter dem Stichwort:

»Maschinen, die nie in Ordnung sind, und ein angenehmer Schlendrian haben aus dem Studio der >musique concrète` einen Flohmarkt der Klänge gemacht, auf dem sich, Gott sei’s geklagt, nicht ein verborgener Schatz aufstöbern läßt. $\ll^{57}$

In eine ähnliche Kerbe schlug Karlheinz Stockhausen, der zwar 1952 bei einer Hospitanz im Pariser Club d'Essay von Pierre Schaeffer erste Erfahrungen mit elektronischer Klangerzeugung gesammelt hatte, sich aber bald deutlich von den Verfahrensweisen der musique concrète distanzierte: diese sei »nichts als die Kapitulation vor dem Unbestimmten« und ein »arg dilettantisches Glücksspiel «. ${ }^{58}$

\section{\Rauschende Interferenzen`: Karlheinz Stockhausen}

Karlheinz Stockhausen selbst wurde am Studio für Elektronische Musik des Westdeutschen Rundfunks zum Antriebsmotor einer >authentischen` elektronischen $\mathrm{Mu}$ sik, die auf Basis von Instrumenten der Nachrichten- und Kommunikationstechnik wie Schwebungssummern, Ringmodulatoren und Sinustongeneratoren geschaffen wurde - und damit ganz konkret auf ausrangiertem Heeresgerät; mehr noch können seine >rauschenden Interferenzen` als kunstimmanenter Ausdruck des Zeitalters elektronischer Medien gelten kann.

55 Brief von Antoine Golea an Heinrich Strobel (29.3.1955), in SWR: Ordner 1955 P 06260.

56 Rudolf Frisius: Elektronik - Live?

57 Pierre Boulez: »Musique Concrète«, in Francois Michel (Hg.): Enzyklopédie de la musique, Band 2, Paris 1959, S. 179f. 1977 gründete Boulez am Pariser Centre Pompidou das IRCAM (Institut de Recherche et Coordination Acoustique/Musique) als bis heute maßgebliches Forschungsinstitut »für die Forschung in allen Bereichen, die das Gebiet der Musik und Akustik betreffen.« Vgl. Pierre Boulez: Wille und Zufall, Stuttgart 1977, S. 25.

58 Karlheinz Stockhausen: »...wie die Zeit vergeht...«, in: Musik-Konzepte (19/1981), S. 3849, hier S. 42. 
Zeitgleich zur Entwicklung der Pariser musique concrète beschäftigte sich der Bonner Akustiker Werner Meyer-Eppler mit den technologischen Grundlagen einer elektronischen Musik, die sich aus rauthentischem` Tonmaterial generieren sollte. Als er nach einem Vortrag vor der Detmolder Tonmeisterkonferenz 1949 Herbert Eimert, den Rundfunkredakteur des (N)WDR traf, wurden die personellen und programmatischen Grundlagen für die Gründung des weltweit ersten Studios für Elektronische Musik 1951 am Westdeutschen Rundfunk gelegt. ${ }^{59}$ Die Institutionalisierung der Pionierleistung sowie die Zusammenarbeit von Schlüsselpersonen wie dem Physiker Meyer-Eppler, dem Tontechniker Robert Beyer und dem Redakteur Herbert Eimert machten den (N)WDR zum zentralen Ort der elektronischen Musik, die mit Karlheinz Stockhausen ihren künstlerischen Mastermind fand.

Auch Stockhausens Werdegang ist ohne die Kriegsereignisse nicht denkbar, wenngleich der 1928 in Mödrath bei Köln geborene Komponist nicht der Generation von Männern angehörte, die aktiv in Kriegshandlungen verwickelt waren. Gleichwohl prägten die Erlebnisse vor 1945 seine Arbeit ebenso ideell wie materiell: Bereits früh trat sein Vater Simon der NDSAP bei und opferte 1932 Stockhausens unter Depressionen leidende Mutter Gertrud dem NS-Euthanasieprogramm ${ }^{60}$, bevor er selbst an der Ostfront fiel. Sein Sohn erlebte das letzte Kriegsjahr als jugendlicher Einsatzhelfer in einem mobilen Lazarett hinter der Westfront. Diese Erfahrungen dürften ein Grund für den künstlerischen Werdegang, aber auch die ästhetischen Mittel Karlheinz Stockhausens gewesen sein, der zu einem herausragenden Vertreter der musikalischen Nachkriegsavantgarde wurde. Mit der visionären Bejahung eines bedingungslosen Schritts nach vorne wurde den jungen Komponisten nach 1945 die radikale Negation der Vergangenheit zum wichtigen künstlerischen Ausdrucksmittel. ${ }^{61}$ Dass sich diese Ästhetik im Schatten und infolge des Kriegs konstituierte, wird deutlich, folgt man den Ausführungen, in denen Stockhausen 1953 den musikalischen Aufbruch seiner Generation in Relation zu den Zerstörungen des Krieges setzte:

»Vergesse man aber nicht, dass selten eine Komponistengeneration so viele Chancen hatte und zu solch glücklichem Augenblick geboren wurde, wie die jetzige: Die Städte sind radiert - und man kann von Grund auf neu anfangen, ohne Rücksicht auf Ruinen und geschmacklose Überreste. ${ }^{62}$

Auf materieller Ebene manifestierte sich der fundamentale Neubeginn im Schatten des Krieges in einer der ersten Amtshandlungen, die Karlheinz Stockhausen 1953 am Elektronischen Studio des WDR ausführte: Der 25jährige Komponist musterte mechanische Musikinstrumente wie Mono- und Melochord aus und bat Fritz Enkel, den Leiter der Messabteilung, um Instrumente der Nachrichtentechnik, die aus alten Beständen der Nachrichtentrupps der Wehrmacht bestanden [Abbildung 10].

59 Dokumente zur Geschichte des Kölner Studio für Elektronische Musik finden sich im historischen Archiv des WDR: 10802.

60 Gedenkbuch und Datenbank der Gedenkstätte Hadamar: Gertrud Stockhausen 30.11.1900 27.05.1941, URL: http://www.gedenkstaette-hadamar.de (Zugriff 31.8.2017).

61 Siehe hierzu ausführlich das Kapitel Agon und Skandal.

62 Karlheinz Stockhausen: »Zur Situation des Metiers« (1953), in Ders.: Texte zur Musik, Band 1, Köln 1963, S. 45-61, hier S. 48. 
Zur Beschreibung der >Elektronischen Eklatanz Stockhausenscher Prägung bietet sich der Begriff der >Interferenzen an: Der physikalische Terminus bezeichnet die Überlagerung von Schallwellen zu einem neuen Klang interferierender Frequenzen (Sinustöne); mit kulturwissenschaftlicher Fokussierung bietet sich für das Phänomen der Begriff der Störung an. ${ }^{63}$ Beide Lesarten charakterisieren die synthetische Lautsprechermusik: Bemühten sich Akustiker durch destruktive Interferenz um eine Reduktion von Störgeräuschen, so wurden diese in Köln konstruktiv und produktiv für eine neue Ästhetik genutzt.

Am Elektronischen Studio des Westdeutschen Rundfunks wurde aus Weißem Rauschen - also Noise - Musik generiert. Auch dieser physikalische Begriff fand Eingang in die Kultur- und Medientheorie: Aus dem Bereich der Sound Studies wurde die ästhetische Komponente des Rauschens im künstlerischen Kurzschluss von Entropie und Information, Oberfläche und Hintergrund, Störung und Metaphysik sowie als Differenzraum für Fortschritt beschrieben. ${ }^{64}$ All diese im Begriffspaar der rauschenden Interferenzen angedeuteten Sinnzusammenhänge offerieren Anschlüsse an die elektronische Musik wie sie Stockhausen prägte: Mit der synthetischen Erzeugung von Musik auf der Basis von Geräten der Messtechnik und Maschinen der Nachrichtenübertragung radikalisierten die Experimentalkomponisten am Kölner WDR-Studio mit den avanciertesten Medientechniken ihrer Zeit das serielle Ideal der Nachkriegsavantgarde, das heißt: Alle musikalischen Parameter wie Tonhöhe, Tondauer, Artikulation und Klangfarbe wurden nach einheitlichen kompositorischen Prinzipien organisiert, der Klang bis in seinen spektralen Aufbau hinein kontrolliert.

63 Siehe zur Indienstnahme des Störungsbegriffs die Arbeit des ERC-Projekts »The Principle of Disruption« an der Technischen Universität Dresden (www.theprincipleofdisruption.eu).

64 Vgl. Sabine Sanio/Christian Scheib (Hg.): Das Rauschen, Hofheim 1995; Andreas Hiepko/Katja Stopka (Hg.): Rauschen. Seine Phänomenologie und Semantik zwischen Sinn und Störung, Würzburg 2001; Caspar Borkowsky: Produktivität der Störung - Über Information, Unfälle und weißes Rauschen, München 2004; Heike Pieler: »Weißes Rauschen«, 1. Ästhetik-Festival der Universität Bielefeld. Eine Dokumentation, Bielefeld 2006. 
Am 19. Oktober 1954 kam es im kleinen Sendesaal des Westdeutschen Rundfunks zu einem historischen Konzertereignis: Nach »Neuer Klaviermusik aus Amerika« es war die zweite Aufführung von John Cage in Europa, nur wenige Tage nach der verlachten Premiere bei den Donaueschinger Musiktagen ${ }^{65}$ - kam es nach der Pause zur ersten Vorführung der sieben ersten am Kölner Experimentalstudio entstandenen Kompositionen und damit zur »Geburtsstunde der elektronischen Musik«, wie sie Herbert Eimert definierte:

»Die elektronische Musik beruht auf der kompositorischen Verarbeitung von elektrisch erzeugten Tönen. Diese Töne werden nicht auf Instrumenten gespielt, sondern von einem Tongenerator unmittelbar auf das Tonband aufgenommen. [...] Die elektronische Musik ist also keine gespielte Musik und demnach auch keine Musik, die einen vorhandenen Musikstil imitiert. ${ }^{66}$

Die elektronische Musik aus dem Kölner Experimentalstudio provozierte kein konkretes Fiasko wie ein Jahr zuvor Pierre Schaeffers Orphée in Donaueschingen, erregte aber immer wieder Emotionen zwischen »Hilflosigkeit, Ablehnung, Angst, Verblüffung, Unsicherheit und Distanz ${ }^{67}$ - und das auf allen Rezeptionsebenen: Beim Publikum und den Kritikern konzertanter Aufführungen, bei den Hörern an ihren Radiogeräten sowie in den Fachkreisen der Avantgarde selbst. In der Presse hieß es infolge der ersten Präsentationen der elektronisch generierten Lautsprechermusik vielstimmig so oder ähnlich: »Das kann sich doch kein vernünftiger Mensch anhören! « ${ }^{68}$ Andere stellten fest, man müsse nicht nur das Hören neu lernen; auch »wer darüber berichten oder mitteilen will, muss sich eine neue Terminologie schaffen. $"{ }^{69}$ Auch Werner Meyer-Eppler bemerkte 1955 beim Baseler Kongress für konkrete und elektronische Musik: »Von nun an ist es erforderlich, auf die Terminologie der Akustik zurückzugreifen. ${ }^{70}$ Während der musiksprachliche Fachwortschatz um physikalische und elektroakustische Terminologie erweitert werden musste, wurde auch die Notation von Musik einem radikalen Wandel unterzogen:

Nach der jahrtausendlangen unmittelbaren Überlieferung von Musik, avancierte die Notenschrift im Schulterschluss mit dem Buchdruck seit dem 15. Jahrhundert zur führenden Kulturtechnik bei der Aufzeichnung von Klängen; im Zuge der Entwicklung elektronischer Musik wurde das tradierte >Aufschreibesystem` der klassischen Musik Mitte des 20. Jahrhunderts von einem weiteren Medienumbruch in Frage und auf die Probe gestellt, indem audiovisuelle Speicher- und Reproduktionsmedien die Notation überflüssig machten, indem sie Klänge originalgetreu aufzeichnen.

65 Siehe hierzu den Abschnitt John Cage und die transatlantische Neuvermessung der klingenden Welt im Kapitel Transkulurelle Transfers.

$66 »$ Musik der Zeit« (1.-6. Konzert 1954/55), Programmnotiz, in WDR: 2240.

67 Marietta Morawska-Büngeler: »Zukunftsmusik? 1954: Das Zweite Konzert des Studios für Elektronische Musik des WDR in Köln im Spiegel der Kritik«, in Gerhard Kilger (Hg.): Musik als Glück und Nutzen für das Leben. Macht Musik, Köln 2005, S. 66-75, hier S. 67.

68 N.N., in: Mannheimer Morgen (2.6.1956).

69 N.N., in: Aachener Nachrichten (23.10.1954).

70 Das Manuskript findet sich im Nachlass von Werner Meyer-Eppler im Archiv der Akademie der Künste Berlin. 
In Reaktion auf diese Herausforderung meldete die Universal Edition am 16. Mai 1956, dass mit der Partitur zu Karlheinz Stockhausens Studie II [\$-13.1] »soeben die erste elektronische Partitur erschienen ${ }^{71}{ }^{71}$ sei [Abbildung 11]:

Abbildung 11 - »Eklatanter Wandel des Aufschreibesystems von Klang«:

Partiturseite von Karlheinz Stockhausens \Studie II^ (1954).

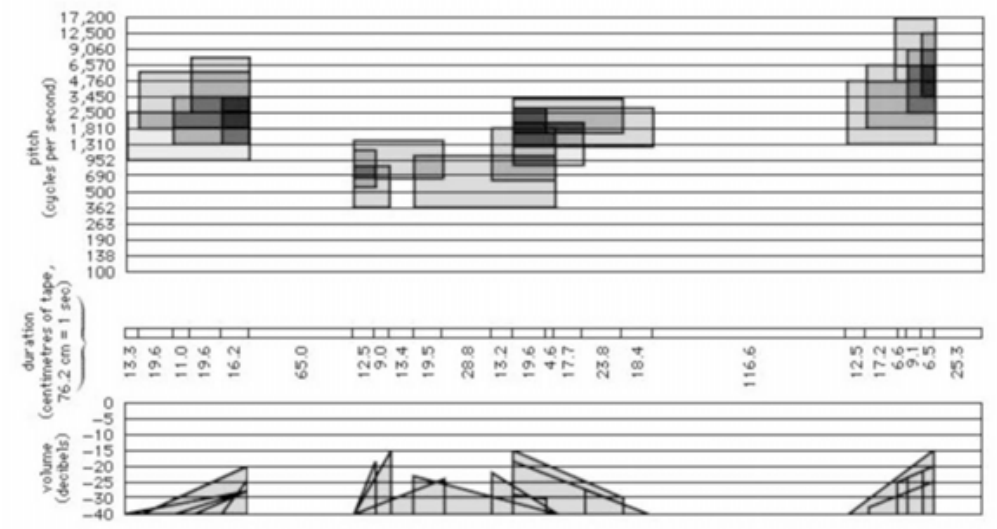

Diese elektronische Partitur notierte anstatt Harmonie, Dynamik und Instrumentation nun Frequenzen, Pegel und Schaltkreise. Diese Verschiebung bedeute, so bemerkte 1955 der Komponist Paul Gredinger, einen »eklatante[n] Wandel des Aufschreibesystems von Klang. «2 $^{72}$ Damit legte er eine Spur zu Friedrich Kittler, der Aufschreibesysteme als »das Netzwerk von Techniken und Institutionen« beschrieb, »die einer gegebenen Kultur die Adressierung, Speicherung und Verarbeitung relevanter Daten erlauben. ${ }^{73}$

Dieser medienarchäologische Zugang schärft den Blick auf die technischen Bedingungen, die das Entstehen gesellschaftlicher Diskurse sowohl ermöglichen als auch verursachen: »Die Rahmung, die man [...] mit dem Objekt der Partitur einst gefunden hatte«, so bemerkte Norbert Schläbitz 2003 aus dem Bereich der Sound Studies, wurde »instabil, als grenzerweiternd das Rauschen der Welt erforscht wurde, das sich in Partituren nicht mehr symbolisch festhalten ließ. ${ }^{74}$ Die Möglichkeiten nicht nur der Speicherung und Reproduktion, sondern auch der synthetischen Generierung von Klang ging also mit einer kulturtechnischen Krise der Sprach- und Schriftlichkeit einher.

71 Universal Edition: »Pressemeldung zur Partitur Karlheinz Stockhausens Studie II«, in WDR: 5769.

72 Paul Gredinger: »Das Serielle«, in Herbert Eimert/Karlheinz Stockhausen (Hg.): Die Reihe, Band 1: Elektronische Musik, Wien 1955, S. 34-41, hier S. 34.

73 Friedrich Kittler: Aufschreibesysteme 1800/1900, München 1985, S. 519.

74 Norbert Schläbitz: »Wie sich alles erhellt und erhält. Von der Musik der tausend Plateuas oder ihrem Bau«, in Marcus S. Kleiner/Achim Szepanski (Hg.): Soundcultures. Über elektronische und digitale Musik, Frankfurt am Main 2003, S. 107-136, hier S. 107. 
Konkret fehlte es den Hörern und Kritikern an diskursiven Beschreibungskategorien dieser Klangsprache und so behalf man sich mit einer an Metaphern reichen Metasprache. Da diese Musik nicht von dieser Welt zu sein schien, knüpften viele Rezensenten Assoziationen zu unerforschten Räumen: Hatte der Südkurier nach der Donaueschinger Premiere von Pierre Schaeffers Orphée 53 von »Unterweltvisionen, Tiefseemärchen, Unterseebootstragödien $\aleph^{75}$ sinniert, bemerkte der Kölner Stadtanzeiger mit Blick auf Karlheinz Stockhausen, man würde »an eine Taucherkugel erinnert, und ein wenig ähnelt ja auch der kühle Klangraum [...] einer unerforschten Unterwasserwelt, gleichen die neuen Klänge irgendwelchen seltsamen [...] Tiefseewesen.«76 In der Frankfurter Allgemeinen Zeitung meinte man dagegen, »Schwingungen aus dem All zu spüren, als ob wir die Sprache des Kosmos vernähmen. «77 Auch Hörer beschrieben die elektronischen Klänge in Zuschriften an den WDR als "phantastische Sternenmusik «, die sich dem Raketenzeitalter anpasse. ${ }^{78}$ Der einflussreiche Musikpublizist Hans Heinz Stuckenschmidt erklärte diesen Assoziationsreichtum 1955 nach dem konzertanten Erleben der ersten Experimente aus dem Kölner Studio damit, dass die »Elektronenmusik kein natürliches Analogon im Bereich der Musik» kenne:

»Denn an einer vom Menschen total prädeterminierten Musik [...] prallen die gewohnten Hörarten ohnmächtig ab. Und so wuchert die synästhetische Metapher. Das gehörte Tongemisch wird umgesetzt in die bekannten Phänomene, die jeder phantasiebegabte Hörer schildert: tönende Projektile aus dem Reich des Mineralischen; singende Metalle, Klang von Spiralen (ich zitiere, pars pro toto, einige meiner eigenen Notizen). $\ll^{79}$

Offenbar eröffnete gerade die scheinbar bezugsfreie und bis dato ungehörte Elektronenmusik eine Projektionsfläche, die bei den Hörern einen starken und beunruhigenden Assoziationsraum hervorrief. Dieser rekurrierte nicht nur auf utopische $\mathrm{Zu}$ kunftsszenarien und unerforschte Räume, sondern griff auch auf Anleihen aus der jüngsten Vergangenheit - den Kriegserlebnissen - zurück, wie ein Hörerbrief belegt:

»Erinnerungen steigen auf, Verdrängtes aus wohlbekannten Kellernächten der Luftangriffe, Bombenteppiche werden gelegt. Keller, Schächte, unterirdische Gänge, schäbig beleuchtet und nass. [...] Wozu der Schreck, Angst, Grauen? Warum sich beengen, einengen lassen. Dabei wirkt diese Musik auf den ganzen Körper, mehr noch als andere. ${ }^{80}$

Wie im Fall der konkreten Musik bezogen sich viele Assoziationen auf den Krieg, der diese Klänge technologisch erst mitermöglichte hatte und beschrieben deren starke affektive und sensorische Wirkmächtigkeit. Ein Kritiker vernahm in den dröhnen-

75 L. E. Reindl: »Die wilde Nacht von Donaueschingen«, in: Südkurier (15.5.1953).

76 N.N., in: Kölner Stadtanzeiger (21.10.1954).

77 N.N., in: Frankfurter Allgemeine Zeitung (15.10.1953).

78 Hörerzuschriften zu Sendungen Neuer Musik (1960-1978) finden sich in WDR: 10868.

79 Hans Heinz Stuckenschmidt: »Die dritte Epoche. Bemerkungen zur Ästhetik der Elektronenmusik«, in: Herbert Eimert/Karlheinz Stockhausen (Hg.): Die Reihe, Band 1: Elektronische Musik, Wien 1955, S. 17-19, hier S. 17.

80 Hörerbrief von Heddi Souchon (10.1.1964), in WDR: 10868. 
den, signalhaften und wummernden Artefakten aus dem Kölner Experimentalstudio $»$ Maschinengewehrknattern ${ }^{81}$. Die rund um den Saal postierten Lautsprechergruppen lösen, so befürchtete ein anderer, »bei dem sozusagen elektroakustisch umzingelten Publikum eine bedrängende Schockwirkung aus, die bei einer noch stärkeren Überziehung des Dynamischen ins Panische ausarten könnte. ${ }^{82}$

Noch eine Dekade später beschwerten sich Hörer mit Verweis auf ihre Kriegserlebnisse über Karlheinz Stockhausens »Musik die man nur am Lautsprecher hören kann « ${ }^{83}$. Ein Erich Seemann schrieb im Juni 1965 erbittert von einem »Skandal«: Der Lärm habe »mit Musik faktisch ebenso viel gemeinsam wie ein Bombeneinschlag einer berstenden Granate - er erinnerte mich liebenswürdig an die schönen Zeiten an der Front im Trommelfeuer. $«{ }^{84}$ Inmitten der entbehrungsreichen Nachkriegszeit sollte das Radio nach Meinung vieler Hörer der unterhaltenden Zerstreuung nach einem schweren Arbeitstag dienen. Damit eröffnen sich Anschlüsse an die Kulturkritik Theodor W. Adornos. ${ }^{85}$ Obwohl er in seiner Ästhetischen Theorie einen avancierten Stand des Materials predigte ${ }^{86}$, bemerkte der Philosoph 1954 in seinem Essay zum »Altern der Neuen Musik«, die elektronisch erzeugten Klänge hören sich an, »als trüge man [Anton] Webern auf einer Wurlitzerorgel vor « und bettete den Tadel in seine sozialwissenschaftliche Gesellschaftskritik ein:

»[D]ie elektronische Musik dementiert bis heute jedenfalls dadurch die eigene Idee, daß [...] in ihrer Praxis - analog dem vom Radio her bekannten Phänomen des musikalischen Konservenbüchsengeschmacks, nur weit extremer - die neu erworbenen Klangfarben untereinander monoton sich ähneln, sei es durch ihre gleichsam chemische Reinheit, sei es, daß jeder Ton durch die dazwischengeschaltete Apparatur geprägt ward. [...] Freilich steht dahin, ob dafür nicht die Beschränktheit und Einsinnigkeit der technischen Entwicklung in der gegenwärtigen Gesellschaft verantwortlicher ist als die Technik selbst. ${ }^{87}$

Die Kritik an der elektronischen Musik verband Adorno also unmittelbar mit der Kulturindustrie, die in ihrer »Reproduktion des Immergleichen « $88 \mathrm{zu}$ ästhetischer Differenz, der Grundlage großer Kunstwerke, nicht mehr fähig sei: »Kunst schlägt heute alles mit Ähnlichkeit. «89

81 Egon Treppmann: »Das kann sich doch kein vernünftiger Mensch anhören«, in: Mannheimer Morgen (2.6.1956).

82 Wolfgang Steinecke: »Höllengelächter und Gesang der Jünglinge«, in: Der Mittag (2./3.6.1956).

83 Zwischen 1964-1966 lief am WDR eine von Karlheinz Stockhausen verantwortete Sendereihe mit dem Titel »Kennen Sie Musik, die man nur am Lautsprecher hören kann?«

84 Hörererbrief von Erich Seeman (25.6.1965), in WDR: 10868.

85 Siehe hierzu weiterführend Anna Schürmer: »Interferences. Posthuman Perspectives on Early Loudspeaker Music«, in Lars Koch/Tobias Nanz/Johannes Pause (Hg.): Disruption in the Arts (erscheint 2017 in der Reihe Culture \& Conflict bei De Gruyter, Berlin)..

86 Theodor W. Adorno: Ästhetische Theorie (Gesammelte Schriften, Band 7), Frankfurt am Main 1996.

87 Adorno: Das Altern der Neuen Musik, S. 160.

88 Horkheimer/Adorno: Kulturindustrie S. 142.

89 Ebd., S. 128. 
Tatsächlich war Adornos Kritik auch dem frühen Entwicklungsstadium der Experimente geschuldet: Die elektronische Musik steckte zu diesem Zeitpunkt in den Kinderschuhen - es waren gerade einmal sieben Stücke produziert - und Pionierstücke wie Stockhausens Studie I und Studie II [ $\delta-13.1]$ sind zwar aus medientechnischer Perspektive Pionierleistungen der elektronischen Musikproduktion, ästhetisch aber eher Etüden, also ein Übungsstück im Prozess der Systematisierung synthetischer Klangfarbenkompositionen. Darüber hinaus sollte die von Adorno gefürchtete massenhafte Vervielfältigung - die Auslöschung jeglicher Differenz zwischen Original und Kopie, Einmaligkeit und Ware - die Musikkultur grundlegend verändern. Dies arbeitete auch Walter Benjamin mit seiner These vom Verlust der Aura des Kunstwerks im Zeitalter seiner technischen Reproduzierbarkeit ${ }^{90}$ heraus. Tatsächlich hat so konstatierte Thomas Macho - »einzig die Geschichte der Musik [...] Benjamins These bestätigt. Der Verlust jener auratischen Einmaligkeit und Originalität, die sich einer bestimmten und nicht wiederholbaren musikalischen Aufführung verdankte. « ${ }^{91}$

Allerdings übersah Adorno in seiner Kritik, dass die elektronische Musik geradezu der Versuch war, mit den Medien der Zeit eine ästhetische Differenz zum gleichförmigen Rauschen der Massenkultur zu erzeugen. »Ein zeitdiagnostisch und gesellschaftskritisch ambitionierter Avantgardismus «, so fügte Macho an, »mußte in dieser Situation vor allem versuchen, den selbstreferenziellen Charakter des akustischen Expansionsgeschehens anzugreifen. $\ll^{92}$ Die Pioniere der elektronischen Klangerzeugung taten dies selbst um den Preis einer radikalen Auflösung der geltenden musikalischen Konstitutionsprinzipien sowie ihrer kulturellen Isolierung. Sie nahmen in Kauf, von der >Kulturindustrie < entweder ignoriert oder abgelehnt zu werden - und zwar nicht als »Warenmarke [...], an deren Ton die Hellhörigen [...] schon die Prominenz witterten $\ll^{93}$. Statt zur Währung im Dienste einer `Ökonomie der Aufmerksamkeit々, wurde die Empörung gegen die frühe Lautsprechermusik zum Ausdruck der nivellierten Massenkultur gegen die intellektuell-sperrige Kunstmusik. Beispielhaft wünschte sich 1956 ein Hörer, »den bisherigen Einfluss der Intellektuellenschichten auf den Westdeutschen Rundfunk zu brechen. «94 Mit ähnlicher Stoßrichtung schrieb bereits 1954 ein Kritiker von Die Tat:

»Die Menschen wollen Dinge hören, von denen sie glauben können, daß es Musik ist [...], der ganze Zauber der seriellen, punktuellen und elektronischen Musik [wäre] längst verflogen, wenn nicht gewisse Radiostationen durch Bereitstellung von Laboratorien und Erteilung von Aufträgen dieser totgeborenen Sache immer wieder Leben einzuhauchen versuchten. ${ }^{95}$

90 Walter Benjamin: »Das Kunstwerk im Zeitalter seiner technischen Reproduzierbarkeit«, in Ders.: Gesammelte Schriften, Band 1, Frankfurt am Main 1980, S. 471-508.

91 Thomas Macho: »Weltenlärm, Schweigen, Stille«, in: Österreichische Musikzeitschrift (78/1994), S. 440-445, hier 442f.

92 Ebd., S. 443.

93 Horkheimer/Adorno: Kulturindustrie, S. 140.

94 Hörzuschrift von Willi Ullrich an den Intendanten des Westdeutschen Rundfunks (2.4.1956), in WDR: Ordner 05769.

95 Karlheinz Ebert: »Elektronische Musik«, in: Die Tat (1954), zitiert nach MorawskaBüngeler, Zukunftsmusik, S. 72. 
Empörten sich Anhänger der Unterhaltungsmusik gegen die doppeldeutig unerhörten Klänge, sprengte die elektronische Musik auch für Hörer klassischer Kunstmusik die heile Welt der Tonalität sowie das bürgerliche Konzertzeremoniell. Denn mit den neuen Möglichkeiten der Speicherung und Distribution von Musik machte das Radio den Konzertbesuch und damit das direkte Musik-Erleben obsolet: durch Sendungen von Mitschnitten und Live-Übertragungen wurden die heimischen Wohnzimmer zu Konzertsälen. Herbert Eimert erkannte im Faktor der Entgrenzung die spezifische mediale Zeitgebundenheit der elektronischen Lautsprechermusik:

»Denn in fast beängstigender Weise wird in dieser die Frequenzen einschmelzenden Musik die Atonalität amortisiert [...]; der Schock scheint wie auf weite, ferne Strecken verteilt. Das ist ein neuer Zustand, der [...] landläufig [...] nicht bekannt ist. [...] Die elektronische Musik gehört in der epochalen Begegnung von akustischer und kompositorischer Situation ganz und nur zu uns. [...] Ihre reproduktive Gebundenheit an den Lautsprecher [...] läßt zuletzt den Gedanken wagen, es könne die auf Band und Platte gebannte Sinfonie das Surrogat und die elektronische Musik das Echte sein. ${ }^{96}$

Der musikalische Einsatz von Reproduktions- und Verstärkungstechnologien verwischte nicht nur die Grenzen zwischen Studio und Bühne, sondern auch die korrespondierenden Funktionsweisen von Autorschaft und Aufführung; das >Lautsprecherdispositiv bedeutete, gesprochen mit Kim Cascone, einen »Verstoß gegen die Regeln musikalischer Performance. $«{ }^{97}$ Es kam zu einer paradigmatischen Entgrenzung, in deren Zuge die polarisierten Debatten, die bis dahin in den Auditorien ausgefochten worden waren, in die Haushalte mit Radiogeräten wanderten und sich statt in Saalschlachten in empörten Hörerbriefen äußerten. 1965 etwa bat der Westdeutsche Rundfunk explizit um Meinungen zur Sendereihe »Kennen Sie Musik, die man nur am Radio hören kann? ${ }^{« 98}$ Wenn dieser Titel das \Unsichtbar-werden` der Musik im Zeitalter ihrer technischen Reproduzierbarkeit illustriert, belegen die zahlreichen und teils hochaffektiven Zuschriften auch eine Entgrenzung der Gefühle des Hörers.

Zwar gab es live immer seltener Einspruch, da das bürgerliche Publikum den Veranstaltungen Neuer Musik immer öfter fernblieb. Dagegen schalteten sich im Radio - zumal vor seiner Privatisierung und dem Siegeszug des Fernsehens - auch >normale Hörer in Sendungen von und über die Musikavantgarde ein. Wie in den Konzertsälen, waren ihre nun nachrichtentechnisch delokalisierten Reaktionen sehr gespalten. Die Kritik spiegelte neben der regelmäßigen und bis heute virulenten Klage über die Rundfunkgebühren auch reichlich Polemik gegen die synthetischen und unerhörten Klänge. So hieß es etwa: »Man kann doch so etwas ganz unmöglich $\mathrm{Mu}$ sik nennen. Jedenfalls kein Mensch mit normalem Verstand. [...] Damit könnten Sie

96 Herbert Eimert: »Die sieben Stücke«, in Ders./Stockhausen: Elektronische Musik, S. 8-13, hier S. 11f.

97 Kim Cascone: »Deterritorialisierung, historisches Bewusstsein, System. Die Rezeption der Performance von Laptop-Musik«, in Kleiner/Szepanski: Soundcultures, S. 101-106, hier S. 101.

98 Hörerzuschriften zur Sendung »Kennen Sie Musik, die man nur am Lautsprecher hören kann?«, in WDR: 10868. 
höchstens Tiere im Urwald zum Selbstmord verleiten. ${ }^{99}$ Ein anderer Hörer klagte über das »unglaubliche Gewimmer, dann wieder wahnsinniges Geplärre [...]. Ja, hätte meine Vernunft nicht über Gefühl und Empfindung gestanden, ich hätte mein Gerät in Stücke geschlagen. « ${ }^{100}$ Neben Wut kam auch diskreditierende Komik zum Vorschein, wenn es etwa hieß: »Sämtliche kalt und heiß Wasserhähne haben wir laufen lassen, doch gegen diese `herrlichen Kompositionen $`$ kamen wir nicht an. Am Schluß der Sendung lagen wir alle vor Lachen auf dem Fußboden. ${ }^{101}$ Die Reaktionen an den Radioapparaten waren also den performativen Tumulten bei Live-Aufführungen durchaus vergleichbar.

Aber auch in den Konzertsälen kochten die Gemüter immer wieder über. Bezeichnenderweise fühlten sich auch die physisch anwesenden Hörer provoziert durch die unsichtbaren Klänge aus den Lautsprechern. Besonders deutlich wurde dies am 30. Mai 1956 anlässlich der Kölner Uraufführung von Karlheinz Stockhausens frühem Meisterwerk der elektronischen Musik: dem Gesang der Jünglinge [א-13.2]. Ursprünglich als >Funkmesse` für den Kölner Dom konzipiert, aber vom Erzbischof Kardinal Frings als unpassend abgelehnt, schuf der Komponist auf der alttestamentarischen Textgrundlage vom »Gesang der Jünglinge im Feuerofen« das erste Werk elektronischer Raummusik. Nicht nur die religiöse Thematik und die zeithistorisch brisante Konnotation der jüdischen Jünglinge im Feuerofen barg Konfliktpotential ${ }^{102}$, sondern auch die elektronische Konzeption: »Befreit von den physischen Grenzen irgendeines Sängers« wollte der Komponist »gesungene Töne mit elektronisch erzeugten in Einklang [...] bringen: sie sollten so schnell, so lang, so laut, so leise, so dicht und verwoben, in so kleinen und großen Tonhöhenintervallen und in so differenzierten Klangfarbenunterschieden hörbar sein, wie die Phantasie es wollte. $«{ }^{103}$ Rezensenten der Uraufführung am 30.05.1956 im großen Sendesaal des WDR [Abbildung 9] kombinierten daraufhin in ihren Kritiken den Vorwurf der Blasphemie mit einer grundsätzlichen Technologiekritik:

$»$ Der Eindruck ist niederschmetternd. Die Knabenstimme wird >manipuliert $<$. Eine vox humana, das edelste Geschenk der Gottheit an den Menschen, wird wie Dreck behandelt, den perversen Möglichkeiten der Apparatur ausgeliefert [...] und fetzenweise in dem höllischen Klangbrei verkocht. ${ }^{104}$

Stockhausen hatte sein Stück zu einer Zeit für fünf Kanäle konzipiert, als Rundfunk und Schallplatte noch einkanalig (mono) ausgelegt waren: Erstmals wurden mit dieser Komposition »Schallrichtung und die Bewegung der Klänge im Raum [...] vom Musiker gestaltet« und mittels der fünf Lautsprechergruppen »eine neue Dimension

99 Brief von [Unleserlich] (23.7.1965), in: Ebd.

100 Brief von Marta Kamphausen (7.8.1965), in: Ebd.

101 Brief von [Unleserlich] (7.2.1963), in: Ebd.

102 Weitere Anmerkungen zu Karlheinz Stockhausens Gesang der Jünglinge finden sich im Abschnitt Passagen ins Medienalter.

103 Karlheinz Stockhausen: Gesang der Jünglinge (1956), in Ders., Texte zu eigenen Werken, S. 49-68, hier S. 49.

104 Alfons Neukirchen: »Und es rauschten weiß die Sinus-Töne«, in: Düsseldorfer Nachrichten (2.6.1956). 
für das musikalische Erlebnis erschlossen. $\ll^{105}$ Bei der Aufführung wurde das Publikum von den im Raum verteilten Lautsprechern quasi akustisch umzingelt. Eine Fotografie der Premiere zeigt, wie die Hörer gebannt auf die Bühne blicken - auf der sich lediglich ein Lautsprecherpaar befindet [Abbildung 9]. Und eben hier lag das Skandalon begründet: In einer Rezension mit dem Titel »Entmaterialisierte Musik für fünf Lautsprecher« hieß es, Stockhausens Gesang der Jünglinge verunsichere und errege »durch den gleichsam magischen Effekt der körperlos klingenden Maschinen. ${ }^{106}$ Andere berichteten irritiert von einer Musik »Ohne Musiker und ohne Instrumente ${ }^{107}$ und kritisierten die Degradierung der Interpreten:

»Diese Musik existiert nur auf dem Tonband, auf dem der Komponist die von einem Generator erzeugten elektrischen Töne nach einem genau festgelegten akustischen Diagramm montiert [...]. Der Konzertbesucher sitzt im Saal keinem Podium mit spielenden Menschen und gespielten Instrumenten gegenüber, sondern lediglich an mehreren Stellen des Raums postierten Apparaten, aus denen die Töne ans Ohr dringen [...]. Der Konzertsaal ist bar jener Atmosphäre, die seit je das Fluidum künstlerischer Darbietungen bestimmt. ${ }^{108}$

Diese Kritik gründete auf dem Verlust der >Aura und insbesondere im fundamentalen Angriff der Elektroakustik auf das musikalische Kunstwerk: Bis dato hatte das Werkkonzept ein künstlerisches Konstrukt mit einem Anfang und einem Ende umfasst, geschaffen von einem Komponisten und notiert in einer Partitur, die von Musikern vor einem räumlich versammelten Auditorium interpretiert und aufgeführt wurde. Die elektronische Musik brach mit nahezu allen dieser Regeln: Musikästhetisch wurden figurative Elemente wie Themen und Motive vermieden, dagegen regierten Zahlenreihen und Codes das musikalische Geschehen. Statt ästhetischer Differenz wurde die Wiederholung des Immergleichen zur Definitionsgrundlage der synthetischen Klangerzeugung und -wiedergabe. Anstelle von Partituren entstanden Schaltkreise und die $»$ Maschine als Hypervirtuose $«{ }^{109}$ ersetzte nicht nur die Interpreten als menschliche Mittler, sondern machte auch die herkömmlichen Musikinstrumente obsolet. Der Komponist - dessen Handwerk immer mehr der Arbeit von Toningenieuren glich - wurde zum Gebieter aller Klänge und wortwörtlich Noise - das weiße Rauschen - zu Musik. Was aus den Lautsprechern strömte war also im wahrsten Sinne des Wortes >unerhört<: nie vernommen und Anstoß erregend.

105 Stockhausen: »Gesang der Jünglinge«, S. 49 f.

106 Alfred Brasch: »Entmaterialisierte Musik für fünf Lautsprecher«, in: Westfalenpost (9.6.1956).

107 Max K. Feiden: »Musik der reinen Töne im Kölner Funkhaus«, in: Weser-Kurier (29.5.1956).

108 N.N.: »Musik aus schwingenden Elektronen«, in: Wuppertaler General-Anzeiger (2.6.1956). Auch andere Zeitungen hoben die konzertierenden Lautsprecher in ihre Schlagzeilen, so Günter Schab in der Neuen Rhein Zeitung: »Es konzertierten: die Lautsprecher des Funks« (2./3.6. 1956) und derselbe im Hamburger Echo: »Es konzertierten: Vier Lautsprecher« (2.6.1956). Eine Pressesammlung findet sich in WDR: 11613.

109 Torbjörn Ericson: Die Maschine in der Musikpraxis, in Humboldt-Universität zu Berlin (Hg.): Musik und Maschine (PopScriptum, Band 7), Berlin 2002, URL: http://www2.huberlin.de/fpm/popscrip/themen/pst07/pst07_ericson.htm [Zugriff: 31.8.2017]. 
Das Publikum der Medienmusik quittierte diesen fundamentalen Angriff auf das musikalische Kunstwerk seinerseits mit einem Bruch der Verhaltensnormen - und zwar unabhängig davon, ob die elektronische Musik in den Konzertsälen oder an den Radioapparaten aufgeführt oder besser gesagt: abgespielt wurde. Sabine Sanio erkannte als ästhetische Strategie hinter dem Einsatz von Medientechnologien ein rezeptionsästhetisches Moment der performativen Selbstreflexion: In der Konfrontation von Geräusch und Rauschen verliere die musikalische Rezeption ihren »Charakter der Andacht und der kontemplativen Versenkung [...], angefangen mit einer Phase der Verständnislosigkeit, wenn alle Hinweise, wie das Geschehen überhaupt aufzunehmen sei, fehlen. ${ }^{110}$ Auch Klaus-Heinz Metzger, der Chronist der Nachkriegsavantgarde, bemerkte rückblickend, die »unsichtbare Stimme« wäre ein Schock gewesen und zeige, in welche Probleme das bürgerliche Konzertleben gerät, wenn die rituellen Aspekte ausfallen:

»Der Wegfall des Ritus bei dieser grundsätzlich akusmatischen Musik, wo es nichts zu sehen gibt, weil sie aus dem Lautsprecher kommt, zeitigt Probleme [...]. Es ist schwer, ohne einen agierenden Aufführenden den Anfang und das Ende zu markieren. Hier merkt man plötzlich: es fehlt das Ritual. $\ll^{111}$

Die Hörer füllten die entstandene Leerstelle innerhalb des Konzertzeremoniells mit eskalierenden und polarisierten Emotionen. Als die elektronische Musik die Ordnung der Klänge genauso wie die der Aufführungspraxis generalüberholte, brachen auch die Rezipienten aus ihren gewohnten Verhaltenskonventionen aus: in Form klingender Eklats.

\section{`Organisierte Interpolationen`: Edgard Varèse}

Einen emotional grundierten Eklat verursachte am 2. Dezember 1954 auch die Pariser Premiere von Edgard Varèses Komposition Déserts. Der Maler Lewin Alcopley erlebte den Skandal am legendären Théâtre des Champs-Elysées, das 1913 schon Schauplatz des berühmtesten Skandals der modernen Musikgeschichte - Igor Strawinskys Le (mas)sacre du printemps - war, als Augen- und Ohrenzeuge:

»Some of the antagonists sat next to each other in the same row and in the rows in front and back of each other. At the top of their voices they shot insults at each other, intermingled with gallic obscenities. [...] Everybody stood up - some standing on their seats - and insulted the neighbors. Some tried in vain to dislodge or break up the seats and use them as weapons. There was manhandling and fistfights and, above all, deafening yelling and angry sounds which, unfortunately, drowned Déserts. ${ }^{112}$

110 Sabine Sanio: »Rauschen - Klangtotal und Repertoire. Zur Selbstreflexivität der ästhetischen Erfahrung«, in Hiepko/Stopka: Rauschen, S. 207-224, hier S. 224.

111 Heinz-Klaus Metzger: »Rituelle Aspekte bürgerlichen Musiklebens«, in Barbara Barthelmes/Helga de la Motte-Haber (Hg): Musik und Ritual, Mainz 1999, S. 18-30, hier S. $22 \mathrm{f}$.

112 Lewin Alcopley: »Deserts at Paris«, in Paul-Sacher-Stiftung (PSS): »Sammlung Edgard Varèse« (KAT. 155), S. 1-2 
Wenn sich an dieser Schilderung auch die charakteristisch polarisierenden Affekte der Konzertbesucher spiegeln und die Ereignisse historisch in unmittelbarer Nähe zu den Skandalen der >konkreten öffnet Edgard Varèse in Hinsicht auf die `Elektronische Eklatanz` noch weitere Anschlussfelder. Allem voran ist die Uraufführung von Déserts in quellentechnischer Hinsicht ein Glücksfall: Als erste radiophone Übertragung wurde erstmals ein Konzert - und in diesem Fall auch der Skandal - vom Ort seiner Aufführung entgrenzt, via Rundfunk live in die Haushalte übertragen und anschließend archiviert. Die Aufnahme ist damit eine der frühesten akustischen Quellen, welche die Schilderungen Lewin Alcopleys verifiziert, wenn auch Tontechniker die Aufnahme von vielen der aufschlussreichen Störgeräusche reinigten [ $\delta-14.1]$. Zum anderen war Dèserts eine der ersten Kompositionen, die instrumentale Musik mit vorproduziertem Klangmaterial vom Tonband - den >Interpolations $«$ - kombinierte. Mit diesem vielschichtigen Terminus lassen sich wichtige Schlaglichter auf das Fallbeispiel werfen:

Hergeleitet vom lateinischen interpolare (umgestalten, verfälschen, entstellen) beschreibt der mathematische Begriff das Errechnen von Werten, die zwischen zwei bekannten Zuständen liegen - was im übertragenen Sinn geradezu paradigmatisch für eine musikhistorisch Verortung von Edgard Varèse gelten kann: Räumlich wie zeitlich stand der 1883 in Paris als Europäer geborene und 1965 in New York als Amerikaner gestorbene Komponist zwischen den Dispositiven, innerhalb derer sich die musik-historischen Diskurse um sein Werk entfalteten. Und gerade aufgrund dieser Außenseiterstellung zwischen den Generationen sowie zwischen >Alter und >Neuer Welt eignet sich Varèse als Mittler zwischen Raum und Zeit.

Wenn der Begriff der Interpolation aus der Mathematik stammt, verdeutlicht dies auch Varèses Ansatz, innovatorische Impulse aus Wissenschaft und Technik für ein physikalisch-objektives Ideal der Musikästhetik nutzbar zu machen. Dem entspricht auch sein Verständnis von Musik als son organisé - also >organisierter Klang « womit der Komponist die bislang streng befolgte Trennung zwischen Ton und Geräusch auszulöschen trachtete und seine monolithische Stellung festigte. Dieses Selbstverständnis zeigt ein Telegramm, in dem sich Varèse 1941 gegen die Verwendung des Begriffes durch John Cage verwehrte:

»Please desist using my expression Organized Sound as title for your series. I'm using it in my own activities, which I don't want confused with any others. Object your borrowing it for publicity. Shall consider unfriendly further use. ${ }^{113}$

Steht die Interpolation in den Naturwissenschaften für eine Klasse von Verfahren und Problemen, denen sich Varèse als Pionier ausgesetzt sah, wird der Begriff in der Literaturwissenschaft im Sinne von Erweiterung, Umgestaltung oder Verfälschung verwendet. In der Musik schließlich wird damit ein unvorhergesehener Einschub bezeichnet - also ein éclat im Sinne eines plötzlich und unerwartet auftretenden Klangs: der Kernkomponente der `Elektronischen Eklatanz $\prec .{ }^{114}$

113 Telegramm von Edgard Varèse an John Cage (5.7.1941), in Paul-Sacher-Stiftung (PSS): »Sammlung Edgard Varèse«, Korrespondenz (Mikrofilm, MF 300.1), S. 0720ff.

114 Die Bedeutungsvielfalt des Terminus inspirierte mich zur Benennung meiner Website www.interpolationen.de, wo meine Forschungen laufend aktualisiert werden. 
Nicht zuletzt um solche >unerhörten`Geräusche ging es Varèse, wie das folgende und viel bemühte Zitat Varèses zeigt:

»Ich wurde eine Art teuflischer Parsifal, nicht auf der Suche nach dem heiligen Gral, sondern nach der Bombe, die das musikalische Universum sprengen könnte, um alle Klänge durch die Trümmer hereinzulassen, die man - bis heute - Geräusche genannt hat. ${ }^{115}$

Sein künstlerisches Ziel - die 〉Befreiung des Klangs $<$ - verfolgte der Komponist mit seiner spröd-abstrakten, prozesshaft-melodietilgenden Klangsprache sowie einem visionären Glauben an die Technik. Bereits seit 1920 setzte er sich für akustische Forschungen ein - also bevor es überhaupt die Mittel für elektronische Musik gab. Hier wird eine weitere Differenz zur jungen Generation um Karlheinz Stockhausen deutlich, welche die technischen Medien ihrer Zeit nutzbar machte, während Varèse im französischen Fin de Siècle und durch die historischen Avantgardebewegungen nach der Jahrhundertwende sozialisiert worden war. Gerade aber diese zeitliche Verschiebung macht Varèse als eine Art >Transmitter` zwischen den Phasen der Neuen Musik so aufschlussreich. An seinem Beispiel lassen sich die Kontinuitäten und Brüche zwischen der Vor- und Nachkriegsavantgarde sowie die transatlantischen Transfers auf dem Feld der Kunstmusik im Verlauf der Moderne nachzeichnen. Varèses Schilderung der umkämpften Déserts-Premiere liefert hier weitere Anschlüsse:

»The premiere of Déserts at the Champs Elysees in Dec. 1954, conducted by Scherchen, took place in the midst of such an uproar that it cannot be said that Paris has yet hear it. It [...] pretended to an audience for the most part completely suninitiated s and outnumbering the sinitiated who did their best to out-brace the boos - in short a regular Parisian scandale. ${ }^{116}$

Mit seiner Beschreibung der Ereignisse als >regelrechtem Pariser Skandalı, gab Varèse selbst das Stichwort für die spezifische Ortsgebundenheit der tumultuösen Dèserts-Premiere im legendären Théâtre des Champs-Elysées, der auf die historischcharakteristische Skandallust der Pariser Auditorien verweist: Seit der Belle Epoque hatte sich die Stadt $\gg z u$ einer regelrechten Hochburg des Bühnenskandals $«{ }^{117}$ entwickelt und dem éclat zu einem Aufstieg vom Störfall zum Erfolgsmodell verholfen. Zur Jahrhundertwende nahm diese Entwicklung Fahrt auf und muss den jungen Edgard Varèse geprägt haben, der nicht nur 1912 den succès de scandale von Claude Debussys Prélude à l'après d'un faune erlebte, sondern ein Jahr später auch den wohl bekanntesten Skandal der Musikgeschichte: Igor Strawinskys Le (mas)sacre du Printemps am Théâtre des Champs-Elysées, eben jener legendären Stätte, an der 1926 auch George Antheil seinen größten Skandalerfolg feierte. ${ }^{118}$

115 Edgard Varèse: »Die Befreiung des Klangs«, in Heinz-Klaus Metzger/Rainer Riehn (Hg.): Edgard Varèse. Rückblick auf die Zukunft (Musik-Konzepte, Band 6), München 1983, S. 3-25, hier S. 3.

116 Brief von Edgard Varèse an Carlos Chavez (24.6.1960), in Paul-Sacher-Stiftung (PSS): »Sammlung Edgard Varèse«, Korrespondenzen, S. 985.

117 Petrik: Die Leiden der Neuen Musik, S. 26.

118 Siehe hierzu ausführlich die Exposition Referenzen und Chiffren. 
1954 provozierte hier Varèse 1954 mit Déserts den Eklat, um den es im Folgenden exemplarisch geht. Es wurde einer der letzten echten Premierenskandale in Paris und markierte darin einen Umbruch in der Typologie klingender Eklats. Wenn schon der von Hermann Danuser analytisch erfasste $»$ Paris-Modus $«{ }^{119}$ auf die skandalrelevante Komponente der Erwartungshaltung verweist, so wird dies noch deutlicher auf Seiten der Rezeption, wie Dieter Nanz in seiner Monographie über Varèse verdeutlichte:

»Daß >Varèse〈 und \Skandalく in der allgemeinen Rezeption bis heute eng zusammengehören, hängt zuerst mit den Mechanismen der amerikanischen Medien zusammen, dann aber auch mit dem Skandalbedürfnis der späteren Varèse-Rezeption, die in diesem Topos ein ebenso einfaches wie interessantes Identifikationsmuster fand. ${ }^{120}$

Der Zusammenhang der Topoi >Varèse` und `Skandal lässt sich in der Tat mit der medialen Berichterstattung - und nicht nur der amerikanischen - in Zusammenhang bringen: In Nicolas Slonimskys Lexicon of Musical Invective ${ }^{121}$ wird deutlich, dass sich Skandalisierungen durch Varèses kompletten Werdegang ziehen, wobei die kritischen Stimmen auch die historische Kontinuität von Vorbehalten gegen Neue $\mathrm{Mu}$ sik im 20. Jahrhundert dokumentieren.

Ganz oben auf der Liste der Varèseschen-Verriss-Prosa stehen animalische Vergleiche: War in Bezug auf sein erstes Skandalwerk Bourgogne (1910) von »Katzenmusik «122 die Rede, erinnerte Intégrales (1925) einen Rezensenten an »dog's cry of pain or a cat's yell of midnight rage [...]«123 und Hyperprism (1924) genauso wie wenig später Amériques (1926) an die Folgen eines Feueralarms in einem Zoo. ${ }^{124}$ Ebenso beständig wurde von Lärm gesprochen, den Varèse schließlich als Geräuschkunst musikalisieren wollte: Octandre (1924) wurde als »just a ribald outbreak of noise «125 und Ionisation (1933) schlicht als »Symphonie of noises «126 bezeichnet. Wie schon bei der konkreten und elektronischen Musik grassierten auch Assoziationen mit Kriegsgeräuschen: Bei Arcana (1927) hörte ein Rezensent »Schlachtenlärm, Schreie von Verwundeten « 127 und ein anderer "series of gunpowder explosions." $128 \mathrm{Die} \mathrm{Be}-$ schreibung von Hyperprism (1924) als "a catastrophe in a boiler factory" 129 weist dagegen eine Gedankenverbindung an den Lärm der fortschreitenden Industrialisierung auf. Vergleiche mit ehemals heftig skandalisierten Komponisten wie Arnold Schönberg (»impotent follower of that eminent Viennese Juggler«130) belegen darüber hin-

119 Danuser: Wer hören will, muß fühlen, S. 96.

120 Dieter Nanz: Edgard Varèse. Die Orchesterwerke, Berlin 2003, S. 58.

121 Nicolas Slonimsky: Lexicon of musical invective, New York 1953.

122 Bruno Schrader, in: Zeit am Montag (19.12.1910), zitiert nach: Ebd., S. 213

123 W. J. Henderson, in: New York Sun (2.3.1925), zitiert nach: Ebd., S. 214.

124 E. Newman, in: New York Evening Post (17.12.1924), zitiert nach: Ebd., S. 214; S. Chotzinoff, in: New York World (14.4.1926), zitiert nach: Ebd., S. 214f.

125 W. J. Henderson, in: New York Herald (14.1.1924), zitiert nach: Ebd., S. 213.

126 N.N., in: Havana Evening Telegram (3.5.1933), zitiert nach: Ebd., S. 217.

127 F. Brust, in: Germania (16.3.1932), zitiert nach: Ebd., S. 215.

128 O. Thompson, in: Musical America, (23.4.1927), zitiert nach: Ebd., S. 215.

129 O. Downes, in: New York Times (17.12.1924), zitiert nach: Ebd., S. 213.

130 W. J. Henderson, in: New York Sun (17.12.1924), zitiert nach: Ebd., S. 214. 
aus die Historisierung ästhetischer Provokationen. Im programmatischen Blatt Germania hieß es 1932 aus dem vorfaschistischen Deutschland zu Arcana: »Straussens Electra und der ganze Strawinsky sind Choräle gegenüber [dieser] Ausgeburt tönenden Wahnsinns. «131 Selbst Heinrich Strobel, der spätere Festivalleiter der Donaueschinger Musiktage, konstatierte: »Kein Ohr hält diese Musik auf Dauer aus [...]. Sie chockiert nicht und amusiert nicht. Sie ist einfach sinnlos. «132 Schließlich spiegelt sich in den Kritiken auch die affektiv-performative Komponente musikskandalöser Ereignisse: Varèse brächte "peaceful lovers of music to scream out their agony, to arouse angry emotions and tempt men to retire to the back of the theater and perform tympanal concertos on each other's faces «133; seine Musik lasse »friedsame Konzertbesucher zu Hyänen werden« ${ }^{134}$. Auch die komische Komponente der affektiven Publikumsäußerungen wurden erwähnt, wenn es etwa hieß: »Some people laughed because they could find no other outlet for their feelings. «135

Blickt man auf diese Chronik der Eklatanz muss streng genommen die komplette Karriere Edgard Varèses unter skandalanalytischer Sicht betrachtet werden. Und tatsächlich lassen sich weitere Angelpunkte bei den historischen Avantgarden finden: Im Paris der 1910er Jahre pflegte Varèse Bekanntschaft mit Künstlern des Kubismus und suchte nach seinem Umzug 1907 nach Berlin den Kontakt zu Ferruccio Busoni, in dessen kühnem Entwurf einer neuen Ästhetik der Tonkunst er seine eigenen Vorstellungen von der Befreiung des Klangs wiedererkannte. ${ }^{136}$ Besonders augenfällig sind Anschlüsse an die Futuristen, die Maschinen und das Geräusch verherrlichten und den bewusst inszenierten Skandal samt zugehöriger emotionaler Empörung zum künstlerischen Programm erhoben. ${ }^{137}$ Dieser Eindruck verfestigt sich, liest man Passagen aus Varèses Werkbeschreibung des unvollendeten Werks Espace, die wie ein futuristisches Manifest anmuten:

»Welt erwache. Die Menschheit auf dem Vormarsch. Nichts kann sie aufhalten. [...] Veränderte Rhythmen. Schnell, Langsam. Staccato, Schleppend, Stampfend, Hämmernd, Schreitend [...]. Das abschließende Crescendo macht den Eindruck, dass zuversichtlich, mitleidlos die Bewegung nie aufhören wird... [...] Stimmen im Himmel, als ob magische unsichtbare Hände die Knöpfe phantastischer Radios an- und ausschalten, den ganzen Raum erfüllen, sich überschneidend, ineinander übergreifend, einander durchdringend, sich spaltend, sich überlagernd, einander abstoßend, kollidierend, sich zertrümmernd. $^{138}$

131 F. Brust, in: Germania (16.3.1932), zitiert nach: Ebd., S. 215.

132 Heinrich Strobel, in: Börsen-Courier (1.3.1932), zitiert nach: Ebd., S. 217.

133 W. J. Henderson, in: New York Herald (5.3.1923), zitiert nach: Ebd., S. 215.

134 Paul Schwers, in: Allgemeine Musikzeitung (18.3.1932), zitiert nach: Ebd., S. 217.

135 W. J. Henderson, in: New York Herald (14.1.1924), zitiert nach: Ebd., S. 113.

136 Dolors Sabaté Planes: Apropos Avantgarde. Neue Einblicke nach einhundert Jahren, Berlin 2012, S. 238.

137 Siehe hierzu den Abschnitt »Futuristengefahr» in der Exposition: Referenzen und Chiffren. Weiterführend siehe Jean-Yves Bosseur: »Der Futurismus und das Werk von Edgard Varèse«, in Otto Koleritsch (Hg.): Der musikalische Futurismus. Ästhetisches Konzept uns Auswirkungen auf die Moderne, Graz 1976, S. 37-49.

138 Rudolf Frisius: »Edgard Varèse. Ein Audio-Portrait« (Feature, WDR 1999), URL: www.frisius.de/rudolf/texte/tx963.htm [Zugriff: 31.8 .2017$]$. 
Wenn das Werk Edgard Varèse auf die spezifische performative Ansprache der Futuristen verzichtet, so war es zweifelsfrei geprägt von den frühen europäischen Avantgardbewegungen. Andererseits schrieb er, der 1915 wie viele andere Pariser Künstler im Zuge des Ersten Weltkriegs nach New York aufgebrochen war, diese Zeilen 1947 als Amerikaner. Hier pflegte er Kontakte mit den Dadaisten und Marcel Duchamp und nahm schließlich 1927 die amerikanische Staatsbürgerschaft an. Varèse kann also nicht nur als Bindeglied der Vor- und der Nachkriegsavantgarde, sondern auch für die transkulturellen Transfers zwischen >Alter« und `Neuer Welt herangezogen werden und engagierte sich darüber hinaus als Pionier einer eigenständigen amerikanischen Musikavantgarde. ${ }^{139}$ Als eine verbindende musikalische Kategorie erwies sich dabei das Geräusch - also der Klang - den Varèse zu befreien trachtete.

War L'arte dei Rumori zunächst ein Hauptanliegen der Futuristen, gewann das Rauschen, wie Sabine Sanio bemerkte, »seit den zwanziger Jahren enorme Bedeutung für die gesamte amerikanische Kunst.«140 Nach 1945 wurde das Geräusch zu einem überwiegend amerikanischen Projekt, als sich die USA im Zuge der weltpolitischen Verschiebungen zunehmend vom hegemonialen Einfluss der europäischen Hochkultur emanzipierte, um eine originäre künstlerische Identität auszubilden. ${ }^{141}$ Zwar muss dabei allen voran John Cage als anarchische Lichtgestalt der spartenübergreifenden Avantgardebewegungen genannt werden, doch war der um knapp 20 Jahre ältere Varèse auch hier ein Pionier und Mittler.

1950 hielt der 67jährige Komponist bei den Darmstädter Ferienkurse für Neue Musik seinen Vortrag Musik auf neuen Wegen ${ }^{142}$ und beschrieb darin die »Krise« der zeitgenössischen Musik, die von allen Künste allein gewillt scheine, »sich von dieser gärenden neuen Welt fernzuhalten. « Kann diese Aussage sowohl auf die »sintflutartigen Ereignisse unseres Zeitalters« als auch als Anspielung auf die künstlerischen Errungenschaften und Möglichkeiten in der Neuen Welt gedeutet werden, benannte Varèse konkret zwei Ursachen als »Grund dieser Krisis«: Die »Mittelsmänner des Musikgeschäfts« - Manager und Presse-Agenten - sowie vor allem die Routine und das Sicherheitsverlangen der Musik selbst:

»Die Musik kann nur aus sich selbst, von innen befreit werden. Sie muß sich beschränken auf die Härten der schöpferischen Unrast, auf die Disziplin der beständigen Spannung, um so zurückzusinken in ihren normalen Zustand der Revolution [...], das wichtigste Element in einem Kunstwerk [ist] seine Neuheit. ${ }^{143}$

Wenn Varèse damit das avantgardistische Innovationsparadigma befeuerte, sah er den aktuellen Progress besonders in der elektronischen Erweiterung des musikalischen Materials:

139 Lange vor dem Aufbau von Institutionen zur Förderung der amerikanischen Avantgarde war Edgard Varése Gründungsmitglied der »International Composers Guild« (1921) sowie der »Pan American Association of Composers« (1928).

140 Sanio: Rauschen - Klangtotal und Repertoire, S. 224.

141 Siehe hierzu ausführlich das Kapitel Transkulturelle Transfers.

142 Edgard Varèse: »Musik auf Neuen Wegen« (1950), in Borio/Danuser (Hg.): Im Zenit der Moderne, Band 3, S. 92-97.

143 Ebd., S. 93. 
»Wir finden es nötig, veraltete Werkzeuge durch andere zu ersetzen, [...] aber wir fahren fort, in einen veralteten und komplizierten Mechanismus von Röhren zu blasen [...]. Aber das auf Menschenkraft beruhende Orchester wird ohne Zweifel einmal für die Musik dasselbe sein wie das Museum für die bildende Kunst. [...] Die elektrischen Instrumente sind der bedeutungsvollste erste Schritt zur Befreiung der Musik. Was die Zukunft betrifft [...], so wird der Interpret verschwinden [...]. Denn es ist logisch einen Apparat vorauszuahnen, auf dem jede beliebige Kombination von Rhythmen und Intervallen herzustellen ist [...]. Zwischen Komponist und Hörer wird kein verzerrendes Prisma stehen. ${ }^{144}$

Zweifellos waren Varèses Visionen von der Abschaffung der Instrumente und Interpreten revolutionär und rührten an der Urbeschaffenheit der tradierten Kunstmusik. Auch seine Einschätzung, dass radikale Veränderungen »fast immer als gefährlich und zersetzend betrachtet « ${ }^{145}$ werden, bestätigte sich 1954 bei der Pariser DèsertsPremiere, als das randalierende Publikum seine Teilnahmslosigkeit abschüttelte.

Wenn Varèse 1950 in »Musik auf neuen Wegen« die Krise der neuen Musik beklagte, befand er sich damals selbst in einer musikalischen Krisis: Seit 1936 - also fast 20 Jahre - hatte der Komponist kein einziges Werk vollendet, wohl auch wegen der technischen Unumsetzbarkeit seiner Visionen. Erst 1953 bekam er durch das Geschenk eines transportablen Ampex-Tonbandes neue Inspiration. Auch hier spielte der Zweite Weltkrieg die Rolle des technischen Innovators: Ein Soldat der US-Army Signal Corps hörte im deutschen Kriegsfunk eine Sendung klassischer Musik von frappierender Qualität; nach der Kapitulation entdeckte er die AEG-Magnetophone (Modell K4), die ab 1948 in den amerikanischen Ampex-Werken zunächst eins zu eins nachgebaut und dann weiterentwickelt wurden. ${ }^{146}$ Elektrisiert von den technischen Möglichkeiten des Ampex Tonbandes, schuf Edgard Varèse im reifen Alter von 70 Jahren mit Déserts eines der ersten mit Tonbandeinspielungen (Interpolations) kombinierten Instrumentalwerke und fügte der langen Skandalchronik des Pariser Théâtre des Champs-Elysée, rund 40 Jahre nach Igor Strawinskys legendärerem Le (mas)sacre du printemps und rund 30 nach George Antheils von Maschinenästhetik befeuertem Ballet Mécanique, einen weiteren Eintrag hinzu.

An drei Stellen unterbrechen die >Interpolationen<, drei zweikanalige Tonbandspuren von 10'08” Minuten Dauer, den gut dreizehnminütigen Instrumentalteil. Beruht die erste auf manipulierten Fabrikgeräuschen, ist das Rohmaterial der zweiten von Schlagzeug eingespielt, während die dritte konkrete und instrumentale Geräusche in einem Klangpool zusammenfasst. Ein- und Ausdruck von Déserts changieren zwischen aggressiven und hochdifferenzierten Schlagwerk- sowie aufreizend sparsamen Instrumentalpassagen, zusammengesetzt aus orgelpunktartigen Einzeltönen und fanfarenartigen Attacken in extremen Lagen. So entstand eine karg wirkende Klanglandschaft, die Varèses Biograph Fernand Oulette als eine Musik interpretierte, »die ihren Ursprung in den Archetypen des Schreckens und des Schmerzes hat.«147

144 Ebd., S. 95ff.

145 Ebd., S. 94.

146 Siehe hierzu NN: »Aus dem AEG K4 wird 1948 das AMPEX 200A«, online abrufbar unter URL: http://www.tonbandmuseum.info/ampex-200a.html [Zugriff: 31.8.2017].

147 Zitiert nach Helga de La Motte- Haber: Die Musik von Edgard Varèse. Studien zu seinen nach 1918 entstandenen Werken, Fulda 1993, S. 38 
Zwar war Varèse der Meinung war, dass die Imagination des Künstlers keinen unmittelbaren emotionalen Ausdruck finden, doch reagierte das Premierenpublikum ausgesprochen affektiv - das belegt auch der Mitschnitt der Premiere [ $\mathcal{\delta}-14.1]$ : Nach etwa fünf Minuten kam es zu ersten Zwischenrufen die sich im Laufe der Aufführung teilweise zu handfesten Störungen des Konzertes auswuchsen. Mit Blick auf die `Elektronische Eklatanz` sind die ersten heftigen Manifestationen von Unruhe tatsächlich im Verlauf der ersten Interpolation auszumachen, was sich während der beiden anderen Tonbandeinschübe wiederholt. Um das Getöse im Saal zu übertönen, schob Pierre Henry am Mischpult die Regler auf höchste Lautstärke. Ganz offensichtlich entlud sich hier Befremden, Ärger und Irritation des Publikums, von dem ein Teil auch erheitert reagierte: ein Hörer bereicherte das Klangmosaik etwa um die Imitation von Hundegebell. Neben zornigen Ausrufen und einem anschwellenden Lärm der Empörung fand sich also auch Komik im Gefühlshaushalt des skandalisierten Auditoriums. Deutlich wird an diesem Beispiel, dass das Publikum als aktiver Rezipient in das musikalische Ereignis eingriff: Indem es den reibungslosen Ablauf der Aufführung durch Unmutsbekundungen störte und einen deutlichen Kontrollverlust seiner Affekte zeigte, wurde es zum aktiven Akteur innerhalb der musikalischen Aufführung. Spielte der Komponist in abstrakter Weise auf der Klaviatur der Gefühle, fand der eigentliche Skandal beim emotional randalierenden Publikum statt.

Warum aber war das Pariser Premierenpublikum 1954 derartig empörunt? - Es waren die üblichen Vorwürfe der Rezipienten gegen die `Entmenschlichung` und >Dehumanisierung` der Elektronischen Musik sowie die Veränderung der bürgerlichen Konzertrituale. Wenn Edgard Varèse 1950 in seinem Vortrag Musik auf neuen Wegen ebenso apologetisch wie provozierend schrieben hatte, der Interpret werde in der Musik der Zukunft verschwinden - »zwischen Komponist und Hörer wird kein verzerrendes Prisma stehen $\aleph^{148}$ - wurde er nicht ganz zu Unrecht »des Wunsches der Zerstörung aller Musikinstrumente und sogar der Abschaffung aller Ausführenden angeklagt. «149 Ein Grund für die Tumulte war also nicht zuletzt auf den Angriff der elektronischen Musik auf das bürgerliche Konzertzeremoniell zurückzuführen.

Dies zeigte sich bei Edgard Varèse noch deutlicher als bei der musique concrète in Donaueschingen oder Karlheinz Stockhausens >authentischer Musik, denn die Premiere von Dèserts fand nicht vor einem Spezialpublikum, sondern innerhalb des regulären Konzertbetriebs statt. Noch dazu brachte der Dirigent, Hermann Scherchen, Déserts in einem Programm mit Pjotr Iljitsch Tschaikowskys Symphonie Pathétique und einer Ouvertüre Wolfgang Amadeus Mozarts zur Uraufführung. Der Verdacht liegt nahe, dass der ästhetische Kontrast des Repertoires seinen Teil zu den empörten Reaktionen der Konzertbesucher beitrug. Dafür spricht auch die Tatsache, dass die Folgeaufführung am 8. Dezember in Hamburg wesentlich ruhiger verlief, als Bruno Maderna Déserts gemeinsam mit Kontra-Punkte von Karlheinz Stockhausen aufführte, der auch die Interpolationen aussteuerte. Es darf also davon ausgegangen werden, dass diese homogene avantgardistische Programmgestaltung ein spezialisiertes Publikum anzog, während bei der Pariser Premiere ein bürgerliches Auditorium verstört auf die unerhörten Klänge reagierte. Daraus resümierte Dieter Nanz:

148 Varèse: Musik auf neuen Wegen, S. 97

149 Varèse: »Rhythmus, Form und Inhalt« (Vorlesung an der Universität Princeton 1959), in Metzger/Riehn (Hg.), Edgard Varèse. Rückblick auf die Zukunft, S. 17. 
$»$ Dass die unbestreitbar bildstarken >Plopp〈-Geräusche der Tempelblocks aus dem Lautsprecher als witzig, in den instrumentalen Partien aber durchwegs als akzeptabel empfunden wurden, weist das Gelächter als Resultat einer klassischen Konstellation der Komik aus, nämlich der unerwarteten Verbindung zweier nicht korrelierter Ebenen. «"

Zwar bezeugt dies die provozierende Wirkung der elektronischen Klänge, allerdings belegt die Inventarisierung der Proteste, dass nicht nur die unvertrauten elektroakustischen Geräusche das Auditorium erregten. Vielmehr stießen einige leise, in kleine Fragmente aufgesplitterte Instrumentalpassagen auf Unverständnis. Nanz folgerte, dass sich ein Teil der Zuhörer nicht so sehr über angeblich skandalöse Geräusche empörte, sondern bei dieser nichts mehr repräsentierenden Musik schlichtweg langweilte. Mitverantwortlich für den Skandal dürfte auch die eklatante Geschichte des Théâtre des Champs-Elysée und eine damit zusammenhängende Erwartungshaltung gewesen sein. Die besondere Aufmerksamkeit der Öffentlichkeit schließlich wurde nicht zuletzt deshalb erregt, weil hier erstmals ein Konzert mit stereophonischer Technik vom Rundfunk live übertragen wurde und als technische Sensation bereits im Vorfeld für Aufregung und gespannte Erwartungen gesorgt hatte. ${ }^{151}$

Parallel zu den unmittelbaren Reaktionen des Pariser Auditoriums kam es infolge der Live-Übertragung zu einer medial grundierten und erweiterten Rezeption: Noch während der Sendung beschwerten sich Rundfunkhörer an höchster Stelle - im Büro des Premierministers Pierre Mendès-France - über die verstörende Geräuschkulisse im Radio. Radiodiffusion-Télévision Française (RTF) wurde daraufhin angewiesen, die Übertragung zu beenden. ${ }^{152}$ Im Anschluss trugen internationale Pressevertreter die Berichte über die Tumulte in eine breite Öffentlichkeit. Das Journal du Dimanche war nach der Premiere überzeugt, dass das Théâtre des Champs-Elysée »seit 1913, als Strawinskys Sacré du Printemps aufgeführt wurde, keine dermaßen stürmische Stimmung erlebt $\ll^{153}$ habe und verwies damit auf einen der legendären und referenziellen Musikskandale aus den Gründerzeiten der Neuen Musik. In Deutschland schrieb die Rhein-Neckar-Zeitung von der »nervenanspannenden Wirkung dieser neuartigen Musik - einige Zuhörer hielten sich die Ohren zu, als die IndustrieKlänge [...] wie donnernde Katarakte mit Heul- und Schleiftönen durch Großlautsprecher ins Publikum geschleudert wurden. ${ }^{154}$

Die Kritiker der Déserts-Premiere bauten in ihren skandalisierenden Berichterstattungen auf lange etablierten narrativen Mustern auf, welche die Topoi >Varèse und `Skandal in einen unmittelbaren Zusammenhang stellten. Dieter Nanz vermutete in diesem Zusammenhang, dass im »Skandaltopos auch ein Aspekt von Varèses aktiver Selbstmythologisierung ${ }^{155}{ }^{10} \mathrm{zu}$ finden sei. Zum Mythos Varèse bemerkte schließlich auch Hermann Danuser:

150 Nanz: Edgard Varèse, S. 558.

151 Vgl. das Interview von Hermann Scherchen (Paris 20.4.1966), in: Luc Ferrari/Gérard Patris: »Hommage à Varèse« (Film), ORTF 1965.

152 Felix Meyer: Edgard Varèse. Komponist, Klangforscher, Visionär, Mainz 2006, S. 335.

153 Zitiert nach Helga de la Motte-Haber: Edgard Varèse (1883-1965). Dokumente zu Leben und Werk, Frankfurt am Main 1990, S. 70 ff

154 Zitiert nach Ebd.

155 Nanz: Edgard Varèse, S. 61. 
»Die Öffnung der Varèseschen Musik zur Sphäre der Geräusche [...] verbündet sich mit einer Rebellion gegen das allzu fein Domestizierte und entfesselt uralte barbarische Sitten [...]. Darum begründen den Mythos [...] auch all jene Elemente, die seine Musik im Zeichen der Provokations- und Skandalästhetik der Moderne festschreiben. $\ll^{156}$

Nanz allerdings erhob Einspruch gegen eine Gleichsetzung von Varèses Karriere mit dem Skandaltopos: »Die Mythologisierung von Varèses Euvre tabuisiert eine realistische und differenzierte Kritik und zieht ihr eine polemische Polarisierung in Befürworter und Gegner vor. $«{ }^{157}$ Wenn auch Hermann Danuser davon sprach, dass sich im Mythos Varèse »Faktum und Fiktum « ${ }^{158}$ verschränken, so bleibt als Fakt festzuhalten: Edgard Varèses musikhistorische Fabel wurde als Skandalgeschichte geschrieben - und erlebte als solche ein Happy End:

Bei der Weltausstellung 1958 in Brüssel entwarf der Architekt Le Corbussier den Philips Pavillon, den der griechische Komponist und Architekt Iannis Xenakis nach mathematischen Funktionen gestaltete ${ }^{159}$, während Edgard Varèse eine Mischung aus konkreter und vokaler Musik zu den dynamischen Licht- und Bildprojektionen komponierte: Sein Poème électronique [\$-14.2] ist das erste elektronisch-räumliche Environment, das Architektur, Film und Musik zu einem Raum und Zeit fusionierenden multimedialen Gesamterlebnis verband. Die visuelle Komponente lieferte eine »collageartige Litanei zur Abhängigkeit des Menschen im 20. Jahrhundert von der Elektrizität statt von Tageslicht, von virtuellen Perspektiven statt von Aussichten auf die Erde. ${ }^{160}$ Akustisch begleiteten diese Vision hunderte von an den Wänden befestigte Lautsprecher, die Klänge durch den Raum jagten. Kurzum: Varèse realisierte seinen Traum von der Befreiung des Klangs.

\section{UTOPIE UND DYSTOPIE:}

\section{PARADIgMEN DER MENSCh-MASChINE-DichotomiE}

Wenn die Geschichte der elektronischen Eklatanz auch eine vielgestaltige ist, lassen sich aus den angeführten Fallbeispielen doch historische Kontinuitäten und analytische Paradigmen herausfiltern, die nicht nur zurück-, sondern auch nach vorne weisen und zum Teil bis in die Gegenwart reichen. Diese lassen sich mit dem dialektisch und diskursiven Gegensatzpaar von Utopie und Dystopie in einem griffigen Bild fassen, denn: technische Neuerungen waren, nicht nur aber besonders auf dem Feld der Kunstmusik, stets begleitet von einer charakteristischen Dichotomie schwärmerischer und entgegengesetzt apokalyptischer Zukunftsvisionen.

156 Hermann Danuser: »Mythos Varèse«, in Heidy Zimmermann/Felix Meyer (Hg.): Edgard Varèse. Komponist-Klangforscher-Visionär, Basel 2006, S. 418-425, hier S. 424.

157 Nanz: Edgard Varèse, S. 61.

158 Danuser: Mythos Varèse, S. 418.

159 Vgl. hierzu weiterführend Richard Jarvis: Music to my Eyes: The design of the Philips Pavilion by Ianis Xenakis, Boston 2002; »The Architectural Design of Le Corbusier and Xenakis«, in: Philips Technical Review 20 (1958/1959), S. 2-8.

160 Marc Treib: Space Calculated in Seconds, Princeton 1996, S. 3 
Das Kreuzfeuer der Kritik speiste sich auch im Fall der elektronischen Musik aus den alten Ängsten vor allem Neuen und insbesondere aus dem Konfliktfeld Mensch versus Maschine. Die Eliminierung der klassischen Instrumente und ihrer Interpreten sowie die leeren oder nur durch Lautsprecher bevölkerten Bühnen beschworen bei den einen die Furcht vor einer >Entmenschlichung〈 und `Denaturierung〈 von Musik herauf, während andere die perfekte Kontrollierbarkeit der elektronischen (und später digitalen) Klangkunst rühmten. Die synthetischen, aus Algorithmen und Rauschgeneratoren geschaffenen Töne ließen Visionäre von der Befreiung des Klangs schwärmen, während Kulturpessimisten das Ende der westlichen Kunstmusik und damit zum wiederholten Male den Untergang des Abendlandes ${ }^{161}$ heraufziehen sahen.

Die Elektronische Musik stellte die Paradigmen des Musikmachens auf den Kopf und damit das musikalische Kunstwerk selbst in Frage. Die kritischen, belustigten und auch begeisterten Affektäußerungen von Kritikern wie Hörern wurden in dieser Situation zum Ausdruck einer für Umbruchphasen charakteristischen Unsicherheit. Diese Gefühle können als liminale Phänomene an der Schwelle zum Zeitalter elektronischer Medien verstanden werden, das von vielen zu einer neuen Epoche der Musikgeschichte stilisiert wurde - nur war man sich uneins, ob diese ein utopisches oder ein dystopisches Zukunftsszenarium bieten würde. Die Kontinuität der MenschMaschine-Dichotomie zeigt sich schließlich auch im Ausblick: So, wie die Mechanik in den 1920er und die Elektronik in den 1950er Jahren die Rezipienten polarisierten, beschwört heute die Digitalisierung gleichermaßen positive Visionen wie pessimistische Fiktionen von einem posthumanen Zeitalter der Musik herauf.

\section{Entmenschlichung und Denaturierung: „Was ist Musik?»}

Technische Innovationen haben von jeher die Angst vor der Maschine heraufbeschworen, die im Zusammenhang mit der elektronischen Musik unter den Schlagwörtern einer >Entmenschlichung « und 〉Denaturierung`von Kunst grassierte. Nach einer ersten Konjunktur während der Industrialisierung, erlebte die kritische Reflexion der Maschinenmusik in der Mitte des 20. Jahrhunderts einen vorläufigen Höhepunkt, der erst mit der digitalen Revolution um die Jahrtausendwende wieder annähernd die Heftigkeit jener Jahre erreichen sollte. Schon 1952 - also kurz vor den Schlüsseljahren der >Elektronischen Eklatanz`1953/54 - wurde in der Neuen Zeitschrift für Musik die Thematik >Musik und Technik ‘ auf- und von einem Pionier der Elektronischen Datenverarbeitung, Hans W. Ulbricht, angegriffen:

»[D]ie moderne Forschung kann niemals das erreichen, was für die wirklichen Meister des Instrumentenbaues die Hauptsache war: dem Instrument eine Seele geben! [...] Dieses unbestimmbare Etwas [...] ist aber das Element der Kunst [...]. Über die Zweckmäßigkeit einer Rationalisierung aller technischen Vorgänge braucht man nicht die geringsten Zweifel hegen. Eine Rationalisierung in der Kunst ist aber ein Totschlag an der Seele! « ${ }^{162}$

161 Oswald Spenglers »Der Untergang des Abendlandes« (Wien 1918/München 1922) erlebte in den beiden Nachkriegsdekaden eine deutliche Konjunktur und belegt so die Kontinuität dystopischer Zukunftsszenarien in historischen Umbruchphasen.

162 Hans W. Ulbricht: »Akustische Artistik oder elektrische Musik«, in: Neue Zeitschrift für Musik (2/1952), S. 69-74, hier 73f. 
Walter Benjamins 1935 geäußerte These vom Aura-Verlust des Kunstwerks im Zeitalter seiner technischen Reproduzierbarkeit hatte also knapp 20 Jahre später nichts von ihrem Erschütterungspotential verloren. In eine ähnliche Richtung zielte der $\mathrm{Mu}-$ sikwissenschaftler Prof. Walter Riezler, der im November 1953 auf Einladung der Münchner Akademie der Schönen Künste mit einer illustren und interdisziplinären Runde über »Die Künste im technischen Zeitalter « ${ }^{163}$ diskutierte. Nach Martin Heidegger, der die philosophische » Frage nach der Technik $"{ }^{164}$ stellte, sprach Werner Heisenberg aus Sicht der Quantenmechanik über »Das Naturbild der heutigen Physik $«{ }^{165}$. Es ist nur folgerichtig, dass man den Geisteswissenschaftlern bei dieser Frage einen Naturwissenschaftler zur Seite stellte, denn die technischen Entwicklungen rückten nicht zuletzt die Musik wieder in Richtung der altgriechischen téchne-dem umfassenden Verständnis der antiken Philosophie von Kunst, Wissenschaft und Technik als Verbund. Während Komponisten wie Edgard Varèse daraus eine utopische Vision von der >Befreiung des Klangs` ableiteten, fürchtete Riezler, dass die neuen Techniken mit der Entgrenzung von Zeit- und Räumlichkeit auch das Kunstwerk Musik auflösen würden:

»Die Schallplatte (und deren unvollkommene Vorstufe, der Phonograph) ermöglicht die Konservierung von Musik, und wird damit Herr über die Vergänglichkeit, der jede Aufführung eines Werkes bisher anheimfiel. Und wie die Zeit wird auch der Raum vernichtet, indem das Radio über alle Ferne weg die eben irgendwo erklingende Musik hörbar macht. $\ll^{166}$

Im Zuge der neuen Möglichkeiten von Speicherung und Distribution stand also auch für Rietzler der auratische Aufführungscharakter von Musik auf dem Spiel. Selbst die Komponisten reflektierten die Folgen des Medienwandels kritisch - und zwar sowohl publizistisch wie auch ästhetisch. John Cage etwa schrieb 1950 in einem Brief an Pierre Boulez, er habe eine Gesellschaft gegründet, die sich »Capitalist Inc. « nennt: »Jeder der ihr beitreten will, muß beweisen, daß er mindestens 100 Schallplattenaufnahmen mit Musikaufnahmen zerstört hat oder ein Aufnahmegerät. « ${ }^{167} 1958$ bemerkte der Amerikaner, ebenfalls mit Blick auf Schallplatten:

»Es wäre ein Akt der Nächsten- und sogar Selbstliebe, sie zu zerschmeißen, wo immer sie zum Vorschein kommen. Sie sind zwecklos außer für diesen Zweck und für die Urheberrechte, die der Komponist, tot seit nunmehr soundsovieldreißig Jahren, nicht mehr kassieren kann. « ${ }^{168}$

163 Bayerische Akademie der Schönen Künste (Hg.): Die Künste im technischen Zeitalter, München 1954.

164 Martin Heidegger: »Die Frage nach der Technik« (1953), in: Ebd., S. 70-192. Siehe auch Ders.: Vorträge und Aufsätze, Pfullingen 1954, S. 13-44.

165 Werner Heisenberg: Das Naturbild der heutigen Physik, in: Ebd., S. 43-69.

166 Walter Riezler: Die Musik, in: Ebd., S. 160-69, hier S. 162.

167 Brief von John Cage an Pierre Boulez (17.1.1950), in Nattiez: Dear Pierre - Cher John, S. 53-57, hier S. 55. Die Phrase entnahm Cage seiner »Lecture on Nothing« (1949), publiziert in Ders.: Silence. Lectures and Writings, Middletown 1961, S. 109-127.

168 John Cage: »Erik Satie« (1958), in Heinz-Klaus Metzger/Rainer Riehn (Hg.): MusikKonzepte (11/1988): Erik Satie, München, S. 29-36, hier S. 30. 
Ungeachtet dieser Kritik erkannte Cage in Anlehnung an die Medientheorien Marshall McLuhans einen "profund change, greater even than that from the Middle Ages into the Renaissance. ${ }^{169}$ Seine Ausführungen zeigen die frühe Anlehnung amerikanischer Komponisten an die Medientheorien McLuhanscher Prägung, während in Europa die kritische Theorie Adornos bestimmend für die Neue und mithin auch die elektronische Musik blieb. Trotz oder wegen seiner kritischen Haltung zum Medienwandel trat Cage als prägende Gestalt der amerikanischen Tape Music und Schöpfer zahlreicher Medienkompositionen in Erscheinung. Diese scheinbar paradoxe Haltung löste der Amerikaner konzeptuell, indem er technische Medien nicht als Mittel musealer Reproduktion, sondern als variable und performative Instrumente einsetzte. Exemplarisch steht dafür eine Reihe von Live-Performance-Werken mit dem Titel Imaginary Landscape: Wurde in No. 1 (1939) eine Schallplatte via Kupplung quasi live-elektronisch verwendet, funktionierte No. 41951 das Radio zum live bespielbaren Musikinstrument um. Konzipiert für 12 Rundfunkgeräte, sind diese jeweils von zwei Musikern zu bedienen, von denen der eine den Sender und der zweite die Lautstärke reguliert. Damit wappnete Cage sein Werk gegen »jede Art der Konserve, der Idee der Wiederholung des Gleichen. «170 Anstatt technischer Musealisierung setzte er Medientechniken ein, um den Aufführungscharakter und die Ereignishaftigkeit von Musik im Zeitalter ihrer technischen Reproduzierbarkeit regelrecht zu betonen. ${ }^{171}$

Es ist allerdings kaum anzunehmen, dass Walter Riezler 1953 bei seiner Kritik an der elektronischen Musik und den Reproduktionsmedien die Arbeiten des amerikanischen Komponisten kannte, der erst 1954 bei den Donaueschinger Musiktagen seine verlachte Europapremiere feierte und nach seinen Auftritten 1958 in Darmstadt eine transatlantische Neuvermessung der klingenden Welt einleitete. ${ }^{172}$ Vielmehr fürchtete der deutsche Musikwissenschaftler in Verteidigung der abendländischen Musikkultur eine »Vernichtung ihrer inneren Würde« durch das technische Zeitalter und bediente dabei Standardpositionen der Technologiekritik:

»Was aber die Elektronenmusik anlangt, die anstelle der Töne unheimliche Geräusche rätselhafter Herkunft aus dem Bereiche der Physik setzt, [...] - sie kommen aus einer Welt, in dem es den Menschen nicht gibt, nur teuflische Wesen, denen der Mensch als seelisches Wesen wahrscheinlich nicht gewachsen ist, die ihn vernichten oder in den Wahnsinn treiben. Sollte hier wirklich mit den Mitteln der modernen Physik ein Einbruch in die Sphäre des letzten Urgrunds der physischen Welt gelungen sein, so würde das eine Gefährdung der Menschlichkeit bedeuten, die nicht geringer ist, als die durch die Atombombe. ${ }^{173}$

169 John Cage: »McLuhan’s Influence« (1967), in Richard Kostelanetz (Hg.): John Cage. An Anthology, New York 1991, S. 170f.

170 Stefan Heyer: "Zwischen Eins und Null. Versuch über John Cage«, in Kleiner/Szepansky: Soundcultures, S. 152-161, hier S. 155.

171 Anna Schürmer: »...es wäre ein Akt der Nächstenliebe, sie zu zerschmeißen...«. John Cage und technische Medien: Random zwischen Differenz und Wiederholung, in: kunsttexte (4/2012), online unter URL: http://edoc.hu-berlin.de/kunsttexte/2012-4/schuermeranna-3/PDF/schuermer.pdf [Zugriff: 31.8.2017].

172 Siehe hierzu das Kapitel Transkulturelle Transfers und darin besonders den Abschnitt John Cage und die transatlantische Neuvermessung der klingenden Welt.

173 Walter Riezler: Die Musik, S. 163. 
Wenn Riezler mit dem Verweis auf die Atombombe zeithistorische Krisenszenarien anklingen ließ, schloss er mit dystopischem Blick auf die Zukunft der Musik, diese würde durch den Einsatz von Elektronik »in einer erschreckenden Weise entmenschlicht und entseelt. «174 Damit setzte und rekurrierte er auf vorgeprägte Topoi kunstimmanenter Technologiekritik. Die Schlagwörter der >Denaturierung〈 und 〉Enthumanisierung der Musik durch Maschinen wurde zum Standardvorwurf gegen die elektronische Musik und auch innerhalb der Szene aufgegriffen und befeuert.

1956 etwa meldete sich der Komponist Luigi Rognoni bei den Darmstädter Ferienkursen in einer Podiumsdiskussion über »Kompositorische Möglichkeiten der elektronischen Musik « ${ }^{175} \mathrm{zu}$ Wort, die infolge von Störungen während eines elektroakustischen Konzerts anberaumt worden war. Beunruhigt stellte Rognoni fest, man spreche schon »von dem Tod der Kunst, von dem im Netze der Technik verstrickten und vernichteten Menschen. $«{ }^{176}$ Die Kritik an der Denaturierung wurde zum ständigen nationen-, zeiten- und spartenübergreifenden Hintergrundrauschen der elektronisch generierten Lautsprechermusik. So fürchteten auch Kritiker aus der Sowjetunion 1956, dass das Spiel elektronischer Musikinstrumente zu einer »Entpersönlichung der Musikausübung « ${ }^{177}$ führe und in Ostdeutschland wurde elektronische Musikerzeugung pauschal als dekadenter Auswuchs bürgerlich-kapitalistischer Musikkultur bewertet. 1954 bemerkte der Musikwissenschaftler Werner Wolf im führenden Fachblatt der DDR, Musik und Gesellschaft, »noch nie etwas Irrsinnigeres und Dekadenteres als diese [...] zusammengemixten Kombinationen von Klängen und Geräuschen gehört zu haben. ${ }^{178}$ Im wichtigen Publikationsorgan der westlichen Avantgardekultur, der Neuen Zeitschrift für Musik, warnte 1952 auch Ernst Krenek vor »apokalyptischen Visionen ${ }^{179}$ in Anbetracht der fundamentalen Umwälzungen von Form und Material der Musik durch die elektronischen Mittel. Die wirkmächtigste Fundamentalkritik an der elektronischen Musikerzeugung aber übte 1958 Friedrich Blume, Herausgeber der Enzyklopädie Musik in Geschichte und Gegenwart, als er bei den Kasseler Musiktagen die polemische Sinnfrage stellte: Was ist Musik?

»Die elektronische Musik verlässt grundsätzlich den Naturklang [...]. Zum ersten Mal seit es Musik gibt wird versucht den Naturklang durch Denaturierung abzutöten [...]. Das Ergebnis [wirkt] auf den Hörer anstrengend, teuflisch oder gelegentlich auch komisch. « ${ }^{180}$

174 Ebd., S. 164.

175 Die Diskussion wurde transkribiert und publiziert in Heinz Klaus Metzger/Rainer Riehn (Hg.): »Kompositorische Möglichkeiten der elektronischen Musik. Eine Diskussion zwischen Ernst Krenek, Luigi Rognoni, Pierre Boulez, Karlheinz Stockhausen, Hermann Heiß, Bruno Maderna, Alois Hába, Stefan Wolpe« [1956], in: Musik-Konzepte (Sonderband: Darmstadt-Dokumente), München 1999, S. 80-105.

176 Ebd., S. 101.

177 Fred Prieberg: Musik des technischen Zeitalters, Zürich 1956, S. 45.

178 Werner Wolf: »Die Entwicklung und Verwendung elektroakustischer Musikinstrumente«, in: Musik und Gesellschaft (4/1954), S. 17-19, hier S. 17.

179 Ernst Krenek: »Den Jüngeren über die Schulter geschaut«, in: Neue Zeitschrift für Musik (2/1952), S. 31-33, hier S. 33.

180 Friedrich Blume: »Was ist Musik?«, Vortrag bei den Kasseler Musiktagen 1958, publiziert in: Musikalische Zeitfragen (Band 5), Kassel 1960, S. 66-68, hier S. 67. 
Thematisierte Blume hier die Unnatürlichkeit der elektronischen Klangerzeugung, prangerte er sie im Anschluss als >unmenschlich im doppelten Wortsinn an:

»Es mag wohl sein, dass diese nur durch Apparate produzierbare und reproduzierende Schallgeneration etwas ist, was unser Zeitalter der Atomzertrümmerung und der Vollautomation spiegelt. Mit Musik aber [...] hat dieses volldenaturierte Produkt [...] nichts mehr zu tun. [...] Nicht mehr der Geist, sondern nur noch die Maschine, nicht mehr das Ethos der Selbstverantwortlichkeit, sondern der Logos der Formeln [vermag] dieses Reich zu beherrschen. ${ }^{181}$

Blumes Ausführungen - die als >Kasseler Axt $८$ in die Musikgeschichte eingingen erzielten eine beträchtliche Breitenwirkung und provozierten vielfältige Reaktionen. Die medial verhandelte Kontroverse offenbart die Polarität zweier Weltanschauungen und Generationen, die sich in der Mitte des 20. Jahrhunderts an den Schnittstellen von Neuer Musik und Technik, Mensch und Maschine entluden.

\section{Passagen ins Medienzeitalter: „Die dritte Epoche»}

Zielscheibe von Friedrich Blumes Polemik gegenüber der elektronischen Musik als »Axt an den Wurzeln einer der vollkommensten Schöpfungen Gottes « ${ }^{182}$ war insbesondere Karlheinz Stockhausens Gesang der Jünglinge [א-13.2]. Die zwei Jahre zuvor uraufgeführte, auf dem gleichnamigen Bibeltext aus dem dritten Buch Daniel basierende elektroakustische Komposition, konnte in den Augen Blumes offenbar nichts als Blasphemie sein. Wenn sich dabei ein über die reine Musikästhetik hinausgehender Generationenkonflikt andeutet, bestätigt sich der Eindruck in den Repliken der jungen Generation, die Heinrich Strobel - Leiter der Donaueschinger Musiktage und Herausgeber von Melos - 1959 in einer Ausgabe der Avantgardezeitschrift zur Gegenrede kommen ließ. Viele der Beiträger nutzten das Forum, um je nach Temperament leidenschaftlich oder gemessen, aggressiv oder reflektierend einen Epochenwechsel der Musik zu verkünden.

Pierre Boulez polemisierte gegen die »engstirnige Konzeption der ehrenwerten Doktoren« sowie deren »panische Angst vor dem Neuen« und schlussfolgerte mit Verweis auf Paul Valérys La Crise de l'Esprit: »Kulturen sind sterblich. $"{ }^{183}$ Klaus Wagner fügte an, dass das Abendland nicht die Welt sei und kritisierte den kulturhegemonialen Anspruch der europäischen Musiktradition. ${ }^{184}$ Wurden hier die sich durch den Krieg verschiebenden Kräfteverhältnisse zwischen der Alten und Neuen Welt thematisiert, sah der französische Kritiker Antoine Goléa in Blumes Verriss, mit Verweis auf die historische Beethoven-Rezeption, den Beweis für die Innovationskraft der Elektroakustik: »Es ist in der Leipziger Allgemeinen Zeitung nachzulesen, deren Musikkritiker genauso wenig in ihrer Zeit apperzipierten wie Professor Blume in der unsrigen. $"{ }^{185}$ Bernd Aloys Zimmermann schließlich bot in seinem Beitrag eine Definition ästhetischer Umbruchphasen an:

181 Ebd.

182 Ebd., S. 68.

183 Pierre Boulez: »Kulturen sind sterblich«, in: Melos (3/1959), S. $69 f$.

184 Klaus Wagner: »Das Abendland ist nicht die Welt«, in: Ebd., S. 85f.

185 Antoine Goléa: »Genug der Wiegenlieder«, in: Ebd., S. 74f. 
»[E]s muß eine gewisse Zeit vergehen, um einen Stil fest werden zu lassen. Während dies noch geschieht, tauchen zu allen Zeiten just dann, wenn [...] eine Konvention sich herausgebildet hat, Vorboten stilistisch anderer Denkweisen auf, beunruhigende Protagonisten eines Kommenden, welche das soeben Gewonnene und Gesicherte fortzuschwemmen drohen. ${ }^{186}$

Hans Curjel warnte dagegen mit Verweis auf die jüngere deutsche Geschichte, als »Hüter ewiger Gesetze [...] vor dem Verfall, vor Entartung, die man gelegentlich in wissenschaftlicher Verbrämung Denaturierung nennt ${ }^{187}$ wetterten. Damit verwies der Kritiker auf Friedrich Blumes fragwürdige Rolle im Nationalsozialismus und Herbert Eimert erinnerte das »formtheoretische Vokabular daran, daß auch die Definitionen ihre Stile haben. Sie färben von der Zeit ab, aus der sie stammen. « ${ }^{188}$ Auch dem Kritiker Heinz Joachim schienen Blumes Ausführungen »eher weltanschaulich als wissenschaftlich gestützt ${ }^{189}{ }^{10}$, die nach Ansicht des Komponisten Giselher Klebe ausschließlich »demagogischen Zwecken ${ }^{190}$ dienten. Jaques Wildberger schließlich verwies konkret auf Friedrich Blumes 1939 entstandene Schrift Das Rasseproblem in der Musik ${ }^{191}$ und damit auf eine Kongruenz musik- und zeithistorischer Konfliktfelder an der Schwelle zu den 1960er Jahren.

An der Beurteilung von Friedrich Blumes Rolle während der NS-Zeit scheiden sich bis heute die Geister: Während Fred Prieberg als kritischer Zeitzeuge anmerkte, dass Blume die NS-Rassenlehre als unwissenschaftlich brandmarkte ${ }^{192}$, bemerkte der Musikwissenschaftler Michael Custodis jüngst, dass sich Blumes Schrift zum Rasseproblem »mit wenigen Blicken [...] als NS-Propaganda überführen lässt. « ${ }^{193}$ Damit offenbarte die Kontroverse auch die konfliktive Aufarbeitung des Dritten Reichs im nur vermeintlich unpolitischen Bereich des Musiklebens. ${ }^{194}$ Wie in allen Gesellschaftsbereichen mobilisierte auch die junge Komponistengeneration seit dem Ende der 1950er Jahre gegen die Verdrängung der NS-Verbrechen: auch im Musikleben verlief ein Riss zwischen den Musikern der Vor- und der Nachkriegszeit. Historische Kontinuitäten und Personalien wie Friedrich Blume wurden in Frage gestellt und oft auch zur eigenen Profilierung instrumentalisiert. Die jungen Komponisten, so bemerkte Blume in einer späteren Replik bitter, hätten ihn »ohne viele Umstände als seniles Petrefakt in den Mülleimer ${ }^{195}$ verfrachtet.

186 Bernd Aloys Zimmermann: »Komponisten bestimmen die Grenzen der Musik«, in: Ebd., S. $89 \mathrm{f}$.

187 Hans Curjel: »Der Brandmeister«, in: Ebd., S. 70f.

188 Herbert Eimert: »Die Kasseler Axt«, in: Ebd., S. 71-73.

189 Heinz Joachim: »Kein Platz für Pessimismus«, in: Ebd., S. 77-79.

190 Giselher Klebe: »Getarnte Demagogie«, in: Ebd., S. 77f.

191 Friedrich Blume: Das Rasseproblem in der Musik: Entwurf zu einer Methodologie musikwissenschaftlicher Rasseforschung, Wolfenbüttel/Berlin 1939.

192 Fred Prieberg: Handbuch Deutsche Musiker 1933-1945, Kiel 2004, S. 509.

193 Michael Custodis: Traditionen - Koalitionen - Visionen. Wolfgang Steinecke und die Internationalen Ferienkurse in Darmstadt, Saarbrücken 2010, S. 59.

194 Siehe hierzu weiterführend Michael Custodis/Friedrich Geiger: Netzwerke der Entnazifizierung. Kontinuitäten im deutschen Musikleben, Münster 2013.

195 »Professor Blume antwortet«, in: Melos (3/1959), S. 148f. 
Einige der älteren Komponisten teilten seine Kritik an der elektronischen Zukunftsmusik. So glaubte Andreas Razumowsky nicht, »daß jemals den kybernetischen Rechenmaschinen das Komponieren überlassen werden wird « ${ }^{196}$ und Gerhard Wimberger war sicher, dass »ein Oberton immer wertvoller sein wird als ein >farbiges Rauschen $\lessdot$ « ${ }^{197}$ Bernd Aloys Zimmermann schließlich bezweifelte,

$»$ daß Elektronengehirne [...] eine Komposition im musikalischen Sinne in des Wortes wahrster Bedeutung wird komponieren können, da eben der Faktor der Phantasie, das Unwägbare, fehlt, das der menschliche schöpferische Geist in jeder Phase des Schöpfungsprozesses frei entscheidend gestaltet und in dessen Dienst Einfall und Zufall, Inspiration und Aleatorik gleichermaßen stehen. ${ }^{198}$

In der kommenden Ausgabe von Melos berichtete Heinrich Strobel, dass »diese Auseinandersetzung mannigfache Reaktionen unserer Leser hervorgerufen [hat], verständnisvolle und aggressive. ${ }^{199}$ Darin sah er die »Auseinandersetzung von zwei Weltanschauungen eingeleitet« und erkannte als tieferen Sinn hinter den kontrovers geführten Debatten die Zeichen eines Umbruchs. Einen solchen hatte Robert Beyer, ein Mitarbeiter am Elektronischen Studio des Westdeutschen Rundfunks, schon 1951 in euphorischer Endzeitstimmung formuliert:

$»$ Die Musik steht heute in einer tiefer greifenden Umwälzung, als dies ihre augenscheinliche Lage dartut. Ihre Entwicklung ist aus dem Zeichen der Evolution in das der Revolution getreten [...]. Die Musik ist am Ende einer tausendjährigen Entwicklung angelangt. Der [...] Beweis hierfür ist ihre letzte Revolution. $\ll^{200}$

Auch der einflussreiche Musikkritiker Hans Heinz Stuckenschmidt formulierte eine Zeitenwende: Zwar gab auch er im Anschluss an den technologiekritischen Topos der >Entmenschlichung « zu bedenken, dass »diese Perfektion, diese störungs- und trübungsfreie Reproduktion und nun auch schon Produktion von Kunst Dehumanisation « bedeute. ${ }^{201}$ Tatsächlich war ja Musik bis dato an die Materialität Körper - nun wurde der Interpret als menschlicher Mittler ausgeschlossen und die Musik damit in gewisser Hinsicht tatsächlich >post-human`. Allerdings, so erkannte Stuckenschmidt, sei diese menschenferne Musik in einem früher unbekannten Maß vom Geist des Menschen durchformt - und bilde daher Die Dritte Epoche einer auf Ausweitung und Extension der Mittel grundierenden Musikgeschichte:

196 Andreas Razumovsky: »Auch Musik ist Menschenwerk«, in: Ebd., S. 81f.

197 Gerhard Wimberger: »Webern kann nicht widersprechen«, in: Ebd., S. 86f.

198 Bernd Aloys Zimmermann: »Komponisten bestimmen die Grenzen der Musik«, in: Melos (3/1959), S. 89f.

199 Heinrich Strobel: »Wer zertrampelt wen?«, in: Melos, Nr. 27, 4/1959, S. 148.

200 Robert Beyer: »Musik und Technik« (1951), in Heinz-Klaus Metzger/Rainer Riehn (Hg.): Musik-Konzepte, Sonderband: Darmstadt-Dokumente, München 1999, S. 45-48, hier S. 46.

201 Hans Heinz Stuckenschmidt: »Musik und Technik«, in Fritz Winkler (Hg.): Klangstruktur der Musik, Berlin 1955, S. 209-216, hier S. 213. 
»Die erste war eng und innig an den Menschen selbst als ausführendes Organ gebunden; begrenzt wie der Umfang der Stimme, wie ihre Möglichkeiten der schnellen und lauten Intonation, wie ihre Farbmodulationen war auch die Technik des vokalen Satzes [...]. Die zweite eroberte sich das Tonwerkzeug als Mittel; auch hier noch war die Bindung an den Menschen als notwendigen Bediener des Tonwerkzeugs gegeben, [...] während virtuose Geläufigkeit, Differenzierung und Farben, rhythmische Komplikationen und extreme Grade der Lautstärke vom Menschen wegführten. Die dritte, eben die elektronische Epoche, stellt den Menschen nur noch an den Beginn des Kompositionsprozesses, schaltet ihn aber als Mittler aus. Ihre >dehumanisierte< Musik ist in der Domäne des reinen Geistes entstanden. Sie bedient sich zwar der Verfahrensweisen [...] aus der Tradition [...], wendet sie aber auf eine radikal neue Materie an. $\aleph^{202}$

Mittels der fortschreitenden Kulturtechniken, so führte Stuckenschmidt weiter aus, sei die medientechnisch generierte Musik dem subjektiven Gefühlsbereich der Hörer entrückt worden, was sich in der »Diskrepanz von Sendung und Empfang" sowie in der »Ratlosigkeit« des Publikums äußere - eben jenen passageren und oft eklatanten Handlungsmustern an der Epochenschwelle zum Zeitalter elektronischer Medien.

Auch Karlheinz Stockhausen proklamierte den Übergang in eine neue, vom Geist durchformte Ära der Musikgeschichte. 1972, bei seiner Lecture »Four Criteria of Electronic Music« an der Oxford Union ${ }^{203}$, bezog sich eine Wortmeldung explizit auf die »dehumanization in electronic music»; der Sprecher äußerte die Frage: »Has this art the potential to touching human concerns [...], is it really valid art? « In seiner Antwort verwies der Komponist auf einen »flash of intelligence « infolge der medientechnischen Neuerungen. Der Begriff der »dehumanization« bezeichne die Angst der Mehrheit: »but what they really mean is [...] supra-humanization.« Dies sei nicht das Ende der musizierenden Menschheit, sondern vielmehr ein evolutionärer Entwicklungssprung: »Everything switches in new level and the next step is a sign of rebirth of humanity.« Der Komponist imaginierte also die vermeintlich >dehumanisierte Elektroakustik als neue Stufe einer - posthumanen - Menschlichkeit in der Musik.

Tatsächlich häuften sich im Verlauf der 1950er Jahre die Indizien eines paradigmatischen Umbruchs: Existentielle Verunsicherungen und empfindliche Empörungen gegenüber dem Neuen sowie Polemiken gegen das reaktionäre Alte mehrten sich in allen gesellschaftlichen Bereichen und entluden sich schließlich in den Revolten der Studentenbewegung mit ihrem Höhepunkt im Jahr 1968. Natürlich war dieser soziale Wandel auch kulturell, medial und ästhetisch grundiert: in Form einer zunehmenden Institutionenkritik und der Bildung neuer Einrichtungen sowie im künstlerischen Willen zur Neuordnung und der forcierten Suche nach neuen Ausdrucksmitteln und Materialen, also ganz konkret: Medien. Die frühe Lautsprechermusik der 1950er Jahre kann dementsprechend als Ausdruck und passagerer Begleiter ins Medienzeitalter verstanden werden; die Skandale und Kontroversen um die `Elektronische Eklatanz belegen ihre Rolle am Nerv der Zeit.

202 Hans Heinz Stuckenschmidt: »Die dritte Epoche. Bemerkungen zur Ästhetik der Elektronenmusik «, in Herbert Eimert /Karlheinz Stockhausen(Hg.): Die Reihe, Band I: Elektronische Musik, Wien 1955, S. 17-19, hier S. 18f.

203 Die Lecture ist inklusive der anschließenden Diskussion, auf die sich die folgenden Zitate beziehen, abrufbar unter URL: https://www.youtube.com/watch?v=SgQmGu93F4\&list=PLCqtKpAgznS7uIRaCVGpbO0ToEAJBI8EJ\&index=13 [Zugriff: 31.8.2017]. 


\section{Ausblick: Elektropop und die digitale Eklatanz}

Nach den turbulenten und eklatanten Ereignissen um die elektronische Musik in den 1950er Jahren legten sich die Proteststürme seit 1960 und kam es zu einer Konsolidierung der Medienmusik, wie auch Carl Dahlhaus anmerkte:

»Sie ist, nachdem sie zunächst von einer aufgestörten Publizistik ins Zentrum der Neuen Musik gerückt worden war, zu einem Randphänomen verblaßt. Und es fällt bereits schwer, sich die Bestürzung ins Gedächtnis zu rufen, die von den frühesten elektronischen Kompositionen ausging. ${ }^{204}$

Diese Konsolidierung lässt sich im Anschluss an das klassische Muster Arnold van Genneps Les rites de passage ${ }^{205}$ im Dreischritt von Verdichtung, Fraktion und DeEskalation exemplarisch nachvollziehen: Die Skandale der elektronischen Musik waren gleichermaßen Trennung- wie Übergangsriten (rites de separation/de marge), die schließlich in Angliederungsriten (rites d'agrégation) und Konsolidierung mündeten. Irgendwann war die synthetischen Klänge nicht mehr >unerhört` und die Rezipienten gewöhnten an die charakteristischen Klänge des Medienzeitalters. Die Deeskalation war aber auch die Folge einer Trennung (rites de separation), die das westliche Musikleben seit der Mitte des vergangenen Jahrhunderts nachhaltig spaltete.

In ihrer Radikalität waren die elektronischen Klangexperimente Mitauslöser der bis heute charakteristischen Segregation von Neuer-, Klassischer- und Populärer Musik. Und auch die Elektroakustik selbst erlebte eine Spaltung: Seit den 1970ern wurde Elektropop durch Pioniere wie Kraftwerk in der Clubkultur salonfähig gemacht und die elektronische Kunstmusik geriet zunehmend in Vergessenheit. In den Anfangsjahren der Pop-Ära aber bezog sich eine Vielzahl von Musikern auf >ernsteく Komponisten und ganz besonders Karlheinz Stockhausen: Verwiesen Frank Zappa, Pink Floyd und David Bowie explizit auf die Vorbildfunktion des Kölner Visionärs, besuchten Mitglieder von The Grateful Dead, Jefferson Airplane, Yello, Can und Kraftwerk sogar Seminare des Komponisten. Die Beatles dagegen verewigten ihn auf dem Cover ihres legendären Albums Sergeant Peppers Lonely Hearts Club Band [Abbildung 12]. Auch jüngere Vertreter der Pop-Avantgarde wie Sonic Youth, Björk und verschiedene Produzenten elektronischer Clubmusik beziehen sich bis heute auf den $»$ Papa des Techno ${ }^{206}$. Es ist also mehr Wahrheit als Eitelkeit, wenn Karlheinz Stockhausen 1998 in einem Interview zu Protokoll gab, er habe den Techno erfunden. ${ }^{207}$ - auch wenn in der aktuellen Technokultur nur noch wenige an den Mann erinnern, der elektronische Klänge in die Musik eingeführt hat.

204 Carl Dahlhaus: »Ästhetische Probleme der elektronischen Musik«, in Ders.: Schönberg und andere. Gesammelte Aufsätze zur Neuen Musik, Mainz 1978, S. 234-244, hier S. 234.

205 Arnold van Gennep: Les rites de passage, Paris 1909; deutsch: Übergangsriten, Frankfurt am Main 2005.

206 So betitelte Eleonore Büning 2007 ihren Nachruf auf den Komponisten in der Frankfurter Allgemeine Zeitung (8.12.2007).

207 Karlheinz Stockhausen, in: De-Bug. Elektronische Lebensaspekte (26.1.2000), URL: http://de-bug.de/mag/haben-sie-techno-erfunden-stockhausen-ja/ [Zugriff: 31.8.2017]. 
Abbildung 12 - >Popmusikalische Verewigung،: Karlheinz Stockhausen auf dem Cover von »Sergeant Peppers Lonely Hearts Club Band»

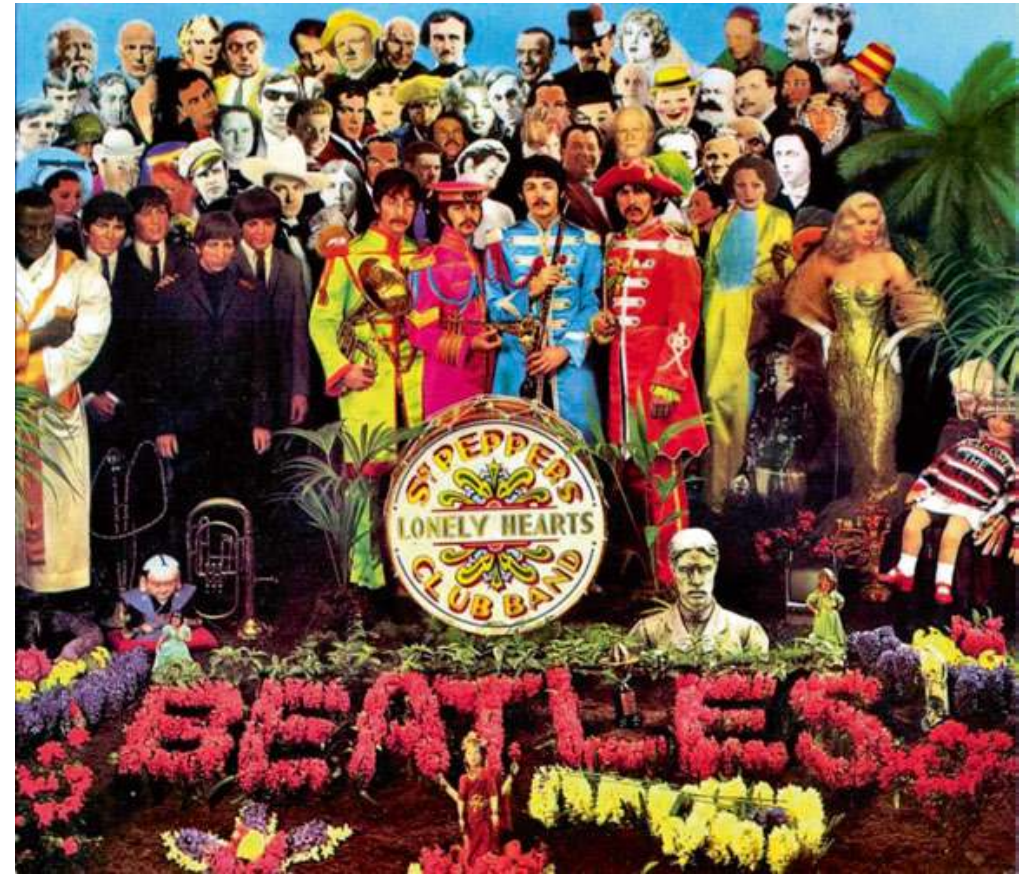

Die dialektischen Ordnungsmuster zeitgenössischer Musik zwischen elitärer Avantgarde und den massenkompatiblen Produkten der Unterhaltungskultur wurden erst mit den Zeichen eines neuerlichen Medienumbruchs seit 1989 und verstärkt seit der Jahrtausendwende auf die Probe gestellt. Wie zur elektronischen Zeitenwende nach 1945 mehren sich infolge der Digitalisierung kritische Stimmen gegen die Computermusik. 1991 etwa erschien ein technologiekritischer Aufsatz des Komponisten Konrad Boehmer, der auf die Kritikpunkte der 1950er rekurrierte und auch im Duktus stark an die Kontroversen jener Jahre erinnerte. Nachdem der Autor die totale Prädetermination der Computer-Komposition aus der seriellen Tradition kritisierte und die seitdem grassierende Rezeption der Thesen Marshall McLuhans von den technischen Ausweitungen des Zentralnervensystems in Form elektrischer Medien infrage stellte, fuhr er fort:

»Inzwischen hat die Info-Technologie die abenteuerlichsten Formen angenommen. [...] Es scheint, als ob diese Schritte es darauf abgesehen hätten, ästhetisches Denken gezielt zu liquidieren. [...] Das katastrophale Ende des bürgerlichen Traums ungebrochener Naturbeherrschung hat nicht nur das aller Natur beraubte, nackte Subjekt hinterlassen, sondern auch die Frage nach dem ästhetischen Sinn künstlerischer Materialbeherrschung. $\ll^{208}$

208 Konrad Boehmer: »Ausgerechnet! ... Computermusik«, in Ders.: Das böse Ohr. Texte zur Musik 1961-1991, Köln 1993, S. 241-255, hier S. 245f. 
Weiter äußerte Boehmer i »sehr ernsthafte Zweifel [...] wo der Computer - oder besser der Kaaba: der Algorithmus - zum Surrogat kompositorischen Denkens selbst erhoben wird«. Methodologisch gesprochen leugne Computermusik all das, was er ästhetische Differenz nenne: »Ohne diese aber ist keine Kunst [...] weil die sinnliche Implikation solcher Phänomene a priori nicht programmierbar ist. ${ }^{209}$ Auch hier scheinen die Motive des Aura-Verlusts sowie der >Entmenschlichung`von Kunst im Zeitalter ihrer technischen (Re-)Produktion auf. Am Ende des Artikels entwarf der Autor das Bild einer »kybernetische Motte, der die Regelkreise durcheinander geraten sind. $\ll^{210}$ Auch der Vorwurf der Entgrenzung und Unsichtbarkeit elektronischer Musik reicht bis in die Gegenwart, weil sich die alten Aufführungsrituale trotz der weltweiten Verbreitung von Musik über Rundfunk, Tonträger und nun auch das Internet weitgehend erhalten haben. Kim Cascone wies 2003 auf die Auswirkungen der aufführungspraktischen Differenzen in instrumentaler und elektronischer Musik hin:

»Die Aufführung von Musik garantiert Präsenz und Authentizität, wohingegen die LaptopPerformance Kunstgriffe und Abwesenheit sowie Verfremdung und Verlagerung von Präsenz repräsentiert. [...] Historisch betrachtet, halten die ungewohnten Regeln, die bei der Performance elektronischer Musik benutzt werden, die Hörer davon ab, dem Performer Präsenz und Authentizität zuzuschreiben. Der Performer elektronischer Musik, der eher als Techniker denn als Musiker wahrgenommen wird, schwebt über einem Gewirr von Kabeln, Griffen und blinkenden Lichtern, während elektronische Schaltkreise den Raum durch einen artifiziellen Prozess mit Klang füllen. ${ }^{211}$

Das Spiel mit Präsenz und Authentizität wurde für die Elektroakustik avantgardistischer Prägung zum Problem, weil sie dem romantischen Genius verhaftet blieb, während allen anderen Kraftwerk explizit die »Aura des Nicht-Hintergehbaren, des Nicht-Zerlegbaren ${ }^{212}$ in der Maschinenmusik ästhetisieren. Nicht nur mit Titeln wie »Wir sind die Roboter« und Albumtiteln wie Radio-Aktivität (1975), Die Mensch Maschine (1978) oder Computerwelt (1981) spielen die Elektropop-Pioniere mit den Paradigmen der Mensch-Maschine-Dichotomie; auch aufführungspraktisch lassen sie ganz bewusst die Grenzen zwischen Realem und Imaginärem verschwimmen: Wenn sie an unsichtbaren Knöpfen der technologischen »Wunschmaschinen ${ }^{213}$ - Computern und Synthesizern - drehen und von Robotern mit ihrem Antlitz vertreten lassen [Abbildung 13] bleibt immer eine generelle Unsicherheit bestehen, die Elena Ungeheuer treffend beschrieb:

209 Ebd., S. 243/258f

210 Ebd., S. 255.

211 Kim Cascone: »Deterritorialisierung, historisches Bewusstsein, System. Die Rezeption der Performance von Laptop-Musik“, in Kleiner/Szepansky: Soundcultures, S. 101-106, hier S. $101 \mathrm{f}$.

212 Elena Ungeheuer: »Ist Klang das Medium von Musik? Zur Medialität und Unmittelbarkeit von Klang in Musik«, in Holger Schulze (Hg.): Sound Studies: Traditionen - Methoden - Desiderate, Bielefeld 2008, S. 57-76, hier S. 73.

213 Mit ihrer »machine désirante« entwarfen Gilles Deleuze und Félix Guattari das Konzept eines produktiven maschinellen Unbewussten, in: Anti-Ödipus. Kapitalismus und Schizophrenie I, Frankfurt am Main 1974. 
»Der [...] Klang wirkt unmittelbar, und zwar nicht auf der Basis konzeptueller Arbeit, sondern als Ausdruck und Zeichen der Maschinenmagie, die nicht verrät, wie sie gemacht ist, sondern nur anzeigt, wie sie macht. $\ll^{214}$

Abbildung 13 - >Musikalische Cyborgsı: Kraftwerk bei ihrer Tour 2014

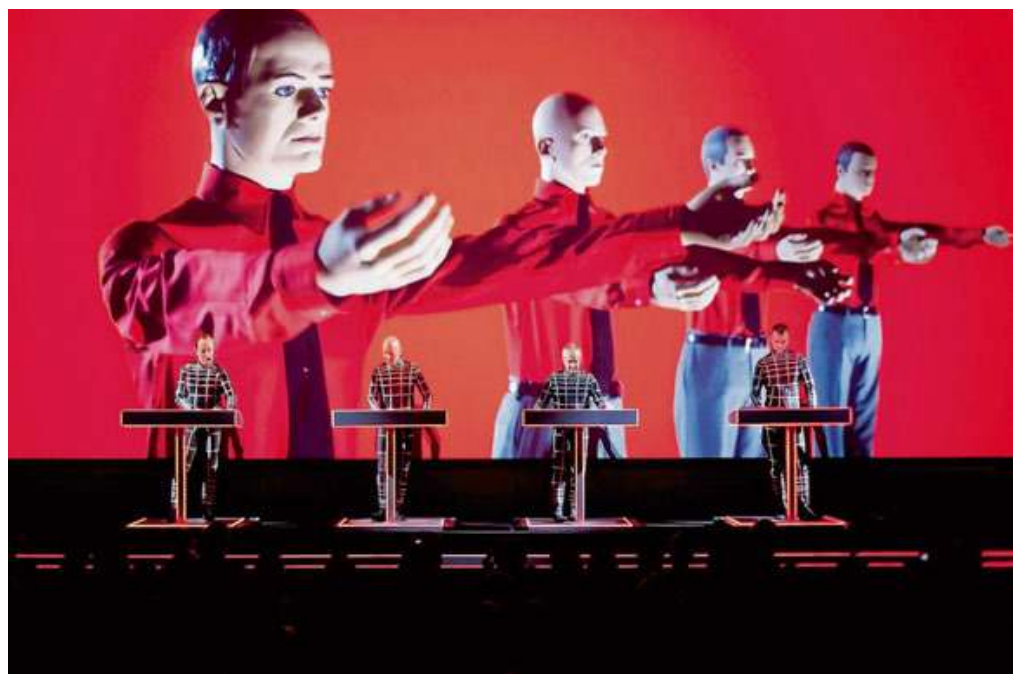

Kraftwerk verschleiern also die musikalische Materialität sowie die ästhetischen und kompositorischen Struktur- und Formbildungsprozesse durch ein schöpferisches Subjekt und setzten dies auch semantisch um, wenn sich etwa bei Radio-Aktivität die »Stimme der Energie« zu Wort meldet:

»Hier spricht die Stimmer der Energie. Ich bin ein riesiger elektrischer Generator. Ich liefere Ihnen Licht und Kraft und ermögliche es Ihnen, Sprache Musik und Bilder durch den Äther auszusenden und zu empfangen. Ich bin Ihr Diener und Ihr Herr zugleich. Deshalb hütet mich gut. Mich, den Deus der Energie.«

Während also in der elektronischen Popkultur die >Maschinenmagie< ästhetisch eingesetzt und nutzbar gemacht wird, ist die >unsichtbare Stimme ২ in der kunstmusikalischen Elektroakustik zum Vermittlungsproblem der Aufführungskunst Musik geworden, deren englisches Pendant nicht zufällig Performance Art lautet. Weiterhin ist die Bühne ein Ort der Repräsentation von menschlichem Schöpfertum und - gesprochen mit Hans Ulrich Gumbrecht: eine »Präsenzdimension des ästhetischen Erlebens $\ll^{215}$

214 Ungeheuer: Ist Klang das Medium von Musik, S. 73. Siehe weiterführend auch Christoph Cox: »Wie wird Musik zu einem organlosen Körper? Gilles Deleuze und die experimentellen Elektronika«, in Kleiner/Szepanski, Soundcultures, S. 162-193.

215 Hans Ulrich Gumbrecht: Diesseits der Hermeneutik. Die Produktion von Präsenz, Frankfurt am Main 2004. 
Das musikalisch-performative Ereignis ist also weiterhin dem Konzept der Aura im Sinne Walter Benjamins als einmaliges und nicht reproduzierbares Ereignen verbunden; dagegen wird die Epiphanie, das wundersam-übernatürliche Erscheinen der gestaltlosen, weil vom Interpreten ent-grenzten und massenhaft reproduzierbaren Elektronenklänge als anti-performativ kritisiert. ${ }^{216}$ Heute wird elektroakustische und akusmatische Musik aufgrund ihres anhaltenden Vermittlungsproblems meist im traditionellen Proszenium von Konzertsälen gespielt und damit im Sinne Gumbrechts das unvermittelte Erleben sinnlicher >Präsenzeffekte` gegen ihre Repräsentation in Stellung gebracht. Dieser Kontext, so bemerkte Kim Cascone, beschwöre die übliche Polarität zwischen dem Publikum und dem Interpreten als einer kulturellen Autorität herauf:

»Während einer Laptop-Performance lösen sich die üblichen visuellen Codes [...] auf und lassen so die Erwartungen des Mainstreampublikums unerfüllt [...]. Der Ursprung der Partitur [wird] nie preisgegeben [...]. Kennzeichnend für diesen Präsentationsstil ist, dass der Komponist zwischen den Hörern sitzt, ein Mischpult [...] bedient und seine Aufführung besteht darin, dass er seine bereits aufgezeichnete Komposition abspielt. Die Hörer sitzen in der Regel auf der Bühne oder den Lautsprechern gegenüber [...]. Dabei ist es schwierig für die Hörer, den Wert einer Performance zu begreifen, bei der der Künstler z.B. lediglich Soundfiles auf einem Gerät abspielt, das eher auf einen Büroschreibtisch passen würde als auf eine Bühne. Es wird also gegen die gängigen Codes musikalischer Performance verstoßen. ${ }^{217}$

Dass der Verstoß gegen die Paradigmen der Musikkultur auch im digitalen Zeitalter provoziert, wurde 2009 bei Harry Lehmanns Thesen zur Digitalisierung der Neuen Musik deutlich: Der Musikphilosoph stellte »nichts anderes als einen epochenmachenden Medienwechsel « und eine »gehaltsästhetische Wende $\ll^{218}$ fest. Anschließend entspann sich eine öffentliche Kontroverse, die unmittelbar an die Debatten der 1950er Jahre anschloss. Digitalaffin reagierte der Komponist Johannes Kreidler, der das Thema Speichermedien und musikalische Reproduktion als »Brachland « bezeichnete und die Neuen Medien zum Anlass für eine weit gefasste Institutionenkritik nutzte: »Die institutionelle Konsolidierung [...] hat wie von unsichtbarer Hand das Grundniveau der Neuen Musik eingependelt. ${ }^{219}$ In einer weiteren Schrift konstatierte er, dass sich der von Theodor W. Adorno lancierte Materialbegriff unter digitalen Vorzeichen zum Medienbau ausweite:

216 Siehe hierzu ausführlicher Anna Schürmer: »Elektronische Eklatanz. Zwischen Anti- und Hyper-Performanz«, in Wolf-Dieter Ernst/Anno Mungen/Nora Niethammer/ Berenika Szymanski-Düll (Hg.): Sound und Performance. Positionen - Methoden - Analysen (Thurnauer Schriften zum Musiktheater, Band 27), Würzburg 2015, S. 191-205.

217 Cascone: Deterritorialisierung, S. 102f.

218 Harry Lehmann: »Die Digitalisierung der Neuen Musik - ein Gedankenexperiment«, in Jörn P. Hiekel (Hg.): Vernetzungen. Neue Musik im Spannungsfeld von Wissenschaft und Technik, Mainz 2009, S. 33-43, hier S. 34. Seine Thesen arbeitete Lehmann aus in: Die digitale Revolution der Musik. Eine Musikphilosophie, Mainz 2012.

219 Johannes Kreidler: »Zum Materialstand der Gegenwartsmusik«, in: Musik \& Ästhetik 52 (Oktober 2009), S. 24-37, hier S. 28. 
»Hier verhilft die neue Technisierung: Synthese-, Verarbeitungs-, Speicher- und Übertragungsmedien der Digitalen Revolution zu einer konstruktiven Position, während sich das Bild des individuellen Materials zugunsten des Konzepts und Gehalts verschiebt. Dank all dieser Optionen kann Neue Musik viel mehr am Maßstab lebensweltlicher Relevanz komponiert und verbreitet werden. Der unbestreitbar tiefgreifende technologische Wandel, die gesamte Gesellschaft innervierend, weil er Kommunikation extensiviert, zeitigt auch eine neue ästhetische Situation, um nicht zu sagen: erzwingt sie. ${ }^{220}$

Gegen diese Positionen platzierte der Komponist Claus-Steffen Mahnkopf eine Replik und warnte vor Technikgläubigkeit: »Rechner mögen schneller werden [...]. Intelligenz [...] liegt indes nicht in der Hardware, sondern in der Software. Dieser entscheidende Denkfehler scheint bis heute unausrottbar. ${ }^{221}$ Daraufhin bestritt er die Stilisierung der Digitalisierung als Revolution; eine solche habe - wenn überhaupt in der Mitte des 20. Jahrhunderts stattgefunden, als »mittels stromversorgter Geräte Musik künstlich erzeugt, auf Tonträger [...] gespeichert und über Lautsprecher zum Erklingen gebracht wurde. «222 Grundsätzlich versage Computermusik bei allen relevanten Dimensionen der musikalischen Schöpfung und Reproduktion:

Lehmanns systematischer Fehler besteht in der Verwechslung von [...] Lautsprechermusik und performativer [...]. Das Barbarische an Lehmanns Argumentation ist, daß die Kastrierung des Musikers und damit auch des Komponisten durch eine aufgezwungene [...] Hybrid-Form von Mensch und Maschine positiv bewertet wird [...]. Musik ist eben nicht nur (mathematisch konstruierbare) Materie, sondern auch und wesentlich Geist [...]. Computer beherrschen das Verallgemeinerbare, Kunst geht auf das Nicht-Verallgemeinerbare. Dazwischen ist eine »Versöhnung « platterdings unmöglich. «223

Auch Mahnkopf beschwor also die Aura und befürchtete ihren Verlust beim Kunstwerk im Zeitalter seiner Digitalisierung. Auf seine Replik hin entspann sich eine publizistisch geführte und öffentlich ausgetragene Debatte, die beweist: Medienmusik und mediale Umbrüche haben bis heute nichts von ihrer Eklatanz verloren. ${ }^{224}$ Die Maschine bleibt auch im dritten Jahrtausend Symbol der ästhetischen Kontroversen um die Zukunft der Musik. Die Konflikte der Mensch-Maschine-Dichotomie entzünden auch im Dämmern der sposthumanen Ära $r^{225}$ gleichermaßen utopische wie auch dystopische Zukunftsszenarien.

220 Johannes Kreidler: »Urheberrecht kontra Kreativität. Partitur eines Musiktheaters für Komponisten«, in: Positionen (77/2008), S. 2-7, hier S. 6.

221 Claus-Steffen Mahnkopf: »Neue Technikgläubigkeit? Computer und Musik«, in MusikTexte 124 (2010), S. 21-29, hier S. 38.

222 Ebd., S. 39.

223 Ebd., S. $47 \mathrm{ff}$.

224 Die Kontroverse wurde publiziert in Johannes Kreidler/Harry Lehmann/Claus-Steffen Mahnkopf (Hg.): Musik-Ästhetik-Digitalisierung. Eine Kontroverse, Hofheim 2010.

225 Die Begriffsbildung zielt auf mein aktuelles Forschungsprojekt mit dem Arbeitstitel Posthumane Sinfonien, das sich für die Grenzbereiche digitaler Musik und für die klingenden Poetiken des Anthropozäns interessiert. 


\section{TRANSKULTURELLE TRANSFERS (Durchführung \#3)}

Die Geschichte der westlichen Kunstmusik ist grundlegend mit Europa und ganz besonders dem deutschen Kulturraum verbunden. Doch erfuhr diese musikalische Weltordnung in der Mitte des 20. Jahrhunderts einen Bruch, der die eurozentrische Kulturhegemonie ins Wanken brachte. Neben den medialen Umbrüchen - der >Elektronischen Eklatanz - markierte die `transkulturelle Neuvermessung der klingenden Welt nach 1945 den deutlichsten Einschnitt der modernen Musikgeschichte. Der Aufstieg Amerikas zur Weltmacht und die infolge der beiden Weltkriege intensivierten Austauschprozesse zwischen der Neuen- und der Alten Welt korrelierten auch mit einer Kräfteverschiebung auf dem Feld der Kunst(musik). Zwar ging das Abendland nicht, wie nach 1918 von Oswald Spengler und nach 1945 von kulturpessimistischen Adepten befürchtet, unter. Zweifellos aber erfuhr die bis dato überwiegend deutsche und eurozentrische Idee der Neuen Musik infolge der weltpolitischen Verschiebungen eine tiefgreifende Transformation. Auch dieser Wandlungsprozess vollzog sich nicht stillschweigend, sondern äußerte sich in Eklats, Skandalen und Affären, die sich infolge der Konfrontation zweier Welt- und Wertordnungen entluden und einen punktuellen Zugriff auf schwelende gesellschaftliche Konfliktfelder erlauben, zu der die transatlantischen Avantgarden den oft kontroversen Sound lieferten.

Auch und gerade mit Fokus auf die Neue Musik westlicher Prägung versprechen transkulturelle Perspektiven Auf- und Anschlüsse in mehrfacher Hinsicht: So wird 1) der Gegenstand mit Blick auf das >Andere geschärft und 2) die gegenseitige und konfliktreiche Durchdringung der beiden transatlantischen Kulturräume der westlichen Welt in der Mitte des 20. Jahrhunderts verdeutlicht. Die europäische Hochkultur trug 3) gegenüber der Neuen Welt hegemoniale Züge und wurde umgekehrt von Abgrenzungsmechanismen gegen den abendländischen >Kulturimperialismus` beantwortet. Die Kunstmusik kann in diesem Konflikt als ein symbolisches Feld gelten: die klingenden Eklats dies- und jenseits des Atlantiks waren Ausdruck einer gesellschaftlich, sozial, ästhetisch, kulturell und räumlich konnotierten Verschiebung, die Anschlüsse an Konzepte aus dem Bereich der Eurozentrismus-Kritik ${ }^{1}$ eröffnet.

1 Vgl. einführend Sebastian Conrad/Shalini Randeria (Hg.): Jenseits des Eurozentrismus. Postkoloniale Perspektiven in den Geschichts- und Kulturwissenschaften, Frankfurt am Main 2002; Ella Shohat/Robert Stam (Hg.): Unthinking Eurocentrism. Multiculturalism and the Media, London 1994. 
Wenn sich postkoloniale Perspektiven der Kulturanalyse üblicherweise auf die nichtwestliche und die Dritte Welt beziehen, so bieten sie doch einen Zugriffsunkt auf die Transfers innerhalb des westlichen Kulturraums, denn die transatlantischen Beziehungen trugen selbst und intrinsisch koloniale Züge. Es geht im Folgenden also nicht um die Beschäftigung mit subalternen Kulturen ${ }^{2}$ - das bleibt ein Desiderat musikhistorischer Forschung - sondern vielmehr um die Konfliktfelder innerhalb des sich im 20. Jahrhundert formierenden Bündnisses zwischen Europa und den USA. Wenn hier Europa als >Kolonialmacht`gegenüber der `hochkulturellen Provinz` Nordamerika verstanden wird, muss freilich festgehalten werden, dass die amerikanischen Kunstbewegungen wegen ihrer direkten Partizipation und Rezeption der europäischen Avantgardekultur in einem anderen Sinne als spostkolonial zu verstehen sind wie subalterne Kulturen der Dritten Welt.

Heute bilden neoeuropäische oder euroatlantische Regionen wie besonders Nordamerika mit Europa scheinbar selbstverständlich die >westliche Welt «; doch die kulturelle Annäherung dieses transatlantischen Kulturraums in der Mitte des 20. Jahrhunderts war konfliktbeladen. In einer Umkehrung des von Arnold van Gennep herausgearbeiteten Modells von ১Übergangsriten`(Rites de Passage), waren die Spannungen weniger Ausdruck einer Trennung (rites de separation), als vielmehr einer krisenhaften Annäherung (rites d'agrégation). ${ }^{3}$ Die Konflikte können als Ausdruck der Unsicherheit in Umbruchphasen verstanden werden, die einen Spot auf die Verflechtung (entanglement) und Verknüpfung (connected histories) zweier Kulturen ungleichen Alters und unterschiedlicher Prägungen erlauben. ${ }^{4}$ In diesem Sinne waren die klingenden Eklats auch Ausdruck der topologischen Verschiebung eines kulturhistorischen `dritten Raums`, den der parsische Postkolonialismus-Theoretiker Homi K. Bhaba in seiner Verortung der Kultur ${ }^{5}$ als Spannungsfeld zwischen Identität und Differenz sowie als Grundvoraussetzung für die Hybridisierung als charakteristisches Moment der Moderne beschrieb. Dabei leisteten die Avantgarden »kulturelle Grenzarbeit « kraft ihres »aufrührerischen Aktes kultureller Übersetzung « ${ }^{6}$. Dieser >dritte Raum ‘ aber ist in der Kunstmusik ein zu großen Teilen unerkannter Nicht-Ort, eine Atopie: In kaum einem kulturellen Feld wurden eurozentrische Sicht-, Denk- und Hörweisen derart konserviert wie in der musikalischen Hochkultur, wo die Tradition weiterhin als Maßstab künstlerischer Wert- und Weltordnung gilt.

2 Siehe hierzu einführend etwa Gayatri Chakravorty Spivak: Can the Subaltern Speak?, London 1988; Alexander Joskowicz/Stefan Nowotny (Hg.): Can the Subaltern Speak? Postkolonialität und subalterne Artikulation, Wien 2007; Partha Chatterjee: »A Brief History of Subaltern Studies«, in Gunilla Budde/Sebastian Conrad/Oliver Janz (Hg.): Transnationale Geschichte: Themen, Tendenzen und Theorien, Göttingen 2006, S. 94-104.

3 Arnold van Gennep: Les rites de passage, Paris 1909; deutsch: Übergangsriten, Frankfurt am Main 2005.

4 Siehe hierzu einführend die Beiträge der Vortragsreihe »Decentering Europe. Postcolonial, postbloc perspectives for a reflexive European Ethnology« an der Humboldt-Universität zu Berlin (25.10.2010-09.02.2011), URL: https:/www.euroethno.hu-berlin.de/de/forschung/ labore/europaeisierungsforschung/decentering-europe [Zugriff: 31.8.2017].

5 Homi K. Bhaba: Die Verortung der Kultur, Tübingen 2000, S. 5.

6 Ebd., S. 10. 
Trotz ihrer Anlehnung an die europäische Hochkultur, bildeten die amerikanischen Avantgarden in der Mitte des 20. Jahrhunderts in einer geradezu expliziten Ablehnung der europäischen Entwicklungen eigene und originäre Konzeptionen aus, die Hans Ulrich Gumbrecht in Kaskaden der Modernisierung beschrieb: Durch die räumliche und chronotopische Deplatzierung im Transfer und den damit verbundenen Transformationen konnte hier der »Akt des Bruches mit der Repräsentation « und die »Beschleunigungsobsession der Avantgarden « überwunden werden. ${ }^{7}$

Wenn Hermann Danuser feststellte, dass die »Idee deutscher Musik [...] zentral bei der Abgrenzung gegen das Andere ${ }^{8}$ sei, kann vice versa auch die Abgrenzung von dieser Idee als wesentlich gelten. So betonte etwa der ägyptische Eurozentrismusforscher Samir Amin, dass Vorurteile gegenüber dem Anderen unumstößliche kulturelle Konstanten und ein universalistisches Phänomen sind. ${ }^{9}$ Auf dem Feld der Kunstmusik verlief die Demarkationslinie der transatlantischen Konfliktfelder zwischen wechselseitigen Vorwürfen von Geschichtslosigkeit in der Neuen- respektive der Musealisierung von Musik in der Alten Welt. Man kann im übertragenen Sinne also von einem Clash of Civilizations ${ }^{10}$ sprechen.

Dichotomische Urteilsmuster und Oppositionsschemata kennzeichneten nach 1945 die kunstmusikalischen Beziehungen dies- und jenseits des Atlantiks. Während man sich in Deutschland auf seine Traditionen als >Kulturnation $<$ besann und amerikanische Kunst kaum ernst nahm, wurden deutsche Musiker auf Gastspielreisen in den USA stellvertretend für die Verbrechen des Dritten Reichs angeprangert. Das galt auch für die Neue Musik und insbesondere Karlheinz Stockhausen, der sich wiederholt mit dem Vorwurf des >Kulturimperialismus konfrontiert sah. Äußerten sich diese Konflikte in zeitcharakteristischen Störmanövern vor und in den Konzertsälen, emanzipierte sich die junge amerikanische Avantgarde - allen voran John Cage - zunehmend auch ästhetisch von ihren europäischen Vorläufern, deren Ideen die Kriegsflüchtlinge als geistig-ästhetisches Gepäck mit in die Neue Welt exportierten.

Können die transatlantischen Kulturbeziehungen vor 1945 als die eines einseitigen Transfers von den (nordwest-)europäischen Metropolen in die hochkulturelle Provinz Nordamerika beschrieben werden, kam es in der zweiten Hälfte des 20. Jahrhunderts zu einem Wandel, der die westliche Welt zu einer transkontinentalen machte und deren Austauschprozesse und Transfers zunehmend in beide Richtungen verliefen. Dies führte in Anlehnung an die These des bengalischen Historikers

7 Hans Ulrich Gumbrecht: »Kaskaden der Modernisierung«, in Johannes Weiß (Hg.): Mehrdeutigkeit der Moderne, Kassel 1998, S. 17-41. Siehe außerdem Wilfried Raussert: Avantgarden in den USA. Zwischen Mainstream und kritischer Erneuerung, Frankfurt am Main 2003; Hermann Danuser: »Gegen-Traditionen der Avantgarde«, in Ders./Dietrich Kämper/Paul Terse (Hg.): Amerikanische Musik seit Charles Ives, Laaber 1987, S. 101-112.

8 Herman Danuser: »Lob des Tadels. Der Skandal in der Musikgeschichte«, in: Programmbuch der Internationalen Musikfestwochen Luzern 1995, S. 115-125., S. 118.

9 Samir Amin: Eurocentrism, New York 1989, S. 7f.

10 Samuel P. Huntington entwickelte mit seiner These vom >Kampf der Kulturen eine politische Theorie der internationalen Beziehungen, basierend auf der These eines grundsätzlichen Antagonismus zwischen einzelnen Kulturräumen, in: The Clash of Civilizations and the Remaking of World Order, New York 1996. 
Dipesh Chakrabarty von der Provinzialisierung Europas ${ }^{11}$ zumindest partiell zu einem Bedeutungsverlust der europäischen Musikavantgarde. Die Neue Musik erlebte in diesem Prozess die Transformation von einer Leitkultur zu einem oft hermetisch betriebenen Spartenprodukt intellektueller Gruppierungen: zu einer ästhetischen »subaltern culture«.

\section{John Cage und die transatlantische Neuvermessung DER KLINGENDEN WELT}

John Cage wurde in der Mitte des 20. Jahrhunderts zur Schlüsselfigur bei der transatlantischen Neuvermessung der klingenden Welt; doch gab es bereits früher Anzeiger dieser Entwicklung: Schon im Umfeld des Ersten Weltkriegs entwickelte die $>$ Neue Welt und besonders New York eine magnetische Anziehungskraft auf europäische Künstler. Marcel Duchamp etwa, der zu einem spartenübergreifenden Pionier der internationalen Avantgardebewegungen avancierte, reizte die Distanz zu den europäischen Kunstzentren mit ihren allgegenwärtigen Gesetzen des Kunstbetriebs. 1915 schrieb er: »Wenn Amerika doch nur einsähe, daß Europas Kunst fertig ist - tot und daß Amerika das Land der Kunst der Zukunft ist. « ${ }^{12}$ Duchamp kritisierte also die kulturelle Unterwürfigkeit der Neuen- gegenüber der Alten Welt und favorisierte die von Traditionen befreite amerikanische Kultur gegenüber der von Normen und Konventionen geprägten europäischen Kunsttradition. Im Schlüsseljahr 1913 - als Igor Strawinsky und Arnold Schönberg in Europa ihre legendären Skandalkonzerte provozierten und damit die musikalische Moderne einleiteten - kam der Franzose erstmals in Kontakt mit der amerikanischen Szene. Damals löste sein Gemälde Nude Descending a Staircase (No. 2) bei der legendären Armory Show ${ }^{13}$ in New York heftige Diskussionen aus und machte Duchamp in den USA auf einen Schlag zu einer bekannten Persönlichkeit. ${ }^{14}$ Wenn bereits hier die amerikanische Orientierung am >Showbusiness` aufblitzt, blieb die europäische Kunst doch vorerst Maßstab aller Hochkultur. Die Neue Musik, so formulierte es noch 2008 Hermann Danuser, fand

»in Amerika keinen Nährboden [...], der sich mit den europäischen Quellen vergleichen ließe, und eine provinzielle Rückständigkeit war umso deutlicher vor Augen getreten, je stärker man auf europäische Vorbilder fixiert blieb.[...] Solange aber die amerikanische Perspektive auf die deutsche Musik fixiert bleibt, das Studium an einem deutschen Konservatorium für die >genteel tradition< eine conditio sine qua non darstellt, solange kann [...] keine Musik entstehen, die uns durch ihre genuine Eigenständigkeit zu fesseln vermöchte. ${ }^{15}$

11 Dipesh Chakrabarty: Provincialising Europe. Postcolonial Thoughts and Historical Difference, Princeton 2007.

12 Zitiert nach Sabine Sanio: 1968 und die Avantgarde, Sinzig 2008, S. 34.

13 Vgl. Milton W. Brown: The story of the Armory Show, New York 1988.

14 Dieter Daniels: Duchamp und die anderen, Köln 1992, S. 64.

15 Hermann Danuser: »Amerikanische Musik - eine unbekannte Welt?«, in Hartmut Krones (Hg.): Multikulturelle und internationale Konzepte in der Neuen Musik, Wien 2008, S. 95102, hier S. 96. 
Beachtenswert ist in dieser Aussage Danusers Schwenk ins Präsens: er verweist auf die Kontinuitäten der europäischen Kulturhegemonie bis in die Gegenwart. Nichtsdestotrotz wurde schon während der 1910er Jahre die Grundlage für eine kleine, aber lebendige Avantgardeszene in New York gelegt, die sich freilich überwiegend aus emigrierten Europäern zusammensetzte, von denen überdies die Mehrzahl nach dem Ende des Ersten Weltkriegs in ihre Heimat zurückkehrte. Sabine Sanio bemerkte in diesem Zusammenhang zwar treffend, dass der »Niedergang der eurozentrischen Weltsicht, die Neuordnung der politischen und ideologischen Machtverhältnisse der westlichen Welt [...] bereits in der ersten Hälfte des 20. Jahrhunderts eingesetzt « ${ }^{16}$ hat; beschleunigt und umgesetzt wurde diese Entwicklung jedoch erst durch den Zweiten Weltkrieg, in dessen Verlauf und Folge Amerika eine singuläre Attraktivität für die internationalen Avantgardebewegungen entwickelte. Zu diesem Emanzipationsprozess bemerkte der amerikanische Künstler Ken Friedmann:

»[I]t was a transnational art in an era that would become increasingly national under the influence of the national movements in art and music that accompanied the break-up of the empires and the liberation of conquered and colonized nations. As a result, this tradition in art excited and stimulated young artists opened the doors to many cultures and at the same time inevitable came into conflicts with the very cultures they enlivened. $\ll^{17}$

War die Kunstmusik bis dato ein europäischer Kulturexport gewesen, erzeugte die Gegnerschaft mit Nazi-Deutschland während des Krieges und in seiner Folge auch künstlerische Frontstellungen. Kampf und Sieg der Alliierten veränderten nicht nur die sozialen und politischen Konstellationen, sondern äußerten sich auch in ästhetischen Konfrontationen. Nicht zufällig, so konstatierte der Kunsthistoriker Hubert Locker, begann in den fünfziger Jahren eine international ausstrahlende expansive Phase der amerikanischen Kunst:

»Für die New Yorker Künstler war die damals propagierte Freiheit gleichzusetzen mit der Befreiung von der europäischen Geisteswelt der totalitären Ideologien und vom geschichtlichen Ballast der europäischen Kunst. ${ }^{18}$

Kaum ein Künstler verkörpert diese Entwicklung so exemplarisch wie John Cage: Der Amerikaner ist die paradigmatische Gestalt bei der stransatlantischen Neuvermessung der klingenden Welt ${ }^{19}$ und wird daher in einem ersten Teil fokussiert.

16 Sanio: 1968 und die Avantgarde, S. 42

17 Ken Friedmann: »Fluxus and Company«, in Ders. (Hg.): The Fluxus Reader, New York 1998, S. 237-255, hier S. 242.

18 Hubert Locker: »Gestus und Objekt. Befreiung als Aktion - Eine europäische Komponente performativer Kunst«, in Peter Noever (Hg.): Out of Actions. Aktionismus, Body Art \& Performance 1949-1979, Ostfildern 1998, S. 159-195, hier S. 162.

19 Anna Schürmer: »Black Magic Mountain. John Cage und die transatlantische Neuvermessung der klingenden Welt« (Feature), in: Südwestrunfunk/SWR2 (11.3.2013); Dies.: »Die transatlantische Neuvermessung der klingenden Welt«, in: Neue Musikzeitung (3/2017), S. 5, URL: https://www.nmz.de/artikel/die-transatlantische-neuvermessung-der-klingendenwelt (Zugriff: 31.8.2017). 
Dabei wird zunächst ein Spot auf das Black Mountain College geworfen, das - so die These - als Mikrokosmos für die transatlantischen Transferbewegungen während und nach dem Zweiten Weltkrieg gelten kann. Hier legte Cage 1948 und 1952 mit skandalträchtigen künstlerischen Manifestationen einen Grundstein für die Entwicklung einer originären amerikanischen Avantgarde. 1954 und 1958 waren es wiederum denkwürdige Auftritte Cages an den avantgardistischen Zentren Deutschlands Donaueschingen und Darmstadt - die illustrieren, wie der bis dato als Einbahnstraße anmutende kulturelle Transfer zu einem wechselseitigen wurde.

\section{Ilnkubation : Black Magic Mountain (1948-1952)}

Geboren 1912, wuchs John Milton Cage Junior als einziger Sohn einer Redakteurin der Los Angeles Times und des Ingenieurs und Erfinders John Milton Cage Senior auf; beide Elternteile hatten nie ein College besucht. Liefert diese Herkunft biographische Anhaltspunkte für den Werdegang des späteren >Musik-Anarchisten`, legte der Zweite Weltkrieg die strukturellen Grundlagen für seine weitere Karriere als Eroberer musikalischen Neulands. Dass der Sohn den Experimentiergeist des Vaters erbte, belegt eine berühmte Aussage Arnold Schönbergs: »Of course he's not a composer, but he's an inventor - of genius. « $^{20}$

Zwar hatte Arnold Schoenberg - wie er sich nach der Emigration in die USA buchstabieren ließ - John Cage 1937 in Komposition und Kontrapunkt unterrichtet; aber für den Kopf der Zweiten Wiener Schule konnte der Amerikaner >kein Komponist`sein. Blitzt hier die traditionsorientierte Kulturhegemonie des Europäers auf, bestätigt Cages Werdegang die wechselseitige Abgrenzung gegen das jeweils >Andere Denn nicht zuletzt aus dem konfliktorientierten Hinterfragen der europäischen $\mathrm{Mu}-$ siktradition bezog der Amerikaner ästhetische Impulse: Er rüttelte durch die Theatralisierung von Musik am Werkbegriff, emanzipierte Geräusch und Stille als musikästhetische Kategorien und trat so als einer der radikalsten Neuerer der Neuen Musik und als zentrale Figur für den Wandel und die Entwicklung der ästhetischen Moderne überhaupt in Erscheinung. Nicht zuletzt war Cage eine Schlüsselfigur bei der für die zweite Hälfte des 20. Jahrhunderts charakteristischen Entgrenzung der künstlerischen Sparten sowie von Kunst und Leben. Schönberg, der zwar die Moderne einleitete, aber doch eindeutiger Erbe der kunstmusikalischen Traditionen Europas war, eignete sich also nur bedingt als künstlerische Vaterfigur für den geschichtsvergessenen und neuerungsbesessenen Amerikaner, der sich stärker an amerikanischen Lehrmeistern wie Henry Cowell, einem Protagonisten der frühen US-Avantgarde, orientierte. Gerade aufgrund der Divergenzen steht das Zusammentreffen von Schönberg und Cage beispielhaft für die Kulturtransfers zwischen Alter und Neuer Welt.

Ähnliches gilt für das Black Mountain College (BMC), das während des Krieges als eine Art Nachfolgeinstitution des Weimarers beziehungsweise Dessauers $>$ Bauhaus` fungierte. Nicht nur der spartenübergreifende Charakter von Walter Gropius' Designschule lebten am BMC in Ashville (NC) fort, dessen Geschichte 1933 begann - dem Jahr, als das Bauhaus seine Pforten in der Alten Welt schließen musste. Auch personell standen beide Institutionen in einem engen Zusammenhang, denn unter der

20 Zitiert nach Richard Kostelanetz: Conversing with Cage, New York 2003, S. 6. 
Leitung der Bauhaus-Meister Josef und Anni Albers fanden viele aus Deutschland vertriebene Künstler in North Carolina eine neue Heim- und Werkstatt. ${ }^{21}$

Am radikal gegen den Mainstream gebürsteten College abseits der noch eurozentrisch geprägten Zentren der USA trafen amerikanische und europäische Kunstund Lebensart quasi unter Laborbedingungen aufeinander und verbanden sich zu einer explosiven Gemengelage, auf deren Basis der Grundstock für eine originäre USAvantgarde gelegt wurde. Angesiedelt in der Provinz, fungierte das Black Mountain College - vergleichbar zu Donaueschingen und Darmstadt in Deutschland - wie ein `Experimentalsystem der Wissenschaftshistoriker, werde allein durch experimentelle Anordnungen ermöglicht, die Unschärfen, Nichtwissen und Kontingenz zu integrieren in der Lage sind. ${ }^{22}$ In den wenigen Jahren seines Bestehens (1933-56) wurde das Black Mountain College zu einem solchen Laboratorium: Es bot Raum für Experimente unterschiedlicher Kunstsparten, erprobte visionäre Formen des Zusammenlebens wie der Ästhetik und bereitete damit auch der Entgrenzung der Künste als charakteristischem Moment der Moderne den Boden. Dabei traten nicht zuletzt die konfliktiven Transfers der transatlantischen Avantgardebewegungen wie durch ein Brennglas zutage: Parallel zu den historischen Ereignissen und Kräfteverschiebungen wird dabei auch das anwachsende Selbstbewusstseins der US-Avantgarde in der zunehmenden Abgrenzung von den europäischen Kulturimporten beobachtbar.

In den ersten Jahren seines Bestehens dominierte am Black Mountain College eine europäische Kunstauffassung, die von deutschen Emigranten als geistiges Gepäck in die Neue Welt exportiert wurde. Im Bereich der Musik etwa tränkte der Schönberg-Schüler Heinrich Jalowetz den Lehrplan mit den atonalen Idealen der Zweiten Wiener Schule. Parallel zum politischen Misskredit Deutschlands infolge der Kriegsgegnerschaft kam es zunehmend zu einer Kräfteverschiebung zugunsten amerikanischer Kunst und Kultur. Das Ende der eurozentrischen Kunstauffassung fällt mit dem Jahr 1945 zusammen, als viele deutsche Flüchtlinge nach Europa zurückkehrten und am Black Mountain ein Vakuum hinterließen, das bald von Amerikanern besetzt wurde. ${ }^{23}$ Nun sammelten sich am College die jungen Kräfte einer originären USKunst, denen der Zugang zu den eurozentrisch geprägten Kulturtempeln der urbanen Kunstzentren Amerikas noch versperrt war. Die künstlerischen Antagonismen zwischen den Vertretern der europäischen Kunstradition und den progressiven Kräften der Neuen Welt spiegeln einen `Kampf der Kulturen`, der in der Schwellenphase zwischen 1948 und 1952 unter dem Einfluss und in Gestalt von John Cage eskalierte.

21 Die einzige deutschsprachige Monographie zum über das Black Mountain College lieferte Andi Schoon: Die Ordnung der Klänge. Das Wechselspiel der Künste vom Bauhaus zum Black Mountain College, Bielefeld 2006. An englischsprachiger Literatur sind zu nennen Martin Duberman: Black Mountain. An Exploration in Community (New York 1972) sowie Vincent Katz: Black Mountain College. Experiment in Art (Cambridge 2013). Die reichhaltigen »Black Mountain College Papers« an den North Carolina State Archives (NCSA) stellen das Hauptmaterial der folgenden Ausführungen.

22 Hans-Jörg Rheinberger: Experimentalsysteme und epistemische Dinge. Eine Geschichte der Proteinsynthese im Reagenzglas, Göttingen 2002.

23 So Alice Sebrell, Leiterin des Black Mountain College Museum and Art Center, im Gespräch mit der Autorin am 19.9.2012 in Asheville (NC). 
Im Frühjahr 1948 erhielt der zu jener Zeit noch völlig unbekannte Komponist die Möglichkeit, ein paar seiner Werke am Black Mountain zu präsentieren. Josef Albers fand Gefallen an dem anarchischen Erfindungsreichtum des Amerikaners, dem sich damit ungeahnte Möglichkeiten eröffneten. Black Mountain wurde in diesem Moment zu einem >Magic Mountain` und das durchaus im Sinne Thomas Manns: ein Zauberberg, der ein Aufeinandertreffen bestimmter Akteure zu einer bestimmten Zeit an einem bestimmten Ort ermöglichte. Davon zeugen allein die Namenslisten der Beleg- und Studentenschaft, die sich wie ein ABC moderner amerikanischer Kunst lesen: Die abstrakten Maler Robert Rauschenberg und Willem de Kooning waren Studenten; der visionäre Architekt, Philosoph und Designer Buckminster Fuller gehörte ebenso dem Lehrkörper an, wie die Dichter Charles Olson und MC Richards sowie der Komponist Lou Harrison; John Cage und seine kongenialen Partner, der Pianist David Tudor und der Tanzpionier Merce Cunningham, unterrichteten schließlich bei den summer sessions des Colleges.

Diesen Exponenten der amerikanischen Avantgardekultur stand weiterhin eine starke deutsche Belegschaft gegenüber, repräsentiert durch die Bauhausmeister Josef und Anni Albers sowie den Komponisten Stefan Wolpe. Diese personelle Gemengelage kann gleichermaßen als Wiege einer transkulturell agierenden Avantgarde wie auch einer eigenständigen amerikanischen Kunst gelten, die sich nicht zuletzt in expliziter Ablehnung der europäischen Kulturexporte begründete. Black Mountain wurde also zu einem magischen Ort, an dem die Ästhetik jener Künstler punktgenau zusammentraf - und dabei einen Nerv berührte. Das College wurde zum Laboratorium einer originären US-Avantgarde nicht obwohl - sondern gerade weil am Black Mountain bis dahin die deutsche Lehre dominiert hatte. In einem Interview bestätigte John Cage 1969, dass er bewusst provokativ gegen die europäische AvantgardeTradition rebellierte. Animiert wurde er dazu von einem Brief Arnold Schönbergs, in dem sein ehemaliger Lehrer schrieb,

»that his discovering of a way of compositing music by means of the twelve tones ensured the supremacy of German music for the next hundred years. And that attitude was not separated from Black Mountain thinking; it was essentially through Albers a Germanic situation. ${ }^{24}$

Der Traditionen ignorierende Amerikaner reagierte mit symbolischem Vatermord, als er 1948 seine Lehrtätigkeit am Black Mountain in 25 Abendkonzerten und einem Festival ausschließlich dem Werk Erik Saties widmete - noch musste mangels amerikanischer Vorbilder ein europäischer Nonkonformist wie der französische Komponist die Abgrenzung von der eurozentrischen Musiktradition symbolisieren. Die Situation eskalierte bei John Cages Vortrag »Defense of Satie«, in dem er nicht nur seinen einstigen Lehrer Arnold Schönberg kritisierte. Für die Negation der europäischen Hochkultur wählte er einen der größten Vertreter der klassischen abendländischen Musiktradition aus - Ludwig van Beethoven - und löste damit einen wohl kalkulierten Eklat aus:

24 John Cage: »Interview mit Martin Duberman« (26.4.1969), in North Carolina State Archives (NCSA): Private Collections, Martin Duberman Collection 1933-1980, Interviews, Released Interview Transcripts: A-H, PC.1678.13. 
»There has been only one new idea since Beethoven. And that new idea can be perceived in the work of [...] Erik Satie. With Beethoven, the parts of a composition were defined by means of harmony. With Satie [...] they are defined by means of the time lengths. The question of structure is so basic, and it is so important to be in agreement about it, that one must now ask: Was Beethoven right or $[\ldots]$ is Satie right? I answer immediately and unequivocally, Beethoven was in error, and his influence, which has been extensive as it is lamentable, has been deadening to the art of music. [...] Beethoven represents the most intense lurching of the boat away from its natural even keel. The derivation of musical thought from his procedures has served not only to put us at the mercy of the waves, but to practically shipwreck the art on an island of decadence. $\ll^{25}$

Cage bezichtigte Beethoven also nicht nur des künstlerischen Irrwegs, sondern warf der Lichtgestalt der Wiener Klassik symbolischen >Schiffbruch an einer Insel der Dekadenzı vor. Der zweite Vorsitzende des Black Mountain College Research Project, Jonathan Hiam, wertet den Vortrag als Cages erstes fundamental-künstlerisches Statement im Versuch, die Orthodoxie der europäischen Musiktradition und ihres klassizistisch-romantischen Gedankenguts zu durchbrechen. ${ }^{26}$ Tatsächlich verlief die Front der alten eurozentrischen und der neuen amerikanischen Avantgarde in jenem Jahr 1948 direkt durch das Gelände des Black Mountain College am Lake Eden. Die eine Hälfte der Belegschaft stand auf Seiten der klassizistischen Tradition, der Kreis um John Cage an der Demarkationslinie der gerade erwachenden US-Avantgarde. In späteren Interviews verdeutlichte Cage seine Motivation für den Affront:

»I infuried Paul Goodman at Black Mountain by speaking against Beethoven. Paul Goodman, bright in other respects, swallowed European thinking hook, line and sinker. ${ }^{27}$ This lecture produced a kind of---it was like a bomb falling in the place [...], he was absolute indignant. That someone would do what I had done [...], to thoroughly denounce Beethoven! $\ll^{28}$

Die eurozentrische Kunsttradition war also auch in amerikanischen Kreisen weiterhin gängig - und das auch bei progressiven Denkern wie dem Schriftsteller Paul Goodman, der in den späten 1960er Jahren mit Essays wie The Politics of Beeing Queer zu einer wichtigen Figur der Homosexuellenbewegung wurde. Der transatlantische Kulturkonflikt am Black Mountain mündete im Sommer 1948 in einer Schlacht, die aktionistisches Potential aus der künstlerischen Frontstellung Saties und Beethovens zog: Anhänger und Gegner Cages bombardierten sich in dadaistischer wie symbolischer Manier mit Wienerschnitzel und Crêpes. ${ }^{29}$ Die Aufbruchsstimmung jenes Jahres 1948 dokumentiert auch Willem de Koonings Gemälde Asheville, das er nach seinem Besuch am Black Mountain College schuf [Abbildung 14]:

25 John Cage: »Defense of Satie«, in Richard Kostelanetz (Hg.): John Cage An Anthology, New York 1991, S. 77-84. Die Arbeitsmanuskripte finden sich bei den »John Cage Papers« der Wesleyan University (Special Collections \& Archives), Folder 24.

26 Jonathan Hiam im Gespräch mit der Autorin am 11.9.2012 in New York.

27 Richard Kostelanetz: John Cage, New York 1970, S. 24.

28 Cage, Interview mit Martin Duberman (26.4.1969), in NCSA: Martin Duberman-Research Papers.

29 Duberman: An Exploration in Community, S. 288f. 
Abbildung 14 - Willem de Koonings abstrakter Blick auf »Asheville»

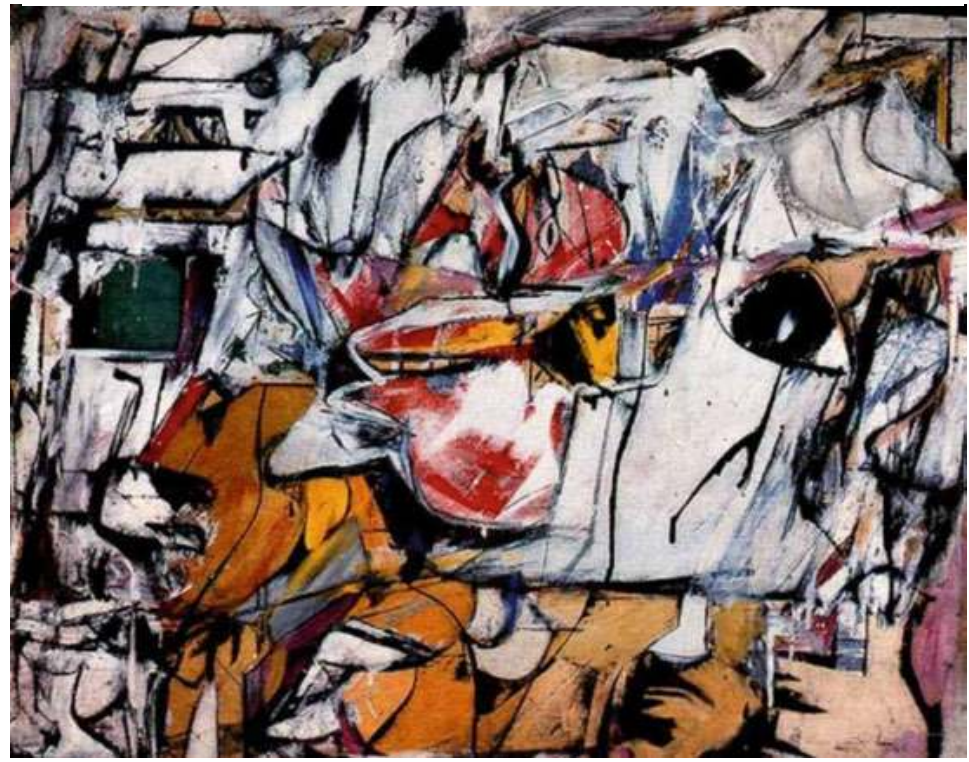

Das kleinformatige aber hochkomplexe Werk ist ein Frühwerk des >Abstrakten Expressionismus - einer von Europa unabhängigen und stilweisenden Strömung der modernen nordamerikanischen Kunst, die als malerisches Analogon der USMusikavantgarde gelten kann. Koonings Asheville verweist in zahlreichen Anspielungen auf das Black Mountain College: Die Konturen am oberen Bildrand zeigen die Blue Ridge Mountains, die hinter dem Gelände des Colleges aufragen, während die blaue Fläche darunter als Lake Eden identifiziert werden kann. Weitere Fragmente zeigen Augen, Hände und Mund, die stilistisch durch einen Fluss von Formen und visuellen Brüche den konzeptuellen Eindruck von Unmittelbarkeit und Zufall erzeugen und als Andeutung auf die spartenübergreifenden Kunst-Werkstätten des Colleges gelten können. Damit charakterisierte das Gemälde gleichermaßen die ästhetische wie die soziale Utopie, die am Black Mountain gelebt und gelehrt wurde. Tatsächlich verbanden sich am College als visionärem `Experimentalsystem〈künstlerische und gesellschaftliche Avantgardebewegungen und wiesen darin auf die für die Moderne charakteristischen Entgrenzung von Kunst und Leben.

Die ebenso zahl- wie umfangreichen Bestände der Black Mountain College Collection $^{30}$ an den North Carolina State Archives in Asheville erlauben ein umfassendes Bild des Collegelebens. Die Materialien - Interviews, Tagebücher, audiovisuelle Ar-

30 Neben offiziellen Dokumenten umfasst der Bestand der »Black Mountain College Collection« zahlreiche Sammlungen. Dazu gehören die Materialien des »Black Mountain College Research Project«, aus dessen Beständen Mary Emma Harris’ Monographie »The Arts at Black Mountain College« (Cambridge, MA 2002) - hervorgegangen ist. Zu nennen sind außerdem die »Martin Duberman-Research Papers«, die alle Grundlagenmaterialien für dessen Collegegeschichte »An Exploration in Community« (New York 1972) umfassen. 
tefakte, Programme etc. - bestätigen Jonathan Hiam und Mary Emma Harris, die das BMC nicht nur als Brutofen der amerikanischen Avantgarde, sondern als »early Hippie-Comunity« und »port of reference« für die Bohème der 1960er Jahre bezeichneten. ${ }^{31}$ Während sich in der McCarthy-Ära das Klima für Andersdenkende in den USA verschlechterte, bot das College den künstlerischen und gesellschaftlichen Gegenbewegungen Freiräume, so dass hier die Lebensführung der 1960er, quasi unter experimentellen Labor-Bedingungen, antizipiert werden konnte. Dies legt auch eine Aussage von John Cage aus dem Jahr 1969 nahe:

»One thing that characterized Black Mountain $[\ldots]$ was $[\ldots]$ an atmosphere of sexual freedom [...]. And that what conduced to this so beautiful was the decentralization of the architectural arrangements. And also of that large studio building [...] with all the small rooms. So that people could get together very easily $[\ldots]$ and also changed from one partnership to another $[\ldots]$ and also their dress, their clothes, everything [...] it's almost a pre-hippie-beatnik. ${ }^{32}$

Das freigeistige Klima am Black Mountain erwies sich als idealer Nährboden für die Innovationskraft der amerikanischen Avantgarden, die sich immer deutlicher von den Exporten der europäischen Kultur emanzipierten. Wieder war es John Cage, der dem Konflikt eine Bühne bot, als er nach seinen umstrittenen Satie-Lectures 1948 vier Jahre später noch einmal als Kompositionslehrer ans BMC zurückkehrte, um wiederum einen Eklat zu provozieren. In der Zwischenzeit hatte er sich der Aleatorik, also dem Zufall als kompositorischem Prinzip, zugewendet und damit alle Brücken zur europäischen Musiktradition abgebrochen. Seit jenem Jahr 1952 hatte das College mit Stefan Wolpe, der den amerikanischen Komponisten Lou Harrison in Cages Worten »in einem Akt der Usurpation« verdrängt hatte, wieder eine deutsche Führungsfigur auf dem Feld der Musik; der Konflikt war damit vorprogrammiert. Wieder bot das College den Schauplatz einer unter deutsch-amerikanischem Antagonismus ausgetragenen Kontroverse um die Zukunft der Musik: Mokierten sich die Vertreter der europäischen Moderne über die Beliebigkeit der Zufallsoperationen, schlug auch John Cage einen schroffen und dogmatischen Ton gegenüber der eurozentrischen Musikkultur an. Hatte er 1948 noch Beethoven als Symbolfigur der Wiener Klassik angegriffen, stellte er nun die serielle Nachkriegsavantgarde infrage, deren Festhalten an Kontrolle und Hierarchisierung er scharf kritisierte:

»That's a European, you know, not an American question, this whole thing of hierarchy - of wanting to make the most the best. And it took us ages [...] to get out of that European thing [...]. Lots of us don't like the German people. We don't like to be in Germany, we don't want to work in Germany; and the ideals we have are not appealing to the Germans. You know that rule they made about any music that involves the performer in choice-making - they charge twice as much. ${ }^{33}$

31 Jonathan Hiam und Mary Emma Harris im Gespräch mit der Autorin am 11.9.2012 in New York.

32 John Cage im Interview mit Martin Duberman (26.4.1969), in NCSA: Martin DubermanResearch Papers.

33 John Cage im Interview mit Richard Kostelanetz, zitiert nach Marjorie Perloff/Charles Junkerman (Hg.): John Cage. Composed in America, Chicago 1994, S. 1. 
Cage hatte mittlerweile die entgegengesetzte Richtung eingeschlagen: Anstelle musikalischer Hierarchisierung setzte er die Aufgabe des schöpferischen Subjekts; anstelle von Kontrolle die Hinwendung zum Zufall als kompositorischem Prinzip. 1952 bot ihm BMC die Möglichkeit, seine ästhetischen Ideen wiederum unter Laborbedingungen zu testen:

»When I announced the classes in composition, I announced also what I would teach [...]. I had meanwhile changed to the use of chance operations exclusively in my work and I was busy on a large project, which took me nine months. [...] It was called Williams Mix [...] because Paul and Vera Williams - who gave so much support to Black Mountain and who had been students and who had been married there - where also financing my work with magnetic tape $[\ldots]$. So I announced $[\ldots]$, that I would not teach people their work, but rathermore $[\ldots]$ they would act as apprentices for me and do my work for me. [...] As a result I had not one student $[\ldots]$ they didn't want to do my work and so I wouldn't to teach them. ${ }^{34}$

Der in Jahresarbeit aus über 600 Tonbandausschnitten montierte, aber nur vierminütige Williams Mix [\$-15.1] belegt nicht nur John Cages Vorreiterrolle für die amerikanische Tape Music - und damit seinen Beitrag zur $>$ Elektronischen Eklatanz ${ }^{35}$ sondern auch den enormen Aufwand in Anbetracht der technischen Mittel jener Zeit. Darüber hinaus zeigt sich im oben angeführten Zitat auch seine vom fernöstlichen Denken geprägte antiautoritäre Lehre, die am antihierarchisch strukturierten BMC, dem ersten amerikanischen College mit Studentenvertretung überhaupt, einen idealen Schauplatz fand. Die interdisziplinär aufgeschlossene College-Gemeinde bildete ein ideales Publikum für Cages verstärkte Hinwendung zu offenen Formen und theatralischer Entgrenzung. Bei seinem Paris-Aufenthalt 1949 wurde Cage von einem Vertreter der eurozentrischen Musikavantgarde auf Antonin Artauds Das Theater und sein Double $^{36}$ aufmerksam gemacht:

»[Pierre] Boulez [...] brought to my attention the work of Artaud and I brought that to MC Richards. And she translated it, and David Tudor and I and MC were reading Artaud constantly. And it was that influence led to that event, which is called the first happening. Because Artaud postulates $[\ldots]$ the centricity within each event and its non-dependence on other events [...] It all fused together into the possibility of making a theatrical event in which the things that took place were not causally related to one another. But in which--- that anything that happened after the happen in the observer himself--- It was an idea which was developed in conversation with David Tudor. [...] And our ideas were so electric [...] that once the idea hit my head, [...] I immediately then implemented it. « ${ }^{37}$

34 John Cage im Interview mit Martin Duberman (26.4.1969), in NCSA: Martin DubermanResearch Papers.

35 Siehe hierzu vertiefend das Kapitel Elektronische Eklatanz.

36 Antonin Artaud: Das Theater und sein Double, Frankfurt 1969. Artaud sah als Double des Theaters die Metaphysik und die Grausamkeit. Eine Aufführung sollte keine Mimesis, also Nachahmung der Wirklichkeit, sondern eine Wirklichkeit für sich selbst sein und wurde damit zur entscheidenden Referenz für die performativen Künste.

37 John Cage im Interview mit Martin Duberman (26.4.1969), in NCSA: Martin DubermanResearch Papers. 
Artauds Theaterutopie traf einen künstlerischen Nerv John Cages, der die neuen Erkenntnisse in seinem Theatre Piece No. 1 in theatrale Aktion überführte: Der Komponist fixierte lediglich verschiedene time brackets, die mit völlig frei wählbaren Aktionen durch kunstspartenübergreifende Interpreten zu füllen waren. Methode und Ziel der Aktion war eine Purposeless purposefulness:

»[I]t was purposeful in that we knew we were going to do, but it was purposeless in that we didn't know what was going to happen in the total [...]. The 1952 event was unintentional [...] a purposeless anarchic situation which nevertheless is made practical and functions. $\ll^{38}$

Das Ergebnis des Experiments: Die Dichter Charles Olson und MC Richards trugen eigene Gedichte vor, während Cage auf einer Leiter stehend zur Relation von Musik und Zen-Buddhismus dozierte. David Tudor improvisierte auf einem mit Schrauben und Radiergummis präparierten Klavier, während Merce Cunningham in Diagonalen durch das Publikum tanzte. An die Wände wurden Filme und Dias projiziert, während Robert Rauschenberg auf einem alten Plattenspieler Edith-Piaf-Schallplatten in doppelter Geschwindigkeit abspielte. An den Wänden hingen die All White Paintings des Malers, denen wiederum entscheidende Bedeutung für die Entstehung von John Cages berühmtestem Werk - 4'33" - zukommt. Erst das Vorbild der monochromen weißen Flächen ermutigte ihn, seine lange gehegte Idee eines >stillen Stücks` umzusetzen, mit der er den Fundus der Avantgarde nach der Emanzipation des Geräuschs nun mit Stille bereicherte:

"You see, I was afraid that my making a piece that had no sounds in it would appear as if I were making a joke. [...] Actually, what pushed my into it was [...] the example of Robert Rauschenberg and his white paintings [...]. When I saw those, I said, >Oh yes, I must; otherwise I'm lagging, otherwise music is lagging «. ${ }^{39}$

Four minutes, thirty-three seconds wurde noch im selben Winter - zwar außerhalb des Colleges, aber nicht denkbar ohne John Cages am Black Mountain gesammelten Erfahrungen, Begegnungen und Experimenten - uraufgeführt. Dort wurde an jenem Sommerabend 1952 mit dem ersten Happening auch die Ära der Aktionskunst kontrovers begrüßt. Merce Cunningham erinnerte sich später folgendermaßen an jenes eklatante Initialereignis der Fluxus-Bewegung:

»It was just an evening of theater. [...] I just started dancing [...]. And there were some other things going on $[\ldots]$ with no other relationship than that they went on at the same time $[\ldots]$. We just did our thing [...]. I don't think any of us did any rehearsing [...]. I have a recollection of suddenly at the last minute something else being included. [...] It is respect to the way life itself is all these separate things going on at the same time. And contemporary society is so extraordinarily complex that way. ${ }^{40}$

38 Ebd.

39 Zitiert nach Kyle Gann: »The Path to 4'33'" ", in Ders.: No Such Thing as Silence. John Cage's 4'33, New Haven 2010, S. 120-166, hier S. 160.

40 Merce Cunningham im Interview mit Martin Duberman (26.4.1969), in NCSA: Martin Duberman-Research Papers. 
Das Theatre Piece No. 1 antizipierte nicht nur die für die zweite Hälfte des 20. Jahrhunderts charakteristische Entgrenzung von Kunst und Leben, sondern sperrte sich in Zeiten der technischen Reproduzierbarkeit gegen jede Form der Fixierung, gegen die sich Cage immer wieder vehement ausgesprochen und mit Blick auf Schallplatten geschrieben hatte: »Es wäre ein Akt der Nächsten- und sogar Selbstliebe, sie zu zerschmeißen, wo immer sie zum Vorschein kommen. ${ }^{41}$ Weil der Musik mit den Möglichkeiten der Aufzeichnung und Reproduktion ihre Ereignishaftigkeit verloren gehe, betonte Cage umso stärker die theatrale Performativität von Konzert-Ereignissen. Auch von jenem Theatre Piece No. 1 existieren keinerlei Aufnahmen: weder Presseberichte, noch Fotos. Ausschließlich Augenzeugenberichte begründen den Mythos des sersten Happenings`, das seit den 1970ern zum Gründungsereignis der Aktionskunst stilisiert wurde. ${ }^{42}$ Die Theaterwissenschaftlerin Erika Fischer-Lichte bezeichnete das Untitled Event als »bemerkenswertes Ereignis in der Theatergeschichte der westlichen Kultur«:

»Meine These lautet, daß es nicht nur das Verhältnis von Akteuren und Zuschauern bei einer Aufführung neu bestimmt hat, sondern auch die Beteiligung verschiedener Künste in einer Aufführung sowie das Verhältnis von Theater zu anderen kulturellen Veranstaltungen. Meiner Ansicht nach hat es damit zugleich auch den geltenden Theater-, Kunst- und Kulturbegriff in Frage gestellt und Perspektiven für ein anderes Verständnis von Theater, Kunst und Kultur eröffnet. $^{43}$

Die Reaktionen zu dem derart stilisierten Ereignis reichten 1952 bei der Aufführung am Black Mountain College von beiläufiger Aufnahme, über Begeisterung bis hin zu unverhohlener Abneigung - und erfüllten damit die musikskandalöse Charakteristik polarisierender Meinungsbekundungen. Abermals befeuerte John Cage den Konflikt zwischen der deutschen Musiktradition und den Kräften einer eigenständigen USamerikanischen Avantgarde mit einer skandalträchtigen Provokation, die Jonathan Hiam als paradigmatischen Wendepunkt in der Musikgeschichte bezeichnete:

»This scandal, as a cultural moment in music history, became increasingly important. The Theater Piece No. 1 provoked no big scandal, but it raises aesthetic tendencies to a moment of highly creative potential. This moment is illustrated by the response of Stefan Wolpe: The German composer reacted very negatively to the open form. For him, there was to much anarchy instead of artistic control. ${ }^{44}$

Auch Augenzeugen erinnerten sich an die empörten Reaktionen der deutschen Belegschaft und speziell des Komponisten Stefan Wolpe. So notierte etwa die damalige Studentin Carrol Williams noch am Abend der Aufführung in ihrem Tagebuch: »Wolpe bitched!«:

41 John Cage: »Erik Satie«, in Klaus-Heinz Metzger/Rainer Riehn (Hg.): Erik Satie (MusikKonzepte, Band 11), München 1988, S. 29-36, hier S. 30.

42 Alice Sebrell im Interview mit der Autorin am 19.9.2012 in Asheville.

43 Erika Fischer-Lichte/Friedemann Kreuder, Isabel Pflug (Hg.): Theater seit den 60er Jahren. Grenzgänge der Neo-Avantgarde, Marburg 1998, S. 2.

44 Jonathan Hiam im Gespräch mit der Autorin am 11.9.2012 in New York. 
»Everybody sat all the way through it except Stefan Wolpe, who was very upset by the whole thing. [...] Got up and left - in protest. [...] They come from the German radicalist tradition [...] all related to Schoenberg and all these people. But they could never make the next step, the next leap. $\aleph^{45}$

Das Selbstbewusstsein der amerikanischen Avantgarde war enorm gewachsen - und ihre Vertreter bezogen nicht zuletzt aus der Abgrenzung vom eurozentrischen Traditionalismus mit seinen kulturellen Hegemonieansprüchen ihre kreative Kraft. In diesem Prozess half auch die spezifische Disposition des Black Mountain College: Durch die abgeschiedene Lage und den chronischen Geldmangel wurden zwangsläufig der interdisziplinäre und experimentierfreudige Gemeinschaftssinn sowie die künstlerischen Entgrenzungstendenzen der Moderne gefördert. Nur eine Künstlerenklave wie das Black Mountain College, isoliert und deshalb unabhängig von Faktoren wie Publikumszuspruch und Konzerteinnahmen, konnte eine solche Freiheit gewähren. Das bestätigt auch die Archivarin der Black Mountain College Papers, Heather South:

»Black Mountain College was isolated from the cultural centers and this allowed a lot of extra freedom [...]. They didn't have restrictions, no worry about your funders, so they could explore this amazing productions and buildings - and being isolated helped a lot. ${ }^{46}$

Als das College 1956 - nach gerade einmal 23 Jahren - seine Tore schloss, brachten die Studenten die am Black Mountain gesammelten Erfahrungen in eine Welt, die nun auch außerhalb der College-Mauern bereit war für die unter Laborbedingungen getestete US-Avantgarde. War die amerikanische Musikavantgarde zunächst von den europäischen Kriegsflüchtlingen beeinflusst worden, wirkten die kreativen Kräfte der deutschen Besatzermacht nun ihrerseits zurück auf den europäischen Kulturraum und dies wiederum in Gestalt von John Cage.

\section{sKulmination، in der Alten Welt (1954-1958)}

Im Jahr seines zweiten und letzten Besuchs am Black Mountain College erregte John Cage erstmals auch in Deutschland Aufmerksamkeit. Am 22. November 1952 sendete der Westdeutsche Rundfunk mit Stücken für prepared piano und den beiden Construction in Metal erstmals Werke des Amerikaners im deutschen Radio, die Vertreter und Veranstalter der Neuen Musik aufhorchen ließen. Auf Vermittlung von Pierre Boulez, mit dem Cage seit seiner Europareise 1949 einen regen Briefaustausch pflegte $^{47}$, wurden bald die deutschen Zentren der Neuen Musik - Darmstadt und Donaueschingen - auf den Amerikaner aufmerksam.

45 Carrol Williams im Interview mit Martin Duberman, zitiert nach Ders., An Exploration in Community, S. 373.

46 Heather South, Archivarin der Black Mountain College Papers an den North Carolina State Archives, im Gespräch mit der Autorin am 20.9.2012 in Asheville.

47 Jean-Jacques Nattiez (Hg.): Dear Pierre - Cher John. Pierre Boulez und John Cage. Der Briefwechsel, Hamburg 1997. 
Angetrieben durch den Fortschrittsimperativ der deutschen und europäischen Nachkriegsavantgarde entstand in der Folge ein Wettlauf, wer den provokanten Musikanarchisten erstmals präsentieren dürfe. Heinrich Strobel schrieb im Frühjahr 1954 an John Cage, dass das im Rahmen der Donaueschinger Musiktage geplante Konzert sein erster Auftritt in Deutschland sein müsse, andernfalls wäre die Sensation verpasst:

"I was very interested to hear that you are in correspondence with various radio stations in Europe concerning other engagements, whiles being abroad. You certainly will allow me to call attention to the fact, that every performance in Germany can only be realized after our Donaueschingen Festival. The attraction of your coming out in Germany [...] would be lost, if you play anywhere in Germany before. ${ }^{48}$

So fand am 17. Oktober 1954 in Donaueschingen die Europapremiere von 12'55.6078 for two pianists [\$-15.2] statt, bei der Cage und sein kongenialer Partner, der Pianist David Tudor, an ihrem mit Schrauben, Papier und Radiergummis präparierten Klavier einen ereignishaften Marker in der modernen Musikgeschichte setzten. Bereits seit 1940 hatte der Komponist in Anlehnung an Henry Cowell sein prepared piano entwickelt und damit den Konzertflügel zum Perkussionsinstrument umfunktioniert. Interpretatorische Parameter wie subjektiver Ausdruck, Gesanglichkeit, klangliche Differenzierung mittels spontaner Anschlagsnuancen und technische Brillanz wurden so auf einen Schlag eliminiert. John Cage eröffnete dem Instrument eine Vielfalt von Klangfarben, nahm aber dafür den Verlust des ganzen Spektrums hoch differenzierter Artikulationsmöglichkeiten in Kauf, welche die europäische Musiksprache maßgeblich geprägt hatten.

Abbildung 15 - John Cage 1948 am BMC, noch klassisch am Flügel komponierend Abbildung 16 - John Cage 1960 beim Präparieren eines Flügels
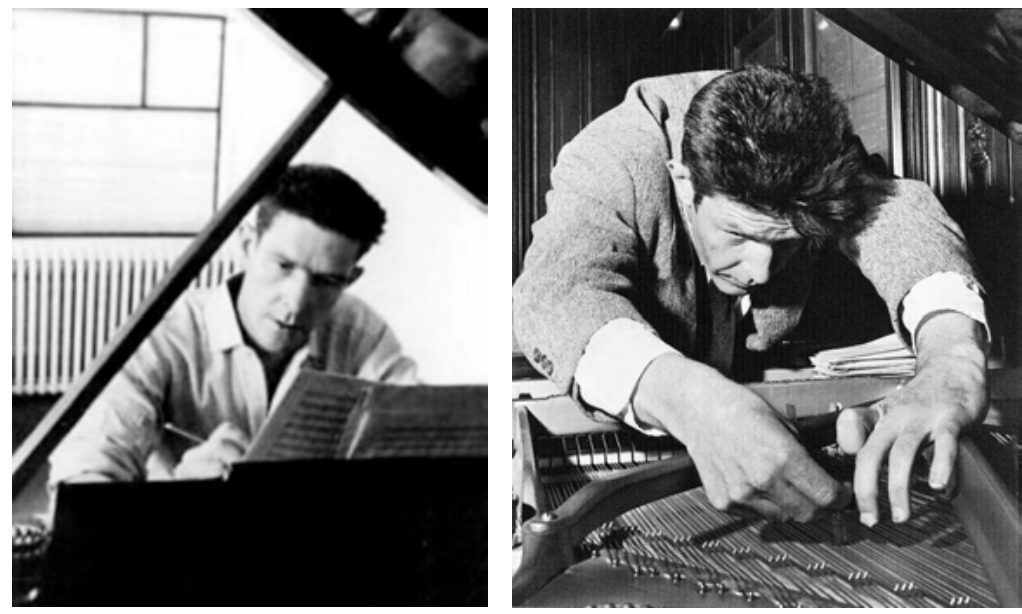

48 Brief von Heinrich Strobel an John Cage (10.3.1054), in SWR Zentralarchiv: P 06261. 
Vor diesem Hintergrund wird der Eklat verständlich, den die erste europäische Präsentation von John Cages prepared piano in Donaueschingen auslöste. Der Komponist erinnerte sich später folgendermaßen an die verständnislosen Reaktionen des deutschen Publikums: »David Tudor and I were thought to be idiots or better: clowns«. Erst 1958, so fügte er hinzu, »there was a marked change. Since that year we were taken quite seriously - for the most part. ${ }^{49}$ Damit beschrieb Cage selbst die Jahre zwischen 1954 und 1958 als Schwellenphase, in der sich sein Durchbruch an den beiden Polen der westlichen Avantgarde in zwei Konzertereignissen mit jeweils aussagekräftiger Charakteristik vollzog: War Cages Donaueschinger Europapremiere von Gelächter begleitet, wandelte sich das Amüsement bis zu seinen Darmstädter Auftritten 1958 in ernste Empörung. Beide Affekte können innerhalb des Konzertrituals als skandalös, weil antinormativ bezeichnet werden und verifizieren in ihrem Wandel auch den eklatanten Durchbruch des Amerikaners in Europa.

Cage Erinnerung, er sei 1954 in Donaueschingen wie ein >Clown< belächelt worden, ist durch den Mitschnitt des Konzerts ${ }^{50}$ belegbar [ $\left.\delta-15.2\right]$. Auf dem Tondokument sind Lachsalven und Zwischenrufe festgehalten, die sich zu einem beträchtlichen Lärmpegel ausweiten und der Aufnahme einen beträchtlichen Zeugenwert als akustische Quelle verleihen. Zwar kam es hier nicht zu Handgreiflichkeiten, aber auch das Gelächter - eine der `Ernsten` Musik per se ferne Gefühlsäußerung - kann als normwidrige Handlung des Publikums dem Phänomens Musikskandal zugeordnet werden. Mehr noch, gibt das Gelächter Hinweise auf eine Epochenschwelle, wenn man dem Metzler Lexikon Avantgarde folgt, in dem das Lachen als anthropologische Handlung und abhängig von Zeit, Ort und Gesellschaft beschrieben wird:

»Alle nichtkörperlichen Anlässe des Lachens [...] können verstanden werden als Berühren der empfindlichen Stellen der moralischen, religiösen, politischen, sozialen, kulturellen >Häuteく, mit denen Menschen als gesellschaftliche Wesen ebenfalls umspannt sind. Das Lachen ist daher weniger eine Sache des individuellen Temperaments oder der zufälligen Alltagsstimmung. In historischen Krisen- und Umbruchszeiten [...] können vielmehr große Teile der gesamten Kultur sich am Lachen als dem natürlichsten Mittel gegen Angst orientieren. $\ll^{51}$

Somit kann das Gelächter des Publikums bei der Donaueschinger Europapremiere John Cages im Herbst 1954 als Indiz für einen anstehenden Paradigmenwechsel interpretiert werden. Allgemein wird in diesem Zusammenhang die Hinwendung zur Groteske als Produktions- und Rezeptionshaltung in großen Teilen der modernen Kunst als Reaktion auf die quasireligiöse Kunstverehrung des 19. Jahrhunderts deutlich. ${ }^{52}$ Bei aller Radikalität hatte die europäische Nachkriegsavantgarde doch noch innerhalb einer kunstmusikalischen Traditionslinie agiert.

49 Zitiert nach Richard Kostelanetz: Conversation with Cage, in Ders., John Cage, S. 17.

50 John Cage: 12'55.6078 for two pianists (prepared piano), auf: 75 Jahre Donaueschinger Musiktage (1921-1996), 12 CD-Box, CD 3, Track 1, Col Legno 1997.

51 »Lachen«, in Hubertus van den Berg/Walter Fähnders (Hg.): Metzler Lexikon Avantgarde, Stuttgart/Weimar 2009, S. 185f. Siehe weiterführend Ludger Scherer/Rolf Lohse (Hg.): Avantgarde und Komik, Amsterdam 2004.

52 Ludger Scherer/Rolf Lohse (Hg.): Avantgarde und Komik, Amsterdam 2004. 
Dies verdeutlicht die Indignation, die sich infolge von John Cages Auftritt in Kritiken ausdrückte, in denen von »unschuldigen Instrumenten« und von »wehrlosen Klavieren« in einer »akustischen Hölle« die Rede war. ${ }^{53}$ Dieter Schnebel, ein bekennender Bewunderer Cages und selbst radikaler Avantgardist jener Jahre, erklärte:

»Wir waren alle ausgebildet in klassischer Musik, und wenn da einer wie Cage im Inneren des Klaviers rummachte, das hatte etwas Obszönes. Dinge, die von der eigenen musikalischen Sozialisation ablenken... - das tut man einfach nicht! « ${ }^{54}$

Die Provokation bestand nicht nur in Cages Missachtung der europäischen Musiktradition, sondern äußerte sich auch im achselzuckenden Lächeln, mit dem er heilig geglaubte Parameter der Musikästhetik beiseite wischte. Mehr noch stilisierte der Amerikaner seine Distanz zu den europäischen Zentren der zeitgenössischen Musikkultur geradezu als Vorteil für die Entwicklung einer >neuen` Neuen Musik stilisierte:

»Once in Amsterdam, a Dutch musician said to me: >It must be very difficult for you in America to write music, for you are so far away from the centers of tradition. I I had to say: >It must be very difficult for you in Europe to write music, for you are so close to the centers of tradition $\ll . \ll^{55}$

Auch Karlheinz Stockhausen beschrieb die ästhetische Geschichtslosigkeit John Cages später als grundlegend für die Rolle, die er in Europas Musikwelt bald spielte:

»John Cage ist der erste Amerikaner der aus der Traditionslosigkeit keinen Hehl macht. Und er spielt nur in Europa den Buhmann, wo er nicht umsonst das Beste, weil schockierteste Publikum hat. Schönberg hat einmal seine Skrupel beschrieben, eine musikalische Wahrheit durch eine neue zu ersetzen [...], wenn man mit aller Tradition in den Knochen eine Sache fahren lassen muss, die heilig ist [...]. Cage hat weder einen Schönberg, noch einen Webern, noch einen Debussy herangelassen [...] wer keine Heimat hat, hat kein Heimweh [...]. Cages Distanz zum kompositorischen Stand der Epoche ist astronomisch. ${ }^{56}$

Wenn die Hochkultur Amerikas auch nach wie vor von europäischen Einflüssen geprägt war, so nutzten viele Künstler der USA nun den Vorteil der jungen Nationalkultur, die sich in Abgrenzung zur imperialen >Import-Kultur Europas entwickelte. ${ }^{57}$ Auch Sabine Sanio stellte mit Blick auf die US-amerikanische Avantgarde fest, dass »traditionelles Kunstverständnis, Rituale des Kulturbetriebs, Sabotage des affirmativen Charakters der Kultur [...] kein Thema waren. ${ }^{58}$

53 Eine Pressesammlung findet sich im Archiv des SWR: Donaueschingen 1954 - P 06261.

54 Dieter Schnebel im Gespräch mit der Autorin am 12.8. 2012 in Murnau.

55 Zitiert nach Kostelanetz, John Cage, S. 185.

56 Karlheinz Stockhausen: »Vieldeutige Form«, Vortrag bei den Internationalen Darmstädter Ferienkursen für Neue Musik (13.7.1960), in Schallarchiv des IMD: B006491334/17b.

57 Monika Lichtenfeld: »Multikulturelle Aspekte in der amerikanischen Musik des 20. Jahrhunderts«, in Hartmut Krones (Hg.): Multikulturelle und internationale Konzepte in der Neuen Musik, Wien 2008, S. 127-136, hier S. 127.

58 Sanio: 1968 und die Avantgarde, S. 34. 
In Europa allerdings provozierte die Musikauffassung des Amerikaners zunehmend die Angst vor dem Anderen, Unberechenbaren und Irrationalen. Wurde John Cage 1954 in Avantgardekreisen belächelt oder freudig als Neuerung begrüßt, mehrte sich in den kommenden Jahren die Kritik an den anarchischen Experimenten, welche die europäische Kunstmusik auf den Prüfstand stellten. Der schwelende Konflikt entlud sich 1958 in Darmstadt. Die vier Jahre seit seinem eklatanten Auftritt in Donaueschingen können als Kulminationszeit verstanden werden, in der das europäische Kulturleben durch die zurückkehrenden Flüchtlinge, die auch amerikanische Einflüsse in die Heimat rückführten, langsam auf den Wandel vorbereitet wurde. Diese Jahre verzeichnen denn auch einen grundsätzlich geführten Diskurs über diese Entwicklung. Stefan Wolpe etwa, der 1952 am BMC gegen Cages erstes Happening - das Untitled event - gewütet hatte, hielt am 19. Juli 1956 bei den Darmstädter Ferienkursen seinen Vortrag »Über neue und nicht so neue Musik aus Amerika« und charakterisierte diese folgendermaßen:

»Das Kalte, das Schäbige, das Harte, das Plötzliche, das Unbewegte, das Starke, das Konfuse, den Witz, das Übermaß, die Wichtigkeit, das Fallenlassen, Allgemeinstes, Unschichtiges, Flaches, Außerordentliches, Verschichtetes, Potenziertes, Loses, Zerfetztes, Unordentliches, Unaufhörliches, dauernd Unterbrochenes, der Schock und die immer größeren Gegensätze, das Simultane und das Geräusch - alles ist möglich, das ist die geschichtliche Situation. ${ }^{59}$

Nicht jeder, so fuhr der ehemalige Dozent des Black Mountain Colleges fort, halte Schritt mit dem Tempo einer Musik, in der nun alles möglich sein sollte. Auch sprach Wolpe von einer radikalen US-amerikanischen Kompositionstechnik, die sich nicht im Geringsten um Traditionen kümmere und definierte damit eben jenen Konflikt, der die Hüter der abendländischen Musik alarmierte. Nun wandelte sich das wohlwollende Amüsement des europäischen Musikestablishments in Abwehr: Pierre Boulez, Cages einstiger Brieffreund, wurde dabei zum Vorkämpfer der eurozentrischen Musiktradition - die er selbst mit der >Darmstädter Schuleく an ihren äußersten Rand geführt hatte. 1956 wurde David Tudor nach Darmstadt eingeladen und präsentierte im Rahmen der Ferienkurse und in Abwesenheit John Cages erstmals dessen Zufallsmusik: Music of Changes. Danach äußerte Pierre Boulez in einem Gespräch mit Karlheinz Stockhausen, der in seinem Klavierstück XI ebenfalls aleatorische Strukturen verwendete, seinen Ärger über die >Aleatorisierung` der Musik:

»Er war zunächst überrascht, wurde dann wütend und schimpfte, solchen Unsinn könne er nicht verstehen, ich hätte Angst, alles genau in der Notation festzulegen und wolle Verantwortung von mir fortschieben. Tudor lachte die ganze Zeit verschmitzt. [...] Als ich Anfang 1957 in Paris war und ihn [Boulez] fragte, warum er solche Artikel wie Alea schreiben müsse, wenn er Cage oder mir eins auswischen wolle und sagen möchte, wie man's besser macht, so könne er das ja direkt mitteilen. Er meinte: >Den Missbrauch will ich verhindern, so Leute wie Cage sind gefährlich ${ }^{6}{ }^{60}$

59 Stefan Wolpe: Über neue und nicht so neue Musik aus Amerika, Vortrag bei den Internationalen Ferienkursen für Neue Musik Darmstadt (19.7.1956), in Schallarchiv des IMD: B006385244/VD 11a.

60 Stockhausen: Vieldeutige Form, S. 190. 
In seinem Aufsatz Alea ${ }^{61}$, kritisierte Boulez 1957 John Cages Experimente mit Zufallsmanipulationen öffentlich aufs Schärfste und verteidigte die notwendige Kontrolle der Komponisten gegenüber der Willkür des Zufalls. Die »Übernahme einer orientalisch getünchten Philosophie« diene lediglich dazu, eine »grundlegende Schwäche der Kompositionstechnik zu verdecken.« Indem jegliche kompositorische Verantwortung und Entscheidung aufgegeben werde, entstünde eine »Anti-Kunst«, deren beruhigend-erheiternde Wirkung mit den Effekten des Haschischkonsums vergleichbar ist. ${ }^{62}$ Die europäische Kulturhegemonie wackelte und Michael Custodis deutete die Kritik an Cage auch als politische Angelegenheit:

»In der Tradition politischer Ausgrenzung von Komponisten erscheint die Position der amerikanischen Komponisten um John Cage während der fünfziger Jahre von weitreichender Ausgrenzung gekennzeichnet, da weder das amerikanische noch das europäische Musikleben, weder das traditionelle Musikpublikum noch das Darmstädter oder Donaueschinger Spezialistentum sie integrieren wollte; auch die anfängliche Unterstützung europäischer Komponistenkollegen schmolz im Verlauf des Jahrzehnts auf wenige Namen zusammen, einschließlich Stockhausen und die Kölner Kreise. ${ }^{63}$

Helga de la Motte erklärte die Empörung über John Cage mit der Emphase des dominanten Schöpfersubjekts, wie man es in Europa seit dem Geniekult der Romantik gepflegt hatte - auch und gerade die >serielle Troika der $>$ Darmstädter Schule $<$ : Pierre Boulez, Luigi Nono und Karlheinz Stockhausen. ${ }^{64}$ Der Amerikaner zog seinerseits eine scharfe Trennlinie zur eurozentrisch geprägten Kunstmusik. In seinem Aufsatz »Zur Geschichte der experimentellen Musik in den Vereinigten Staaten « brandmarkte er 1958 die Vertreter der europäischen Moderne als rückständig gegenüber der amerikanischen Avantgarde:

»Der Komponist steht [...] am Scheideweg. Er hat die Wahl. Wenn er nicht dazu bereit ist, den Versuch, den Klang zu kontrollieren, aufzugeben, wird er seine musikalische Technik nicht in Richtung einer Annäherung an die neuen Möglichkeiten und das neue Bewußtsein entwickeln [...]. Er kann [...] den Wunsch die Klänge zu kontrollieren aber auch aufgeben, seinen musikalischen Geist freimachen und [...] Klänge sich selbst sein lassen [...]. Die von mir erwähnten Arten zu komponieren sind jene, die von Christian Wolff, Morten Feldman, Earle Brown und mir selbst angewandt werden [...]. Luciano Berio, Pierre Boulez, Bo Nilsson, Henry Pousseur und Karlheinz Stockhausen [...] setzen den europäischen Versuch fort, den Klang zu kontrollieren $[\ldots] . \ll^{65}$

61 Pierre Boulez: Alea (1957), in Ders.: Werkstatt-Texte, Berlin 1972, S. 100-113.

62 Ebd., S. 100/102.

63 Custodis: Soziale Isolation, S. 113.

64 Helga de la Motte-Haber: »Aus der Neuen Welt. Die Rezeption der amerikanischen Musik in Europa«, in Danuser: Amerikanische Musik seit Charles Ives, S. 113-125, hier S. 122.

65 John Cage: »Zur Geschichte der experimentellen Musik in den Vereinigten Staaten« (1958), in Rainer Nonnenmann (Hg.): Mit Nachdruck. Texte der Darmstädter Ferienkurse für Neue Musik, Mainz 2010, S. 189. 
Der seit 1954 schwelende Konflikt eskalierte 1958, das als Schlüsseljahr der transkulturellen Neuvermessung der klingenden Welt durch John Cage gelten kann. Als Pierre Boulez kurzfristig seine Vortragstätigkeit bei den Darmstädter Ferienkursen absagte, übernahm ausgerechnet der Amerikaner einen Teil der ausfallenden Seminare und markierte mit seinen umstrittenen Auftritten einen ästhetischen Umbruch. Im selben Schlüsseljahr 1958 provozierte sein aleatorisches Concert for Piano and Orchestra transnational übergreifend nicht nur in New York, sondern auch in Köln, Düsseldorf und Stockholm sowie ein Jahr später in Wien ausufernde Eklats und verstörte gleichermaßen die Musiker, das Publikum und die Kritiker.

\section{`Eskalationء: Das Schlüsseljahr 1958 und die Folgen}

In einem Essay bemerkte 1958 der einflussreiche Musikpublizist Heinz-Klaus Metzger, dass John Cage »jedem europäisch tradierten Begriff von Kunst ins Gesicht« schlage. ${ }^{66}$ Die aleatorischen Kompositions- und die performativen Werkkonzepte des Amerikaners forderten nicht nur die bürgerliche Musikkultur, sondern auch die europäischen Avantgardekreise heraus. Sinnbildlich stehen dafür die Kontroversen, die John Cage 1958 mit seinen legendären Auftritten bei den Darmstädter Ferienkursen auslöste.

Im seriell dominierten Mekka der Neuen Musik europäischer Prägung negierte der Amerikaner die auch von der radikalen Nachkriegsavantgarde beibehaltene geschlossene Werkkonzeption und machte die »Unbestimmtheit« zum eigentlichen Thema seiner Vorstellung von Composition as Process, die er in drei Lectures Changes, Indeterminacy und Communication [\$-15.3] - theoretisch vortrug. ${ }^{67}$ Zur praktischen Untermalung seiner Ausführungen performte David Tudor Water Music für einen Pianisten, in dem es im Gegensatz zu Georg Friedrich Händels Wassermusik wirklich spritzte und plätscherte: Der Pianist schlug nur ab und zu in die Tasten und arbeitete mit präparierten Klaviersaiten, er benutzt eine Entenlockpfeife, eine Sirene, ein Kartenspiel, ein Radiogerät und natürlich Wasser. Die zeitlichen Proportionen der Ereignisse legte Cage durch Münzwürfe bis auf 1/4 Sekunden genau fest. In diesem Konzept der Musikperformance erkannte der Musikwissenschaftler Volker Straebel die gegenseitige Beeinflussung von Europa und Nordamerika ${ }^{68}$ und diese wurde nicht zuletzt durch wechselseitige Polemiken deutlich. Während John Cage immer wieder seiner Hoffnung Ausdruck gab, »that the Europeans will become more American « ${ }^{69}$, wetterten europäische Komponisten wie Henry Pousseur gegen John Cages Werk als:

66 Heinz-Klaus Metzger: »John Cage oder Die freigelassene Musik«, in Ders/Rainer Riehn (Hg.): John Cage (Musik-Konzepte Sonderband), München 1978, S. 5-17, hier S. 10.

67 Die Lectures sind publiziert in John Cage: Silence. Lectures and Writings, Middletown 1961. Ein akustischer Mitschnitt von »Communication« findet sich auf der CD Darmstadt Aural Documents (2012) sowie im Schallarchiv des IMD: B006461243.

68 Volker Straebel: ") ...that the Europeans will become more American<. Gegenseitige Einflüsse von Europa und Nordamerika in der Geschichte der Musikperformance«, in Thomas Dészy/Christian Utz (Hg.): Das Innere Ohr, Linz 1995, S. 80-94.

69 John Cage: Interview mit Roger Reynolds (1961) publiziert unter dem Titel »John Cage and Roger Reynolds. A Conversation, in: The Musical Quaterly (4/1979), S. 537-594. 
»Dada-ähnlichem Manifest gegen Stil und Wert der Musik [...], der musikalischen (oder besser noch jeder künstlerischen, geistigen) Intention fremd, [...] die bei einem durch Kulturtradition geprägten Bewusstsein ständig mitschwingen. Gewiß werden diese sogleich abgebrochen, gewissermaßen geohrfeigt, doch ist das nichts weiter als eine [...] Provokation, und es hat wenig mit der Behauptung zu tun, alles in der Welt wäre [...] der Aufmerksamkeit würdig. «"

Die Ablehnung Cages war auf den >Absolutismus der Moderne « zurückzuführen, den die Nachkriegsavantgarde rund um die sserielle Troika ২ Pierre Boulez, Karlheinz Stockhausen und Luigi Nono bei den Darmstädter Ferienkursen installierte. ${ }^{71}$ Diese Meinung äußerte auch Sabine Sanio, die »Darmstadt 1958« in ihrer Monographie 1968 und die Avantgarde ein Extrakapitel widmete:

»[E]s mangelte offensichtlich an der Bereitschaft, [...] Unterschiede zu respektieren. Die Serialisten lehnten Cage als Clown ab, für ihn waren die Europäer auf schwer erträgliche Weise reaktionär - auch hinsichtlich ihrer politischen Überzeugungen (oder deren Fehlen) [...]. ${ }^{72}$

Angesichts dieser grundlegenden Differenzen überrascht es also nicht, dass John Cage bei seinem Auftritt 1958 in Darmstadt zu keiner Verständigung mit der Mehrheit der serialistisch orientierten Komponisten gelangte. Die Ablehnung Cages illustriert nicht nur die Politisierung, sondern auch das konfliktive Verhältnis zwischen der >hochkulturellen Kolonialmacht` Europa und ihrer früheren >Kolonie`: der aufstrebenden Avantgardemacht USA, die das eurozentrische Überlegenheitsgefühl ins Wanken brachte. Dennoch fand der »amerikanischen Wanderprediger«, wie ein Rezensent 1958 schrieb, bei seinem »Kranichsteiner Fischzug eine Reihe von Kursteilnehmern sanft und unversehens in seinem Netz vor. ${ }^{73}$ Neben Dieter Schnebel und Klaus-Heinz Metzger gilt das insbesondere für Mauricio Kagel, der 1971 mit seiner szenischen Komposition Staatstheater eklatantes Aufsehen im Zusammenhang mit der Politisierung der Avantgarden in den 1960er Jahren erregen sollte. ${ }^{74} 1958$ bemerkte er als Korrespondent einer argentinischen Musikzeitschrift:

»Es duldet keinen Zweifel, daß der amerikanische Komponist John Cage mit Fug die meisten kompositionstechnischen Konzepte hinwegfegte, die bei den jungen europäischen Komponisten bis heute Verwendung fanden. So trug er [...] zum Zusammenbruch jener modernen seriellen Mythen bei, die von den Akademikern der Zwölftonnachfolge und den würdelos ernsthaften Geistern des Reklamewesens aufgerichtet worden waren. [...] Zwar bringt der Einfluß von Cages komplexer Persönlichkeit in den letzten Jahren veritable Konzeptrevolutionen hervor, doch schon beim ersten Konzert mit amerikanischer Klaviermusik reagierte das Publikum mit heftigem Tumult. $\ll^{75}$

70 Henri Pousseur: »Theorie und Praxis in der neuesten Musik«, Vortrag gehalten am 5.9.1958 in Darmstadt, publiziert in Nonnemann: mit Nachdruck, S. 15-29, hier S. 23.

71 Siehe hierzu ausführlich das Kapitel Agon und Skandal.

72 Sanio: 1968 und die Avantgarde, S. 73.

73 Nils Kayser: »Kein Überblick aus dem Netz«, in: Darmstädter Echo (18.9.1958).

74 Siehe hierzu das Kapitel Querstand von Musik und Politik und darin insbesondere Abschnitt: Eine »opera to end all operas«: Mauricio Kagels »Staatstheater« (1971).

75 Mauricio Kagel: »John Cage in Darmstadt 1958«, in Buenos Aires Musical (16.10.1958). 
Jenseits der innerästhetischen Kontroversen reagierten also auch die Hörer höchst performativ auf John Cages Ästhetik; genauso wie die Rezensenten, die in der Mehrzahl mit Polemik auf die ereignishaften Aktionen Bezug nahmen:

»Ein Problem scheint mir noch ungelöst: das Umblättern. Ob man es nicht in die Komposition einbeziehen könnte? Vielleicht dergestalt, daß die abgespielten Blätter entweder zerknüllt oder zerrissen würden. Eventuell fänden sich auch Verleger, die die Noten in Form von Tüten herstellten, die man zerknallen könnte, wobei unterschiedliche Tonhöhen durch unterschiedliche Tütengrößen erreicht würden. ${ }^{76}$

Die Kritik an John Cage verdeutlicht grundsätzliche Differenzen zwischen den amerikanischen und den europäischen Avantgarden. Während sein Schaffen in direkter Linie zu Bewegungen wie dem Futurismus oder Dada interpretiert werden kann, beriefen sich die Europäer erstaunlicherweise kaum auf die Pionierbewegungen des frühen 20. Jahrhunderts. In diesem Zusammenhang bemerkte Sabine Sanio:

»[S]ie tendierten zur historisch-resignativen Position, die bereits Arnold Schönberg gegenüber einem verständnislosen Publikum einnahm. [...] Sie hielten an der ästhetischen Autonomie und der Werkidee fest; das hierarchisch strukturierte Verhältnis von Komponist, Interpret und Publikum war für sie kein Gegenstand der ästhetischen Reflexion, sondern ein fraglos gültiger $\mathrm{Zu}$ sammenhang. $\ll^{77}$

Mit dem Rückgriff auf die »Kunst des Skandals«, den die frühen europäischen Avantgardebewegungen in Ablehnung des klassischen Werkbegriffs inszenierten, opponierte Cage zeitgemäß gegen die hierarchischen Strukturen der in Europa konservierten historischen Aufführungspraxis:

»Bei ihm stand nicht mehr der provokative Charakter im Zentrum, sondern der performative. Cage verwandelte die dadaistische Provokation des Publikums in kunstimmanente Verfahren, um Hörgewohnheiten aufzubrechen und die Aufmerksamkeit für den gegenwärtigen Augenblick zu schärfen. ${ }^{78}$

Damit stärkte Cage nicht nur den ereignishaften Moment der Musikaufführung in Zeiten der technischen Reproduzierbarkeit ${ }^{79}$, sondern konnotierte die Unbestimmtheit als anarcho-politisches Statement: Statt den Vorgaben von Komponist und Dirigent zu folgen, sollten die Spieler selbst die Regeln für ihr Spiel bestimmen. Kompositorisch fixierte Cage seine Ideen im Concert for Piano and Orchestra [\$-15.4] dem er folgende Erläuterungen voranstellte:

76 N.N.: »Catch as Cage can«, in: Darmstädter Echo (12.9.1958). Heinz-Klaus Metzger bezichtigte den Artikel eines »unseriösen Tenors«: Klaus-Heinz Metzger: »...geschultest und entfaltest...«, in: Darmstädter Echo (16.9.1958)

77 Sanio: 1968 und die Avantgarde, S. 74.

78 Ebd., S. 55f.

79 Vgl. Anna Schürmer: »Es wäre ein Akt der Nächstenliebe, sie zu zerschmeißen...«, in: kunsttexte (4/2012): John Cage und technische Medien, URL: www.kunsttexte.de/ auditive_perspektiven [Zugriff: 31.8.2017]. 
»Es gibt keine Partitur, aber jeder Part ist detailliert niedergeschrieben - sowohl spezifische Anweisungen wie auch spezifische Freiheiten, die jedem Spieler einschließlich des Dirigenten gegeben werden [...]. Der Part des Pianisten ist ein $>$ Buch $\measuredangle$, das 84 unterschiedliche Kompositionsarten enthält [...]. Dem Pianisten steht es frei, irgendwelche Teile seiner Wahl ganz oder teilweise und in beliebiger Reihenfolge zu realisieren. Die Orchesterbegleitung kann jede beliebige Anzahl von Spielern einer beliebigen Zahl von Instrumenten umfassen, und eine Aufführung kann beliebig lange dauern [...]. Ich betrachte es als niemals abgeschlossen, obgleich ich jede Realisation für endgültig halte.. ${ }^{80}$

John Cages anarchistisches Concert for Piano and Orchestra löste 1958 einen transnationalen Skandal aus: Sowohl in der New Yorker Carnegie Hall als auch in Köln, Düsseldorf und Stockholm sowie ein Jahr später bei der österreichischen Erstaufführung in Wien provozierte das Klavierkonzert ausufernde Publikums- und Pressereaktionen. In Köln, so erinnerte sich die damals anwesende Malerin und Aktionskünstlerin Mary Bauermeister, wurde die Aufführung im kleinen Sendesaal des WDR zum »Desaster [...], als die interpretierenden Instrumentalisten John Cages Ansatz weder verstanden noch verstehen wollten: Sie trieben schlicht Unfug, klapperten mit Schlüsseln und Sonstigem und boykottierten damit jede Auseinandersetzung mit Cages Werk. $\ll^{81}$ Mit Blick auf die New Yorker Aufführung am 15. Mai 1958 in der Town Hall berichtete die New York Times noch 1981 von John Cages legendärer »Night of Uproar« und sprach mit Blick auf Igor Strawinsky (mas)sacre du printemps 1913 von "more of a disturbance than anything that happened at the Champs Elysées « ${ }^{82}$. Heftig waren auch die Stimmen bei der österreichischen Erstaufführung 1959 in Wien, wo man nach dem Untergang der KuK-Monarchie ganz besonders an den musikalischen Traditionen - von der Wiener Klassik bis zur Zweiten Wiener Schule - festhielt. Die Produkte der »überwiegend amerikanisch beeinflussten extremen Musikavantgarde«, so wurde mehrheitlich konstatiert, hätten mit »Musik oder mit Kunst [...] nichts mehr zu tun«:

»Am tollsten ging es [...] in den beiden Versionen des »Klavierkonzerts« von John Cage, dem Oberhaupt dieser überspitzten Moderne zu, bei dem selbst die Ausführenden nicht mehr ernst bleiben konnten. [...] In der ersten Fassung quietschte und kreischte dazu eine Singstimme einen völlig unverständlichen Text, und bei der zweiten Version gerät man dann mitten hinein in einen wüsten Faschingsrummel. Laut Partiturvorschrift müssen die Musiker Stühle umwerfen, bellen und miauen, außerdem wird von allen Seiten gefiedelt und geblasen und auf dem Podium das Klavier brutal mißhandelt. Die Reaktionen des Publikums auf dieses Spektakel war sehr geteilt, lebhaftes Klatschen, Pfeifen und schallendes Gelächter. Ein Teil der jungen Zuhörer nahm die Darbietungen freilich allzu ernst und diskutierte erbittert in den Pausen. [...] Die Musik des John Cage ist eine der vielen Revolten [...] gegen die Backhendlkultur. ${ }^{83}$

80 John Cage: Concert for Piano and Orchestra, in Ders.: Anarchic Harmony, Mainz 1992, S. 222.

81 Mary Bauermeister: Ich hänge im Triolengitter. Mein Leben mit Karlheinz Stockhausen, München 2011, S. 30.

82 Robert Palmer: »John Cage's Night of Uproar«, in: New York Times (25.10.1981), S. 25.

83 Otto Baril: »Avantgarde auf fossilen Spuren«, in: Arbeiter Zeitung (22.11.1959), in Archiv der Zeitgenossen (Krems): Kritiken 0008, Programme und Kritiken der Saison 1959/60. 
Die Rezensenten waren sich einig, dass dies $» m e h r$ Sensation als Musik « ${ }^{84}$ sei und unkten von »Jugendverdummung « und einem »Schritt vom Lächerlichen zum Gemeingefährlichen $\aleph^{85}$. Für viele war »klar, daß diese Komponisten Skandal hervorrufen wollen. Denn davon leben sie. $\ll^{86}$ Diesen Eklat allerdings inszenierten nicht zuletzt die Pressevertreter selbst. Im Wiener Samstag etwa wurden großformatige Bilder von pfeifenden Zuhörern abgedruckt und mit der Unterschrift versehen: »Da blieb nur Notwehr. ${ }^{87}$ Andere Kritiker sprachen von irrenhausreifen Darbietungen:

»In der Nacht nach dem Konzert habe ich viel Blödsinn geträumt. Wie muß es erst in der Psyche ihrer Autoren aussehen? Eine seltsame Zeit, in der man in Wien derlei Darbietungen mit einer anderen Straßenbahnlinie, als mit dem Siebenundvierziger erreicht. ${ }^{88}$

Jene Straßenbahnlinie 47 fuhr, wie jeder Wiener wusste, zum Psychiatrischen Krankenhaus an der Baumgartner Höhe. Beschreibungen wie diese belegen die heftigen Reaktionen, die John Cages Experimente dies und jenseits des Atlantiks auslösten. Leider spiegelt der Mitschnitt des New Yorker Konzerts [ $\delta-15.4]$ nicht diese drastischen Schilderungen - zu sehr wurde das Tonband von den skandalanalytisch relevanten Störgeräuschen bereinigt. Aussagekräftig ist allerdings auch die Musik selbst: Hörbar zufällige Tonfolgen und Tempovariationen werden vom Gackern und Röcheln der Musiker konterkariert. Frappierend ist dabei vor allem die Ähnlichkeit der Klangergebnisse zu denen des europäischen Serialismus, den Cage auch via Konzeption ad absurdum führte: Er degradierte den Dirigenten zu einer lebenden Uhr und parodierte damit die hierarchischen Grundstrukturen der abendländischen Musik. Damit sprach er dem Werkbegriff der europäischen Musiktradition und ihrer Avantgarde Hohn - und steht damit symbolisch für das Ende der eurozentrischen Kulturhegemonie. Die hysterischen Presse- und Augenzeugenberichte verdeutlichen die Anzeichen des Umbruchs und damit die mythenbildende Kraft skandalöser Ereignisse. Viele fühlten sich durch Cages Konzerte an die legendären Premierenskandale der frühen Moderne erinnert; ein Zeuge der New Yorker Aufführung, der 1913 Igor Strawinskys (mas)sacre du printemps am Pariser Théatre des Champs Elysées miterlebt hatte, verglich später die beiden eklatanten Konzertereignisse:

»Sie müssen bedenken, daß sich im Verlauf von 45 Jahren die Leute von Jahr zu Jahr mehr an Lärm erinnern. Bevor ich sterbe, erwarte ich, daß erzählt wird, das Publikum habe die Bühne gestürmt, den Musikern die Kleider vom Leib gerissen und versucht, die Noten zu zerstören. In Wirklichkeit war es ein groberes Publikum als das dieses Abends, aber damals war es niemand gewohnt, in einem Konzertsaal erschreckt zu werden [...]. Schade, daß das Konzert heute Abend aufgenommen wurde. Welche Geschichten hätten meine Urenkel darüber hören können, wie Cage und Merce Cunningham [...] von der Polizei [...] hatten geleitet werden müssen! « ${ }^{89}$

84 N.N.: »Tumulte im Mozartsaal «, in: Neues Österreich (21.11.1959), in: Ebd.

85 Marcel Rubin: »Versuchte Jugendverdummung« [nicht näher bezeichnet], in: Ebd.

86 Rudolf Weishappel: »Ein gutes Tier ist das Klavier«, in Kurier (20.11.1959), in: Ebd.

87 NN: »Johann Käfig ließ die Wecker rasseln«, in: Wiener Samstag (5.12.1959), in: Ebd.

88 Nicht näher bezeichneter Artikel, in: Ebd.

89 Booklet der CD »The 25-Year Retrospective Concert of the Music of John Cage«, Recorded and performed at Town Hall, New York, May 15. 1958, Wergo 1997. 
Auch Igor Strawinsky selbst zeigte sich beeindruckt von dem eklatanten Ereignis:

»Is it only that Mr. Cage does things that Europeans do not dare do and that he does them naturally and innocently, not as self-conscious stunts? Whatever the answers, no sleight of hand, no trap-doors, are ever discovered in his performances: in other words, no >tradition not only no Bach and no Beethoven, but also no Schoenberg and no Webern either. This is impressive, and no wonder the man on your left keeps saying >sehr interessant..$^{90}$

Aussagekräftig ist hier auch die Tatsache, dass Strawinsky seine letzte Bemerkung auf Deutsch, der >Mutterspracheく musikalischer Hochkultur, notierte. Mit dem Einsetzen der europäischen Rezeption war die Neuvermessung der klingenden Welt durch Cages anarchische Innovationen nicht mehr aufzuhalten, die James Harding 2003 treffend in der Formel $»$ From Anti-Culture to Counter-Culture ${ }^{91}$ fasste. Die transatlantische Entgrenzung der Kunstmusik spiegelte sich auch in der für Cage charakteristischen Entgrenzung der Künste selbst: der Amerikaner ist der einzige nominelle Komponist, der kunstspartenübergreifend rezipiert wird. Abwehr schlug ihm dabei überwiegend aus der Musikkultur entgegen, deren Weltordnung er ins Wanken gebracht hatte. Aufschlussreich sind dabei auch die ablehnenden Reaktionen durch die Interpreten, die Cage durch endlose Liegetöne und anarchische Spielanweisungen nicht nur entnervte, sondern in ihrem virtuosen Selbstverständnis brüskierte. Bei der Aufführung von Atlas Eclipticalis etwa kam es 1964 zu Szenen, die vier Jahre später in einem Artikel des Spiegels beschrieben wurden:

»Wo immer der Amerikaner John Cage, 35, zwischen präparierte Klaviere, Schlaginstrumente, Tonbandgeräte, Radios und Verstärkerkästen aufs Podium tritt, gibt es Tumult. Er dringt als verzerrtes Schwirren, Heulen, Zischen, Kratzen, Sägen und Donnern aus den Lautsprechern, und er kommt zumeist auch aus dem Parkett: Dort zischt und heult eine Publikums-Majorität, der diese neue Tonkunst einfach nicht ins Ohr gehen will. Doch Protest im Saal hat ihn noch nie gestört. Seit nahezu drei Jahrzehnten macht Cage, radikaler Komponist der Gegenwart, unbeirrt seine Klangexperimente [...]. Als 1964 die mit Kontaktmikrophonen gerüsteten New Yorker Philharmoniker den Atlas Eclipticalis im Lincoln Center aufführten - vorausgegangen waren Vivaldis Vier Jahreszeiten und Tschaikowskis Pathetique - buhte nicht nur das Publikum, auch die Musiker zischten und lachten. ${ }^{92}$

Auch Mary Bauermeister, die damalige Ehefrau Karlheinz Stockhausens und Zeugin des Konzerts erinnerte sich, dass die Uraufführung von Atlas Eclipticalis »ein Desaster« war: Die Musiker machten Quatsch woraufhin Stockhausen Cage trösten musste und feststellte, dass die Interpreten keine Freiheit vertragen. ${ }^{93}$

90 Ebd.

91 James Harding: »From Anti-Culture to Counter-Culture. The Emergence of the American Avant-Garde Performance Events«, in Thomas Rathmann (Hg.): Ereignis. Konzeption eines Begriffs in Geschichte, Kunst und Literatur, Köln 2003, S. 243-260.

92 NN: »Fisch im Klavier«, in: Der Spiegel (6/1968), S. 122.

93 Mary Bauermeister in einem Zeitzeugengespräch am 30.10.2013 im Rahmen der »Tage neuer Musik« in Weimar. 
Von den Musikern wie vom Publikum befehdet, avancierte Cage für viele Komponisten zum Heilsbringer, von denen laut Michael Rebhan viele »eine Zeitrechnung >post Cagei adventum « ${ }^{94}$ heraufbeschworen. Die Bedeutung Cages, so beschrieb es 1964 Calvin Tomkins für den New Yorker, offenbarten viele Komponisten nicht zuletzt durch das explizite Abstreiten eines Einflusses Cages auf das eigene Schaffen:

»Yet although the current crop of avant-garde leaders in Europe and the United States now tend to say that they have not even influenced by Cage - some of them spend a great deal of time explaining just how their music differs from his. It can hardly be denied that Cage's work and ideas continue to exert an extraordinary influence $[\ldots]$ on the work of contemporary composers throughout the world. ${ }^{95}$

Diese Aussage belegt die eingangs geäußerte These, dass der zunächst einseitige Kulturtransfer zwischen Europa und Amerika im Zuge einer transatlantischen Neuvermessung der klingenden Welt bald zu einem wechselseitigen Austausch wurde: Amerika schüttelte seinen künstlerischen Provinzstatus ab und entwickelte seinerseits zunehmend Einfluss auf die europäischen Entwicklungen.

Zeit seines Lebens behielt John Cage die Rolle des Provokateurs: das zeigt die Anekdote um seinen 75. Geburtstag 1987, zu dem sich die Redaktion von WDR 3 ein besonderes >Geschenk ausschließlich Werke des Amerikaners gesendet und damit ein »Nachtcagetag« ausgerufen. Eine solche Hommage, die das komplette Programmschema außer Kraft setzte, hat es bis heute für keinen anderen Komponisten gegeben und wurde der unkonventionellen Ereignishaftigkeit von Cages Werk gerecht. Während die Feuilletons das Radioexperiment mit großer und meist wohlwollender Aufmerksamkeit bedachten, offenbarten die Hörerreaktionen die ungebrochen polarisierende Provokationskraft des Amerikaners. Zwar zitierte das WDR-interne Haus Forum Stimmen, die den »Nachtcagetag« als »kulturelles Ereignis« feierten, »wie es so nur noch nicht gewinnorientierte, öffentlich-rechtliche Sendeanstalten initiieren können. ${ }^{96}$ Vonseiten der Hörer allerdings dominierte Empörung, wie eine Auflistung von Anrufen im Archiv des WDR dokumentiert: Bei 13 Telefongesprächen wurde nur eine einzige positive Stimme registriert, die restlichen waren, wie der Protokollant handschriftlich vermerkte, »extrem aggressiv und oft brüllend « vorgetragene Beschimpfungen. Ausgehend von den alten Vorwürfen, dies sei »keine Musik«, sondern »kaputt« und »nicht anhörbar«, wurden das »Geheul« und der »Lärm« wahlweise als »Zumutung«, »Unverschämtheit«, »Verarschung« oder »Gemeinheit« bezeichnet. Das Klangergebnis sei »Irrenanstaltsreif«, nur »für Chaoten, Jecke, psychisch Erkrankte« zu ertragen und letztlich nichts Anderes als »Selbstbefriedigung« beziehungsweise »geistige Onanie eines oder zweier WDR-Redakteure «. ${ }^{97}$

94 Michael Rebhan: »Jeder Tag ist ein guter Tag. John Cage in Darmstadt«, in: Dissonance. Schweizer Musikzeitschrift für Forschung und Kreation (6/2012), S. 16-18.

95 C. Tomkins: »Figure in an Imaginary Landscape«, in: New Yorker (28.11.1964), S. 64.

96 Jutta Müller: »Öffentlich-rechtliche Verrücktheit?«, in: Haus Forum (3/1987).

97 Handschriftliches Protokoll der Anrufe zum »Nachtcagetag«, in WDR: Hörerzuschriften, Ordner 10890. 
Auffällig war schließlich der wiederholt vorgebrachte Verdacht, dass sich in diesem Radioexperiment Amerikanismus niederschlage. In einer ausschweifenden Zuschrift hieß es etwa: »Wie weit geht eigentlich Ihre Amerika-Hörigkeit? « Weiter betonte die Verfasserin, dass ausländische Orchester »fast ausschließlich deutsche Komponisten auf ihr Programm setzen und die ihrer Heimatländer aussparen«. Sie ließe sich allenfalls die »Kultursprachen Französisch und Italienisch noch gefallen«, aber Herr Cage »sieht wie ein Lumpensammler aus, er könnte sich ruhig die Haare mal schneiden lassen und Schlips und Kragen umbinden. Aber das ist ja die Mode, die in Amerika üblich und leider hier in Deutschland nachgeäfft wird, wie vieles von drüben. $\ll^{98}$ Das hegemoniale Gebaren der europäischen Hochkultur gegenüber der amerikanischen `Kulturprovinz` überlebte also bis weit hinein in die Postmoderne.

Zeigt das Beispiel John Cage die Ablehnung amerikanischer Künstler in Europa, wurden vice versa auch die Exegeten der deutschen Musiktradition in den USA eklatant abgestraft. Dies belegt die eingangs geäußerte These, dass dichotomische Urteilsmuster und Oppositionsschemata die transatlantische westliche Welt im Prozess ihrer kulturellen Formierung prägten. Als Gegenstück zu der von John Cage angestoßenen >transatlantischen Neuvermessung der klingenden Welt wird daher im Folgenden das `Ende der Eurozentrischen Kulturhegemonie skizziert, das sich auch in den USA durch klingende Eklats äußerte.

\section{Das Ende Der eurozentrischen Kulturhegemonie}

Das spannungsreiche Zusammenwachsen der europäischen und amerikanischen Kultur nach 1945 zu einer transatlantisch verbundenen westlichen Welt war ein wechselseitig konfliktreichreiches. Nicht nur in Europa wehrte man sich gegen amerikanische Kulturimporte; parallel zur politischen Weltmachtwerdung der USA wuchs auch das Selbstbewusstsein ihrer Avantgarden, die sich zunehmend gegen das imperiale Gebaren der eurozentrischen Kulturhegemonie wehrten. Immer wieder gab es Proteste gegen deutsche Dirigenten und Komponisten, Solisten und Orchester, die zweifelsfrei zeithistorisch konnotiert waren und die transkulturellen Transfers und Wechselwirkungen auf dem Feld der avancierten Kunstmusik widerspiegeln.

Dem konfliktreichen Autonomisierungsprozess der amerikanischen Kunstmusik von den europäischen Kulturimporten wird im Folgenden in zwei Schritten nachgegangen: Auf einer ersten Ebene wird die Instrumentalisierung des allgemeinen Musiklebens im Zuge und infolge des Zweiten Weltkriegs als Medium politischer Agitation in globalen Konfliktlagen beleuchtet. Hatte die deutsche Hochkultur in den USA bis dato eine leicht unterwürfige Verehrung genossen, veränderte sich diese Haltung in der zweiten Hälfte des 20. Jahrhunderts grundlegend. Betraf dies nach $1945 \mathrm{zu}-$ nächst die klassische Musikkultur, wurde der Konflikt seit den 1960er Jahren zunehmend auch auf dem Feld der Avantgarde ausgetragen, auf das in einem zweiten Schritt der spezifische Fokus gerichtet wird. Insbesondere Karlheinz Stockhausen wurde zur Schlüsselfigur eines >eurozentrischen Kulturimperialismus` stilisiert und als solche stellvertretend durch politische Agitation und klingende Eklats bekämpft. 


\section{„Fight Musical Racism»}

Ab 1933 nahm das kulturelle Feld eine wichtige Rolle bei der Errichtung der nationalsozialistischen Herrschaft in Deutschland ein; aber auch jenseits des Atlantiks wurden die Künste zum Symbol der politischen Welt- und Wertordnung sowie ihre Schöpfer zu klaren politischen Bekenntnissen angehalten. Betrachteten sich bis dato viele Kulturschaffende als unpolitisch und international, wurde diese Haltung im $\mathrm{Zu}$ ge der weltpolitischen Konflikte nahezu unmöglich. Musik bekam in dieser Situation auch wegen ihrer international verständlichen Sprache symbolischen Charakter. Der Verweis auf die getrennten Sphären von Kunst und Politik musste in dieser spannungsgeladenen Situation scheitern, worüber auch die klingenden und oftmals eklatanten Ereignisse auf Konzertbühnen Aufschlüsse geben.

Ein gutes Beispiel für diese zeithistorische Konstellation ist Wilhelm Furtwängler. Der weltbekannte Dirigent wurde von den Nationalsozialisten hofiert und arrangierte sich zugunsten seiner Karriere mit dem Regime, das ihn 1933 zum Direktor der Berliner Staatsoper und zum Vizepräsident der Reichsmusikkammer ernannte. Gleichwohl kritisierte er in einem offenen Brief an Joseph Goebbels die Diskriminierung jüdischer Musiker ${ }^{99}$ und dirigierte trotz Sanktionen Konzerte >entarteter` Komponisten wie Felix Mendelssohn-Bartholdy oder Paul Hindemith. Obwohl sich dem Dirigenten 1936 die Möglichkeit bot, die Nachfolge Arturo Toscaninis bei den New York Philharmonics zu übernehmen, lehnte er das Angebot zugunsten seiner deutschen Engagements ab und verweigerte der Philharmonic-Symphonic Society of New York zudem eine öffentliche Positionierung gegen das NS-Regime. In einem publizistisch verbreiteten und kontrovers diskutierten Telegramm bemerkte der Dirigent: »Political controversy disagreeable to me. I am not politician but exponent of German music, which belongs to all humanity regardless of politics. ${ }^{100}$ Furtwänglers Schaffen im Dritten Reich war ein janusköpfiges und geschah laut seiner Einlassungen im Denazifizierungsverfahren im Sinne einer taktischen Zusammenarbeit: mit den Zugeständnissen an das Regime habe er Schlimmeres verhindern wollen. ${ }^{101}$

Wenn Furtwängler also betonte, dass Politik und Musik getrennte Sphären seien, zeigt sein Beispiel doch vielmehr, dass das Feld der Kunst noch vor den ersten Kriegshandlungen zur politischen Kommunikation der transatlantischen Gegner instrumentalisiert wurde. Während und besonders nach dem Zweiten Weltkrieg wurden die Proteste gegen deutsche Musik(er) zum Zeitzeichen der veränderten globalen Hierarchie. Mit der politischen Niederlage wackelte auch die Kulturhegemonie des deutschen Kulturraums, der nun - zumindest teilweise - zur amerikanischen Besatzungszone wurde. Musik wurde in dieser Situation zu einem Symbol der Kriegsaufarbeitung und die um sie geführten Kontroversen veranschaulichen die Neuordnung innerhalb der transatlantisch verbundenen westlichen Welt nach Kriegsende.

99 Der Briefwechsel zwischen Wilhelm Furtwängler und Joseph Goebbels erschien im Berliner Tageblatt (11./12.4.1933).

100 »Politics leads Furtwaengler to decline Philharmonic Post. German Conductorc cables: He is a Musician not a Politican«, in: N.Y. Herald Tribune (15.3.1936).

101 Siehe hierzu weiterführen Fred K. Prieberg: Kraftprobe. Wilhelm Furtwängler im Dritten Reich, Wiesbaden 1986. 
Zwar warb der jüdische Spitzengeiger Yehudi Menuhin schon 1945 um Verständnis für seinen »großen Musikerkollegen Furtwängler « ${ }^{102}$, der nach einem kurzzeitigen Berufsverbot entnazifiziert worden war. ${ }^{103}$ Doch stießen solche Solidaritätsbekundungen in den USA auf herbe Kritik und führten zu publizistisch geführten Grundsatzdebatten über den Umgang mit dem besiegten Kriegsgegner im Allgemeinen und seinen Künstlern im Besonderen. Wenn diese Kontroversen zunächst auch kaum die Avantgarde berührten, so lohnt dennoch ein Blick auf die ersten kulturellen Transfers nach dem Krieg, um die Dynamik auch für die Neue Musik nachvollziehbar zu machen. 1946 berichtete der Journalist Charles Steward für den Observer über eines der ersten Konzerte der Berliner Philharmoniker nach Kriegsende und sprach dabei der Musik symbolischen Charakter für den Wiederaufbau Berlins zu:

»Amid the ruins and the political wrangling, one gets the impression that in Berlin music is the only sanely surviving thing. Great orchestras have been re-born, their splendor untarnished by debacle, their vigor apparently unwrapped by individual privation, it is doubtful if the full brass of the Berlin Philharmonic Orchestra ever had a nobler bloom. ${ }^{104}$

Symbolisch waren auch die Proteste, die 1950 infolge der Ankündigung von der ersten Amerikatournee der Berliner Philharmoniker nach dem Krieg laut wurden. Diese führten zur Absage der geplanten Konzertreise des ehemaligen >Reichsorchesters und seines Dirigenten Wilhelm Furtwängler und standen damit exemplarisch für die Verhandlungen um die deutsche Kriegsschuld auf amerikanischem Boden. ${ }^{105}$ Erst nach dem Tod Furtwänglers 1954 wurde unter dem neuen Maestro Herbert von Karajan - obwohl auch dieser in den NS-Jahren eine zweifelhafte Rolle spielte ${ }^{106}$ - eine weitere Amerikatournee der Berliner Philharmoniker geplant. Unter dem Eindruck der eklatanten Ereignisse von 1950 versicherte der deutsche Botschafter in Amerika, Heinz L. Krakeler, dem Columbia Artist Management Inc. in einem Brief:

»The Berlin Philharmonic Orchestra was the first orchestra to give a concert in Berlin after the end of hostilities. It has since developed into a cultural center of free Berlin, due largely support and assistance of American music lovers who helped the orchestra to overcome most difficult times. When the Berlin Philharmonic Orchestra comes to this country for a good will tour, it brings with it the warm feelings of millions of Germans. $\ll^{107}$

102 NN: »Menuhin Calls on Allied World to Accept Furtwaengler Again. Cities Snubs to Nazis«, in: New York Times (5.12.1945).

103 Siehe hierzu den groß angelegten Artikel von Curt Riess: »Furtwängler. Das Leben eines großen Musikers«, in: Die Weltwoche (12.12.1952), S. 8ff.

104 Charles Stuart: »Rebirth In Berlin«, in: The Observer (29.9.1946).

105 Eine Sammlung amerikanischer Pressestimmen zum Fall Furtwängler findet sich in der New York Public Library for the Performing Arts (NYPL): Clipping File: »Wilhelm Furtwängler«.

106 Siehe weiterführend Oliver Rathkolb: Führertreu und gottbegnadet. Künstlereliten im Dritten Reich, Wien 1991, S. 194-219.

107 Brief des deutschen Botschafters Heinz L. Krekeler an André Mertens am 21.2.1955, in NYPL: Clipping File »Berlin Philharmonics«. 
Trotz dieser diplomatischen Bemühungen stieß das deutsche Spitzenorchester in Vertretung des einstigen Kriegsgegners wiederum auf Widerstand. Verschiedene Zeitungen berichteten von Protesten und einer Petition der American Federation of Musicians gegen die Konzerte. ${ }^{108}$ Vor der Carnegie Hall fanden Demonstrationen mit über 500 Teilnehmern statt, während es im Konzert selbst bei der Ouvertüre von Beethovens Leonore zu einigem Aufsehen kam, als aufgeregtes Geflatter im Auditorium zu vernehmen war, gefolgt von einem jungen Mann, der aus der Künstlergarderobe stürzte. Dort fand man zwei tote Tauben, versehen mit einer Notiz in fehlerhaftem >Denglisch $\iota: »$ Heil von Karajen the cleansed Nazi. Death the Nazis« und »Deutsland Unter Alles Now and Forever «. ${ }^{109}$

Die eklatante Aufnahme deutscher Künstler in Amerika spiegelte nicht nur die Ressentiments gegen den einstigen Kriegsgegner und war in diesem Sinne eine Fortführung der feindlichen Handlungen auf dem symbolischen Feld der Musik. In den Aktionen äußerte sich zugleich das wachsende Selbstbewusstsein der ehemaligen kulturellen Kolonie Europas, der politischen Weltmacht Amerika, in künstlerischen Belangen. Innerhalb dieser Dynamik wurden die amerikanischen Konzertsäle und Theater zu Bühnen der Politik.

In der Carnegie Hall etwa kam es 1948 während einer Aufführung von Johann Strauss' Operette Der Zigenuerbaron zu einer »scene of shouted arguments and threatened fisticuffs«, wie die New York Times berichtete. Nach dem zweiten Akt habe sich ein »David of Jerusalem« zu Wort gemeldet und, begleitet von »boos, applause and catcalls«, seine Unterstützung für eine jüdische Extremistengruppe in Palästina bekundet. Der Störenfried, so die Zeitung weiter, wäre gesponsert durch die American League for a free Palestine. ${ }^{110}$ Im selben Jahr protestierten Mitglieder des musician's chapter des American Veterans Committee auch gegen Walter Gieseking, der auf Plakat-Schmierereien als "Hitler's musical educator « ${ }^{111}$ angegriffen wurde. Im Dezember 1948 berichtete die New York Times über ein weiteres eklatantes Konzert des deutschen Ausnahmepianisten:

»The protest was based, as have been others in the past, on the activities of these artists in allegedly furthering the German cause during the war by giving recitals under the aegis of the Ministry of Propaganda. Mr. Giesking was blacklisted by the American Military Government in 1945 and reinstated in 1947. The pickets, carrying placards reading $>$ We fought them, they import them<. ${ }^{112}$

108 N.N.: »1,000 Sign Protest on Orchestra Visit«, in: New York Times (23.2.1955); NN: »Petrillo Bids Dulles `Clarify« Berlin Orchestra Clearance«, in: N. Y. Herald Tribune (23.2.1955).

109 N.N.: »3 Piegeons Loosed as Protest at Concert Of Berlin Orchestra in Carnegie Hall«, in: New York Times (31.3.1955).

110 N.N.: »Irgun Speech Starts Uproar At Operetta«, in: New York Times (28.6.1948), S. 5.

111 N.N.: »AVC Units Protest Tour by Gieseking: Veterans Picket C.L. Wagner Office to Oppose Projected Concerts by Germans«, in: New York Times (20.4.1948), S. 32.

112 N.N.: »Carnegie Hall Picketed: AVC Group Protests Flagstad and Gieseking Recitals«, in: New York Times (8.12.1948), S. 33. Siehe weiterführend die Pressesammlung, in NYPL: Clipping File »Gieseking«. 
Die Proteste richteten sich also explizit gegen die kulturimperiale Importpolitik Europas. Auch Kirsten Flagstad hatte mit ernsthaften Ressentiments zwischen politischen und ästhetischen Beweggründen zu kämpfen. Die norwegische Sängerin hatte sich trotz amerikanischer Avancen für einen Verbleib in Europa entschieden, wo ihr Mann eine Funktion in der pro-faschistischen norwegischen Quisling Gruppe bekleidete. Als Folge wurde der Wagner-Interpretin nicht nur ihre Entscheidung für den Verbleib in Europa, sondern auch ihre ästhetische Linie zum Vorwurf gemacht. »A person devoted to Wagnerian Roles«, so argumentierte etwa der Kritiker des Birmingham Age-Herald, »is likely influenced by Wagnerian philosophy«:

$»$ Richard Wagner was not only a composers, poet and dramatist; he was an intense nationalist, deeply influenced by those who insisted upon the leadership in European culture of Teutonic concepts of life. His operas revived the spirit of Teutonic tradition and although written before Hitler was born, influenced the whole Nordic trend in Europe of which Hitlerism was a manifestation. "113 $^{113}$

In den Aktionen gegen Musiker wie Giesking, Flagstad und Furtwängler meldeten sich verschiedenste gesellschaftliche Gruppierungen - von Kriegsveteranen über jüdische und zionistische Interessensgruppen bis hin zu künstlerischen Organisationen - zu Wort, um in Manifest(ation)en, Petitionen und Pressekampagnen die eigenen Positionen bei der Neuvermessung der (klingenden) Welt abzustecken. Dabei erfuhr die politische Instrumentalisierung der Künste kongruent zu den historischen Entwicklungen einen Wandel.

Mit der Zuspitzung des Ost-West-Konflikts etwa trafen Proteste immer häufiger sowjetische Künstler: 1971 rief die Jewish Defense League infolge der Verfolgung von Juden in der Sowjetunion zu »boycotts [...] against the products of United States companies doing business with the Soviet Union« auf. ${ }^{114}$ Die Forderung wurde bei diversen Konzerten russischer Musiker durch publikumswirksame Straßenproteste und Störmanöver im Konzertsaal umgesetzt. Exemplarisch sei hier nur die Aktion 1976 gegen den Geiger Vladimir Spivakov zitiert:

»Two incidents occurred before intermission, the first during the opening selection, Schubert's Sonata in A minor, as a man stormed down the aisle shouting in Russian, >Remember the Soviet Jews`, and threw a crumpled object toward the back of the stage, past Mr. Spivakov and his accompanist, Boris Bechterev. The second disturbance came halfway through the next item on the program, Bach's unaccompanied Chaconne in D minor, when another man hurled a paint bomb at Mr. Spivakov, whose white dress shirt was suddenly spattered with blood-red paint. $\ll^{115}$

113 George E. Sokolsky: »Kirsten Flagstad«, in: Birmingham Age-Herald (15.4.1947), S. 11. Siehe weiterführend die Pressesammlung, in: NYPL, Clipping File »Flagstad «.

114 Will Lissner: «Jewish Defense League to Boycott Products of Concerns Dealing With Soviet«, in: New York Times (21.1.1971), S. 9.

115 Peter G. Davis: »Paint Bomb Is Hurled at Spivakov, But Violinist Never Drops a Beat«, in: New York Times (9.11.1976), S 32. Vgl. hierzu auch N.N.: »Paint-Toss Incident Fails to Halt Concert«, in: New York Times (8.11.1976), S. 38. 
Im Zuge der amerikanischen und sowjetischen Konflikte im Kontext des Kalten Krieges wurden deutsche Musiker weitgehend rehabilitiert, was auch den weltpolitischen Realitäten entsprach. Allerdings häuften sich seit 1960 die Konflikte innerhalb der transatlantischen Avantgarden. Die Neue Musik deutscher Prägung wurde in dieser Situation zum Symbol der eurozentrischen Kulturhegemonie, von der sich die junge amerikanische Kunst im Prozess ihrer Formierung und im Zeichen der gesamtgesellschaftlichen Politisierung zunehmend abgrenzte. Am 29.4.1964 etwa wurde ein Galakonzert in der New Yorker Town Hall mit Werken von Hans Werner Henze und Karlheinz Stockhausen bestreikt und mit postkolonialem Blickwinkel angeprangert, dass diese Komponisten jegliche Form nichteuropäischer Musik ablehnen. ${ }^{116}$ Insbesondere Stockhausen wurde zum Symbol des eurozentrischen Kulturimperialismus, während die transkulturelle Fluxus-Bewegung zur entscheidenden Strömung nicht nur künstlerischer Entgrenzung wurde. Als zeitgenössische Ausprägung historischer Avantgardebewegungen wie dem Futur- und Dadaismus, machten die FluxusAktivisten abermals aus dem Kunst-Skandal eine Kunst des Skandals.

\section{»Stockhausen serves Imperialism «: Originale - ein transatlantischer Skandal (1961/64)}

1974 prägte der britische Komponist Cornelius Cardew in einer Form moderner Invektive die Formel »Stockhausen serves Imperialism $«{ }^{117}$. Die Phrase wirft einmal mehr das Schlaglicht auf Karlheinz Stockhausen, diesmal als »leading figure of the bourgeois musical avant garde« und "part of the cultural superstructure of the largest-scale system of human oppression and exploitation the world has ever known: imperialism. ${ }^{118}$ Diesen Kulturimperialismus sah Cardew in den Exponenten der europäischen Nachkriegsavantgarde verwirklicht. Insbesondere mit Blick auf den absolutistisch vertretenen Dogmatismus der seriellen >Darmstädter Schule ${ }^{119}$ mit ihren »abstruse, pseudo-scientific tendencies, encouraged in ivory tower conditions « ${ }^{120}$ forderte er: »Smash the decaying ideological and cultural superstructure! Smash the bourgeois class and its corrupt capitalist system! Down with imperialism. ${ }^{121}$

Die Anekdote veranschaulicht nicht nur die anhaltende politische Instrumentalisierung des allgemeinen Kulturlebens, sondern lenkt den Blick explizit auf die Vertreter der musikalischen Avantgarde. Als prinzipiell gegen den Kanon agierende Kräfte, wurden die Konflikte um Komponisten Neuer Musik zu kulturellen Seismographen der westlichen Kulturlandschaft, deren konfliktreiches Zusammenwachsen sich nicht zuletzt in der eklatanten Rezeption ihrer Normen sprengenden Kunstauffassung und -ausführung spiegelte. Oftmals wurden Aufführungen zu performativen Manifestationen divergierender Weltsichten.

116 Custodis: Die soziale Isolation der neuen Musik, S. 129.

117 Cornelius Cardew: Stockhausen serves Imperialism, London 1974.

118 Ebd., S. 46.

119 Siehe hierzu vertiefend das Kapitel Agon und Skandal und darin besonders den Abschnitt Die Darmstädter Ferienkurse als agonale Ereignisgeschichte.

120 Ebd., S. 48.

121 Ebd., S. 32. 
Karlheinz Stockhausen wurde kraft seiner Popularität nicht nur zum Symbol der eurozentrischen Kulturpolitik und den damit einhergehenden postkolonialen Konfliktfeldern. Zugleich standen der weltberühmte deutsche Komponist und sein Werk für die zunehmenden Transfers innerhalb des westlichen Kulturraums. Eklatant rezipiert auf beiden Seiten des Atlantiks, fiel seine Aufnahme jedoch deutlich verschieden aus, wodurch transkulturelle Vergleichsebenen eröffnet werden. Wenn der Musikwissenschaftler Volker Straebel im Konzept der >Musikperformance` die gegenseitige Beeinflussung von Europa und Nordamerika erkannte ${ }^{122}$, so kann das Beispiel Karlheinz Stockhausens hierfür als paradigmatisch gelten. Einen Zugriffspunkt bietet insbesondere das musikalische Theater Originale, das 1961 in Köln und drei Jahre später in New York jeweils für einen Skandal sorgte - allerdings unter gänzlich unterschiedlichen Vorzeichen und mit eklatant abweichenden Ausprägungen. An dem Fallbeispiel lassen sich vergleichend nicht nur die wirkungsästhetischen Konflikte, sondern auch die weltanschaulichen Differenzen innerhalb der transatlantischen westlichen Welt fassen. ${ }^{123}$

1961 erhielt Karlheinz Stockhausen vom Kölner Theater am Dom den Auftrag für ein musikalisches Theater. Dass dabei mit Originale ein Happening nach Art von John Cages legendärem Untitled Event am Black Mountain College entstand, ist kein Zufall, sondern auf eine Verschiebung des musikkulturellen Raums zurückzuführen. Das legt auch die Aussage des amerikanischen Multimedia-Künstlers Mark Bloch nahe: »Karlheinz Stockhausen was transformed by his meeting with John Cage in Darmstadt [...] in 1958. The result was more graphic scores and a more theatrical direction for his music. ${ }^{124}$ Tatsächlich reagierte Stockhausen auf die Konfrontation mit Cages Werk unmittelbar mit einem Vortrag, in dem er Cages Aufführungen als >Musikperformances` beschrieb. ${ }^{125}$ Kompositionsästhetisch reflektierte er die Ausführungen des Amerikaners zu offenen Formen in seinem Werk Kontakte für elektronische Klänge, Klavier und Schlagzeug [ $\delta-17.1]$, die das musikalische Grundgerüst seiner Originale bildeten. Hatte sich die amerikanische Kunst bis dato in einer kulturellen Einbahnstraße an der europäischen Hochkultur orientiert, floss der ästhetische Grenzverkehr nun also in beide Richtungen.

Neben der strukturellen und ästhetischen Einflussnahme John Cages, spielte der Amerikaner auch auf biographischer Ebene eine entscheidende Rolle für die Entstehung der Originale: 1958 hatte die Malerin Mary Bauermeistern an Stockhausens Kompositionsseminar bei den Darmstädter Ferienkursen teilgenommen und erlebte dort Cages eklatanten Durchbruch in Europa. In der Folge wurde sie zur treibenden Kraft bei der Förderung amerikanischer Avantgardekünstler in Europa und ihr legendäres Atelier in der Kölner Lintgasse $28 \mathrm{zu}$ einem visionären Ort, an dem die topographische und ästhetische Entgrenzung der Künste zelebriert wurde.

122 Straebel: »...that the Europeans will become more American«, S. 80.

123 Vgl. hierzu auch Anna Schürmer: »>Picket Stockhausen Concert!‘ Originale - eine auditive Spurensuche« (Feature), in: Deutschlandfunk (6.12.2014).

124 Mark Bloch: On Originale, New York 1964, URL: www.panmodern.com/ OnStockhausen-sOriginale.pdf [Zugriff: 31.8.2017].

125 Karlheinz Stockhausen: »Momentform « (1960), in Ders.: Texte, Band 1, Köln 1964, S. 189-210, hier S. 205. 
Bauermeister veranstaltete in ihrem Atelier Konzerte mit neuester Musik sowie Ausstellungen und intermediale Performances, die als >Prä-Fluxus` bezeichnet werden können: Mit bis dato unbekannten avantgardistischen Dichtern, Komponisten und bildenden Künstler wie George Maciunas, Joseph Beuys, Wolf Vostell, Hans G Helms, David Tudor, John Cage, Christo, George Brecht und Name June Paik wurde großer Einfluss auf die spätere Bewegung ausgeübt. Mary Bauermeisters häufige Titulierung als >(Groß-)Mutter des Fluxus $\triangleleft$, ist also nicht zu hoch gegriffen. ${ }^{126}$ Seit 1961 führte sie mit Karlheinz Stockhausen unter Billigung seiner Frau Doris eine Ménage-à-trois, die nicht nur Anstoß in konservativen Kreisen erregte, sondern auch künstlerische Prozesse anregte. Das wohl wichtigste Ergebnis dieser Zusammenarbeit waren die Originale, für deren Realisation Mary Bauermeisters Einfluss als CoAutorin nicht unterschätzt werden darf. Sie selbst gab zu Protokoll:

»Das Stück war eine Synthese aus Stockhausens streng durchstrukturierter Kompositionsmethode und allem, was in meinem Atelier stattgefunden hatte an Spontanem, Anarchischem, spielerisch Experimentellem, auf jedem Fall Unvorhersehbarem. Ausgewählte Persönlichkeiten, eben Kölner 〉Originale〈, sollten sich darin selbst darstellen, während Stockhausen ihre Einsätze und Lautstärken dirigierte. Unter den Mitwirkenden waren bekannte Theaterschauspieler sowie Regisseur, Kameramann und Beleuchter, die sich selbst spielten. Es gab eine Modedame, einen Straßensänger mit Hund, eine Zeitungsverkäuferin, eine Garderobenfrau und einen Affen samt Wärterin vom Kölner Zoo. « ${ }^{127}$

Bauermeister selbst verkörperte die Malerin und bespritzte Leinwände mit fluoreszierenden Farben, die sie ineinanderlaufen ließ und anschließend mit einem Schwamm verwischte. Außerdem versprühte sie verschiedene Düfte und warf rostige, mit bunten Federn beklebte Nägel auf eine Eisenplatte, auf deren Rückseite ein großer Magnet befestigt war. Dieser wurde während der Aufführung entfernt und die Geräuschkulisse durch herabfallendes Metall bereichert. Als Aktionskünstler fungierte ein gewisser Nam June Paik, der als Begründer der Medienkunst und Protagonist der Fluxus-Bewegung bald jede Menge eklatanter Aufmerksamkeit ernten sollte: Der Koreaner bewarf das Publikum mit Erbsen, beschmierte sich mit Rasiercreme und sprang, nachdem er einen Beutel Reis über seinen Kopf geleert hatte, in eine mit Wasser gefüllte Badewanne. Schließlich hatte man mit David Tudor einen Interpreten gewinnen können, der 1952 die Ära der Aktionskunst mit dem legendären ersten Happening am Black Mountain College eingeleitet hatte. Die Konzeption der Originale wies deutliche Parallelen mit John Cages Untitled Event auf und zeugte von der transkulturellen Beeinflussung, die nun in entgegengesetzter Richtung über den Atlantik zog.

126 Vgl. Reinhard Spieler: Welten in der Schachtel. Mary Bauermeister und die experimentelle Kunst der 1960er Jahre, Bielefeld/Leipzig/Berlin 2010, S. 151; Historisches Archiv der Stadt Köln (Hg.): Intermedial - kontrovers - experimentell: Das Atelier Mary Bauermeister in Köln 1960-1962, Köln 1993.

127 Mary Bauermeister: Ich hänge im Triolengitter. Mein Leben mit Karlheinz Stockhausen, München 2011, S. 73. 
Mary Bauermeister bezeichnet das musikalische Theater heute als $»$ Knollenstück ${ }^{128}$ und trifft damit seine besondere Charakteristik: die musikhistorische Rezeption der Originale spiegelt rhizomatische Verzweigungen sowie zeit- und ortgebundene Metamorphosen. Sowohl 1961 in Köln, als auch drei Jahre später in New York, provozierte das Stück eklatante Reaktionen, jedoch in gänzlich verschiedenen Ausprägungen. Damit eröffnet es die Kulisse für eine vergleichende Analyse im Kontext der transnational aktiven und konfliktiven Fluxus-Bewegung.

Abbildung 17 - >Uraufführung täglich«: Plakat der Kölner »Originale»

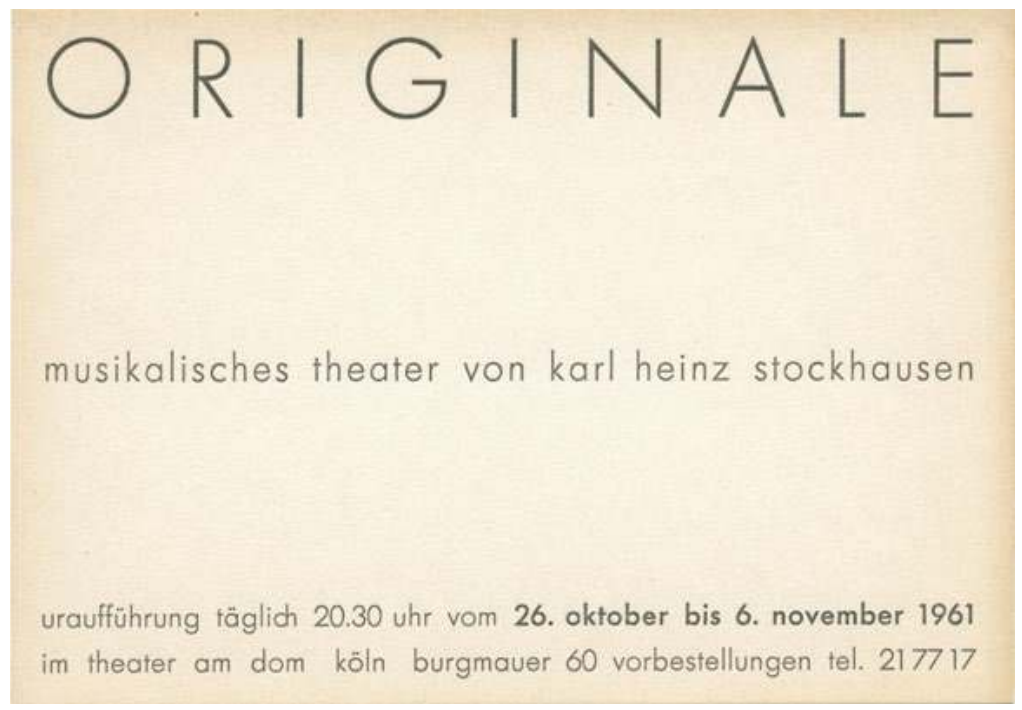

In Köln, so Bauermeister, wurde das Stück schnell zum Bürgerschock: »Die Presse erging sich in teils hilflosen, teils zynischen Kommentaren. Das Kölner Kulturamt entzog uns bereits nach der zweiten Aufführung die finanzielle Unterstützung. $«{ }^{129} \mathrm{Im}$ Zuge des Skandals initiierte, sendete und archivierte der WDR eine Diskussionsrunde, welche die kulturellen Befindlichkeiten der Bundesrepublik anno 1961 veranschaulicht. ${ }^{130}$ Einleitend spricht der Moderator von einem »handfesten Krachs«:

»Dabei handelt es sich um eine seltsame Uraufführung eines gewöhnlichen Klamauks - anders kann man es nicht bezeichnen, im Kölner Theater am Dom. Kölner Zeitungen kritisierten das Ganze mit noch unfreundlicheren Bezeichnungen wie Blödsinn, Gehirnwäsche und organisierter Wahnsinn. Am meisten regte die Kritiker und die unverständlicherweise recht zahmen Besucher die Uraufführung des Stücks mit dem Titel Originale, ein Musiktheater des Kölners Karlheinz Stockhausen, auf. $\ll^{131}$

128 Mary Bauermeister im Gespräch mit der Autorin am 16.12.2013 in Rösrath.

129 Bauermeister: Ich hänge im Triolengitter, S. 74f.

130 »Diskussion - Stockhausen - Originale«, in WDR: 5128711.

131 Ebd. 
$\mathrm{Zu}$ Karneval, so der Moderator weiter, herrsche Narrenfreiheit am Rhein. Unter normalen Umständen aber müsse man sich fragen, ob so etwas wirklich angebracht sei:

»Ein Pianist aus Korea

[Nam June Paik] warf mit beiden Händen weiBe Bohnen [andere Quellen sprechen von Reis] ins Publikum, überschüttete sich selbst mit einer Tüte Mehl und sprang quiekend in einen mit Wasser gefüllten Bottich. Anschließend begann ein Höllenlärm, in dem sieben Personen verschiedene Texte sprachen, ein Mann am Klavier [David Tudor] sich auf der Bühne umzog und zum Teil mit den Ellenbogen über die Tasten raspelte. Dazwischen schrie eine Zeitungsfrau von Soraya und von den Panzern in Berlin. Zwischendrin erklang immer wieder eine ohrenbetäubende Begleitmusik. « ${ }^{132}$
Abbildung 18 - Aufgehender Stern des Fluxus: Nam June Paik bei den >Kölner Originalen «.

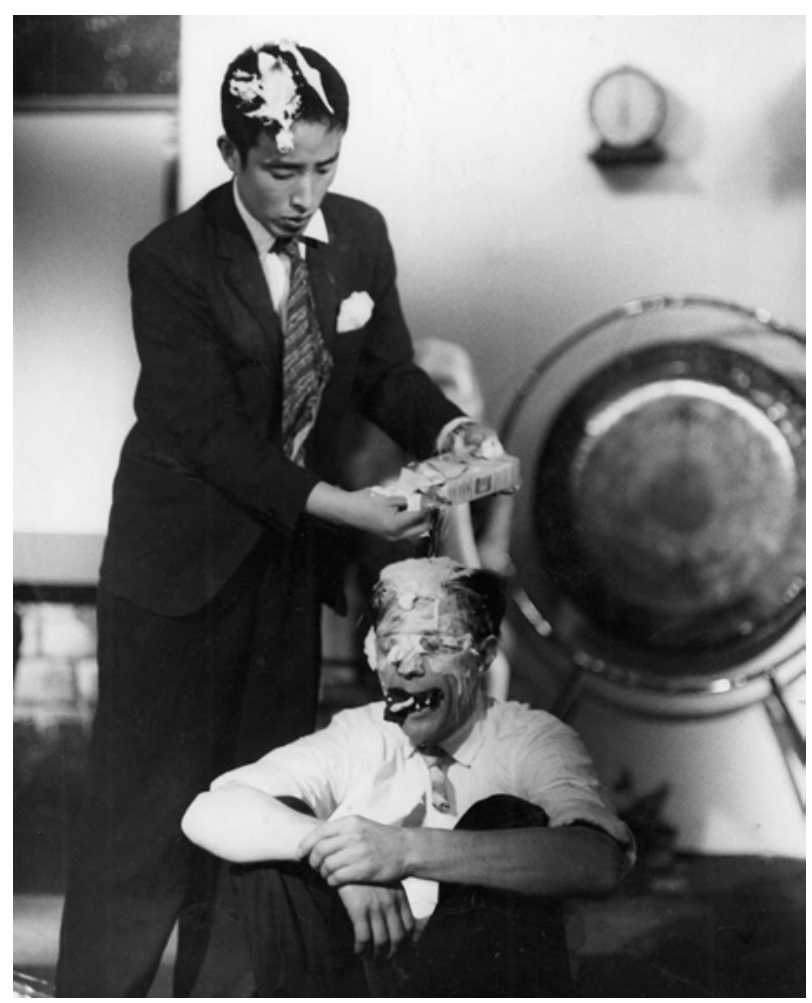

Diese ohrenbetäubende Begleitmusik waren Karlheinz Stockhausens Kontakte in der Fassung für Klavier und Schlagzeug und vierkanalige elektronische Klänge vom Band, die das Publikum akustisch umzingelten und die scheinbar bezugsfreien Aktionen der zwölf Originale zeitlich strukturierten [ $\mathcal{\delta}-17.1$ ]. Neben der Empörung über die ungewohnten Klänge kam es im weiteren Verlauf zu hitzigen Debatten zwischen den ästhetischen und politischen sowie sozialen und kulturellen Anschauungen der Diskussionsteilnehmer:

Die heftige Kritik an Paiks hochperformativen Aktionen mit »wichtigen Volksernährungsmitteln« wie Mehl, Zucker und Reis wurde, wie eine Wortmeldung zeigt, auf die prekäre Situation der Kriegs- und Nachkriegsjahre bezogen: »Es ist nicht von der Hand zu weisen, dass Millionen Menschen verhungern.« Hubertus Durek, der Direktor des Theater am Dom, zog sich als Geldgeber aus der Verantwortung zurück, denn: »hier passiert etwas, das nicht greifbar und jeden Abend neu ist.« Tatsächlich hieß es bereits auf der Ankündigung der Originale ebenso paradox wie zu Recht: »uraufführung täglich 20:30 uhr« [Abbildung 17]. Und gerade in dieser als einmali- 
ges Ereignis angelegten Konzeption verweigerter Wiederholbarkeit liegt der performative und rhizomatische Charakter des >Knollenstücks` begründet, das durch die Abhängigkeit von Zeit und Ort seine jeweils spezifische historische Ausdrucksfähigkeit bezieht.

Während die New Yorker Originale 1964 einen Anlass zur Verhandlung der Konflikte um die eurozentrische Kulturhegemonie boten, empörte man sich 1961 im kriegszerstörten Köln über die unsinnige Verschwendung von Lebensmitteln in Nam June Paiks dadaistischen Aktionen [Abbildung 18]. Hinter dieser Empörung stand jedoch nicht zuletzt der Angriff auf das musikalische Kunstwerk und die damit einhergehende konzeptionelle Entgrenzung von Kunst und Leben, die dem abendländischen Musikverständnis grundlegend zuwiderlief. Zum Skandalon wurde in Köln laut Mary Bauermeister insbesondere die Einbeziehung von >originalen` Persönlichkeiten des Alltagslebens: »einen Bettler mit Hund der seine Liedchen sang, eine Verkäuferin der Bild-Zeitung, welche die News durch die Stadt gesungen hat sowie ein Tier aus dem Zoo - wir bekamen nur ein Äffchen, aber eigentlich wollten wir einen richtigen Gorilla. ${ }^{133}$

Der geschlossene Charakter des Kunstwerks wurde nicht nur durch das Engagement alltäglicher Akteure als künstlerische Interpreten infrage gestellt, sondern auch, indem diesen die Bühnenaktionen völlig freigestellt wurden. Mit ihrer Konzeption warfen Stockhausen und Bauermeister eine der heikelsten Fragen auf, der sich zeitgenössische Kunst zu stellen hat: Was definiert das Kunstwerk? In der Diskussionsrunde des WDR betont der Regisseur Karl-Heinz Caspari, dieses offene Kunstkonzept sei nicht nur neu, sondern auch erstrebt. Er selbst suche nach Möglichkeiten der Grenzüberschreitung, die in Anlehnung an Theodor W. Adorno mehr biete, als die bisherige »Sitzplatzatmosphäre« mit ihrer »kaufbaren 20-Dollar-Perfektion.« Wer aber den Anspruch auf ein Kunstwerk erhebe, so erwidert ein Diskussionsteilnehmer, müsse auch den Anspruch haben, dass es vom Betrachter erlebt werde. Der Komponist aber betreibe »eine Innenschau: Das Vergnügen am Experiment mag für Herrn Stockhausen ein Genuss gewesen sein - für uns aber war es nicht auszuhalten. « Zwischenrufer mokieren sich über die »Arbeit eines Schizophrenen«, der nur »seiner eigenen Selbstbefriedigung« huldige. Karlheinz Stockhausen beendet die erhitzte Debatte schließlich selbst mit einem Hinweis auf die Kunstfreiheit: »Wenn wir wollen, dass die Kunst Blüten treibt, müssen wir das Wagnis der Phantasie eingehen. $«{ }^{134} \mathrm{Da}$ nach gibt das Band eine Schlagermelodie wieder, was auf medienarchäologischer Ebene von der Praxis der Rundfunkanstalten zeugt, die Bänder aus Kostengründen mehrfach zu verwenden und also zu überschreiben.

Fasst man die Kölner Befindlichkeiten des Jahres 1961 zusammen, so spiegelten die Ereignisse und Kontroversen um die Originale stellvertretend das innenpolitische Klima Westdeutschlands im Lichte ästhetischer Debatten. Einen gänzlich anders gelagerten Eklat provozierten drei Jahre später die New Yorker Originale, als das `Knollenstück` transkulturelle Problemfelder freilegte und das Ende der amerikanischen Unterwürfigkeit gegenüber der europäischen Hochkultur symbolisierte.

133 Mary Bauermeister im Gespräch mit der Autorin am 16.12.2013 in Rösrath.

$134 »$ Diskussion - Stockhausen - Originale«, in WDR: 5128711. 
Schon während der Proben in Köln hatte David Tudor an John Cage geschrieben: »Karlheinz theater is not so interesting. ${ }^{135}$ Während die ästhetische Konzeption der Originale 1961 in Köln noch provozierten, waren Happenings in New York längst gang und gäbe. Bauermeister, die seit 1963 in New York lebte, erinnert sich außerdem, dass in amerikanischen Kreisen mit Blick auf den europäischen Serialismus von »mindfuck « die Rede war. ${ }^{136}$ Die Vorbehalte entluden sich 1964, als die von Edgard Varèse als >Jeanne d'Arc der Neuen Musikı titulierte Cellistin Charlotte Moorman eine Wiederaufnahme der Originale für ihr »2nd Annual New York Avant Garde Festival« ansetzte. Schon in ihren Absprachen mit Karlheinz Stockhausen wurde das neue Selbstbewusstsein der New Yorker Avantgarde gegenüber der deutschen Hochkultur deutlich:

$»[\mathrm{I}]$ said: $>$ I want to do the Originaler. And he said: >Well, I did that for certain people. I did that for Hans G Helm. « I said: >Well, we've got Allen Ginsberg here, the poet.> He said: >Well, you need Caspari, the director.< I said: >We have Allan Kaprow, who invented the happening more or less. What better director do you have than that? He said: >Well you have to have Paik. And I said: >What’s a Paik? «. $\ll{ }^{137}$

Nur Nam June Paik, der aufgehende Stern der Aktions- und Medienkunst, war offensichtlich unverzichtbar. Glücklicherweise residierte der Südkoreaner mittlerweile ebenfalls in New York und bildete damit eine personelle Konstante zwischen den Kölner- und den New Yorker Originalen. Darüber hinaus gewann man für die Darstellung der achtzehn sich selbst spielenden Originale die Speerspitze der amerikanischen Avantgarde: Allan Kaprow - der Erfinder des Namens >Happening « - war ebenso beteiligt wie Allen Ginsberg, einem Anführer der literarischen BeatGeneration sowie die Komponisten Alvin Lucier und Christian Wolff aus dem Umkreis von John Cage.

Bevor der transkulturelle Kampf der internationalen Fluxus-Bewegung ins analytische Zentrum rückt, soll zunächst die Szenerie der New Yorker Originale beleuchtet werden, die Mary Bauermeister in ihren Erinnerungen wiederauferstehen ließ:

»Der lustigste Abend war, als sie uns den Affen nicht gebracht hatten. Als die Tier-Szene nahte wurde ich unruhig und bin raus auf die Straße, wo gerade eine kleine, geschminkte und gepuderte Dame mit einem Hündchen vorbeikam. Sie hat gesagt: `Das mache ich gerne. Also habe ich sie vor das Publikum geholt, wo der Pinscher sein Bein gehoben und gepinkelt hat. Es war herrlich. Als ich sie wieder hinausgeleiten wollte, wollte sie nicht gehen, sondern fragte: >What are you doing here? « Ich hab zunächst geflüstert, aber weil sie nichts verstanden hat, habe ich das Ganze dann laut via Mikrophon erklärt und sie erwiderte: `Oh, we did this in Milano everytime. « - Sie war tatsächlich eine italienische Dada-Künstlerin. ${ }^{138}$

135 Brief von David Tudor an John Cage (30. Oktober 1960), in Northwestern University Music Library: John Cage Correspondence Collection.

136 Mary Bauermeister im Gespräch mit der Autorin am 16.12.2013 in Rösrath.

137 Zitiert nach Benjamin Piekut: Experimentalism Otherwise. The New York Avant-Garde and Its Limits, Berkeley/Los Angeles 2011, S. 140f.

138 Mary Bauermeister im Gespräch mit der Autorin am 16.12.2013 in Rösrath. 
Will man sich einen audiovisuellen Eindruck der Ereignisse verschaffen, lohnt ein Blick auf Peter Moores Stockhausen's Originale. Doubletakes, The Film [\$-17.2]. Obwohl qua Konzept jeder Abend der Originale eine Premiere war, dokumentierte der Filmemacher doch immerhin zwei Aufführungen: Während Charlotte Moorman an einem Seil hängend klassische Cellostücke spielt, besprüht sich Paik über und über mit Rasierschaum, taucht anschließend den Kopf in einen Wassertrog, lehrt diesen über sich aus und trinkt daraus - doch statt der Empörungsstürme des Kölner Publikums, wird er in New York nur von freundlichem Gelächter begleitet. Ab Minute 20'33" gerät zunächst kurz die Dada-Dame mit Hündchen ins Blickfeld der Kamera, bevor diese auf eine Gestalt in Schutzmontur mit einem überdimensionierten aufblasbaren Penis schwenkt, die durch die Publikumsreihen schreitet und anschlieBend unter die Bühne kriecht. Auch hier spiegelt die Tonspur des Films nur Gelächter und das neugierige Vergnügen des Publikums. ${ }^{139}$

Mit der freundlichen Rezeptionshaltung des Auditoriums tut sich ein erster aussagekräftiger Unterschied zu den Kölner Originalen auf, die so aufgeregte Debatten über Sinn und Unsinn solcher >Anti-Kunstく ausgelöst hatten. An dieser Stelle war die Neue Welt voraus: mit den Happenings der Fluxus-Bewegung war man derlei Eskapaden in New York längst gewohnt. Proteste provozierten die New Yorker Originale dennoch allerdings an einer anderen, nicht minder aussagekräftigen Front: Auf der Straße vor dem Saal, wo Aktivisten gegen die eurozentrische Kulturhegemonie in Gestalt Karlheinz Stockhausens protestierten [Abbildung 22].

Schon am Abend des 29. April, also knapp ein halbes Jahr vor den Ereignissen um die New Yorker Originale, hatte sich vor der Town Hall eine Gruppe postiert, die sich

\section{Abbildung 19 - »Action Against Cultural Imperialism!« (8.9.1964)}

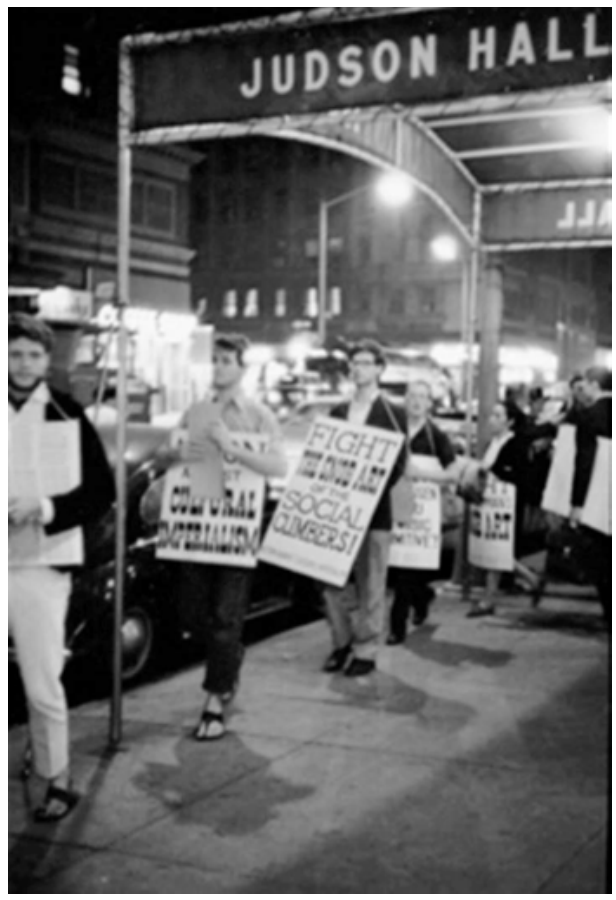
Action Against Cultural Imperialism (AACI) nannte und aus namhaften Künstlern der amerikanischen Fluxus-Bewegung zusammensetzte: Der Philosoph und Komponist Harry Flynt gehörte ihr ebenso an, wie die Künstler Ben Vautier, Ay-O und Takako Saito sowie der Geiger und Filmemacher Tony Conrad. Angeleitet wurden diese von der Führungsfigur der Fluxus-Bewegung: George Maciunas.

139 Peter Moore: »Stockhausen's Originale. Doubletakes, The Film« (1964), eingesehen in: Electronic Arts Intermix (EAI). 
Der Anlass zu den Protesten war ein von Deutschland gesponsertes Galakonzert mit Werken von Vertretern der deutschen Nachkriegsavantgarde. ${ }^{140}$ Dieselbe Gruppe versammelte sich am 8. September 1964, dem Premierenabend der New Yorker Originale, vor der Judson Hall, wo das musikalische Theater Karlheinz Stockhausens aufgeführt wurde. Diesmal waren es keine Kriegsveteranen oder jüdisch-zionistische Organisationen, die gegen deutsche Musiker protestierten; vielmehr nutzten namhafte Aktionskünstler die nach 1945 erprobten New Yorker Praktiken der Konzertboykotte für ihre Anliegen. Harry Flynt und George Maciunas gestalteten und verteilten Flugblätter, auf denen die Demonstranten ebenso aktionistisch wie performativ forderten: »Picket Stockhausen-Concert!« [Abbildung 20].

Abbildung 20 - »Picket Stockhausen-Concert!«

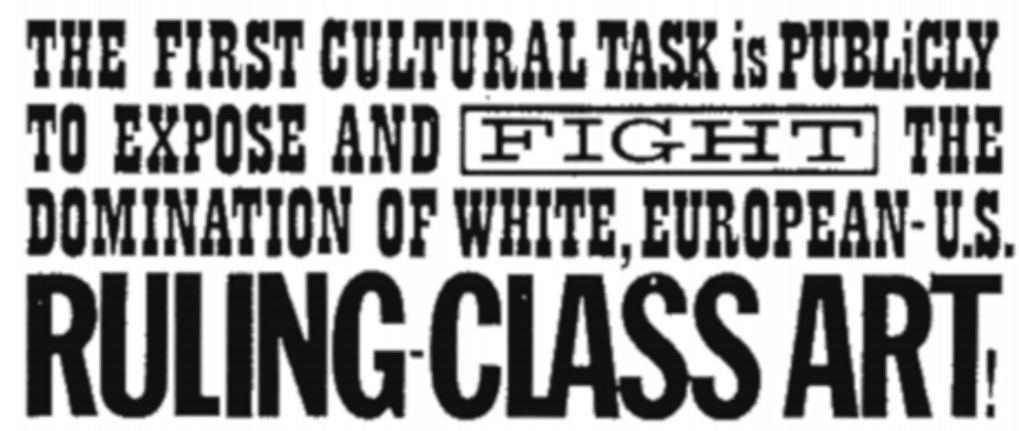

Die Hintergründe der Aktion reichten weit über interne Grabenkämpfe der FluxusBewegung hinaus und werden bei der weiteren Lektüre des Flugblattes deutlich. Darauf wurde Stockhausen zitiert, der sich abfällig gegenüber nicht-europäischer Musik geäußert hatte: »Jazz [Black music] ist primitive... barbaric... beat and a few simple chords... garbage... [or words to that effect]. $\ll^{141}$ Gemeinhin werden die Aktionen der AACI im Umfeld New Yorker Originale von Kunsthistorikern wie Michael Oren oder Hannah Higgins auf interne Grabenkämpfe zwischen rivalisierenden FluxusSträngen reduziert. ${ }^{142}$ Doch greift diese Interpretation auch nach Meinung des $\mathrm{Mu}$ sikwissenschaftlers Benjamin Piekut zu kurz. Er verortete die Manifestation als »part of a larger intervention into the public discourse of avant-gardism, European imperialism, and the structure of power and knowledge supporting these systems. ${ }^{143}$ Diese Sichtweise belegen auch weitere Passagen des Flugblatts:

140 Benjamin Piekut: «Demolish Serious Culture!« Henry Flynt and Workers World Party, in Robert Adlington (Hg.): Sound Commitments. Avant-garde music and the Sixties, Oxford 2009, S. 37-55, hier S. 37.

141 Action Against Cultural Imperialism: »Picket Stockhausen-Concert!«, Flugblatt von Harry Flynt und George Maciunas, in: Gilbert and Lila Silverman Fluxus Collection (Detroit), URL: http://id3419.securedata.net/artnotart/fluxus/hflynt-actionagainst.html [Zugriff: 31.8.2017].

142 Michael Oren: Anti-Art as the Ende of Cultural History, Berkeley 2002; Hannah Higgins: Fluxus Experience, Los Angeles 2002.

143 Piekut: Experimentalism Otherwise, S. 68. 
"Of all the world's cultures, aristocratic European Art has developed the most elaborate doctrine of it supremacy to all plebian and non-European, non-white cultures. It has developed the most elaborate body of «Laws of Music « ever known: Common-practice Harmony, 12-Tone, and all the rest, not to mention concert-etiquette. ${ }^{144}$

Die Neue Musik wurde stellvertretend für den westlichen Imperialismus stigmatisiert und berührte darin auch Diskurse im Zusammenhang mit gesellschaftlichen >Avantgarden wie dem civil rights movement. Die Proteste verdeutlichen damit auch die um 1960 transatlantisch einsetzende Politisierung. Die Kritik war mehr als nur die Absetzung von der eurozentrischen Hochkultur, sondern offenbarte auch postkoloniale Diskursfelder, die am Beispiel Karlheinz Stockhausens festgemacht wurden:

»Stockhausen is a characteristic European-North American ruling-class artist. His $[\ldots]$ doings are supported by the West German Government, as well as the rich Americans [...]. If there were $[\ldots]$ no discrimination against non-European cultures, Stockhausen couldn't possibly enjoy the status he does now. But Stockhausen's real importance [...] is that he is a fountainhead of «ideas « to shore up the doctrine of white plutocratic European Art's supremacy [...]. STOCKHAUSEN-PATRICIAN >THEORIST , OF WHITE SUPREMACY: GO TO HELL!«

Hier wurden Europa und Nordamerika also bereits als transkontinentale westliche Welt wahrgenommen und in ihrem imperialen Habitus gegenüber subalternen Kulturen kritisiert. Neben der politischen und kulturkritischen Komponente besaßen die Proteste vor und im Konzertsaal auch eine explizit ästhetische Ebene, die fraglos den zeitgenössischen Praktiken öffentlicher Kundgebungen entlehnt wurde. Die performativen Aktionen auf der Straße ähnelten der Ereignisfolge von Happenings, welche die Originale auf der Bühne der Judson Hall inszenierten. Und so verstand auch eine Mehrzahl der amerikanischen Medienvertreter die Kampagne als Teil einer aufmerksamkeitsträchtigen Inszenierung und beglückwünschten Karlheinz Stockhausen zu seiner Idee, das eigene Stück zu bestreiken. In der New York Times etwa hieß es: »Some said they were part of the show. Others said no, including the picketers, but nobody believed them. [...] [T] hey looked like the participants in Originale. $"{ }^{145}$

Mit innerästhetischem Blickwinkel wies die seltsame Dopplung der Aktionen vor und in der Judson Hall auf die transkulturellen Grabenkämpfe der amerikanischen und europäischen Fluxus-Aktivisten zwischen extremen ästhetischen und politischen Positionen. Die Fehden wurden in Boykotts der Fluxus-Aktivisten gegen Aufführungen sowie Ausführende der Originale ausgetragen, die radikal-performativ mehrmals die Grenze zu kriminellen Handlungen überschritten. Der amerikanische Verleger Billy Klüver beschuldigte die AACI in der Village Voice illegaler Aktionen wie der Fesselung Paiks während einer Aufführung an ein Gerüst, Einbrüche in das Haus eines Sponsors und Diebstahl von Aufnahmen, Technik und Partituren sowie Drohanrufen. ${ }^{146}$ In diesem Punkt liefern Mary Bauermeisters Erinnerungen weitere Details:

144 Action Against Cultural Imperialism: Picket Stockhausen-Concert!

145 Harold C. Schonberg: »Stockhausen's \Originale` Given at Judson«, in: New York Times (9.9.1964), S. 46.

146 Eine ausführliche Auflistung der Aktionen lieferte der Historiker Thomas Kellein: Der Traum von Fluxus. George Maciunas - eine Künstlerbiographie, Köln 2007. 
»Maciunas hatte sich als neueste Attacke etwas echt \Musikalisches` ausgedacht, nämlich sie [Charlotte Moorman] und mich durchs Telefon mit einem extrem lauten künstlich erzeugten Ton zu erschrecken. Nachdem ich selbst bereits beim Abnehmen des Hörers, also noch mit einer Armeslänge Abstand, einen unglaublichen Stich in die Ohren bekommen hatte, wollte ich Charlotte warnen. Doch es war schon zu spät. [...]. Sie musste in die Notaufnahme des Krankenhauses gebracht werden. ${ }^{147}$

Die Ereignisse besiegelten eine nachhaltige Spaltung der bis dato international agierenden Fluxus-Bewegung. Während George Maciunas die Aktivisten mit einem politischen Programm zusammenhalten wollte, so argumentierten Michael Oren und Hannah Higgins, riss er stattdessen eine große Kluft. ${ }^{148}$ Mary Bauermeister rückte diese Interpretation in transkulturelle Zusammenhänge:

$»$ Das hat die Fluxus-Bewegung, insbesondere zwischen Europa und Amerika, gespalten. Dies hing auch mit der unterschiedlichen Geschichte zusammen, ob man aus Fun oder aus Not agiert, wie bei den europäischen Kriegskindern. Wenn du solche Erfahrungen gemacht hast, gehungert und auf der Flucht - dann hat man eine andere Art von Anarchismus wie in einer satten Gesellschaft. ${ }^{149}$

Auf Mary Bauermeisters Frage, warum Maciunas seinen Vorstellungen nicht im politischen Protest Ausdruck verleihe, antwortete dieser: »Das wäre nicht möglich, da landet man in Amerika sofort im Gefängnis. $«{ }^{150}$ Damit spielte er auf die restriktive amerikanische Politik in der Tradition der McCarthy-Ära an, als antikommunistische Verschwörungstheorien das politische Klima bestimmten und insbesondere Künstler mit pauschalen Verdachtsmomenten belastet wurden. Maciunas Angst vor Strafverfolgung bewahrheitete sich 1967 in einer weiteren \Knolle`der Originale.

Mary Bauermeister berichtete, dass Charlotte Moorman schon während der Arbeit an den Originalen »keine Engagements bei klassischen Konzerten mehr bekam zu weit hatte sie sich vorgewagt mit ihrem Festival der Avantgardemusik. Stattdessen musste sie ihr Geld als Telefonistin in einem Hotel verdienen - was niemand wissen durfte. ${ }^{151}$ Diese Sanktionen verschärften sich drei Jahre nach den Ereignissen um die New Yorker Originale im Skandal um die Opera Sextronique und dem folgenreichen Gerichtsprozess um die >Topless Cellist $\iota$, der in einem ersten transferierenden Exkurs beleuchtet wird, bevor abschließend ein weiterer exkursiver Transfer ins Jahr 2001 unternommen wird: Karlheinz Stockhausens umstrittene Äußerungen zu den Anschlägen auf das World Trade Center als »größtes Kunstwerk « heben die transkulturellen Transfers in die Gegenwart und belegen: Der Querstand von Kunst und Weltpolitik ist eine historische Konstante und Karlheinz Stockhausens eine ihrer historischen Schlüsselfiguren.

147 Bauermeister: Ich hänge im Triolengitter, S 167.

148 Michael Oren: Anti-Art as the Ende of Cultural History, Berkeley 2002; Hannah Higgins: Fluxus Experience, Los Angeles 2002.

149 Mary Bauermeister in einem Zeitzeugengespräch am 30.10.2013 im Rahmen der »Tage neuer Musik « in Weimar.

150 Bauermeister: Ich hänge im Triolengitter, S. 168.

151 Ebd., S 167. 


\section{TRANSFERIERENDE EXKURSE}

Standen in diesem Kapitel die kulturellen Transfers der transatlantischen Avantgarden nach 1945 im Fokus, so werden abschließend zwei analytische `Exkursionen< unternommen, die gleichsam als Ableger des Knollenstücks Originale gedacht werden können. Zwar sind weder der Skandal um die Opera Sextronique noch die Empörung infolge Karlheinz Stockhausens Äußerungen zu den Anschlägen von 9/11 im unmittelbaren Kontext der europäischen Nachkriegsavantgarde - dem Gegenstand dieser Arbeit - situiert. Gleichwohl offerieren die beiden Fallbeispiele weiterführende Anschlüsse an das diskursive Themendoppel Skandal und Neue Musik.

\section{»Topless Cellist«: People \& C. v. Charlotte Moorman (1967)}

Als sich Charlotte Moorman und Nam June Paik anlässlich der New Yorker Originale kennenlernten, suchte der südkoreanische Pionier von Fluxus, Aktions- und Medienkunst händeringend nach einem »beautiful girl to striptease ${ }^{152}$, um eines der letzten Tabus der Hochkultur zu brechen: Die Verbindung von Kunstmusik und Sex. In einem unveröffentlichten Brief an Mary Bauermeister schrieb Paik im April 1967:

»Ich habe sie fuer ein ganzes Jahr in 1964-65 fuer nude music ueberredet [...]. Du weiss welche Schwierigkeiten ich gehabt hatte, um ein Maedchen ihre panty VOLLbekleidet ausziehen zu lassen in Deutschland 1960-61,,,doch vergebens,,, und in Japan auch verschiedene Maedchen hat abgelehnt. ${ }^{153}$

Moorman ließ sich zur Umsetzung von Paiks Manifest überreden, in dem dieser verkündete: »music history needs ist D.H. Lawrence, ist Sigmund Freud. ${ }^{154}$ Dieses Motto intonierte die Cellistin nicht nur mit einschlägigen Kompositionen wie der Sonata No. 1 for Adults only [S-18]; auch visuell wurde der Anspruch auf der Ankündigung der Premiere von Paiks Opera Sextronique am 9. Februar 1967 in der New Yorker Filmmakers Cinemateque unterstrichen. Auf dem Plakat war die Cellistin in Unterwäsche abgebildet und wurde provokativ verkündet [Abbildung 21]:

»After three emancipations in 20th century music, (serial-indeterministic, actional)... I have found that there is still one more chain to lose.... that is.... PRE-FREUDIAN HYPOCRISY. Why is sex a predominant theme in art and literature prohibited ONLY in music? How long can New Music afford to be sixty years behind times and still claim to be a serious art? The purge of sex under the excuse of being >serious` exactly undermines the so-called >seriousness of music as a classical art, ranking with literature and painting. ${ }^{155}$

152 Fred Stern: »Charlotte Moorman and the New York Avantgarde« (Video-Interview), New York 1980, einsehbar unter URL: http://www.youtube.com/watch?v=wiEJdOlgcDE [Zugriff: 31.8.2017].

153 Brief von Nam June Paik an Mary Bauermeister (12.4.1967), in: Privatarchiv von Mary Bauermeister in Rösrath.

154 Ebd.

155 Barbara Moore (Hg.): The World of Charlotte Moorman, Ausstellungskatalog, New York 2000, Section IV. Chronology: Paik Collaborations, Nr. 18. 
Abbildung 21 - >Die Königin der Nacktı: Charlotte Moorman auf dem Plakat von Nam June Paiks »Opera Sextronique» (1967)

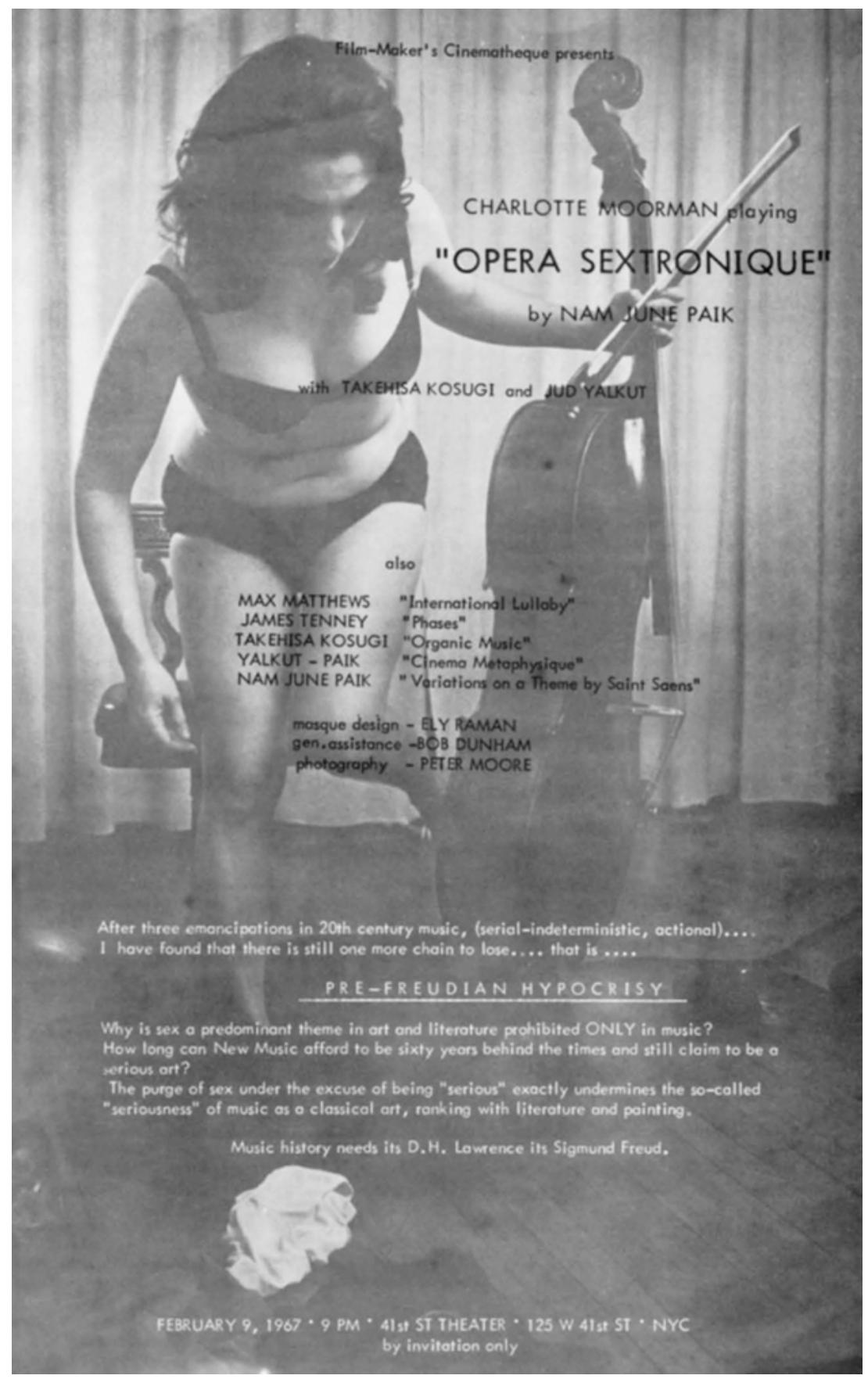


Wie Paiks unveröffentlichter Brief zeigt, erschwerte die transatlantisch verbreitete Prüderie derlei Experimente und sorgte beim Premierenabend der Opera Sextronique für einen folgenreichen Skandal, der die Sphären von Ästhetik, Leben und Rechtsprechung verwischte und damit den Querstand von Kunst und Politik um 1968 verdeutlicht. ${ }^{156}$ Die Szenen, die sich am Abend des 9. Februar 1967 in der Filmmakers Cinemateque abspielten, beschrieb das Magazin LIFE:

»Both theater and stage were plunged into complete darkness before Charlotte's first entrance, but she provided her own illumination: a triangle of small, white electric lights was fitted around each of her naked breasts and a third triangular set of them outlined a more private area of her body. [...] The stage lights came on for her second appearance and she strode forth nude to the waist in a formal black skirt [...] interrupting herself from time to time to put on various masks and caps and [...] affix two electrically driven propellers to her breasts. She did not finish. The plainclothesmen leaped on stage and arrested her amidst thunderous boos from the audience. ${ }^{* * * *}$ Dirty cops! Dirty cops! howled the audience. ${ }^{157}$

Laut Mary Bauermeister war Paik und Moorman die Problematik eines solchen Auftritts wohl bewusst und die Erregung öffentlichen Ärgernisses durchaus kalkuliert: Seit der skandalösen Premiere von Jack Smiths Film Flaming Creatures (1963) zeigte die Polizei Präsenz in der Filmmakers Cinemateque und Paik hätte die anwesenden Ordnungshüter bewusst provoziert, indem er bei jeder neuen Aktion seiner Cellistin vor die Bühne trat und in Richtung der anwesenden Sicherheitskräfte fragte: »Is this still ok? « ${ }^{158}$ Bei der vollständigen Entblößung von Moormans Brüsten war die Toleranzgrenze offensichtlich überschritten: über 20 Polizisten räumten den Saal und verhafteten die Urheber der nackten Tatsachen [Abbildung 22].

Abbildung 22 - >Topless Cellist : Charlotte Moorman wird bei der Premiere der »Opera Sextronique« von Polizisten abgeführt

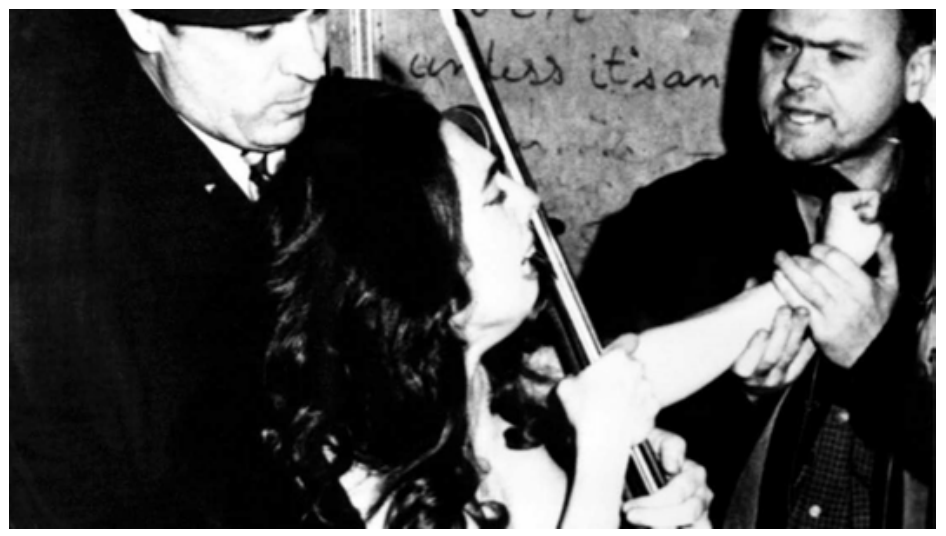

156 Der Fall der >Topless Cellist $\measuredangle$ ist im deutschsprachigen Raum wenig bekannt; wertvolle Vorarbeit leistete Stefan Fricke mit seinem Artikel »Sex and music. Der Moorman-PaikSkandal«, in: Zeitschrift für Neue Musik 161 (2000), S. 26.-29.

157 Paul O’Neil: »A Rather Scandalized Report«, in: LIFE (13.10.1967), S. 107ff.

158 Mary Bauermeister im Gespräch am 17.12.2013 in ihrem Haus in Rösrath. 
Nach einer Nacht im Gefängnis wurde allerdings nur gegen die Cellistin Anklage erhoben. Diese Tatsache wirft einen Spot auf feministische Problemlagen, aber auch die Grenzen der Kunstauffassung, die hier mitverhandelt wurden: nicht Nam June Paik, der Schöpfer des anstoßerregenden Werks wurde belangt, sondern seine Interpretin: Charlotte Moorman.

Die Gerichtssache »People \& C. v. Charlotte Moorman« wurde in einem viertägigen Prozess verhandelt zu dem der verantwortliche Richter, Judge Milton Shalleck, am 9. Mai 1967 eine 29-seitige Urteilsbegründung (Opinion Paper) vorlegte. ${ }^{158}$ Die Anklage lautete, Moorman »did perform an act in which she did willfully and lewdly expose her private parts in a theatre where others were present«. Daraus wurden strafrechtliche Verstöße gegen die Paragraphen 1140 und 43 des Penal Law wegen Unzüchtigkeit (»lewdness«) und Sittenwidrigkeit (»indecency«) abgeleitet. Shalleck befand Moorman »guilty of a violation of section 1140« und belegte die Cellistin mit einer Bewährungsstrafe (»suspended sentence«). Tatsächlich aber reichte das Urteil weit über den eigentlichen Verhandlungsgegenstand hinaus, wie der Richter selbst ausführte: »For it touches upon current approach to a way of life which is puzzling «. Damit sprach er die gesellschaftlichen Umbruchsprozesse an und machte sie zum Bestandteil der Gerichtsverhandlung. »The pristine beauty of human female breasts «, so setzte er in seiner Urteilsbegründung an,

»has been immortalized by painters and sculptures and writers [...]. But in no poem, in no prose $[\ldots]$, in no valued oil, in no statue or bust $[\ldots]$ have I seen $[\ldots]$ a picture of a nude or stopless < cellist in the act of playing the instrument - or $[\ldots]$ of a >topless $<$ waitress with breasts pendant over a plate $[\ldots] . \ll$

Mit diesem impliziten Verweis auf die Kellnerin Carol Doda, die 1964 mit dem >Monokini< des homosexuellen Designers Rudi Gernreich für eklatante Schlagzeilen gesorgt hatte ${ }^{159}$, setzte der Richter die künstlerische Avantgarde mit Grundpfeilern der Protestbewegungen in den 1960er Jahren - wie der Schwulenbewegung, dem Feminismus und der aufstrebenden Pornoindustrie - gleich. Seine Strategie war es, diese als Minderheiten-Bewegungen zu klassifizieren:

»That small group of rushing, impetuous persons (most of them youthful) wandering fretfully somewhere for some unknown goal of intangible value and for uncertain reason will look askance [...]. It will shout out loudly that I am a >square and stagnant in my thinking: that I do not understand the new dimensions in art [...]. It will come from sophisticated and generally dependable sources, too - the communication media. The noise emanates from a mighty vocal minority whose actual pipsqueak voice receives stentorian publicity because what is angrily said and done makes good copy.«

158 Milton Shalleck: »People \& C. v. Charlotte Moorman« (Opinion Paper), in New York Law Journal (11.5.1967). Alle folgenden Zitate beziehen sich, soweit nicht anders gekennzeichnet, auf dieses Schriftstïck.

159 Hatte der Bikini noch 1946 Skandale ausgelöst, entwickelte Rudi Gernreich Anfang der 1960er Jahre den >Monokiniく. Carol Doda präsentierte das Anstoß erregende Kleidungsstück erstmals 1964 und wurde in der Folge wegen Sittenwidrigkeit arretiert und damit zu einer Symbolfigur der sexuellen Befreiung. 
Shalleck wetterte also auch gegen die aufstrebenden und sensationslüsternen Massenmedien. Damit hatte der Richter, folgt man den Erinnerungen Bauermeisters, nicht ganz unrecht. Sie zitiert Nam June Paik mit den Worten: »Great success. Finally press reacting « ${ }^{160}$ Wenn die von Edgard Varèse sie als $>$ Jeanne d'Arc der Neuen Musikı geadelte Moorman ihrer aufsehenerregenden Rolle in der Opera Sextronique auch ihren Legendenstatus als >Topless Cellist ${ }^{161}$ verdankt und von der liberalen Presse zur »queen of artistiv-intellectual-avant-garde [...] nakedness « ${ }^{162}$ gekrönt wurde, so musste die >Königin der Nackt $\iota$ nicht nur in Form der Gerichtsverhandlung empfindliche Sanktionen erfahren. Noch vor Beginn des Prozesses schrieb Nam June Paik den schon zitierten, äußerst schuldbewussten Brief an Mary Bauermeister:

»Sie hat ALLE klassische job verloren wegen mein stueck. Vor zwei Jahre koennte sie knapp Leben halten mit classic music job, aber jetzt,,, nach ihre Arrest,,, dass sie jeder Abend 8 Stunden als Telephonisten arbeiten [handschriftliche Anmerkung: »secret! DON'T TELL Any Body«]. [...] Weil ich sie fuer ein ganzes Jahr in 1964-65 fuer nude music ueberredet habe, muss ich doch gewisse Konsequenze tragen. $\ll^{163}$

Wenn Prüderie und progressive Gegenbewegungen in jenen Jahren auch transkulturell übergreifende Phänomene waren, wurde der Konflikt zwischen staatlich verordneter Züchtigkeit und der aufstrebenden Aufklärungsbewegungen in den USA verschärft. Wurde diese Diskrepanz in den Künsten thematisiert und oft provozierend reflektiert, sorgten die Mechanismen der Massenmedien durch auflageträchtige Schlagzeilen für eine publizistische Öffentlichkeit. Diese Tendenzen aufgreifend, ließ Richter Shalleck eine unmittelbare Aburteilung der Avantgardebewegungen im Zusammenhang mit den Boulevardmedien anschließen:

$»$ Whether with tongue in cheek or in earnest, reporters on television over radio and in newspapers and magazines give broad coverage to what can in measure be attributed to a John Cage breakthrough in art. [...] What may be disturbing is >The Other Culture led by that limited number comprising the underground (as it is called) - those >happeners) whose belief it is that art is >supposed to change life < as most of us know it. [...] Is all of this the outcome of the inner urge to artful accomplishment, which the community has grown to admire and accept? Or is it the result of the unsequential momentary place in the sun of the bearded, bathless >Beats ? «

Der Richter erkannte also nicht nur die Rolle der Massenmedien, sondern auch Anhaltspunkte zwischen den Happenings der künstlerischen Avantgarde und den >Sitins der revoltierenden Studenten.

160 So zitiert Bauermeister die Reaktion Nam June Paiks in einem Interview vom November 2006. Die nicht weiter bezeichnete Transkription findet sich im Privatarchiv von Mary Bauermeister in Rösrath.

161 Bei ihrem Tod im Jahr 1991 gab es nicht einen Nachruf, der sich nicht auf den Skandal und den Prozess um ihre nackten Brüste bezog, obwohl nur 5 ihres 200 Werke umfassenden Repertoires Nacktheit inkludierten.

162 Paul O’Neil: »A Rather Scandalized Report«, S. 108.

163 Unveröffentlichter Brief von Nam June Paik an Mary Bauermeister (12.4.1967), eingesehen im Privatarchiv von Mary Bauermeister in Rösrath. 
Mit der Verurteilung Moormans zielte Shalleck also in Vertretung auf die verschiedensten Gruppierungen des gesellschaftlichen und kulturellen Wandels, dem er juristisch mit Urteilen wie gegen die >Topless Cellist $<$ vorzubeugen trachtete. Shallecks Argumentation fußte auf der Taktik, die Oben-ohne-Performance nicht als künstlerischen Ausdruck zu werten, sondern als anstößig und vulgär. Werden dabei paternalistische und anti-feministische Strukturen sichtbar, äußerten sich diese auch in der ästhetisch kuriosen Tatsache, dass im Prozess nicht der Urheber der Opera Sextronique - Nam June Paik - sondern sein Werkzeug - Charlotte Moorman - belangt wurde. Klassischerweise ist der Interpret in der Musik dazu angehalten, das Werk möglichst Partitur getreu wiederzugeben, wie auch Charlotte Moorman in ihrer Verteidigung betonte. Der Richter erwiderte: »The defendant here was not prosecuted for anything she believed but for what she did."

Musikhistorisch und -ästhetisch interessant ist diese Handhabe, wenn man bedenkt, dass damals die Rolle des Interpreten - durch Entwicklungen wie Improvisation und individuelle Notation sowie die großen Interpretationsspielräume der Aleatorik - enorm aufgewertet wurde. Waren Musiker bislang vor allem virtuose Werkzeuge des Komponisten, wurden die Interpreten nun zunehmend selbstverantwortlich schaffende Künstler. Nam June Paik komponierte für die Cellistin nicht nur Stücke, sondern benutzte ihren ganzen Körper im Interesse der Kunst. Man kann Moormans Bedeutung für das Werk des Aktionskünstlers daher mit ihrer Biographin Joan Rothfuss als die eines Mediums definieren: „somewhere between a performer of his, a collaborator of his, and an artwork of his. ${ }^{164}$

Die Opera Sextronique spiegelt sinnbildlich die radikal-performativen Praktiken der zeitgenössischen Avantgarde und dies gilt umso mehr für den Skandal, den sie erregte. Für Mary Bauermeister war »der heulende Widerstand Charlottes« das, was die Performance eigentlich ausmachte: »Sie stach und schlug mit ihrem Cellobogen um sich und leistete erbitterten Widerstand unter dem johlenden Tumult des Publikums. $«{ }^{165}$ Damit war die Uraufführung der Opera Sextronique ein Paradebeispiel für die Happenings, mit denen Fluxus-Aktivisten eine Entgrenzung von Kunst und Leben in ereignishaft inszenierten Momentaufnahmen anstrebten. >Anti-Kunst< wurde als provokatives Schockmoment gegen die bourgeoise Konsumgesellschaft inszeniert und war zweifelsfrei eine zeitgenössische Variante der historischen Futur- und Dadaisten: wiederum kam es zu einer politischen wie ästhetischen Funktionalisierung des Kunst-Skandals zu einer Kunst des Skandals.

Es ist allerdings nicht davon auszugehen, dass der Richter mit seinem Urteil auf die veränderten musikalischen Produktionsbedingungen abzielte. Vielmehr sprach die Verurteilung Moormans wegen Unzucht (»sexual offense«), Obszönität (»obscenity«) und unsittlicher Entblößung (»indecent exposure«) entgegen der öffentlichen Moral (»injurious to public morals«) der Opera Sextronique und seiner Interpretin jeglichen Kunstcharakter ab. In seiner Urteilsbegründung räumte Shalleck ein, dass der Tatbestand der Sittenwidrigkeit keiner präzisen Definition folge, sondern in Relation zu Zeit, Ort und gesellschaftlichen Tendenzen bewertet werden müsse:

164 Joan Rothfuss: The Ballad of Nam June and Charlotte: A Revisionist History, Cambridge 2011, URL: http://irez.me/2012/07/29/pixel-paiked-out-part-ii/ [Zugriff: 31.8.2017]; Dies.: Topless Cellist. The improbable Life of Charlotte Moorman, Cambridge 2011. 
»What is done, worn and accepted depends on good measure on the desires, likes and wants of the community as a whole it is that general bent of mind which impels the laws by which we are governed. If our wishes change, so will the laws.«

Damit lieferte Richter Shalleck selbst den Hinweis auf eine historisch gebundene und auf dem Prinzip der Verhältnismäßigkeit gründende Bewertung der Anklage. Tatsächlich war der betreffende Paragraph schon im April 1967 infolge der lautstarken Proteste gegen die Verhaftung und Anklage Charlotte Moormans durch Gouverneur Nelson Rockefeller geändert worden. Von nun an sollten nackte Brüste im Rahmen von Kunstaktionen erlaubt sein. Nichtsdestotrotz verkündete Shalleck in seinem Opinion Paper: »The coming section has no effect upon one of the questions in this case. [...] However, the exemption of the defendant's bare breasts could be argued under the new section. « Im Zusammenhang mit der Gesetzesnovelle kann die Verhandlung um die >Topless Cellist « als eine Art Schauprozess interpretiert werden, in dem der konservative Richter zum letztmöglichen Zeitpunkt ein Exempel statuierte. Dies belegt im Anschluss an den Kunstjuristen Peter M. Lynen, dass Recht und Kunst keine statischen, sondern veränderliche Systeme sind: »Der Künstler verändert das Recht. Er kann nicht nur auf die Kunst, sondern auch auf das Recht in seiner Entwicklung kreativ und prägend einwirken. « ${ }^{166}$

Darüber hinaus eröffnen die Ereignisse um die Opera Sextronique auch Anschlüsse an feministische Kunst und Theorie, die seit den 1960ern insbesondere in den USA und Deutschland virulent wurden. Der ästhetische Fokus lag dabei auf den performativen Ausdruckspraktiken von Fluxus, indem hier die Körperlichkeit von Kunst als Aktion zelebriert und inszeniert wurde. ${ }^{167}$ Auf die mediale Durchschlagskraft der feministischen Bewegung deutete ein Kommentar Nam June Paiks in dem schon zitierten Brief an Mary Bauermeister hin. Darin schrieb er, Moormans Verhaftung könne »mein >Tod sein in ihren Freundeskreis besonders in N.Y. Times and [Herald] Tribune Kreis (hypokratische feministische NYC). ${ }^{168}$ Schließlich zeigt das Fallbeispiel exemplarisch die gegenseitige Bezugnahme von Ästhetik und Gesellschaft sowie den charakteristischen Querstand von Kunst und Politik, der charakteristisch für die 1960er Jahre wurde und im Kapitel Querstand von Kunst und Politik fokussiert herausgearbeitet wird. Davor aber soll ein weiter Exkurs zu Karlheinz Stockhausen unternommen werden, der die Verschränkung politischer und ästhetischer Konflikte um gesellschaftliche Welt- und Wertungsordnungen ins 21. Jahrhundert transferiert und in gewisser Hinsicht eine weitere Wucherung des »Knollenstücks« Originale bildet.

166 Peter M. Lynen: Das ambivalente Verhältnis des Künstlers zum Recht. Am Beispiel von Joseph Beuys, in Bettina Paust/Johannes Bilstein/Peter M. Lynen/Hans Peter Thurn (Hg.): Aufbauen - Zerstören. Phänomene und Prozesse der Kunst (Moyländer Diskurse zu Kunst und Wissenschaft, Bd. 1), Oberhausen 2007, S. 44ff.

167 Siehe hierzu weiterführend Kathy O’Dell: »Fluxus Feminism«, in: Drama Review Nr. 41 (1/1997), S. 43-60; Janelle G. Reinelt/Joseph R. Roach (Hg.): »Critical theory and performance«, Ann Arbor 1992, S. 248-256; Tanja Modleski: »Some Functions of Feminist Criticism, or, the Scandal of the Mute Body«, in: October (49/1989), S. 3-24.

168 Unveröffentlichter Brief von Nam June Paik an Mary Bauermeister (12.4.1967) 


\section{»Das größte Kunstwerk«: Karlheinz Stockhausen und 9/11 (2001)}

Am 16. September 2001 wurde Karlheinz Stockhausen im Senatszimmer des Hotel Atlantic in Hamburg zu einem Pressegespräch [\$-19] mit dem Intendanten der Musikhalle, Benedikt Stampa, geladen. Anlass waren zwei Konzerte mit Werken des Komponisten unter Ingo Metzmacher. Unter dem Eindruck der aktuellen Weltereignisse fragte der Moderator auch nach der Meinung des Komponisten zu den Anschlägen auf das World Trade Center, der antwortete:

»Hm. Also was da geschehen ist, ist natürlich - jetzt müssen Sie alle Ihr Gehirn umstellen das größte Kunstwerk, was es je gegeben hat. ${ }^{169}$

Mit dieser Aussage provozierte der 73jährige Komponist sechs Jahre vor seinem Tod noch einmal einen handfesten Skandal und ein echtes Medienereignis: In erregten Zeitungskommentaren wurde Karlheinz Stockhausen "galatisches Spinnieren « (Die Welt), ein »Höllensturz« (Frankfurter Allgemeine Zeitung), »Wahnsinn eines Musikgenies« (Hamburger Morgenpost), ein »Durchknaller vom Größenwahn zum Größenwahnsinn « (Der Spiegel) und sogar »Musikerneid auf Terroristenerfolg « (Basler Zeitung) attestiert. Daneben verbreiteten sich die Aussagen des berühmten Komponisten in Windeseile im neuesten Wissensarchiv, dem Internet, und lösten einen, insbesondere für die Neue Musik, beispiellosen \Shitstorm`aus. Infolge der inkriminierenden Äußerungen wurden darüber hinaus diverse Engagements wie zum Beispiel eine große Konzertveranstaltung zur Grundsteinlegung der Hamburger Elbphilharmonie abgesagt, zwei seiner sechs Kinder distanzierten sich öffentlich von ihrem Vater und in seiner Heimatgemeinde Kürten forderten erzürnte Bürger, Karlheinz Stockhausen die Ehrenbürgerwürde zu entziehen.

Freilich war dieser Skandal nicht mehr ästhetisch grundiert - oder etwa doch? Hier wird im Folgenden die These vertreten, dass Stockhausens Äußerungen keine sensationsorientierte Transaktion im Sinne einer Ökonomie der Aufmerksamkeit waren; jenseits aller verständlichen Entrüstung warf der Komponist unter zeithistorischen Konfliktlagen vielmehr eine der heikelsten Fragen auf, der sich die zeitgenössische Kunst zu stellen hat: Was definiert das Kunstwerk? Die Antwort Stockhausens lautete:

»Daß also Geister in einem Akt etwas vollbringen, was wir in der Musik nie träumen könnten, daß Leute zehn Jahre üben wie verrückt, total fanatisch, für ein Konzert. Und dann sterben. [Zögert.] Und das ist das größte Kunstwerk, das es überhaupt gibt für den ganzen Kosmos. Stellen Sie sich das doch vor, was da passiert ist. Das sind also Leute, die sind so konzentriert auf dieses eine, auf die eine Aufführung, und dann werden fünftausend Leute in die Auferstehung gejagt. In einem Moment. ${ }^{170}$

169 Das Pressegespräch ist als Audioaufnahme sowie als Transkription verfügbar. Die Audioversion findet sich unter URL: http://web.archive.org/web/20060829003224/http:// www.danskmusiktidsskrift.dk/doku/stockhausen-16sep2001.mp3 [Zugriff: 31.8.2017]. Eine Transkription wurde unter dem Titel »Huuuh!« veröffentlicht in: MusikTexte (91/2001), S. 69-77, hier S. 76.

170 Ebd., S. $76 f$. 
Der Komponist betonte also das performative Moment der terroristischen >Aufführungく als singuläres, unwiederholbares Ereignis. Diese Idee hatte er bereits in den 1960er Jahren mit Werken wie seinem musikalischen Theater Originale angestrebt, so dass seine Aussagen zu den Anschlägen von 9/11 in gewisser Hinsicht als späte Wucherung des >Knollenstücks`gelten können. Mit den Kontakten [₹-17.1], dem musikalischen Gerüst der Originale, hatte Stockhausen 1961 sein Konzept der >Momentformen< entwickelt,

»die sofort intensiv sind und - ständig gleich gegenwärtig - das Niveau fortgesetzter >Hauptsachen bis zum Schluß durchzuhalten suchen, in denen entweder jedes Gegenwärtige zählt oder gar nichts; Formen, in denen [...] die Konzentration auf das Jetzt - auf jedes Jetzt - gleichsam vertikale Schnitte macht, die eine horizontale Zeitvorstellung quer durchdringen bis in die Zeitlosigkeit, die ich Ewigkeit nenne: Eine Ewigkeit, die nicht am Ende der Zeit beginnt, sondern in jedem Moment erreichbar ist. ${ }^{171}$

In den überwältigenden Ereignissen des 11. September 2001 erkannte Stockhausen die Verdichtung und Inszenierung der ästhetischen Substanz »gleich einer Materie, die sich durch konzentrischen Druck derart verdichtet, bis sie explodiert, ihre Energie freigibt und sich mit anderer Materie verbindet. " $^{172}$ Kurzum: Karlheinz Stockhausen erkannte »das größte Kunstwerk, was es je gegeben hat« und war nicht der einzige Künstler mit dieser Ansicht. Ein Jahr nach den Terroranschlägen äußerte sich der Brit-Art-Künstler Damien Hirst in ähnlicher Diktion auf BBC News Online:

»The thing about $9 / 11$ is that it's kind of an artwork in its own right. It was wicked, but it was devised in this way for this kind of impact. It was devised visually. [...] So on one level they kind of need congratulating. ${ }^{173}$

2011 hielt Anselm Kiefer, Friedenspreisträger des Deutschen Buchhandels, am Pariser Collège de France einen Vortrag in dem er Osama bin Laden als >bildenden Künstler bezeichnete. Mit 9/11 habe dieser, so zitierte die Frankfurter Allgemeine Zeitung den Maler, »das perfekteste Bild geschaffen, das wir seit den Schritten des ersten Mannes auf dem Mond gesehen haben. $«{ }^{174}$ Alle drei Künstler bezogen sich in ihren Äußerungen darauf, dass die Attentäter ihren >Auftritt< über Jahre hinweg einstudiert hatten, um die ganze Welt durch eine beispiellose apokalyptische Inszenierung zu erschüttern und betonten damit die Ereignishaftigkeit als grundlegendes ästhetisches Merkmal großer Kunst. Parallel zum emotionalen Codex (Angst, Entsetzen, Besonnenheit) reflektierten sie die Faszination des Schreckens, die von diesen Bildern ausging: das \Sublime` als Kategorie der Erhabenheit, deren wesentliche Ei-

171 Karlheinz Stockhausen: Momentform. Neue Zusammenhänge zwischen Aufführungsdauer, Werkdauer und Moment (1960), in Ders. (Hg.): Texte zur Musik, Band 1, Köln 1963, S. 189-210, hier S. 198 f.

172 Ebd., S. 209.

173 Damien Hirst im Interview mit BBC News Online (11.9.2002). Am 18.9. folgte im selben Medium, wohl auf Druck des Senders, eine Entschuldigung Hirsts.

174 Lena Bopp: »Bin Ladin - eine Kunst-Performance?«, in: Frankfurter Allgemeine Zeitung (3.2.2011). 
genschaft eine Anmutung von Größe oder sogar Heiligkeit ist, die über das gewöhnlich Schöne hinausreicht und stets mit dem Gefühl von Unermesslichkeit, Ehrfurcht und Schrecken verbunden ist und das stets über die menschliche Wahrnehmung hinausreicht. ${ }^{175}$ Karlheinz Stockhausen faszinierte insbesondere »dieser Sprung aus der Sicherheit, aus dem Selbstverständlichen, aus dem Leben«:

»Dagegen sind wir nichts als Komponisten. Ich meine, es kann sein, daß [...] da ein paar Leute im Saal sitzen, denen das passiert, was ein alter Mann mir vorige Woche gesagt hat: ^Na, sagen Sie mal. Zweieinhalb Stunden, da waren doch diese unglaublich tiefen Klänge, die wie Wolken über uns schwebten und sich bewegten die ganze Zeit, die segelten und dazu dann ganz schnelle Schüsse von anderen Klängen - sagen Sie mal, was ist denn das für ein Orchester?< Ich sage: ১Gar keins.〈 Sagt er: ১Was? Wie haben Sie's denn gemacht? Sie müssen das doch irgendwie machen! Wer spielt das? Wer hat das gesungen oder gespielt?〉 Ich sage: >Niemand ‘. \a, wie denn? « Ich sage: >Mit Generatoren und Synthesizern.〈 Sagt er: >Was? Dann brauchen wir ja gar kein Orchester mehr! « Ich sage: `Nein.く Dann lief der raus, als ob der innerlich, im Geiste gestorben wäre [...]. Das war eine Explosion wie für die Menschen in New York: Bum. ${ }^{176}$

Das Skandalon lag in der Identifizierung des Komponisten mit den Tätern anstatt mit den Opfern sowie der Empörung darüber, dass da einer etwas aussprach, das den Regeln des Diskurses widersprach und diese damit ex negativo sichtbar werden ließ: Konkret verweigerte sich Stockhausen der von Judith Butler beschriebenen binären Logik der USA $-»$ Either you're with us or you're with the terrorists $«{ }^{177}$ - und thematisierte offen, was die Inszenierung der Ereignisse auf mediale Ebene ohnehin offenlegte: dass sich in das Entsetzen über die Bilder der brennenden WTC-Türme auch die Aura des Faszinosums mischte - eben das Sublime. ${ }^{178}$ Stockhausen ging es nicht um den kalkulierten Tabubruch oder gar um aufklärerische Entlarvung, sondern wie stets nur um sein Werk. Als der Komponist während des Pressegesprächs das betretene Schweigen der Redaktion wahrnahm fragte er, gleichsam sich selbst: »Wo hat er mich hingebracht, Luzifer?«

175 Mit Theodoer W. Adorno (in seiner »Ästhetischen Theorie«) und Jean-François Lyotard (»Die Analytik des Erhabenen«) widmeten sich zwei ausgesprochene Musikdenker dem philosophischen Gefühl des `Sublimen<.

176 Stockhausen: »Huuuh!«, S. 77.

177 Judith Butler: Precarious Life. The Powers of Mourning and Violance, London/New York 2004, S. 1f.

178 Siehe weiterführend zur ästhetischen Kategorie des Sublimen Karin Harrasser: »Das atomare Sublime und die standardisierte Katastrophe«, in Charlotte Bigg/Jochen Hennig (Hg.): Atombilder. Ikonographien des Atoms in Wissenschaft und Öffentlichkeit des 20. Jahrhunderts, Göttingen 2009, S. 168-176; Monika Fludernik: »Erhabene Postmoderne? Technologie, Gewalt und Ästhetik zwischen der Atombombe und dem 11. September 2001 «, in Dies./Jan Alber (Hg.): Moderne/Postmoderne, Trier 2003, S. 243-267; Christel Fricke: »Kunst und Öffentlichkeit. Möglichkeiten und Grenzen einer ästhetischen Reflexion über die Terrorakte auf das World Trade Center am 11. September 2001 «, in Ursula Franke/Josef Früchtl (Hg.): Kunst und Demokratie. Positionen zu Beginn des 21. Jahrhunderts, Hamburg 2003, S. 1-17. 
Den >Lichtträger der lateinischen Mythologie machte er in bester faustischer Künstlertradition in seinem siebenteiligen Opern-Zyklus LICHT (1077-2003) zum zerstörerischen Gegenspieler Evas (das Menschliche, die Geburt) und des Erzengels Michael (das Gute, Schöpferische) sowie zur Allegorie einer universellen Erscheinungsform negativer Kräfte. DIENSTAG aus LICHT besteht über weite Strecken aus musikalisch ausgetragenen Kämpfen zwischen guten - michaelischen - und bösen - luziferischen - Kräften. Klangbomben explodieren und Töne werden von einer Art musikalischer Flak abgeschossen, denn der Krieg war für Stockhausen »ein kosmisches Prinzip, wie Geburt, Liebe, Lernen, Versuchung, Tod, Auferstehung. « ${ }^{179}$ Schon bei anderen Gelegenheiten vertrat der Komponist die stark theosophisch geprägte Vorstellung, dass sich das Leben in immer höhere geistige Sphären entwickelt und der Tod lediglich zeitlich begrenzte Intervalle bilde:

»Daher kann ich durch Bewährung einem Bewusstsein immer näher kommen, dass wir Schritt für Schritt höhere Wesen werden, die viel mehr überblicken, den ganzen Sinn viel besser verstehen. Dass man sich also immer mehr auf Gott zubewegt, der die gesamte Intelligenz aller Intelligenzen ist: Das Licht der Welt. ${ }^{180}$

Insofern mutet es zwar esoterisch, doch durchaus glaubhaft an, dass der Komponist die Terrorakte in den USA als einen luziferischen Akt, als Moment eines äonenlangen Kampfes der Kräfte des Lichtes gegen jene der Finsternis interpretierte. Über die gnostische und ästhetische Selbststilisierung des Komponisten hinaus, machten Karlheinz Stockhausens Äußerungen zu den Anschlägen vom 11. September 2001 auch die faszinierende und sublime Ikonographie der Ereignisse deutlich, deren mediale Inszenierung eine Ästhetisierung des Terrors spiegelte: Dass Bilder und Filmszenen der Anschläge, insbesondere im amerikanischen Fernsehen, oft mit Monumentalmusik unterlegt wurden und dem Skript eines Katastrophenfilms zu folgen schienen, animierte die Kommunikationswissenschaftlerin Joan Kristin Bleicher zu ihrem treffenden Bonmot eines »terror made in Hollywood ${ }^{181}$.

Nur in den ersten drei Jahren nach den Ereignissen galt Künstlern und Denkern das Gebot der Pietät gegenüber den Opfern und den USA; danach griff zunehmend eine die Zirkel der Semiotik negativ aufsprengende und von der Gewalt faszinierte Poetik des Terrors ${ }^{182}$ um sich. Die Bedeutung der Medien bei der Inszenierung der terroristischen Akte als künstlerische Inszenierungen betonte 2011 der Philosoph Roman Meinhold:

179 FREITAG aus LICHT, in: Leipziger Opernblätter, Spielzeit 1996/97, Heft 2, S. 65.

180 Karlheinz Stockhausen: »Über LICHT - Komponist und Interpret - Zeitenwende«, in Ders. (Hg.): Texte zur Musik 1984-1991, Band 9, Kürten 1998, S. 601 ff, hier S. 601.

181 Joan Kristin Bleicher: »Terror made in Hollywood«, in Ronald Rietzler/Jo Reichertz (Hg.): Irritierte Ordnung. Die gesellschaftliche Verarbeitung von Terror, Konstanz 2003, S. 157-172, hier S. 168.

182 Michael König: Poetik des Terrors. Politisch motivierte Gewalt in der deutschen Gegenwartsliteratur, Bielefeld 2014. Einen Überblick über literarische Bezugnahmen auf die Anschläge vom 11. September 2001 lieferte Birgit Däwes: Ground Zero Fiction. History, Memory, and Representation in the American 9/11 Novel, Heidelberg 2011. 
»Terroristen und Medien haben in von beiden Seiten kalkulierter Zusammenarbeit ein $>$ Werk geschaffen, dass sich als Endprodukt [...] nur unscharf von bestimmten Genres der Popularkultur oder der avantgardistischen Kunst abhebt. ${ }^{183}$

Konkret nannte Meinhold die für die Avantgarde vielfältig belegbare Faszination an Destruktion sowie die Diffusion von Realität und Fiktion in der Performancekunst. Diese suchte er in einer weiteren Publikation durch religionswissenschaftliche Begrifflichkeiten wie das Numinose, das Erhabene oder Katharsis zu fassen. Über den kunsttheoretischen Diskurs zur Phänomenologie der Inszenierung versuchte er darüber hinaus, gleichermaßen die Durchführung der Anschläge wie auch ihre Dramatisierung in den Medien beschreibbar zu machen. ${ }^{184}$

Vor diesem Hintergrund werden Karlheinz Stockhausens provozierende Äußerungen zu 9/11 ebenso nachvollziehbar wie Jean Baudrillards brisante Thesen zum Geist des Terrorismus ${ }^{185}$. Der Poststrukturalist charakterisierte die Twin Towers bereits 1976 in L'échange symbolique et la mort ${ }^{186}$ als architektonische Verkörperung des westlich-kapitalistischen Systems. Nach den Anschlägen von 2001 beschrieb er die Angriffe als >absolutes Ereignis $\triangleleft$, hervorgerufen durch die Globalisierung und damit letztlich die Kolonialisierung der Welt durch die hegemonialen Übermacht der amerikanischen Nation.

Im 21. Jahrhundert kam es also zu einer charakteristischen Umdeutung bei der transkulturellen Neuvermessung der Welt: Erregten in der Mitte des 20. Jahrhunderts die Vertreter der eurozentrischen Kulturhegemonie die Gemüter in Amerika, haben sich die Konfliktfelder global ausgeweitet und stehen nun die USA am Pranger; wurden nach 1945 deutsche Künstler stellvertretend für die Kriegsgräuel der NS-Zeit verantwortlich gemacht, wird der zeitgenössische amerikanische Imperialismus im dritten Jahrtausend mit unmittelbaren Akten der Gewalt beantwortet, die durch ästhetische Inszenierungsstrategien in den Rang von Kunstwerken gehoben werden. Die Terroristen, so betonte Baudrillard im Einklang mit Karlheinz Stockhausen, hätten ein einzigartiges, unwiederholbares Werk gegen den westlichen Imperialismus geschaffen: »die Singularität kann alle Formen annehmen, auch die bösartige oder die terroristische. Sie bleibt dennoch ein Kunstwerk. ${ }^{187}$

Wie es der Dynamik von Skandalen entspricht, markierten auch die Kontroversen im Umfeld der Ereignisse von `Nine Eleven` eine Epochenschwelle. Dass »der 11. September und der daraus resultierende >Krieg gegen den Terror` eine Zäsur in der geopolitischen Weltordnung geschaffen hat«, steht heute nicht nur für den Medien-

183 Roman Meinhold: »Demolition Performance 9/11. Die ästhetisierte Inszenierung der Anschläge des 11. Septembers 2001 und Parallelphänomene in Kunst und Popularkultur«, in Thomas Jäger (Hg.): Die Welt nach 9/11. Auswirkungen des Terrorismus auf Staatenwelt und Gesellschaft, Wiesbaden 2011, S. 807-818, hier S. 817.

184 Roman Meinhold: „Catharsis and Violence. Terrorism and the Fascination for Superlative Destruction«, in: Boleswa. Journal of Philosophy, Theology and Religion (3/2012), S. 172-184.

185 Jean Baudrillard: Der Geist des Terrorismus, Wien 2002.

186 Jean Baudrillard: Der symbolische Tausch und der Tod, München 1991.

187 Jean Baudrillard: »Das ist der vierte Weltkrieg«, in: Spiegel Online (15.1.2002). 
wissenschaftler Christer Petersen »bereits außer Frage. ${ }^{188}$ Als Medienereignis haben die Anschläge vom 11. September einen unüberhörbaren Widerhall gefunden und dabei auch den kulturtheoretischen Diskurs herausgefordert ${ }^{189}$, in dem sich praktisch alle führenden westlichen Intellektuellen - von Paul Virilio, über Slavoj Žižek, bis hin zu Jürgen Habermas und Jaques Derrida - zu Wort meldeten. ${ }^{190}$ Dies legte eine Einbettung des Fallbeispiels >Karlheinz Stockhausen und 9/11 « als Exkurs zu diesem Kapitel über Transkulturelle Transfers nahe; zugleich kann der Konflikt als aktuelle Variation des Querstands von Kunst und Politik verstanden werden, der insbesondere in den 1960er Jahre virulent wurde und der im vierten Kapitel dieser Durchführung über Musikskandale als konfliktven Seismographen sozialer Problem- wie ästhetischer Experimentierfelder in den Fokus rückt.

188 Christer Petersen: ')... Jetzt müssen Sie Ihr Gehirn umstellen...く. Eine Nachlese von Jean Baudrillards 〉Der Geist des Terrorismus««, in Thorsten Schüller/Sascha Seiler (Hg.): Von Zäsuren und Ereignissen - Historische Einschnitte und ihre mediale Verarbeitung, Bielefeld 2010, S. 29-48, hier S. 29.

189 Vgl. Sandra Poppe/Thorsten Schüller/Sascha Seiler (Hg.): 9/11 als kulturelle Zäsur. Repräsentationen des 11. September 2001 in kulturellen Diskursen, Literatur und visuellen Medien, Bielefeld 2009; Ingo Irsigler/Christoph Jürgensen (Hg.): Nine eleven - Ästhetische Verarbeitungen des 11. September 2001, Heidelberg 2008; Dietrich Helms/Thomas Phleps (Hg.): 9/11 - The world's all out of tune. Populäre Musik nach dem 11. September, Bielefeld 2004; Matthias N. Lorenz (Hg.): Narrative des Entsetzens. Künstlerische, mediale und intellektuelle Deutungen des 11. September 2001, Würzburg 2004; Wheeler Winston Dixon (Hg.): Film and television after 9/11, Carbondale 2004.

190 Vgl. Paul Virilio: Ground Zero, London/New York 2002; Slavoj Žižek: Welcome to the Desert of the Real, London/New York 2002; Jürgen Habermas/Jaques Derrida: Philosophie in Zeiten des Terrors. Zwei Gespräche, Hamburg 2006. 


\section{QUERSTAND von KUNST und POLITIK (Durchführung \#4)}

Dieses Kapitel ist mit Querstand von Kunst und Politik überschrieben, weil der Begriff gleichermaßen Bezug nimmt auf den musiktheoretischen Terminus, wie auch auf den querständigen Geist, der durch die 1960er Jahre spukte. Auch ist damit auch die charakteristische Annäherung von Kunst und Politik im Verlauf dieser ereignisreichen und widersprüchlichen Dekade des Wandels angedeutet, in der "politische und künstlerische Avantgarde wieder vereint oder doch eng verknüpft schienen. «

In der Musiklehre, und konkret den Grundlagen des Kontrapunkts, gehört der Querstand zu den >Fortschreitungen ২ die darauf abzielen, dem mehrstimmigen Satz Harmonie in Zusammenklang und Bewegung zu verleihen sowie der Einzelstimme im Verbund mit den anderen eine größtmögliche Eigenständigkeit zu sichern. Damit ist eine soziale Implikation des Querstands angedeutet, der in die Kategorie der >verbotenen Fortschreitungen ‘ fällt und chromatische Varianten in einer Stimme oder gegen eine andere bezeichnet, wodurch sich Reibungen in der Harmonie ergeben. ${ }^{2}$ Bisweilen werden diese Regeln des Kontrapunkts im Dienste eines höheren Kunstsinns sowie des musikalischen Fortschritts wegen durchbrochen - und können so exemplarisch für den Innovationsgedanken innerhalb der (Musik-)Geschichte eingesetzt werden. Die Anwendung der kontrapunktischen Stimmführungsregeln auf die Bewegungen gesellschaftlicher Akteure versprechen systematische Anschlüsse auf die hier gestellten Fragen nach der Verknüpfung von Musik- und Sozialgeschichte und können als Allegorie für die 1960er Jahre gedeutet werden, als eine ganze Reihe an Normen und Regeln durch >verbotene Fortschreitungen wertet wurde. Diese radikale Verdichtung gesellschaftlicher und ästhetischer Neuerungsbestrebungen revitalisierte nicht nur die künstlerischen Kampfesimpulse zwischen den widerstreitenden Polen von Tradition und Innovation, sondern auch das politische Konfliktfeld zwischen progressiven und konservativen Kräften. Zu diesem charakteristischen Querstand gehörten schließlich auch die Anschlüsse und Reibungspunkte zwischen den künstlerischen und gesellschaftlichen Avantgarden, als welche sich die Protestbewegungen in den 1960er Jahre verstanden.

1 Hanns Werner Heister (Hg): Geschichte der Musik im 20. Jahrhundert, Laaber 2005, S. 287.

2 Ulrich Michels/Gunter Vogel: dtv-Atlas Musik, Band 1: Systematischer Teil, München 1977, S. 93. 
Nach dem Kahlschlag des zweiten Weltkriegs und der Agonie der Nachkriegszeit erfuhr die gesamte westliche Gesellschaft eine Re-Politisierung, die nahezu alle Gesellschaftsbereiche erfasste und bis in Bezirke geistiger und künstlerischer Tätigkeiten vordrang: »Unter der Gunst zeitpolitischer Vermittlungen und Kontaktsprünge«, so resümierte der Musikwissenschaftler Ulrich Dibelius, »standen sich [...] plötzlich Staatsmoral [...] und Kunstmoral [...] als Exponenten eines offenen Konflikts frontal wie nie einander gegenüber. ${ }^{3}$ Wenn Dibelius damit auch den 〉Querstand tik und Kunst treffend beschrieb, so ist doch ein durch das Wort >plötzlich suggerierter punktueller Umbruch kritisch zu hinterfragen. Dieser wird üblicherweise auf das zum Symbol gewordene Jahr 1968 datiert, das ähnlich ungenau und mythenbeladen ist, wie das zur >Stunde Null« stilisierte Jahr 1945. In beiden Fällen scheint die Jahreszahl Eindeutigkeit zu signalisieren, verweist aber auf ein ganzes Spektrum von Themen innerhalb eines längeren Kulminationszeitraums.

Angesichts der Fülle an Zusammenhängen erkennt man nicht nur in den Geschichtswissenschaften die »historiographische Tücke des Objekts. $\aleph^{4}$ Auch in den Musikwissenschaften besteht Konsens darüber, wie etwa Jörn Peter Hiekel vor dem »kontroversen und durchaus heiklen Forschungsgegenstand « ${ }^{5} \mathrm{zu}$ warnen. Die Gesamtheit historischer Wandlungsprozesse, so sein Kollege Arnold Jacobshagen, sei wesentlicher als die symbolische Jahreszahl 1968, die allerdings als »Kulminationspunkt von langfristigen politischen und soziokulturellen Veränderungsprozessen verstanden werden kann. Sie setzen um die Mitte der 1950er Jahre ein und reichten bis in die 1970er Jahre ${ }^{6}$. Diese Prozesshaftigkeit ähnelt der Struktur des Phänomens Musikskandal selbst: auch dieser entwickelt sich über einen längeren Zeitpunkt mit einem Vor- und Nachspiel - seine Ereignishaftigkeit aber liegt in einem punktuell bestimmten Eskalationsmoment: jenem »Sturz ins Jetzt des Augenblicks « ${ }^{7}$. Auch Sabine Sanio sprach in ihrer Monographie zu 1968 und die Avantgarde von einer $» \mathrm{La}-$ tenzphase für einen gesellschaftlichen Umbruchprozess«, der allerdings »1968 mit Vehemenz an verschiedenen Schauplätzen der nördlichen Hemisphäre zu Tage trat« und [...] sich dauerhaft mit dem Chiffre jenes Jahres « ${ }^{8}$ verband. Insofern kann 1968 als verdichteter Eskalationspunkt dieses Prozesses gelten und markiert auch in der Musikgeschichte eine historische Zäsur. Dies konkretisierte Beate Kutschke in ihrer einschlägigen Monographie Neue Linke - Neue Musik:

3 Ulrich Dibelius: Moderne Musik nach 1945, München 1998, S. 436.

4 Norbert Frei: 1968. Jugendrevolte und globaler Protest, München 2008, S. 211.

5 Jörn Peter Hiekel: Warum sich jetzt mit $>1968$ < befassen? - Aspekte des Widerständigen in der Musik, in Ders. (Hg.): Die Kunst des Überwinterns. Musik und Literatur um 1968, Köln/Weimar/Wien 2011, S. 9-21, hier S. 9.

6 Arnold Jacobshagen/Markus Leniger (Hg.): Rebellische Musik. Gesellschaftlicher Protest und kultureller Wandel um 1968, Köln 2007, S. 9.

7 Martin Thrun: Der Sturz ins Jetzt des Augenblicks. Macht und Ohnmacht ıästhetischer Polizei im Konzert nach 1900, in Sven Oliver Müller/Jürgen Osterhammel/Martin Rempe (Hg.): Kommunikation im Musikleben. Harmonien und Dissonanzen im 20. Jahrhundert, Göttingen 2015, S. 42-67.

8 Sabine Sanio: 1968 und die Avantgarde. Politisch-ästhetische Wechselwirkungen in der westlichen Welt, Sinzig 2008, S. 10. 
»Spätestens ab 1968 war das Bedürfnis, selber am Gesellschaft verändernden Impetus zu partizipieren, allgegenwärtig; und die Mittel [...] entsprachen dabei durchaus denjenigen, der sich auch die Studenten- und Protestbewegungen bedienten: neben Demonstrieren und Lärmschlagen, Agitieren und Bloßstellen die Entwicklung alternativer musikalischer Verhaltensstile und Codes, die einen Wandel des bisherigen Musikbetriebs vorantrieben; innovative Kompositionsrichtungen, die neue Richtungen Formen des Musizierens erforderten, die Gründung von dem herkömmlichen Musikbetrieb entgegenarbeitenden, politisch positionierten und agitierenden Gegeninstitutionen, die Reflexion und Verarbeitung linksintellektuellen Wissens in musikalischen Werken. ${ }^{9}$

Auch Gianmario Borio, der vor den Schwierigkeiten warnte, »die Vielfalt der unter jenem Begriff subsumierten Erscheinungsformen auf einen Nenner zu bringen ${ }^{10}$, verstand 1968 als symbolische Jahreszahl für Transformationen im Denken sowie sozialem Handeln und wendete dieses polyvalente Gesellschaftsbild auch auf die musikalische Avantgarde an:

»In Hinblick auf die Kunstmusik der westlichen Welt stellen die Jahre vor 1968 eine Zeit dar, in der die schärfsten Angriffe gegen die traditionelle Vorstellung von Komposition, die musikalischen Institutionen und das Produktionssystem insgesamt geführt wurden. ${ }^{11}$

Wenn auch vor einer Degradierung der Künste zu Illustrationen zeitgeschichtlicher Bewegungen zu warnen ist, so ist sich die Forschung doch grundsätzlich einig über die Folgen des gesellschaftlichen Umbruchs auch für die (Hoch-)Kultur. Damals, so der weitgehende Konsens, sei es durch die Infragestellung von Institutionen, Konventionen, Konsumgewohnheiten und bürgerlichen Musik-Ritualen zu einer Verdichtung von im weiteren Sinne als politisch zu bezeichnender Konzepte gekommen. Kunst, so lautete die offen erklärte Hoffnung vieler Kulturschaffender, sollte aktiv zu gesellschaftlichen Veränderungen beitragen.

Diese implizite Politisierung im Musikbetrieb äußerte sich jedoch auf unterschiedlichste Art und Weise, so dass sich ein extrem weitgefächerter Gegenstand ergibt: Forderten einige Musiker eine leicht verständliche Musik für die Massen - die Rock- und Popmusik sowie die Konjunktur politischer Liedermacher löste diesen Anspruch partiell ein - protestierten andere gegen die traditionelle klassische Musik und ihre Aufführungspraxis, die als Ausdruck der hierarchischen Gesellschaftsverhältnisse gedeutet wurde. Innerhalb der Neuen Musik reicht das Spektrum politischer Ausdrucksformen von kompositionstechnischen und ästhetischen Konzepten über die konkrete Kritik an gesellschaftlichen Missständen und Institutionen bis hin zu performativ-aktionistischen Ausdrucksformen wie Fluxus, Aktions- und Medienkunst, welche die Praktiken der Straßenproteste - Demonstrationen, Sit-ins und Manifeste ästhetisch nutzbar machten.

9 Beate Kutschke: Neue Linke - Neue Musik. Kulturtheorien und künstlerische Avantgarde in den 1960er und 70er Jahren, Köln/Weimar/Wien 2007, S. 18.

10 Gianmario Borio: Avantgarde als pluralistisches Konzept. Musik um 1968, in: Jacobshagen/Leniger: Rebellische Musik, S. 15-33, hier S. 15.

11 Ebd., S. 17. 
Viele Künstler bezogen sich auf links-intellektuelle Theorien, deren Verfasser wiederum oft explizit auf die Kunst Bezug nahmen. Geeint wurden diese sozioästhetischen Avantgarden laut Gianmario Borio durch die Kritik an Affirmation:

»Die Struktur der Botschaften und die Bedingungen ihrer Rezeption sind nicht nur Gegenstand der Schriften von Adorno, Marcuse, McLuhan, Abraham Moles, Max Bense, Umberto Eco, Guy Debord - von Theoretikern also, die sich mit den Avantgarden der Kunst auseinandergesetzt haben, sondern stellen den Berührungspunkt der disparaten Strömungen jener Jahre dar. $\ll^{12}$

Neben den von Borio genannten Theoretikern, spiegelt insbesondere Peter Weiss' programmatische Schrift zur Ästhetik des Widerstands die zeittypische Dynamik der gesellschaftlichen und künstlerischen Avantgarden: der zentrale Gedanke des Roman-Essays ist eine zu erreichende Einheit zwischen der künstlerischen Moderne und der progressiven Arbeiterbewegung. ${ }^{13}$ Wenn die Kritik am affirmativen Charakter von Kunst auch überwiegend Bestandteil der westlichen `Kulturrevolution` war, zeigt sich am Beispiel von Peter Weiss auch ihr systemüberschreitender Charakter. Dies belegt etwa die Anekdote um die Pläne in der DDR, dessen Thesen zur offiziellen Doktrin zu erheben. ${ }^{14}$ Hier könnte man pointiert bilanzieren, dass die westliche Gegenbewegung Bestandteil der ostdeutschen Herrschaftspolitik war. Aber auch und nicht zuletzt abseits der Institutionen übten sich die DDR-Künstler im ästhetischen Widerstand gegen die starren Regeln des öffentlichen Kulturbetriebsbetriebs in der sozialistischen Gesellschaft. Dies betraf nicht nur politische Liedermacher wie Wolf Biermann oder die subversive Rock-, Pop- und Agitprop-Szene, sondern auch die Ost-Avantgarde: Anspielungsreiche Stücktitel und Chiffren hatten Hochkonjunktur und das Publikum verstand es, zwischen den Notenzeilen zu lesen. ${ }^{15}$ Im Westen wiederum gab es nicht nur Risse im Adenauer-Deutschland - die Konflikte betrafen ebenso die »halbautoritär gaullistische ehemalige Kolonialmacht Frankreich und [...] die amerikanische Gesellschaft infolge der imperialistischen Ambitionen in Vietnam ${ }^{16}$. Die Politisierung war also ein transkulturelles Phänomen, wenn auch nationale Problemlagen meist den Anstoß gaben.

12 Ebd., S. 27.

13 Peter Weiss: Ästhetik des Widerstands, 3 Bände, Frankfurt am Main 1975-1981.

14 Werner Mittenzwei: Ästhetik des Widerstands. Gedanken zu dem Versuch, eine ästhetische Kategorie für die Kunstentwicklung während des Kampfes gegen den Faschismus zu entwickeln (Sitzungsbericht der Akademie der Wissenschaften der DDR vom 7.12.1978), Berlin 1979.

15 Das belegen zahlreiche Interviews der Autorin mit DDR-Komponisten. Während die Widerständigkeit innerhalb der Unterhaltungskultur hinreichend erforscht ist, liegt im Bereich der ostdeutschen Kunstmusik ein Forschungsdesiderat vor. Siehe einführend Anna Schürmer: »Taktgeber oder Tabuisierte? Neue Musik und ihre Komponisten in Ostdeutschland Zwischen Zwängen und Möglichkeiten«, in GEMA virtuos (9/2009), S. 10-14.

16 Hans-Klaus Jungheinrich: »1968 - Ästhetik des Aufbruchs?«, in Jörn P. Hiekel (Hg.): Die Kunst des Überwinterns. Musik und Literatur um 1968, Köln/Weimar/Wien 2011, S. 118124, hier S. 118. 
So wichtig der grenz- und spartenübergreifende Fokus mit Blick auf politische Musik auch ist, so müssen doch die Rock- und Popmusik, politische Lieder und Agitprop zugunsten einer Fokussierung eklatanter Ereignisse in der Neuen Musik fragmentarisch bleiben. Die Analyse der politischen Musikskandale folgt dem Konsens der Forschung, die 1960er als Latenzphase zu verstehen, deren Zusammenhänge sich allerdings seit der Mitte der Dekade verdichteten und 1968 zur Eskalation kamen. Die allgemein dem symbolischen Jahr zugeschriebenen Ereignisse werden also als länger anhaltende Entwicklung verstanden, die vom Ende der 1950er Jahre bis in die Mitte der 1970er Jahre wirksam war. Über diese historische Prozesshaftigkeit hinausgehend, folgt auch die Analyse der musikskandalösen Fallbeispiele der Struktur einer jeweils in ein Vor- und ein Nachspiel eingebetteten punktuellen und ereignishaften Eskalation.

\section{Politische MusiksKandale IM UMfELd Von $>1968$ ،}

Die Politisierung der 1960er Jahre besaß insgesamt ein hohes Maß an Sprengkraft; dennoch notierte die Musikwissenschaftlerin Beate Kutschke, dass sich »[d]irekter Aufruhr und Revolte [...] im Kontext der Avantgardemusikveranstaltungen [...] selten verzeichnen $\ll{ }^{17}$ lassen. Dem soll zumindest partiell widersprochen werden: Selbst, wenn Konzertskandale auch im Umfeld von >1968 « eher die Ausnahme waren, lassen diese außergewöhnlichen Ereignisse doch Rückschlüsse auf die Normen der Zeit zu - gerade weil sie nicht alltäglich waren. Zudem lässt sich in jenen konfliktreichen Jahren eine Häufung klingender Eklats feststellen. So bezeugte etwa Dieter Schnebel, der radikale Avantgardist und evangelische Pastor, dass es der »Skandale jener Jahre [...] nicht wenige gab. ${ }^{18}$ In einem ersten Punkt werden an seiner Figur die oft skandalträchtigen Tendenzen der avantgardistischen Politisierung beispielhaft nachgezeichnet, um in einem zweiten den Blick noch einmal auf die Darmstädter Ferienkurse für Neue Musik zu richten. Am Nucleus der westlichen Avantgarde kam es im `Krisenjahr 1970< zu einem Aufstand der Teilnehmer, der den Umgang der Neuen Musik mit den Zeichen der bewegten Zeit beispielhaft illustriert.

\section{Ein Überblick mit Dieter Schnebel}

Wenn Dieter Schnebel im Folgenden als Beispiel für die oft skandalträchtige Politisierung einer ganzen Komponistengeneration herangezogen wird, geschieht dies aus mehreren Gründen: Erstens, weil Schnebel als prominenter Zeitzeuge unschätzbares Quellen- und Detailwissen mitbringt - was die Analyse im Stile einer >oral history< stützt. ${ }^{19}$ Zweitens aus methodischen Gründen, um das komplexe Beziehungsbündel des Querstands von Kunst und Politik exemplarisch einzugrenzen. Drittens erlaubt Schnebel als damals bekennender Marxist und Befürworter der Studentenbewegung

17 Kutschke: Neue Linke - Neue Musik, S. 20.

18 Zitiert nach Gisela Nauck: Dieter Schnebel. Lesegänge durch Leben und Werk, Mainz 2001, S. 48.

19 Grundlage dieser >oral history< bildet ein Interview der Autorin mit Dieter Schnebel am 4.8.2012 in Murnau. 
auch durch seine künstlerischen Tätigkeiten aussagekräftige Einblicke in den klingenden Klassenkampf im Umfeld von >1968<. Auch Simone Heilgendorff bemerkte, dass der evangelische Theologe und radikale Avantgardist eine besonders facettenreiche Figur bei der Untersuchung sozioästhetischer Fragestellungen sei, da er verschiedene Tätigkeiten in sich vereinte:

»Schnebel verband Zeitgenossenschaft mit der studentischen Protestbewegung der späten 1960er Jahre, insofern hier [...] ein Sinn für die insgeheim wirksamen Mechanismen gesellschaftlichen und individuellen Agierens erwachte und sich dies [...] auch in der experimentellen Kunst vielerorts manifestierte. $\ll^{20}$

Dieter Schnebel sprach mit Blick auf die Skandal- und Provokationsimpulse seiner Komponistengeneration von etwas Heroischem: »Wir waren Kämpfer für eine bessere Zeit. $\ll^{21}$ Man habe damals gleichermaßen gegen musikalische wie gesellschaftliche Konflikte und Problemfelder rebelliert: Den vehementen Anti-Kommunismus und das Verbot der Kommunistischen Partei, die Wiederbewaffnung und Atomgefahr sowie die mangelnde Aufarbeitung des Nationalsozialismus in der Bundesrepublik. Viele avancierte Komponisten, so führte Schnebel aus, trieb das Bewusstsein dafür, dass ästhetische, gesellschaftliche und ökonomische Phänomene in Beziehung zueinanderstehen an. Bei den Einen mündete dieser Antrieb in konkreter politischer Agitation; bei anderen in der experimentalästhetischen Radikalität: »Der klassische Musikbetrieb mit seinen elitären Strukturen einer Oberschichtenkultur wurde ihnen zum Sinnbild der gesellschaftlichen Zustände. « $^{22}$

Wenn Dieter Mersch aus kulturphilosophischer Perspektive bemerkte, dass die Avantgarde »im Medium des Ästhetischen zugleich eine politische Revolution ${ }^{23}$ vollziehe so bestätigte dies Schnebel aus Komponistenperspektive: man habe etwa in »Tonika-Dominant-Verhältnissen auch die Abbildung von Herrschaftsverhältnissen ${ }^{24}$ erkannt. Schnebels Werk kann von den späten 1950er bis in die 1970er Jahre hinein vielfältigen Subversionsstrategien zugeordnet werden, die mehrere Bereiche der zunehmend pluralistischen Ausprägungen der zeitgenössischen Musik umfassen: Aus kompositionsästhetischer Sicht belegt sein Werk nicht nur die Tendenzen der radikalen Avantgarde aus dem Kreis der `Darmstädter Schuleく, sondern auch die Hinwendung zur performativen Aktionskunst aus dem Umfeld John Cages und der Fluxus-Bewegung. Seine Stellung als Pastor gewährt darüber hinaus Einblicke in die Politisierung christlicher Kreise im Kontext der künstlerischen Avantgarde, die schließlich auch durch konkrete publizistische Stellungnahmen Dieter Schnebels dokumentiert sind.

20 Simone Heilgendorff: »Glossolalische Stimmen. Politisches Ethos, Selbsterfahrung und Spiel in Dieter Schnebels experimentellen Kompositionen der 1960er und 70er Jahre«, in: Kutschke: Musikkulturen in der Revolte, S. 127-140, hier S. 128.

21 Zitiert nach Nauck: Dieter Schnebel, S. 48.

22 Dieter Schnebel im Gespräch mit der Autorin am 4.8.2012 in Murnau.

23 Dieter Mersch: Vom Werk zum Ereignis. Philosophie der Gegenwartskunst, Fünf Vorlesungen, 3: Das Politische, online einsehbar unter URL: http://nyitottegyetem.phil-inst.hu/ kmfil/Mersch/kunst_t.htm [Zugriff: 31.8.2017].

24 Zitiert nach Nauck: Dieter Schnebel, S. 139. 
Spätestens ab 1959 war der sozialkritische Anspruch in Dieter Schnebels Werk omnipräsent. Damals entstand die Vokalkomposition Glossolalie [ $\boldsymbol{\delta}-20]$, die zu seinem »ersten Konzertskandal $\ll^{25}$ wurde. Mit der Montage von Fragmenten aus über 30 Sprachen und Dialekten ließ Schnebel die Musiker subversiven Klang erzeugen: Altsüdarabische Gesetze werden verlesen, türkische und indonesische Zeitschriften sowie Poesie zitiert. Glossolalie schockte die Hörer nicht nur durch die Verweigerung konkreter Sinnzusammenhänge, sondern auch durch die Parodie des Publikums, indem Schnebel mögliche Invektiven einfach ein-komponierte, die er als Zeuge der eklatanten Neuformierung der Nachkriegsavantgarde in Donaueschingen und Darmstadt erlebte: »Ideen eines Übergeschnappten!«, »Alles nicht neu, gibt's schon bei den Dadaisten«, »Für so was gibt man gutes Geld aus!« oder mit der Zunge zwischen den Zähnen gesprochen: »Ist das noch Musik?« Dass Schnebel in der Komposition das im Ersten Korintherbrief beschriebene Phänomen des Zungenredens (Glossolalie) aufgriff, wurde besonders in kirchlichen Kreisen als Provokation empfunden. Weil »Pfarrer wie Gemeindemitglieder [...] immer besonders konservativ« sind, informierte der Komponist 1962 seine Pfarrei vorsorglich nicht über die Liveübertragung der Ursendung im WDR. Dennoch löste sie einen kleinen Eklat aus:

»Ich war damals junger Pfarrer und hatte als Vorgesetzten einen Dekan, der ein strammer CDU-Mann war. Und dieser Dekan hörte dann also meine Glossolalie im Radio. Ich hatte von der Sendung extra niemanden im Pfarrkreis erzählt; aber irgendjemand hat das wohl doch weitergegeben. Und so saßen die Kollegen dann nachts am Radio. [...] Bei der nächsten Pfarrkonferenz bat mich der Dekan zu einem Gespräch und sagte: >Ich habe ihr Stück im Radio gehört und die ganze Nacht nicht mehr schlafen können [...]. Was mir nicht in den Kopf will: Wie kann ein vernünftiger Mensch so etwas machen? « ${ }^{26}$

Übrigens wurde nicht nur Dieter Schnebels künstlerisches Schaffen in kirchlichen Kreisen zum Skandalon. Auch Karlheinz Stockhausen, seinerseits ein bekennender Katholik, provozierte Mitte der 1950er Jahre mit der Planung einer elektronischen Funkmesse für den Kölner Dom den Unwillen des Erzbischofs Kardinal Frings, der verordnete: »Lautsprecher gehören nicht in eine Kirche! « ${ }^{27}$ Aufgrund der Aussagekraft des Beispiels sei an dieser Stelle ein kleiner Exkurs von Dieter Schnebel zu Karlheinz Stockhausen unternommen:

Nach der Ablehnung durch den Erzbischof sah sich der Kölner Komponist gezwungen, das Werkkonzept zu ändern und schuf auf der alttestamentarischen Grundlage aus dem 3. Buch Daniel mit dem Gesang der Jünglinge [\$-13.2] die erste elektronische Raummusik. Das Projekt barg gleich mehrere - gesellschaftlich, ästhetisch, technologisch und kirchlich konnotierte - Kritikpunkte. Erstens besaß das Sujet der singenden Juden im Feuerofen im Nachkriegsdeutschland eine mehr als aussagekräftige historische Komponente mit Blick auf den Holocaust. Zweitens spiegelte das biblische Gleichnis des babylonischen Königs Nebukadnezar den Wiederstand

25 Constantin Gröhn: Dieter Schnebel und Arvo Pärt. Komponisten als Theologen, Münster 2006, S. 26.

26 Dieter Schnebel im Gespräch mit der Autorin am 4.8.2012 in Murnau.

27 Zitiert nach Michael Kurtz: Stockhausen. Eine Biographie, Kassel/Basel 1988, S. 117. 
Stockhausens gegen die kircheninstitutionellen Weisungen. Schließlich und drittens provozierte der Gesang der Jünglinge auch durch die avancierte Kompositionstechnik und Musikästhetik: Der Komponist mischte »gesungene Töne mit elektronisch erzeugten «, die »so schnell, so lang, so laut, so leise, so dicht und verwoben, in so kleinen und großen Tonhöhenintervallen und in so differenzierten Klangfarbenunterschieden hörbar sein« sollten und »befreit von den physischen Grenzen irgendeines Sängers. $\ll^{28}$ In einem Rückblick erinnerte Stockhausen 1992 an den $>$ Neochristianismus` jener Zeit, infolgedessen Kritiker das Werk als `Gotteslästerung im Konzertsaal« sowie als `Fratze Gottes in der Musik` bezeichneten. Tatsächlich symbolisierten die drei Jünglinge den zeittypischen Protest der Nachkriegsgeneration:

»Ich fühlte mich absolut identisch mit einem dieser Jünglinge - dagegen, dass man von uns verlangen wollte, etwas ganz Bestimmtes zu glauben. So wie Nebukadnezar verlangte, dass die Leute jetzt irgendwelche vergoldeten Götterfiguren anbeteten, und die sich weigerten, weil sie eine andere Vision Gottes hatten, und sie sollten verbrannt werden. Also das ist das Beispiel, dass jemand ganz klar seinen Weg geht, ganz egal, was die andern gegen ihn sagen. ${ }^{29}$

Diesen sozialkritischen Anspruch setzte Stockhausen mit avancierten Mitteln um: Er schuf eine sakrale Musik, die nicht an die Kirche als Aufführungsort gebunden war und dem religiös-musikalischen Erlebnis den Raum als neue Dimension erschloss. Der Skandal, den die fünfkanalige Tonbandkomposition 1956 bei ihrer Kölner Uraufführung provozierte, belegt schließlich die Elektronische Eklatanz ${ }^{30}$ des Werks. Dieter Schnebel erlebte die Premiere von Karlheinz Stockhausens Gesang der Jünglinge als Zeuge und berichtet von der Schockwirkung: »Gegner und Befürworter sind wütend aufeinander losgegangen - ich natürlich auf Seiten der Progressiven. $\ll^{31}$

Dieter Schnebels eigenes künstlerisches Schaffen war, wie Constantin Gröhn in seiner Monographie über Komponisten als Theologen herausarbeitete, gleichermaßen "Provokation gegenüber >Spießbürgertum 〈 und Kirche. $"{ }^{32}$ In diesen Kontext sind seine Projekte mit Clythus Gottwald, dem Kantor der Stuttgarter Paulus-Kirche sowie dessen Spezialensemble, der Schola Cantorum, zu verstehen. War Schnebel im Fall der Glossolalie von seinem Dekan nur getadelt und das polarisierte Publikum skandaltypisch in Gegner und Befürworter gespalten worden, so gab es für Gottwald drastischere Folgen. In einem Brief an Schnebel vom 13. November 1965 schrieb der Kantor ahnungsvoll: »Das Gewitter, das mich meine Kirchenmusikerstelle gekostet

28 Karlheinz Stockhausen: „Gesang der Jünglinge. Elektronische Musik« (1956), in Ders.: Texte zu eigenen Werken, zur Kunst Anderer, Aktuelles, Band 2: Aufsätze 1952-1962 zur musikalischen Praxis, Köln 1988, S. 49f., S. 49.

29 Max Nyffeler: »Karlheinz Stockhausen 75. Kleiner Rückblick auf ein langes Komponistenleben« (Feature), in: Westdeutscher Rundfunk (22.8.2003), online einsehbar unter URL: www.beckmesser.de/komponisten/stockhausen75.html [Zugriff: 31.8.2017].

30 Siehe hierzu weiterführend das Kapitel Elektronische Eklatanz und besonders den Abschnitt Rauschende Interferenzen: Karlheinz Stockhausen.

31 Dieter Schnebel im Gespräch mit der Autorin am 4.8.2012 in Murnau.

32 Gröhn: Komponisten als Theologen, S. 22. 
hätte, blieb bis jetzt aus. ${ }^{33}$ Aber schon Ende des Jahrzehnts donnerte und blitzte es, als Clythus Gottwald wegen seines Engagements für die Avantgarde seine Kirchenmusikerstelle an der Stuttgarter St. Paul-Gemeinde verlor. ${ }^{34}$ Ein Auslöser war Schnebels zwischen 1956 und 1970 entstandener dreiteiliger Werkzyklus Für Stimmen (...missa est), den Clythus Gottwald mit seiner Schola Cantorum realisierte:

»dt 31,6 hinterließ oft eine gewisse Ratlosigkeit, während sich das Publikum bei $A M N$, dem zweiten Satz, $[\ldots]$ immer tief beeindruckt zeigte. Allerdings wurde diese Wirkung durch den dritten anarchischen Satz, :! (madrasha 2) [...] wieder aufgehoben. Der komponierte Aufruhr und die Losgelassenheit wollten, obwohl das Stück als Lobgesang gedacht wurde, Attacke sein auf die Tradition des chorischen Schöngesangs. ${ }^{35}$

In der erweiterten Fassung von :! (madrasha) von 1967/68 wurden - gemäß der Aufforderung aus Psalm 150,6 »Alles, was Odem hat, lobe den Herrn « - Tierstimmen per Tonband eingespielt: Esel, Kröten, Hühner, Affen und Möwen stimmten in die Lobpreisung des Herrn ein und der Vorwurf der Blasphemie ließ nicht lange auf sich warten. Auch konkrete politische Agitation wird hörbar, wenn sich der Lobgesang in ein akustisches Signal von politischer Aussagekraft auflöst: »Ho-Ho-Ho...«. Weitere Silben darf der Interpret laut Anweisung ad libitum artikulieren, Schnebel nennt in der Partitur als Beispiel: »Tschi-minh«. Die vielzitierte Formel war nicht nur, wie Clythus Gottwald bemerkte, ein »modisches Accessoire«; sie wurde zum Klangzeichen des Zeitgeists: »die gesamte neue Musik seit 1945 kann als Antizipation der revolutionären Situation von $>1968$ < aufgefasst werden, ohne dass diese sich in solcher Funktion erschöpfen würde. ${ }^{36}$ Den Komponisten ging es laut Schnebel »gleichermaßen um gesellschaftliche Neuerungen wie um ästhetischen Fortschritt, Wiederstände wurden einkalkuliert. « ${ }^{37}$ Auch im wohl größten politischen Musikskandal der Dekade wurde die >Ho-Tschi-minh-Formel zum Klangzeichen eines klingenden Ereignisses: Hans Werner Henze komponierte sie nicht nur in sein >oratorio volgare e militare> Das Floß der Medusa ein; protestierende Studenten skandierten die Parole während der skandalumwitterten Uraufführung 1968 beim Einmarsch der Polizei. Dieser performativ-flüchtige Moment wurde auf Tonband gebannt und legt ein sinnliches akustisches Zeugnis des Querstands von Kunst und Politik ab. ${ }^{38}$

33 Brief von Clythus Gottwald an Dieter Schnebel (13.11.1965), zitiert nach Gisela Nauck, Schnebel, S. 82.

34 Dieter Schnebel im Gespräch mit der Autorin am 4.8.2012 in Murnau. Siehe auch Gröhn, Komponisten als Theologen, S. 27.

35 Clythus Gottwald: Der religiöse Aufruhr, in: Jacobshagen/ Leniger, Rebellische Musik, S. 291-305, hier S. 292.

36 Ebd., S. 304.

37 Dieter Schnebel im Gespräch mit der Autorin am 4.8.2012 in Murnau. Siehe auch Reinhard Oehlschlägel: Avantgarde und Vermittlung. Dieter Schnebel im Gespräch, in: MusikTexte 57/58 (März 1995), S. 97-113, hier S. 104.

38 Siehe hierzu ausführlich den Abschnitt Der Schiffbruch von Hans Werner Henzes >Floß der Medusa (1968) in diesem Kapitel. 
Seit 1960 wendete sich Schnebel den aktionistischen Kompositionsformen der Fluxus-Bewegung zu. Damit hebt sein Werk die These von Dieter Mersch in die Mitte des 20. Jahrhunderts, der den historischen Avantgarden politische Intentionen zuschrieb: Mit performativ-ereignishaften Mitteln, so Mersch, hätten Strömungen wie der Dadaismus oder der Surrealismus den Aufstand geprobt und die Spießbürger wachgerüttelt. ${ }^{39} 1962$ entstand mit visible music II. Nostalgie eine stumme, nur noch szenisch nachvollziehbare Komposition, die das Konzertritual gestisch bloßstellte: Der Dirigent agiert nach einer graphischen Partitur und ist dem Publikum als imaginärem Orchester von der Bühne aus zugewandt. Das Werk wurde 1962 beim Festum Fluxorum, dem Gründungsereignis von Fluxus in Wiesbaden uraufgeführt. Destruktive Aktionen wie Phil Corners legendäre Piano Activities, bei denen ein Klavier systematisch auseinandergenommen und zerstört wurde [Abbildung 24; $\delta$-21], belegen den symbolischen Angriff auf die bürgerliche Hochkultur und können im Anschluss an Jacques Lacan ${ }^{40}$ auch als >Ent-Stellung « des Symbolischen und damit als subversive >Destituierung $<$ der bestehenden Ordnung interpretiert werden. Die Devise der Fluxus-Leute lautete: `Produktion durch Destruktion`:

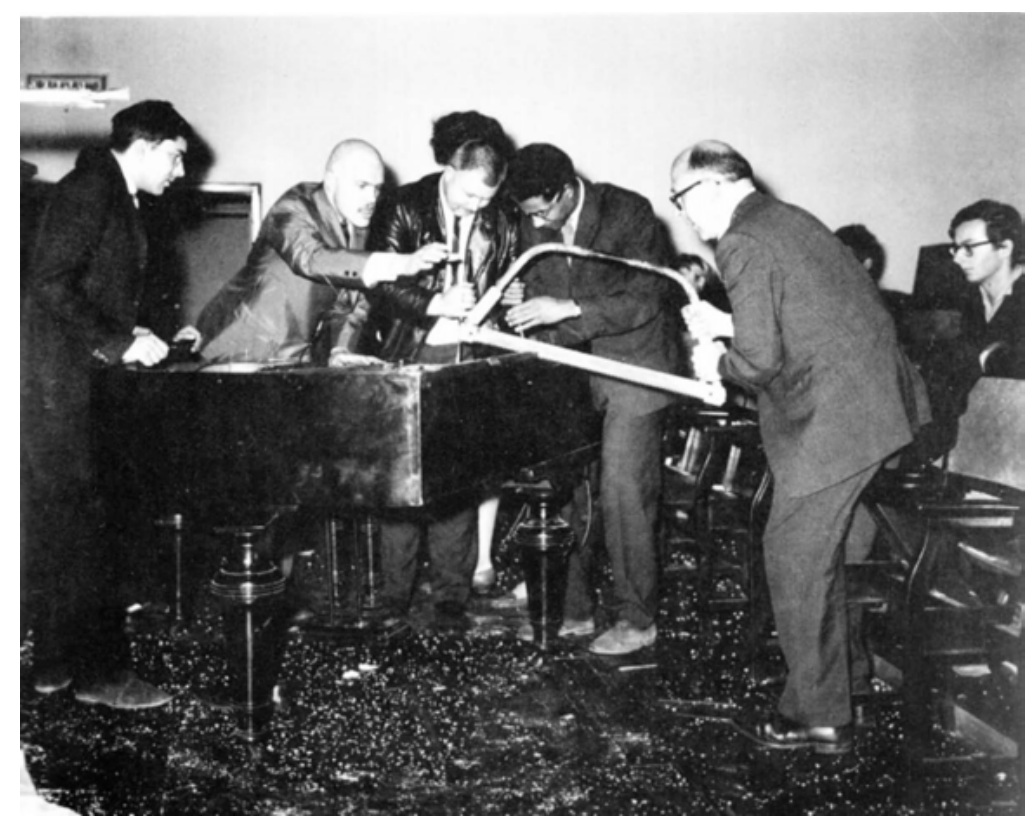

39 Mersch: Vom Werk zum Ereignis.

40 Jacques Lacan: »Subversion des Subjekts und Dialektik des Begehrens im Freudschen Unbewußten«, in Ders.: Schriften II, Olten 1975, S. 167-204. 
Die Zerstörungswut der Fluxus-Bewegung erinnerte nicht nur an historische Vorläufer der Aktionskunst wie den Futur- und Dadaisten ${ }^{41}$; Sabine Sanio erkannte in der Ästhetisierung des Destruktiven auch Vorboten der Studentenbewegung und ihrer politischen Revolten:

»Die Kritik an der bürgerlichen Kultur prägt seit den 60er Jahren neoavantgardistische Strömungen wie Happening, Fluxus und Performance, in denen das alltägliche Leben erneut das zentrale Thema der künstlerischen Aktivitäten bildet. Happening und Performance wirken im Rückblick wie die Vorboten der Studentenrevolte mit ihren happeningartigen Aktionen, Demonstrationen und Sit-ins. « $^{42}$

Die Aktionskünstler nutzten die Praktiken der Straßendemonstrationen, indem sie ihre >Anti-Kunst $८$ symbolisch aufluden und performativ umsetzten. Gianmario Borio machte in diesen ästhetischen Strategien Merkmale gesellschaftlicher Kommunikationsweisen aus:

»Der ästhetische Schwerpunkt verlagerte sich vom Kunstwerk als produziertes Objekt auf die Vermittlungsweisen von Kunst als Handlung, als Motor oder Umfunktionierung der gesellschaftlichen Kommunikation, als Quelle einer >totalen Erfahrung.${ }^{43}$

Das szenisch-performative Element kann als paradigmatische künstlerische Ausdrucksform der 1960er angesehen werden, indem hier die Konventionen des traditionellen Konzertbetriebs stellvertretend für die gesellschaftlichen Normen bloßgestellt wurden. Gast beim Wiesbadener Festum Fluxorum war auch Dieter Schnebel. Gegen die Sprengkraft dessen szenischer Aufführungskonzepte machte 1968 der Spiegel in einer Konzertkritik aufschlussreiche Bemerkungen:

»[W]o Musik so offensichtlich gegen die Konsumgewohnheiten verstößt, muß es zum Skandal, zum Konflikt zwischen fortgeschrittener Musik und reaktionärer Gesellschaft kommen. Schnebel, Befürworter der Studenten-Revolte, militanter Gegner der Notstandsverfassung und verhinderter KP-Wähler, hat diese >Réactions` (Titel des Stücks) [...] bereits komponiert. In diesem >Konzert für einen Instrumentalisten und Publikum২, [...] darf der Spieler unter anderem das Publikum so lange reizen, bis es tobt. Falls die Konzertbesucher nicht vorzeitig den Saal verlassen, muß der Instrumentalist sodann den Skandal umfunktionieren. [...] Sylvano Bussotti beispielsweise, der in Padua >Réactions` provozierte, funktionierte so: Er kratzte mit Glassplittern und Metallspitzen im Flügel herum und schrieb, als das Auditorium zu meutern begann, in riesigen Lettern BAST an eine Wandtafel, hielt dann inne, blickte ins Parkett - und das Protestgeschrei ging in ein langgezogenes AAA über: BASTA - genug davon. ${ }^{44}$

41 Siehe hierzu im Kapitel Referenzen und Chiffren den Abschnitt Die Krise der Jahrhundertwende und das Schlüsseljahr 1913.

42 Sabine Sanio: »Aspekte einer Theorie der auditiven Kultur«, in: kunsttexte (4/2010), S. 5. Online abrufbar unter URL: http://edoc.hu-berlin.de/kunsttexte/2010-4/sanio-sabine-2/ PDF/sanio.pdf [Zugriff: 31.8.2017].

43 Borio: Avantgarde als pluralistisches Konzept, S. 30ff.

44 NN: »Ho-Ho-Ho«, in: Der Spiegel 45 (4.11.1968), S. 174-177, hier S. 175. 
Wenn Dieter Schnebel mit avancierten ästhetischen Mitteln seiner Politisierung Ausdruck verlieh, war der musikalische Umgang mit den politischen Zeichen der Zeit doch höchst unterschiedlich und oft auch konfliktreich: »Entscheidend für die Beurteilung, ob etwas revolutionär sei oder nicht«, so Clythus Gottwald, »war [...] nicht der kompositorische Stand der Musik, sondern die Gesinnung des Komponisten. ${ }^{45}$ Innerhalb des linken Lagers kam es zu mitunter eklatant geführten Kontroversen: während einige Komponisten ästhetische Radikalität als Ausdruck politischer Revolte verstanden, forderten andere eine leicht verständliche Musik für die Massen. In seinem Radio-Essay Autonome Kunst politisch griff Dieter Schnebel 1971 diese schwelende Debatte auf:

»Also wird [...] um der gesellschaftlichen Wirkung willen und auch um die Einstimmung breiterer Massen zu erreichen [gefordert], auf autonome Gestaltung von Kunst zu verzichten; etwa indem ein Komponist statt fortgeschrittener Kompositionstechnik ältere anwendet, etwa indem er die komplexere Emotionalität neuer Kunst preisgibt und auf einfache Gefühlstönungen zurückgreift; etwa indem man Kunst, statt diffusen Strebungen nachzugeben, auf drastische politische, ja agitatorische Willensäußerungen bringt. ${ }^{46}$

Schnebel Fazit lautete: Musik, die zum Zweck politischer Verständlichkeit die Kompositionstechnik zurücknehme, bediene reaktionäre Denkweisen. Politisch engagierte Musik stand vielen avancierten Komponisten für ein ästhetisch retardierendes Moment und geriet deshalb an den Zentren der Neuen Musik mit ihren paradigmatischen, normativ und dogmatisch vertretenen Axiomen >Innovation< und >Fortschritt unter Generalverdacht. Nichtsdestotrotz schlugen sich auch bei den Musiktagen in Donaueschingen und besonders bei den Darmstädter Ferienkursen für Neue Musik die politischen Zeichen der Zeit nieder - wenn auch mit einiger Verzögerung.

\section{Politisierung im Elfenbeinturm: Darmstadt im `Krisenjahr 1970،}

Bei den Internationalen Ferienkursen für Neue Musik in Darmstadt, so konstatierte der Musikwissenschaftler Frank Hentschel, »fürchtete man nichts so sehr wie eine Politisierung. $\ll^{47}$ 〉Engagierte Musik $\iota$, so lautete die verbreitete Lehrmeinung am autonomieästhetischen Nucleus der westlichen Avantgarde, schade der künstlerischen Qualität und drapiere Gedankenlosigkeit. ${ }^{48}$ Karlheinz Stockhausens kann auch für diese Tendenz als Schlüsselfigur gelten, was sich in seiner von Pfiffen begleiteten Aussage im Rahmen einer Vollversammlung der Teilnehmer bei den Ferienkurse 1970 spiegelt:

45 Gottwald: Der religiöse Aufruhr, S. 304.

46 Dieter Schnebel: »Autonome Kunst politisch. Über einige Sprachbarrieren«, in Ders.: Denkbare Musik. Schriften 1952-72, Köln 1972, S. 474-488, hier S. 477.

47 Zitiert nach Albrecht Dümling: »Gegen die affirmative Funktion von Musik«, in: Neue Musikzeitung (7/2008).

48 Diese Meinung vertrat Carl Dahlhaus in seinem Vortrag »Politische und ästhetische Kriterien der Kompositionskritik bei den Darmstädter Ferienkursen 1972«, publiziert bei Ernst Thomas (Hg.): Darmstädter Beiträge zur Neuen Musik, Band 13, Mainz 1972, S. 14-27. 
$»$ Ich bin gefragt worden, was ich von politisch engagierter Musik halte [...]: wenn sie gut ist, kann sie von mir aus Mao Tse Tungs kleine Zehen besingen. Aber mich interessiert überhaupt nicht, ob sie politisch engagiert ist oder nicht. $\ll^{49}$

Wenngleich Karlheinz Stockhausen also der autonomieästhetischen Strömung der Avantgarde entsprach, steuerte er doch mit der Affäre um sein sogenanntes Vietnam Tamtam eine Anekdote zur Politisierung der Musik bei. Im Juni 1968 gab der Komponist und Leiter des Elektronischen Studios am WDR im Wiener-Brahms-Saal ein Konzert, bei dem ein Tamtam - ein überdimensionierter Gong - in den Mittelpunkt der Debatten rückte. Unter dem Eindruck der weltpolitischen Ereignisse hatte Karlheinz Stockhausen in großen Kreidelettern das Wort »Vietnam« auf die Frontseite des riesigen Instruments mit einem Durchmesser von $155 \mathrm{~cm}$ geschrieben. Trotz der Intervention durch die veranstaltende Gesellschaft für Musikfreunde weigerte sich der Komponist, die politisch brisante Beschriftung zu entfernen und provozierte damit nicht nur die Wiener Presse ${ }^{50}$, sondern auch eine Beschwerde der Musikfreunde beim WDR. Der Vorfall wurde vom Intendanten Karl Koch an den Hörfunkdirektor Dr. Brühl weitergetragen ${ }^{51}$, woraufhin dieser den Komponisten ermahnte: »Zu unserer Bestürzung haben wir [...] erfahren [...], daß Sie in ähnlicher Form schon in früheren Konzerten sich glaubten politisch engagieren zu sollen. $\aleph^{52}$ Karlheinz Stockhausen erwiderte:

»Was meinen Sie eigentlich mit politischer Propaganda? In Vietnam werden mehr Kinder verbrannt, verwundet, umgebracht als Soldaten [...]. Es ist wichtig, daß wir [...] unsere Mitmenschen daran erinnern. Ein >rein musikalisches Ereignis [ [...] gehört nicht mehr in unsere Welt. Die Musik hat lange genug dazu gedient, ein Land der Illusionen getrennt vom Leben darstellen zu müssen. ${ }^{53}$

Zeigte der Komponist also durchaus Anzeichen der zeithistorischen Politisierung, ist sein Schaffen doch in einem autonomen Bereich singulärer Ästhetik zu verorten. Es ist daher kein Zufall, dass das Ende seiner Darmstädter Tätigkeit mit dem gesellschaftspolitischen Einbruch der Wirklichkeit bei den Ferienkursen zusammenfällt: 1970 probten politisierte Studenten in einer Vollversammlung den Aufstand, dem Karlheinz Stockhausen als 〉letzter König`von Darmstadt zum Opfer fiel. Wurde diese Entwicklung bereits im Kapitel Agon und Skandal nachgezeichnet ${ }^{54}$, sollen im Folgenden speziell die kontroversen Debatten um politisch engagierte Musik im Darmstädter $>$ Krisenjahrgang 1970 « herausgearbeitet werden.

49 Protokoll der Vollversammlung der Ferienkursteilnehmer am 03.09.1970, in IMD: A100111-201270-14.

50 F.T.: »Tamtam«, in: Die Presse (10.6.1968); N.N.: »Vietnam-Tamtam«, in: Kurier (10.6.1968).

51 Brief des Intendanten Karl O. Koch an den Hörfunkdirektor Dr. Brühl (11.6.68), in WDR: 04060.

52 Brief von Dr. Brühl an Karlheinz Stockhausen (3.7.1968), in WDR: 04060.

53 Brief von Karlheinz Stockhausen an Dr. Brühl (8.7.1968), in WDR: 04060.

54 Siehe hier besonders den Abschnitt: Der Absolutismus der Moderne: Die Revolution frisst ihre Kinder. 
Auf der Agenda der Vollversammlung, die am letzten Tag der Darmstädter Ferienkurse 1970 zusammenkam, standen unverkennbar von der Studentenbewegung inspirierte, und auf die Musikavantgarde übertragene Themen: Demokratisierung, Internationalisierung und Ent-Hierarchisierung. Die Transkription der Debatte ${ }^{55}$ gibt weitere Charakteristika jener Jahre preis: Mit den vielen verzeichneten Zwischenrufen wird auf einer ersten Ebene der von den studentischen Straßenprotesten inspirierte Charakter eines \Sit-Ins` sowie eine ganz spezifische Diskussionshaltung deutlich, die sich passend zu den Internationalisierungsplänen zweisprachig auf Deutsch und Englisch äußerte. Inhaltlich konkret wurde die Debatte mit der Diskussion von Alternativen zur gesellschaftlich isolierten Behandlung von Musik. Solche wurden nicht nur in politisch motivierten Kompositionen, sondern auch in der Pop-Musik vermutet und damit zwei entscheidende musikhistorische Entwicklungen der 1960er Jahre aufgegriffen.

Auch in diesem Punkt muss einmal mehr Karlheinz Stockhausen herangezogen werden, der an der Debatte teilnahm und die beiden zeithistorisch aktuellen Strömungen dem autonomieästhetischen Charakter der Avantgarde gegenüberstellte: »Es hat sich gezeigt, dass wir den Pop-Musikern [...] enorm viel zeigen können [...], aber wir passen irgendwie fachlich nicht zusammen. Dazu sind wir zu intellektualisiert.« Ähnlich verhalte es sich mit den »Free-Jazz-Leuten«, die lediglich »versuchen, die extremsten Produkte der Neuen Musik einfach zu imitieren.« Ähnlich äußerte sich Stockhausen über politisch engagierte Komponisten, gegen deren Ästhetik selbst Musik »aus dem vordritten Reich noch höchste Klasse« sei:

»Wenn Sie hier anfangen mit politischen Geschichten, dann bin ich das letzte Mal hier gewesen. [...] Ich sage Ihnen nur, wenn hier eine Umfunktionierung stattfinden soll der künstlerischen Ambitionen in politische Geschichten. Sie wollen ja Leute engagieren, nur weil sich jemand politisch festgelegt hat und nicht wegen ihrer musikalischen Qualität [...]. Wenn hier die Qualität runtergeht, und sie wählen Leute, nur weil sie gut reden können oder politisch festgelegt sind, dann habe ich hier nichts mehr zu suchen. ${ }^{56}$

Dieser Meinung war insbesondere der marxistische Musikkritiker Reinhard Oehlschlägel, der Stockhausen vorwarf, Musik für »reiche Kapitalisten« zu machen und monopolistisch seine Ästhetik durchsetzen zu wollen - er rüttelte also an der in den 1950er Jahren etablierten Hierarchie der `Darmstädter Schule`, an deren Spitze Karlheinz Stockhausen thronte. Nachdem dieser die Versammlung wegen eines Kompositionskurses verließ - und damit auch einen symbolischen Abgang hinlegte - diskutierte die Versammlung die Wahl und Ausrichtung eines Gremiums zur Vertretung der Studentenschaft, wobei zeittypische Praktiken der 68er-Bewegung aufgegriffen wurden. In seinem Wahlplädoyer bezog sich der Komponist Peter Michael Hamel explizit auf den Querstand von Kunst und Gesellschaft: »Das muss ich also ganz laut betonen. Wer meint, dass Musik und Politik nichts miteinander zu tun haben, der sollte mich nicht wählen.«

55 Protokoll der Vollversammlung der Ferienkursteilnehmer am 03.09.1970, in IMD: A100111-201270-14. Alle folgenden Zitate beziehen sich, soweit nicht anders gekennzeichnet, auf dieses Dokument.

56 Ebd., S. 82f. 
In der Folge erarbeitete die Delegation eine Resolution, in der es hieß, »daß die Teilnehmer eine Fortsetzung der bisherigen Programmpolitik [...] nicht länger hinnehmen werden. ${ }^{57}$ Hamel notierte im Anschluss euphorisch:

»Es tut sich was! Zwei mehrstündige, spontane Vollversammlungen führen zu Mitbestimmungsforderungen der Teilnehmer, zur Wahl einer Delegation von Dozenten, Komponisten, Journalisten und Studierenden (!) [...]. Es wurde ein Resümee der Veränderungs- und Konzeptionswünsche veröffentlicht, das sich [...] immer noch revolutionär und innovativ anhört: Teamwork- und Kollektivkomposition werden gewünscht, Improvisationsgruppen [...] sowie elektronische und Computer-Musik werden gefordert, Grenzgebiete sollen einbezogen werden $[\ldots]$, mehr Demokratisierung wird verlangt. ${ }^{58}$

Überprüft man die Quellenlage, scheinen Peter Michael Hamels Erinnerungen von einer gewissen Romantisierung getüncht. Er selbst gestand ein, »dass über all dem [...] damals dieses mich heute beschämende Pathos, das verbissen Besserwisserische lag. ${ }^{59}$ Tatsächlich musste die Delegation im Dezember 1970 bei einer Unterredung mit Ernst Thomas, dem Leiter der Darmstädter Ferienkurse, erfahren, nicht als offizielles Mitbestimmungsorgan anerkannt zu werden. ${ }^{60}$

Auch Hans G Helms, der ideologiekritische Schriftsteller und Teilnehmer der Vollversammlung, sprach in einer WDR-Produktion 1972 also zurecht von einer $»$ misslungenen Revolution ${ }^{61}{ }^{-}$und doch hatten die Ereignisse ein Nachspiel: Nach einer Resolution der Vollversammlung ${ }^{62}$ beraumte der offizielle Programmbeirat für Mai 1971 eine Sitzung an, in der auch die »angebliche Krise« auf die Tagesordnung gesetzt und auf die »Gefahr einer Aufwertung des Komitees« infolge der medialen Berichterstattung hingewiesen wurde. ${ }^{63}$ Aus »Furcht vor einer unfruchtbaren Politisierung der Kurse«, so schrieb Ernst Thomas in einem Brief an den Oberbürgermeister Darmstadts, habe man »beschlossen, den Mitbestimmungsforderungen nicht zu entsprechen. ${ }^{64}$

57 Resolution der Vollversammlung der Teilnehmer und Dozenten der Ferienkurse 1970, in IMD: A100111-201272-12.

58 Peter Michael Hamel: »Politisches Komponieren damals und heute. Persönliche Rückblicke und Einsichten«, in Ders.: Ein neuer Ton. Ausgewählte Schriften zu einer ganzen Musik, München 2007, S. 93-105, hier S. 94.

59 Ebd., S. 99.

60 Max E. Keller: »Gedächtnisprotokoll der Unterredung vom 1. Dezember 1970 zwischen Winfried Sabais (Kulturdezernent der Stadt Darmstadt), Ernst Thomas (Leiter des IMD), den Musikkritikern Ernstalbrecht Stiebler und Reinhard Oehlschlägel sowie Beauftragten der Teilnehmerdelegation“, in: Privatarchiv von Max E. Keller.

61 Helms, Hans G: »Dokumentation einer misslungenen Revolution. Internationale Ferienkurse für Neue Musik Darmstadt, 23.8.-4.9. 1970“, in: Westdeutscher Rundfunk (1972).

62 Resolution der Vollversammlung 1970, in IMD: A100111-201272-12.

63 Vorbereitende Sitzung des Programmbeirats der Ferienkurse zur Dozententagung im August 1971 am 27./28.05.1971, in IMD: A100118-201330-12.

64 Brief von Ernst Thomas an Heinz Winfried Sabais (4.6.1971), in IMD: A100062-20204613. 
Mit ästhetischem Fokus zielte der Musikwissenschaftler Carl Dahlhaus 1972 in seinen »Thesen über engagierte Musik« gegen die aufständischen Ferienkursteilnehmer:

»Der Begriff der engagierten Musik ist zwiespältig. Und wegen der trügerischen Prägnanz, durch die er besticht, [...] taugt die Vokabel zum Schlagwort, mit dem sich Gedankenlosigkeit drapiert. [...] Entweder verfällt sie, um des politischen Effekts willen, der Trivialität. Oder sie opfert der musikalischen Integrität die politische Wirkung. ${ }^{65}$

Zwar übertünchten die Verantwortlichen die politische Sprengkraft der Ereignisse mit ästhetischen Argumenten, doch zogen die Konflikte 1972 weitere Kreise, als verschiedene Medien publik machten, dass einige der Unruhestifter von 1970 für ihr »unseriöses berufliches Verhalten, mangelnde Objektivität, böswillige publizistische Verdrehungen, Aufwiegelei, Brunnenvergiftung, Verstöße gegen ihre berufliche Moral ${ }^{66}$ von den Ferienkursen ausgeschlossen worden waren. Die Betroffenen sprachen daraufhin öffentlich und zeittypisch »von Affront, von Vorenthaltung elementarer Grundrechte, von schwerem Verstoß gegen die Meinungs-, Informations- und Pressefreiheit, von Gefährdung der Demokratie. ${ }^{67}$ Der Schweizer Komponist Max E. Keller war einer der aus Darmstadt Verbannten, nachdem er in der National-Zeitung Basel seine Sicht auf die Ereignisse des Krisenjahrgangs 1970 publiziert hatte. ${ }^{68}$ Noch aufschlussreicher sind seine »Darmstädter Geschichten«, in denen er seine Suspendierung infolge der Unterzeichnung des Forderungsblattes der Teilnehmerdelegation $1970^{69}$ durch den Programmbeirat im typischen Jargon der Zeit skizzierte.

»Ich will nicht, da Gruppe >Polit. Musik^ um 12 Uhr tagt. Es sei dringend. Ich willige ein. [...] Im Büro [Ernst] Thomas am Schreibtisch. [...] Ich vor Thomas' Schreibtisch. Thomas im Verhörton: Wer hat das geschrieben? [...] Sie wollen mich mürbe machen [...]. Ich [...] beharre auf meinem demokratischen Grundrecht. [...] Nun wird es härter. In Demokratien sind sie halt eben schwach. [...] Stellen dann Alternative: a) Rückzug meiner Unterschrift, b) Ausschluss von den Kursen [...]. [Wilhelm] Schlüter gibt mir eine Stunde Zeit, das Zimmer zu räumen (immer scheiss-freundlich). $\ll^{70}$

65 Carl Dahlhaus: »Thesen über engagierte Musik«, in: Neue Zeitschrift für Musik (1/1972), S. 3-8, hier S. 3.

66 N.N.: »Skandal?«, in: Frankfurter Allgemeine Zeitung (Datum unbekannt; aus dem Privatarchiv von Max E. Keller).

67 Reinhard Oelschlägel: »Dabeisein \& Dafürsein«, in: Frankfurter Rundschau (Datum unbekannt; aus dem Privatarchiv von Max E. Keller); Wolfgang Ignée: »Die Moral von Darmstadt. Zum Hinauswurf unliebsamer Kritiker«, in: Stuttgarter Zeitung (3.8.1972); N.N. »Hausverbot für Journalisten«, in: Darmstädter Echo (1.8.1972); G. A. Trumpf: »Diskussion über die Ferienkurse«, in: Darmstädter Echo (2.8.1972).

68 Max E. Keller: »Seltsame `Demokratien« in Darmstadt«, in: National-Zeitung Basel (16.8.1972).

69 »Brief der Teilnehmerdelegation an Ernst Thomas« (9.11.1970) und »Resumé von Wünschen und Vorschlägen der Teilnehmer«. Beide Dokumente finden sich im Privatarchiv von Max E. Keller.

70 Max E. Keller: »Darmstädter Geschichten« (30.07.1972), handschriftliche Notizen aus dem Privatarchiv des Komponisten. 
Trotz solcher Maßnahmen entluden sich die Konflikte zwischen autonomer und engagierter Musikauffassung auch im Ferienkurs-Jahrgang 1974. Wieder war es Karlheinz Stockhausen, der durch die Verbannung marxistischer Studenten aus seinem Kompositionsseminar wütende Reaktionen und polemische Pamphlete provozierte. In einem Brief linksorientierter Kompositionsstudenten um Gerhard Stäbler wurde Stockhausen »faschistischer Methoden« bezichtigt. Man habe »außerordentlich reiche und tiefe Eindrücke in das reaktionäre Wesen der Avantgarde « gewonnen. ${ }^{71}$ In einem weiteren Handout bemerkten dieselben Verfasser: »Wäre Stockhausen Politiker, hätten wir einen Diktator mehr in der Welt« und zitierten Mao Tse-tungs kulturrevolutionäre These, es sei »für Künstler, die hartnäckig an ihren individualistischen und kleinbürgerlichen Positionen festhalten, unmöglich, den werktätigen Massen wirklich zu dienen. ${ }^{72}$

Der Querstand von Kunst und Politik sowie der Konflikt um autonome und engagierte Musik spaltete die Avantgardegemeinde nachhaltig. ${ }^{73}$ Dennoch blieben die Darmstädter Ferienkurse in der historischen Gesamtschau weiterhin einem autonomieästhetischen Innovationsimperativ verpflichtet. Wenn man sich auch nicht gänzlich den gesellschaftlichen Tendenzen der Politisierung verschließen konnte, so waren diese doch nur ein Schatten im Vergleich zu dem, was politisierte Komponisten jenseits des Elfenbeinturms vor bildungsbürgerlichem Publikum veranstalteten. Dabei kristallisierte sich die Oper als Schlüsselmedium engagierter Musik und ihrer gesellschaftlichen Provokationskraft heraus.

\section{Das Musiktheater: >BÜhnen der Politikı}

Dass das Musiktheater zum Schlüsselmedium des politischen Musikskandals der 1960er Jahre wurde, hat vielfältige und wiederum gleichermaßen ästhetisch wie gesellschaftlich konnotierte Ursachen - auch hier wird also der charakteristische Querstand von Kunst und Politik in den 1960er Jahren deutlich: Die musikalische Gattung wie auch die Institution 〉Oper〈 bargen als Inbegriff des bürgerlichen Establishments und sinnbildliche Repräsentation gesellschaftlicher Hierarchisierungen beträchtliche Symbol- und Sprengkraft. Hans Werner Henze, ein Protagonist dieser Geschichte, erläuterte diesen Zusammenhang 1990 rückblickend:

»Offenbar entsprechen die hierarchische Gliederung eines Opernhauses mit den verschiedenen Logen und Rängen und dem Parkett, wo früher die Lakaien stehen durften, und das überholte Herrschaftsdenken des Opern-Establishments nicht mehr den neuesten Ideen und Vorstellungen unseres Jahrhunderts. Wir haben ja Republiken, Demokratien. ${ }^{74}$

71 Brief von Jürgen Lösche, Johannes Vetter und Gerhard Stäbler an das Internationale Musikinstitut Darmstadt vom (4.9.1974), in IMD: A100112-201279-18.

72 Dies.: »Verpackungskünstler Stockhausen« (1974), in IMD: A100112-201279-19.

73 Siehe weiterführend Klaus Trapp: >Darmstadt und die 68er-Bewegung«, in Internationales Musikinstitut Darmstadt (Hg.): Von Kranichstein zur Gegenwart. 50 Jahre Darmstädter Ferienkurse, Darmstadt 1995, S. 369-375, hier S. 374.

74 N.N.: »Immer für die Sünder«. Neutöner Hans Werner Henze über zeitgenössisches Musiktheater, in: Der Spiegel (7.5.1990), S. 243-254, hier S. 248. 
Mit seinen Möglichkeiten der multimedialen Verschmelzung von Klang, Gesang und Szene war das Musiktheater ein auch semantisch aussagekräftiges Medium: Politische Botschaften konnten hier, im Gegensatz zur absoluten Musik, mit szenischen und sprachlichen Ausdrucksformen vermittelt und Zensur durch inszenatorische Verschlüsselung umgangen werden. Aus diesen Gründen wurden Opernaufführungen, wie es Sven-Oliver Müller und Jutta Toelle so anschaulich wie treffend formulierten, zu »Bühnen der Politik ${ }^{75}$.

Was Müller und Toelle für die soziale Verfasstheit der Oper seit dem 19. Jahrhundert herausarbeiteten, lässt sich zum großen Teil auch auf das avantgardistische und politische Musiktheater der 1960er Jahre übertragen und analytisch nutzbar machen: Weil der Rahmen von Opern über den bloßen Kunstgenuss hinausweise, so eine ihrer Thesen, ergäben sich neben musikwissenschaftlichen auch neue historische Perspektiven. Die Oper stelle über ihre ästhetische Form hinaus »einen öffentlich wirksamen und politisierbaren Kommunikationsraum zur Verfügung « und generiere so die »Relevanz einer Untersuchung des Politischen in einer kulturgeschichtlichen Perspektive«, die sich »durch das Zusammenspiel zwischen musikalischen Reizen, kulturellen Bedingungen und der gesellschaftlichen Rezeption« ergebe. Opernaufführungen können in diesem Sinne als sensible Indikatoren für das mehrheitsfähige historische Wissen ihrer Zeit gelesen werden: »Sie sind gleichermaßen Produkte wie Momentaufnahmen der sie umfassenden gesellschaftlichen Vorgänge. ${ }^{76}$ Sozialhistorisch betrachtet kann man die Oper, auch in Anlehnung an die australische Kulturwissenschaftlerin Ruth Bereson ${ }^{77}$, sowohl als Institution, als Aufführung wie auch architektonisch als Teil einer impliziten und expliziten Herrschaftsstrategie regierender Eliten begreifen:

»Das Genre Oper und der soziale Raum Opernhaus begünstigten die öffentliche Inszenierung idealer politischer Verhältnisse und Beziehungen. Das gibt Herrschenden die Möglichkeit, [...] ihre Macht zu legitimieren. [...] Auch in der Architektur eines Opernhauses wird Macht durch ihre Darstellung legitimiert. Das geschmückte Auditorium, die reich dekorierten Logen, Treppenhäuser und Foyers versinnbildlichen [...] die glänzende Welt der Mächtigen. Auch die kulturellen Rituale im Auditorium und die sozialen Trennlinien [...] können dazu beitragen, politische Gesellschaftsentwürfe zu verfestigen. [...] Der festliche öffentliche Raum der Oper versprach Herrschaft zu legitimieren, wie umgekehrt politische Phänomene einer wirkungsmächtigen Inszenierung bedurften. ${ }^{78}$

Allerdings gaben Opern nicht nur den Herrschaftseliten die Möglichkeit sich aufmerksamkeitswirksam in Szene zu setzen, sondern auch dem bürgerlichen Publikum. Dieses Potential zu öffentlicher Meinungsäußerung und Kritik manifestierte sich nicht selten durch Saalschlachten, die in diesem Sinne als symbolische Kulturkämpfe verstanden werden können:

75 Sven Oliver Müller/Jutta Toelle (Hg): Bühnen der Politik. Die Oper in europäischen Gesellschaften im 19. und 20. Jahrhundert, Wien/München 2008.

76 Ebd., S. 16.

77 Ruth Bereson: The Operatic State: Cultural Policy and the Opera House, London 2002.

78 Müller/Toelle: Bühnen der Politik, S. 14f. 
»Die europäische Kulturgeschichte [...] kennt zahlreiche Beispiele lautstarker und zuweilen gewaltsamer politischer Demonstrationen im Zuschauerraum. [...] Da die Oper ein wichtiger und öffentlich zugänglicher Raum war, ließen sich hier politische Positionen einerseits relativ ungehindert, andererseits überaus breitenwirksam verkünden. Gerade in Zeiten politischer Spannungen und Repressionen konnten oppositionelle Gruppen im Opernhaus alternative politische Ordnungsvorstellungen demonstrieren. [...] Die Akteure in diesen vermeintlich rein ästhetischen Stellvertreterkriegen konnten hoffen, in und durch die Oper politischen Wandel zu forcieren. ${ }^{79}$

Dies gilt auch und gerade für das 20. Jahrhundert, als die augenscheinlich elitäre Kunstform Oper unter einen neuen demokratischen Anpassungsdruck gesetzt wurde. Hierzu lieferte Sven-Oliver Müller in seinem Aufsatz zu Saalschlachten in Londoner Opernhäusern im 19. Jahrhunderts ${ }^{80}$ Stichpunkte, die auch mit Blick auf die 1960er Jahre relevant sind. Man dürfe das Publikumsverhalten nicht allein als Reaktion auf musikalische Reize verstehen, sondern vielmehr als Ausdruck kultureller Überzeugungen, politischer Ordnungsvorstellungen sowie als Indikator für die Verschiebung gesellschaftlicher Normen des geltenden Geschmacks und sozialer Regeln:

$»$ Unruhen im Opernhaus [...] waren oft bewusst zur Schau gestellte Emotionen im Zuge von kulturellen Demonstrationen und politischen Deutungskämpfen. Den Raum Oper nutzten verschiedene politische, soziale und ethnische Gruppen, um ihre Interessen öffentlich zu bekunden. Vermeintlich spontan-emotionale Operntumulte und augenscheinlich rein ästhetische Angelegenheiten konnten so eine mächtige politische Sprengkraft erlangen. ${ }^{81}$

Will man die Rezipienten sowie ihre Gefühle und performativen Praktiken thematisieren, ist die Tatsache entscheidend, dass das Publikumsverhalten keine anthropologische Konstante, sondern historischen Wandlungsprozessen unterworfen ist. So waren lebhafte und handgreifliche Anteilnahme am künstlerischen Geschehen bis Mitte des 19. Jahrhundert durchaus angemessene Verhaltensmuster. Erst um 1850 wurde die Zurückhaltung der Gefühle im abgedunkelten Saal zu einer Regel des Anstands, was der Kulturhistoriker Peter Gay als »The Art of Listening ${ }^{82}$ und Elias Canetti in Masse und Macht als >Ritual des Stockens` bezeichneten: »Jede Bewegung ist unerwünscht, jeder Laut verpönt [...], alle äußeren Reaktionen [...] unterbleiben. ( $^{83}$

79 Ebd., S. 18f.

80 Sven Oliver Müller: »Saalschlachten. Ausschreitungen in Londoner Opernhäusern in der Mitte des 19. Jahrhunderts«, in Müller/Toelle: Bühnen der Politik, S. 160-176.

81 Sven Oliver Müller: »Distinktion, Demonstration und Disziplinierung. Veränderung im Publikumsverhalten in Londoner und Berliner Opernhäusern im 19. Jahrhundert«, in: International Review for the Aesthetics and Sociology of Music (37/2006), S. 167-187, hier S. 171.

82 Peter Gay: »The Art of Listening«, Vorwort zu: The Naked Heart (The Bourgeois Experience: Victoria to Freud), New York 1995, S. 1-25. Unter dem Titel fand 2012 in Berlin eine Tagung zu »Trends und Perspektiven des Musikhörens« statt, siehe weiterführend den Tagungsbericht unter URL: http://www.hsozkult.de/conferencereport/id/tagungsberichte4434 [Zugriff: 31.8.2017].

83 Elias Canetti: Masse und Macht, München 1994, S. 39. 
Wenn James H. Johnson mit kulturhistorischem Blickwinkel auf die normativen Verhaltensweisen des Hörens die Forschungsfrage stellte: »Why did [...] audiences become silent? ${ }^{84}$, wurden die Auditorien im 20. Jahrhundert zumindest in Hörweite der künstlerischen Avantgarden wieder laut. Zwar blieb Schweigen die Rezeptionsnorm und waren Unruhen der Sonderfall, aber gerade die Ausnahme von der Regel macht Saalschlachten historisch relevant und lässt die geltenden sozialen Regeln im Umkehrschluss umso deutlicher hervortreten.

Insbesondere im Umfeld von $>1968$ « boten Opern unterschiedlichen Akteuren, von den Komponisten bis zum Publikum, eine öffentliche Bühne um politische aber auch ästhetische Grundsatzfragen auszutragen. Während die einen das Musiktheater qua seiner performativen Kraft zur Sprengung von Ritualen und Konventionen im bürgerlichen Musikleben nutzten oder dieses vice versa verteidigten, forderten radikalere Komponisten ganz konkret die Detonation der überkommenen Institution. Zum »Leichenredner der modernen Oper« wurde Pierre Boulez, der 1967 vom Spiegel mit der provozierenden Forderung zitiert wurde: »Sprengt die Opernhäuser in die Luft!« Dies, so führte der Komponist aus, wäre die teuerste, aber eleganteste Lösung der musikalischen Agonie:

»Die neuen deutschen Opernhäuser sehen zwar sehr modern aus - von außen; innen sind sie äußerst altmodisch geblieben. In einem Theater, in dem vorwiegend Repertoire gespielt wird, da kann man doch nur mit größten Schwierigkeiten moderne Opern bringen - das ist unglaubwürdig. Die [...] Oper mit ihrem traditionellen Publikum hat nichts von den Veränderungen der Zeit gespürt. Sie lebt im Getto. Die Oper ist mit einer Kirche zu vergleichen, in der man höchstens die Kantaten des 18. Jahrhunderts singt. $\ll^{85}$

Wenn Boulez auch die Abhandlung von Sozialproblemen als »pittoreske Nebensache« und »Banalisierung der Musik« bezeichnete, solle man doch »ruhig eine ganze Menge Rotgardisten importieren! Vergessen Sie nicht, die Französische Revolution hat auch sehr viel kaputtgemacht, und das war sehr gesund. « Kurzum: die Opernhäuser seien >auf gut deutsch voller Staub und Scheiße« und das Publikum, »diese Operntouristen sind zum Kotzen.« Banal sei auch die kompositorische Auseinandersetzung mit dem Genre durch seine Kollegen:

»Henzes Produkte sind wahrhaft keine modernen Opern. Ich denke da immer an einen lackierten Friseur, der einem ganz oberflächlichen Modernismus huldigt. [...] Eine Beatles-Platte ist ja auch wirklich cleverer und obendrein kürzer als eine Oper von Henze. [...] Doch besonders Kagel [...] mangelt es an umfassender Theaterkenntnis. Und manchmal ist die musikalische Seite recht dünn. ${ }^{86}$

84 James H. Johnson: Listening In Paris. A Cultural History, Berkeley/Los Angeles 1995, S. 1. Siehe hierzu auch Steven Huebner: »Opera Audiences in Paris 1830-1870«, in: Music and Letters (70/1989), S. 206-225.

85 Felix Schmidt: »Sprengt die Opernhäuser in die Luft!« Gespräch mit Pierre Boulez, in: Der Spiegel (40/1967), S. 166-174, hier S. 172.

86 Ebd., S. 167. 
Mit Hans Werner Henze und Maurizio Kagel brandmarkte Boulez Komponisten, die zwei der aussagekräftigsten politischen Opernskandale der 1960er produzierten und als Fallbeispiele der Analyse von Luigi Nonos >azione szenica Intolleranza folgen. Im Winter 1968 erlitt Henzes Che Guevara gewidmetes >oratorio volgare e militare Das Floß der Medusa spektakulären Schiffbruch in Hamburg, während Kagel 1971 mit der >szenischen Komposition` Staatstheater das Jahrzehnt der politischen Opernskandale abschloss. Dass alle drei Komponisten genrebeschreibende Untertitel wählten, ist als Ausdruck einer kritischen Distanz zur Gattung Oper zu interpretieren, wie auch Thorsten Teubl in seiner Dissertation zum Musiktheater in der Krise herausarbeitete:

»Das experimentelle Kammermusiktheater entwickelt sich zu einer Art protestierenden Gegenwelt gegen den bestehenden politischen, wie auch ästhetischen und kompositionstechnischen Status Quo der Nachkriegsjahre bis in die späten 60er hinein. Die Ablehnung durch die reaktionären Kräfte war vorprogrammiert. $\ll^{87}$

Die drei exemplarischen Fallbeispiele rahmen die politische Dekade und sind gleichermaßen Zeugen der Annäherung zwischen politischer und künstlerischer Avantgarde in einer Zeit, als sich auch Musiker als `Kampftruppe` für gesellschaftlichen Fortschritt verstanden und sich in einem klingenden Klassenkampf engagierten. Nicht zufällig griffen die politisierten Komponisten auf die Gattung des Musiktheaters zurück, das nicht nur einen öffentlich wirksamen Kommunikationsraum bot, sondern in seiner charakteristischen Medienvielfalt auch ein semantisch aussagekräftiges Medium politischer Botschaften war.

Bei der folgenden Analyse wird die charakteristische Verlaufsform von Musikskandalen verdeutlicht, indem jeweils eine zeitliche Dreiteilung in ein >Vor`, ein >Während ‘ und ein >Danach ` der eklatanten Ereignisse gewählt wird. Dieser Aufbau steht auch in Analogie zu den Strukturen der Gattung Oper in ein >Vorspiel`, einen >Hauptakt` sowie ein `Nachspiel<. Die Auswahl der Fallbeispiele erfolgte nach der Relevanz und Reichweite der Ereignisse, aber auch durch den quellentechnischen Glücksfall, dass alle drei Premieren als Mitschnitte archiviert sind und damit eine exakte Rekonstruktion der tumultuösen Ereignisse ermöglichen.

\section{Klingender Klassenkampf: Luigi Nonos Intolleranza (1961)}

Luigi Nono konzipierte 1960 seine sazione szenica Intolleranza als politisches Statement gegen Rassismus, Intoleranz und staatliche Gewalt. Damit bot er den polarisierenden Kräften im postfaschistischen Italien die Bühne für einen Konzertskandal, bei dem am 14. April 1961 im venezianischen Teatro la Fenice Neofaschisten und Kommunisten sowie Anhänger traditioneller und avancierter Musik mit Trillerpfeifen, Stinkbomben und Flugblättern gegeneinander fochten.

87 Thorsten Teubl: Musiktheater in der Krise. Situationsbeschreibung und Alternativen für das Musiktheater unter besonderer Berücksichtigung der Kammeroper, Hamburg 2007, S. 182 . 


\section{Vorspiel: facismo e resistenca}

Der Skandal um Intolleranza war das Ergebnis einer langfristigen Politisierung Luigi Nonos, die der Komponist in seinen autobiographischen Mitteilungen gegenüber Enzo Restagno skizzierte:

»Als ich 1954 zum ersten Mal nach Turin ging, war ich seit zwei Jahren in der PCI eingeschrieben. Die Entdeckung Gramscis, des Ordine Nuovo, Elio Vittorinis Il Politecnico und der von Giulio Einaudi in Bewegung gebrachten Kultur hat ein anderes Gestern, ein anderes Heute, ein anderes Morgen umrissen. ${ }^{88}$

Mit dem Bezug auf Antonio Gramsci, 1921 Mitbegründer der PCI (Partito Comunista Italiano), der 1926 von den italienischen Faschisten zu einer 20-jährigen Gefängnisstrafe verurteilt wurde und 1937 an den Folgen der Haft starb, bewegte sich Nono in einem speziellen Gefüge Italiens. Gramsci schrieb Intellektuellen eine besondere Rolle für die Reform einer Gesellschaft zu, in der Kultur ein Gemeingut für alle sein sollte. Ihre Aufgabe sei es, der Arbeiterklasse die Kunst zu erschließen, denn nur eine von allen Klassen getragene Kultur könne zu einer Versöhnung innerhalb eines `historischen Blocks` (blocco storico) führen. ${ }^{89}$

Mit dem Bezug auf Gramsci war Luigi Nonos Politisierung zwar in der spezifischen Situation im Italien der Nachkriegszeit zu verorten, sie war aber auch von einer gesinnungsmäßigen Annäherung an den Osten und einer Intensivierung seiner Beziehungen mit führenden Intellektuellen und Künstlern aus den kommunistisch regierten Ländern begleitet. ${ }^{90}$ Wenn Nono auch zu den Protagonisten der westlichen Nachkriegsavantgarde gehörte und bis heute zählt, hinterfragte er im Verlauf der 1950er Jahre doch zunehmend kritisch den elitären und künstlerisch-abstrakten Anspruch der seriellen und autonomieästhetischen Darmstädter Schule und wandte sich selbst explizit politischem Komponieren zu.

1956 entstand mit Il canto sospeso, der Vertonung von Abschiedsbriefen zum Tode verurteilter Widerstandskämpfer, ein erstes politisches Schlüsselwerk Nonos. Bezeichnend ist dabei auch die Kontroverse, zu der es infolge der gesellschaftskritischen und ästhetischen Werkkonzeption mit Karlheinz Stockhausen kam, die ein Schlaglicht auf die Konflikte der Nachkriegsavantgarde zwischen autonomieästhetischen und politisch engagierten Konzeptionen wirft. ${ }^{91}$ Die Spannungen innerhalb der jungen Komponistengeneration eskalierten 1959, als Luigi Nono im Rahmen der Darmstädter Ferienkurse für Neue Musik seinen Vortrag zu »Geschichte und Gegenwart in der Musik heute« hielt und mit einem Eklat aus der `Darmstädter Schule

88 Luigi Nono: »Eine Autobiographie des Komponisten. Enzo Restogni mitgeteilt«, in Andreas Wagner (Hg.): Luigi Nono. Dokumente, Materialien, Saarbrücken 2003, S. 34-138, hier S. 70.

89 Siehe hierzu weiterführend Antonio Gramsci: Gefängnishefte, 10 Bände, Hamburg 2012.

90 Siehe hierzu weiterführend Christian Storch/Birgit Wertenson (Hg.): Luigi Nono und der Osten (Musik im Metrum der Macht), Mainz 2015.

91 Kristin Peukert: Der Konflikt um Luigi Nonos »Il canto sospeso«, Berlin 2001. 
ausschied. ${ }^{92}$ In seinem Referat forderte der Italiener die gesellschaftskritische Indienstnahme der Musik und kritisierte seine geschichts- und politikvergessenen Kollegen. Insbesondere griff er John Cage an, dessen aufsehenerregenden und folgenreichen Darmstädter Vorträge über aleatorische Kompositionsverfahren er im Jahr zuvor erlebt und vehement abgelehnt hatte. Der Amerikaner, so Nono, setze den »Zufall und seine akustischen Produkte als Erkenntnis an die eigenen Entscheidungen« und dieser Ansatz berge die Gefahr, »Komposition mit Spekulation zu verwechseln. ${ }^{93}$ Der Disput eröffnet Einblicke in die divergierenden Vorstellungen vom kulturellen Fortschritt in einer transnationalen Musikkultur und speziell zwischen der Alten und der Neuen Welt. ${ }^{94}$ Während der Italiener den Amerikaner in seinem Darmstädter Vortrag persönlich angriff ${ }^{95}$, kritisierte Nono implizit auch seine europäischen Komponistenkollegen und forderte diese auf, den autonomieästhetischen Elfenbeinturm zu verlassen und sich der historischen Verantwortung zu stellen:

»In selbstgefälliger, naiver Ahnungslosigkeit ist man nun dabei, das zusammengebrochene europäische Denken von seinem Katzenjammer zu erlösen, indem man ihm die resignierte Apathie des Es ist ja alles egal in der gefälligen Form des ICH bin der Raum; ICH bin die Zeit als moralische Auffrischung vorsetzt und ihm damit erspart, sich seiner geschichtlichen Verantwortung und seiner Zeit stellen zu müssen. ${ }^{96}$

Ganz eindeutig war diese Kritik gegen Karlheinz Stockhausen gerichtet, der die Komponenten Raum und Zeit als musikalische Parameter erschloss. ${ }^{97}$ Luigi Nonos Vortrag war ein wohlkalkulierter Affront gegen den in Darmstadt vorherrschenden unpolitischen Experimentiergeist und ging weit über rein fachliche oder ästhetische Aspekte hinaus. In einem Brief an Wolfgang Steinecke, den Leiter der Darmstädter Ferienkurse, bezeichnete Nono sein Statement im Anschluss an die Kontroversen als das Wichtigste, was 1959 in Darmstadt gesagt worden sei; die Bedeutung lasse sich an den wütenden Reaktionen ablesen. Zu Recht, so Nono, habe sich Karlheinz Stockhausen von dem Vortrag angegriffen gefühlt und sei dementsprechend aggressiv aufgetreten ${ }^{98}$ [Abbildung 25].

92 Luigi Nono: »Geschichte und Gegenwart in der Musik heute« (1959), in Jürg Stenzl (Hg.): Luigi Nono. Texte, Studien zu seiner Musik, Zürich 1975, S. 34-40.

93 Luigi Nono: »Gitterstäbe am Himmel der Freiheit«, in: Melos 27 (3/1960), S. $74 f$.

94 Siehe hierzu ausführlich das Kapitel Transkulturelle Transfers.

95 David Tudor berichtete John Cage in einem Brief vom 8. Oktober 1959 von Luigi Nonos Vortrag: »Nono was just a shadow in the corner and hoped to gain everything with violence. [...] It was all quite obvious, unfortunate and disgusting «, in: Northwestern University Music Library: John Cage Correspondence Collection.

96 Nono: Geschichte und Gegenwart, S. 36f.

971956 hatte Karlheinz Stockhausen mit der fünfkanaligen Tonbandkomposition Gesang der Jünglinge die erste Raummusik geschaffen. Die kompositorische Verwendung zeitlicher Dimensionen formulierte er in seinem bis heute maßgeblichen Aufsatz »...wie die Zeit vergeht...« [1957].

98 Brief von Luigi Nono an Wolfgang Steinecke (21.1.1960), zitiert nach Borio/Danuser: Im Zenit der Moderne, Band 2, S. 259. 
Abbildung 25 -Kontroverse: Karlheinz Stockhausen und Luigi Nono 1959 bei den Darmstädter Ferienkursen

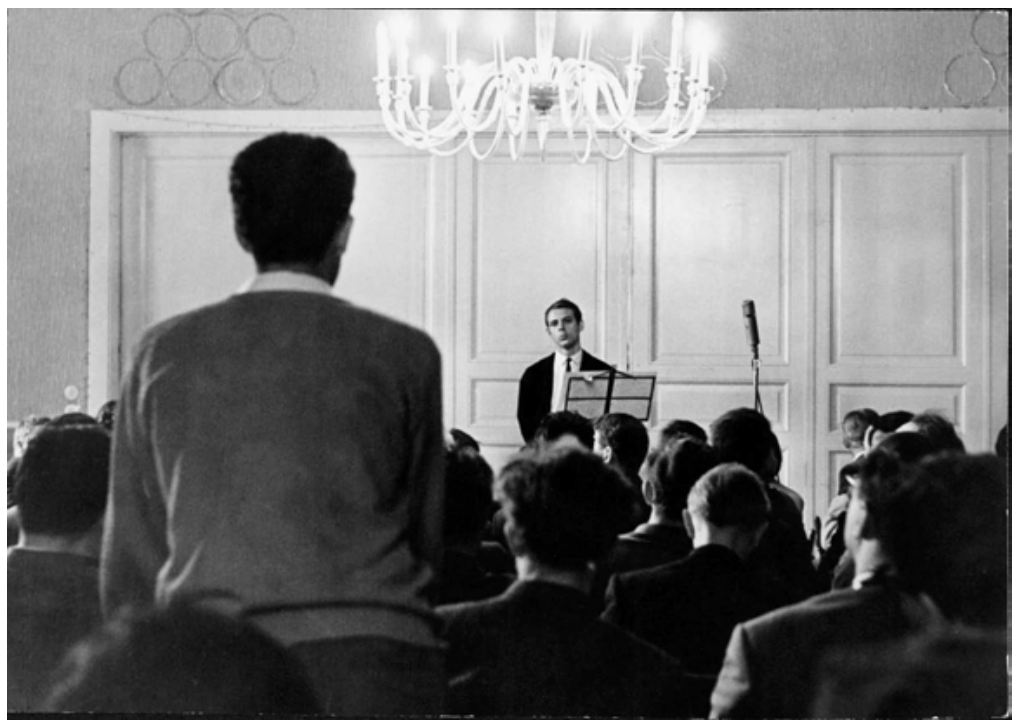

Der Affront gegen seine Kollegen bedeutete Luigi Nonos Abschied von der >Darmstädter Schuleく und fällt mit dem Arbeitsprozess an Intolleranza zusammen. Die sazione szenica markierte in den Worten des Komponisten »doch recht deutlich die Wende von einer einseitig vergangenheitsbezogenen politischen Haltung zur Ausrichtung auf Gegenwart und Zukunft. « ${ }^{99}$ Er verorte sich, so erläuterte Nono in seinem Aufsatz »Musik und Revolution«, in einer »Position [...], die die Kultur als Moment der Bewusstwerdung, des Kampfes, der Provokation, der Diskussion, der Teilnahme versteht. ${ }^{100}$ Dieser Ansatz mündete am 13. April 1961 im venezianischen Teatro La Fenice in den Premierentumulten um Intolleranza. Es war nicht nur die erste Premiere Luigi Nonos in seinem Heimatland, sondern auch der erste große politische Musikskandal der Dekade.

\section{Hauptakt: »Basta! Vogliamo Musica!» - «Viva la polizia»}

Die politische Haltung, der Luigi Nono mit Intolleranza 1960 Ausdruck verlieh, speiste sich aus verschiedenen Quellen. So verwies schon die Nennung des Entstehungsjahres 1960 im Titel auf die zeithistorische Verfasstheit der Komposition. Diese manifestierte sich auch im Libretto, das vielfältige intertextuelle Bezüge zur politischen Gesinnung des Komponisten aufweist. Das Textbuch entstand zunächst in $\mathrm{Zu}$ sammenarbeit mit dem italienischen Dichter Angelo Maria Rippelino, der sich jedoch nach Differenzen aus dem Projekt zurückzog woraufhin Luigi Nono selbst eine

99 Luigi Nono: »Gespräch mit Hansjörg Pauli« (1969), in: Stenzl: Luigi Nono, S. 198-210, hier S. $201 \mathrm{f}$.

100 Luigi Nono: »Musik und Revolution« (1969), in: Stenzl: Luigi Nono, S. 107-115, hier S. 113. 
Textcollage als Allegorie auf die Leiden eines namenlosen Flüchtlings und Gastarbeiters anfertigte: Gedichten von Paul Élouard, Berthold Brecht, Jean-Paul Sartre und Vladimir Majakowskij stellte der kommunistische Komponist vielsprachige politische Parolen wie »Nie wieder!« oder »Morte al faschismo! Libertá ai populi!« gegenüber. Diese lud er wiederum durch Briefe des 1943 in Berlin hingerichteten Journalisten Julius Fucik mit zeithistorischem Gehalt auf. Mit Auszügen aus Verhören algerischer Häftlinge stellte Nono schließlich einen unmittelbaren Bezug zum Algerienkrieg her, der damals Intellektuelle aus ganz Europa beschäftigte. ${ }^{101}$

Trotz der Verwendung programmatischer Vorlagen, vermied Luigi Nono in seiner Komposition explizit eine Textverständlichkeit der politischen Inhalte, wohl auch, um sich dem Vorwurf propagandistischer Agitation zu entziehen. Vielmehr entfaltet der Vokalpart der szenischen Aktion durch Fragmentierung eine atmosphärische Wirkung, die sich den Rezipienten als chiffrierte Botschaft mitteilen sollte. ${ }^{102}$ Dies wurde noch verstärkt durch das Bühnenbild von Emilio Vedova, einem Meister des abstrakten Informel, der dem Werkgehalt durch audiovisuelle Projektionen weitere Wahrnehmungsebenen hinzufügte. Weniger konkret steht auch Luigi Nonos experimentell gesetzte Musik für das Bestreben, mit musikalischen Normen auch gesellschaftliche Hierarchien aufzubrechen. Bettina Ehrhardt stellte in ihrer filmischen Dokumentation der Ereignisse die These auf, dass Nonos Verwendung der Allintervallreihe die Idee absoluter Gleichberechtigung imaginiere und also mit ästhetischen Mitteln eine reale Revolution darstelle. ${ }^{103}$ Schließlich kann Nonos Konzept nichtlinearer Handlungen und das Überlagern mehrerer struktureller Schichten mit Caroline Lüderssen dahingehend verstanden werden, dass »der Gedanke der Zirkularität von Geschichte ästhetisch umgesetzt und dem Zuschauer die Möglichkeit gegeben [wird], sich in einem Kontinuum von gleichberechtigt nebeneinander stehenden Äußerungen zu positionieren. ${ }^{104}$

Es kann allerdings nicht davon ausgegangen werden, dass die Premierentumulte auf die subtilen politischen Botschaften des Werkkonzepts zurückzuführen waren. Vielmehr bot die Premiere rivalisierenden gesellschaftlichen Gruppierungen, vorrangig anti- und profaschistischen Kräften Italiens, eine Bühne. Eine gewichtige Rolle spielten dabei die Medien: Am 13. April 1961, dem Tag der Premiere, erschien ein Pamphlet in der Tageszeitung Il Borghese, in dem nicht nur die Mitwirkenden (Komponist und Darsteller) und das Werk (Text, Inszenierung und Musik), sondern auch die das Ereignis tragenden Institutionen (Biennale und RAI) mit faschistischem Vokabular beschimpft wurden. Auch findet sich in dem Artikel ein kaum verblümter Hinweis auf die bevorstehende Störung der Aufführung. ${ }^{105}$

101 Luigi Nono: Einige genauere Hinweise zu >Intolleranza 1960<(1962), in Stenzl: Luigi Nono, S. 68-81, hier S. 68f.

102 Caroline Lüderssen: »Luigi Nonos und Giacomo Manzonis Musiktheater. Politisches Engagement im Zeichen Gramscis«, in Jacobshagen/Leniger: Rebellische Musik, S. 93-107, hier S. $101 \mathrm{f}$.

103 Bettina Ehrhardt: »Intolleranza 2004«, Film zu Luigi Nonos Szenischer Aktion (58’, bce films \& more), in: Westdeutscher Rundfunk (2004).

104 Lüderssen: Luigi Nonos und Giacomo Manzonis Musiktheater, S. 100.

105 Matteo Taibon: Luigi Nono und sein Musiktheater, Wien 1993, S. 63. 
Es darf also davon ausgegangen werden, dass die Sabotage der Premiere keine spontane Aktion, sondern vielmehr bewusst inszeniert war. Dafür spricht nicht nur die Tatsache, dass vorbereitete Flugblätter und Trillerpfeifen zum Einsatz kamen; auch die Erinnerungen der Sopranistin Carla Henius legen dies nahe:

»Wir Künstler waren auf alles gefasst, vorgewarnt von den Kellnern unserer Stammkneipen, die uns versprachen, ihrerseits die Faschisten zu verprügeln, weil sie uns vor denen beschützen wollten. Zusammengerottet hätten sie sich und wir sollten ja nicht alleine ins Theater oder nach Hause gehen. ${ }^{106}$

Die Kellner hatten recht, am 13.4.1961 notierte Henius in ihrem Tagebuch: »Abends Premiere. Die Faschisten machen organisierten Skandal - einige werden von der Polizei verhaftet, als sie in ihren Logen grade riefen: >Viva la polizia! ২ Sie pfiffen von Anfang an, schmissen auch Stinkbomben. « ${ }^{107}$ Auch Emilio Vedova erinnerte sich, dass sich »Faschisten positioniert» und versucht hätten, »die Aufführung platzen zu lassen. ${ }^{108}$ Es kann also davon ausgegangen werden, dass die öffentlichkeitswirksame Premiere bewusst als Plattform für die Skandalisierung von Werk und Komponist genutzt wurde. War der Konflikt damit auch vorgezeichnet, so darf der Moment der Eskalation doch als Ereignis verstanden werden: Von RAI (Radiotelevisione Italia$n a$ ) in Auftrag gegeben und als Live-Ausstrahlung zur besten Sendezeit konzipiert, wurde die Premiere inklusive Störungen aufgezeichnet und archiviert. ${ }^{109}$ Der Mitschnitt [ $\delta-22]$ verifiziert die Aufzeichnungen des Musikpublizisten Luigi Pestalozza:

»Kaum hatte Bruno Maderna den Taktstock erhoben, fing ein Heiden-Lärm an. Ein Mordskrach, Geschrei, Flugblätter gegen Nono, gegen Intolleranza. Stinkbomben. [...] Und wir schrien natürlich vom Parkett zurück und verteidigten Nono. [...] Währenddessen dirigierte Bruno einfach weiter. ${ }^{110}$

Die Analyse des Tondokuments offenbart ein stetiges Anheben und Abebben undifferenzierter Unruheherde, an mehreren Stellen wird die Musik durch Zwischenrufe und Gelächter unterbrochen. Für das eklatante Agieren des Publikums, so mutmaßte der Musikwissenschaftler Habakuk Traber, mag auch die Reihe von Lautsprechern auf der Galerie eine Rolle gespielt haben, über die vorgefertigte Choraufnahmen in die Inszenierung eingespielt wurden: »Damit entstand ein Raumklang, der die Trennung von Bühne und Auditorium überwand. Das Publikum wurde akustisch vom Geschehen umgeben und mitten in die Ereignisse geholt. « ${ }^{111}$

106 Carla Henius: »Arbeitsnotizen und Berichte von zwei Vokalwerken Luigi Nonos: Intolleranza 1960 und La fabbrica illuminata, in Stenzl: Luigi Nono, S. 329-347, hier S. 334.

107 Ebd., S. 335.

108 Zitiert nach Erhard: Intolleranza 2004.

109 Der Premierenmitschnitt von Intolleranza befindet sich im Deutschen Rundfunkarchiv: Tondokumente 11-0104.

110 Zitiert nach Erhard: Intolleranza 2004.

111 Habakuk Traber: »Musik ergreift die Fahnen. Die Skandale um Henzes Floß der Medusa und Nonos Intolleranza 1960«, in: Neue Zeitschrift für Musik (3/2000), S. 39-42, hier S. 39. 
Diese Wirkung wurde durch Emilio Vedovas Animation einer Szene aus Stand- und Bewegt-Bildern auf der Basis der Laterna magica von Josef Svoboda und Alfréd Radok noch verstärkt [Abbildung 26].

\section{Abbildung 26->Bilderflut:: Bühnenbild bei der Premiere von Luigi Nonos »Intolleranza« im Teatro La Fenice (1961)}

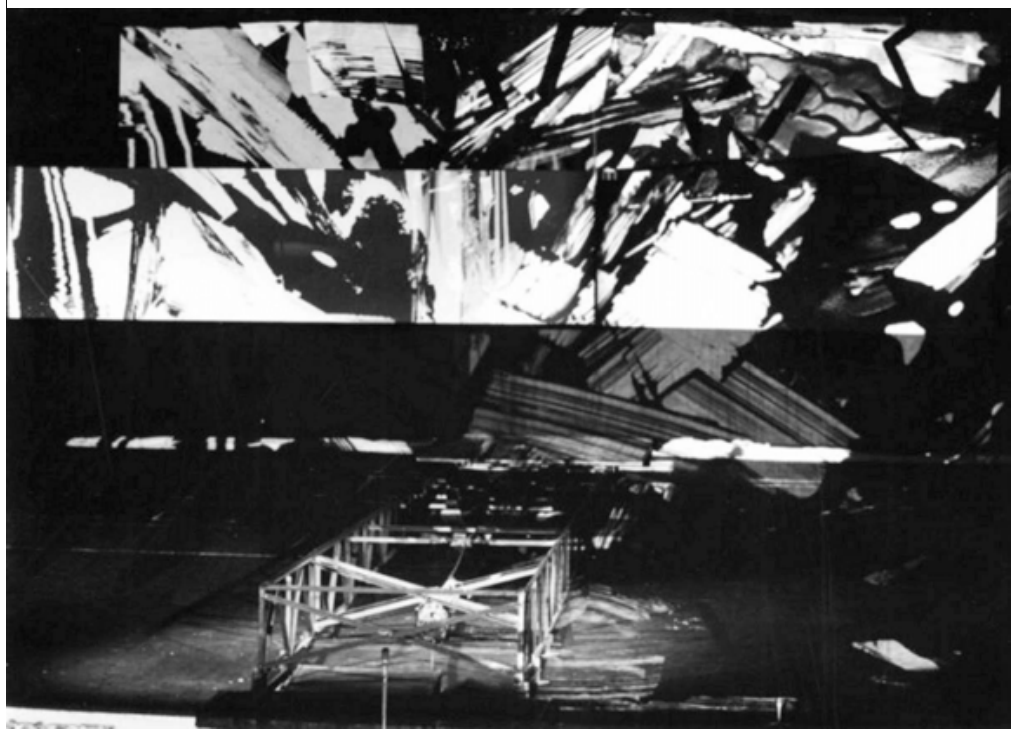

Über diese mediale Überwältigungsthese hinausgehend, entlud sich im eskalierenden Gegeneinander polarisierender Kräfte ein explosiver Cocktail ästhetischer und politischer Grundsatzfragen. Neben dem Nachäffen der elektronischen Montage und dem Insistieren auf klangschöne Musik durch traditionelle Hörerkreise - dokumentiert durch die wiederholten Zwischenrufe »Basta! Vogliamo Musica!« - spiegeln aufgebrachte Rufe wie »Fascista!« und »Viva la polizia!« auch den polarisierenden Dualismus von fascismo und resistenza im postfaschistischen Italien.

\section{Nachspiel: Medialisierung und Sanktionen}

Neben der historischen und politischen Aussagekraft in einem »speziell italienischen Gefüge ${ }^{112}$ erlaubt der Skandal um Intolleranza Rückschlüsse auf die medialen Praktiken, die spätestens seit den 1960er Jahren zum `Stellhölzchen` jeder Skandalisierung wurden. Auf die zwar nicht ganz unerwartete aber doch alle Erwartungen übertreffende Sensation, so resümierte der italienische Nono-Forscher Mateo Taibon, reagierten die Medien mit großer Resonanz: »Der Opernskandal am Teatro La Fenice wurde zum großen Thema, dessen Aufriss zum Teil schnell, zum Teil zwielichtig, und zu einem geringen Teil vertiefend und hinterfragend präsentiert wurde. ${ }^{113}$

112 Lüderssen: Luigi Nonos und Giacomo Manzonis Musiktheater, S. 95.

113 Taibon: Luigi Nono und sein Musiktheater, S. 63f. 
Während die Claquere im Konzertsaal nicht nur gegen die politische Gesinnung Luigi Nonos, sondern auch gegen seine moderne Kompositionstechnik protestierten, lobte die Mehrzahl der Rezensenten die innovative und radikal experimentelle Klangsprache des Komponisten. Alfred Schlee, der langjährige Leiter der Wiener Universal Edition, konstatierte nach der Uraufführung, dies sei »das bedeutendste Werk und Opernereignis«, das er seit Alban Bergs Wozzek 1925 in Berlin miterlebt habe. ${ }^{114}$ Zwar forderten viele politisierte Musiker damals eine verständliche Musik für die Massen und kritisierten daher Nonos informell-komplexe Tonsprache. Allerdings ist diese der Grund dafür, dass Intolleranza bis in die Gegenwart zum Repertoire gehört, während die formalistischen und nur politisch engagierten Kunstkonzepte der 1960er Jahre heute weitgehend von den Spielplänen verschwunden sind.

Trotz dieser anhaltenden Wertschätzung hatte Luigi Nono im Anschluss an die skandalöse Premiere und seine unüberhörbare Politisierung mit kulturpolitischem Druck zu kämpfen. Wenn allgemein auch die öffentliche Wirkung als entscheidende Zutat von künstlerischen Skandalerfolgen gilt, muss die These mit Blick auf politische Musikskandale im Allgemeinen und Luigi Nono im Besonderen hinterfragt werden. Tatsächlich bekam der Komponist als Folge seines linkspolitischen Engagements empfindliche Sanktionen zu spüren. Der Dirigent Max Pommer erinnerte sich etwa, dass Luigi Nono vorgeworfen worden wäre, »er hätte sich im Osten >verkrümelt< [...]. Nono ist, besonders in Westdeutschland, kaum noch aufgeführt worden seit den frühen sechziger Jahren $[\ldots] \ll{ }^{115}$. Nichtsdestotrotz muss die westliche Rezeption als entscheidend für sein Werk angesehen werden und das auch mit Blick auf die politische Sprengkraft. So bot 1964 die Mailänder Produktion von Al gran sole carico d'amore den antagonistischen christdemokratischen und sozialistischen Kräften Italiens abermals eine Bühne, als Abgeordnete im Mailänder Stadtrat die Aufführung als Wahlpropaganda der KPI bezeichneten:

»Sie behaupteten Unsinn wie: Das ganze Theater solle mir roten Fahnen drapiert werden [...]. Am politischen und ökonomischen Druck auf die Scala beteiligten sich auch die Kirche und die Regierung. Es gab Solidaritätserklärungen der Gewerkschaften. Belegschaften ganzer Fabriken [...] protestierten gegen die Zensurversuche der Rechtskräfte, ebenfalls die Universität. Aber auch in Rom und in anderen Städten gab es Solidaritätskundgebungen - es war keine regionale, sondern eine nationale Auseinandersetzung. $\ll^{116}$

Mit La fabbrica illuminata für Sopran und Tonband entstand ebenfalls 1964 ein Werk, das zu einem weiteren Paradigma politischen Komponierens wurde. Entstanden aus Reflexionen über eine neue gesellschaftliche Funktion der Musik, stellte Luigi Nono die Fabrik als Symbol der Arbeiter und ihrer Unterdrückung, aber auch als musikalischen Ton- und Taktgeber ins Zentrum des Werks: Die klangliche Grundlage bilden Aufnahmen von Fabrikgeräuschen, die mit elektronischen Klängen verarbeitet und Transformationen unterworfen werden. Eine Frauenstimme singt live zu

114 Henius: Arbeitsnotizen und Berichte, S. 334.

115 Zitiert nach Andreas Wagner (Hg.): Luigi Nono. Dokumente - Materialien, Saarbrücken 2003, S. 153.

116 Luigi Nono: »Interview mit Hans Brender und Max Nyffeler«, in: Deutsche Volkszeitung (12.6.1975). 
den Bandaufnahmen und nimmt unmittelbar Bezug zum Entstehungsort der Klänge, wie ihn Peter Michael Hamel definierte: »den Arbeitsprozess in einer Fabrik und die sozialen Ungerechtigkeiten, die ihn in kapitalistischen Gesellschaftsformen in Gang halten. ${ }^{117}$

Im Jahr der Uraufführung von La fabbrica illuminata erregte auch Intolleranza noch einmal Empörung auf internationaler Ebene, als die amerikanische Erstaufführung 1965 in Boston wegen Luigi Nonos kommunistischen Schriften boykottiert wurde. Im selben Jahr wurde er von Paul Dessau als korrespondierendes Mitglied der Ostberliner Akademie der Künste vorgeschlagen. Die Annahme erfolgte nicht zuletzt aufgrund »seiner leidenschaftlichen Anklagen gegen Krieg, Terror und Faschismus«, wie er sie insbesondere in Intolleranza erhoben habe. ${ }^{118}$ Eine Zeitlang schien es, so konstatierte Andreas Wagner, dass Nono im Osten »eine neue geistige Heimat ${ }^{119}$ würde finden können. Doch zeigte sich bald, dass Nonos individueller und intellektuell verstandener Kommunismus, genauso wie sein radikal-experimentelles musikästhetisches Verständnis, nicht konform zur formalistischen Lesart der Sowjetunion war. Luigi Nono blieb trotz seines politischen Engagements ein Komponist Neuer Musik und abstrakter Tonsprache, während andere linksorientierte Musiker eine leicht verständliche Sprache für die Massen forderten und damit auch ästhetische Angriffsflächen boten. Einen Mittelweg beschritt Hans Werner Henze, der zwar der Neuen Musik zuzuordnen ist, aber niemals die Welt der tonalen Harmonien gänzlich verließ. Er provozierte im Winter 1968 den wohl größten und aussagekräftigsten Musikskandal der Bundesrepublik, der auch die innenpolitischen Problemlagen Deutschlands paradigmatisch beleuchtet.

\section{Der Schiffbruch von Hans Werner Henzes Floß der Medusa (1968)}

Anfang des bewegten Jahres 1968 fand in Berlin der Internationale Vietnamkongress mit etwa 5000 Teilnehmern und 44 Delegationen aus 14 Staaten statt. Auf der Straße marschierte der Komponist Hans Werner Henze »Arm in Arm mit Luigi Nono ${ }^{120}$, der sich später erinnerte:

»Am Sonntag, den 18. Februar, füllten etwa 20000 Demonstranten die Straßen des Westberliner Zentrums. Studenten aus verschiedenen Ländern, evangelische, christliche Vereinigungen, Arbeiter, Intellektuelle. [...] Vier Stunden dauert dieser Strom von roten und vietnamesischen Fahnen, Gesängen, Begeisterung, eine Explosion politischen Lebens in den großen Straßen Westberlins. ${ }^{121}$

117 Peter Michael Hamel: »Politisches Komponieren damals und heute. Persönliche Rückblicke und Einsichten«, in Ders.: Ein neuer Ton. Ausgewählte Schriften zu einer ganzen Musik, München 2007, S. 93-105, hier S. 96.

118 Archiv der Akademie der Künste: Sektion Musik, Korrespondenz mit und über Luigi Nono 1965-1966.

119 Wagner: Luigi Nono, S. 149.

120 Hans Werner Henze: Reiselieder mit böhmischen Quinten. Autobiographische Mitteilungen. 1926-1995, Frankfurt am Main 1996, S. 291.

121 Luigi Nono: »Vietnam in Berlin« (1968), in Stenzl: Luigi Nono, S. 155-158, hier S. 158. 
Mit den beiden Komponisten demonstrierte nicht zufällig auch Peter Weiss, der in seiner Ästhetik des Widerstands dafür plädiert hatte, die Kunst der Revolution und die Revolution der Kunst als gesellschaftliche Avantgarden (wieder) zusammenzudenken. ${ }^{122}$ Damit verdeutlichte Weiss den Querstand von Kunst und Politik als ein wesentliches musikgeschichtliches Merkmal von 1968, als »politische und künstlerische Avantgarde wieder vereint oder doch eng verknüpft schienen « ${ }^{123}$. In Abgrenzung zur seriellen Darmstädter Schule hatte Henze als Gegenentwurf das Konzept einer >Musica impura< entwickelt, die seinem 1969 formulierten Diktum »Musik ist nolens volens politisch « entsprach: »Wenn wir statt Waffe Musik sagen, dann ist sehr viel darüber gesagt, was Musik in der Revolution sein könnte oder vielmehr ist. ${ }^{124}$ Henze artikulierte diesen Satz ein Jahr nach dem wohl größten und aussagekräftigsten politischen Musikskandal der Dekade: dem Schiffbruch seines >oratorio volgare e militare $<$ Das Floß der Medusa. Die Saalschlacht in Halle B des Hamburger Konzertsaal Planten und Bloomen wurde zu einem der wenigen echten Medienereignisse innerhalb der Neuen Musik, dessen paradigmatische Bedeutung sich aus den unmittelbaren innenpolitischen Problemlagen der BRD im Schlüsseljahr 1968 ableitet.

\section{Vorspiel: Ästhetischer Sonderweg und Studentenbewegung}

Ähnlich wie bei Luigi Nono, dessen Politisierung mit dem Kompositionsprozess an Intolleranza zusammenfiel, markierte Hans Werner Henzes Arbeit am Floß der Medusa seine künstlerische Wendung hin zu einer explizit politisch motivierten Musik, die ihren Ursprung in den Erfahrungen und dem Ende der nationalsozialistischen Herrschaft nahm und in den 1960er Jahren virulent wurde:

$»$ Dies war ein von Neubeginn [...] erfüllter Zustand [...]. Zu sehen, dass wenige Jahre nach der Diktatur [...] Regungen wach geworden sind [...] bedeutet eine Enttäuschung, die [...] wächst und sich mit Zorn und Scham verbindet. Sie bringt mich dazu, in meiner Arbeit bewusster als bisher gegen den Strom zu schwimmen, und mit ihr [...] für ein Leben zu plädieren, in dem Vernachlässigung der Nächstenliebe, Brutalität und Bevormundung gedanklicher und gesellschaftlicher Freiheit ausgeschlossen sind. ${ }^{125}$

War Nonos Politisierung in einem speziell italienischen Gefüge verortet, so betraf Henzes Engagement die spezifischen Bedingungen der Bundesrepublik und konkret die mangelnde Aufarbeitung der NS-Vergangenheit. Was Antonio Gramsci für Luigi Nono war, war für Henze die Studentenbewegung und speziell Rudi Dutschke: Der Komponist war nicht nur bekannt mit dem Kopf der Außerparlamentarischen Opposition (APO), sondern bot Dutschke nach dem Attentat vom 11. April 1968 Zuflucht auf seinem Anwesen in Italien. Hier beherbergte der Komponist außerdem Ulrike

122 Peter Weiss: Ästhetik des Widerstands, 3 Bände, Frankfurt am Main 1975-1981.

123 Heister, Geschichte der Musik im 20. Jahrhundert, Band 3, S. 287.

124 Hans Werner Henze: »Musik ist nolens volens politisch« (1969), in Ders.: Musik und Politik. Gespräche 1955-1975, München 1976, S. 136-143, hier S. 143.

125 Hans Werner Henze: »Musik als Resistenzverhalten« [1964], in Ders.: Schriften und Gespräche 1955-1979, Berlin 1981, S. 85-91, hier S. 86. 
Meinhof, Gudrun Ensslin, Andreas Baader und andere RAF-Prominente, bevor sie in Kriminalität und Illegalität abtauchten. ${ }^{126}$

Eröffnen sich damit Anschlussfelder über das ambivalente Verhältnis zwischen künstlerischer und politischer `Avantgarde`, spielten bei Henzes Politisierung nicht nur das Trauma des Zweiten Weltkriegs, sondern auch persönliche Aspekte wie die Diskriminierung als Homosexueller und sein ästhetischer Sonderweg innerhalb der musikalischen Nachkriegsavantgarde eine Rolle. Als sich ab 1948 die Darmstädter Ferienkurse zum Nucleus der Neuen Musik entwickelten, nahm Hans Werner Henze neben Pierre Boulez, Karlheinz Stockhausen und Luigi Nono zunächst eine wichtige Rolle unter den Vertretern der jungen Generation ein, wurde mit der dogmatischen Durchsetzung des Serialismus jedoch bald an den Rand gedrängt. Während Nono erst 1959 mit seinem politischen Bekenntnis »Geschichte und Gegenwart in der Musik heute« mit einem Eklat aus dem seriellen Zirkel ausschied, kam es im Fall Henzes schon zu Beginn der 1950er Jahre zum Bruch. Während seine Kollegen einen bedingungslosen Innovationsimperativ auf der Basis seriellen Komponierens formulierten, war Henze nicht bereit, die Welt der Harmonien gänzlich aufzugeben. Damit wurde er zur Zielscheibe seiner radikaleren Altersgenossen, die Henze als rückständigen Ästheten brandmarkten und boykottierten. ${ }^{127}$ Hans-Klaus Jungheinrich etwa bemerkte, dass der Komponist »deutlich traumatisiert von seiner Ungleichzeitigkeit, seiner Nichtintegriertheit in die strenge Gemeinschaft der Darmstädter Serialisten « ${ }^{128}$ und dem Verlust seiner repräsentativen Funktion unter den jungen Komponisten gewesen sei. Dafür spricht auch die Erklärung, die Henze als Grund für seine Auswanderung 1953 nach Italien angab:

»Hier ruhen keine skandaltrunkenen Augen auf mir, [...] ich bin verschont von Gerüchten [...]. Hier lebend habe ich keine Veranlassung, mich an dem Wettstreit der Künstler zu beteiligen. ${ }^{129}$

Als Mitglied der >seriellen Troika gehörte Luigi Nono zu den ästhetischen Kritikern Hans Werner Henzes: als Repräsentant des radikalen Avantgarde-Flügels brachte der Italiener sowohl bei den Donaueschinger Musiktagen, als auch bei den Darmstädter Ferienkursen mit Pfiffen seine Verachtung für die traditionsorientierte Kompositionsweise Henzes zum Ausdruck. Politisch aber verband die beiden Komponisten eine Freundschaft. Auch Henze wurde nach seinem Umzug nach Italien Mitglied der Partito Comunista Italiano (PCI) und knüpfte darüber hinaus enge Verbindungen zur westdeutschen Studentenbewegung, die auch sein künstlerisches Schaffen nachhaltig prägte.

126 Jungheinrich: 1968 Ästhetik des Aufbruchs?, S. 121. Weitere Bezüge der Musikavantgarde zur RAF finden sich bei Helmut Lachenmann. Den Komponisten verbindet mit Gudrun Ensslin eine Jugendfreundschaft, die er 1997 in seiner Oper Das Mädchen mit den Schwefelhölzern künstlerisch verarbeitete.

127 Siehe hierzu ausführlich das Kapitel Agon und Skandal und darin besonders den Abschnitt Der Absolutismus der Moderne.

128 Jungheinrich: Ästhetik des Aufbruchs?, S. 121.

129 Hans Werner Henze: »Die Bundesrepublik Deutschland und die Musik« (1967/68), in Ders.: Schriften und Gespräche 1955-1979, Berlin 1981, S. 115-122, hier S. 120. 
»Mit einem Mal«, so erinnerte sich Henze später, »hatte ich den Eindruck, nichts mehr zu verstehen, nichts mehr zu haben, abgeschnitten zu sein. [...] Und das war vielleicht der Anfang meiner Bewusstwerdung. ${ }^{130}$ Diese Politisierung spiegelte sich wie bei Luigi Nono nicht nur in theoretischen Schriften, sondern auch in seinem kompositorischen Schaffen. Anders als der Italiener setzte Hans Werner Henze allerdings weniger auf avancierte Mittel, als auf politische Werkkonzepte in einer verständlichen Tonsprache. Waren frühe Werke wie die Dritte Symphonie 1952 noch wegen ihres Avantgardismus ausgepfiffen worden ${ }^{131}$, wurde 1953 sein erstes Musiktheater Boulevard Solitude von der Presse als »provinziell, altmodisch, ja als gymnasiastenhaft unreif « ${ }^{132}$ kritisiert. Nach störungsfreien Aufführungen in Hannover, Düsseldorf und Neapel provozierte das Werk im Römischen Teatro Reale einen Skandal, der einige Aussagekraft besitzt: Ausgelöst wurden die Tumulte diesmal weniger durch ästhetische Grundsatzfragen, wie Hubert Lengauer aufzeigte, sondern vielmehr durch moralische Vorwürfe - nämlich die Homosexualität des Komponisten:

»Skandal lag hier auf zwei Ebenen vor: auf der einen Öffentlichkeit, die sich an der sexuellen Orientierung erregt, und auf einer zweiten [...], welche Kunst als Leiden an der Gesellschaft, als Antagonismus zur Normalität schlechthin bestimmt. Das coming out [...] ist skandalös. « ${ }^{133}$

Kurz nach den Ereignissen schrieb Hans Werner Henze an Ingeborg Bachmann, mit der ihn eine enge private und auch künstlerisch ergiebige Freundschaft verband (und die während der Aufführung von Boulevard Solitude in Ohnmacht fiel), der Skandal wäre bezeichnend für die »schande meiner existenz «. ${ }^{134}$

Neben dieser Deutung lässt am Beispiel von Boulevard Solitude eine weitere eklatante Anekdote aufhorchen: Igor Strawinsky war bei der Premiere von den Türstehern abgewiesen worden, weil er ohne Smoking erschienen war. Henze soll über so viel Formalismus außer sich gewesen sein, vor allem aber eröffnet der Zwischenfall Einblicke in die bürgerlichen Normen des Opernbetriebs, gegen die zunehmend rebelliert wurde. Der Musikpublizist Hans Heinz Stuckenschmidt schrieb in der Folge spitzfindig, dass es zwar offenbar verboten sei ohne Smoking eine Opernpremiere zu betreten, nicht aber, diese Premiere durch Trillerpfeifen zu stören:

130 Hans Werner Henze: »Die Krise des bürgerlichen Künstlers - Politisierung - Nutzbarmachung der Kunst für die Revolution« (1971), in Ders., Musik und Politik, S. 149-155, hier S. 150 .

131 Über die umkämpfte Uraufführung im Rahmen der Münchner Neue-Musik-Reihe »Musica Viva« berichteten: Die Südpost (7.4.1952), Münchner Merkur (7.4.1952), Süddeutsche Zeitung (7.4.1952), Mannheimer Morgen (8.4.1952).

132 Siehe hierzu »Opernskandal in Rom. Hans Werner Henzes >Boulevard Solitude〈 ausgepfiffen / Wortwechsel mit Strawinsky« (Hamburger Anzeiger), »Großer Opernskandal in Rom« (Niederdeutsche Zeitung), »Der römische Skandal um Henze« (Allgemeine Zeitung), gesammelt in IMD: Komponisten, Hans Werner Henze 1948-1959, A 294.

133 Hubert Lengauer: »Nachgelassener (oder nachlassender) Skandal? «, in Neuhaus: Literatur als Skandal, S. 491-502.

134 Hans Höller (Hg.): Ingeborg Bachmann/Hans Werner Henze. Briefe einer Freundschaft, München 2004, S. 32f. 
»Die Habitués nehmen es a priori übel, dass nicht Wagner oder Verdi gespielt wurde, und versuchten lachend, pfeifend, >Basta ‘-rufend einen Skandal zu provozieren. [...] Es muss vermerkt werden, dass irgendjemand für die Premiere eine bezahlte Cláque bestellt hatte, mit Trillerpfeifen die Aufführung zu stören. « ${ }^{135}$

Der römische Tumult war also organisiert und spiegelte nach Meinung Karl Heinz Ruppels die Verfassung des italienischen (Musik-)Lebens wider. Zum einen thematisierte der Kritiker den nur scheinbaren Postfaschismus, denn bezeichnenderweise habe der Skandal in einem Theater stattgefunden, über dessen Bühnenportal man noch lesen könne, dass es vom »Duce Benito Mussolini« erneuert worden sei. Zum anderen sei Italien rezeptionsästhetisch traditionell reaktionär:

»Gehören Hausschlüssel und Trillerpfeifen zum >Abito da sera< wie die Nelke im Knopfloch oder das goldene Zigarettenetui? [...] Dass in Italienischen Opernhäusern bei modernen Werken gepfiffen wird, wird niemanden verwundern, der um die unerschütterliche Vorherrschaft des Belcanto-Ideals im Lande Verdis und Puccinis weiß. [...] Sie empfanden ein modernes Werk in ihrem traditionsgeheiligten Theater einfach als Provokation und demonstrierten - wie unbewusst doch sinnbildlich auch jener Türhüter, der Strawinsky zurückgewiesen hatte - gegen eine Kunstanschauung, die den Primat des Smokings, d.h. des Gesellschaftlichen, im Theater zu bedrohen scheint. ${ }^{136}$

Schließlich wurden bereits bei Boulevard Solitude die medialen Zusammenhänge offensichtlich, die beim Floß der Medusa signifikant werden sollten: Henzes Mainzer Musikverlag Schott bezog in seinen Nachrichten vom 29.4.1954 Stellung zu den abwertenden Meldungen vieler deutscher Zeitungen, in denen »durch Nachdruck einer dpa-Meldung Besprechungen veröffentlicht« worden seien, deren Urteile jedoch in keiner Weise den Tatsachen entsprechen würden. Man habe daher »eine Reihe von authentischen Urteilen [...] über die schmählichen Ereignisse zusammengestellt « und erwarte zur Ehrenrettung von den Zeitungen eine Richtigstellung. ${ }^{137}$ Dennoch haftete Hans Werner Henze von nun an die Erwartungshaltung des Skandals an. Das stellte auch die Westfalen Zeitung fest, als kurz nach dem römischen Skandal von Boulevard Solitude auch in Bielefeld Pfiffe gegen Henze und sein Cellokonzert Ode an den Westwind laut wurden:

»Die Pfeiffer hatten wohl davon gehört, dass man in Rom [...] Trillerpfeifen mitgebracht hatte. Und so durfte man natürlich in der Heimatstadt des Komponisten nicht zurückstehen. Wir haben nichts $[\ldots]$ gegen einen tapferen und spontanen Pfiff. Da man aber schon einige Tage vorher in Bielefeld wusste: >Bei Henze wird gepfiffen` konnte man sich des Eindrucks einer >Organisation $\wedge^{\text {nicht erwehren. }}{ }^{138}$

135 N.N., in: Die Neue Zeitung (16.4.1954), in IMD: Komponisten, Hans Werner Henze 1948-1959, A 294.

136 Karl-Heinz Ruppel, in: Das Musikleben (5/1954), in: Ebd.

137 Schott: Verlagsnachrichten, Mainz 29.4.1954, in: Ebd.

138 N.N., in: Westfalen Zeitung (7.5.1954), in: Ebd. 
In Bielefeld fand 1968 auch der Skandal um Das Floß der Medusa seinen Auftakt. In den 14 Jahren zwischen hatte die Ausrichtung der Skandalisierung Hans Werner Henzes einen musik- und zeithistorischen Wandel erfahren: Stritt man in den 1950er Jahren insbesondere gegen seine Ästhetik - die von der Avantgarde als zu regressiv, vom bürgerlichen Publikum als zu progressiv gewertet wurde - bekamen die Proteste im Verlauf der 1960er eine immer deutlichere politische Färbung.

Zum Auslöser wurden nur wenige Tage vor der Premiere von Das Floß der Me$d u s a$ die eklatanten Ereignisse rund um die Uraufführung von Hans Werner Henzes Klavierkonzert Nr. 2. Der Komponist hatte von Rudolf August Oetker einen Kompositionsauftrag zur Einweihungsfeier der neuen Bielefelder Kunsthalle erhalten, die den Namen seines Stiefvaters tragen sollte: Die Benennung der Kunsthalle nach Richard Kaselowsky - seit 1933 Mitglied der NSDAP, später SS-Gruppenführer sowie Mitglied des »Freundeskreises Reichsführer SS« und 1944 bei einem Luftangriff getötet $^{139}$ - war in Bielefeld bereits stark umstritten; Henze aber erfuhr erst nach Fertigstellung seiner Komposition, dass der Namensgeber der Kunsthalle aus dem $»$ Freundeskreis Himmler ${ }^{140}$ stamme, woraufhin er sich in einem offenen Brief an die Freie Presse zur »Weltrevolution« bekannte:

»Unsere Gesellschaft lebt im Wohlstand. Schnelle Autos, gut funktionierende Kücheneinrichtungen und wirtschaftliche Beziehungen, Schickeria und `Bild-Zeitung〈, die für sie denkt, lassen jede Äußerung von Zweifel an diesem Zustand als Unvernunft, Kriminalität oder >von Osten inspirierte Intrige erscheinen. [...] Musik kann unter den bestehenden Verhältnissen nur noch als Akt der Verzweiflung gesehen werden, als Verneinung. [...] Wo immer Kunst noch sich positivistisch geben will, verhält sie sich als lügenhaftes Abziehbild von Kultur. Notwendig sind nicht neue Museen, Opernhäuser und Uraufführungen. Notwendig ist, die Verwirklichung der Träume in Angriff zu nehmen. Notwendig ist die große Abschaffung der Herrschaft des Menschen über den Menschen [...], und das heißt: Notwendig ist die Schaffung des größten Kunstwerks der Menschheit: die Weltrevolution. ${ }^{141}$

Indem Henze die Weltrevolution als größtes Kunstwerk der Menschheit bezeichnete, gab er selbst den medialen Auftakt zum Skandal um sein >oratorio volgare e militare Das Floß der Medusa. Denn eine solche Aussage konnte in dieser politisch bewegten Zeit nur als Akt der Provokation verstanden werden. Postwendend wurde vom Spiegel eine polemische Replik veröffentlicht, in der Felix Schmidt den Komponisten als Epigonen und 〉Champagner-Linken` bezeichnete; darüber hinaus wagte der Kritiker eine musikalische Vorabkritik von Hans Werner Henzes Oratorium nur aufgrund eines Klavierauszugs, die den Komponisten auch künstlerischer Rückständigkeit bezichtigte:

139 Siehe weiterführend Rüdiger Jungbluth: Die Oetkers. Geschäfte und Geheimnisse der bekanntesten Wirtschaftsdynastie Deutschlands, Frankfurt am Main 2004.

140 So wurde der Komponist vom Mannheimer Morgen (1.10.1968), der Frankfurter Allgemeinen (2.10.1968) und in Die Zeit (4.10.1968) zitiert, in IMD: Komponisten, Hans Werner Henze 1964-1970, A 296.

141 Hans Werner Henze: »Musik als Akt der Verzweiflung«, publiziert in Ders.: Schriften und Gespräche, S. 122f. 
»Das ist Henzes große Revolution: Sie reproduziert das bourgeoise Musikideal. Dabei will er doch, wie er sagt, bestimmte Zustände von Unterdrückung aufheben, eine bestimmte Bewußtwerdung mittels Musik erreichen. Denn Henze komponiert fürs Volk. [...] Sein Publikum aber kommt in Smoking und Nerz [...]. Es knabbert nicht an den Fingernägeln, es riecht nicht nach Acht-Stunden-Tag. [...] Mögen auch Che Guevaras Verdammte dieser Erde auf die Revolution warten - Professor Henze schaut auf zu den Sternen. Er ist der Privatier der Modernen Musik. $\ll^{142}$

Wird hier die Vermengung ästhetischer und politischer Grundsatzfragen deutlich, so trat diese Vorabkritik eine Flut von publizistischen Gegenreaktionen los. Ein Teil der Kommentare richtete sich gegen die unangemessene Form der Kritik. Beispielhaft wurde dem Kritiker in einem Leserbrief polemisch zu seinem »außerordentlich gründlichen Verfahren, eine Premiere [...] bereits eine Woche vor der Premiere zu beurteilen ${ }^{143}$ gratuliert. Die Redaktion konterte in der Süddeutschen Zeitung mit einer nicht minder bissigen Stellungnahme, in der es hieß, man glaube »immerhin einen Klavierauszug [...] lesen zu können, wenn er in Henzes konventioneller Sprache notiert ist. $\ll{ }^{144}$ Damit weitete sich die Affäre schon vor der Premiere zu einer prominent geführten Mediendebatte aus, die öffentlichkeitswirksam am Köcheln gehalten wurde. Am Tag der Medusa-Premiere veröffentlichte der Spiegel einen Brief von Rudi Dutschke, der ausgehend von den Angriffen auf Henze feststellte: »Es kracht an allen Ecken und Enden«. Anschließend nutzte der APO-Anführer den Anlass, um gegen die »Herren der anderen Seite« in Medien und Politik zu polemisieren:

»Der Fall Hans Werner Henze zeigt die sich permanent wendende Form der Lüge und Halbwahrheiten der SPIEGEL-Maschinerie, die der `neo-liberale` Bestandteil der Erhaltungsstrategie des Spätkapitalismus darstellt. Warum berichtet der SPIEGEL nicht über die neuen Erschießungsformen des Schahs in diesen Tagen? Über Hans Werner Henzes Musik können der praktische Revolutionär und Kommunist Luigi Nono und andere mehr sich äußern. [...] Warum habe ich eigentlich dem SPIEGEL diesen Brief gegeben? [...] Zur rechten Zeit [...] versuche ich politisch anzugreifen. Sehe darin die Rolle dieser einen Integrationsmöglichkeit über die Medien der Lüge. [...] Es kracht an allen Ecken und Enden. [...] Wir warten nicht auf die Revolution, der Aufstand wird vielmehr systematisch vorbereitet. ${ }^{145}$

Dutschke nahm also den Fall Henze als Anstoß, um »gegen den US-Imperialismus, Spätkapitalismus und autoritären Staatssozialismus« sowie die Praktiken der Medien zu protestieren. Die Debatten Pro und Contra Henze wurden auch in Künstlerkreisen aufgegriffen und kontrovers diskutiert, was die These eines Querstands von Kunst und Politik im Umfeld von >1968 « noch einmal bekräftigt. Das Aufeinanderprallen der beiden gesellschaftlichen Sphären bildete die Kulisse der Ereignisse, die sich am 9. Dezember 1968 im Hamburger Konzertsaal Planten und Bloomen abspielten, als Hans Werner Henzes Floß der Medusa eklatanten Schiffbruch erlitt.

142 Felix Schmidt: »Kindliches Entzücken«, in: Der Spiegel (49/1968), S. 182.

143 Leserbrief, in: Der Spiegel (1968), Nr. 51.

144 N.N., in: Süddeutsche Zeitung (11./12.01.1969).

145 Rudi Dutschke: »Es kracht an allen Ecken und Enden«, in: Der Spiegel (50/1968), S. 185 . 


\section{Hauptakt: Die Rote Fahne im Konzertsaal}

Mit dem >oratorio volgare e militare Das Floß der Medusa kam Hans Werner Henze seinem Berufsverständnis - »Wahrheiten ihrer Explosion näherzubringen ${ }^{146}$ - so nahe wie nie. Die detonationsähnlichen Hamburger Ereignisse im Dezember 1968 wurden nicht nur medial befeuert, sondern auch inhaltlich durch die Wahl des Stoffes lanciert: Hatte Luigi Nono 1961 in Intolleranza die gesellschaftlichen Vorurteile am Schicksal eines namenlosen Gastarbeiters thematisiert, stellte Henze das Werk durch die Widmung, dies sei »als ein Requiem für den Comandante Ernesto Guevara zu betrachten, der im Oktober 1967 in Bolivien fiel ${ }^{147}$, in einen explizit zeithistorischen Kontext. Konkreter noch als bei Nono finden sich bei Henze intermediale Anknüpfungspunkte zur Überlieferung des politischen Werkkonzeptes.

\section{Abbildung 27 - Théodore Géricault: »Das Floß der Medusa« (1819)}

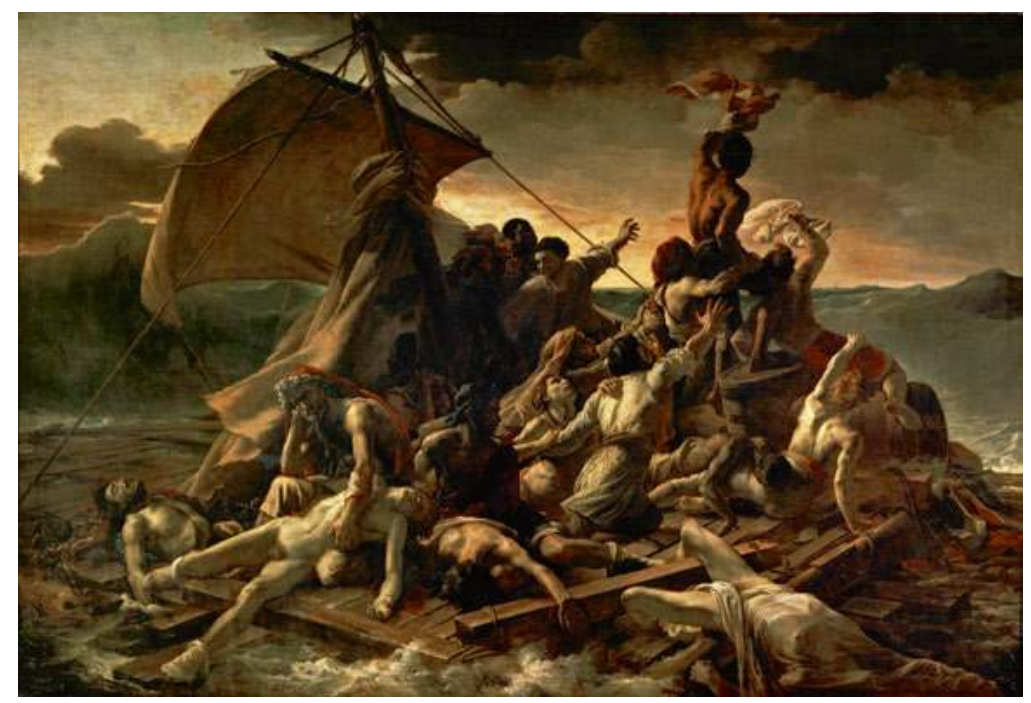

Das Sujet des Henze-Oratoriums geht auf die realen Ereignisse um die französische Fregatte Medusa zurück, die 1816 Schiffbruch erlitt. Von den Offizieren zurückgelassen, trieb ein Teil der Passagiere und der Mannschaft vier Wochen auf einem Floß auf dem Atlantik. Im Überlebenskampf kam es zu Kannibalismus; nur eine Handvoll Schiffbrüchiger konnte gerettet werden. Ausgehend von den Augenzeugenberichten, wurde das Thema in der Folge von Künstlern aufgegriffen und als Allegorie auf den Missbrauch von Herrschaft gedeutet: über die bildsprachliche Übersetzung 1819 in Théodore Géricaults Le radeau de la Méduse [Abbildung 27] und die narrative Reflexion des Gemäldes in Peter Weiss' Ästhetik des Widerstands bis hin zum Libretto Ernst Schnabels und seiner musikalischen Ausdeutung durch Hans Werner Henze.

146 Henze: Die Bundesrepublik Deutschland und die Musik, S. 116.

147 Hans Werner Henze: »Das Floß der Medusa (1975). Eine Einführung in das Oratorium«, in Ders.: Schriften und Gespräche, S. 214-215, hier S. $214 \mathrm{f}$. 
Der Komponist gab später an, er habe beim Kompositionsprozess Gericaults Gemälde deutlich vor Augen gehabt: »Die Menschenpyramide [...], an deren Spitze unser Held [...] erkennbar ist, wie er den roten Fetzen [...] schwenkt [...] ist gleich zu Anfang unseres Stückes präsent ${ }^{148}$ - und auch in den Ereignissen der Hamburger Premiere sollte die rote Fahne eine sehr konkrete Rolle spielen.

Besonders deutlich wird der politische Gehalt der Partitur in der Schlusssequenz, wo es heißt: »[...] belehrt von der Wirklichkeit, fiebernd, sie umzustürzen [...]«. Dazu pocht ein allbekannter Rhythmus untergründig und widerständig gegen das Metrum der Komposition: lang - lang - kurz - kurz - lang. Hatte das rhythmische Signal zunächst der Anfeuerung auf Fußballplätzen gegolten, verliehen die »Meister des Umfunktionierens«, so Habakuk Traber in seiner Reflexion der Ereignisse, »diesem Klatschsymbol für die Wunscheinheit en masse einen neuen Sinn: »Ho-Ho-HoTschi-Minh. ${ }^{149}$ Jenseits der Partituranweisung kam es bei der Medusa-Premiere zu einer weiteren Verwendung des akustischen Zeitzeichens: weil es durch den Abbruch des Konzerts nicht zur Aufführung des Oratoriums kam, fand es beim Einmarsch der Polizei seinen performativen Ausdruck, als Studenten im Saal klatschend das rhythmische Signal anstimmten und damit die Partitur in eine symbolische Ordnung überführten. Da das Konzert zur Live-Ausstrahlung im Norddeutschen Rundfunk bestimmt war ist dieser Moment aufgezeichnet und archiviert worden. ${ }^{150}$ Sowohl diese akustische Quelle [ $\delta-23$ ], als auch visuelle Zeugnisse [Abbildungen 28 und 29] belegen Hans Werner Henzes briefliche Schilderung der eklatanten Ereignisse:

»Der Anlass zum Tumult war folgender: Ein junger Hamburger hat, bevor die Solisten und ich rauskamen, ein Bild von Guevara an das Podium geheftet. O.K. er hätte es auch lassen können, aber immerhin ist die >Medusa diesem Mann gewidmet. Da hat der Programmdirektor des N.D.R. [...] den blödsinnigen Fehler gemacht, das Bild abzureissen und zu zerstückeln. Erst daraufhin wurde ein neuer $>$ Che` angeklebt, und obendrein die rote Fahne (später auch die schwarze Fahne der Anarchisten). Dies war noch im Gange, als wir auftraten. Dann verlangte der RIAS-Chor die Entfernung der Fahne, und als ich nichts dergleichen tat, verließ er das Podium. [...] Dann versuchten einige Genossen, mit dem RIAS-Chor zu diskutieren (ich auch) und das war noch im Gange als die Polente erschien. So sah das aus. ${ }^{151}$

Der Mitschnitt der Ereignisse zeichnet ein deutliches akustisches Bild der heftig eskalierenden Randale, mit denen die Studentenschaft symbolisch den Kurzschluss zur Politik herstellte. Neben dem Konterfei Che Guevaras besaß auch die rote Fahne symbolische Signalmacht: insbesondere für die Sänger des Westberliner RIASKammerchores, die sich weigerten unter dem Symbol des Kommunismus zu singen

148 Henze: Reiselieder mit böhmischen Quinten, S. 283.

149 Traber: Musik ergreift die Fahnen, S. 34-41.

150 »Uraufführung des Oratoriums $>$ Das Floß der Medusa . Mitschnitt der gestörten Uraufführung, die abgebrochen wird«, in Archiv des Norddeutschen Rundfunk: Wortarchiv F802037 (HF802037).

151 Brief von Hans Werner Henze an Bernhard Conz (2.1.1969). Der Brief ist verzeichnet und einsehbar im Katalog der Autographenhandlung J. A. Stargardt: www.stargardt.de /download/file/kataloge/695/IV_Musik.pdf [Zugriff: 31.8.2017]. 
und deutlich vernehmbar skandierten: »Fahne weg!« Unmittelbar vor Abbruch der Premiere verkündete der Programmdirektor des NDR, Franz Reinholz:

»Meine Damen und Herren. Sie sind Zeuge, dass diese Aufführung nicht ordnungsgemäß beginnen kann, weil eine Handvoll junger Leute [...] den Beginn der Aufführung verzögert haben. Sie haben Transparente und rote Fahnen angebracht und Chor und Orchester weigern sich zu spielen [...] Der Norddeutsche Rundfunk ist nicht bereit, die Veranstaltung durchzuführen. Die Fahne wird hiermit entfernt. $\ll^{152}$

Danach eskalierten die Ereignisse gut hör- und nachvollziehbar, untermalt von einem von Teilen des Publikums geklatschten Ho-Ho-Ho-Chi-Minh-Rhythmus. Der Einmarsch der Polizei wurde von Henze kommentiert, der den Musikern den Rücken und sich stattdessen dem Saalgeschehen zuwandte. In diesem Moment wurde das Dirigentenpodest zur politischen Bühne umfunktioniert: »Lassen Sie die Leute in Ruhe. Die Polizei verhindert bewusst die Diskussion. [...] Ich distanziere mich von den Brutalitäten der Polizei!«

Abbildung 28 - Symbolische Wendung: Hans Werner Henze nutzt das Dirigentenpodest als politischen Bühne

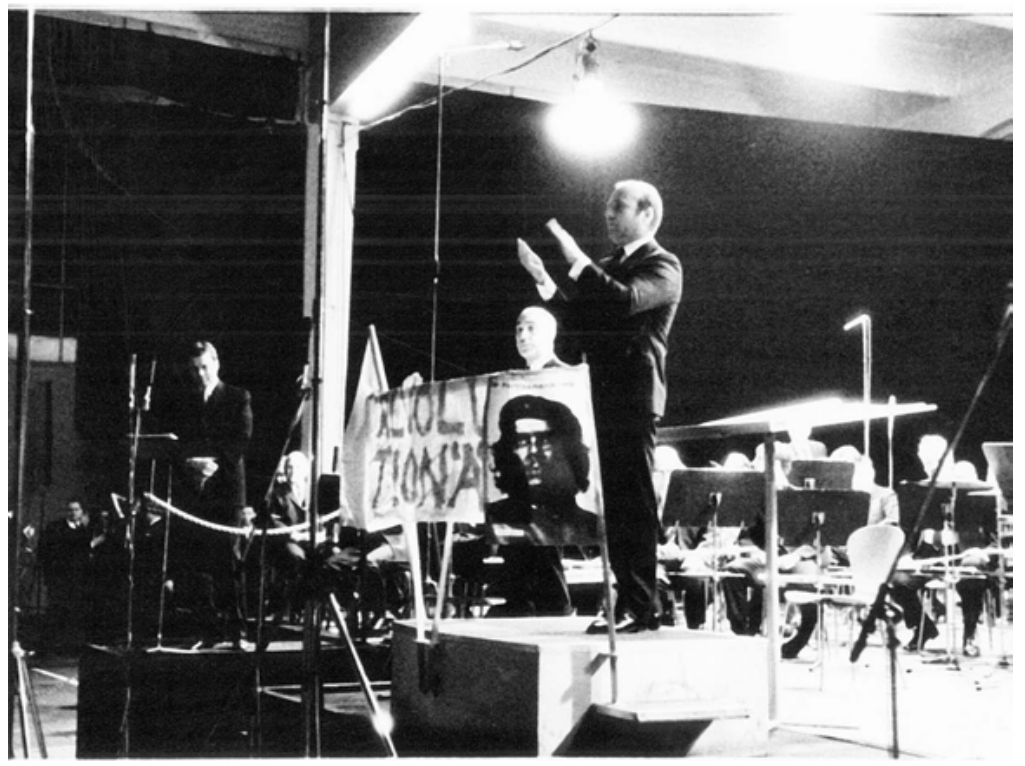

Danach endet der Mitschnitt. Während die Diskussionen im Saal weitergingen und in Handgreiflichkeiten zwischen den studentischen Unruhestiftern und der Polizei eskalierten [Abbildung 29], beendete der NDR die Übertragung und sendete stattdessen einen Mitschnitt der Generalprobe. 
Abbildung 29 - Querstand von Kunst und Politik: Polizisten bringen das »Floß der Medusa« bei seiner Jungfernfahrt zum Kentern

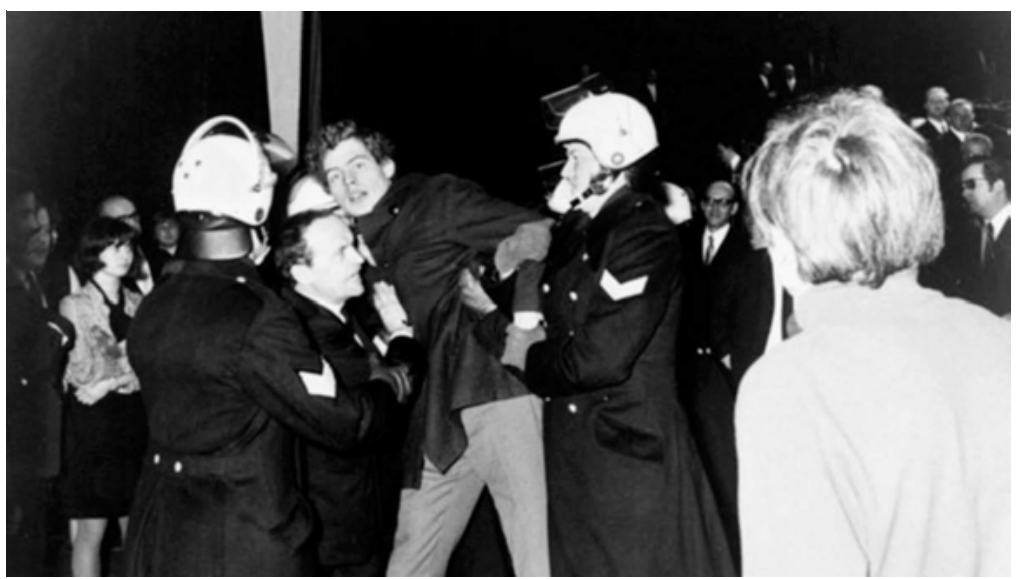

Durch den Abbruch der Live-Übertragung und die Sendung des Probenmitschnitts kam es am 9. Dezember 1968 zu einer paradoxen Dopplung der Ereignisse und zu einer medial herbeigeführten Spaltung des Auditoriums. Wurde das Hamburger Premierenpublikum zu Zeugen des Skandals im Konzertsaal, erlebten die Hörer an den Radiogeräten »die Komposition in Form eines Generalprobenmitschnitts [...], als ob nichts geschehen wäre. ${ }^{153}$ Diese Teilung geschah allerdings nicht ohne Einsprüche: der NDR berichtete später »von zahlreichen Höreranrufen, die die Diskussion im Saale hören wollten. ${ }^{154}$

Aus den gut 20 Minuten des Mitschnitts werden verschiedene charakteristische Faktoren des politischen Musikskandals der 1960er Jahre deutlich: Wie bei der Uraufführung von Luigi Nonos Intolleranza, entlud sich im eskalierenden Gegeneinander antagonistischer gesellschaftlicher Kräfte auch bei der tumultuösen MedusaPremiere ein explosiver Cocktail ästhetischer und politischer Grundsatzfragen. Beide Aufführungen waren Momentaufnahmen und Produkte der sie umfassenden gesellschaftlichen Vorgänge: Beteiligten sich bei Nono überwiegend die pro- und antifaschistischen Kräfte Italiens, stimmte im Fall Henze ein äußerst heterogenes Netz von Akteuren die wesentlich komplexeren Debatten um den >Schiffbruch`seines Flo $\beta$ der Medusa ein. Die Streitpunkte lassen sich klar im aufgeheizten Klima der Bundesrepublik im Schlüsseljahr 1968 verorten: Die Saalschlacht wurde beeinflusst von den Kontroversen um die Aufarbeitung des Zweiten Weltkriegs sowie die Teilung Deutschlands im Zuge des Kalten Kriegs. Dies geschah vor der Folie der Studentenunruhen, die durch sozialistische Musikstudenten aus Hamburg und Berlin in den Konzertsaal getragen wurden. Die Studenten gaben durch das Hissen der roten Fahne nicht nur den unmittelbaren Auftakt für die Randale, sondern reflektierten auf Flug-

153 N.N., in: Süddeutsche Zeitung (11.12.1968) in IMD: Komponisten, Hans Werner Henze 1964-1970, A 296.

154 N.N., in: Hamburger Abendblatt (10.12.1968), in: Ebd. 
blättern auch den charakteristischen Querstand von Kunst und Politik. ${ }^{155}$ Bei der Lektüre des Schriftstücks In Sachen Henze, das die Berliner SDS-Gruppe »Kultur und Revolution« verteilte, wird nicht nur der Widerstand gegen die `bürgerliche Presse und die >kapitalistische Kulturindustrie< deutlich, sondern auch die Instrumentalisierung der Musikavantgarde in der politischen Praxis reflektiert [Abbildung 30].

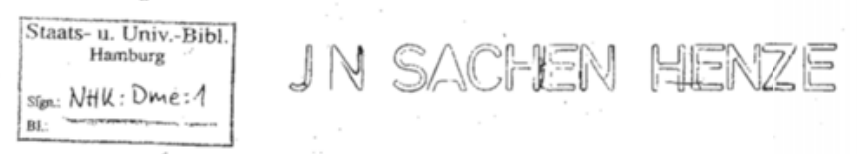

\footnotetext{
Das organisierte Kesseltrelben, das die bürgerliche Presse in jungster'Zo1t gegen den Komponisten Hans Werner Henze entfacht hat, verfolgt die Abaicht, revolutionare Tendenzen, die sich is bislang so ontschlossen verte1digten Kultraum der Kus1k elnzusohloichen und thn au durchbrechen dpohten, in Kelm zu erstioken. On diese Vérnichtungaktion wirkungsvell zu gestalten hst sich das bürgerliche Lager eine besonders abgefeinte Strategie ausgedacht:

Ein restaurativer Liberalismus gibt vor, er verteidige die Revoliution sowohl in der Kunst wie in der polftisches' Praxis. Der Komponist Henze, no befand man, handlø "konterrevolutionär", da er bourgeoiso Musik für ein bourgeoises Publikum komponiere.

- Plötzlich entdecken die, die sich nie gescheut haben, den Linken eins asuwisohen, ihr Herz fur'die Revoluticn.

- Plötzlich propagieren die, die bislang 1mmer die fortachrittliche Burgerliche Kunst unter Kontrollo gehal ten haben, das Neue, das Avantgardistische, weil sie es gegen die "Bingängigkeit" des Komponisten Henze ausspielen können, von der'sle furchteł, auch die lohnabhängigen Massen könnter. bald 1hre revclutionären Absichten erkennen.

DAZU EÄRE ZUNÄCHST FESTZUSTELLEN:
}

Unter dom Einflus der kapitalistischen Kulturindustrie ist die Kunst zun Tauschobjekt geworden, das nur noch dazu dient, Profit zu machen. Die Kunst als unschuldig autonones Produkt kritischen BewuBtsoins hat ihr unsbhangiges asein aufgeben mussen. Die Intentionon von Kunstlern sind irrolevant gewordon. Der seghanisaus der $V$ erkaufsatrategie bestime die Kultur.

Katogorien wie bourgeois oder revolutionär sind "ertmarken geworden, die den einselnen Kunstworken, die als Waren unterm Aspokt ihrer bknnomischen Verwertbarkeit gesehen werden, nach Belleben aufgeklebt werden könnon. Unter den Bedingungen der kaplitalistischen Kul tur kann revolutionltr Kunst den Bedingungen dor kapilalis Vertetlung rovolutionare Kunst mieht rovolutienar wirken. D1 Verteilung von Kunst, die kritische Inhalte in unverbindliche Reizwerto unwandelt, dio gestouorto Rezeption, die dieso Reizwerte auf Kommando verspeist, verhindern eine adăquate Realisierung revolutionärer Gehalte. Der Begriff REvOLUTIONARB KUNST ist zus Spiolball oines auf Profit hin orientierten Distributionsapparates gevorden.

Wenn die bürgerliche Presse die "revolutionäre" Kunst gegen die "bourgeoise Kusst in Schutz nimet, so kann sie sich darauf verlassen, daB beides Phantose sind, daB also die gepsiosene rovolutiobire Kunst, solange sie sich dem kapitalistiscken Apparat ausliefern muB, nie gefahrlich werden kann.

155 SDS-Projektgruppe Kultur und Revolution/AStA der Hochschule für Musik Berlin: »In Sachen Henze« (Flugblatt), in Staats- und Universitätsbibliothek Hamburg: NHK:Dme:1; Siehe weiterführend auch das Flugblatt des Arbeitskreis Sozialistischer Musikstudenten Hamburg: »In Sachen Medusa«, in: Ebd. 
In der Folge setzt das Flugblatt diese allgemeinen und offensichtlich von Theodor W. Adorno inspirierten doch radikalisierten Reflexionen über den »Einfluss der kapitalistischen Kulturindustrie« fort: Kunst verkomme zum »Tauschobjekt« und verliere damit ihre subversive Kraft gegen das Affirmative. Hans Werner Henze habe eingesehen, dass die »bürgerliche Klasse wahrhaft avantgardistische Kunst ebenso wie die gesamte revolutionäre Befreiungsbewegung unschädlich machen will«:

Abbildung 30b - Spaltung der Studentenschaft »In Sachen Henze»

\begin{abstract}
Honze, der in seine kompositurischen tberlegungen die Rezeption mit einbezieht, ist den professionellen Kulturverwaltern verdachtig geworden, die mit dem Fortschritt der Kunst einon Fortschritt der entfreadeten Arbeit und damit die zunehmonde Distanz der Kunst von gesellschaftlicher Konaunikation propagieren. In der Verselbstandigung as thetischer Technik, in 1hrer Unverstandlichkelt für die Ungebildeten haben sie ein willkonaenes Mittel zur Einschuchterung der Xasisen entdeckt. Wenn sie nun einen Kunstproduzonten dafür scheltén, dả ex sich dieser Strategie entzieht, dann köpinen sie darauf bauen, daB jeder Binbruch konkret Gesellachafticher Isplikate in die. Tempel der Kunst von den NutznieBern der Kultur'sowohl ais künstlerisches wie als gesellschaftiches Delikt geahndet wird,

Die subjektiven revolutioniiren Intontionen Henzes gehen nicht bruchlos in der asthetiachen Objektivation seiner Werke auf. In Gegensatz aber zu seinen birgerlichen Gegnern, die. ihn nun wegen des Verrats an ihrer K Lasse attackieren, hat er eingesehen, daB eben diese Klasse wahrKaft avantgardistische Kunst obenso wio gesamte revolutionăre Befreiungsbewegung unschadilich machen will.

WAN SCHLXCT DEN SACK OND YEINT DEN ESEL : DIE KANPAGNE GILT NICHT DÉ KOMPONISTEX HENZE SONDERN SEINEM BINSATZ FUR DIB POLITISCHE BEFRE IUAG '

Wenn houte abend ein "Publikue in Smoking und Nerz" erscheint, so ist das nicht Henze anzulasten. Jas Konzert sellte vor Arboitern stattfinden, jetzt ist die Bourgeoisio zu Gast. Iie Sachwalter der Klassenkultur haben zu verhindern. govußt, dal die Kunst ihr 2iel erre1cht. D1e Bürger klatschen der Hevolution Beifall. Das Konzert wird aufs neue für die Featigung des herrschenden Systems sorgen.

Noch darf das. erlesene bürgerlicho Publikum, das die Musik Henzes zwar als die seine okkuplert hat, aber in Wahrheit nicht begreift, ungestört von den lohnabhängigen Masseh seine teure Garderobe zeigen.

Honze aber wird in Zukunft revolutionare Wusik schroiben und dafür sorgen, daß sie auch von denea, fur die sie genacht ist, gohört und verstanden wird.
\end{abstract}

\author{
SDS-Projektgruppe \\ "Kultur und Revolution" \\ Berlia \\ AStA ler Hochschule \\ für Masik Berlin
}




\section{Nachspiel: Der >Champagner-Linker}

Wurde der Eklat durch gesellschaftspolitische Problemlagen und mediale Inszenierungsstrategien vorbereitet und eskalierte im Moment der Aufführung durch die polarisierenden Praktiken der revoltierenden Studenten und der Polizei, so stießen die Ereignisse in der Folge weitreichende und wiederum medial verhandelte Debatten an. Nach der gescheiterten Premiere zählte der Librettist Ernst Schnabel in seinem Postscriptum »einhundertzwei Zeitungsartikel, Kritiken, Pressemeldungen und Offene Briefe ${ }^{156}{ }^{2}$, die sich mit den Ereignissen um Hans Werner Henzes Flo $\beta$ der Medusa beschäftigten. Beispielhaft sprach Klaus Geitel in Die Welt von einer »Karawane der in- und ausländischen Musikkritik. « ${ }^{157}$

Der Großteil der Beiträge setzte mithilfe sensationsheischender Schlagzeilen auf große Auflagen. Wurde die Aufmerksamkeit der Leser im Fall von Nonos Intolleranza durch Überschriften wie »Skandal in Fenice ${ }^{158}$ mit direktem Bezug auf die tumultuösen Ereignisse erzeugt, bezogen sich die Schlagzeilen zu Henzes MedusaPremiere insbesondere auf deren politische Motiviertheit. Häufig wählten die Zeitungen feuilletonistische Wortspielereien mit dem Werktitel. Im Hamburger Abendblatt etwa hieß es: »Henzes Floß der Medusa in den APO-Wogen untergegangen. « ${ }^{159}$ Ähnliche Überschriften fanden sich in nahezu allen großen deutschen Zeitungen. Schrieb die Hamburger Morgenpost von einem »Krawall nach Noten. Henzes Floß der Medusa ist zerschellt ${ }^{160}$, sprach die Frankfurter Allgemeine Zeitung von der »Hamburger Strandung von Henzes Floß der Medusa «. ${ }^{161}$ Auch Die Welt und die Süddeutsche Zeitung beriefen sich auf das »gekenterte « beziehungsweise »gestrandete « Floß. ${ }^{162}$

Dagegen berichtete Die Presse, Henze habe »einen von Millionen Radiohörern verfolgten, spektakulären Theaterskandal $«{ }^{163}$ ausgelöst und thematisierte damit die enorme Reichweite der Ereignisse. Tatsächlich war das Auditorium durch die Rundfunkübertragung schlagartig um ein Vielfaches erweitert worden: zusätzlich zu den etwa 1.000 Zuhörern im Konzertsaal konnte jeder Besitzer eines Radios die Aufführung live miterleben. Nicht nur die zahlreichen Pressestimmen und die enorme nachrichtentechnisch generierte Reichweite der Geschehnisse machten den Skandal um Hans Werner Henzes Floß der Medusa zu einem transnationalen Medienereignis; Auch die Prominenz der Wortführer trug dazu bei, denn in der Folge schalteten sich nahezu alle namhaften deutschen Kulturredakteure in die Debatten ein.

156 Ernst Schnabel: Das Floß der Medusa. Text zum Oratorium von H. W. Henze. Zum Untergang einer Uraufführung. Postscriptum, München 1969, S. 65.

157 Klaus Geitel, in: Die Welt (11.12.1968), in: Ebd.

158 N.N., in: Cannstädter Zeitung (20.4.1961), in: Ebd.

159 N.N., in: Hamburger Abendblatt (10.12.1968), in: Ebd.

160 N.N.: »Krawall nach Noten. Henzes Floß der Medusa ist zerschellt«, in: Hamburger Morgenpost (10.12.1968), in: Ebd.

161 N.N.: »Requiem auf ein Requiem. Zur Hamburger Strandung von Henzes >Floß der Medusa«, in: Frankfurter Allgemeine Zeitung (10.12.1968), in: Ebd.

162 N.N.: »Das gekenterte Floß«, in: Die Welt: (11.12.1968). N.N.: Das Floß der Medusa gestrandet, in: Süddeutsche Zeitung (11.12.1968), in: Ebd.

163 N.N., in: Die Presse (11.12.1968), in: Ebd. 
Der Spiegel-Herausgeber Rudolf Augstein bezog persönlich Stellung gegen Henze, den er als »objektiv reaktionären Komponisten« bezeichnete. Dazu wurde ein APOPlakat abgebildet, auf dem es hieß: »Auf Stern-Schwänze und SPIEGEL-Votzen kann Henze musikalisch kotzen. ${ }^{164}$ In den folgenden Ausgaben veröffentlichte das Magazin eine Reihe von Leserbriefen prominenter Künstler und Intellektueller: von Karlheinz Stockhausen, über Peter Weiss bis hin zu Hans Werner Henze selbst. ${ }^{165}$ Die Frankfurter Rundschau veröffentlichte ein Solidaritätstelegramm italienischer Künstler unter Federführung des Regisseurs Luccino Visconti, in dem es hieß:

»In einer Periode revolutionärer Aktion wird den Kritikern das Recht bestritten, den revolutionären Charakter des Kunstwerks nach sprachlichen Kategorien zu bestimmen. [...] Das soziale und politische Engagement von Hans Werner Henze kann nicht in Zweifel gestellt werden. Wir protestieren gegen den Versuch, ihn von seinem Werk getrennt zu beurteilen. ${ }^{166}$

In derselben Ausgabe erschien Luigi Nonos »Gruß an Henze«, der die Verantwortlichkeit der Musiker an einer sozialrevolutionären Menschlichkeit betonte: »Kommunist ist man nicht, Kommunist wird man«. Dies gelte auch für Komponisten:

»Jemand wählt USA (mit allen ästhetischen und ökonomischen Bequemlichkeiten), aber der bewußte Musiker in Westdeutschland wählt ApO und SDS. Was in Hamburg mit >Floß der Medusa und Hans Werner Henze [...] passiert ist, zeigt das als klares Beispiel. Von einer Seite Bürokraten und Manipulateure des Rundfunks [...] zusammen mit der Brutalität der Polizei, von anderer Seite neue Ideen, Menschen, Musik, die für die Veränderung [...] der Gesellschaft in Westeuropa arbeiten. Zu diesen gehöre ich, und ich will öffentlich meine Solidarität meinem Freund Hans Werner Henze und den Studenten von Hamburg [...] ausdrücken. ${ }^{167}$

Die Berliner SDS-Projektgruppe »Kultur und Revolution« freute das »brutale Eingreifen der Polizei, das ganze Spektakel hat unserer Sache einen unschätzbaren Dienst erwiesen. $«{ }^{168}$ Dagegen bedauerten konservative Kräfte den »vorschnellen Ruf nach der Polizei «, denn »so schafft man Märtyrer « ${ }^{169}$. Das harte Durchgreifen der Polizei erfuhr auch Ernst Schnabel, der in seinem »Postscriptum« zu Protokoll gab:

»Der Student, den ich gerade ansah wurde an beiden Armen gepackt, obwohl er nur dagestanden hatte [...]. Ich [...] rief den Polizisten zu: \Lassen Sie den Mann los! [...] Dann ergriffen auch mich zwei Polizisten [...]. Ich kann sagen, dass keine Gefahr bestand, für niemanden. Trotzdem hatten es die Polizisten sehr eilig, die große Tür aus Riffelglas zu erreichen, und obwohl sie nicht abgeschlossen war, traten wir durch eine der beiden Glasscheiben hindurch ein [...]. In Halle B ist das Glas dick, so dass man mich zweimal hineinstoßen musste. « ${ }^{170}$

164 Rudolf Augstein: »Apropos Henze«, in: Der Spiegel (51/1968), S. 154.

165 Der Spiegel (1968), Nr. 50 und 51.

166 N.N., in: Frankfurter Rundschau (16.12.1969).

167 Ebd.

168 Ebd.

169 N.N., in: Hamburger Abendblatt (10.12.1968).

170 Schnabel: Postscriptum, S. 59f. 
Schnabels Verhaftung folgte eine Anklage wegen Widerstands gegen Vollstreckungsbeamte und versuchte Gefangenenbefreiung. Die Polizei sah sich in der Folge mit Vorwürfen des Missbrauches von Staatsgewalt und Vergleichen mit den Praktiken während der NS-Zeit konfrontiert. ${ }^{171}$

Neben diesem Arsenal sozial- und medienkritischer Themen wurden die Premierenrandale auch immer wieder in ästhetische Zusammenhänge gestellt. Dabei wurde Henze der pseudo-revolutionären Agitation beschuldigt, da er durch seine rückwärtsgewandte Ästhetik dem Establishment verpflichtet sei. So kritisierte Die Zeit, dass der Komponist »Sozialkritik in der Verpackung des Schönen und Artifiziellen « ${ }^{172}$ übe. Auch in Ernst Schnabels Libretto - so ergänzte Die Welt - würde »für Gutgebildete gestorben, in geschmackvoller Sprache, auf Deutsch und Italienisch. ${ }^{173}$ Zudem sollte »die Formgattung Oratorium, die konzertante Zelebration, die obsolete Hierarchie Chor-Orchester-(Kollektiv)-Solisten-Dompteur, in der sich immer noch Herrschaftssysteme spiegeln, gegen revolutionäres Denken allergisch sein. « ${ }^{174}$ Wolle Henze wahrhaft revolutionäre Musik machen, müsse er »lernen von der wahrhaft revolutionären Musik im China nach der Kulturrevolution ${ }^{175}$ denn $»$ musikalisch wird man heute für die Masse nur verständlich, wenn man einen Fastnachtsschlager zu kreieren versteht. ${ }^{176}$

Weitere ästhetische Kritik bezog sich auf Hans Werner Henzes ästhetische Abkehr von den aktuellen Entwicklungen der Musikavantgarde. Dabei wurde insbesondere der Vergleich zu Luigi Nono gezogen, der als »Revolutionär unter den Komponisten der Henze-Generation wie kein zweiter immer bestrebt ist, seine politische Überzeugung [...] mit einer qualitätsstarken Musik zu vereinen « ${ }^{177}$ und der »ähnliche, politisch brisante Themen mit musikalischem Dynamit geladen ${ }^{178}$ habe. War Nono beim Premierenskandal der >azione szenica〈 Intolleranza gerade wegen seiner avancierten Tonsprache angegriffen worden, war es bei Hans Werner Henze genau anders herum: sein inhaltlich provozierendes, in der musikalischen Grundhaltung aber lyrisches >oratorio volgare e militare` wurde als rückwärtsgewandt gebrandmarkt und führte nach einhelliger Pressemeinung zum musikalischen Schiffbruch seines Floß der Medusa.

Zum großen und auch mit analytischem Blick auf das Phänomen Musikskandal relevanten Thema wurde der Inszenierungscharakter der Ereignisse. Dieser wurde nahezu allen beteiligten Akteuren wechselseitig und je nach Standpunkt vorgeworfen. Ernst Schnabel bemerkte in seinem »Postscriptum«, dass vor dem Konzert ein Mitarbeiter des Spiegels beim Hamburger SDS erschienen sei und zur Sabotage aufgefordert habe: »Das war Masche. Allenfalls ein Triumph der Musikredaktion des Spiegels. $«{ }^{179}$ Dagegen berichtete das Hamburger Abendblatt, dass »der Staatsschutz-

171 Ebd., S. 65.

172 N.N., in: Die Zeit, (13.12.1968).

173 N.N., in: Die Welt (11.12.1968).

174 N.N., in: Der Spiegel (1/2 1969).

175 N.N., in: Süddeutsche Zeitung (11.12.1968).

176 N.N., in: Christ und Welt (20.12.68).

177 Ebd.

178 N.N., in: Rheinische Post (11.12.1968).

179 Schnabel: Postscriptum, S. 48f. 
Abteilung der Hamburger Kriminalpolizei [...] gemeldet worden [sei], dass Henze vor der Veranstaltung ein Gespräch mit dem SDS hatte, in dem er gefragt haben soll, ob die vereinbarten Störungen auch wirklich stattfinden würden. ${ }^{180}$ Allerdings, so bemerkte Schnabel, habe der Komponist kein anderes Interesse gehabt, als das Oratorium aufzuführen. Er wendete den Vorwurf der öffentlichkeitswirksamen Inszenierung gegen den Norddeutschen Rundfunk: der stellvertretende Intendant habe ihm am Vorabend der Premiere gesagt »er habe Vorkehrungen getroffen. Im Falle einer Störung des Konzerts werde anstatt der Uraufführung ein Mitschnitt der Generalprobe auf der Mittelwelle des NDR und WDR gesendet werden. Er habe Anweisung gegeben, etwa demonstrierende Studenten gewähren zu lassen. ${ }^{181}$ Schließlich darf auch von Seiten der Randalierer davon ausgegangen werden, dass die Sabotage der Premiere keine spontane Aktion war. Dafür spricht nicht nur der Einsatz von Flugblättern und Trillerpfeifen, sondern auch die Tatsache, dass - wie Die Welt berichtete - einige Musiker außer ihren Instrumenten auch Fotoapparate mitbrachten und Erinnerungsbilder schossen. ${ }^{182}$

Es kann also davon ausgegangen werden, dass die breitenwirksame und als LiveMitschnitt zur besten Sendezeit konzipierte Premiere bewusst als Plattform für die Skandalisierung von Werk und Komponist genutzt wurde. Mit Blick auf die Inszenierungsstrategien der verschiedenen Akteure lässt sich zusammenfassen, dass die Randalierer im Publikum politisch motiviert handelten, dagegen dürften die Presseberichte nicht zuletzt mit Blick auf die Auflage zu bewerten sein. Die öffentliche Aufmerksamkeit war aber auch im Interesse der Veranstalter und nicht zuletzt des Komponisten selbst. Darauf weist ein Leserbrief hin, in dem der italienische Komponist Renato de Grandis den Medusa-Skandal mit Blick auf die gesellschaftliche Isolation der Neuen Musik reflektierte und in Bezug auf Strategien im Sinne einer Ökonomie der Aufmerksamkeit setzte:

»Heute leidet die Avantgarde unter Altersbeschwerden. [...] Das Interesse des Publikums ist erlahmt. Deshalb verschieben wir Musiker den Rahmen des Spiels von der Musik auf andere Probleme, um das Interesse des Publikums wieder auf uns zu lenken. ${ }^{183}$

Überblickt man das gewaltige Medienecho auf die skandalumwitterte Premiere von Hans Werner Henzes Floß der Medusa, lässt sich konstatieren, dass die Aufführung ein hohes und im Bereich der Neuen Musik sogar außergewöhnliches Maß an öffentlicher Aufmerksamkeit erhielt. Dennoch darf der Nutzen des Skandals für den Komponisten bezweifelt werden. In dem schon zitierten Brief an den Dirigenten Bernhard Conz bemerkte Henze, die »Konsequenzen, z.B. den vorauszusehenden Boykott, scheue ich nicht. $\ll{ }^{184}$ Deutlich bitterer klingen dagegen die Erinnerungen, die er 1986 in einem Interview zu Protokoll gab:

180 N.N., in: Hamburger Abendblatt (12.12.1968).

181 Schnabel, Postscriptum, S. 48.

182 N.N., in: Die Welt (10.12.1968).

183 N.N., in: Der Spiegel (1969), Nr. 1.

184 Brief von Hans Werner Henze an Bernhard Conz (2.1.1969), in: Autographenhandlung J. A. Stargardt. 
„Das habe ich sehr bitter erfahren in den Jahren nach dem `Medusa'-Skandal von 1968, als plötzlich die Werke nicht mehr gespielt wurden, die Theater die Stücke absetzten und die Verträge rückgängig machten. [...] Wie oft bin ich dort ausgebuht worden, verhöhnt worden, wie oft habe ich Schiffbruch erlitten! Als er Stücke von mir dirigierte, wurde selbst Karajan ausgebuht, als ob ich es selber sei. ${ }^{185}$

Diese Aussage ist belegbar: Kuriosestes Beispiel ist der Münchner König-LudwigClub, der in einem Brief an den damaligen Intendanten der Bayerischen Staatsoper Bedenken gegen einen Kompositionsauftrag anmeldete, den Henze anlässlich der Olympischen Spiele 1972 erhalten hatte: Es bestehe »bei der augenblicklichen Haltung Henzes, auf Bühnen rote Fahnen zu hissen, für Bayern keinen Anlass, ihn noch zu honorieren. Vor allem liegt es nicht in der bayerischen Art, Edelkommunismus zu züchten. ${ }^{186}$ Tatsächlich zog die Bayerische Staatsoper, und das ist nur ein Beispiel, den Auftrag zurück. Er habe damals, so führte der Komponist später aus, »vorgeschlagen, Peter Weiss' frühes Anarcho-Stück >Die Versicherung< [...] als Libretto zu verwenden. [...] Aber das hat man in der Staatskanzlei wohl nicht für einen olympiageeigneten Stoff gehalten. $"{ }^{187} »$ Politisches Handeln«, so schlussfolgerte der Komponist Peter Michael Hamel, »hatte damit [...] das politische Komponieren verhindert, seiner Rezeption beraubt. ${ }^{188}$ Der Boykott gegen Hans Werner Henze traf nicht zuletzt Das Floß der Medusa selbst, und zwar grenz- und ideologieübergreifend: Nach seinem Austritt aus der Westberliner Akademie der Künste 1968 wurde Henze als korrespondierendes Mitglied ihres Ostberliner Pendants vorgeschlagen. Dort plante man zunächst eine Aufführung des Oratoriums, allerdings wurde der Plan aus ideologischen Gründen verworfen. Diese Entscheidung bedauerte der Präsident der Akademie, Konrad Wolf, im Januar 1969 in einem Brief an den Ministerrat der DDR:

»Die Sache ist für uns darum so kompliziert, weil Hans Werner Henze nun einerseits der Hamburger Affäre und zum anderen unserer Absage gegenübersteht. Feindlich gesinnte Kräfte können also die Möglichkeit haben, tendenziöse Parallelen zu ziehen. « ${ }^{189}$

Erst 1974 realisierte Herbert Kegel, Chefdirigent des Leipziger RundfunkSinfonieorchesters, die Erstaufführung des Oratoriums in Ostdeutschland und auch hier provozierte Das Floß der Medusa einen politisch motivierten Eklat: Infolge harscher Kritik seitens der ostdeutschen Kulturfunktionäre an der Che-GuevaraDarstellung sowie Henzes Kompositionsstil trat Kegel in der Folge im Protest aus dem Verband der Komponisten und Musikwissenschaftler der DDR aus. ${ }^{190}$

185 Hans Werner Henze: »Die Unruhe mobilisieren «, in: Die Zeit (27.6.1986).

186 N.N., in: Die Presse (28./29.12.1968).

187 N.N.: »Immer für die Sünder«.Hans Werner Henze über zeitgenössisches Musiktheater«, in: Der Spiegel (7.5.1990), S. 243-254, hier S. 251.

188 Hamel: Politisches Komponieren damals und heute, S. 93.

189 Brief von Konrad Wolf an Alexander Abusch (31.1.1969), in Archiv der Akademie der Künste Ost: Sektion Musik, Korrespondenz mit und über Hans Werner Henze 1968-69.

190 Gerhard Müller: »Musik wird politisch - Politik wird musikalisch«, in: Booklet der CD Politische Oratorien (RCA 2005). 
Im Westen dagegen blieb das Stigma des >Champagner-Linken Henze haften. 1971 etwa wurde in Berlin Der langwierige Weg in die Wohnung der Natascha Ungeheuer ${ }^{191}$ aufgeführt und provozierte die Bild-Zeitung zu einem Beitrag über die »Uraufführung eines tönenden kommunistischen Manifests«. Darin mokierte sich der Chefredakteur Peter Boenisch über die Textvorlage von Gastón Salvatore, der 1969 infolge seiner Teilnahme an den 68er-Protesten verurteilt worden war:

»Der Komponist ist der Salon-Kommunist Hans Werner Henze. Der Textdichter ein Überzeugungstäter, ehemaliger Berliner Soziologiestudent. Vorbestraft. Wegen schwerem Landfriedensbruch. Neun Monate Gefängnis. (Bedauerlicherweise musste er sie nie absitzen.) Die Stadt, der er die Fensterscheiben einwarf, gibt nun Steuergelder dafür aus, dass sein Revolutionsgeschrei statt auf der Straße auf der Bühne stattfindet. Musische Resozialisierung. Durch seine Taten gehen nicht mehr die Scheiben entzwei, sondern nur noch die Ohren. ${ }^{192}$

Ein Artikel zur Neuen Musik in der Bild, noch dazu aus der Feder des Chefredakteurs, war fraglos ein seltenes Ereignis. Die pointierte Kritik liefert heute mit Stichpunkten wie >akustischer Landfriedensbruch` oder >musische Resozialisierung`von `Salonkomponisten ven Querstands von Musik und Politik im Umfeld von 1968. Allerdings wies das Bühnenwerk trotz des direkten Bezugs zur Studentenbewegung in der Interpretation Arnold Jacobshagen zugleich auf die Postmoderne hin:

»Es kommt hier zur Entgrenzung traditioneller Gattungen, stilistischer Codes, performativer Praktiken und [...] des musikalischen Materials. Avancierte Stilmerkmale wie die Theatralisierung der Musiker oder die Einbeziehung von elektronisch erzeugten Klängen [...] sind keineswegs bloß Vehikel einer musikalischen Ästhetik, die politischen Fortschrittsdrang und avancierte Materialbehandlung möglichst schlüssig zu vereinen suchte, sondern vielmehr zugleich Mittel der Ironie, der Parodie und Persiflage. Musikhistorisch und phänomenologisch kann Henzes Auseinandersetzung mit der Studentenbewegung somit am Übergang von der informellen Musik der 1960er Jahre zur Polystilistik der Postmoderne verortet werden. ${ }^{193}$

Noch deutlicher als Hans Werner Henze setzte 1971 Maurizio Kagel mit seiner klingenden Institutionenkritik Staatstheater die öffentliche Performanz der politischen Bewegungen in Szene und verkündete dabei zugleich auch das musikalische Ende der politischen Dekade. Mit dadaistischem Aktionismus komponierte er eine multimediale Überleitung in die Postmoderne und beendete den für die 1960er charakteristischen Querstand von Kunst und Politik.

191 In dem Bühnenwerk thematisierte Henze die reale Figur der Malerin Ursula Rosa (Natascha) Ungeheuer, deren Wohnung in Berlin-Kreuzberg als eine Art 68er-Salon Bekanntheit erlangte.

192 Peter Boenisch: »Meine Meinung. Die Knaben zwischen Marx und Mao stehen in Berlin auf der Bühne«, in: Bild-Zeitung (4.10.1971).

193 Arnold Jacobshagen: »Musica impura. Der langwierige Weg in die Wohnung der Natascha Ungeheuer von Hans Werner Henze und die Berliner Studentenbewegung «, in Jacobshagen/Leniger (Hg.): Rebellische Musik, S. 109-124, hier S. 123. 


\section{Eine Oper »to end all operas«: Mauricio Kagels Staatstheater (1971)}

War die politische Ausrichtung Luigi Nonos im Gefüge Italiens verortet und spiegelte der Fall Henze das gesellschaftliche Klima der Bundesrepublik Deutschland, so agierte auch Mauricio Kagel aus einer spezifischen Herkunftssituation heraus: Der gebürtige Argentinier und in Köln musikalisch sozialisierte Komponist, so arbeitete Thorsten Teubl in seiner Dissertation zum Musiktheater in der Krise heraus, »formulierte einen interdisziplinären Ansatz, welcher im Gegensatz zur kulturellen Haltung Argentiniens und dessen ununterbrochenen politischen Katastrophe steht ${ }^{194}$ : hierarchische Ordnungen stellte Kagel als künstlerische Reaktion auf eine Tradition politischer Gewalt grundsätzlich infrage. Als Land europäischer Zuwanderer war zwar auch Argentinien künstlerisch der westlichen Welt zuzuordnen, doch fand hier - so stellte Marco Bosshard fest - »die Überwindung der Trennung von Kunst und Leben [...] auf eine sehr viel erfolgreichere Weise statt«. Ihre Produkte seien »poéticas de la era postcolonial ${ }^{195}$ und weisen damit auch auf die transkulturellen Transfers, die Mitte des 20. Jahrhunderts zu einem Ende der eurozentrischen Kulturhegemonie und zu einer Neuvermessung der klingenden Welt führten. ${ }^{196}$ Dank der räumlichen Deplatzierung führte die Transformation der nichteuropäischen künstlerischen Avantgarden im Anschluss an Hans Ulrich Gumbrechts »Kaskaden der Modernisierung « ${ }^{197}$ zu einem >Akt des Bruches mit der Repräsentation`, der bei Kagel exemplarisch in Formen der De-Temporalisierung, De-Subjektivierung und De-Referentialisierung mündete - also charakteristischen Momenten der Postmoderne.

\section{Vorspiel: Composition und Decomposition}

Hatten Luigi Nono und Hans Werner Henze das Musiktheater als Symbol des bürgerlichen Establishments sowie als multimediale und auch semantisch aussagekräftige Gattung zum Leitmedium des politischen Musikskandals erhoben, höhlte Mauricio Kagel die Institution im Sinne der aufstrebenden und performativ wirksamen Fluxusund Aktionskunst aus. Diese Entwicklung gipfelte am 25. April 1971 in der Premiere der szenischen Komposition Staatstheater, deren Konzept Kagel im Programmheft der Hamburgischen Staatsoper folgendermaßen skizzierte:

»Dieses Stück hat zum Thema, dass die übliche Oper nicht mehr geht [...]. Wir haben nun $[\ldots]$ ihren präzise durchkomponierten Unsinn [...]. Im Übrigen ist Staatstheater eine Oper >to end all operas $\left\llcorner.{ }^{198}\right.$

194 Thorsten Teubl: Musiktheater in der Krise, Hamburg 2008, S. 188.

195 Marco Bosshard: La reterritorializaciòn de lo humano. Una teoría de las vanguardias americanas, Pittsburgh 2012, S. 40f.

196 Siehe hierzu ausführlich das Kapitel Transkulturelle Transfers.

197 Hans Ulrich Gumbrecht: »Kaskaden der Modernisierung«, in Johannes Weiß (Hg.): Mehrdeutigkeit der Moderne, Kassel 1998, S. 17-41.

198 Marianne Kesting: Instrumentales Theater und Anti-Oper, in: Programm der Hamburgischen Staatsoper (1970/71), S. 90-94, hier S. 92f. 
Mit dem titelgebenden Zitat zu diesem Vorspiel der Ereignisse - einem Werktitel aus dem Jahr 1964 - wird Mauricio Kagels Verweigerung einer affirmativen Kunstauffassung und Musikpraxis deutlich: »Komposition ist die Dekomposition einer Vorstellung. ${ }^{199}$ Sein Werk hat wenig Drang zum Positiven und pflegt eine Affinität zum Geräuschhaft-Szenischen; performative Aktionen und unreine Klänge sind wesentlicher Bestandteil seiner Ästhetik. Kagels >negative` Kunstauffassung schürte bei vielen politischen Komponisten die Hoffnung auf eine gesellschaftsrelevante wie ästhetische Erneuerung der Neuen Musik und besonders des zeitgenössischen Musiktheaters. Mit der Dekonstruktion der Institution Kunst, so bemerkte etwa Dieter Schnebel 1970, zielte Kagel auf die Herstellung einer »Metonymie zwischen dem Subsystem Kunst und der gesamtgesellschaftlichen Realität. ${ }^{200}$ Diese kritische Kunstauffassung äußerte sich seit Kagels Übersiedlung 1957 nach Europa und steigerte sich beständig bis zum Skandal um sein Staatstheater 1971.

Bereits in Anagrama (1958) für Sprechchor, Vokalsolisten und Instrumentalensemble gibt sich der Argentinier lustvoll dem Konventionsbruch hin: Grunzen, Zischen und Nonsens-Gebrabbel des Sprechchors lassen sich als Befreiung des Individuums von gesellschaftlichen Zwängen verstehen. Gleiches gilt mit Blick auf die `Darmstädter Schule`, dem Zentrum seriellen Avantgarde: Zwar besitzt das Werk eine Reihenstruktur; diese wurde aber, wie Björn Heile feststellte, bewusst gegen die mit der seriellen Technik verbundenen ästhetischen Dogmen verwendet:

»Anagrama $[\ldots]$ macht sich zunutze, dass serielle Permutationen grundsätzlich unabschließbar sind, das heißt, dass das Produkt jeder Permutation wiederum ein Ausgangspunkt einer weiteren Permutation sein kann. Auf diese Weise scheint sich das Stück rhizomatisch in alle Richtungen auszubreiten; [...] in jedem Augenblick [wird] deutlich, dass Grenzen willkürlich gesetzt sind [...] Es geht ihm [...] um das Element der Abstrusität und Irrationalität, das jedem System $[\ldots]$ innewohnt. $\ll^{201}$

Auch Transición II (1958) kann als Parodie des zeitgenössischen Materialdenkens sowie als Kritik am Autonomiegedanken der Neuen Musik interpretiert werden: Serielle Verordnung, Aleatorik, graphische Notation, Live-Elektronik, Clusterbildung, Klavierpräparation (in Echtzeit) stellen die Möglichkeit von musikalischem Sinn in Frage, das Fortschrittsdenken und der Materialfetischismus der westlichen Avantgarden werden ad absurdum geführt. Ähnliches gilt für Sur scène (1962), einem kammermusikalischen Theaterstück in einem Akt für Sprecher, das als eines der ersten Werke von Kagels >instrumentalem Theater gilt. Die Komposition steht einer im klassischen Sinne verstandenen Oper entgegen und scheint dem Musikbetrieb einen Spiegel vorzuhalten: Ein Mime, der als Allegorie des Publikums agiert, folgt dem Treiben der drei Instrumentalisten und des Baritons mit wachsendem Befremden, begleitet durch die szenische Personifizierung der Musikkritik durch einen Sprecher abstruser Weisheiten.

199 Mauricio Kagel über Composition und Decomposition (1964), zitiert nach Dieter Schnebel: Mauricio Kagel. Musik - Theater - Film, Köln 1970, S. 141.

200 Dieter Schnebel: Mauricio Kagel: Musik - Theater - Film, Köln 1970, S. 22.

201 Björn Heile: The Music of Mauricio Kagel, Aldershot 2006, S. 83. 
Diese Unterminierung der Aufführungssituation wurde konstitutiv für Kagels musiktheatrales Schaffen, das Thorsten Teubl als Grundsatzkritik am Institutionscharakter von zeitgenössischer Kunst deutete. ${ }^{202}$ Brisant wurde dies besonders bei der Premiere 1963 im Rahmen der Darmstädter Ferienkurse, wo Sur scène zurecht als erfrischende Parodie auf die Hermetik der Institution wahrgenommen wurde.

1963 folgte Antithèse für elektronische und öffentliche Klänge, zu dem 1965 auch eine Filmfassung entstand, in der Kagel durch Verfremdungen das Verhältnis von akustischen und visuellen Ereignissen reflektierte und infrage stellte: »Der Schauspieler agiert als Hörer, der Rezipient ist eher Betrachter als Hörer, an einer Stelle hört man das Publikum eines nicht zu hörenden Konzerts. $\ll^{203}$ Wenn die tabuisierten Aktionen der Ausführenden als Befreiung von gesellschaftlichen Zwängen und aufführungspraktischen Normen gelesen werden können, ist in Kagels Werk auch die szenische Präsentation von Machtkämpfen von Bedeutung: Das ıSportstück Match (1965) etwa thematisiert dies durch den Wettkampf zweier Cellisten und ihr ständiges Revoltieren gegenüber dem Schlagzeuger als \Schiedsrichter . Hier vollzieht sich die vollkommene Einbeziehung des Orchesterparts in die szenische Aufführung, die Verschmelzung zwischen Klang und Szene. Im gleichen Jahr entstanden mit Pas de cinq, Camera oscura und Himmelsmechanik Kagels wohl radikalsten Umsetzungen im Sinne seines instrumentalen Theaters, das bald um filmische Arbeiten erweitert wurde und damit ein weiteres Medium in das zeitgenössische Musiktheater einführte.

Zwischen 1962 und 1968 entstanden Verfilmungen dreier Werke, die nicht nur optische und akustische Möglichkeiten durch multimediale Erweiterung neuartig kombinierten, sondern mit der Kirchenmusik ein weiteres Tabu ankratzten: In Improvisation ajoutée (1962) schlägt ein Organist vehement in die Tasten - weil aber kein Register eingeschaltet ist, erklingen nur klappernd-mechanische Geräusche. In Phantasie für Orgel mit Obbligati (1967) wird der Filmschnitt genutzt, indem auf das Betätigen der Klospülung nicht das bekannte Geräusch folgt - sondern die Orgel einsetzt, bevor der Organist am Ende ohne Schuhe und mit gesenktem Haupt den Mittelgang entlanggeht und einen Platz in den Reihen des Publikums einnimmt. Halleluja für Stimmen (1967/68) wird von 16 unabhängigen Solisten gestaltet, die Tonleitern wie Sprachstörungen wirken lassen. In einem Abschnitt des Films über Stimmschäden wird eine Kalbszunge auf einer Glasplatte vorgeführt: Ekel angesichts dieser - durch militärische Folterpraktiken inspirierten - Verstümmelungen ist die beabsichtigte Folge. So wird Kunst in eine schockierende Realität zurückgeholt.

Im Auftrag des WDR entstand schließlich 1969/70 der Film Ludwig Van zum 200. Geburtstag Beethovens. Ähnlich wie John Cage, der 1948 am Black Mountain College den Einfluss Beethovens auf die Musikgeschichte aufmerksamkeitsträchtig bedauert hatte ${ }^{204}$, nutzte Kagel den Wiener Klassiker als Symbol, um gegen die verstaubte Hochkultur zu revoltieren: Mittels einer Filmlandschaft, die nur noch aus Beethoven-Ikonen besteht - Büsten in einer Badewanne, Partituren als Tapete und ein Soundtrack aus Bruchstücken Beethovenscher Werke - ironisiert Kagel die bil-

202 Teubl: Musiktheater in der Krise, S. 190.

203 Borio: Avantgarde als pluralistisches Konzept, S. $23 \mathrm{f}$.

204 Siehe hierzu den Abschnitt John Cage und die transkulturelle Neuvermessung der klingenden Welt im Kapitel Transkulturelle Transfers. 
dungsbürgerliche Tradition und die damit verbundene Musealisierung der klassischen Musik. ${ }^{205}$ Mit diesem Sakrileg löste der Argentinier eklatante Reaktionen aus, die sich bei der Hamburger Premiere von Staatstheater am 25.4.1971 noch einmal steigerten. Dabei kam es bis zu anonymen Drohungen einer Aktionsgemeinschaft junger Freunde deutscher Opernkunst:

»Wir werden uns nicht mit Stinkbomben, Pfeifkonzerten und dergleichen begnügen, sondern Bomben und gezielte Flächenbrände im Zuschauerraum, auf der Bühne und in den Garderoben einsetzen. $\ll^{206}$

Die gesellschaftliche Radikalisierung der 68er-Bewegung, die in der Bundesrepublik Deutschland im Terror der RAF mündete, spiegelte sich also zumindest publizistisch auch auf musikalischem Gebiet.

\section{Hauptakt: Eine Oper »to end all operas«}

Auch der Skandal um Staatstheater wurde, wie in den Fallbeispielen der politischen Musikskandale um Luigi Nono und Hans Werner Henze, bereits durch die Vorberichterstattung sowie gezielt platzierte Äußerungen des Komponisten vorbereitet. Konkret reagierte Kagel auf Pierre Boulez, der ihm 1967 im berühmten SpiegelInterview »Sprengt die Opernhäuser in die Luft! « umfassende Theaterkenntnis abgesprochen und die musikalische Seite als »recht dünn« bezeichnet hatte. ${ }^{207} \mathrm{Im}$ Kurier konterte Mauricio Kagel den Vorwurf mit Verweis auf den »Zorn und Neid vieler Kollegen« mit ihren »mondänen kunstgriffreichen Kompositionstechniken. $«{ }^{208}$ In der Düsseldorfer Zeitung antworte der Argentinier auf die anspielungsreiche Frage, ob er die Opernhäuser nicht verbrannt sehen wolle: »Solange ich nicht in Bayreuth dirigiere, werde ich nicht sagen, dass Opernhäuser in die Luft gejagt werden sollen. $«{ }^{209} \mathrm{Ge}$ nau dies aber tat wenige Jahre später ausgerechnet Pierre Boulez, der seine frühere Kritik am musikalischen Establishment selbst ad absurdum führte und das endgültige Ende des Querstands von Kunst und Politik markierte: als der Franzose 1976 beim Jubiläum der Bayreuther Festspiele anlässlich ihres hundertjährigen Bestehens den sogenannten `Jahrhundert-Ring leitete, der erst zum Skandal erklärt und wenig später zu einem Höhepunkt der Festspielgeschichte verklärt wurde. ${ }^{210}$

205 Ludwig van wurde am 28.5.1970 bei den Wiener Festwochen uraufgeführt am 1. Juni desselben Jahres erstmals im westdeutschen Fernsehen gezeigt.

206 Zitiert nach Werner Klüppelholz: Mauricio Kagel 1970-1980, Köln 1981, S. 42.

207 Felix Schmidt: »Sprengt die Opernhäuser in die Luft!« Gespräch mit dem französischen Komponisten und Dirigenten Pierre Boulez, in: Der Spiegel (40/1967), S. 166-174.

208 Karlheinz Roschitz: »Gegen Messerstecherei«, in: Kurier (22.7.1970).

209 N.N. im Gespräch mit Mauricio Kagel: »Deshalb ein Konglomerat«, in: Düsseldorfer Zeitung (21.4.1971).

210 Der Jahrhundertring unter der Regie von Patrice Chereau und dem Dirigat von Pierre Boulez löste unter Wagnerianern einen Skandal aus, da die Handlung in die Ära der frühen Industrialisierung verlegt wurde. Es kam zu Schlägereien, Unterschriftenlisten gegen die Inszenierung, Flugblätter wurden verteilt, Stinkbomben geworfen und Morddrohungen ausgesprochen. Wenige Jahre später galt der >Jahrhundert-Ring` als Höhepunkt in 
Neben dieser innermusikalischen Fehde schürte Maurizio Kagel das mediale Interesse, indem er via Presse seine provozierende Programmatik verkündete. Im Hamburger Abendblatt etwa ließ er vermelden, Staatstheater richte sich »gegen Opernkonvention, musikalische Konsumgewohnheit und das unsinnige Zeremoniell von Musik überhaupt. $\ll^{211}$ Der Spiegel prognostizierte daraufhin in seinem Vorbericht, dass es sicher Auseinandersetzungen geben werde. ${ }^{212}$ Die Tumulte ereigneten sich aber nicht zuletzt durch die provozierende Konzeption und Ästhetik der >Anti-Oper`. Staatstheater erscheint als Gegenentwurf zur traditionellen Opernkultur und ihrer repräsentativen Funktion, die Kagel bereits mit der spezifischen Doppeldeutigkeit des Titels attackierte. Dazu bemerkte Dieter Schnebel: "Staatstheater ist möglich, weil es STAATS-Theater und Staats-THEATER gibt. ${ }^{213}$ In seiner Analyse des Werks führte Karl-Heinz Zarius aus:

»Oper, das untersuchte Objekt, [...] ist sowohl staatliche Institution als auch von eben dieser Institution [...] spezifisch repräsentierte Gattung, ein Komplex von Kräften, Interessen und Rollen, der in einer Aufführung mehr oder minder kostümiert auf beiden Seiten des Orchestergrabens sich darstellt, eine gewaltige Maschinerie mit der Tendenz, sich zwanghaft zu verselbständigen, ein musikalisches Personal, dessen Hierarchie seine Rollen prägt, ein Publikum, das mitspielt, mag es wollen oder nicht, schließlich ein breites Repertoire mit seinen offenen und verborgenen Absurditäten und ein Theaterfundus als Arsenal abgetakelter Phantasmagorien. $\ll^{214}$

Mit seiner szenischen Komposition kritisierte Kagel also nicht nur die architektonischen, ökonomischen und wirkungsästhetischen Konventionen der Gattung Oper als Staatstheater, sondern stellte auch die staatlichen und politischen Institutionen als theatralische Inszenierungen bloß. Kompositorisch löste er diesen Anspruch ein, indem er gleichsam alle Bestandteile, die gemeinhin das Opernereignis ausmachen, nicht nur verweigerte, sondern persiflierte.

Die Partitur ${ }^{215}$ umfasst stolze 466 Seiten. Sie könnte aber ebenso aus losen Blättern bestehen, da der musikalische Zusammenhang gänzlich aufgelöst und nur durch zehn übergeordnete Anweisungen verbunden wird, die den Werkcharakter infrage stellen: REPERTOIRE umfasst hunderte musikalisch-szenische Einzelmomente, von denen viele »Situationen zum Gegenstand [haben], in denen die Ausführenden gefährdet, durch die Instrumente erheblich behindert oder quasi verkrüppelt erscheinen. ${ }^{216}$ EINSPIELUNGEN bezeichnet Musik für Lautsprecher, die das im Opern-

der Geschichte der Bayreuther Festspiele. Siehe etwa N.N.: »Der Ring-Kampf von Bayreuth«, in: Der Spiegel (32/1976), S. 106-107.

211 Sabine Tomzig: »Trimm dich mit Mauricio Kagel«, in: Hamburger Abendblatt (17./18.4.71)

212 N.N.: »Za Za Pum Zaza«, in: Der Spiegel (19.4.1971), S. 170-172.

213 Schnebel: Mauricio Kagel, S. $12 f$.

214 Karl-Heinz Zarius: Staatstheater von Mauricio Kagel. Grenze und Übergang, Wien 1977, S. 7.

215 Mauricio Kagel: Staatstheater, Auftragswerk der Hamburgischen Staatsoper AG, Universal Edition (UE) 15197.

216 Zarius: Staatstheater, S. 17. 
graben versteckte Orchester und den Chor - die Stützpfeiler herkömmlicher Musikdramatik - durch Zuspielungen aus versteckten Kassettenrekordern als konservierte Rudimente bloßstellen. ENSEMBLE für sechzehn Stimmen beinhaltet sechzehn rein phonetischen Gesangspartien, die jeweils typische Gebärden des ihr zugeordneten Rollenfachs karikieren. DEBÜT für sechzig Stimmen besteht aus Gesangspartien, deren Reihenfolge und Kombination nicht festgelegt sind und die Publikumsreaktionen - erregtes Gestammel, exaltiertes Schwadronieren, Dauergeschwätz, schrille Schreie und hysterisches Gelächter - als musikalische Gesten persiflieren. SAISON bezeichnet ein Singspiel in 65 Bildern, die beliebig ausgewählt werden können und mit Versatzstücken verschiedenster Repertoirewerke - wie etwa den Trompeten aus Aida (Giuseppe Verdi) oder dem Amboss des Siegfried (Richard Wagner) - die klassische Opernliteratur verspotten. SPIELPLAN umfasst aktionistische Instrumentalmusik, während KONTRA-DANSE für Nicht-Tänzer Figuren des klassischen Balletts karikiert. Bei FREIFAHRT soll der Klang einzelner Instrumentalfamilien durch Verstimmungen denaturiert und als »böse Karikatur für integer gehaltener Refugien subtiler Geistigkeit ${ }^{217}$ dilettiert dargestellt werden. PARKETT bezeichnete Kagel als »Konzertante Massenszenen«, in denen 〉Orale Ereignisse` wie Husten, Zischen und Flüstern zum Einsatz kommen, die nicht zufällig auch an eklatante Publikumsreaktionen erinnern: »Dabei werden weniger die Gäste als solche aufs Korn genommen als vielmehr bestimmte Muster kollektiven Reagierens, ritualisierte Zwangshandlungen. $\ll^{218}$ In AKUSTISCHE KALLISTHENIE vereinigen sich alle Interpreten »zum wohligen Räkeln psychosomatischer Hygiene in Dur und Moll. ${ }^{219}$ Kurz: Staatstheater hinterfragte nicht nur die Oper als Gattung, Institution und Spektakel unter dem Aspekt ihrer offenen und verborgenen Defekte, sondern auch die Gesellschaft selbst. Dies verdeutlicht schließlich auch folgender Ausspruch Maurizio Kagels: »Sie wissen, daß ich unsere Gesellschaft als eine institutionalisierte Krankheit in Permanenz betrachte. $\ll^{220}$

Der Komponist leitete die Hamburger Premiere selbst und konnte so, clownesk kostümiert mit einem grünen Frack und der Maske eines Greises, die lautstarken Reaktionen des Auditoriums entgegennehmen: Den Protesten der musikbesessenen Melomanen antwortete der jugendliche Teil des Publikums mit Begeisterung. Auch hier existiert, wie schon in den politisch motivierten Opernskandalen Hans Werner Henzes und Luigi Nonos, eine Aufnahme [ $\delta-24]$. Diese reproduziert freilich nur den akustischen Teil der Ereignisse, während die für das Werk integralen visuellen Bestandteile unterschlagen werden. Einen deutlicheren Eindruck vermitteln in diesem Fall daher die Stimmen der durch den prognostizierten Skandal in Scharen angelockten Pressevertreter, deren Konzertkritiken hilfreiches Material für die Beschreibung der für Musikskandale so typischen Ereignisse bieten. ${ }^{221}$

217 Ebd., 54f.

218 Ebd., S. 60.

219 Ebd.

220 Martin Geck: Musiktherapie als Problem der Gesellschaft, Stuttgart 1973, S. 43.

221 Die Pressesammlung befindet sich in der Paul-Sacher-Stiftung (PSS): Sammlung Mauricio Kagel. Dokumentation und Programmhefte. Nach Werken geordnet [STAATSTHEATER]. 
In den ersten Presseberichten am 26. April 1971, dem Tag nach der Premiere, wurden die skandalösen Ereignisse insbesondere von den Boulevardmedien öffentlichkeitswirksam aufgegriffen. Die Bild-Zeitung titelte: »In Hamburgs Oper brach ein Buh-Sturm los $\aleph^{222}$, während die Hamburger Morgenpost unter der Schlagzeile »Opern-Premiere mit Stinkbomben« weiter ausholte:

»Die Hamburgische Staatsoper überlebte gestern Abend den größten Tumult ihrer Geschichte. Die Uraufführung [...] wurde immer wieder von entrüsteten Zwischenrufen, von Stinkbombenwürfen und lautstarken Forderungen >Aufhören! unterbrochen. Zu Anfang gab es manches amüsierte Gelächter; in das tobende Buh-Geschrei am Schluss mischte sich auch immer wieder Beifall [...]. Das Stück ist eine gezielt ätzende Veralberung der Oper als Kunstform [...] und des Publikums. ${ }^{223}$

In dieser Beschreibung werden mit dem Inszenierungscharakter und dem Gegeneinander polarisierter Reaktionen einmal mehr elementare Bestandteile klingender Eklats deutlich. In den folgenden Tagen berichteten über hundert internationale Pressevertreter ausführlich über die skandalöse Premiere. Die größte Ablehnung erzeugte demnach Mauricio Kagels »Hetze auf die traditionsgeheiligten Opernfiguren $«{ }^{224}$ wie etwa die Tattergreise, die zwei überdimensionalen Aida-Fanfaren folgen. Besonders aber erregte der über die Bühne schwimmende Lohengrin-Schwan den Zorn des Publikums, worüber die Süddeutsche Zeitung treffend reflektierte:

»Seit fast einem Jahrhundert witzelt man in Opernkreisen über nichts ausdauernder [...] als über Lohengrin und seinen Schwan. Hat das Publikum aber ein einziges Mal den Eindruck, dass ihm Held und Tier nicht (wie in jeder Provinzaufführung) in ein lächerliches Gralshüterland aus Pappe und Tüll, sondern [...] in einen Abgrund des Überwundenseins und der Vergessenheit zu entschwinden drohen - dann steht der Zuschauer auf und pfeift und buht, als hätte es Kagel auf sein Haus, Geld und Kind abgesehen. ${ }^{225}$

Das Skandalon lag also im Angriff auf die geheiligten Figuren und Etikette des Opernbetriebs. Weil das »Ritual der Oper [...] gründlich zerstört« wurde, so das Hamburger Abendblatt, »kochte und kagelte es im Zuschauerraum. ${ }^{226}$ Der Rezensent vom konservativen Flensburger Tageblatt war sich sicher, dass »Mozart, Bizet, Verdi und Wagner noch immer die Opernpläne attraktiv erhalten, wenn Kagel und

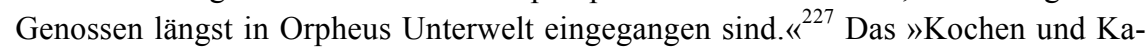
geln« des Hamburger Premierenpublikums nahm »stellenweise derartige Ausmaße an [...], daß einige der Bühnenaktionen im Lärm der Zuschauer untergingen. ${ }^{228}$

222 N.N.: »In Hamburgs Oper brach ein Buh-Sturm los«, in: Bild-Zeitung (26.4.1971).

223 N.N.: »Opern-Premiere mit Stinkbomben«, in: Hamburger Morgenpost (26.4.1971).

224 Helmut Lesch: »Ki-ka-ko auf Gold-Stühlchen«, in: Münchner Abendzeitung (27.4.1971).

225 Ivan Nagel: »Welches Musiktheater wollt ihr?«, in: Süddeutsche Zeitung (28.4.1971).

226 N.N.: »Demontage der Oper«, in: Hamburger Abendblatt (27.4.1971).

227 Wilhelm Hambach: »Trommelfeuer auf die alte Oper«, in: Flensburger Tageblatt (27.4.1971).

228 N.N.: »Theater um Kagels \Staatstheater««, in: Rheinische Rundschau (27.4.1971). 
Die Publikumsreaktionen zeugten, wie der Mannheimer Morgen berichtete, durchaus von Phantasie: "Zwischenrufe in reicher Auswahl, von >Wauwau bis zur Feststellung: >Dann doch lieber Zirkus Krone! « « ${ }^{229}$ Auch Die Welt berichtete: »Etliche Protestler in den oberen Rängen störten durch Zwischenrufe und Mißfallensbekundungen die Aufführung beträchtlich. Die jungen Besucher brüllten >Aufhören〉 während eine junge Dame all ihren Mut zusammennahm und >Scheisse schrie. $\varkappa^{230}$ Andere Stimmen fragten »Wo bleibt der Gruppensex? « ${ }^{231}$ oder beklagten die Verschwendung von Steuergeldern. Dass in diesen Störmanövern viel Inszenierung steckte, erkannte die Bild-Zeitung: »Da [...] auch ein paar Stinkbomben fielen merkte man im Tumult auch einige Regie von außen: Man führt solche Requisiten ja normalerweise wohl nicht im Opern-Abendanzug. « ${ }^{232}$

Das Moment der Inszenierung lag nicht nur aufseiten des Publikums, sondern auch des Komponisten, wie Mauricio Kagel im Gespräch mit der Opernwelt später offenlegte. Zwar wolle er »auf keinen Fall partout Skandale entfachen.« Allerdings habe er schon im Vorfeld den Sängern gesagt »dass wir auf Proteste nur mit musikalischen Maßnahmen reagieren dürften, dass wir der Publikumswut nur mit Intelligenz begegnen könnten. ${ }^{233}$ Dass Ritualbruch und Publikumsreaktionen geradezu intrinsisch in Kagels Musiktheater ein-komponiert waren, erkannten nur die Frankfurter Allgemeine- und die Süddeutsche Zeitung. Erstere notierte, dass - sollte Kagel die Reaktion einkalkuliert und heimlich mitkomponiert haben - die Rechnung aufgegangen sei: »Das alles hätte der Szenenkomponist Kagel sich nicht besser ausdenken können. ${ }^{234}$ Die $S Z$ führte den Gedanken aus:

»Kagel parierte mit Hilfe seiner aus beweglichen, lenkbaren Teilen zusammengesetzten Komposition. Sobald von unten Buhrufe kamen, rief er bei den betörend schön singenden Damen [...] ab. Sobald es von den Rängen pfiff, ließ er William Workmanns triumphalen Tenor ertönen. Die Sänger wirkten unerschütterlich $[\ldots]$ und spielten mit dem rebellierenden Publikum, wie es ihnen gefiel. ${ }^{235}$

Für viele Kritiker wurde Staatstheater »zu einem der wichtigsten musiktheatralischen Werke der jüngsten Zeit « ${ }^{236}$ und zu einem »Theater-Ereignis«, das in seiner bewussten Unzulänglichkeit die »Hohlräume, innerhalb deren sich affirmativer Kulturkonsum ereignet ${ }^{237}$ bloßstelle. Dagegen notierte Klaus-Henning Bachmann von

229 N.N.: »Was nach der Oper kommt, bleibt weiter offen«, in: Mannheimer Morgen (27.4.1971).

230 N.N.: »Puzzeln mit dem Staatstheater«, in: Die Welt (27.4.1971).

231 N.N.: »Aus höheren Regionen ein Krokodil«, in: Frankfurter Rundschau (28.4.1971).

232 Walter Schröder: »Erst Beifall, dann gab es Tumult«, in: Bild-Zeitung (27.4.1971).

233 N.N.: »Den Nerv der Opernillusion treffen. Ein Gespräch mit Kagel«, in: Opernwelt (10/1971), S. 31-36, hier S. 31.

234 Klaus Wagner: »Die Opernleute probten den Kopfstand«, in: Frankfurter Allgemeine (27.4.1971).

235 Ivan Nagel: »Welches Musiktheater wollt ihr?«, in: Süddeutsche Zeitung (28.4.1971).

236 Wolfgang Burde: »Die Oper macht sich über sich selbst lustig«, in: Der Tagesspiegel (27.4.1971).

237 N.N., in: Musica (4/1971), S. 367-70. 
der Wiener Zeitung, dass »der sogenannte Skandal« nicht darüber hinwegtäuschen könne, dass sich die Opposition gegen den Kunst-Betrieb zwar betriebsam gebe, aber nur eine Tatsache verdecke: »der Avantgarde beginnen die Zähne auszufallen. « $^{238}$

\section{Nachspiel: Ende des Querstands und Dämmern der Postmoderne}

Wenn Claus-Henning Bachmann infolge des »genußreichen Skandals« um Maurizio Kagels Staatstheater mutmaßte, dass die Avantgarde ihren Biss verliere, hatte der Kritiker der Wiener Zeitung damit nicht ganz unrecht. Denn die teils euphorischen Rezensionen der szenischen Komposition als das »vielleicht [...] wichtigste Musiktheater der Nachkriegszeit ${ }^{239}$ und als $»$ meistbesprochenes Ereignis des Musiktheaters in der letzten Zeit ${ }^{240}$ zeugten von einer Konsolidierung der Avantgarde. Auch in der Zeitschrift Opernwelt wurde die Premiere als »Aufführung des Jahres« besprochen und zur »Haupt- und Staatsaktion der Hamburger Opernsaison« gekürt. In seiner Kritik formulierte Hans-Klaus Jungheinrich die Hoffnung auf eine politische Erneuerung der Musikkultur durch den »Aggressionsmobilisator Kagel«, der es vermieden habe, »die Rolle des Publikums zu mystifizieren. ${ }^{241}$ Nun war es allerdings gerade jener Hans-Klaus Jungheinrich, der sich nur zwei Jahre später enttäuscht von Mauricio Kagel abwendete. In einem mit »Kunst - Antikunst - Kunst« überschriebenen Artikel bemerkte der Kritiker:

»Kagels musikpädagogisches Konzept wäre schlüssig, läge ihm eine historische Theorie und relevante soziale Ethik zugrunde. Gerade das aber klammert Kagel aus. So scheint er im Augenblick an einem Punkt seiner Überlegungen angelangt, da erneut das Musikmachen als Ideologie beschreibbar wird. Wo das Machen mit politischem Inhalt zu verbinden wäre, kneift Kagel aus, diffamiert kunst-transzendierende Motivationen mit der Ängstlichkeit eines um seinen singulären Geltungsanspruch besorgten Oberverwertungsstrategen gar als Salonmarxismus. ${ }^{242}$

Die Vehemenz Jungheinrichs richtete sich gegen Mauricio Kagels Rückzug in die Autonomieästhetik absoluter und unpolitischer Musik. Davon zeugt auch die Enttäuschung im linken Lager der gesellschaftlichen und musikalischen Avantgardebewegungen, denen Kagel, so bemerkte der Musikwissenschaftler Björn Heile, »als so etwas wie ein Hoffnungsträger eines gesellschaftlicher Erneuerung dienenden Avantgardismus $\aleph^{243}$ gegolten habe. Auch die bekannten linksorientierten Musiktheoretiker Heinz-Klaus Metzger und Reinhard Oehlschlägel wendeten sich schließlich, enttäuscht von dessen mangelnder Radikalität, gegen den Argentinier.

238 Claus-Henning Bachmann: »Der genußreiche Skandal«, in: Wiener Zeitung, (1.5.1971).

239 Helmut Lesch: »Ki-ka-ko auf Gold-Stühlchen«, in: Münchner Abendzeitung (27.4.1971).

240 Inter Nationen: »Kagel demontiert die Oper«, in: Deutsche Kulturnachrichten (6-7/1971).

241 Hans-Klaus Jungheinrich: »Kritik an den Institutionen - Kagel und die Gesellschaft«, in: Opernwelt (13/1971), S. 25f.

242 Hans-Klaus Jungheinrich: »Kunst - Antikunst - Kunst. Wie Hören und Sehen vergehen, neu gelernt und totalisiert werden «, in: Hifi-Stereophonie (1/1973), S. 14-23, hier S. 23.

243 Björn Heile: »Avantgarde, Engagement und Autonomie. Mauricio Kagel in den sechziger Jahren«, in Jacobshagen/Lenige (Hg.): Rebellische Musik, S. 81-91, hier S. 81. 
Diese Ablehnung resultierte aus Mauricio Kagels Hinwendung zu einer Autonomieästhetik und seinem Widerwillen, sich von der Linken vereinnahmen zu lassen. 1971 - unmittelbar nach dem Trubel um Staatstheater - stellte der Komponist klar:

»Ich will mich nicht an dieses Schablonendenken verkaufen, das behauptet, Künstler und Bürger wären eins, ergo müsse man gegen den Krieg in Vietnam nicht nur als Bürger protestieren, sondern auch in der Kunst. Das ist so platt gedacht und so totalitär wie nur etwas und läuft auf ein Herrschaftssystem hinaus, das genauso zweifelhaft ist [...]. Man sagt, meine Stücke gehörten in einen gewissen Bereich, der Anarchie und des Non-Konformistischen. Das mag stimmen. Und weil dieser Bereich mehr nach links tendiert als nach rechts, bin ich links. Aber ich kann nicht mit der Linken über Musik sprechen. ${ }^{244}$

Die Identifikation als Künstler mit politischer Tagespolitik verstand Kagel also als negative Ideologisierung. Wenn engagierte Musik »etwas taugen soll, muss [sie] so tief eingedrungen sein in alle Schichten des Musikdenkens und Musikmachens, dass Komponisten nicht Partei-Funktionäre werden, nicht Aparatschiki ihres eigenen Systems, auch nicht Priester ${ }^{245}$. Später befand Mauricio Kagel, dass »1968 als Entladung einer immanenten Unzufriedenheit viel zu klischeehaft verlief. ${ }^{246}$ Daher beendete er den für die 1960er Jahre charakteristischen Querstand von Kunst und Politik und markierte in neodadaistischer Manier den Einbruch der Postmoderne, in der politisch-provokative Konzepte nur noch ein Steinchen innerhalb des avantgardistischen Mosaiks waren. Die politische Implementierung löste sich schließlich, wie Hans Werner Heister feststellte, im Zuge der Annäherung und schließlich dem Ende des Kalten Kriegs vollends auf:

$»$ Die fortschreitende politische Entspannung der 80er Jahre und das Ende der Ost-WestKonfrontation nach 1989 führte zwangsläufig auch zu einem Nachlassen des offensichtlich, gar offensiv politischen Engagements. ${ }^{247}$

Mit dem Ende des Ost-West-Konflikts lockerten sich auch die musikalischen Frontstellungen: Die ideologisch-weltanschaulichen Fronten waren geklärt und Geschmack wurde im Hochgefühl postmoderne Distanziertheit zur Privatsache. Wenn aber alles möglich ist, scheint der Widerstandsgeist gegen ästhetische und/oder gesellschaftliche Missstände aus der Zeit gefallen. Aus historischer Perspektive kann nur gemutmaßt werden, inwieweit die aktuellen weltpolitischen Konflikte und technische Entwicklungen erneut die herrschenden sozioästhetischen Paradigmen unterlaufen und infrage stellen. All das bleibt aber vorerst: Zukunftsmusik.

244 Mauricio Kagel im Gespräch mit Hansjörg Pauli, in Ders.: Für wen komponieren Sie eigentlich?, Frankfurt am Main 1971, S. 87-105, hier S. 97 und 103.

245 Ebd, S. 194.

246 Klüppelholz: Kagel, S. 18.

247 Hans Werner Heister: »Musik und Gesellschaft. Politisches Komponieren seit 1945«, in Michael Raeburn/Alan Kendall (Hg.): Geschichte der Musik, Band 4: Das 20. Jahrhundert, Mainz 1991, S. 301-312, hier S. 311. 



\section{ANALYTISCHE KONTRAPUNKTE (Reprise)}

Nach der 〉Exposition und der >Durchführung $८$, ist die >Reprise $<$ die dritte Komponente einer Sonatenhauptsatzform, die dieser Arbeit aus mehr als nur stilistischen Gründen als Formungsprinzip gedient hat. Dieses >mehr $<$ bezog sich zum einen auf die mehrsätzige Anlage, zum anderen auf die methodische Fokussierung von zwei kontrastierenden Hauptthemen: Skandal und Neue Musik. Diese wurden in Referenzen und Chiffren zunächst expositioniert, um in den vier Teilen der Durchführung motivisch moduliert und variiert zu werden. Stand in diesem Hauptteil die zeithistorische Analyse von Fallbeispielen im Fokus, sollen die Motive in der folgenden und diese Studie beschließenden Reprise auf einer reflexiven Ebene noch einmal zusammengeführt und verdichtet werden. Zum Ende wird also noch einmal der diskursive Humus der Arbeit freigelegt und unters kulturtheoretische Mikroskop gelegt.

Die folgenden Ausführungen sind Ausdruck des interdisziplinären Anspruchs, der eingangs am Kreuzungspunkt zwischen Geschichts- und Musikwissenschaften verortet und das perspektivenoffenere Feld der Medienkulturwissenschaften als verbindendes Scharnier definiert wurde: Im zeitgeschichtlichen Rahmen wurde Wert auf eine intensive Material- und Quellenarbeit im Sinne einer >Klingenden Historiographie gelegt, wie sie in der Exposition vorgestellt wurde. Auf musikwissenschaftlicher Ebene spiegelten Künstlerbiographien und Werkgeschichten, aber auch gesellschaftsbezogene und rezeptionsästhetische Ansätze die potentielle Vielfalt des Fachs zwischen systematischen, kulturtheoretischen, ästhetischen sowie ideen- und geistesgeschichtlichen Fragestellungen. Unter medienkulturwissenschaftlichem Blickwinkel wurde zum einen der Einfluss der technischen Dispositive auf die Wissens- und Klanggenerierung einbezogen sowie zum anderen auf den theoretischen Gehalt der auditiven Medienkultur ausgerichtet. Schwangen abstrakte Implikationen in der zeithistorisch ausgerichteten Untersuchung eher zwischen den Zeilen mit, sollen sie als eine Art kontrapunktisches Prinzip abschließend näher bezeichnet werden: Der musikalische Kontrapunkt umspielt und begleitet das Thema, erfindet Gegenstimmen und besitzt innerhalb des mehrstimmigen Satzes eine gewisse Eigenständigkeit. Dieses Prinzip gilt auf methodischer Ebene auch für diesen reflexiven Schlusssatz.

Zunächst wird der klingende Eklat im Anschluss an differenzphilosophische und wissenschaftshistorische Ansätze skizziert, bevor seine Anatomie diskursiv durchleuchtet und der Musikskandal aus der Perspektive störungs- und ereignistheoretischer Spuren diskutiert wird, um schließlich auf klassische kulturkritische Theoreme einzugehen. In der Coda wird abschließend ein cross-musikalischer und -temporaler Transfer in die Gegenwart unternommen. 


\section{RITORNELL: Der klingende Eklat als sepistemisches Objektı}

In der Musiklehre steht die Reprise für die Wiederaufnahme von Motiven innerhalb einer Komposition und auch der Forschungsgegenstand `Musikskandal ist eine wiederkehrende Formation. Mit Gilles Deleuze und Félix Guattari kann er als Ritornell, als >kleine Melodie $<$ gedacht werden, die sich >zu einer Funktion erhebt $<.{ }^{1}$ Mit musikhistorischem Fokus heißt das: Das Erkenntnispotential klingender Eklats verbirgt sich weniger hinter einer linearen Erzählung, als in den »Windungen, Verknotungen [...] Gebärden und verschiedene[n] Klänge[n] $\aleph^{2}$, die übergeordnete Strukturen und Prozesse bezeichnen. Skandale können in diesem Sinne als »Ritornelle der Konfrontation oder des Aufbruchs« verstanden werden, als »Orte des Übergangs«, deren »innere Gliederungen, die Intervalle und die Zwischennoten ${ }^{3}{ }^{3}$ es analytisch zu dekodieren gilt. Diese Ereignisse werden so als >Beziehungsbündel〈 innerhalb eines historischen Gefüges beschreibbar, das sich um die zentralen Topoi Skandal und Neue Musik schlingt. Ein solch diskursives Feld von Zusammenhängen und -klängen bezeichneten Deleuze und Guattari als >Milieu $<$ und verwiesen auf dessen Übergangscharakter: »Ein Milieu kommt zwar durch eine periodische Wiederholung zustande, aber diese führt nur dazu, daß eine Differenz geschaffen wird, durch die es in ein anderes Milieu übergeht. " ${ }^{4}$ Angewendet auf den klingenden Eklat, kann man diesen als >Wiedergänger` verstehen, der sich stets zeittypisch kleidet und wandelbar, also historisch, ist. Sein analytisches Potential liegt am Schnittpunkt von Differenz und Wiederholung $^{5}$, das heißt: Die zeitspezifischen Unterschiede der wiederkehrenden Formation $>$ Musikskandal< produzieren zeithistorisches Wissen.

In ihren Schriften bedachten Deleuze und Guattari auch die Rolle des Künstlers, der sich »auf ein außergewöhnliches und gefährliches Abenteuer« einlasse: »Er gliedert die Milieus, trennt und harmonisiert sie, steuert ihre Vermischung und geht von einem zum anderen über. ${ }^{6}$ Im Anschluss daran ist diese Arbeit als Milieustudie der Musikavantgarde in der Mitte des 20. Jahrhunderts mit besonderem Fokus auf die Bundesrepublik Deutschland zu verstehen. Der Musikskandal erwies sich dabei als eine passagere Formation des Übergangs, der historische Umbruchprozesse markiert, die in den drei Nachkriegsdekaden gehäuft und verschärft zutage traten: Der Wandel Deutschlands von einer >Kulturnation`zur >Kulturindustrie ${ }^{7}$, die Entwicklung der Massenmedien und neuer Kulturtechniken sowie die kontroversen Aushandlungen ästhetischer Paradigmen im Kontext zeit- und kulturhistorischer Gemengelagen.

1 Gilles Deleuze/Félix Guattari: »1837 - Zum Ritornell«, in: Tausend Plateaus. Kapitalismus und Schizophrenie, Berlin 2005, S. 424-479.

2 Ebd., S. 446.

3 Ebd., S. 450

4 Ebd., S. 428.

5 Gilles Deleuze: Differenz und Wiederholung, München 1992.

6 Deleuze/Guattari: Zum Ritornell, S. 461.

7 Die pointierte Gegenüberstellung der beiden Begriffe soll nicht verschleiern, dass sie systematisch nicht auf einer Ebene liegen: Ist die `Kulturnation`als gesellschaftliche Selbstbeschreibungsformel bildungsbürgerlicher Eliten zu verstehen, ist die $>$ Kulturindustrie $<$ ein pejorativer Kampfbegriff zur kulturkritischen Analyse von marktförmiger Massenkultur. 
Diese Themen wurden nach 1945 auch auf dem symbolischen Feld der Neuen Musik, einem spezifischen Intellektuellenmilieu der Nachkriegszeit, ausgefochten. In den exemplarisch analysierten klingenden Eklats der Avantgardebewegungen traten die Kontinuitäten und Brüche als Klangzeichen intensiviert und verdichtet in Erscheinung. Im Anschluss an Deleuze wurden sie zu »reinen Ereignissen«, die »ganz wie ein Musikstück über den Anlass, zu dem man es spielt, und die Ausführung, die es erhält, hinausreich[en]. $\varkappa^{8}$

Die assoziative und musikalisierte Sprache der französischen Philosophie offeriert Möglichkeiten, welche Begriffssprache zusätzlich angewandt, wie der Gegenstand theoretisch auch gedacht und methodisch außerdem arrangiert werden kann. Die in Mille Plateaux aufgeworfene Struktur eines Rhizoms, die Idee der unterirdischen Durchdringung der Wissensgenese, lassen den Skandal als diskursiven Knoten denkbar werden: Die topologische Einbettung in den dreidimensionalen Raum, in dem verschiedene Kräfte wirksam sowie Möglichkeiten und Grenzen individuellen Verhaltens oder die Herausbildung von Strukturen netzwerkanalytisch gefasst werden können. ${ }^{9}$ Es geht also um Diskurse, die sich um den Musikskandal als >epistemisches Objekt ' gruppieren.

Hans-Jörg Rheinberger charakterisierte >epistemische Dinge` als Wissensobjekte, ausgehend von ihrer Eigenschaft, durch ein gewisses Maß an Unbestimmtheit genügend Fragen offen zu lassen, um `Orteく, >Räumeく oder 〉Ordnungen` des Wissens zu schaffen. ${ }^{10}$ Konkret ging es in der Arbeit um die Freilegung von gesellschaftlichen, kulturellen und ästhetischen Strukturen, die von den klingenden Eklats unter den jeweils zeitspezifischen Bedingungen intoniert und freigelegt wurden. Der Musikskandal kann in diesem Sinne als historisches Brennglas, oder noch einmal in den Worten von Gilles Deleuze und Félix Guattari: als Glass harmonica, als »Raum-ZeitKristall ${ }^{11}$ verstanden werden.

Das Prisma der in dieser Arbeit vorgenommenen klingenden Historiographie reichte von einer das ( $\mathrm{Zu}$-)Hören fokussierenden Sinnesgeschichte, über die Betrachtung von Musik als Gegenstand und Quelle einer soziale und ästhetische Prozesse verschränkenden Intellektuellengeschichte bis hin zur Erforschung des Klangs als auditive Medienkultur. Diese Geschichte wurde grundiert durch politische, transkulturelle und mediale Prozesse, die sich in den Musikskandalen als klingenden Ereignissen brachen. Manchmal erfolgte ein Zoom auf konkrete Akteure oder Schlüsselwerke, ohne aber die übergeordneten historischen Strukturen aus den Augen zu verlieren: Von der Rolle der Kunst nach 1945 in dem von Kontinuitäten und Brüchen durchzogenen Wandel der Bundesrepublik Deutschland in der langen Nachkriegszeit, über das Dämmern des massenmedialen und elektronischen Zeitalters und dem endgültigen Aufstieg Amerikas zur Weltmacht, bis hin zum Querstand von Kunst und Politik um 1968.

8 Gilles Deleuze: Kritik und Klinik, Frankfurt am Main 2000, S. 22.

9 Markus Gamper/Linda Reschke/Marten Düring (Hg.): Knoten und Kanten III: Soziale Netzwerkanalyse in Geschichts- und Politikforschung, Bielefeld 2015.

10 Hans-Jörg Rheinberger: Experimentalsysteme und epistemische Dinge. Eine Geschichte der Proteinsynthese im Reagenzglas, Göttingen 2002.

11 Deleuze/Guattari: Tausend Plateaus, S. 476. 


\section{DISKURSE: Zur Anatomie des Musikskandals}

Klingende Eklats können nur durch das Zusammenspiel zwischen musikalischen Reizen, kulturellen Bedingungen und der gesellschaftlichen Rezeption geklärt werden. Sie sind dergestalt als diskursive Bündel zu verstehen, die eine zwar wandelbare, aber doch nachvollziehbare >Anatomieく aufweisen. Der Schweizer Historiker Philipp Sarasin verwendete den medizinischen Begriff mit Blick auf Michel Foucaults historische Diskursanalyse, indem er zeigte, dass dessen »Analyse-Methode für Diskurs-

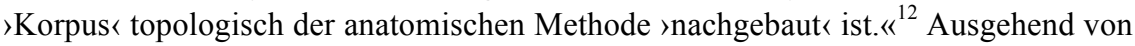
der zentralen diskursanalytischen Fragestellung - »Wie kommt es, daß eine bestimmte Aussage erschienen ist und keine andere an ihrer Stelle? ${ }^{13}$ - ging es in dieser Arbeit um die Frage, warum sich Musikskandale wann und wie, auf welche spezifische Weise und mit welchen Folgen ereigneten. Dahinter stand auch der erkenntnisleitende Gedanke, dass das, was nicht denk- und sagbar ist, manchmal doch hör- und sinnlich erfahrbar wird.

Die Bedeutung diskursanalytischer Perspektiven für eine Geschichte klingender Eklats liegt auf der Hand. Denn musikalisch motivierte Skandale verlaufen - wie die zurückliegenden Fallstudien zeigten - niemals nur linear, sondern sind eingebettet in vielschichtige Strukturen und Prozesse, Ausdrucks- und Verhaltensweisen, Konventionen und Normbrüche sowie daraus resultierender Sinnkonstruktionen. Die diskursive Verfasstheit von Musikgeschichte manifestiert sich grundsätzlich in dem ihr eigenen Spannungsverhältnis zwischen Konstanz und Kontingenz: Als Glied einer Entwicklungskette ist der jeweils zeithistorisch definierte state of the art stets von einer starken Bindung an die Tradition geprägt und zugleich durch die im AvantgardeBegriff enthaltene Innovationsdynamik, also eine konstituierende Vorreiterfunktion, bestimmt. Ihre Akteure operierten am Schnittpunkt sozialer und gesellschaftlicher sowie ästhetischer und kultureller Reizpunkte und damit, pointiert ausgedrückt, am Kreuzungspunkt von Vergangenheit und Zukunft. Hinter den heterogenen Phänomenen Skandal und Neue Musik steckt also eine prozesshafte Struktur, deren Anatomie es zu sezieren galt. Dabei wurden drei übergeordnete Schichten freigelegt: Produktion (schöpferischer Prozess, historische Bedingungen) - Rezeption (Wahrnehmung, Affekte) - Reflexion (Ideen- und Mentalitätsgeschichte). In einem anderen Bild lässt sich die anatomische Verlaufsform klingender Eklats in metaphorischer Analogie zum Krankheitsverlauf veranschaulichen, denn jeder der hier exemplarisch verhandelten Musikskandale folgte einem grundsätzlichen Muster: Inkubation - Eskalation/Krise - Regeneration.

12 Philipp Sarasin: »)Un analyse structurale du signifiéく. Zur Genealogie der Foucault'schen Diskursanalyse«, in Franz X. Eder (Hg.): Historische Diskursanalysen. Genealogie, Theorie, Anwendungen, Wiesbaden 2006, S. 115-129. Siehe weiterführend Ders.: Geschichtswissenschaft und Diskursanalyse, Frankfurt am Main 2003; Siegfried Jäger: »Diskurs und Wissen. Theoretische und methodische Aspekte einer Kritischen Diskurs- und Dispositivanalyse«, in Reiner Keller/Andreas Hirseland/Werner Schneider/Willy Viehöver (Hg.): Handbuch der Sozialwissenschaftlichen Diskursanalyse, Band 1: Theorien und Methoden, Opladen 2001, S. 81-112, hier S. 82.

13 Michel Foucault: Archäologie des Wissens, Frankfurt am Main 1981, S. 42. 
In Kritik und Klinik charakterisierte Deleuze die Literatur als >Zustand der Gesundheit $\iota$ und auch die Diagnose der Musikgeschichte als eklatant zwischen Tradition und Progress verlaufende Historie kann als `klinischer Befund verstanden werden, den es also zu >behandeln ' gilt. Konkret heißt das: In der Inkubationsphase die Symptome erkennen, Diagnosen stellen und Verläufe dokumentieren. Manche >Erreger in dieser Geschichte klingender Eklats waren akut virulent (Stunde Null, 1968), andere chronisch (Tradition versus Innovation, Medienumbrüche). Die Fälle verliefen wechselseitig anfallsartig, zyklisch oder latent fortschreitend. Je nach Ansteckungsgrad und äußeren Faktoren kam es zur Eskalation oder Krise. Als eine solche wird laut medizinischer Terminologie die entscheidende Phase im Verlauf einer Krankheit bezeichnet in der eine Veränderung zur Besserung oder aber eine Verschlechterung eintreten kann: Der Ausgang der Krise besitzt also eine offene Dramaturgie. ${ }^{14}$

Legt man dieses metaphorische Negativ auf das Phänomen Musikskandal, kann man dessen Anatomie als zyklischen Prozess verstehen, der Umbruchszenarien begleitet und mit Arnold van Gennep als rites de passage, als Übergangsrituale, begreifbar wird. ${ }^{15}$ Aufschlussreich sind dabei besonders die Differenzen zwischen den Fallbeispielen: unter dem jeweiligen historischen Klima bildet sich ein je zeitspezifischer Nährboden für klingende klats, die als Störungen der gewohnten Ordnung auftreten und damit erst klinisch manifest und somit kulturdiagnostisch und zeithistorisch aussagekräftig werden.

Inkubation und Regeneration, die rahmenden Phasen des musikskandalösen Prozesses, zeigen im analytischen Anschluss an Philipp Sarasins anatomische Deutung der Diskursanalyse die jeweiligen historischen Singularitäten und diskursiven Konstellationen sowie ihre stetige Transformierbarkeit. ${ }^{16}$ Der klingende Eklat kann innerhalb dieses Feldes als Ort der Verdichtung und als analytisches Brennglas verstanden werden, das die Diskurse im Umfeld der Musikavantgarde sichtbar macht. Auch Deleuze beschrieb den Mehrwert einer für historische Fragestellungen sensibilisierten Diskursforschung im Anschluss an Michel Foucault: Dieser verorte die »Bestimmung des Sichtbaren und des Sagbaren in jeder Epoche« dort, wo es »die Verhaltensweisen und die Mentalitäten, die Ideen überschreitet. « ${ }^{17}$ Gleiches, so ist hinzuzufügen, gilt für das Hörbare.

Unter ereignisgeschichtlicher Fragestellung galt das besondere Augenmerk der zweiten Phase in der zyklischen Anatomie des Musikskandals: Der >krisenhaften Eskalation< also, wenn die Symptome akut werden und zum Ausbruch kommen. Hier fand der eigentliche éclat statt: punktuell, transitorisch und vergänglich. An dieser Stelle wurden aus dem Musikskandal ein klingendes Ereignis und ein ästhetischer Störfall.

14 Siehe hierzu etwa Reinhart Koselleck: »Krise«, in: Geschichtliche Grundbegriffe, Band 3, Stuttgart 1982, S. 617-650; Manfred Pfister (Hg.): Krisis! Krisenszenarien, Diagnosen und Diskursstrategien, München 2007.

15 Arnold van Gennep: Les rites de passage, Paris 1909; deutsch: Übergangsriten, Frankfurt am Main 2005.

16 Philipp Sarasin: »Wie weiter mit Foucault?«, in Hamburger Institut für Sozialforschung (Hg.): »Wie weiter mit...?«, Hamburg 2008, S. 1-48, hier S. 18f.

17 Gilles Deleuze: Foucault, Frankfurt am Main 1992, S. 71. 


\section{INTERMEZZO: Klingende Ereignisse und ästhetische Störfalle}

Wenn von Musikskandalen als `klingenden Ereignissen sonders die Eskalationsphase, wenn der rollende Stein des Anstoßes in der Zeitgeschichte aufschlägt: Nur in den Konzertsälen wird das Ereignis punktuell manifest. Das a priori und a posteriori, also >Inkubation` und `Regeneration ২ des musikskandalösen Prozesses, sind stets diskursiv verfasst und weisen den Musikskandal als kontingentes Konstrukt kommunikativen oder rituellen Handelns aus. Aus ereignisanalytischer Sicht aber folgte die Arbeit der erkenntnisleitenden Idee eines bestimmten Moments, wenn das Pendel kurz stillsteht und in dem die Zeit wie eingefroren ist: dieses Intermezzo galt es historisch dingfest zu machen.

Die analytische Ergreifung des eklatanten Moments geschah methodisch durch die Fokussierung von audiovisuellen Quellen und besonders Live-Mitschnitten, aber auch Augenzeugenberichten sowie Zeitzeugengesprächen im Sinne der >oral historyく. Aber auch ereignis- und störungstheoretische Konzepte formten - im direkten $\mathrm{Zu}$ sammenhang mit der institutionellen Entstehungsgeschichte dieser Arbeit ${ }^{18}-$ das Denken über Klingende Eklats. Beide Denkmodelle fokussieren im Anschluss an Reinhart Koselleck die >Antithese $<$ zwischen Ereignis und Struktur ${ }^{19}$ - also das Außergewöhnliche im Kontext eines allgemeinen Gefüges.

In der französischen Ereignisphilosophie besteht Konsens über den liminalen, außergewöhnlichen und einmaligen Charakter des Ereignisses: nicht nur für Jaques Derrida muss es »per se als absolute Überraschung [...] hereinbrechen. ${ }^{20}$ Der Spur, die das Ereignis als antistrukturelle Kategorie ausweist, folgt auch Jean Braudillard, laut dem das wirkliche Ereignis ex nihilo stattfindet: »Es wird immer eine Chance für die beunruhigende Fremdheit des Ereignisses, des Ereignishaften gegen die beunruhigende Monotonie der Weltordnung, der virtuellen Ordnung geben. ${ }^{21}$ Allerdings, so zitiert Josef Vogl Gilles Deleuze: »Das Ereignis ist auch Erwartungshaltung« und fügt an, es existiere nur in einer »spezifischen Zwischen-Zeit, in einem spezifischen Zwischenraum. ${ }^{22}$ Eben jenem Intermezzo, in dem das zeithistorische Pendel kurz stillsteht. Gerade, weil Ereignisse $» f l u ̈ c h t i g$ und wolkig « ${ }^{23}$ sowie in einem Netz aus gesellschaftlichen Erwartungen, kulturellen Konventionen und medialen Bedingungen eingebettet sind, ist es reizvoll, jenen Umbruchsmoment im ereignishaften Zentrum des musikskandalösen Prozesses zu fassen.

18 Die Arbeit wurde zunächst inspiriert und unterstützt von einem DFG-Stipendium beim Graduiertenkolleg »Transnationale Medienereignisse« an der Justus-Liebig UniversitätGießen (2011-14). Seit 2014 wurde sie im Rahmen der vom European Research Council geförderten interdisziplinären Forschergruppe »The Principle of Disruption« am Lehrstuhl für Medien- und Literaturwissenschaft der Technischen Universität Dresden beendet.

19 Reinhard Koselleck: »Darstellung, Ereignis, Struktur«, in Ders.: Vergangene Zukunft, Frankfurt 1979, S. 144-157.

20 Derrida: Eine gewisse unmögliche Möglichkeit, S. 35.

21 Jean Baudrillard: Das Ereignis, Weimar 2007, S. 16.

22 Josef Vogl: »Was ist ein Ereignis?«, in Peter Gente/Peter Weibel (Hg.): Gilles Deleuze und die Künste, Frankfurt am Main 2007, S. 67-83, hier S. 75.

23 Ebd., S. 69. 
Dieter Mersch nennt seine kunstphilosophische Schrift zum Verhältnis und Kunst und Ereignis nicht zufällig Der versteinerte Augenblick und bezeichnet diesen als »Epiphanie, die plötzlich und wie der >Blitz` einfällt und die gewohnten Beziehungen zur Wirklichkeit untergräbt. ${ }^{24}{ }^{24}$ Ohne diesen Blitz«, so zitiert er Jean-François Lyotard, »gäbe es nichts ${ }^{25}$. Die »experimentelle Ästhetik der Avantgarde «, so Mersch weiter, strebe nach einem »Umsturz der Kunstauffassung« und verweise auf die »Maßlosigkeit des >dionysischen Rausches`, die für einen Großteil der Avantgardekunst des 20. Jahrhunderts zum ästhetischen Ideal [..., ] zum ästhetisch sublimierten Schock« avancierte: »Ästhetische Erfahrung ist dann Differenzerfahrung; sie gehorcht dem Bruch, der Revolte.« Diese Performativität habe moderne Kunst »in den Rang eines Ereignisses« gehoben. ${ }^{26}$

Es ist auch kein Zufall, dass die sogenannte performative und also ereignishafte Kunst kongruent mit den Fortentwicklungen der Medientechniken entstand. Schon die Neue Musik als Klangkunst im engeren Sinne entwickelte Verfahren - wie Aleatorik oder Improvisation - mit denen kompositorische Verläufe jenseits zielgerichteter Linearität organisiert und damit ereignishaft wurden. Besonders deutlich wurde dieses Moment in den Aktionskünsten der 1960er Jahre, denen es nicht mehr um dauerhafte Werke, sondern um singuläre Ereignisse ging: Immer einzigartig und der technischen Reproduzierbarkeit wie zum Trotz nicht wiederholbar. Wenn Mersch die Frage nach der Dokumentierbarkeit stellte - »denn was sich lediglich als Handlung in der Zeit vollzieht duldet [...] keine Abbildung « - so führten die medientechnischen Möglichkeiten der Aufnahme, Speicherung und Distribution zu einem »Paradox des Archivs«, also der »Präsentation von etwas, das sich jeder Präsentierbarkeit entzieht. $\ll^{27}$ Wenn audiovisuelle Zeugnisse auch die Wirklichkeit nicht abbilden können, so wird hier doch zumindest eine »Spurensammlung« des versteinerten Augenblicks akustisch und bildlich transportiert, und zwar als:

»Differenz zwischen Ereignis und Erinnerung, zwischen einmaligem Geschehen und dessen historischer Aufzeichnung [...]. Anders ausgedrückt, sie [die Reproduktion] bildet als Spur keine Repräsentation, keine Verkörperung, sondern nurmehr Marke, Signifikant ohne verbindliches Signifikat oder bestimmbare Semantik. ${ }^{28}$

Der Verweis auf die Semiotik verdeutlicht den Zusammenhang zwischen der materiellen Form und der Bedeutung von Zeichen - wie etwa Mitschnitten von Musik - der als arbiträr und durch Konvention geprägt definiert wird. Wenn in audiovisuellen Quellen Signifikant und Signifikat auch nicht zusammentreten können, so sind sie doch eine Art analytisches Fernglas in den versteinerten Augenblick der klingenden Ereignisse.

24 Dieter Mersch: »Der versteinerte Augenblick: Zum Verhältnis von Kunst und Ereignis zwischen Barock und Moderne« (24.3.2011), online unter URL: www.momo-berlin.de/ mersch_augenblick.html (Zugriff: 31.8.2017), S. 11.

25 Jean-François Lyotard: »Der Augenblick, Newman«, in Ders.: Philosophie und Malerei im Zeitalter ihres Experimentierens, Berlin 1986, S. 7-23, hier S. 13.

26 Mersch: Der versteinerte Augenblick, S. 7ff.

27 Ebd., S. 12.

28 Ebd., S. 14. 
Die unmittelbare Präsenz von Musikskandalen manifestiert sich besonders in den affektiven Kontrollverlusten des Publikums im Moment der Aufführung. Wenn ästhetische Normen und Wahrnehmungskonventionen durchbrochen werden, zeigt sich der klingende Eklat als ästhetischer `Störfall<: als Werkzeug einer »funktionalen Kulturkritik« sowie als »Metakategorie der kulturwissenschaftlichen Beschäftigung mit den politisch-sozialen, epistemischen und medialen Konstitutionsbedingungen von Wirklichkeits- und Gesellschaftsbildern. ${ }^{29}$

In ihrem Aufsatz »Zur Ereignishaftigkeit und Funktion von Störungen in den Künsten« sprechen Lars Koch und Tobias Nanz von »Ästhetiken der Verunsicherung« und machen die avantgardistische Erzeugung von Provokation als reflexiven Experimentalraum nutzbar. Die Skandale der Neuen Musik können im Anschluss daran als Störungsprinzip innerhalb eines diskursiven und symbolischen Voraussetzungs- und Wahrnehmungsraums sowie als »ereignis- oder prozesshafte Perturbation von Bedeutungs- und Sichtbarkeitsordnungen« verstanden werden. Als Störung unterbrechen sie »den gewöhnlichen Gang der Geschichte« und legen damit die »Produktionsdynamik kultureller Schemata $\ll^{30}$ offen. Der Musikskandal kann in diesem Sinne als Negativ einer jeweils formulierten 〉Ordnung der Dinge〈 und als punktueller Einbruch des >Anderen $<$ gelten. Auch Koch und Nanz betonen, dass im avantgardistischen Störmoment »in konstitutiver Weise Ästhetik und Epistemologie« verklammert werden und bezeichnen solche epistemologischen Ereignisse als kulturdiagnostischen »Erkenntnisoperator «, indem sie »auf der Inhalts- und/oder Formseite Irritationsmomente und Unterbrechungen implementieren und damit Erwartungshaltungen, Aufmerksamkeitskonventionen und Verhaltensroutinen reflexiv ausstellen. $\ll^{31}$

Die Neue Musik nach 1945 vertrat das Störungsmoment durch das selbst auferlegte Fortschrittstheorem auf paradigmatische Weise: Die Avantgarden spielten mit gesellschaftlichen, wahrnehmungsbezogenen und ästhetischen Erwartungshorizonten und produzierten durch die Verschmelzung von performativen und repräsentativen Verfahren Widerstände und Kontroversen. Neue Musik war antiaffirmativ und damit auch eine Form von `Kulturkritik ‘ am warenförmigen und marktorientierten Charakter der aufstrebenden Unterhaltungs- und Massenkultur.

\section{DISSONANZEN: Kulturindustrie vs. Kulturräsonnement}

Die avantgardistischen Unruhestifter umgab ein Glanz - wörtlich éclat - der über den Moment und das Produkt hinausging und sich aus einer grundsätzlich kulturkritischen Haltung speiste. »Die großen Werke der Avantgarde«, so betont der Komponist und Zeitzeuge Dieter Schnebel, »waren nie affirmativ« und fügt hinzu: »Die historischen Saalschlachten wurden stets in einem Geist der Widerständigkeit geboren. ${ }^{32}$ Schnebel spielt damit auf einen besonders für die Neue Musik bedeutsamen Diskurs an: jenen um die Kulturindustrie im massenmedialen Dispositiv der Moderne.

29 Lars Koch/Tobias Nanz: »Ästhetische Experimente. Zur Ereignishaftigkeit und Funktion von Störungen in den Künsten«, in: Zeitschrift für Literaturwissenschaft und Linguistik (173/2014): Krisen, Katastrophen, Störungen, S. 94-115, hier S. 94.

30 Ebd., S. 95.

31 Ebd., S. 96.

32 Dieter Schnebel im Gespräch mit der Autorin am 12.8.2012. 
Es ist kein Zufall, dass Theodor W. Adorno, der bis heute wichtigste Theoretiker und Philosoph der Neuen Musik, zugleich ein Protagonist der Kritischen Theorie war. Seine musiktheoretischen Schriften können als Quellen zur Entwicklung der Nachkriegsavantgarde gelesen werden und besitzen auch inhaltlich noch immer gültiges Erkenntnispotential. Das von Adorno forcierte avancierte Materialdenken, sein Kanon des Verbotenen und die in seinem Fortschrittstheorem enthaltene Innovationsdynamik beschreiben die Entfremdung der Kunstmusik von der Kulturindustrie, zu deren Negativabbild die Neue Musik nach 1945 wurde.

In seinem »Résumé über die Kulturindustrie« beschrieb Adorno die gesellschaftliche Implikation von kulturellen Ereignissen und künstlerischen Erzeugnissen und kritisierte die Anwendung des kapitalistischen Verwertungsprinzips auf die Kunst: »Geistige Gebilde kulturindustriellen Stils sind nicht länger auch Waren, sondern sind es durch und durch. ${ }^{33}$ Die Neue Musik bekam in diesem Denken die Rolle des »Aufstörenden und selber Verstörten ${ }^{34}$ und wurde der systemfördernden Kulturindustrie als systemsprengende Kraft gegenübergestellt. In dieser folgenreichen Dialektik zwischen >Kulturware` und >authentischen Kunstwerken der bis heute gültigen Spartentrennung in eine >Unterhaltungs- $\prec$ und eine $>$ Ernste Musik. Ungeachtet der vielfältigen Schattierungen der zeitgenössischen Musikkultur, stand von nun an eine am geistigen Gehalt orientierte Kunstmusik einer am aufmerksamkeitsökonomischen Gehalt interessierten Popkultur gegenüber. In dem Maße, wie hier Aufmerksamkeit zu blanker Währung wurde, berief sich die Neue Musik nach 1945 auf autonomieästhetische Prinzipien und den Bildungsauftrag. Diese Entwicklung hing nicht zuletzt mit den öffentlich-rechtlichen Rundfunkanstalten zusammen, mit denen die Nachkriegskomponisten eine intrinsische Genese verband. Paradoxerweise wurde das Radio zum Gegenbeispiel der kulturkritischen These vom Kulturzerfall durch die massenmediale Warenlogik. Mit dem Siegeszug des Fernsehens in den 1960er Jahren und der Dualisierung des Rundfunks in den 1980ern wurde aber schließlich auch diese öffentlich-rechtliche Oase der Konkurrenzlosigkeit von der Marktwirtschaft eingeholt. Neue Musik rutschte in dem Moment in eine Nische, als Kulturräsonnement in dominanter Weise vom Kulturkonsum abgelöst wurde.

Diese Begriffe wurden zu Schlüsselwörtern im Strukturwandel der Öffentlichkeit, den Jürgen Habermas 1962 im Anschluss an Adornos Thesen insbesondere im zentralen Kapitel »Vom kulturräsonierenden zum kulturkonsumierenden Publikum« beschrieb: Durch die marktförmige Organisation und massenmediale Verbreitung käme es zu einem aktiven Rückgang der Kulturaneignung und die Öffentlichkeit zerfalle in einzelne, passiv konsumierende Rezipienten: »Mit der privaten Form der Aneignung entfällt auch die öffentliche Kommunikation über das Angeeignete. ${ }^{35}$ Wenn Habermas die literarische Öffentlichkeit als politische Gruppierung ausmachte, gilt dies

33 Theodor W. Adorno: »Résumé über Kulturindustrie«, in Ders.: Ohne Leitbild. Parva Aesthetica, Frankfurt am Main 1967, S. 60-70, hier S. 62.

34 Theodor W. Adorno: Das Altern der Neuen Musik, in Ders.: Dissonanzen. Musik in der verwalteten Welt, Göttingen 1991, S. 136-159, hier S. 143.

35 Jürgen Habermas: »Vom kulturräsonierenden zum kulturkonsumierenden Publikum«, in Ders.: Strukturwandel der Öffentlichkeit, Frankfurt am Main 1990, S. 248-266, hier S. $251 \mathrm{f}$. 
auch für die musikalischen - wie alle aktiv rezipierenden - Publika, deren kommunikative Bedeutung Habermas unter den massenmedialen Dispositiven in Gefahr sah:

»Die neuen, elektronischen Medien beschneiden, im Vergleich zu gedruckten Mitteilungen eigentümlich die Reaktionen des Empfängers. Sie ziehen das Publikum als Hörende und Sehende in ihren Bann, nehmen ihm aber zugleich die Distanz der `Mündigkeit`, die Chance nämlich, sprechen und widersprechen zu können. $\ll^{36}$

Dieser Punkt ist entscheidend auch für den Musikskandal, der einer öffentlichen Resonanz bedarf und sich aus polarisierenden Meinungen konstituiert. Der musikhistorische Kommunikationsprozess fand bis zur Mitte des 20. Jahrhunderts insbesondere in Konzertsälen und Opernhäusern statt, für deren soziokulturelle Funktion sich Habermas' »architektonische Metaphern des umbauten Raumes« wie »Foren, Bühnen, Arenen « - also allgemein zugängliche Versammlungsorte, anbieten. ${ }^{37}$ Hier hat die Öffentlichkeit, die `Sphäre der zum Publikum versammelten Privatläute`, die Chance unmittelbar >sprechen und widersprechen zu können<. Diese Eigenschaft ging durch die Entgrenzung infolge der medialen Übertragungstechniken verloren und so kann Habermas entgegnet werden, dass mit den Nachrichten auch die affektive Anteilnahme entgrenzt wurde, wie etwa die in den Rundfunkarchiven dokumentierten Höreranrufe und -briefe belegen. Auch schloss Habermas kulturräsonierende TeilÖffentlichkeiten aus seinen Überlegungen aus und vertrat eine Vereinheitlichungsthese, die spätestens nach 1968 und der Pluralisierung der Lebenswelt durch die postmodernen Fliehkräfte nicht mehr gelten kann.

Erst spät, in der Neuausgabe des Strukturwandels von 1990, gestand Habermas dem von Massenmedien umgebenen Publikum ein eigenständiges Medienhandeln zu und konstatierte mit Verweis auf die cultural studies, dass sich die »Maßstäbe der Beurteilung selber verändern. ${ }^{38}$ Darüber besteht heute Konsens in den medienwissenschaftlich arbeitenden Disziplinen. Entgegen der medienkritischen Großnarration einer >Disziplinierung der Gefühle`schrieben etwa Frank Bösch und Daniel Borutta 2006, dass Gefühle in der Moderne maßgeblich durch die Medien beeinflusst werden: "sie veränderten die Ausdrucksformen und [...] sie produzierten Diskurse«, welche so der Titel des Sammelbands: Die Massen bewegen. ${ }^{39}$

1962 bemerkte Jürgen Habermas in der Erstausgabe des Strukturwandels, nur eine Aufhebung der Trennung von Sender und Empfänger könne die massenmedialen Wirkungen der Entfremdung, der Manipulation, der Überwältigung und der dumpfen Zerstreuung des Publikums überwinden. Angesichts der Neuen Medien scheint sich diese Hoffnung ein stückweit zu erfüllen: Im Internet werden Medienkonsumenten wieder zu Medienproduzenten und idealtypische Kriterien der Öffentlichkeit - wie Zugänglichkeit, gleichwertige Kommunikation, offene Themenwahl und ein unbegrenzter Teilnehmerkreis - erfüllt. Allerdings ohne kulturräsonierende Kontrol-

36 Ebd., S. $188 f$.

37 Jürgen Habermas: Faktizität und Geltung. Beiträge zur Diskurstheorie des Rechts und des demokratischen Rechtsstaats, Frankfurt am Main 1992, S. 437.

38 Habermas: Strukturwandel der Öffentlichkeit, S. 30.

39 Frank Bösch/ Borutta, Daniel (Hg.): Die Massen bewegen. Medien und Emotionen in der Moderne, Frankfurt am Main/New York 2006, S. 9. 
linstanz, ohne die >funktionalen Eliten`, die Habermas 1958 in seiner Schrift »Zum Begriff der Politischen Beteiligung « zu Schlüsselakteuren einer Revitalisierung des soziopolitischen Bereichs erklärt hatte. ${ }^{40}$ Der entscheidende Punkt für einen neuerlichen Strukturwandel der Öffentlichkeit infolge der Digitalisierung, ist die Frage nach ihrer Nutzung. Die Diskussionen um die Bedeutung und die Folgen der digitalen Revolution für die (Neue) Musik sind bereits im vollen Gange. ${ }^{41}$

Im hier behandelten Zeitraum, den drei Dekaden der langen Nachkriegszeit nach 1945, bildeten die künstlerischen und mithin auch die musikalischen Avantgarden durchaus eine >repolitisierte〈 Sozialsphäre: sie reflektierten und hinterfragten nicht nur ästhetische und kulturelle, sondern auch gesellschaftliche Normen und mediale Konventionen - wenn auch zunehmend abseits des grellen Scheinwerferlichts der massenmedialen Öffentlichkeit. Dies gilt besonders für die kommunistischen Komponisten und die performativen Aktionskünste im Umfeld von 1968, die im Anschluss an Hans-Thies Lehmanns Begriffsbildung zum Postdramatischen Theater statt Affirmation >Afformativität betrieben: Momente nicht konsumierbarer Opazität, die statt durch Inhalte, mit performativen Darstellungsweisen politisch wurden. ${ }^{42}$ Aber auch die autonomieästhetischen Neuerer der Musik und ihre Kompositionskonzepte wie Atonalität, Serialismus oder Aleatorik können als subversive Praktiken im Boykott gegen die Kulturindustrie verstanden werden: Neue Linke und Neue Musik teilten linksintellektuelles Wissen, Theorien und Diskurse, die nicht zuletzt die Musikavantgarde kulturalisierte und damit gewissermaßen konservierte. ${ }^{43}$

\section{CODA: ,Skandal Im Sperrbezirkı oder: >Nicht-Ereignisseı}

Die éclats der historischen- und der Nachkriegsavantgarden waren beseelt von einem Geist der Widerständigkeit gegen ästhetische, politische oder institutionelle Obrigkeiten. Ob mit performativ-subversiven Praktiken oder autonomieästhetischen Vorstößen auf schockierendes und wortwörtlich >unerhörtes` Neuland, forderten die Avantgarden der Neuen Musik geltende Konventionen heraus und machten so auch Weltbilder ex negativo sichtbar. Allerdings, so bemerkte Wolfgang Welsch aus postmoderner Perspektive, enthielt auch die auf dem von Theodor W. Adorno geprägten Fortschrittstheorem gründende avantgardistische Dauerinnovation eine kulturindustrielle Dynamik:

40 Jürgen Habermas: »Zum Begriff der politischen Beteiligung« (1958), in Ders./Ludwig von Friedeburg/Christoph Oehler/Friedrich Weltz (Hg.): Student und Politik, Berlin 1961, S. 13-55, hier S. 51.

41 Sie hierzu die hitzigen und öffentlich ausgetragenen Debatten um Harry Lehman: Die digitale Revolution der Neuen Musik. Eine Musikphilosophie, Mainz 20013. Die Kontroverse findet sich gesammelt publiziert in Johannes Kreidler/Harry Lehmann/Claus-Steffen Mahnkopf (Hg.): Musik-Ästhetik-Digitalisierung. Eine Kontroverse, Hofheim 2010.

42 Hans-Thies Lehmann: Das Postdramatische Theater, Frankfurt am Main 2005.

43 Siehe zu den Verbindungen politischer Theorien und musikalischer Avantgarden ausführlich Beate Kutschke: Neue Linke - Neue Musik. Kulturtheorien und künstlerische Avantgarde in den 1960er und 70er Jahren, Köln/Weimar/Wien 2007. 
»Das Innovations-Theorem reflektiert eigentlich eine ökonomische, nicht eine künstlerische Logik. Es trifft Kunst nicht als Kunst, sondern als Ware und Investitionsobjekt. Daher hat es im Kunstmarkt nicht nur seine beredtsten Apologeten, sondern auch seinen eigentlichen Ort und Sinn. Der doxa-einschlägige Innovationstyp [...] ist die Leitform marktökonomischer Dynamik. Eine Konsequenz davon ist: Wer wissenschaftlich dieses Theorem propagiert, spricht in der Bahn der Marktperzeption von Kunst und ist de facto ein wissenschaftlicher Zuarbeiter der tendenziellen Vereinnahmung und potentiellen Vernichtung der Kunst durch den Markt. $^{44}$

Ein stückweit zimmerten die musikalischen Avantgarden also selbst die Nische - den vielbeschworenen Elfenbeinturm - in den sie sich nach und nach zurückzogen: Das Spiel mit den massenmedialen Funktionsweisen einer Ökonomie der Aufmerksamkeit $^{45}$ beherrschte die aufstrebende Popkultur besser, weil sie überwiegend unabhängig von ästhetischen Komplexitätsansprüchen agierte. Im grellen Scheinwerferlicht der Unterhaltungsindustrie und dem postmodernen anything goes implodierte die avantgardistische Überbietungstendenz in der sensationsorientierten Inszenierungslogik einer Gesellschaft des Spektakels ${ }^{46}$, in der künstlerische Provokation nahezu unmöglich und die Kunstmusik als hochkulturelle subaltern culture von der Popindustrie als Leitkultur abgelöst wurde.

Diese Entwicklung ist nicht zuletzt auf die von Kulturkritikern und insbesondere Adorno mitgestaltete Sezession der Musik in einen U- und einen E-Sektor zurückzuführen. Die nun als >ernst` deklarierte Neue Musik zog sich in einem letzten Akt von Radikalität, selbst zum Preis ihrer Marginalisierung, vom Markt und der Kulturindustrie zurück und ihre Skandale, so könnte man pointiert ausdrücken, verhallten im isolierten Sperrbezirk der Neuen Musik. Die aufstrebende Unterhaltungsmusik wiederum bediente sich zwar kaum ästhetischer Vorbilder, übernahm aber den avantgardistisch erprobten Provokationscharakter und die von Adorno deklarierte Funktion des >Aufstörens unter aufmerksamkeitsökonomischen Vorzeichen. Zwar haben sich in der Popkultur Überreste der avantgardistischen Skandallust erhalten, doch die hier provozierten Eklats verloren ihren ereignishaften Charakter und wurden vielmehr zum: Nicht-Ereignis.

1977 leiteten die Sex Pistols mit »God save the Queen« die Ära des Punks ein, der mit den Relikten der Musik als Kunst radikaler brach, als es die avantgardistische Kunstmusik durch ihren handwerklichen Anspruch je gekonnt hätte. Auf Elvis Presleys eindeutig zweideutige Hüftschwünge folgte mit Madonna eine Ikone der Provokation, die in den 1980ern eine beispiellose Skandalserie hinlegte: Auf Masturbationsszenen 1984 in Like a Virgin folgten 1989 Anzüglichkeiten gegenüber einer schwarzen Jesusgestalt (Like a Prayer) und ein Jahr später sadomasochistische Anspielungen (Justify my love), bevor die >Queen of Pop 2003 mit einer Skandalnudel der 1990er - Britney Spears - bei den MTV Video Music Awards einen Zungenkuss tauschte und damit wieder einmal Schlagzeilen machte. Wenn Miley Cyrus 2013 nackt auf einer Kanonenkugel reitet und damit Wrecking Ball zum meistgeklickten Video des Jahres macht oder wenn Justin Bieber seinen Affen am Münchner Flughafen vergisst, ohne Fahrerlaubnis illegale Autorennen fährt und mit Drogen auffällig

44 Wolfgang Welsch: Unsere postmoderne Moderne, Berlin 2002, S. 94.

45 Georg Frank: Ökonomie der Aufmerksamkeit. Ein Entwurf, München/Wien 1998.

46 Guy Debord: Gesellschaft des Spektakels, Berlin 1996. 
wird, ist den Ikonen der heutigen Popindustrie die Aufmerksamkeit der Illustrierten und die ersehnten Klicks auf den Videoportalen sicher. Mit ihrer Kunst oder éclats im Sinne der Avantgarden haben solche massenhaft rezipierten Vorkommnisse freilich kaum mehr zu tun. Mit einer engagierten Musik für die Massen, wie sie um 1968 die linkspolitischen Komponisten diskutierten, erst recht nicht.

Natürlich gibt es in der Vielfalt der zeitgenössischen Ausdrucksformen auch subtilere Arten der Provokation: die Pluralisierung der Sparten bietet Nischen für nahezu jeden Anspruch. Aber die massenhafte Aufspaltung macht übergreifende Störungsprozesse aus den Reihen der Kunst nahezu unmöglich. Reibt sich die Neue-MusikSzene in ihrer weitegehend institutionalisierten Marktnische höchstens unter- und aneinander, kann der Begriff einer >Leitkultur` am ehesten noch für die global wirksame >warenförmige< Popkultur des angloamerikanischen Raums gelten. Hier allerdings steht das Marketing meist vor dem Produkt, während es in der Kunstmusik geradewegs umgekehrt ist. Der Siegener Medienwissenschaftler Jochen Venus beschrieb die basale Funktionsweise der Populärkultur anhand der Merkmale von Serialität und spektakulärer Selbstreferenz:

»Wann immer populäre Kulturen einen Aufmerksamkeitserfolg erzielen, kristallisiert an diesem Erfolg sofort ein Konvolut ähnlicher Produkte. Jedes Faszinosum geht unmittelbar in Serie, strahlt aus, metastasiert und bezieht immer mehr Rezipienten in die spezifische Form spektakulärer Selbstreferenz ein. Auf diese Weise emergieren Stilgemeinschaften normalisierten Spektakels. $\ll^{47}$

Innerhalb dieses >normalisierten Spektakels` wird der Musikskandal, um noch einmal in das metaphorische Bild eines Krankenverlaufs zurückzukehren, zum Ausdruck einer massenmedialen Hypochondrie. Zwar grassiert das eklatante Fieber, doch ist dem nur noch mit medialem Placebo beizukommen und bezeichnet statt klingender Eklats nun vielmehr: >Nicht-Ereignisse .

Jean Baudrillard konstatiert, dass ein Ereignis per se ein überraschendes und spontanes Element enthalten müsse. Er grenzt es explizit von >Nicht-Ereignissen〉ab, die im Gegensatz den Eintritt von etwas Vorhergesehenem und Vorausberechneten bezeichnen und also geradewegs in umgekehrter Richtung verlaufen. Die »beunruhigende Befremdung « des Ereignisses wird von der nur scheinbar beruhigenden »Vertrautheit « des Nicht-Ereignisses abgelöst. ${ }^{48} \mathrm{Zu}$ greifen ist diese widerstreitende Logik in der griffigen These, die Tobias Nanz und Johannes Pause in ihrer Einleitung des Sammelbandes Politiken des Ereignisses mit Blick auf >echte< Ereignisse formulieren: »Zuerst ereignen sie sich, und dann erst werden sie möglich gewesen sein. ${ }^{49}$

In diesem Zusammenhang deutet sich ein Wandel der Definition des Skandals selber an: Während dieser vormals im Sinne eines ereignishaften pars pro toto das Außergewöhnliche bezeichnete, sind Skandale heute geradewegs zur Struktur selbst

47 Jochen Venus: Die Erfahrung des Populären. Perspektiven einer kritischen Phänomenologie, in Marcus S. Kleiner/Thomas Wilke (Hg.): Performativität und Medialität Populärer Kulturen. Theorien, Ästhetiken, Praktiken, Wiesbaden 2013, S. 49-73, hier S. 67.

48 Jean Baudrillard: Das Ereignis, Weimar 2007, S. 12/7.

49 Tobias Nanz/Johannes Pause (Hg.): Politiken des Ereignisses. Mediale Formierungen von Vergangenheit und Zukunft, Bielefeld 2015, S. 18. 
geworden: Zum ursprünglichen Wortsinn eines allgemeinen Ärgernisses kam erst im 19. Jahrhundert öffentliches Aufsehen, also der mediale Faktor, zur enzyklopädischen Definition hinzu. Parallel zum Aufstieg der Massenmedien - so die Hypothese - hat dieser Aspekt im Verlauf des 20. Jahrhunderts nahezu alle anderen Bedeutungskomponenten verdrängt und damit den Skandal zu einer bloßen Form degradiert: Ist das Ereignis vorprogrammiert und vorhersehbar, verflacht es in der Retextualisierung durch die Medien unvermeidlich zum Spektakel, zum >Nicht-Ereignis $<$. Heißt dies im Umkehrschluss, dass Musikskandale als ereignishafte Stürze in das Jetzt des Augenblicks heute ausgestorben sind? Nicht unbedingt: Klingende Eklats wurden in dieser Arbeit als prozesshaft und wandelbar charakterisiert und insbesondere an historischen Schwellenphasen und in medialen Umbruchsszenarien ausgemacht, die spezifische Ermöglichungsräume für Skandalisierungen eröffnen. In diesem Kontext kam es 2016 zu einem Eklat, in dem die Nerven- und Reizpunkte der aktuellen deutschen Gesellschaft einmal mehr in einem Konzertsaal als >Bühne der Politikı verhandelt wurden und der als aktualisierender Exkurs diese Arbeit beschließen soll:

Am 29. Februar veranstaltete die Kölner Philharmonie ein Konzert des iranischen Cembalist Mahan Esfahani, der mit Steve Reichs Piano Phase aus dem Jahr 1967 eine Komposition aus dem für diese Arbeit maßgeblichen Zeitraum auf das Programm setzte. Es war allerdings weniger die repetitive Ästhetik der >minimal music, welche die Störungen durch das Publikum provozierten; vielmehr bot das Konzert gesellschaftlichen Debatten eine Bühne, indem sich in den Ereignissen aktuelle Problemlagen verdichteten und brachen: In diesem Falle die Flüchtlingskrise sowie die national-populistischen Strömungen in Deutschland, Europa und der Welt. Es ist kein Zufall, dass sich der Skandal am 29. Februar gerade in Köln ereignete - das wenige Wochen zuvor beim Jahreswechsel 2015/16 in den Fokus der Debatten geriet, die als >Kölner Silvesternacht $\prec$ bereits in den festen Sprachgebrauch eingegangen sind: für >jagdartige Szenen südländischer Männer auf deutsche Frauen ২ - was die Stimmung in der Region und im Land umschlagen ließ von einer Willkommenskultur in eine Kultur der Angst vor dem Anderen. In der Kölner Philharmonie entluden sich die Ressentiments während der englischen Werkeinführung des iranischen Solisten, als 〉besorgte Bürger〈 im Auditorium forderten: »Sprechen Sie gefälligst Deutsch!« unmittelbar gefolgt von zustimmenden Reaktionen und empörten Buhrufen, während sich die lokale, überregionale und sogar die internationale Presse in den kommenden Tagen ausgiebig dem Eklat widmete. Die Musik wurde also einmal mehr zu einem symbolischen Verhandlungsort und zum kulturellen `Schlacht`-Feld der aktuellen Krise, die sich auf politischem Feld in mittlerweile flächendeckenden Wahlerfolgen rechtspopulistischer Parteien in Europa und darüber hinaus niederschlagen.

Inwieweit die weiteren politischen Entwicklungen auch Auswirkungen auf die Kunstmusik zeitigen und ob solche Wandlungsprozesse die Neue Musik in ihrem hochkulturellen Elfenbeinturm ergreifen und ästhetisch zu transformieren vermögen, bleibt abzuwarten und ist angesichts der Aktualität der Ereignisse vorerst Zukunftsmusik. Ähnliches gilt für den Einfluss der Neuen Medien in Hinblick auf die Herausbildung einer kultur- und medienkritischen Öffentlichkeit vonseiten der Künste, wenngleich sich hier auf ästhetischem Gebiet bereits eine Revitalisierung des zeitgenössischen Musiklebens andeutet. 
Derzeit hat es den Anschein, als ob infolge der digitalen Revolution die längst überfällige Spartenteilung der Musik endlich untergraben wird. Es entsteht ein hybrider Raum, der weder den Paradigmen von Populär- noch denen der Hochkultur folgt und für den sich infolge der Frontstellung zeitgenössischer Musikkultur zwischen >U< und $>\mathrm{E}<$ niemand zuständig zu fühlen scheint. Will man sich diesem bislang unerforschten Feld einer `Ü-Musik « nähern, bedarf es jedoch einer nicht nur diskursiven Neuordnung musikkultureller Paradigmen. ${ }^{50}$ Bis die zeitgenössische Musikkultur die im Umlaut von >Uく und 〉E enthaltene Überraschung als ereignishaftes Moment entdeckt und gegen die Musealisierung der Kunstmusik in Stellung bringt, verbleibt die avancierte Klangkultur der Gegenwart in ihrer Nische und sind mithin auch ihre éclats nicht mehr als: ১Skandale im Sperrbezirkı.

50 Siehe hierzu erste Vorlegungen in Anna Schürmer: »Ü-Musik entsteht in den Grenzbereichen. Ein Gedankenmodell zur Überwindung einer belastenden Sezession«, in: Neue Musikzeitung (12/2016), online unter URL: https://www.nmz.de/artikel/ue-musik-entsteht-inden-grenzbereichen (Zugriff: 31.8.2017). 



\section{BIBLIOGRAPHIE}

\section{LITERATUR: VERÖFfENTLICHTES MATERIAL ${ }^{1}$}

- A -

Adlington, Robert (Hg.): Sound Commitments. Avant-garde music and the Sixties, Oxford 2009.

Adorno, Theodor W.: Gesammelte Schriften in zwanzig Bänden, Frankfurt am Main 1997.

— Ästhetische Theorie, Frankfurt am Main 1996.

— Negative Dialektik, Frankfurt am Main 1966.

— »Résumé über Kulturindustrie« [1963], in Ders.: Ohne Leitbild. Parva Aesthetica, Frankfurt am Main 1967, S. 60-70.

— »Ideen zur Musiksoziologie« [1958], in Ders.: Musikalische Schriften, Band 1: Klangfiguren, Frankfurt am Main 1959, S. 9-31.

— »Das Altern der Neuen Musik« [1954], in Ders.: Dissonanzen. Musik in der verwalteten Welt, Göttingen 1991, S. 136-159.

— »Prismen. Kulturkritik und Gesellschaft« [1951], in Ders.: Kulturkritik und Gesellschaft I, Darmstadt 1998, S. 9-30.

— »Die auferstandene Kultur«, in: Frankfurter Hefte (5/1950), S. 469-477.

— Philosophie der neuen Musik, Tübingen 1949.

Allen, Louis: Political Scandals and Causes Celébres since 1945, Chicago 1990.

Amin, Samir: Eurocentrism, New York 1989.

Antheil, George: Bad Boy of Music, Berlin 1960.

Apollonio, Umbro: Der Futurismus. Manifeste und Dokumente einer künstlerischen Revolution 1909-1918, Köln 1972.

Applegate, Celia/Potter, Pamela (Hg.): Music and German National Identity, Chicago 2002.

Arno, Paul: Aggressive Tendenzen des Theaterpublikums, München 1969.

Artaud, Antonin: Das Theater und sein Double, Frankfurt 1969.

Asholt, Wolfgang/Fähnders, Walter (Hg.): Manifeste und Proklamationen der europäischen Avantgarde (1909-1938), Stuttgart/Weimar 2005.

1 In diesem Verzeichnis wird sämtliche verwendete Sekundär- wie Primärliteratur alphabetisch aufgelistet. Eine Zuordnung war in vielen Fällen nicht möglich, so dass auf eine getrennte Auflistung bewusst verzichtet wurde. 
- Die ganze Welt ist eine Manifestation. Die europäische Avantgarde und ihre Manifeste, Darmstadt 1997.

Attali, Jaques: Noise. The political Economy of Music, Mineapolis 1985.

Audinet, Gérard: Les grands scandales de l'histoire de l'art : cinq siècles de ruptures, de censures et de chefs-d'œuvre, Paris 2008.

Augstein, Rudolf: »Apropos Henze«, in: Der Spiegel (51/1968), S. 154.

Auslander, Philip: Liveness. Performance in a Mediatized Culture, London/New York 2008.

Austin, William W.: Music in the 20th Century, New York 1966.

\section{- B -}

Bálint, Andréas Varga: Gespräche mit Iannis Xenakis, Zürich/Mainz 1995.

Balke, Friedrich/Siegert, Bernhard/Vogl, Joseph (Hg.): Archiv für Mediengeschichte, Paderborn 2001ff.

Balme, Christopher / Schläder, Jürgen (Hg.): Inszenierungen: Theorie - Ästhetik Medialität. Ausgewählte Beiträge des Kongresses »Ästhetik der Inszenierung«, Stuttgart 2002.

Barck, Karlheinz/Fontius, Martin/Schlenstedt, Dieter/Steinwachs, Burkhart/Wolfzettel, Friedrich (Hg.): Ästhetische Grundbegriffe, 7 Bände, Stuttgart/Weimar 1992-2005.

Barthelmes, Barbara/de la Motte-Haber, Helga (Hg): Musik und Ritual, Mainz 1999.

Barthes, Roland: »Zuhören«, in Ders.: Der entgegenkommende und der stumpfe Sinn, Frankfurt am Main 1990, S. 249-263.

Bartl, Andrea: Skandalautoren. Zu repräsentativen Mustern literarischer Provokation und Aufsehen erregender Autorinszenierungen, Würzburg 2014.

Bartsch, Anne (Hg.): Audiovisuelle Emotionen Emotionsdarstellung und Emotionsvermittlung durch audiovisuelle Medienangebote, Köln 2007.

Baudrillard, Jean: Das Ereignis, Weimar 2007

— Der Geist des Terrorismus, Wien 2002.

— »Das ist der vierte Weltkrieg«, in: Spiegel Online (15.1.2002).

— Der symbolische Tausch und der Tod, München 1991.

Bauermeister, Mary: Ich hänge im Triolengitter. Mein Leben mit Karlheinz Stockhausen, München 2011.

Bayerische Akademie der Schönen Künste (Hg.): Die Künste im technischen Zeitalter, München 1954.

Bayreuther, Rainer: »Friedrich Kittlers Bedeutung für die Musikwissenschaft«, in: Musikforschung 65 (2/2012), S. 99-113.

Beil, Benjamin/Engell, Lorenz/Schröter, Jens/Schwaab, Herbert/Wentz, Daniela (Hg.): Die Serie. Einleitung in den Schwerpunkt, in: Zeitschrift für Medienwissenschaft 7 (2/2012), S. 10-16.

Bekker, Paul: Neue Musik (Gesammelte Schriften, Band 3), Stuttgart/Berlin 1923.

Bellinger Andréa / Krieger, David J. (Hg.): Ritualtheorien. Ein einführendes Handbuch, Opladen 1998.

Bendikowski, Tillmann (Hg.): Die Macht der Töne. Musik als Mittel politischer Identitätsstiftung im 20. Jahrhundert, Münster 2003. 
Benjamin, Walter: »Das Kunstwerk im Zeitalter seiner technischen Reproduzierbarkeit« [1935], in Ders.: Gesammelte Schriften, Band 1, Frankfurt am Main 1980, S. 471-508.

— Über den Begriff der Geschichte [1940], in ders.: Gesammelte Werke, Band 1, Frankfurt am Main 1991, S. 690-708.

Bennet, Susan: Theatre Audiences. A Theorie of Production and Reception, London 1990.

Bentz, Oliver: Thomas Bernhard - Dichtung als Skandal, Würzburg 2000.

Berendt, Joachim-Ernst: Nada Brahma. Die Welt ist Klang, Reinbek bei Hamburg 1986.

— Das Dritte Ohr. Vom Hören der Welt, Reinbek bei Hamburg 1990.

Bereson, Ruth: The Operatic State: Cultural Policy and the Opera House, London 2002.

Berg, Alban: Alban Berg: Prospekt des »Vereins für musikalische Privataufführungen« (September 1919).

Berg van den, Hubertus/Fähnders, Walter (Hg.): Metzler Lexikon Avantgarde, Stuttgart/Weimar 2009.

Berghaus, Günter: Theater, Performance, and the Historical Avant-garde, New York 2005.

Bergius, Hanne: Das Lachen Dadas, Gießen 1989.

Bergmann, Jens/Pörksen, Bernhard (Hg.): Skandal! Die Macht öffentlicher Empörung, Köln 2009.

Bhaba, Homi K.: »A Narrative of divided Civilizations «, in: The Chronicle of Higher Education (28.9.2001).

— Die Verortung der Kultur, Tübingen 2000.

Blackadder, Neil (Hg.): Modern Theatre and the Scandalized Audience, Westport 2003.

Blasberg, Cornelia: »Skandal«, in Gerd Ueding (Hg.): Historisches Wörterbuch der Rhetorik, Band 8, Tübingen 2007, Sp. 923-929.

Bleicher, Joan Kristin: »Terror made in Hollywood «, in Ronald Rietzler/Jo Reichertz (Hg.): Irritierte Ordnung. Die gesellschaftliche Verarbeitung von Terror, Konstanz 2003, S. 157-172.

Bloch, Ernst: Erbschaft dieser Zeit, Frankfurt am Main 1985.

Bloch, Mark: On Originale, New York 1964.

Blume, Friedrich: »Was ist Musik?« [1958], in: Musikalische Zeitfragen (Band 5), Kassel 1960, S. 66-68.

- Das Rasseproblem in der Musik: Entwurf zu einer Methodologie musikwissenschaftlicher Rasseforschung, Wolfenbüttel/Berlin 1939.

Blumenberg, Hans: Aspekte der Epochenschwelle, Frankfurt am Main 1976.

Blumröder von, Christoph: Kompositorische Stationen des 20. Jahrhunderts. Debussy, Webern, Messiaen, Boulez, Cage, Ligeti, Stockhausen, Höller, Bayle, Münster 2004.

— Der Begriff »neue Musik« im 20. Jahrhundert, München 1981.

Boenisch, Peter: »Die Knaben zwischen Marx und Mao stehen in Berlin auf der Bühne«, in: Bild-Zeitung (4.10.1971).

Boll, Monika: Nachprogramm. Intellektuelle Gründungsdebatten in der frühen Bundesrepublik, Münster 2004. 
Bollenbeck, Georg: Tradition, Avantgarde, Reaktion. Deutsche Kontroversen um die kulturelle Moderne 1880-1945, Frankfurt am Main 1999.

Boltanski, Luc/Claverie, Elisabeth/ Offenstadt, Nicolas/van Damme, Stéphane (Hg.): Affaires, Scandales et Grandes Causes. De Socrate à Pinochet, Paris 2007.

Bolter, Jay David/Grusin, Richard: Remediation. Understanding New Media, Cambridge 2002.

Borio, Gianmaria: »Avantgarde als pluralistisches Konzept. Musik um 1968«, in Arnold Jacobshagen/Markus Leniger (Hg.): Rebellische Musik. Gesellschaftlicher Protest und kultureller Wandel um 1968, Köln 2007, S. 15-33.

— /Danuser, Hermann (Hg.): Im Zenit der Moderne. Die internationalen Ferienkurse für Neue Musik Darmstadt 1946-1966, Geschichte und Dokumentation in vier Bänden, Freiburg im Breisgau 1997.

Borkowsky, Caspar: Produktivität der Störung - Über Information, Unfälle und weißes Rauschen, München 2004, S. 241-255.

Bormann, Hans Friedrich: Verschwiegene Stille. John Cages performative Ästhetik, München 2005.

Boehmer Konrad: »Ausgerechnet! ... Computermusik«, in Ders.: Das böse Ohr. Texte zur Musik 1961-1991, Köln 1993, S. 241-255.

Bösch, Frank: Öffentliche Geheimnisse. Skandale, Politik und Medien in Deutschland und Großbritannien 1880-1914, München 2009.

— /Borutta, Daniel (Hg.): Die Massen bewegen. Medien und Emotionen in der Moderne, Frankfurt am Main/New York 2006.

— Historische Skandalforschung als Schnittstelle zwischen Medien-, Kommunikations- und Geschichtswissenschaft, in Fabio Crivellari/Kay Kirchmann/Marcus Sandl/Rudolf Schlögl (Hg.): Die Medien der Geschichte. Historizität und Medialität in interdisziplinärer Perspektive, Konstanz 2004, S. 445-464.

- Vowinckel, Annette: »Mediengeschichte, Version: 2.0«, in: DocupediaZeitgeschichte (29.10.2012), URL: http://docupedia.de/zg/Mediengeschichte Version_2.0_Frank_B.C3.B6sch_Annette_Vowinckel?oldid=97423.

Bosseur, Jean-Yves: Der Futurismus und das Werk von Edgard Varèse, in Otto Koleritsch (Hg.): Der musikalische Futurismus. Ästhetisches Konzept uns Auswirkungen auf die Moderne, Graz 1976, S. 37-49.

Bosshard, Marco: La reterritorializaciòn de lo humano. Una teoría de las vanguardias americanas, Pittsburgh 2012.

Boulez, Pierre: Wille und Zufall, Stuttgart 1977.

— Sprengt die Opernhäuser in die Luft, in: Der Spiegel (40/1967), S. 166-174.

— »Musique Concrète«, in Francois Michel (Hg.): Enzyklopédie de la musique, Band 2, Paris 1959, S. 179f.

— »Kulturen sind sterblich «, in: Melos (3/1959), S. 69f.

— $\gg$ Alea« [1957], in Ders.: Werkstatt-Texte, Berlin 1972, S. 100-113.

— Schönberg est mort!« [1951], dt. Fassung: Schönberg ist tot, in: Melos (2/1974), S. 62-64.

Bourdieu, Pierre: Die Regeln der Kunst, Frankfurt am Main 2001.

Brandl, Rudolf M.: »Musik und veränderte Bewußtseinszustände«, in Herbert Bruhn/Rolf Oerter/ Helmut Rösing (Hg.): Musikpsychologie. Ein Handbuch, Reinbek bei Hamburg 1993, S. 599-610. 
Braun, Thomas Manfred: Karlheinz Stockhausens Musik im Brennpunkt ästhetischer Beurteilung, Kassel 2004.

Braun, Hans Joachim: »Themen der Technik in der Musik des 20. Jahrhunderts«, in Gerhard A. Stadler/Anita Kuisle (Hg.): Technik zwischen Akzeptanz und Widerstand. Gesprächskreis Technikgeschichte 1982-1996, Münster/New York/München/Berlin 1999, S. 167-189.

- Maschinenmusik und Musikmaschinen, in Wolfgang König (Hg.): Propyläen Technikgeschichte, Band 5: Energiewirtschaft, Automatisierung, Information seit 1914, Berlin 1992, S. 274-279.

Braun, Hans /Gerhard, Ute/Holtmann, Everhard: Die lange Stunde Null. Gelenkter sozialer Wandel in Westdeutschland nach 1945, Baden-Baden 2007.

Brown, Milton W.: The story of the Armory Show, New York 1988.

Bruhn, Siglind: Hindemiths große Bühnenwerke, Waldkirch 2009.

Brunner, Otto/Conze, Werner/Koselleck, Reinhart (Hg.): Geschichtliche Grundbegriffe: Historisches Lexikon zur politisch-sozialen Sprache in Deutschland, 8 Bände, Stuttgart 1972-1997.

Budde, Elmar/de la Motte-Haber, Helga/Mauser, Siegfried/Riethmüller, Albrecht/Schmidt, Christian Martin (Hg.): Handbuch der Musik im 20. Jahrhundert in 14 Bänden, Laaber 2011.

Budde, Gunilla/Conrad, Sebastian/Janz, Oliver (Hg.): Transnationale Geschichte: Themen, Tendenzen und Theorien, Göttingen 2006.

Bulkow, Kirsten (Hg.): Strategien öffentlicher Aufmerksamkeitserzeugung, Wiesbaden 2011.

Bull, Michael/Back, Les (Hg.): The Auditory Culture Reader, Oxford 2003.

Büning, Eleonore: »Papa Techno«, in: Frankfurter Allgemeine Zeitung (8.12.2007).

- »Tempo und Terror. Die Skandale der Maschinenmusiker«, in: Neue Zeitschrift für Musik (3/2000), S. 8.

Burckhardt, Jakob: »Der koloniale und agonale Mensch«, in Ders.: Griechische Kulturgeschichte, Band 4, München 1977, S. 82-117.

Burkhardt, Steffen: Medienskandale. Zur moralischen Sprengkraft öffentlicher Diskurse, Köln 2006.

Bürger, Peter: Theorie der Avantgarde, Frankfurt am Main 1974.

Busoni, Ferruccio: Entwurf einer neuen Ästhetik der Tonkunst [1906], Wilhelmshaven 2001.

Butler, Judith: Precarious Life. The Powers of Mourning and Violance, London/New York 2004.

\section{- C -}

Cage, John: »McLuhan's Influence« [1967], in Richard Kostelanetz (Hg.): John Cage. An Anthology, New York 1991, S. 170f.

— Interview mit Roger Reynolds [1961], publiziert unter dem Titel »John Cage and Roger Reynolds. A Conversation, in: The Musical Quaterly (4/1979), S. 537-594.

— »Zur Geschichte der experimentellen Musik in den Vereinigten Staaten« [1958], in Rainer Nonnemann (Hg.): Mit Nachdruck. Texte der Darmstädter Ferienkurse für Neue Musik, Mainz 2010, S. 189-196. 
— »Composition as Process « [1958], in Ders.: Silence. Lectures and Writings, London 1968, S. 18.

— »Changes« [1958], in Ders.: Silence. Lectures and Writings, London 1968, S. 1834.

— »Indeterminacy« [1958], in Ders.: Silence. Lectures and Writings, London 1968, S. 35-40.

— »Communication « [1958], in Ders.: Silence. Lectures and Writings, London 1968, S. 41-56. Auch als Tonbandmitschnitt veröffentlicht in Internationales Musikinstitut Darmstadt (Hg.): Darmstadt Aural Documents, Box 2, NEOS Music GmbH 2012.

— »Erik Satie« [1958], in Heinz-Klaus Metzger/Rainer Riehn (Hg.): MusikKonzepte, Heft 11: Erik Satie, München 1988, S. 29-36.

— »Defense of Satie« [1948], in Kostelanetz, Richard (Hg.): John Cage An Anthology, New York 1971, S. 77-84.

Canetti, Elias: Masse und Macht, München 1994.

Cardew, Cornelius: Stockhausen serves Imperialism, London 1974.

Cascone, Kim: »Deterritorialisierung, historisches Bewusstsein, System. Die Rezeption der Performance von Laptop-Musik«, in Marcus S. Kleiner/Achim Szepanski (Hg.): Soundcultures. Über elektronische und digitale Musik, Frankfurt am Main 2003, S. 101-106.

Chakrabarty, Dipesh: Provincialising Europe. Postcolonial Thoughts and Historical Difference, Princeton 2007.

Chakravorty Spivak, Gayatri: Can the Subaltern Speak?, London 1988.

Chatterjee, Partha: »A Brief History of Subaltern Studies«, in Gunilla Budde/Sebastian Conrad/Oliver Janz (Hg.): Transnationale Geschichte: Themen, Tendenzen und Theorien, Göttingen 2006, S. 94-104.

Classen, Christoph/Großmann, Thomas/Kramp, Leif: »Zeitgeschichte ohne Bild und Ton? Probleme der Rundfunk-Überlieferung und die Initiative >Audiovisuelles Erbe«", in: Zeithistorische Forschungen (8/2011), S. 130-140, URL: https://www.zeithistorische-forschungen.de/1-2011/id\%3D4434.

Classen, Constanze: Worlds of Sense. Exploting the Senses in History and Across Cultures, London 1993.

du Closel, Amaury: Erstickte Stimmen. »Entartete Musik« im Dritten Reich, Wien/Köln 2010.

Conrad, Sebastian/Randeria, Shalini (Hg.): Jenseits des Eurozentrismus. Postkoloniale Perspektiven in den Geschichts- und Kulturwissenschaften, Frankfurt am Main 2002.

Corbin, Alain: Pesthauch und Blütenduft. Eine Geschichte des Geruchs, Berlin 1984.

- Die Sprache der Glocken. Ländliche Gefühlskultur und symbolische Ordnung im Frankreich des 19. Jahrhunderts, Frankfurt am Main 1995.

- »Geschichte und Anthropologie der Sinneswahrnehmung «, in Sebastian Con$\mathrm{rad} /$ Martina Kessel (Hg.): Kultur \& Geschichte. Neue Einblicke in eine alte Beziehung, Stuttgart 1998, S. 121-140.

Christoph Cox: »Wie wird Musik zu einem organlosen Körper? Gilles Deleuze und die experimentellen Elektronika«, in Marcus S. Kleiner/Achim Szepanski (Hg.): Soundcultures. Über elektronische und digitale Musik, Frankfurt am Main 2003, S. 162-193. 
Crivellari, Fabio/Kirchmann, Kay/Sandl, Marcus/Schlögl, Rudolf: Die Medien der Geschichte. Historizität und Medialität in interdisziplinärer Perspektive, Konstanz 2004.

Crunden, Robert Morse: Body \& Soul. The Making of American Modernism, New York 2000.

Custodis, Michael /Geiger, Friedrich: Netzwerke der Entnazifizierung. Kontinuitäten im deutschen Musikleben, Münster 2013.

- Traditionen - Koalitionen - Visionen. Wolfgang Steinecke und die Internationalen Ferienkurse in Darmstadt, Saarbrücken 2010.

— Die soziale Isolation der neuen Musik. Zum Kölner Musikleben nach 1945, Stuttgart 2004.

\section{- D -}

Dahlhaus, Carl: »Ästhetische Probleme der elektronischen Musik«, in Ders.: Schönberg und andere. Gesammelte Aufsätze zur Neuen Musik, Mainz 1978, S. 234244.

— »Das musikalische Kunstwerk als Gegenstand der Soziologie«, in: IRASM (5/1974).

— »Politische und ästhetische Kriterien der Kompositionskritik«, in Ernst Thomas (Hg.): Darmstädter Beiträge zur Neuen Musik, Band 13, Mainz 1972, S. 14-27.

— »Thesen über engagierte Musik«, in: Neue Zeitschrift für Musik (1/1972), S. 3-8.

Daniels, Dieter: Duchamp und die anderen, Köln 1992.

Danuser, Hermann: »Wer hören will, muß fühlen - Anti-Kunst oder Die Kunst des Skandals«, in Dietrich Kämper (Hg.): Der musikalische Futurismus, Laaber 1999, S. $95-110$.

— »Neue Musik«, in Finscher, Ludwig (Hg.): Musik in Geschichte und Gegenwart (MGG), Band 7, Kassel 1997, Sp. 75-122.

— $»$ Lob des Tadels. Der Skandal in der Musikgeschichte«, in: Programmbuch der Internationalen Musikfestwochen Luzern (16.8.-9.9.1995), S. 115-125.

- Die Musik des 20. Jahrhunderts (Neues Handbuch der Musikwissenschaft, Band 7), Laaber 1992.

- /Kämper, Dietrich/Terse, Paul (Hg.): Amerikanische Musik seit Charles Ives, Laaber 1987.

Däwes, Birgit: Ground Zero Fiction. History, Memory, and Representation in the American 9/11 Novel, Heidelberg 2011.

Dayan, Daniel / Katz, Elihu: »Medienereignisse«, in: Ralf Adelmann/Jan O. Hesse (Hg.): Grundlagentexte zur Fernsehwissenschaft. Theorie - Geschichte - Analyse, Konstanz 2002, S.412-453.

Debord, Guy: Gesellschaft des Spektakels [1967], Berlin 1996.

Decroupet, Pascal: »Tudors letzter Auftritt in Darmstadt«, in Gianmaria Borio/Hermann Danuser (Hg.): Im Zenit der Moderne. Die internationalen Ferienkurse für Neue Musik Darmstadt 1946-1966, Geschichte und Dokumentation in vier Bänden, Band 2, Freiburg im Breisgau 1997, S. 273-275.

Deleuze, Gilles Kritik und Klinik [1993], Frankfurt am Main 2000.

— »Was ist ein Ereignis? « [1988], in Ders.: Die Falte. Leibniz und der Barock, Frankfurt am Main 2000, S. 126-136. 
— Foucault [1986], Frankfurt am Main 1992.

- /Guattari, Félix: Tausend Plateaus. Kapitalismus und Schizophrenie II [1980], Berlin 2005.

— /Guattari, Félix: Anti-Ödipus. Kapitalismus und Schizophrenie I [1972], Frankfurt am Main 1974.

— Differenz und Wiederholung [1968], München 1992.

Derrida, Jaques: Eine gewisse unmögliche Möglichkeit vom Ereignis zu sprechen, Berlin 2003.

Dibelius, Ulrich: Moderne Musik nach 1945, München 1998.

— /Frank Schneider (Hg.): Neue Musik im geteilten Deutschland, Band 4, Berlin 1999.

Diederichs-Lafite, Marion (Hg.): 1913 - Skandalkonzerte (Themenheft), in: Österreichische Musikzeitschrift (2/2013).

Dirks, Walter: »Bericht über ein Scherbengericht«, in: Melos (7-8/1956), S. 233f.

- Bericht und Reflexion über Donaueschingen. Zur Problematik zeitgenössischer Musik, in: Frankfurter Hefte (11/1953), S. 833-841.

Dixon, Wheeler Winston (Hg.): Film and television after 9/11, Carbondale 2004.

Dobberstein, Marcel: Neue Musik. 100 Jahre Irrwege - eine kritische Bilanz, Wilhelmshaven 2007.

Donhauser, Peter: Elektrische Klangmaschinen, Böhlau 2007.

Dorflein, Erich: »Pfiffe als Stichwort für Zeitfragen«, in: Melos (24/1957), S. 103f.

Droysen, Johann Gustav: Historik, Band 1: Rekonstruktion der ersten und vollständigen Fassung der Vorlesungen (1857), Stuttgart/Bad Cannstatt 1977.

Duberman, Martin: Black Mountain. An Exploration in Community, New York 1972.

Dümling, Albrecht: »Gegen die affirmative Funktion von Musik«, in: Neue Musikzeitung (7/2008).

Dutschke, Rudi: »Es kracht an allen Ecken und Enden«, in: Der Spiegel (50/1968), S. 185.

\section{- E -}

Ebbeke, Klaus (Hg.): Bernd Alois Zimmermann. Dokumente zu Leben und Werk, Berlin 1989.

Ebbinghausen, Rolf/Neckel, Sighard (Hg.): Anatomie des politischen Skandals, Frankfurt am Main 1989.

Eco, Umberto: Die Geschichte der Hässlichkeit, München 2007.

— Das offene Kunstwerk [1962], Frankfurt am Main 1973.

Ehrhardt, Bettina: »Intolleranza 2004«, Film zu Luigi Nonos Szenischer Aktion, in: Westdeutscher Rundfunk (2004).

Ellis, Katharine: »Who Cares if You Listen? Audience Behaviour(s) in NineteenthCentury Paris«, Vortrag auf der Tagung »The Art of Listening - Trends und Perspektiven einer Geschichte des Musikhörens« (12.-14.7.2012) in Berlin.

Eimert, Herbert/Stockhausen, Karlheinz (Hg.): Die Reihe. Information über serielle Musik, 8 Bände, Wien 1955-1962.

— Die Kasseler Axt«, in: Melos (3/1959), S. 71-73.

— »Gruß an Hanns Hartmann« (Vorwort), in Ders./Karlheinz Stockhausen (Hg.): Die Reihe, Band 1: Elektronische Musik, Wien 1955, S. 5. 
— »Die sieben Stücke«, in Ders./Stockhausen (Hg.): Die Reihe, Band I: Elektronische Musik, Wien 1955, S. 8-13.

Engell, Lorenz/Oliver Fahle/Britta Neitzel/Claus Pias/Joseph Vogl (Hg.): Kursbuch Medienkultur. Die maßgeblichen Theorien von Brecht bis Baudrillard, Stuttgart 2002.

Engelmann, Hans Ulrich: »Zur Genesis der Darmstädter Schule« (1946), in Rudolph Stephan (Hg.): Von Kranichstein zur Gegenwart. 50 Jahre Darmstädter Ferienkurse, Stuttgart 1996, S. 50-54.

Ericson, Torbjörn: »Die Maschine in der Musikpraxis«, in Forschungszentrum Populäre Musik der Humboldt-Universität zu Berlin (Hg.): Musik und Maschine (PopScriptum, Band 7), Berlin 2002, URL: http://www2.hu-berlin.de/ fpm/popscrip/themen/pst07/pst07_ericson.htm.

Erlmann, Veit (Hg.): Hearing Cultures. Essays on Sound, Listening, and Modernity, Oxford 2005.

Ernst, Petra /Haring, Sabine A./Suppanz, Werner (Hg.): Aggression und Katharsis. Der Erste Weltkrieg im Diskurs der Moderne, Wien 2004

Espinet, David: Phänomenologie des Hörens. Eine Untersuchung im Ausgang von Martin Heidegger, Tübingen 2009.

Eybl, Martin: Die Befreiung des Augenblicks. Schönbergs Skandalkonzerte 1907 und 1908. Eine Dokumentation, Wien 2004.

— »Skandal als Phänomen moderner Öffentlichkeit«, Vortrag auf dem 4. Workshop des SFB »Moderne. Wien und Zentraleuropa um 1900« (Budapest, Oktober 1998).

\section{- F -}

Farge, Arlette: Der Geschmack des Archivs, Göttingen 2011.

Febvre, Lucien: »Sensibilität und Geschichte. Zugänge zum Gefühlsleben früherer Epochen«, in Claudia Honegger (Hg.): Schrift und Materie der Geschichte, Frankfurt am Main 1977, S. 313-334.

Fellner, Sabine: Kunstskandal! Die besten Nestbeschmutzer der letzten 150 Jahre, Wien 1997.

Ferrari, Luc/Patris, Gérard: »Hommage à Varèse«, in: Radio Télévision Française (1965).

Fieschi, Jean-André: »Autour du Cinématographe. Entretien avec Marcel L’Herbier«, in: Cahiers du Cinéma (202/1968), S. 26-43.

Finscher, Ludwig (Hg.): Die Musik in Geschichte und Gegenwart (MGG), 29 Bände, Kassel 1994-2008.

Firme, Annemarie/Hocker, Ramona (Hg.): Von Schlachthymnen und Protestsongs. Zur Kulturgeschichte des Verhältnisses von Musik und Krieg, Bielefeld 2006.

Fischer-Lichte, Erika: Ästhetik des Performativen, Frankfurt am Main 2004.

— / Wulf, Christoph (Hg.): Theorien des Performativen, in: Paragrana 10 (1/2001).

— /Kolesch, Doris (Hg.): Kulturen des Performativen, Berlin 1998.

— /Kreuder, Friedemann/Pflug, Isabel (Hg.): Theater seit den 60er Jahren. Grenzgänge der Neo-Avantgarde, Marburg 1998. 
— »Performance as Art - Art as Performance«, in Ulla-Britta Lagerroth/Hans Lund/Erik Hedling: Interart Poetics. Essays on the Interrelations of the Arts and Media, Amsterdam/Atlanta 1997, S. 69-84.

Fludernik, Monika:» Erhabene Postmoderne? Technologie, Gewalt und Ästhetik zwischen der Atombombe und dem 11. September 2001«, in Dies./Jan Alber (Hg.): Moderne/Postmoderne, Trier 2003, S. 243-267.

Forschungszentrum Populäre Musik der Humboldt-Universität zu Berlin (Hg.): $\mathrm{Mu}-$ sik und Maschine (PopScriptum, Band 7), Berlin 2002, URL: http://www2.huberlin.de/fpm/popscrip/themen/pst07/index.htm.

Foucault, Michel: Dispositive der Macht. Über Sexualität, Wissen und Wahrheit, Berlin 1978.

— Archäologie des Wissens [1969], Frankfurt am Main 1981.

- Interview mit P. Caruso [1967], in ders.: Schriften, Band 1, Frankfurt am Main 2014, S. 770-793.

— Die Ordnung der Dinge. Eine Archäologie der Humanwissenschaften [1966], Frankfurt am Main 1971.

Frank, Georg: Ökonomie der Aufmerksamkeit. Ein Entwurf, München/Wien 1998.

Frei, Norbert: 1968. Jugendrevolte und globaler Protest, München 2008.

Frevert, Ute: »Was haben Gefühle in der Geschichte zu suchen?«, in: Geschichte und Gesellschaft (35/2009), S. 183-208.

Fricke, Christel: »Kunst und Öffentlichkeit. Möglichkeiten und Grenzen einer ästhetischen Reflexion über die Terrorakte auf das World Trade Center am 11. September 2001«, in Ursula Franke/Josef Früchtl (Hg.): Kunst und Demokratie. Positionen zu Beginn des 21. Jahrhunderts, Hamburg 2003, S. 1-17.

Fricke, Stefan: »Sex and music. Der Moorman-Paik-Skandal«, in: Zeitschrift für Neue Musik 161 (2000), S. 26.-29.

Friedmann, Ken: Fluxus and Company, in ders. (Hg.): The Fluxus Reader, New York 1998.

Friedrich, Hans-Edwin: Literaturskandale, Frankfurt am Main 2009.

Fries, Helmut: Die große Katharsis: Der Erste Weltkrieg in der Sicht deutscher Dichter und Gelehrter, Konstanz 1995.

Frisius, Rudolf: »Unsichtbare Musik - Akustische Kunst - Veränderungen des Hörens«, in URL: http://www.frisius.de/rudolf/texte/tx348.htm.

— Elektronik - Live?« (1997), URL: http://www.frisius.de/rudolf/texte/tx801.htm.

— $\gg$ Edgard Varèse. Ein Audio-Portrait«, in: Westdeutscher Rundfunk (1999).

Führer, Karl Christian: »»Pfui, Gemeinheit, Skandal!‘ Bürgerlicher Kunstgeschmack und Theaterskandale in der Weimarer Republik«, in: Zeitschrift für Geschichtswissenschaft (57/2009), S. 389-412.

\section{- G -}

Gamboni, Dario: Zerstörte Kunst. Bildersturm und Vandalismus im 20. Jahrhundert, Köln 1998.

Gamper, Markus/Reschke, Linda/ Düring, Marten (Hg.): Knoten und Kanten III: Soziale Netzwerkanalyse in Geschichts- und Politikforschung, Bielefeld 2015.

Gann, Kyle: »The Path to 4'33'" «, in Ders. (Hg.): No Such Thing as Silence. John Cage's 4'33, New Haven 2010, S. 120-166. 
Garrard, John/Newell, James (Hg.): Scandals in Past and Contemporary Politics, New York 2006

Gay, Peter: The Naked Heart (The Bourgeois Experience: Victoria to Freud), New York 1995.

Geck, Martin: Musiktherapie als Problem der Gesellschaft, Stuttgart 1973.

Geisthövel, Alexa: »Auf der Tonspur. Musik als zeitgeschichtliche Quelle«, in Martin Baumeister/Moritz Föllmer/Philipp Müller (Hg.): Die Kunst der Geschichte. Historiographie, Ästhetik, Erzählung, Göttingen 2009, S. 157-168.

Gelz, Andreas/Hüser, Dagmar/Ruß-Sattar, Sabine (Hg.): Skandale zwischen Moderne und Postmoderne. Interdisziplinäre Perspektiven, Berlin/Boston 2014.

van Gennep, Arnold: Les rites de passage, Paris 1909; Übergangsriten, Frankfurt am Main 2005.

Glaubitz, Nicola/Groscurth, Henning/Hoffmann, Katja/Schäfer, Jörgen/Schröter, Jens/Schwering, Gregor/Venus, Jochen (Hg.): Eine Theorie der Medienumbrüche 1900/2000, Siegen 2011.

Gottwald, Clythus: »Der religiöse Aufruhr«, in Arnold Jacobshagen/Markus Leniger (Hg.): Rebellische Musik. Gesellschaftlicher Protest und kultureller Wandel um 1968, Köln 2007, S. 291-305.

Gramsci, Antonio: Gefängnishefte, 10 Bände, Hamburg 2012.

Gredinger, Paul: »Das Serielle«, in Herbert Eimert/Karlheinz Stockhausen (Hg.): Die Reihe, Band 1: Elektronische Musik, Wien 1955, S. 34-41

Gröhn, Constantin: Dieter Schnebel und Arvo Pärt. Komponisten als Theologen, Münster 2006.

Gumbrecht, Hans Ulrich: Diesseits der Hermeneutik. Die Produktion von Präsenz, Frankfurt am Main 2004.

— Kaskaden der Modernisierung, in Johannes Weiß (Hg.): Mehrdeutigkeit der Moderne, Kassel 1998, S. 17-41.

Gruber, Gernot (Hg.), Musikwissenschaft als Kulturwissenschaft, Wien 2003.

\section{$-\mathrm{H}$ -}

Habermas, Jürgen/Derrida, Jaques: Philosophie in Zeiten des Terrors. Zwei Gespräche geführt, eingeleitet und kommentiert von Giovanna Borradori, Hamburg 2006.

- Faktizität und Geltung. Beiträge zur Diskurstheorie des Rechts und des demokratischen Rechtsstaats, Frankfurt am Main 1992.

- Strukturwandel der Öffentlichkeit. Untersuchungen zu einer Kategorie der bürgerlichen Gesellschaft [1962], Frankfurt am Main 1990.

— Zum Begriff der politischen Beteiligung [1958], in ders. (Hg.): Student und Politik, Berlin 1961, S. 13-55.

Hacke, Jens /Pohlig, Matthias (Hg.): Theorie in der Geschichtswissenschaft, Frankfurt/New York 2008.

Haedeke, Gerd (Hg.): Kulturradio. Erinnerungen und Erwartungen, Köln 1996.

Haefeli, Anton: Die Internationale Gesellschaft für Neue Musik (IGNM). Ihre Geschichte von 1922 bis zur Gegenwart, Zürich 1982. 
Hamel, Peter Michael: »Politisches Komponieren damals und heute. Persönliche Rückblicke und Einsichten«, in Ders.: Ein neuer Ton. Ausgewählte Schriften zu einer ganzen Musik, München 2007, S. 93-105.

Harding, James: »From Anti-Culture to Counter-Culture. The Emergence of the American Avant-Garde Performance Events«, in Thomas Rathmann (Hg.): Ereignis. Konzeption eines Begriffs in Geschichte, Kunst und Literatur, Köln 2003, S. 243-260.

Harris, Mary Emma: The Arts at Black Mountain College, Cambridge (MA) 2002.

Haungs, Julia: »13.03.1861 - Die Pariser Premiere von Wagners >Tannhäuser` gerät zum Skandal«, in: Südwestrundfunk/SWR2 (13.03.2013).

Häusler, Josef: Spiegel der Neuen Musik: Donaueschingen. Chronik - Tendenzen Werkbesprechungen, Kassel 1996.

Heidegger, Martin: »Die Frage nach der Technik« [1953], in Ders.: Vorträge und Aufsätze, Pfullingen 1954, S. 13-44.

Heile, Björn: »Avantgarde, Engagement und Autonomie. Mauricio Kagel in den sechziger Jahren«, in Arnold Jacobshagen/Markus Leniger (Hg.): Rebellische Musik. Gesellschaftlicher Protest und kultureller Wandel um 1968, Köln 2007, S. 81-91.

— The Music of Mauricio Kagel, Aldershot 2006.

Heilgendorff, Simone: »Glossolalische Stimmen. Politisches Ethos, Selbsterfahrung und Spiel in Dieter Schnebels experimentellen Kompositionen der 1960er und 70er Jahre«, in Beate Kutschke (Hg.): Musikkulturen in der Revolte. Studien zu Rock, Avantgarde, Klassik im Umfeld von $>1968$ «, Stuttgart 2008, S. 127-140.

Heisenberg, Werner: »Das Naturbild der heutigen Physik«, in Bayerische Akademie der Schönen Künste (Hg.): Die Künste im technischen Zeitalter, München 1954, S. 43-69.

Heister, Hanns Werner: Geschichte der Musik im 20. Jahrhundert, Laaber 2005.

— /Edelgard Spaude: »Musik und Gesellschaft. Politisches Komponieren seit 1945«, in Michael Raeburn/Alan Kendall (Hg.): Geschichte der Musik, Band 4: Das 20. Jahrhundert, Mainz 1991, S. 301-312.

Helms, Hans G: Musik zwischen Geschäft und Unwahrheit, Musikkonzepte 1972.

- Dokumentation einer misslungenen Revolution. Internationale Ferienkurse für Neue Musik Darmstadt, 23. August bis 4. September 1970, in: Westdeutscher Rundfunk (1972).

Helms, Dietrich/Phleps, Thomas (Hg.): »9/11 - The world's all out of tune. Populäre Musik nach dem 11. September«, Bielefeld 2004.

Henius, Carla: »Arbeitsnotizen und Berichte von 2 Vokalwerken Luigi Nonos: Intolleranza 1960 und La fabbrica illuminata«, in Jürg Stenzl (Hg.): Luigi Nono. Texte, Studien zu seiner Musik, Zürich 1975, S. 329-347.

Hensel, Georg: Theaterskandale und andere Anlässe zum Vergnügen, Stuttgart 1983.

Hentschel, Frank: Bürgerliche Ideologie und Musik, Frankfurt am Main/New York 2006.

- Ästhetische Erfahrung und die Ideologie der Hochkultur in der neuen Musik, in: Paragrana 15 (2/2006), S. 121-132.

Henze, Hans Werner: Reiselieder mit böhmischen Quinten. Autobiographische Mitteilungen. 1926-1995, Frankfurt am Main 1996. 
— »>Immer für die Sünder $\measuredangle$ Hans Werner Henze über zeitgenössisches Musiktheater«, in: Der Spiegel (7.5.1990), S. 243-254.

— »Die Unruhe mobilisieren. Gespräch mit Heinz Josef Herbort«, in: Die Zeit (27.6.1986).

— »Musik ist nolens volens politisch« [1969], Gespräch mit J.A. Makowsky, in Ders.: Musik und Politik. Gespräche 1955-1975 München 1976, S. 136-143

— $»$ Die Schwierigkeit, ein bundesdeutscher Komponist zu sein. Neue Musik zwischen Isolierung und Engagement« [1980], in Hanns-Werner Heister/Dietrich Stern (Hg.): Musik 50er Jahre, Berlin 1980, S. 50-77.

— »Die Krise des bürgerlichen Künstlers - Politisierung - Nutzbarmachung der Kunst für die Revolution « [1971], in Ders.: Musik und Politik. Gespräche 19551975 München 1976, S. 149-155.

— »Brief an Bernhard Conz« (2.1.1969), verzeichnet und einsehbar im OnlineKatalog der Autographenhandlung J. A. Stargardt GmbH \& Co. KG, URL www.stargardt.de/download/file/kataloge/695/IV_Musik.pdf.

— »Musik als Akt der Verzweiflung« [1968], in Ders.: Schriften und Gespräche 1955-1979, Berlin 1981, S. 122f.

— »Die Bundesrepublik Deutschland und die Musik« [1967/68], in Ders.: Schriften und Gespräche 1955-1979, Berlin 1981, S. 115-122.

— »Musik als Resistenzverhalten « [1964], in Ders.: Schriften und Gespräche 19551979, Berlin 1981, S. 85-91.

Herding, Klaus / Stumpfhaus, Bernhard: Pathos, Affekt, Gefühl. Die Emotionen in den Künsten, Berlin 2004.

Hess, Barbara/Grosenick, Uta (Hg.): Abstrakter Expressionismus, Köln 2005.

Heßler, Hans-Joachim: Philosophie der postmodernen Musik: Jean-François Lyotard, Dortmund 2001.

Heyer, Stefan: »Zwischen Eins und Null. Versuch über John Cage«, in Marcus S. Kleiner/Achim Szepanski (Hg.): Soundcultures. Über elektronische und digitale Musik, Frankfurt am Main 2003, S. 152-161.

Hiekel, Jörn P.: »Warum sich jetzt mit \1968 « befassen? - Aspekte des Widerständigen in der Musik, in Ders. (Hg.): Die Kunst des Überwinterns. Musik und Literatur um 1968, Köln/Weimar/Wien 2011, S. 9-21.

- Vernetzungen. Neue Musik im Spannungsfeld von Wissenschaft und Technik, Mainz 2009.

- (Hg.): Darmstädter Diskurse, Band 1: Komponieren in der Gegenwart, Saarbrücken 2006; Band 2: Musik-Kulturen, Saarbrücken 2008.

Hiepko, Andreas /Stopka, Katja (Hg.): Rauschen. Seine Phänomenologie und Semantik zwischen Sinn und Störung, Würzburg 2001.

Higgins, Hannah: Fluxus Experience, Los Angeles 2002.

Hilmes, Michele: »Is There a Field Called Sound Culture Studies? And Does It Matter?«, in: American Quarterly (57/2005), S. 249-259.

Historisches Archiv der Stadt Köln (Hg.): Intermedial - kontrovers - experimentell: Das Atelier Mary Bauermeister in Köln 1960-1962, Köln 1993.

Hondrich, Karl Otto: Enthüllung und Entrüstung. Eine Phänomenologie des politischen Skandals, Frankfurt am Main 2002.

Höhne, Heinz: Mordsache Röhm. Hitlers Durchbruch zur Alleinherrschaft, 19331934, Reinbek bei Hamburg 1984. 
Höller, Hans (Hg.): Ingeborg Bachmann/Hans Werner Henze. Briefe einer Freundschaft, München 2004.

Hörisch, Jochen: Der Sinn und die Sinne. Eine Geschichte der Medien, Frankfurt am Main 2001.

Horkheimer, Max/Adorno, Theodor W.: »Kulturindustrie. Aufklärung als Massenbetrug«, in Ders: Dialektik der Aufklärung (Gesammelte Schriften, Band 5), Frankfurt am Main 1987, S. 128-176.

Howes, David: Sensual Relations. Engaging the Senses in Culture and Social Theory, Ann Arbor 2003.

- (Hg.): Empire of the Senses. The sensual Culture Reader, Oxford 2005.

Hübler, Klaus-Karl: »Futuristengefahr. Hans Pfitzners Auseinandersetzung mit Feruccio Busoni im Jahr 1917«, in: Bayerischer Rundfunk/Bayern 2 (23.9.1984).

Hucke, Helmut: »Das Dekret 〉Docta sanctorum Patrum〈 Papst Johannes’ XXII.«, in: Musica Disciplina (38/1984), S. 119-131.

Huebner, Steven: »Opera Audiences in Paris 1830-1870«, in: Music and Letters (70/1989), S. 206-225.

Huizinga, Johan: Homo ludens. Vom Ursprung der Kultur im Spiel (1939), Reinbek bei Hamburg 2009.

Huntington, Samuel P.: The Clash of Civilizations and the Remaking of World Order, New York 1996.

- I -

Iddon, Martin: »Pamphlets and Protests: The End of Stockhausen's Darmstadt«, in Beate Kutschke (Hg.): Musikkulturen in der Revolte. Studien zu Rock, Avantgarde, Klassik im Umfeld von >1968<, Stuttgart 2008, S. 55-63.

Illies, Florian: 1913. Der Sommer des Jahrhunderts, Frankfurt am Main 2012.

Internationales Musikinstitut Darmstadt ( $\mathrm{Hg}$ ): Darmstädter Beiträge zur Neuen $\mathrm{Mu}-$ sik, 20 Bände, Darmstadt 1958-1994.

— Von Kranichstein zur Gegenwart. 50 Jahre Darmstädter Ferienkurse, Darmstadt 1995.

Irsigler, Ingo/Jürgensen, Christoph (Hg.): Nine eleven - Ästhetische Verarbeitungen des 11. September 2001, Heidelberg 2008.

\section{- J -}

Jaeger, Friedrich (Hg.): Enzyklopädie der Neuzeit, 16 Bände, Stuttgart 2005-2012.

Jäger, Thomas (Hg.): Die Welt nach 9/11. Auswirkungen des Terrorismus auf Staatenwelt und Gesellschaft, Wiesbaden 2011.

Jäger, Siegfried: »Diskurs und Wissen. Theoretische und methodische Aspekte einer Kritischen Diskurs- und Dispositivanalyse«, in Reiner Keller/Andreas Hirseland/Werner Schneider/Willy Viehöver (Hg.): Handbuch der Sozialwissenschaftlichen Diskursanalyse, Band 1: Theorien und Methoden, Opladen 2001, S. 81112.

Jacobshagen, Arnold: »Musica impura. Der langwierige Weg in die Wohnung der Natascha Ungeheuer von Hans Werner Henze und die Berliner Studentenbewe- 
gung«, in Ders./Markus Leniger (Hg.): Rebellische Musik. Gesellschaftlicher Protest und kultureller Wandel um 1968, Köln 2007.

— / Reininghaus, Frieder: Musik und Kulturbetrieb. Medien, Märkte, Institutionen, in: Handbuch der Musik im 20. Jahrhundert, Band 10, Laaber 2006.

Jakubczik, Andreas: Donaueschingen und Paul Hindemith. Stationen einer Doppelkarriere 1921-1930, Hamburg 2004.

Jameux, Dominique: Pierre Boulez, Cambridge 1991.

Jappe, Elisabeth: Performance, Ritual, Prozeß. Handbuch der Aktionskunst in Europa, München 1993.

Jauß, Hans Robert: Die Theorie der Rezeption - Rückschau auf ihre unerkannte Vorgeschichte, Konstanz 1987.

— »Rezeption, Rezeptionsästhetik«, in: Historisches Wörterbuch der Philosophie, Band 8, Basel 1992, Sp. 996-1004.

Jeschke, Lydia: »Hören, fühlen, denken. Über Lust und Frust des Musikerlebens«, Teil 3: Aufruhr im Konzertsaal, in: Südwestrundfunk/SWR2 (2009).

John, Eckhard: Musikbolschewismus. Die Politisierung der Musik in Deutschland 1918-1938, Stuttgart 1994.

Johnson, James H.: Listening in Paris. A Cultural History, Berkeley/Los Angeles 1995.

Joskowicz, Alexander/Nowotny, Stefan (Hg.): Can the Subaltern Speak? Postkolonialität und subalterne Artikulation, Wien 2007.

Jungbluth, Rüdiger: Die Oetkers. Geschäfte und Geheimnisse der bekanntesten Wirtschaftsdynastie Deutschlands, Frankfurt am Main 2004.

Jungheinrich, Hans-Klaus: »1968 - Ästhetik des Aufbruchs?«, in Jörn P. Hiekel (Hg.): Die Kunst des Überwinterns. Musik und Literatur um 1968, Köln/Weimar/Wien 2011, S. 118-124.

Jütte, Robert: Geschichte der Sinne. Von der Antike bis zum Cyberspace. München 2000.

\section{$-\mathrm{K}$ -}

Kaden, Christian: »Skandal und Ritual in der Musik«, in Joachim Brügge (Hg.): Musikgeschichte als Verstehensgeschichte, Tutzing 2004, S. 583-596.

Kagel, Maurizio: Staatstheater, Auftragswerk der Hamburgischen Staatsoper AG, Universal Edition (UE) 15197.

— »Gespräch mit Hansjörg Pauli«, in Ders.: Für wen komponieren Sie eigentlich?, Frankfurt am Main 1971, S. 87-105.

— »Composition und Decomposition « [1964], in Dieter Schnebel: Mauricio Kagel. Musik - Theater - Film, Köln 1970, S. 141

— John Cage in Darmstadt 1958«, in: Buenos Aires Musical (16.10.1958).

Kahlert, Joachim/Schröder, Michael/Schwanebeck, Axel (Hg.): Hören, München 2001.

Kammen, Michael G.: Visual Shock. A History of Art Controversies in American Culture, New York 2006.

Kamper, Dietmar/Wulf, Christoph (Hg.): Das Schwinden der Sinne, Frankfurt am Main 1984. 
Käsler, Dirk: Der politische Skandal. Zur symbolischen und dramaturgischen Qualität von Politik, Opladen 1991.

Katz, Vincent: Black Mountain College. Experiment in Art, Cambridge 2013.

Kellein, Thomas: Der Traum von Fluxus. George Maciunas - eine Künstlerbiographie, Köln 2007.

Kellerer, Sidonie/Nierhoff-Fassbender, Astrid/Theofilakis, Fabien (Hg.): Missverständnis/Malentendu: Kultur zwischen Kommunikation und Störung (Studien zur Moderneforschung, Band 4), Würzburg 2008.

Kelly, Thomas Forrest: First Nights. Five Musical Premieres, New Haven 2000.

Keppler, Diana: »Der Futurismus oder Die Musik im Zeitalter der Maschine«, in Forschungszentrum Populäre Musik der Humboldt-Universität Berlin ( $\mathrm{Hg}$ ): Mensch und Maschine (PopScriptum, Band 7), Berlin 2001, URL: https://www2.hu-berlin.de/fpm/popscrip/themen/pst07/pst07_keppler.htm.

Kepplinger, Hans Matthias: Die Kunst der Skandalierung und die Illusion der Wahrheit, München 2001.

- Die Mechanismen der Skandalisierung. Die Macht der Medien und die Möglichkeiten der Betroffenen, München 2005.

- Publizistische Konflikte und Skandale, Wiesbaden 2009.

- Die Mechanismen der Skandalisierung. Zu Guttenberg, Kachelmann, Sarrazin \& Co. Warum einige öffentlich untergehen - und andere nicht, München 2012.

Kesting, Marianne: »Instrumentales Theater und Anti-Oper«, in: Programm der Hamburgischen Staatsoper (1970/71), S. 90-94.

Kilger, Gerhard (Hg.): Musik als Glück und Nutzen für das Leben. Macht $\mathrm{Mu}$ sik, Köln 2005.

Kittler, Friedrich: Musik und Mathematik, 4 Bände, Paderborn 2009-2015.

— »Rock Musik. Ein Mißbrauch von Heeresgerät«, in Theo Elm/Hans H. Hiebel (Hg.): Medien und Maschinen. Literatur im technischen Zeitalter, Freiburg 1991, S. 245-257.

- Grammophon, Film, Typewriter, Berlin 1986.

- Aufschreibesysteme 1800/1900, München 1985.

Klatt, Johanna/Lorenz, Robert (Hg.): Manifeste. Geschichte und Gegenwart des politischen Appells (Studien des Göttinger Instituts für Demokratieforschung zur Geschichte politischer und gesellschaftlicher Kontroversen, Band 1), Bielefeld 2011.

Klee, Ernst: Das Kulturlexikon zum Dritten Reich. Wer war was vor und nach 1945, Frankfurt am Main 2007.

Kleiner, Marcus S./Szepanski, Achim (Hg.): Soundcultures. Über elektronische und digitale Musik, Frankfurt am Main 2003.

Klüppelholz, Werner: Mauricio Kagel 1970-1980, Köln 1981, S. 42.

Koch, Friedrich: Sexuelle Denunziation. Die Sexualität in der politischen Auseinandersetzung, Hamburg 1995.

Koch, Lars/Nanz, Tobias: »Ästhetische Experimente. Zur Ereignishaftigkeit und Funktion von Störungen in den Künsten«, in Stefan Habscheid/Lars Koch (Hg.): Zeitschrift für Literaturwissenschaft und Linguistik (173/2014): Krisen, Katastrophen, Störungen, S. 94-115.

— »Der Erste Weltkrieg als kulturelle Katharsis und literarisches Ereignis«, in Ders./Stefan Kaufmann/Niels Werber (Hg.): Der Erste Weltkrieg. Ein interdisziplinäres Handbuch, Stuttgart/Weimar 2013, S. 97-142. 
Kogler, Susanne: Adorno versus Lyotard. Moderne und postmoderne Ästhetik, Freiburg/München 2014.

Köhler, Armin/Stoll, Rolf W. (Hg.): Erlebte Geschichte. Aufbrüche, Rückblicke, Zeitläufte (DVD), Mainz 2009.

— Die Innovation bleibt immer auf einem Fleck. Die Donaueschinger Musiktage und ihr Metier. Begleitende Texte zum Festival, Mainz 2011.

Kolleritsch, Otto (Hg.): Der musikalische Futurismus. Ästhetisches Konzept uns Auswirkungen auf die Moderne (Studien zur Wertungsforschung, Band 8), Graz 1976.

König, Michael: Poetik des Terrors. Politisch motivierte Gewalt in der deutschen Gegenwartsliteratur, Bielefeld 2014.

Konold, Wulf: »Adorno - Metzger. Überblick zu einer Kontroverse«, in Heinz-Klaus Jungheinrich (Hg.): Nicht versöhnt. Musikästhetik nach Adorno, Kassel 1987.

Korn, Peter Jonas: Musikalische Umweltverschmutzung. Polemische Variation über ein unerquickliches Thema, Wiesbaden 1975.

Koselleck, Reinhart: Vergangene Zukunft, Frankfurt am Main 1988.

- (Hg.): Epochenschwellen und Epochenbewusstsein (Poetik und Hermeneutik, Band 12), München 1987.

— Krise, in: Geschichtliche Grundbegriffe, Band 3, Stuttgart 1982, S. 617-650.

- Kritik und Krise. Ein Beitrag zur Pathogenese der bürgerlichen Welt, Freiburg 1954.

Kostelanetz, Richard: Conversing with Cage, New York 2003.

— John Cage. An Anthology, New York 1991.

— John Cage, New York 1970.

Krämer, Sybille (Hg.): Performativität und Medialität, München 2004.

Krabiel, Klaus-Dieter: Brechts Lehrstücke. Entstehung und Entwicklung eines Spieltyps, Stuttgart und Weimar 1993.

Kraus, Karl: »Die vorletzten Tage«, in: Der Spiegel (26/1964), S. 76.

Krebs, Wolfgang: »Kultur, Musik und der 〉Untergang des Abendlandes $\measuredangle$. Bemerkungen zu Oswald Spenglers Geschichtsphilosophie«, Antrittsvorlesung vom 3. Dezember 1996 in Frankfurt am Main, URL: http://www.wk-wkw.de/texte/aufs/AKultur-Musik-Untergang.pdf.

Kreidler, Johannes /Lehmann, Harry/Mahnkopf, Claus-Steffen (Hg.): MusikÄsthetik-Digitalisierung. Eine Kontroverse, Hofheim 2010.

Krenek, Ernst: »Vom Altern und Veralten der Musik«, in Ders.: Zur Sprache gebracht. Essays über Musik, München 1958, S. 371-378.

— »Den Jüngeren über die Schulter geschaut«, in: Neue Zeitschrift für Musik (2/1952), S. 31-33.

Krones, Hartmut: »31. März 1913 - Wiens größtes `Skandalkonzert««, in: Magazin der Gesellschaft der Musikfreunde Wien (April 2013).

- Multikulturelles, Internationales, Neues und `Fremdes` in der Musik. Zweieinhalb Jahrtausende Ächtung des Andersartigen, in ders. (Hg.): Multikulturelle und internationale Konzepte in der Neuen Musik, Wien 2008.

Kuhlmann, Andreas: Philosophie der neuen Musik, in Axel Honneth (Hg.): Schlüsseltexte der Kritischen Theorie, Wiesbaden 2006.

Kuhn, Thomas S.: Die Struktur wissenschaftlicher Revolutionen [1962], Frankfurt am Main 1976. 
Kuhn, Robert/Kreutz, Bernd (Hg.): Das Buch vom Hören, Freiburg im Breisgau 1991.

Kühnelt, Wolf D.: »Elektroakustische Musikinstrumente«, in Akademie der Künste (Hg.): Für Augen und Ohren (Katalog 127), Berlin 1980.

Kurtz, Michael: Stockhausen. Eine Biographie, Kassel/Basel 1988

Kutschke, Beate (Hg.): Musikkulturen in der Revolte. Studien zu Rock, Avantgarde, Klassik im Umfeld von >1968«, Stuttgart 2008.

- Neue Linke - Neue Musik. Kulturtheorien und künstlerische Avantgarde in den 1960er und 70er Jahren, Köln/Weimar/Wien 2007.

Krämer, Sybille (Hg.): Performativität und Medialität, München 2004.

\section{- L -}

Labelle, Brandon: Acoustic Territories. Sound Culture and Everyday Life, New York 2010.

Lacan, Jacques: »Subversion des Subjekts und Dialektik des Begehrens im Freudschen Unbewußten«, in: Ders., Schriften II, Olten 1975, S. 167-204.

Lagerroth, Ulla-Britta/Lund, Hans/Hedling, Erik: Interart Poetics. Essays on the Interrelations of the Arts and Media, Amsterdam/Atlanta 1997.

Latour, Bruno: »Zirkulierende Referenz. Bodenstichproben aus dem Urwald am Amazonas«, in Ders. (Hg.): Die Hoffnung der Pandora, Frankfurt am Main, S. 36-95.

Laux, Karl: »Skandal in Baden-Baden. Bericht von 1929 und Kommentar von 1972«, in Hindemith-Institut (Hg.): Hindemith-Jahrbuch, Frankfurt am Main 1972, S.166-180.

Lehmann, Harry: Die digitale Revolution der Musik. Eine Musikphilosophie, Mainz 2012.

- Die Digitalisierung der Neuen Musik - ein Gedankenexperiment, in Jörn P. Hiekel (Hg.): Vernetzungen. Neue Musik im Spannungsfeld von Wissenschaft und Technik, Mainz 2009, S. 33-43.

Lehmann, Hans-Thies: Das Postdramatische Theater, Frankfurt am Main 2005.

Lengauer, Hubert: »Nachgelassener (oder nachlassender) Skandal?«, in Stefan Neuhaus/Johann Holzner (Hg.): Literatur als Skandal. Fälle - Funktionen - Folgen, Göttingen 2007, S. 491-502.

Lesure, François: Igor Stravinsky. Le sacre du printemps - dossier de presse, Genf 1980.

Leukert, Bernd: »Musik aus Trümmern. Darmstadt 1949«, in: MusikTexte (45/1992), S. 20-27.

Lichtenfeld, Monika: »Multikulturelle Aspekte in der amerikanischen Musik des 20. Jahrhunderts«, in Hartmut Krones (Hg.): Multikulturelle und internationale Konzepte in der Neuen Musik, Wien 2008, S. 127-136.

Lindenberger, Thomas: »Das vergangene Hören und Sehen. Zeitgeschichte und ihre Herausforderung durch die audiovisuellen Medien«, in: Zeithistorische Forschungen (1/2004), URL: http://www.zeithistorische-forschungen.de/1$2004 / \mathrm{id}=4586$. 
Locker, Hubert: »Gestus und Objekt. Befreiung als Aktion - Eine europäische Komponente performativer Kunst«, in Peter Noever (Hg.): Out of Actions. Aktionismus, Body Art \& Performance 1949-1979, Ostfildern 1998, S. 159-195.

Lorenz, Matthias N. (Hg.): Narrative des Entsetzens. Künstlerische, mediale und intellektuelle Deutungen des 11. September 2001, Würzburg 2004.

Lück, Hartmut: »Vom Skandal zum Klassiker. Igor Stravinskij: Le Sacre du Printemps«, in : FonoForum (5/1993), S. 24-30.

Lüderssen, Caroline: »Luigi Nonos und Giacomo Manzonis Musiktheater. Politisches Engagement im Zeichen Gramscis«, in Arnold Jacobshagen/Markus Leniger (Hg.): Rebellische Musik. Gesellschaftlicher Protest und kultureller Wandel um 1968, Köln 2007, S. 93-107

Luhmann, Niklas: Rechtssoziologie, Band 1, Reinbeck 1972.

Lütteken, Laurenz: »Komponieren am Ende der Zeit. Überlegungen zum musikalischen Ereignis-Begriff am Beispiel von Bernd Alois Zimmermanns Ekklesiastischer Aktion«, in Thomas Rathmann (Hg.): Ereignis. Konzeptionen eines Begriffs in Geschichte, Kunst und Literatur, Köln/Weimar/Wien 2003, S. 119-136.

— »Wie sautonom thodischen Wandels«, in: Archiv für Musikwissenschaft (57/2000), S. 31-39.

Lynen, Peter M.: »Das ambivalente Verhältnis des Künstlers zum Recht. Am Beispiel von Joseph Beuys«, in Bettina Paust/Johannes Bilstein/Peter M. Lynen/Hans Peter Thurn (Hg.): Aufbauen - Zerstören. Phänomene und Prozesse der Kunst (Moyländer Diskurse zu Kunst und Wissenschaft, Bd. 1), Oberhausen 2007.

Lyotard, Jean-François: Das postmoderne Wissen, Wien 2012.

— Der Widerstreit, München 1989.

— »Der Augenblick, Newman«, in Ders.: Philosophie und Malerei im Zeitalter ihres Experimentierens, Berlin 1986, S. 7-23.

- Mehrfache Stille - Vielfältiges Schweigen, in Ders.: Essays zu einer affirmativen Ästhetik, Berlin 1982, S. 95-122.

\section{- M -}

Macho, Thomas: »Weltenlärm, Schweigen, Stille«, in: Österreichische Musikzeitschrift (7-8/1994), S. 440-445.

Maconie, Robin: Other Planets. The Music of Karlheinz Stockhausen, Oxford 2005.

Mahnkopf, Claus-Steffen: Kritische Theorie der Musik, Weilerswist 2006.

Makropoulos, Michael: »Historische Semantik und Positivität der Kontingenz. Modernitätstheoretische Motive bei Reinhart Koselleck«, in Hans Joas/Peter Vogt (Hg.): Begriffene Geschichte. Beiträge zum Werk Reinhart Kosellecks. Frankfurt am Main 2011, S. 481-513.

Mannheim, Karl: »Das Problem der Generationen«, in: Kölner Vierteljahreshefte für Soziologie 7 (1928/29), S. 157-184.

Herbert Marcuse: »Über den affirmativen Charakter der Kultur« [1937], in: Zeitschrift für Sozialforschung (6/1980), S. 54-94.

Marinetti, Filippo Tommaso: »Manifest des Futurismus«, in: Le Figaro (20.2.1909).

Markovitz, Andrei S./Silverstein, Mark: The Politics of Scandal. Power and Process in Liberal Democracies, New York 1988. 
Marßolek, Inge/von Saldern, Adelheid (Hg.): Zuhören und Gehörtwerden, Tübingen 1998.

Martin, Silke: Die Sichtbarkeit des Tons im Film. Akustische Modernisierungen des Films seit den 1920er Jahren, Marburg 2010.

Martschukat, Jürgen/Patzold, Steffen (Hg.): Geschichtswissenschaft und »performative turn«. Ritual, Inszenierung und Performanz vom Mittelalter bis zur Neuzeit, Köln 2003.

Matzker, Reiner: Ästhetik der Medialität. Zur Vermittlung von künstlichen Welten und ästhetischen Theorien, Hamburg 2008.

Mayer, Andreas: Enthüllung und Erregung. Kleine Physiologie des Skandals, Frankfurt 2005.

Mayer-Rosa, Eugen: Musik und Technik. Vom Futurismus bis zur Elektronik, Wolfenbüttel 1974.

McLuhan, Marshall: Das Medium ist die Massage. Ein Inventar medialer Effekte, Stuttgart 2011.

— Die magischen Kanäle - Understanding Media, Dresden/Basel 1994.

— The Gutenberg Galaxy, London 1962.

Meinhold, Roman: "Catharsis and Violence: Terrorism and the Fascination for Superlative Destruction«, in: Boleswa Journal of Philosophy, Theology and Religion (3/2012), S. 172-184.

— »Demolition Performance 9/11. Die ästhetisierte Inszenierung der Anschläge des 11. Septembers 2001 und Parallelphänomene in Kunst und Popularkultur«, in Jäger, Thomas (Hg.): Die Welt nach 9/11. Auswirkungen des Terrorismus auf Staatenwelt und Gesellschaft, Wiesbaden 2011, S. 807-818.

Mersch, Dieter: Medientheorien zur Einführung, Hamburg 2006.

- Ereignis und Aura. Untersuchungen zu einer Ästhetik des Performativen, Frankfurt am Main 2002.

— Vom Werk zum Ereignis. Philosophie der Gegenwartskunst«. Fünf Vorlesungen, URL: http://nyitottegyetem.phil-inst.hu/kmfil/MERSCH/kunst_t.htm.

— Ereignis und Aura: Untersuchungen zu einer Ästhetik des Performativen, Frankfurt am Main 2002.

- Der versteinerte Augenblick: Zum Verhältnis von Kunst und Ereignis zwischen Barock und Moderne, URL: www.momo-berlin.de/mersch_augenblick.html.

Metzger, Heinz-Klaus: »Erinnerung nicht nur an die Vorfreude«, in Stefan MüllerDoohm (Hg.): Adorno-Portraits. Erinnerungen von Zeitgenossen, Frankfurt am Main 2007, S. 164-174.

— $»$ Rituelle Aspekte bürgerlichen Musiklebens «, in Barbara Barthelmes/Helga de la Motte-Haber (Hg): Musik und Ritual, Mainz 1999, S. 18-30.

— /Rainer Riehn (Hg.): Darmstadt-Dokumente I, München 1999.

— »John Cage oder Die freigelassene Musik« [1958], in Ders./Rainer Riehn (Hg.): John Cage (Musik-Konzepte, Sonderband), München 1978, S. 5-17.

— »Kompositorische Möglichkeiten der elektronischen Musik. Eine Diskussion zwischen Ernst Krenek, Luigi Rognoni, Pierre Boulez, Karlheinz Stockhausen, Hermann Heiß, Bruno Maderna, Alois Hába, Stefan Wolpe« [1956], in: MusikKonzepte (Sonderband: Darmstadt-Dokumente), München 1999, S. 80-105. 
— »Fragment zum Thema Komet (Erinnerungen an Cage)«, in Rudolph Stephan (Hg.): Von Kranichstein zur Gegenwart. 50 Jahre Darmstädter Ferienkurse, Stuttgart 1996, S. 250f.

— »Veränderte Situation«, in: MusikTexte (22/1987), S. 25.

- /Riehn, Rainer (Hg.): Edgard Varèse. Rückblick auf die Zukunft (MusikKonzepte, Band 6), München 1983.

— »Das Altern der jüngsten Musik« [1962], in Ders.: Musik wozu, Frankfurt am Main 1980, S. 113-128.

— $»$ Kranichsteiner Musiktreffen beendet «, in: Der Mittag (11.9.1959).

— »Das Altern der Philosophie der Neuen Musik«, in Herbert Eimert/Karlheinz Stockhausen (Hg.): Die Reihe, Band 4: Junge Komponisten, Wien 1958, S. 64-80. Meyer, Felix: Edgard Varèse. Komponist, Klangforscher, Visionär, Mainz 2006.

Meyer, Petra Maria (Hg.): Acoustic Turn, München 2008.

Meyers Großes Konversations-Lexikon. Ein Nachschlagewerk des allgemeinen Wissens, 20 Bände, Leipzig/Wien 1905-1909.

Michel, Francois (Hg.): Enzyklopédie de la musique, Band 2, Paris 1959.

Michels, Ulrich/Vogel, Gunter: dtv-Atlas Musik, 2 Bände, München 2013.

Misch, Imke/Bandur, Markus: Karlheinz Stockhausen bei den Internationalen Ferienkursen für Neue Musik in Darmstadt 1951-1996. Dokumente und Briefe, Kürten 2001.

Mißfelder, Jan-Friedrich: „Ganzkörpergeschichte. Sinne, Sinn und Sinnlichkeit für eine historische Anthropologie«, in: Internationales Archiv für Sozialgeschichte der deutschen Literatur 39 (2/2014), S. 457-475.

- »Endlich Klartext. Medientheorie und Geschichte«, in Hacke, Jens/Pohlig, Matthias (Hg.): Theorie in der Geschichtswissenschaft, Frankfurt/New York 2008, S. 181-198.

Mittenzwei, Werner: Das Leben des Bertolt Brecht oder Der Umgang mit den Welträtseln, 2 Bände, Frankfurt am Main 1987.

— »Ästhetik des Widerstands. Gedanken zu dem Versuch, eine ästhetische Kategorie für die Kunstentwicklung während des Kampfes gegen den Faschismus zu entwickeln« (Sitzungsbericht der Akademie der Wissenschaften der DDR vom 7.12.1978), Berlin 1979.

Mixner, Manfred: »Der Aufstand des Ohrs«, in: Paragrana - Internationale Zeitschrift für Historische Anthropologie (1-2/Berlin 1993, S. 29-39.

Modleski, Tanja: Some Functions of Feminist Criticism, or, the Scandal of the Mute Body, in: October (49/1989), S. 3-24.

Moldenhauer, Hans/ Moldenhauer, Rosaleen: Anton Webern. Chronik seines Lebens und Werkes, Zürich 1980.

Moore, Barbara (Hg.): The World of Charlotte Moorman. Archive Catalogue, New York 2000.

Morat, Daniel: »Der Klang der Zeitgeschichte«, in: Zeithistorische Forschungen (8/2011): Politik und Kultur des Klangs im 20. Jahrhundert (Themenheft), S. 172-177, URL: http://www.zeithistorische-forschungen.de/16126041-Inhalt-22011.

- Sound Studies - Sound Histories. Zur Frage nach dem Klang in der Geschichtswissenschaft und der Geschichte in der Klangwissenschaft, in KunstTexte (4/2010), S. 1-8. 
Morawska-Büngeler, Marietta: »Zukunftsmusik? 1954: Das Zweite Konzert des Studios für Elektronische Musik des WDR in Köln im Spiegel der Kritik«, in Kilger, Gerhard (Hg.): Musik als Glück und Nutzen für das Leben. Macht Musik, Köln 2005, S. 66-75.

- Donaueschinger Musiktage im Spiegel der Musikkritik (1981-89), in Ekkehard Jost: Die Musik der achziger Jahre (Veröffentlichungen des Instituts für Neue Musik und Musikerziehung Darmstadt, Band 31), Mainz 1990.

- Schwingende Elektronen. Eine Dokumentation über das Studio für Elektronische Musik des Westdeutschen Rundfunks in Köln 1951-1986, Köln 1988.

Moritz, Kirsten: »Zeitgeschichte ohne Ressourcen? Probleme der Nutzung audiovisueller Quellen« (Mainz 25.9.-28.9.2012 Mainz), in: H-Soz-Kult (18.10.2012), URL: http://hsozkult.geschichte.hu-berlin.de/tagungsberichte/id=4417\&view=pdf.

Motte-Haber de la, Helga/Rilling, Lydia/Schröder, Julia H. (Hg.): »Dokumente zur Musik des 20. Jahrhunderts«, in Dies./ Elmar Budde/Siegfrid Mauser/Albrecht Riethmüller/Christian Martin Schmidt (Hg.): Handbuch der Musik im 20. Jahrhundert in 14 Bänden, Band 14, Laaber 2011.

— /Frisius, Rudolf (Hg.): Musik und Technik, Mainz/London 1996, S. 22-48.

- Die Musik von Edgard Varèse. Studien zu seinen nach 1918 entstandenen Werken, Fulda 1993.

— Edgard Varèse. Die Befreiung des Klangs, Hofheim 1992.

- Edgard Varèse (1883 - 1965). Dokumente zu Leben und Werk (Ausstellung der Akademie der Künste und der Technischen Universität Berlin), Frankfurt am Main 1990.

— »Aus der Neuen Welt. Die Rezeption der amerikanischen Musik in Europa«, in Hermann Danuser/Dietrich Kämper/Paul Terse (Hg.): Amerikanische Musik seit Charles Ives, Laaber 1987, S. 113-125.

Mrozek, Bodo: »Geschichte in Scheiben. Schallplatten als zeithistorische Quellen«, in: Zeithistorische Forschungen (8/2011), S. 295-304, URL: http://www.zeithisto rische-forschungen.de/2-2011/id $=4610$.

Müller, Gerhard: Musik wird politisch - Politik wird musikalisch, in: Musikforum (4/2007), S. 30ff.

Müller, Sven Oliver/Osterhammel, Jürgen/Rempe, Martin (Hg.): Kommunikation im Musikleben. Harmonien und Dissonanzen im 20. Jahrhundert, Göttingen 2015.

— /Toelle, Jutta (Hg.): Bühnen der Politik. Die Oper in europäischen Gesellschaften im 19. und 20. Jahrhundert, Wien/München 2008.

— $\gg$ Distinktion, Demonstration und Disziplinierung. Veränderung im Publikumsverhalten in Londoner und Berliner Opernhäusern im 19. Jahrhundert«, in: International Review for the Aesthetics and Sociology of Music (37/2006), S. 167-187.

Müller-Doohm, Stefan (Hg.): Adorno-Portraits. Erinnerungen von Zeitgenossen, Frankfurt am Main 2007.

\section{$-\mathbf{N}-$}

Nanz, Tobias/Pause, Johannes (Hg.): Politiken des Ereignisses. Mediale Formierungen von Vergangenheit und Zukunft, Bielefeld 2015, S. 7-32.

Nanz, Dieter: Edgard Varèse. Die Orchesterwerke, Berlin 2003. 
Nattiez, Jean-Jaques (Hg.): »Dear Pierre«- »Cher John«. Der Briefwechsel zwischen Pierre Boulez und John Cage, Hamburg 1997.

Nauck, Gisela (Hg.): Sound Studies (Themenheft), in: Positionen (86/2011).

— Dieter Schnebel. Lesegänge durch Leben und Werk, Mainz 2001.

Nägele, Reiner/Trost, Vera: Hoch Stuttgart! Hoch die Musik-Kritik! Hoch die Säue! Paul Hindemith in Stuttgart (Ausstellungskatalog), Stuttgart 1995.

Neuhaus, Stefan/Holzner, Johann (Hg.): Literatur als Skandal. Fälle - Funktionen Folgen, Göttingen 2007.

Nietzsche, Friedrich: »Homers Wettkampf« [1872], in Ders.: Werke in drei Bänden, München 1954, Band 3, S. 291-299.

Nijinsky, Romola: Nijinsky. Der Gott des Tanzes, Berlin 2009.

Noack, Bernd: Theater Skandale. Von Aischylos bis Thomas Bernhard, St. Pölten/Salzburg 2008.

Noever, Peter (Hg.): Out of Actions. Aktionismus, Body Art \& Performance 19491979, Ostfildern 1998.

Nono, Luigi: »Eine Autobiographie des Komponisten. Enzo Restogni mitgeteilt« [1987], in Andreas Wagner (Hg.): Luigi Nono. Dokumente, Materialien, Saarbrücken 2003, S. 34-138.

— »Interview mit Hans Brender und Max Nyffeler«, in: Deutsche Volkszeitung (12.6.1975).

— »Gespräch mit Hansjörg Pauli« [1969], in Jürg Stenzl (Hg.): Luigi Nono. Texte, Studien zu seiner Musik, Zürich 1975, S. 198-210.

— »Musik und Revolution« [1969], in Jürg Stenzl (Hg.): Luigi Nono. Texte, Studien zu seiner Musik, Zürich 1975, S. 107-115.

— Vietnam in Berlin« [1968], in Jürg Stenzl (Hg.): Luigi Nono. Texte, Studien zu seiner Musik, Zürich 1975, S. 155-158

— »Einige genauere Hinweise zu >Intolleranza 1960« «1962], in Jürg Stenzl (Hg.): Luigi Nono. Texte, Studien zu seiner Musik, Zürich 1975, S. 68-81

— »Gitterstäbe am Himmel der Freiheit«, in: Melos 27 (3/1960), S. 74f.

— »Geschichte und Gegenwart in der Musik heute« [1959], in Jürg Stenzl (Hg.): Luigi Nono. Texte, Studien zu seiner Musik, Zürich 1975, S. 34-40.

Nowak, Kai: Projektionen der Moral. Filmskandale in der Weimarer Republik, Göttingen 2015.

Nyffeler, Max: »Karlheinz Stockhausen 75. Kleiner Rückblick auf ein langes Komponistenleben«, in: Westdeutscher Rundfunk (2003), online als Manuskript einsehbar unter URL: www.beckmesser.de/komponisten/stockhausen75.html.

\section{- 0 -}

Oehlschlägel, Reinhard: »Avantgarde und Vermittlung. Dieter Schnebel im Gespräch«, in: MusikTexte 57/58 (März 1995), S. 97-113.

O’Dell, Kathy: »Fluxus Feminism«, in: Drama Review 41 (1/1997), S. 43-60.

Oja, Carol J.: Making Music Modern. New York in the 1920s, New York 2000.

Omray, Imre: Skandal in der Oper [eine anekdotische Darstellung], Leipzig 1964.

O’Neil, Paul: »A Rather Scandalized Report. Nudity in Public«, in: LIFE (13.10.1967), S. 107ff.

Oren, Michael: Anti-Art as the Ende of Cultural History, Berkeley 2002. 


\section{- P -}

Padurean, Vasile: »Das Phänomen des Agon«, in Ders.: Spiel - Kunst - Schein. Nietzsche als ursprünglicher Denker, Stuttgart 2008.

Panowsky, Walter: Protest in der Oper. Das provokative Musiktheater der zwanziger Jahre, München 1966.

Passig, Kathrin: »Standardsituationen der Technologiekritik«, in: Merkur (12/2009), URL: http://www.eurozine.com/articles/2009-12-01-passig-de.html.

Paris, Rainer: »Der kurze Atem der Provokation«, in: Kölner Zeitschrift für Soziologie und Sozialpsychologie 41 (1989), S. 33-52.

Paul, Gerhard: Sound des Jahrhunderts. Geräusche, Töne, Stimmen 1889 bis heute, Bonn 2013.

— Visual History, Version: 2.0«, in: Docupedia-Zeitgeschichte (29.10.2012), URL: https://docupedia.de/zg/Visual_History_Version_2.0_Gerhard_Paul.

— Visual History. Ein Studienbuch, Göttingen 2006.

- Das historische Auge. Kunstwerke als Zeugen ihrer Zeit von der Renaissance zur Revolution, Göttingen 2004.

Pauli, Hansjörg (Hg.): »Für wen komponieren Sie eigentlich?«, Frankfurt am Main 1971.

Pasler, Jann: Composing the Citizen. Music as Public Utility in Third Republic France, Berkeley 2009.

Paust, Bettina/Bilstein, Johannes/Lynen, Peter M./Thurn, Hans Peter (Hg.): Aufbauen - Zerstören. Phänomene und Prozesse der Kunst (Moyländer Diskurse zu Kunst und Wissenschaft, Band 1), Oberhausen 2007.

Perloff, Marjorie/Junkerman, Charles (Hg.): John Cage. Composed in America, Chicago 1994.

Petersen, Christer: '")... Jetzt müssen Sie Ihr Gehirn umstellen...< Eine Nachlese von Jean Baudrillards Der Geist des Terrorismus«, in Thorsten Schüller/Sascha Seiler (Hg.): Von Zäsuren und Ereignissen - Historische Einschnitte und ihre mediale Verarbeitung, Bielefeld 2010, S. 29-48.

Petrik, Ursula: Die Leiden der Neuen Musik. Die problematische Rezeption der Musik seit etwa 1900, Wien 2008.

Peukert, Kristin: Der Konflikt um Luigi Nonos »Il canto sospeso«, Berlin 2001.

Pfister, Manfred (Hg.): Krisis! Krisenszenarien, Diagnosen und Diskursstrategien, München 2007.

Pfitzner, Hans: »Futuristengefahr. Bei Gelegenheit von Busoni’s Ästhetik«, in: Süddeutsche Monatshefte, Leipzig/München 1917.

— »Die neue Ästhetik der musikalischen Impotenz: ein Verwesungssymptom?«, München 1920.

Pieler, Heike: Weißes Rauschen. 1. Ästhetik-Festival der Universität Bielefeld. Eine Dokumentation, Bielefeld 2006.

Pinch, Trevor/Bijsterveld, Karin (Hg.): The Oxford Handbook of Sound Studies, New York 2011.

Piekut, Benjamin: Experimentalism Otherwise. The New York Avant-Garde and Its Limits, Berkeley/Los Angeles 2011. 
— »>Demolish Serious Culture!< Henry Flynt and Workers World Party«, in Robert Adlington (Hg.): Sound Commitments. Avant-garde music and the Sixties, Oxford 2009, S. 37-55.

Platon: Nomoi II (660b), in Guther Eigler (Hg.): Platon. Werke in acht Bänden, Band 8, Darmstadt 1990.

Polzer, Joachim (Hg.): Sound - Der Ton im Kino, Berlin 1996.

Poppe, Sandra/Schüller, Thorsten/Seiler, Sascha (Hg.): 9/11 als kulturelle Zäsur. Repräsentationen des 11. September 2001 in kulturellen Diskursen, Literatur und visuellen Medien, Bielefeld 2009.

Porcile, François: La belle époque de la musique française 1870-1940, Paris 1999.

Pörksen, Bernhard/Hanne Detel (Hg.): Der entfesselte Skandal. Das Ende der Kontrolle im digitalen Zeitalter, Köln 2012.

Pousseur, Henri: »Theorie und Praxis in der neuesten Musik« [1958], in Rainer Nonnemann, (Hg.): Mit Nachdruck. Texte der Darmstädter Ferienkurse für Neue Musik, Mainz 2010, S. 15-29.

Prieberg, Fred K.: Handbuch Deutsche Musiker 1933-1945, Kiel 2004.

— Kraftprobe. Wilhelm Furtwängler im Dritten Reich, Wiesbaden 1986.

— Musik im NS-Staat, Frankfurt am Main 1982.

- Musica ex machina. Über das Verhältnis von Musik und Technik, Berlin 1960.

— »Der musikalische Futurismus«, in: Melos (25/1958), S. 124ff.

— Musik des technischen Zeitalters, Zürich 1956.

\section{- R -}

Raeburn, Michael/Kendall, Alan (Hg.): Geschichte der Musik, Band IV: Das 20. Jahrhundert, Mainz 1991.

Rancière, Jacques: The politics of aesthetics: the distribution of the sensible, London 2004.

Rathkolb, Oliver: Führertreu und gottbegnadet. Künstlereliten im Dritten Reich, Wien 1991.

Rathmann, Thomas (Hg.): Ereignis. Konzeption eines Begriffs in Geschichte, Kunst und Literatur, Köln 2003.

Raussert, Wilfried: Avantgarden in den USA. Zwischen Mainstream und kritischer Erneuerung, Frankfurt am Main 2003.

Rebhan, Michael: »Jeder Tag ist ein guter Tag. John Cage in Darmstadt«, in: Dissonance. Schweizer Musikzeitschrift für Forschung und Kreation (6/2012), S. 16-18.

Reichenbach, Roland: Skandal und politische Bildung. Aspekte zu einer Theorie des politischen Gefühls, Berlin 2005.

Reinecke, Hans-Peter: »Popularmusik und geängstigte Musikologen«, in Helmut Rösing (Hg.): Rock, Pop, Jazz im musikwissenschaftlichen Diskurs, Hamburg 1992, S. 5-14.

Reinelt, Janelle G./Roach, Joseph R. (Hg.): Critical theory and performance, Ann Arbor 1992, S. 248-256.

Resch, Christine: Kunst als Skandal. Der steirische Herbst und die öffentliche Erregung, Wien 1994.

Richter, Hans Werner: »Warum schweigt die junge Generation?«, in: Der Ruf (2/1946), S. 55. 
Riezler, Walter: »Die Musik«, in Bayerische Akademie der Schönen Künste (Hg.): Die Künste im technischen Zeitalter, München 1954, S. 160-69.

Rietzler, Ronald/Reichertz, Jo (Hg.): Irritierte Ordnung. Die gesellschaftliche Verarbeitung von Terror, Konstanz 2003.

Ritter, Joachim/Gründer, Karlfried/Gabriel, Gottfried (Hg.): Historisches Wörterbuch der Philosophie, 13 Bände, Basel 1971-2007.

Rheinberger, Hans-Jörg: Experimentalsysteme und epistemische Dinge. Eine Geschichte der Proteinsynthese im Reagenzglas, Göttingen 2002.

Rölli, Marc (Hg.): Ereignis auf Französisch. Von Bergson bis Deleuze, München 2004.

Ross, Alex: The Rest is Noise: Das 20. Jahrhundert hören, München 2009.

Rothfels, Hans: »Zeitgeschichte als Aufgabe«, in: Vierteljahrshefte für Zeitgeschichte (1/1953), S. 1-8.

Rothfuss, Joan: Topless Cellist. The improbable Life of Charlotte Moorman, Cambridge 2011.

— The Ballad of Nam June and Charlotte: A Revisionist History, Cambridge 2011.

Rusch, Gebhard (Hg.): Einführung in die Medienwissenschaft. Konzeptionen, Theorien, Methoden, Anwendungen, Wiesbaden 2002.

Russolo, Luigi: »Die Kunst der Geräusche«, in Wolfgang Asholt/Walter Fähnders (Hg.): Manifeste und Proklamationen der europäischen Avantgarde (1909-1938), Stuttgart/Weimar 2005, S. 30f.

\section{- S -}

Sabaté Planes, Dolores/Feijóo, Jaime (Hg.): Apropos Avantgarde. Neue Einblicke nach Einhundert Jahren, Berlin 2012.

Sabato, Larry J./Stencel, Marc/Lichter, S. Robert (Hg.): Peepshow. Media and Politics in Age of Scandal, Lanham 2001.

Sabrow, Martin (Hg.): Skandal und Diktatur. Formen öffentlicher Empörung im NSStaat und der DDR, Göttingen 2004.

— Die Macht der Bilder, Radebeul 2013.

Said, Edward: »The Clash of Ignorance«, in: The Nation (22.10.2001).

Samhaber, Ernst: »Vom Untergang des Abendlandes«, in: Die Zeit (16.5.1946).

Sanio, Sabine: »Aspekte einer Theorie der auditiven Kultur«, in: kunsttexte (4/2010), S. 1-14, URL: http://edoc.hu-berlin.de/kunsttexte/2010-4/sanio-sabine2/PDF/sanio.pdf.

- 1968 und die Avantgarde. Politisch-ästhetische Wechselwirkungen in der westlichen Welt, Sinzig 2008.

— »Rauschen - Klangtotal und Repertoire. Zur Selbstreflexivität der ästhetischen Erfahrung«, in Andreas Hiepko/Katja Stopka (Hg.): Rauschen. Seine Phänomenologie und Semantik zwischen Sinn und Störung, Würzburg 2001, S. 207224.

—/Scheib, Christian (Hg.): Das Rauschen, Hofheim 1995.

Sarasin, Philipp: »Wie weiter mit Foucault?«, in Hamburger Institut für Sozialforschung (Hg.): »Wie weiter mit...?«, Hamburg 2008, S. 1-48 
—» Un analyse structurale du signifiéく. Zur Genealogie der Foucault'schen Diskursanalyse«, in Franz X. Eder (Hg.): Historische Diskursanalysen. Genealogie, Theorie, Anwendungen, Wiesbaden 2006, S. 115-129.

— Michel Foucault zur Einführung, Hamburg 2005.

- Geschichtswissenschaft und Diskursanalyse, Frankfurt am Main 2003.

Sauer, Heike: Traum, Wirklichkeit, Utopie: das deutsche Musiktheater 1961-1971 als Spiegel politischer und gesellschaftlicher Aspekte seiner Zeit, Münster/New York 1994.

de Saussure, Ferdinand: Grundfragen der allgemeinen Sprachwissenschaft, Berlin 1967.

Schaal, Hans-Jürgen: »Mord auf der Ballettbühne. Der Uraufführungsskandal um Strawinskys `Le Sacre du Printemps««, in: Neue Zeitschrift für Musik (3/2000), S. 16-19.

Schaeffer, Pierre: Musique Concrète - von den Pariser Anfängen um 1948 bis zur Elektroakustischen Musik heute, Stuttgart 1974.

Schafer, Richard Murray: Klang und Krach. Eine Kulturgeschichte des Hörens [The Tuning of the World], Frankfurt am Main 1988.

Scherer, Ludger/Lohse, Rolf (Hg.): Avantgarde und Komik, Amsterdam 2004.

Scherliess, Volker: Igor Strawinsky und seine Zeit, Laaber 1983.

Schläbitz, Norbert: »Wie sich alles erhellt und erhält. Von der Musik der tausend Plateuas oder ihrem Bau«, in Marcus S. Kleiner/Achim Szepanski (Hg.): Soundcultures. Über elektronische und digitale Musik, Frankfurt am Main 2003, S. 107-136.

Schmicking, Daniel: Hören und Klang. Empirisch-phänomenologische Untersuchungen, Würzburg 2003.

Schmidt, Patrick (Hg.): Medialisierte Ereignisse. Performanz, Inszenierung und Medien seit dem 18. Jahrhundert, Frankfurt 2010.

Schmidt, Leigh Eric: Hearing Things. Religion, Illusion and the American Enlightenment, Chicago 1999.

Schmidt-Bergmann, Hansgeorg: Futurismus. Geschichte, Ästhetik, Dokumente, Reinbek bei Hamburg 1993.

Schmidt, Felix: »Hans Werner Henze. Kindliches Entzücken«, in: Der Spiegel (49/1968), S. 182.

Pierre Boulez: »Sprengt die Opernhäuser in die Luft!«, in: Der Spiegel (40/1967), S. 166-174.

Schnabel, Ernst: Das Floß der Medusa. Text zum Oratorium von H. W. Henze. Zum Untergang einer Uraufführung. Postscriptum, München 1969.

Schnebel, Dieter: Mauricio Kagel. Musik - Theater - Film, Köln 1970.

- Autonome Kunst politisch. Über einige Sprachbarrieren, in ders.: Denkbare Musik. Schriften 1952-72, Köln 1972, S. 474-488.

— »Ho-Ho-Ho«, in: Der Spiegel 45 (4.11.1968), S. 174-177.

- Musica sacra ohne Tabus, in: Melos (35/1968), S. 65-101.

Schneider, Irmela; Hahn, Torsten; Bartz, Christina (Hg.): Diskursgeschichte der Medien, 3 Bände, Wiesbaden 2003.

— Hybridkultur. Medien - Netze - Künste, Köln 1997.

Schoeps, Julius H. (Hg.): Der politische Skandal, Stuttgart/Bonn 1992. 
Schoon, Andi: Die Ordnung der Klänge. Das Wechselspiel der Künste vom Bauhaus zum Black Mountain College, Bielefeld 2006.

Schott Music (Hg.): Skandal! (Themenheft), in: Neue Zeitschrift für Musik (3/2000).

— Jahresbericht 1928, in: Zeitgenössische Musik aus dem Verlag B. Schott's Söhne, Mainz 1928.

Schönberg, Arnold: Stil und Gedanke, Frankfurt am Main 1995.

Schramm, Holger: Musik und Medien, Baden-Baden 2007.

Schüller, Thorsten/Seiler, Sascha (Hg.): Von Zäsuren und Ereignissen - Historische Einschnitte und ihre mediale Verarbeitung, Bielefeld 2010.

Schulmeister, Stephan: »Die große Krise im Kontext des >langen Zyklus kriegszeit«, in Manfred Oberlechner/Gerhard Hetfleisch (Hg.): Integration, Rassismen und Weltwirtschaftliche Krise, Wien 2010, S. 1-34.

Schulze, Holger (Hg.): Sound Studies. Traditionen - Methoden - Desiderate. Eine Einführung, Bielefeld 2008.

Schürmer, Anna: » Theremin: Ein alarmierender Missbrauch eines (meta)physi(kali)schen Musikgeräts«, Vortrag auf der Jahrestagung der Gesellschaft für Medienwissenschaften 2017 zum Thema 〉Zugängeく (Erlangen, 5. Oktober 2017).

— »Topless Cellist«. Charlotte Moorman, Fluxus und die sexuelle Revolution der Kunstmusik (Feature), in: Deutschlandfunk (4.3.2017).

— »Von >Arms« zu >Artsく. Musikalische Umnutzung von Heeresgeräten«, in: Deutschlandfunk (20.2.2016).

— »Interferences. Critical Perspectives on Early Loudspeaker Music«, Vortrag auf der internationalen Konferenz »Critical Theory, Film and Media: Where is >Frankfurt now? «, Frankfurt am Main (20.-23.8.2014); überarbeitet und publiziert in Lars Koch/Tobias Nanz/Johannes Pause (Hg.): Disruption in the Arts (erscheint 2017 in der Reihe Culture \& Conflict bei De Gruyter, Berlin).

— Ü-Musik entsteht in den Grenzbereichen. Ein Gedankenmodell zur Überwindung einer belastenden Sezession«, in: Neue Musikzeitung (12/2016), URL: https://www.nmz.de/artikel/ue-musik-entsteht-in-den-grenzbereichen (Zugriff: 31.8.2017).

— »)Topless Cellist . Nackte Tatsachen und eine folgenreiche Verhandlung um die Kunstfreiheit«, in Sandra Frimmel/Mara Traumane (Hg.): Kunst vor Gericht. Ästhetische Debatten im Gerichtssaal, Berlin 2017.

- / Zuzana Bil'ová/Lisa Marie Bowler/Madalina Rosca/Rusch, Mara (Hg.): Gesetze der Kunst. Recht und Ritual, Berlin 2017.

— »Musikalischer Klassenkampf«, in Christian Storch/Birgit Wertenson (Hg.): Luigi Nono und der Osten (Musik im Metrum der Macht), Mainz 2015 S. 279-302.

— »Elektronische Eklatanz. Zwischen Anti- und Hyper-Performanz«, in: WolfDieter Ernst/Anno Mungen/Nora Niethammer/Berenika Szymanski-Düll (Hg.): Sound und Performance. Positionen - Methoden - Analysen (Thurnauer Schriften zum Musiktheater, Band 27), Würzburg 2015, S. 191-205.

— »Klingende Skandale - Laute(r) Emotionen?«, in Iris Cseke/Sebastian Jung/Lars Krautschik/Georg Schneider/Johanna Zorn (Hg.): Produktion, Affektion, Rezeption, Berlin 2014, S. 113-134.

— »Darmstadt hatte stets seine Opfer, oder: Die Revolution frisst ihre Kinder«, in: Neue Musikzeitung (2/2014), S. 4. 
— »Elektronische Musik, ein Missbrauch von Heeresgerät?«, in: Neue Musikzeitung (11/2014), S. 3.

— »Klingende Eklats«, in: Bayerischer Rundfunk/Bayern 4 Klassik (18.8.2014).

- »>Picket Stockhausen Concert!〈ORIGINALE - eine auditive Spurensuche«, in: Deutschlandfunk (6.12.2014).

— »Black ^Magic Mountain. John Cage und die transnationale Neuvermessung der klingenden Welt«, in: Südwestrundfunk/SWR2 (11.3.2013).

— »Der Skandal als kreativer Störfall im Sperrbezirk. Von der produktiven Eklatanz der Neuen Musik 1913|2013«, in: Neue Musikzeitung (8/2013), S. 3.

— »»...es wäre ein Akt der Nächstenliebe, sie zu zerschmeißen...< John Cage und technische Medien: Random zwischen Differenz und Wiederholung «, in kunsttexte (4/2012), URL: http://edoc.hu-berlin.de/kunsttexte/2012-4/schuermer-anna3/PDF/schuermer.pdf.

— »Taktgeber oder Tabuisierte? Neue Musik und ihre Komponisten in Ostdeutschland - Zwischen Zwängen und Möglichkeiten«, in GEMA virtuos (9/2009), S. $10-14$.

Schuessler, Jennifer: »Shock Me if You Can«, in: New York Times (14.9.2012).

Schulze, Stephan: »Melos - die Geschichte einer außergewöhnlichen Musikzeitschrift«, in: Jahrbuch für Kommunikationsgeschichte (1/1999), S. 173-191.

Schütze, Christian: Skandal. Eine Psychologie des Unerhörten, Bern/München 1985.

Schwerfel, Heinz Peter: Kunstskandale [über spontane Ablehnung und nachträgliche Anerkennung, über Tabu und Skandal, Verdammung und Verehrung zeitgenössischer Kunst], Köln 2000.

Segeberg, Harro/Schätzlein, Frank (Hg.): Sound. Zur Technologie und Ästhetik des Akustischen in den Medien, Marburg 2005.

Shalleck, Milton: »People \& C. v. Charlotte Moorman« (Opinion Paper), in New York Law Journal (11.5.1967).

Shohat, Ella/Stam, Robert (Hg.): Unthinking Eurocentrism. Multiculturalism and the Media, London 1994.

Sinfield, Alan: »The Theatre and its Audiences«, in Ders. (Hg.): Society and Literature 1945-1970, London 1983.

Slonimsky, Nicolas: Lexicon of Musical Invective. Critical Assaults on Composers since Beethoven's Time, New York 1953.

Smith, Mark M.: »Making Sense of Social History«, in: Journal of Social History (37/2003), S. 165-186.

— Listening to Nineteeth-Century America, Chapel Hill 2001.

- (Hg.): Hearing History. A Reader, Athens u.a. 2004.

- (Hg.): Sensing the Past. Seeing, Hearing, Smelling, Tasting, and Touching in History, Berkeley/Los Angeles 2007.

Spengler, Oswald: Der Untergang des Abendlandes, Band 1: Gestalt und Wirklichkeit, Wien 1918; Band 2: Welthistorische Perspektiven, München 1922.

Spieler, Reinhard: Welten in der Schachtel. Mary Bauermeister und die experimentelle Kunst der 1960er Jahre, Bielefeld/Leipzig/Berlin 2010.

Stachel, Peter/Ther, Philipp (Hg.): Wie europäisch ist die Oper? Die Geschichte des Musiktheaters als Zugang zu einer kulturellen Topographie Europas, Wien/Köln/Weimar 2009. 
Stadler, Gerhard A./Kuisle, Anita (Hg.): Technik zwischen Akzeptanz und Widerstand. Gesprächskreis Technikgeschichte 1982-1996, Münster/New York/München/Berlin 1999.

Stähr, Wolfgang: »Konzertskandal und Straßenkampf. Hans Werner Henze und die Weltrevolution«, in: Berliner Philharmoniker - das Magazin (11/122006), S. 4-8.

Steinert, Heinz: Adorno in Wien, Münster 2003.

Steffen, Burkhardt: Medienskandale. Zur moralischen Sprengkraft öffentlicher Diskurse, Köln 2006.

Stenzl, Jürg (Hg.): Luigi Nono. Texte, Studien zu seiner Musik, Zürich 1975.

Stephan, Rudolf: (Hg.): Von Kranichstein zur Gegenwart. 50 Jahre Darmstädter Beiträge zur Neuen Musik, Stuttgart 1996.

Stern, Fred: »Charlotte Moorman and the New York Avantgarde« (Video-Interview, 9'52”), New York 1980, URL: http://www.youtube.com/watch?v=wiEJdOlgcDE (4.02.2014).

Sterne, Jonathan (Hg.): The Sound Studies Reader, London 2012.

— The Audible Past. Cultural Origins of Sound Reproduction, Durham 2003.

Stiftung Haus der Geschichte der Bundesrepublik Deutschland (Hg.): Skandale in Deutschland nach 1945, Bielefeld 2007.

Stockhammer, Robert (Hg.): Grenzwerte des Ästhetischen, Frankfurt am Main 2002.

Stockhausen, Karlheinz: Texte zur Musik, 10 Bände, Köln 1963-89/Kürten 1998.

— »Huuuh! Das Pressegespräch am 16. September im Senatszimmer des Hotel Atlantic in Hamburg«, in: MusikTexte (91/2001), S. 69-77.

— Haben Sie Techno erfunden? Stockhausen: Ja! Karlheinz Stockhausen im Interview«, in: De-Bug. Elektronische Lebensaspekte (26.1.2000), URL: http://debug.de/mag/haben-sie-techno-erfunden-stockhausen-ja/.

— »Über LICHT - Komponist und Interpret - Zeitenwende«, in Ders. (Hg.): Texte zur Musik 1984-1991, Band 9: Über LICHT. Komponist und Interpret. Zeitenwende, Kürten 1998, S. $601 \mathrm{ff}$.

— Der Widerstand gegen die Neue Musik. Diskussion mit Theodor W. Adorno« [1960], in Ders: Texte zur Musik, Band 6, Köln 1989, S. 458-483.

— »Momentform. Neue Zusammenhänge zwischen Aufführungsdauer, Werkdauer und Moment« [1960], in Ders.: Texte zur Musik, Band 1, Köln 1964, S. 189-210, hier S. 205.

— »Vieldeutige Form « [1960], in Ders.: Texte zur Musik, Band 1: Zur elektronischen und instrumentalen Musik, Köln 1963, S. 245-251.

— »...wie die Zeit vergeht...« [1957], in Ders: Texte zur Musik, Band 1: Zur elektronischen und instrumentalen Musik, Köln 1963, S. 99-139.

— »Gesang der Jünglinge« [1956], in Ders., Texte zur Musik, Band 2: Zu eigenen Werken, zur Kunst Anderer, Aktuelles, Köln 1964, S. 49-68.

— »Zur Situation des Metiers« [1953], in Ders.: Texte zur Musik, Band 1: Zur elektronischen und instrumentalen Musik, Köln 1963, S. 45-61.

Storch, Christian/Wertenson, Birgit (Hg.): Nono und der Osten (»Musik im Metrum der Macht«, Band 6), Mainz 2016.

Straebel, Volker: ") ...that the Europeans will become more American`. Gegenseitige Einflüsse von Europa und Nordamerika in der Geschichte der Musikperformance«, in Thomas Dészy/Christian Utz (Hg.): Das Innere Ohr, Linz 1995, S. 80-94. 
Strobel, Heinrich: »Neue Musik und Humanitas«, Beilage in: Melos (11/1953).

Stuckenschmidt, Hans Heinz: »Entwicklung oder Experiment?«, in: Melos (3/1955), S. 65-67.

— »Die dritte Epoche. Bemerkungen zur Ästhetik der Elektronenmusik«, in: Herbert Eimert/Karlheinz Stockhausen (Hg.): Die Reihe, Band 1: Elektronische Musik, Wien 1955, S. 17-19.

— »Die unbedeutende Minderheit«, in Melos (5/1952), S. 129-134.

Stuppner, Hubert: Endzeit-Sonate. Frankenstein oder Die Minnesänger des Untergangs. Eine Satire, ein Totentanz, eine Parabel, Regensburg 1999.

\section{- T -}

Taibon, Matteo: Luigi Nono und sein Musiktheater, Wien 1993

Tarnow, Volker: »Chronique scandaleuse. Spucken, Beißen, Stühle schmeißen«, in: Partituren (12/2007), URL: http://www.kultiversum.de/Musik-Partituren/ParisMusikleben-Skandal.html.

Teubl, Thorsten: Musiktheater in der Krise. Situationsbeschreibung und Alternativen für das Musiktheater unter besonderer Berücksichtigung der Kammeroper, Hamburg 2007.

Thadeusz, Frank: »Oskar Vierling - Tarnname Schornsteinfeger«, in: Der Spiegel (16/2011), S. 122.

Tholen, Christoph / Schade, Sigrid (Hg.): Konfigurationen. Zwischen Kunst und Medien, Kassel 2007.

Thompson, Emily: The Soundscape of Modernity, Cambridge 2004.

Thompson, John B.: Political Scandal. Power and Visibility in the Media Age, Cambridge 2000 .

Thomsen, Christian W. (Hg.): Hybridkultur. Bildschirmmedien und Evolutionsformen der Künste. Annäherungen an ein interdisziplinäres Forschungsproblem, Siegen 1994, S. 9-24.

Thrun, Martin: Neue Musik im deutschen Musikleben bis 1933, Band 2, Bonn 1995.

— »Der Sturz ins Jetzt des Augenblicks. Tumulte in Konzertsälen und ihre Folgen in den Jahren der Weimarer Republik«, Vortrag bei der Tagung »Kommunikationschancen. Entstehung und Fragmentierung sozialer Beziehungen durch Musik im 20. Jahrhundert« (Berlin 24.-26.1.2013); bearbeitet und publiziert unter dem Titel: »Der Sturz ins Jetzt des Augenblicks. Macht und Ohnmacht ‘ästhetischer Polizeiく im Konzert nach 1900«, in Sven Oliver Müller/Jürgen Osterhammel/Martin Rempe (Hg.): Kommunikation im Musikleben. Harmonien und Dissonanzen im 20. Jahrhundert, Göttingen 2015, S. 42-67.

Tiedemann, Rolf: »Nur ein Gast in der Tafelrunde. Theodor W. Adorno: kritisch und kritisiert«, in Rudolph Stephan (Hg.): Von Kranichstein zur Gegenwart. 50 Jahre Darmstädter Ferienkurse, Stuttgart 1996, S. 149-155.

Tomkins, Calvin: »John Cage - Figure in an Imaginary Landscape«, in: New Yorker (28.11.1964), S. 64f.

Traber, Habakuk: »Musik ergreift die Fahnen. Die Skandale um Henzes Floß der Medusa und Nonos Intolleranza 1960«, in: Neue Zeitschrift für Musik (3/2000), S. $39-42$. 
Trapp, Klaus: »Darmstadt und die 68er-Bewegung «, in Internationales Musikinstitut Darmstadt (Hg.): Von Kranichstein zur Gegenwart. 50 Jahre Darmstädter Ferienkurse, Darmstadt 1995, S. 369-375.

Treib, Marc: Space Calculated in Seconds, Princeton 1996.

Turner, Victor: »Dramatisches Ritual, rituelles Theater. Performative und reflexive Ethnologie«, in Uwe Wirth (Hg.): Performanz. Zwischen Sprachphilosophie und Kulturwissenschaft, Frankfurt am Main 2008, S. 193-209.

— Das Ritual. Struktur und Anti-Struktur, Frankfurt am Main 1993.

Tzara, Tristan: Sieben (7) Dada Manifeste, Hamburg 1998.

- U -

Ueding, Gerd (Hg.): Historisches Wörterbuch der Rhetorik, 10 Bände, Tübingen 1987-2011.

Ulbricht, Hans W.: »Akustische Artistik oder elektrische Musik«, in: Neue Zeitschrift für Musik (2/1952), S. 69-74.

Ungeheuer, Elena: »Ist Klang das Medium von Musik? Zur Medialität und Unmittelbarkeit von Klang in Musik«, in Holger Schulze (Hg.): Sound Studies: Traditionen - Methoden - Desiderate, Bielefeld 2008, S. 57-76.

- Martin Supper: »Elektronische Musik«, in Ludwig Finscher (Hg.): Die Musik in Geschichte und Gegenwart (MGG), Band 2, Kassel 1995, Sp. 1717ff.

Universal Edition (Hg.): Der Anbruch 1919-1937 (Faksimile-Ausgabe auf CDROM), Wien 2001.

\section{$-\mathrm{V}$ -}

Varèse, Edgard: »Die Befreiung des Klangs« (Auszüge aus Vorlesungen), in HeinzKlaus Metzger/Rainer Riehn (Hg.): Edgard Varèse. Rückblick auf die Zukunft (Musik-Konzepte, Band 6), München 1983, S. 3-25.

Venus, Jochen: »Die Erfahrung des Populären. Perspektiven einer kritischen Phänomenologie«, in Marcus S. Kleiner/Thomas Wilke (Hg.): Performativität und Medialität Populärer Kulturen. Theorien, Ästhetiken, Praktiken, Wiesbaden 2013, S. 49-73.

Vierling, Oskar: »Das elektrische Musikinstrument. Schwingungserzeugung durch Elektronenröhren«, in: Zeitschrift des Vereins deutscher Ingenieure, Bd. 76 (26/1932), S. 627.

- Das elektroakustische Klavier, Berlin 1936

— Eine neue elektrische Orgel, Berlin 1938.

Virilio, Paul: Ground Zero, London/New York 2002.

Voegelin, Salomé: Listening to Noise and Silence. Toward a Philosophy of Sound Art, New York 2010.

Vogel, Thomas (Hg.): Über das Hören. Einem Phänomen auf der Spur, Tübingen 1996.

Vog1, Josef: »Was ist ein Ereignis?«, in Peter Gente/Peter Weibel (Hg.): Gilles Deleuze und die Künste, Frankfurt am Main 2007, S. 67-83 
Voigt, Wolfgang: »Zum Problem der Akzeptanz und der »natürlichen« Klangwirkung elektronischer bzw. mechanisch-elektronischer Musikinstrumente«, in: Systematische Musikwissenschaft (6/2003), S. 307-312.

\section{$-W$ -}

Wagner, Andreas (Hg.): Luigi Nono. Dokumente - Materialien, Saarbrücken 2003.

Waldenfels, Bernhard: Phänomenologie der Aufmerksamkeit, Frankfurt am Main 2004

- Der Stachel des Fremden, Frankfurt am Main 1990.

Walser, Martin: »Geburtstag einer Oase«, in Gerd Haedeke (Hg.): Kulturradio. Erinnerungen und Erwartungen, Köln 1996, S. 75f.

Walther, Gerrit: »Skandal«, in Friedrich Jaeger (Hg.): Enzyklopädie der Neuzeit, Band 12, Stuttgart 2010, Sp. 54-57.

Waltner, Paul: Internationale Ferienkurse in der Krise, in: Melos (16/1949), S. 242245.

Watzlawik, Paul: Menschliche Kommunikation. Formen, Störungen, Paradoxien, Bern 1971.

Wehmeyer, Grete: Erik Satie, Regensburg 1974.

Wense von der, Hans Jürgen: Geschichten einer Jugend. Tagebücher und Briefe. Ausgewählt, erläutert und mit einem Nachwort von Dieter Heim, München 1999.

Weiß, Johannes (Hg.): Mehrdeutigkeit der Moderne, Kassel 1998.

Weiss, Peter: Ästhetik des Widerstands, 3 Bände, Frankfurt am Main 1975-1981.

Welsch, Wolfgang: Unsere postmoderne Moderne, Berlin 2002.

— »Auf dem Weg zu einer Kultur des Hörens?«, in: Paragrana - Internationale Zeitschrift für Historische Anthropologie, Band 2, Heft 1-2, Berlin 1993, S. 87103.

Wiegand, Wilfried: Picasso, Reinbek 2002.

Willems, Herbert / Jurga, Martin (Hg.): Inszenierungsgesellschaft, Opladen 1998.

Winkel, Fritz (Hg.): Klangstruktur der Musik. Neue Erkenntnisse musikelektronischer Forschung, Berlin 1955.

Wirth, Uwe (Hg.): Performanz - Zwischen Sprachphilosophie und KulturwissenFrankfurt am Main 2008.

Wolf, Werner: »Die Entwicklung und Verwendung elektroakustischer Musikinstrumente«, in: Musik und Gesellschaft (4/1954), S. 17-19.

Woetzel, Harold: »75 Jahre Donaueschinger Musiktage: Das Ende der Musik«, in: SWF (1969).

Wulf, Christoph: »Das mimetische Ohr«, in Ders./Dietmar Kamper/Jürgen Trabant (Hg.): Das Ohr als Erkenntnisorgan (Paragrana 1-2/1993), S. 9-14.

\section{- Z -}

Zarius, Karl-Heinz: Staatstheater von Mauricio Kagel. Grenze und Übergang, Wien 1977

Zenck, Claudia: »Und dann ins Eck gestellt. Ernst Krenek als vermittlungswillige (und geschmähte) Vaterfigur«, in Rudolph Stephan (Hg.): Von Kranichstein zur Gegenwart. 50 Jahre Darmstädter Ferienkurse, Stuttgart 1996, S. 157-163. 
Ziegler, Hans Severus: Entartete Musik - Eine Abrechnung (Begleitheft zur Ausstellung Entartete Musik), Düsseldorf 1938.

Zielinski, Siegfried: Audiovisionen. Kino und Fernsehen als Zwischenspiele der Geschichte, Reinbek bei Hamburg 1989.

Ziemer, Hansjakob: Die Moderne hören. Das Konzert als urbanes Forum 1890-1940, Frankfurt am Main/New York 2008.

Zintgraf, Werner: Neue Musik 1921-1950. Donaueschingen, Baden-Baden, Berlin, Pfullingen, Mannheim, Horb am Neckar 1987.

Zimmermann, Heidy/Meyer, Felix (Hg.): Edgard Varèse. Komponist-KlangforscherVisionär (Begleitbuch zur gleichnamigen Ausstellung, 28./27.8.2006, Museum Tinguely), Basel 2006.

Zimmermann, Bernd Alois: »Unzeitgemäßen Betrachtungen zur Musik der jungen Generation«, in Melos (11/1952), S. 305-307.

— »Komponisten bestimmen die Grenzen der Musik«, in: Melos (3/1959), S. 89f.

Ziolkowski, Theodor: Scandal on Stage. European Theater as Moral Trial, Cambridge 2013.

Žižek, Slavoj: Welcome to the Desert of the Real, London/New York 2002.

\section{ORAL HISTORY: INTERVIEWS ${ }^{2}$}

Dieter Schnebel Deutscher Avantgarde-Komponist (*1930) am 12.08.2012 in Murnau

Jonathan Hiam Vorsitzender »Black Mountain College Research Project« am 11.09.2012 in New York

Mary Emma Harris Vorsitzende »Black Mountain College Research Project» am 11.09.2012 in New York

Alice Sebrell Leiterin »Black Mountain College Museum and Art Center« am 19.9.2012 in Asheville (NC)

Heather South Archivarin »North Carolina State Archives« am 20.09.2012 in Asheville (NC)

Mary Bauermeister Künstlerin / Zweite Ehefrau Karlheinz Stockhausens (*1934) am 30.10.2013 in Weimar und am 16.12. 2013 in Rösrath

Friedrich Cerha Österreichischer Avantgarde-Komponist (*1926) am 11.05.2013 in Wien

Phil Corner

Amerikanischer Komponist und Fluxus-Aktivist (*1933) am 11.07.2014 per Telefon (aus New York)

Johannes Kreidler Konzeptkomponist (*1980)

am 20.06.2014 per Telefon (aus Berlin)

2 Die Tonbandmitschnitte finden sich im Besitz der Autorin. 


\section{ARCHIVE: UNGEDRUCKTES MATERIAL ${ }^{3}$}

\section{Deutschland und deutschsprachiger Raum}

AdK Archiv der Akademie der Künste Ost/West (Berlin)

AdZ Archiv der Zeitgenossen (Krems)

DRA Deutsches Rundfunkarchiv (Frankfurt am Main/Potsdam-Babelsberg)

IMD Internationales Musikinstitut Darmstadt (Darmstadt)

MB Privatarchiv Mary Bauermeister (Rösrath)

MK Privatarchiv Max E. Keller

PC Privatarchiv Phil Corner (New York)

PSS Paul-Sacher-Stiftung (Basel)

StS Stockhausen-Stiftung (Kürten)

SWR Historisches Archiv des Südwestrundfunks (Baden-Baden)

WDR Historisches Archiv des Westdeutschen Rundfunks (Köln)

\section{Amerika}

BC Bard College / John Cage Trust (Annandale-on-Hudson)

MOMA Archiv des Museum of Modern Art (New York)

NCSA North Carolina State Archives / Black Mountain College Papers (Asheville)

NYPL New York Public Library for the Performing Arts

WU Wesleyan University / Cage Papers (Middletown)

\section{Systematisch AusgeWertete PERIODIKA ${ }^{4}$}

Die Zeit

Der Spiegel

Bild-Zeitung

Süddeutsche Zeitung

Frankfurter Allgemeine Zeitung

New York Times

Melos (1920-1943/1946-1979)

Neue Zeitschrift für Musik

[Musikblätter des] Anbruch (1919-1937)

3 Mein Dank geht an alle Archive für die Unterstützung und Bereitstellung von Materialien. Alle hier gefundenen Quellen wurden mit Verweis auf den Fundort und die Signatur in den Fußnoten aufgeführt und mit dem entsprechenden Kürzel gekennzeichnet.

4 Die hier aufgeführten Periodika wurden systematisch für den Kernzeitraum dieser Arbeit 1945-75 - ausgewertet. Viele zusätzliche Presseerzeugnisse wurden in entsprechenden Sammlungen in den für diese Arbeit besuchten Archiven gefunden und wurden in den Fußnoten dementsprechend kenntlich gemacht. 


\section{AUDIOVISIONEN ${ }^{5}$}

\section{Referenzen und Chiffren}

\section{[§-1] ,Wiener Watschenkonzertes}

$1.1 \quad$ Arnold Schönberg Streichquartett Nr. 2, fis-Moll, op. $10(1907 / 98)$

Aron Quartett: Arnold Schönberg Streichquartette Preiser/Naxos (2003): LC 00992

$1.2 \quad$ Alban Berg

5 Orchester-Lieder nach Ansichtskartentexten von Peter Altenberg (1912)

London Symphony Orchestra / Claudio Abbado Deutsche Grammophon (1998): 6443669

$[\delta-2] \quad>$ Le (mas) sacre du printemps

Igor Strawinsky Le sacre du printemps (1913)

Israel Philharmonic Orchestra / Leonard Bernstein

Deutsche Grammophon (1983), LC 00173

[§-3] >Futuristengefahr: Vom Kunst-Skandal zur Kunst des Skandals

Luigi Russolo Risveglio di una città (1913)

Edition Neue Zeitschrift für Musik (NZfM): Die

Kunst der Geräusche (CD-Beilage, 11/2000)

$[\mathcal{S}-4] \quad>$ Bad Boy of Music

4.1. George Antheil Airplaine Sonata/Tod den Maschinen (1922/23)

Guy Livingston (Klavier), auf: Antheil the Futurist

WERGO (2013): ÖC 00846

4.2. Marcel L'Herbier L'Inhumaine (1924)

Stummfilm, Frankreich

4.3. Fernand Léger Ballett Mécanique (1924)

Stummfilm, Frankreich

4.4. George Antheil Ballett Mécanique (1927)

Maurice Peress / New Palais Royal Orchestra

Nimbus Records/Naxos (2014): LC 5671

[^-5] Skandal in Zeiten der Diktatur

Ernst Krének Jonny spielt auf

Lothar Zagrosek / Gewandhausorchester Leipzig

DECCA 1993: B00000E551

5 Geordnet nach der Logik der Arbeitsgliederung, siehe Lesezeichen $\delta$. 


\section{Agon \& Skandal}

[§-6] Hindemiths skandalöse Opern-Einakter

6.1. Paul Hindemith

6.2. Paul Hindemith

6.3. Paul Hindemith

\section{[^-7-9] Die serielle Troika}

7.1. Pierre Boulez

7.2. Pierre Boulez

8.2. Karlheinz Stockhausen

9.1. Luigi Nono

9.2. Luigi Nono
Mörder, Hoffnung der Frauen (1919)

Gerd Albrecht / Radio-Sinfonieorchester Berlin WERGO (1996): B000025R24

Das Nusch Nuschi (1920)

Gerd Albrecht, Radio-Sinfonieorchester Berlin WERGO (1996): B000025R40

Sancta Susanna (1921)

Gerd Albrecht, Radio-Sinfonieorchester Berlin WERGO (1996): B000025R0N

\section{Polyphonie X (1951)}

Donaueschinger Musiktage (Live-Mitschnitt)

Col legno (1996): LC 07989

Deuxième Sonate (1948)

Dimitri Vassilakis (Klavier)

Cybele Records (2012): LC 3738

Spiel für Orchester (1952)

Stockhausen Edition, Nr. 2

Stockhausen-Verlag (1991)

Kreuzspiel (1952)

Stockhausen Edition, Nr. 1

Stockhausen-Verlag (1990)

Due espressioni (1953)

Donaueschinger Musiktage (Live-Mitschnitt)

Col legno (1996): LC 07989

3 epitaffi per Federico Garcia Lorca

Herbert Kegel / MDR Sinfonieorchester

Berlin Classics (1994): 0021412BC

[§-10] Stochastische Komposition

Iannis Xenakis:

Metastaseis (1953/54)

Donaueschinger Musiktage (Live-Mitschnitt)

Col legno (1996): LC 07989

[§-11] Harmonische Anklänge

Hans Werner Henze

Nachtstücke und Arien (1957)

NDR-Sinfonieorchester/Peter Ruzicka

WERGO (2001): LC 00846 


\section{Elektronische Eklatanz}

[§-12] Konkretes Waterloo

Pierre Schaeffer/

Orpheé 53 - Spectacle lyrique (1953)

Pierre Henry:

Donaueschinger Musiktage (Live-Mitschnitt)

Col legno (1996):LC 07989

[§-13] Rauschende Interferenzen

13.1. Karlheinz Stockhausen

Studie I / Studie II (1953)

Stockhausen Edition, Nr. 3

Stockhausen-Verlag (1993)

13.2. Karlheinz Stockhausen

Gesang der Jünglinge (1956)

Stockhausen Edition, Nr. 3

Stockhausen-Verlag (1993)

[א-14] Organisierte Interpolationen

14.1. Edgard Varèse

Déserts (1954)

Uraufführung am 2.12.1954 im Théâtre des

Champs-Elysées, Hermann Scherchen /

Orchestre National de France

14.2. Edgard Varèse

INA Mémoire vive (2007): IMV075

Poéme Electronique

CD: »Music of Edgard Varèse «

One Way Records (1999): 26791

\section{Transkulturelle Transfers}

[א-15] Die transatlantische Neuvermessung der klingenden Welt

15.1. John Cage

15.2. John Cage

15.3. John Cage

15.4. John Cage
Williams Mix (1952)

»The 25-Year Retrospective Concert « WERGO (1995): WER 6247

12'55.6078 for two pianists (prepared piano) Donaueschinger Musiktage (Live-Mitschnitt) Col legno (1996): LC 07989

Communication 1-6 (Lecture, 1958)

Darmstadt Aural Documents, Box 2

NEOS (2012): 11213

Concert for Piano and Orchestra (1957/58)

»The 25-Year Retrospective Concert"

WERGO (1995): WER 6247

[א-17] ORIGINALE - ein transatlantischer Skandal

17.1. Karlheinz Stockhausen

Kontakte (1960)

David Tudor (Klavier)/Christoph Caskel (Schlagzeug) / Gottfried Michael König / Karlheinz Stockhausen (Elektronik)

WERGO (1992): LC 00846 
17.2. Peter Moore

Stockhausen's Originale. The Film (USA 1964) Producer: Barbara Moore / Editor: Susan Brockman. Sound Mix: Jacob Burkhardt

[^-18] Die Königin der Nacktく

Nam June Paik

Sonata No. 1 for Adults only (1964)

CD: Charlotte Moorman, Cello Anthology (2)

Plana-M (2014): 27NMN 064-2

[ร-19] "...jetzt müssen Sie alle Ihr Gehirn umstellen...»

Karlheinz Stockhausen $\quad$ Pressegespräch am 16.9.2001

URL: http://web.archive.org/web/20060829003 224/http://www.danskmusiktidsskrift.dk/doku/s tockhausen-16sep2001.mp3

\section{Querstand von Kunst und Politik}

[א-20] Zungenreden

Dieter Schnebel

Glossolalie (1959/2000)

URL: http://www.maulwerker.de/repertoire/

R-schnebel-glosso.html

[א-21] Fluxus: Produktion durch Destruktion

Phil Corner

Piano Activities (1962)

Mitschnitt (Privatarchiv des Komponisten)

[ร-22] Klingender Klassenkampf

Luigi Nono

Intolleranza 1960 (1961)

Mitschnitt der Premiere (14.4.1961)

Deutsches Rundfunkarchiv: 11-0104

[§-23] Hans Werner Henzes politischer Schiffbruch

Hans Werner Henze $\quad$ Das Floß der Medusa (1968)

Mitschnitt der gestörten Uraufführung

Archiv des NDR: F802037 (HF802037)

[^-24] Eine Oper »to end all operas«

Maurizio Kagel

Staatstheater (1971)

Philharmonisches Staatsorchester und

Staatsopernchores Hamburg

"Aufbrüche und Revolten" Oper 1961-1971

BMG Ariola Classics (2002): LC 00316 


\section{AbBildungen}

0) Umschlag: Karlheinz Stockhausens Kugelauditorium auf der Weltausstellung in Osaka (1970)

(C) Albert Breiteneicher (BJV)

1) Eklatanter Startschuss in die musikalische Moderne: Arnold Schönberg provoziert das >Wiener Watschenkonzert (1913)

(C) N.N., in: Die Zeit (6.4.1913)

2) Luigi Russolo 1914 mit seinen $>$ Intonarumori<

(C) Luigi Russolo, in: http://www.medienkunstnetz.de/werke/intonarumori

3) Das futuristische Orchester: >Herrschaft der Maschine

(C) Enrico Novelli Yambo, in: Numero Settimanale umoristico illustrato (4.2.1914)

4) George Antheil: >Prophet der Maschinenmusik

(C) Courtesy of the Estate of George Antheil

5) Ernst Kréneks Jonny wird zum Symbol »Entarteter Musik« (1938)

(C) Titelblatt von Hans Severus Zieglers Hetzschrift »Entartete Musik - Eine Abrechnung« (Düsseldorf 1938)

6) Die sserielle Troika $<$ Luigi Nono, Pierre Boulez und Karlheinz Stockhausen bei den Donaueschinger Musiktagen 1957

(C) Dr. Gert Baruch, in: Archiv des Südwestrundfunks (SWR)

7) »Pfeifen ist hier nicht verboten«: Der Skandal als Ritual

(C) Finke, in: Südkurier (20.10.1959).

8) Das »unspielbare Instrument«: Johannes Kreidler protestiert 2012 in Donaueschingen gegen die Fusion der SWR-Klangkörper

(C) Katharina Herkommer / nmzMedia

9) >Die Maschine als Hypervirtuose «: Uraufführung von Karlheinz Stockhausens Gesang der Jünglinge am 30.05.1956 im großen Sendesaal des WDR

(c) Historisches Archiv des WDR: Bildnummer 1426933.

10) >Deus ex Machina $<$ Karlheinz Stockhausen mit elektronischem Instrumentarium (C) Historisches Archiv des WDR: Bildnummer 1471862

11) »Eklatanter Wandel des Aufschreibesystems von Klang«: Partiturseite von Karlheinz Stockhausens Studie II (1954)

(C) Mit freundlicher Genehmigung des Stockhausen-Verlags (Kürten) 
12) >Popmusikalische Verewigung : Karlheinz Stockhausen auf dem Cover von »Sergeant Peppers Lonely Hearts Club Band «

(C) Sir Peter Blake

13) >Musikalische Cyborgs $`$ Kraftwerk bei ihrer Tour 2014

(C) Denise Balibouse / Reuters

14) Willem de Koonings abstrakter Blick auf »Asheville« (1948)

(C) The Willem de Kooning Foundation/Artists Rights Society (ARS), New York

15) John Cage 1948 am BMC - noch klassisch am Flügel komponierend

(C) Courtesy of John Cage Trust.

16) John Cage 1960 beim Präparieren eines Flügels

(C) Ross Welser, Courtesy of John Cage Trust.

17) >Uraufführung täglich`: Plakat der Kölner Originale

(C) Mary Bauermeister (Privatarchiv)

18) Aufgehender Stern des Fluxus: Nam June Paik bei den Kölner Originalen

(C) Mary Bauermeister (Privatarchiv)

19) »Action Against Cultural Imperialism!« (8.9.1964)

(C) Fred W. McDarrah, Getty Images Nr. 93324964.

20) »Picket Stockhausen-Concert!«

(C) Courtesy of the Gilbert and Lila Silverman Fluxus Collection (Detroit).

21) >Die Königin der Nackt $<$ : Charlotte Moorman auf dem Plakat von Nam June Paiks Opera Sextronique

(C) Barabara Moore: The World of Charlotte Moorman (Archive Catalogue).

22) >Topless Cellist $<$ Charlotte Moorman wird bei der Premiere der Opera Sextronique von Polizisten abgeführt (C) imago / United Archives International

23) `Human Celloく: Paik und Moorman üben musikalisches `Embodyment` (1965)

(C) Barbara Moore/Licensed by VAGA (New York)

24) >Produktion durch Destruktion`: Philip Corners Piano Activities beim Festum Fluxorum 1962 in Wiesbaden

(C) Hartmut Rekort

25) Kontroverse: Karlheinz Stockhausen und Luigi Nono 1959 bei den Darmstädter Ferienkursen

(C) Fotograf: Pit Ludwig. Mit freundlicher Genehmigung des Internationales Musikinstitut Darmstadt (IMD) 
26) >Bilderflut: Bühnenbild bei der Premiere von Luigi Nonos Intolleranza im Teatro La Fenice (1961)

(C) Cameraphoto/Archivio Luigi Nono

27) Théodore Géricault: »Das Floß der Medusa« (1819)

(C) Théodore Géricault, in: Louvre

28) Symbolische Wendung: Hans Werner Henze nutzt das Dirigentenpodest als politische Bühne

(C) Jürgen Corleis.

29) Querstand von Kunst und Politik: Polizisten bringen das Flo $\beta$ der Medusa bei seiner Jungfernfahrt zum Kentern

(C) picture-alliance/dpa.

30) Spaltung der Studentenschaft: »In Sachen Henze« (Flugblatt)

(C) SDS-Projektgruppe Kultur und Revolution/AStA der Hochschule für Musik Berlin, in Staats- und Universitätsbibliothek Hamburg: Signatur NHK:Dme:1 


\section{Geschichtswissenschaft}

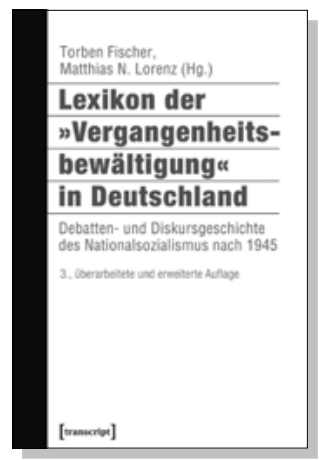

Torben Fischer, Matthias N. Lorenz (Hg.)

Lexikon der "Vergangenheitsbewältigung"

in Deutschland

Debatten- und Diskursgeschichte des Nationalsozialismus nach 1945

2015, 494 S., kart.

$34,99 €(D E), 978-3-8376-2366-6$

E-Book

PDF: $34,99 €(D E)$, ISBN 978-3-8394-2366-0

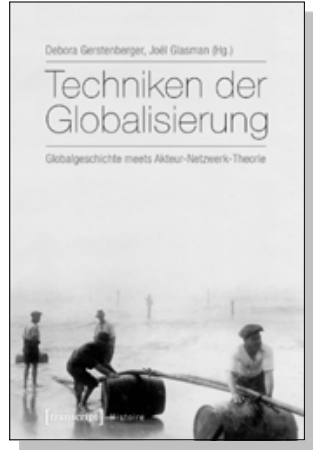

Debora Gerstenberger, Joël Glasman (Hg.)

Techniken der Globalisierung

Globalgeschichte meets Akteur-Netzwerk-Theorie

2016, 296 S., kart.

$29,99 €(D E), 978-3-8376-3021-3$

E-Book

PDF: 26,99€ (DE), ISBN 978-3-8394-3021-7

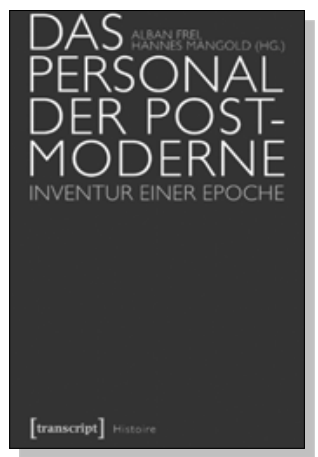

Alban Frei, Hannes Mangold (Hg.)

Das Personal der Postmoderne

Inventur einer Epoche

2015, 272 S., kart.

$19,99 €(D E), 978-3-8376-3303-0$

E-Book

PDF: 17,99 € (DE), ISBN 978-3-8394-3303-4 


\section{Geschichtswissenschaft}

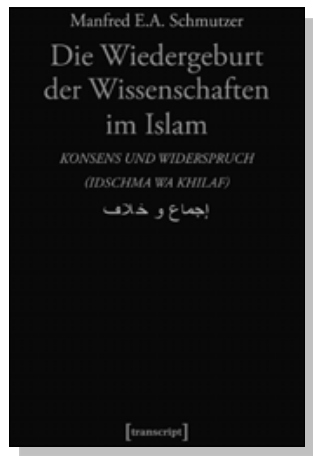

Manfred E.A. Schmutzer

Die Wiedergeburt der Wissenschaften im Islam

Konsens und Widerspruch (idschma wa khilaf)

2015, 544 S., Hardcover

$49,99 €(D E), 978-3-8376-3196-8$

E-Book

PDF: $49,99 €(D E)$, ISBN 978-3-8394-3196-2

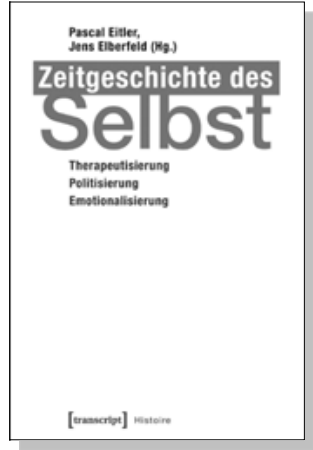

Pascal Eitler, Jens Elberfeld (Hg.)

Zeitgeschichte des Selbst

Therapeutisierung - Politisierung - Emotionalisierung

2015, 394 S., kart.

$34,99 €(D E), 978-3-8376-3084-8$

E-Book

PDF: 34,99€ (DE), ISBN 978-3-8394-3084-2

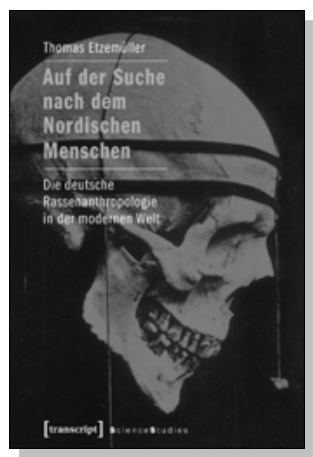

Thomas Etzemüller

Auf der Suche nach dem Nordischen Menschen Die deutsche Rassenanthropologie in der modernen Welt

2015, 294 S., kart., zahlr. z.T. farb. Abb.

29,99€ (DE), 978-3-8376-3183-8

E-Book

PDF: $26,99 €$ (DE), ISBN 978-3-8394-3183-2 